\title{
A rainfall-runoff model for the highly regulated Lake Taupo catchment, using a constrained Ensemble Kalman Filter to improve the accuracy and reliability of model output
}

\author{
by
}

Deborah H. Maxwell

\begin{abstract}
A thesis
submitted to the Victoria University of Wellington

in fulfilment of the requirements for the degree of

Doctor of Philosophy
\end{abstract}

Victoria University of Wellington 



\section{Abstract}

Lake Taupo is the effective source of the Waikato River. The Waikato Power Scheme relies on the outflow from the lake for moderated flows throughout the year. As the lake is maintained between a $1.4 \mathrm{~m}$ operating range, it is the inflows to the lake that determine the amount of water available to the scheme for electricity generation. These inflows have not been modelled in any detail prior to this dissertation.

This dissertation aims to develop a predictive rainfall-runoff model that can provide accurate and reliable inflow and lake level forecasts for the Lake Taupo catchment. Model formulation is guided by a fundamental understanding of catchment hydrologic principles and an in-depth assessment of catchment hydrologic behaviour. The model is a semi-distributed physically-consistent conceptual model which aims to provide a parsimonious representation of different storages and flow pathways through a catchment. It has three linear sub-surface stores. Drainage to these stores is related to the size of the saturation zone, utilising the concept of a variable source area. This model is used to simulate inflows from gauged unregulated sub-catchments. It is also used to estimate the inflow from ungauged areas through regionalisation. For regulated sub-catchments, the model is modified to incorporate available data and information relating to the relevant scheme's operation, resource consent conditions and other physical and legislative constraints.

The output from such models is subject to considerable uncertainty due to simplifications in the model structure, estimated parameter values and imperfect driving data. For robust decision making, it is important this uncertainty is reduced to within acceptable levels. In this study, a constrained Ensemble Kalman Filter (EnKF) is applied to the four unregulated gauged catchments to deal with model structure and data uncertainties. Used in conjunction with Monte Carlo simulations, all three sources of uncertainty are addressed. Simple mass and flux constraints are applied to the four (soil storage, baseflow, interflow and fastflow) model states. Without these constraints states can be adjusted beyond what is physically possible, compromising the integrity of model output. It is demonstrated that the application of a constrained EnKF improves the accuracy and reliability of model output. 
Due to the complexity of the Tongariro Power Scheme (TPS) and the limited data available to model it, the conceptual model is not suitable. Rather, a statistical probability analysis is used to estimate the discharge from this scheme given the month of the year, day of the week and hour of the day.

Model output is combined and converted into a corresponding change in lake level. The model is evaluated over a wide range of hydrological and meteorological conditions. An in-depth critical evaluation is undertaken on eight events chosen $a$ priori as representation of both extreme and 'usual' conditions. The model provides reasonable predictions of lake level given the uncertainty with the TPS, complexity of the catchment and data/information constraints. The model performs particularly well in 'normal' and dry conditions but also does a good job during rainfall events in light of errors associated with driving data. However, for real-time operational use the integration of the model with meteorological forecasts is required. Model recalibration would be required due to the issue of moving from point estimation to areal rainfall data. Once this is achieved, this operational model would allow robust decision-making and efficient management of the water resource for the Waikato Power Scheme. Although there is room for improvement, there is considerable scope for extending the application of the constrained EnKF and techniques for incorporating regulation to other catchments both in New Zealand and internationally. 


\section{To Elliot and Addison}

"Your talent makes you who you are. You should be proud of it."

Tinkerbell 


\section{Acknowledgements}

There are a number of people that I would like to thank that have been especially helpful and supportive during my studies. Firstly, I would like to thank my supervisors - Dr James McGregor, for organising the financial support of this project as well as his supervision and editorial advice, and Dr Bethanna Jackson for her untiring help and encouragement with all things Matlab and modelling. I am also grateful to Mighty River Power Ltd who provided the financial support to make this project possible.

There are a number of people who have assisted me with computing and data queries that I would particularly like to acknowledge - Kathy Walter (NIWA) and Doug Stewart (Environment Waikato) have been especially helpful with providing data for the Taupo catchment. I would also like to thank Kevin Buckley (VUW) for his help with the VUW Science Facility High Performance Computing Facility and Stacey Dravitzki for her help with some of the more tricky Matlab codes. I am also grateful to Genesis Energy Ltd., TrustPower Ltd., King Country Energy Ltd., and SCION Ltd for granting permission to use data for many of the sites within the catchment.

I am very fortunate to have many wonderful friends who have provided much entertainment and distraction over the last few years. I would like to particularly acknowledge Jan and Katrin - when I first started this adventure I didn't expect to make such great friendships. I am also grateful for the continued support and encouragement from my family. I am especially indebted to my sister, Joanna, for proof-reading my entire Thesis!

A big thank you goes to my girls, Elliot and Addison, for the many afternoon teaparties, Tinkerbell movies and make-believe fun - often welcome distractions and reminders of the really important things in life.

Finally, I would like to thank Stuart. Without his boundless support, understanding, encouragement and enthusiasm, this thesis would never have been started, or finished. 


\section{Table of Contents}

Introduction

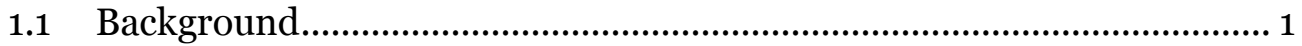

1.2 Reservoir inflow forecasting ................................................................. 3

1.3 Specific context of this work...................................................................... 3

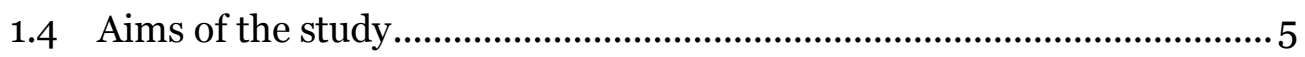

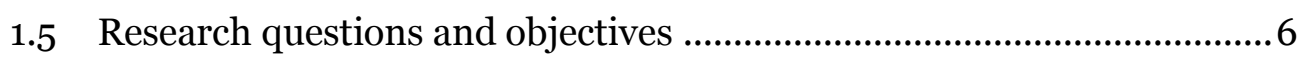

1.5.1 Hydrological objectives ...................................................... 6

1.5.2 Modelling objectives ............................................................ 6

1.5.3 Objective interactions ........................................................ 7

1.6 Structure of thesis ….............................................................................. 7

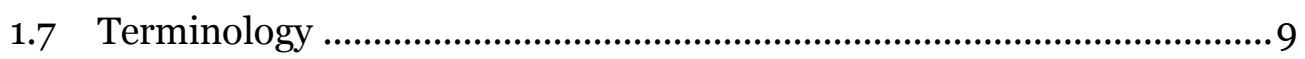

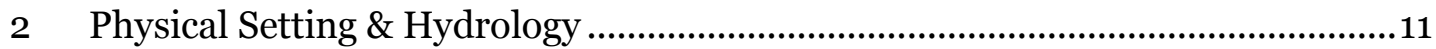

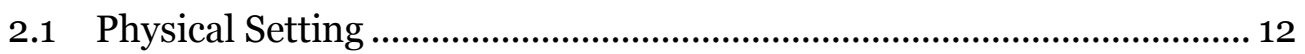

2.1.1 Location ................................................................................... 12

2.1.2 Tectonic setting and volcanic history ................................. 12

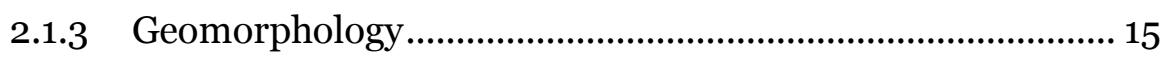

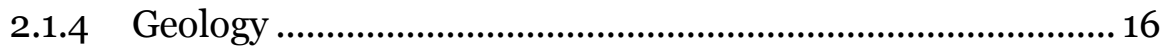

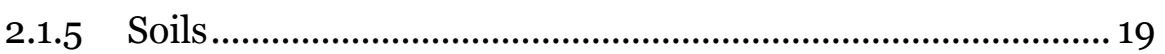

2.1.6 Vegetation and land use ................................................... 21

2.2 Climatology ...........................................................................................23

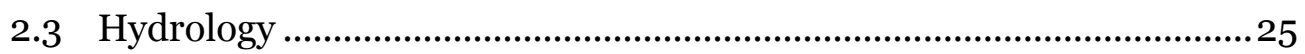

2.3.1 Surface water inflows to Lake Taupo.......................................25

2.3.2 Groundwater .......................................................................43

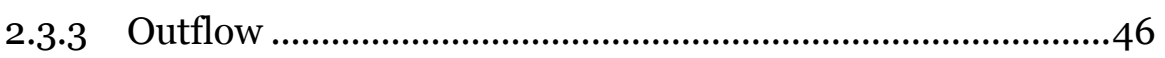

2.3.4 Lake level ..............................................................................4

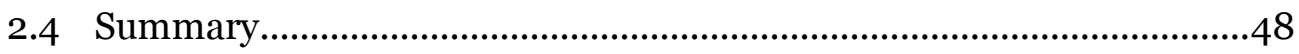

3 Rainfall-runoff modelling for reservoir inflow forecasting ................................. 51

3.1 General overview of rainfall-runoff models ......................................... 51

3.2 Rainfall-runoff modelling for reservoir inflow forecasting ....................5 54

3.3 Reducing uncertainty for more accurate and reliable model output....56

3.4 Summary 
4 Data availability, processing and preparation ......................................................65

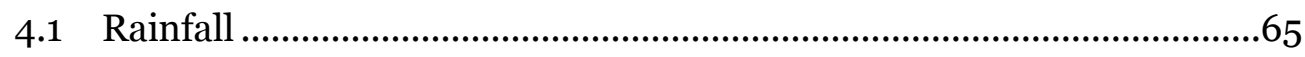

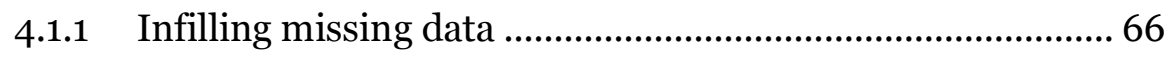

4.1.2 Estimation of catchment areal rainfall .............................. 70

4.2 Evapotranspiration..............................................................................73

4.3 Streamflow and Outflow ..........................................................................74

4.4 Lake level.......................................................................................78

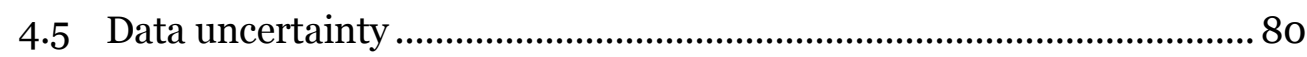

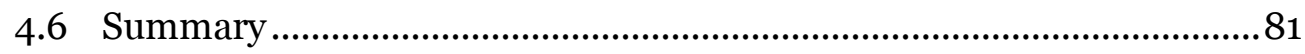

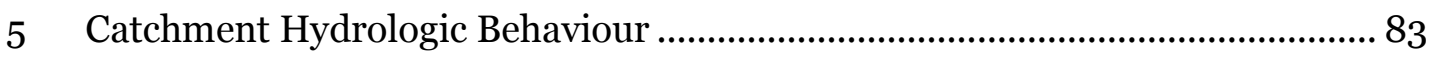

5.1 Catchment hydrologic response and behaviour .................................... 84

5.1.1 Effect of climatic attributes on catchment flow regimes ..... 84

5.1.2 Effect of physiographic attributes on catchment flow regimes........................................................................ 85

5.1.3 Effect of regulation on natural flow regimes .......................87

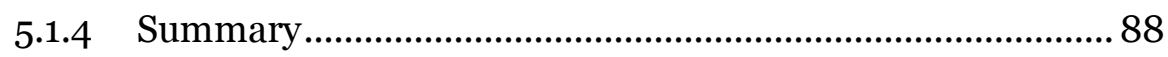

5.2 Assessment of catchment physical attributes in relation to

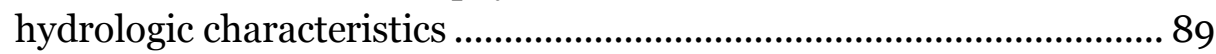

5.2.1 Hydrologic indices................................................................. 90

5.2.2 Climatic indices ............................................................ 94

5.2.3 Catchment physiographic indices ........................................95

5.2.4 Statistical analysis of relationships ....................................... 96

5.2.5 Impacts of regulation ........................................................97

5.3 Hydrological behaviour and response of the Lake Taupo catchment.. 98

5.3.1 Natural flow regimes ............................................................. 98

5.3.2 Impact of regulation on catchment runoff response ..........105

5.4 Conclusions ..............................................................................................106

6 A rainfall-runoff model for the Lake Taupo catchment ......................................111

6.1 Conceptual model structure................................................................... 112

6.1.1 Model Inputs ...................................................................... 113

6.1.2 Surface soil layer ................................................................. 115

6.1.3 Drainage to subsurface …......................................................117

6.1.4 Subsurface stores.............................................................. 118

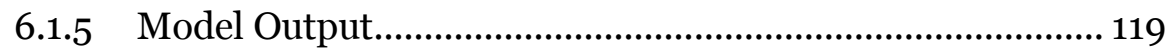

6.1.6 Numerical implementation ..............................................120

6.1.7 Summary....................................................................120

6.2 Calibration and evaluation data selection ......................................... 121

6.3 Model identification and calibration.................................................126

6.3.1 Monte Carlo simulations......................................................126 
6.3.2 Objective function ................................................................. 129

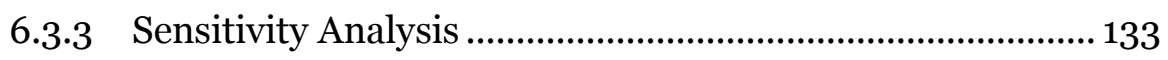

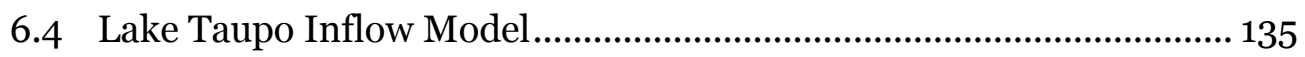

6.4.1 Unregulated Gauged Catchments .......................................... 135

6.4.2 Regulated Gauged catchments............................................ 136

6.4.3 Tongariro Power Scheme ......................................................141

6.4.4 Ungauged catchments ........................................................... 143

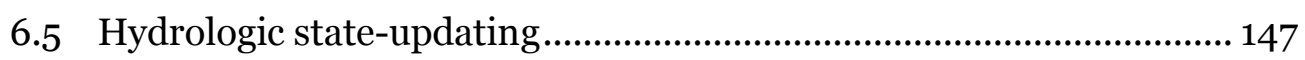

6.5.1 The Ensemble Kalman Filter................................................. 149

6.5.2 Perturbations to model states ..............................................151

6.5.3 Constraints .......................................................................... 152

6.6 Prediction of lake level changes .......................................................... 154

6.7 Model evaluation............................................................................... 155

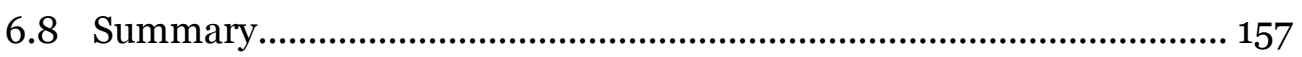

$7 \quad$ Model calibration and sensitivity analysis........................................................ 159

7.1 Sensitivity analysis ............................................................................... 159

7.2 Model calibration and parameter estimation results ..........................168

7.2.1 Unregulated catchments..................................................169

7.2.2 Regulated catchments.......................................................... 174

7.3 Conclusions........................................................................................... 18 .

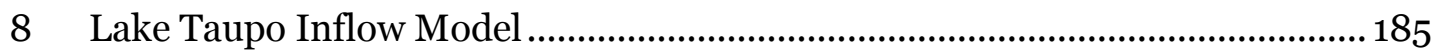

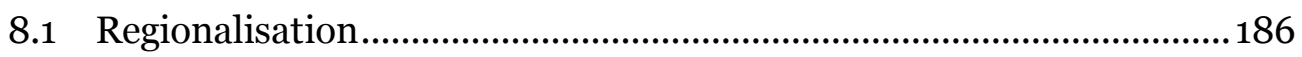

8.1.1 Catchment specific regionalisation .................................... 187

8.1.2 Regionalisation of remaining ungauged areas and direct groundwater contribution ......................................189

8.2 Tongariro Power Scheme (TPS) Statistical Probability Analysis......... 192

8.3 Lake Taupo Inflow Model performance ..............................................196

8.4 Constrained Ensemble Kalman Filter (EnKF) ....................................198

8.4.1 Filter performance ...............................................................199

8.4.2 Physically consistent state updating .................................. 204

8.4.3 Improving the accuracy of model predictions .....................207

8.4.4 Issues and possible improvements to the

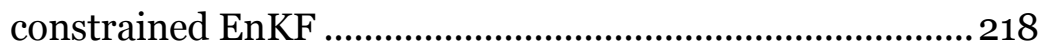

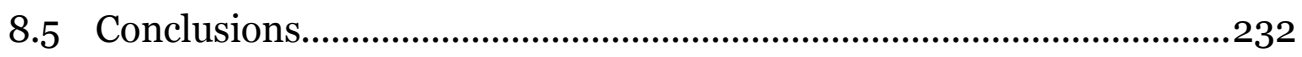

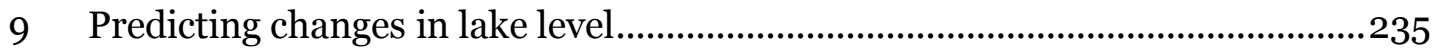

9.1 Dry/Drought Conditions .....................................................................237

9.1.1 August 2001......................................................................237

9.1.2 August 2003 …..............................................................245

9.1.3 May 2010 ...........................................................................253 
9.2 Normal operating conditions.................................................................261

9.2.1 November 2006...................................................................261

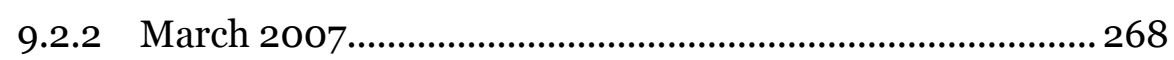

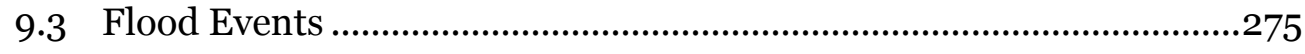

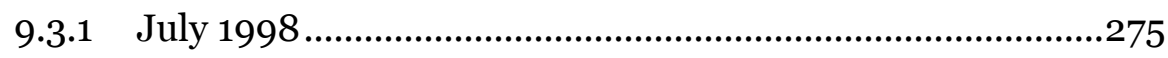

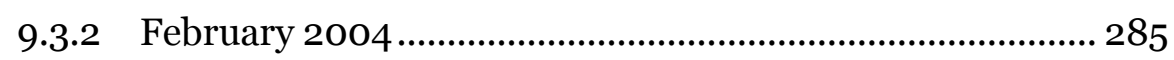

9.3.3 September 2010.................................................................... 293

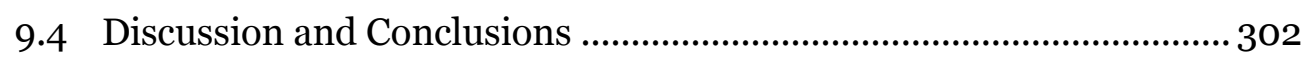

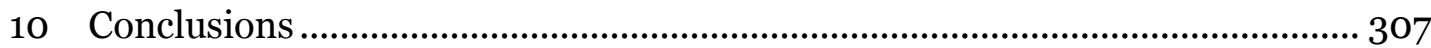

10.1 Main Contributions ............................................................................... 309

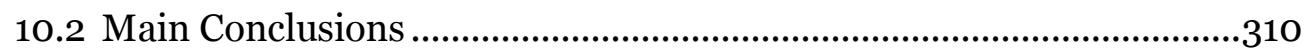

10.2.1 Dataset implications............................................................

10.2.2 Catchment hydrologic function ................................................. 311

10.2.3 Constrained Ensemble Kalman Filter...................................313

10.2.4 Lake Taupo Inflow Model......................................................314

10.3 Recommendations for future research ................................................. 315

10.4 Final Summary …............................................................................. 318

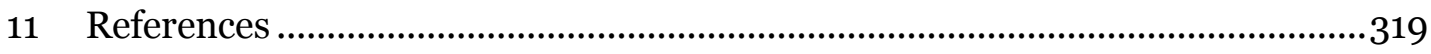

\section{Appendices}

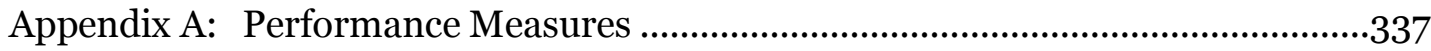

A.1 Background ........................................................................................337

A.2 Results and discussion ....................................................................... 338

A.3 Conclusions ................................................................................... 340

Appendix B: Sub-catchment hydrological analyses.................................................. 343

Appendix C: Sub-catchment model calibration and sensitivity analyses ............... 345

Appendix D: Bivariate Sensitivity Analysis …...........................................................347

Appendix E: Correlation Analysis: physiographic attributes and parameter values

E.1 Correlation analysis. 


\section{Introduction}

\subsection{Background}

Lake Taupo, located in the central North Island, is New Zealand's largest lake. It covers an area of $611 \mathrm{~km}^{2}$ and holds over $59 \mathrm{~km}^{3}$ of water. The lake is the effective source of the Waikato River along which the Waikato Power Scheme has been developed. This hydro system, operated by Mighty River Power Ltd, stretches over $160 \mathrm{~km}$ from the Taupo Control Gates to Karapiro. Figure 1.1 shows the location of the eight dams and nine power stations of the scheme. The scheme generates electricity for the national grid accounting for approximately $10 \%$ of New Zealand's electricity needs (Mighty River Power Ltd, 2007). The eight hydro dams have relatively little storage capacity and rely on the outflows from Lake Taupo, which holds $93 \%$ of the total storage for the system, for sustained flows throughout the year (Mighty River Power Ltd, 2008).

Outflows from Lake Taupo are carefully managed to be consistent with both operational requirements and energy demands. In accordance with resource consent obligations, lake levels must be kept within a $1.4 \mathrm{~m}$ operating range (which holds $0.855 \mathrm{~km}^{3}$ ) to reflect natural lake level fluctuations (Mighty River Power Ltd, 2007) ${ }^{1}$.

\footnotetext{
1 Current flood rules include a minimum outflow of $50 \mathrm{~m} 3 / \mathrm{s}$ (Opus International Consultants Limited, 2009). In drought conditions, if lake level drops below the minimum control level outflow from Lake Taupo must equal the inflows to the Lake, so outflow could be below $50 \mathrm{~m}^{3} / \mathrm{s}$. This situation has not yet occurred (pers comm. MRP 2011).
} 


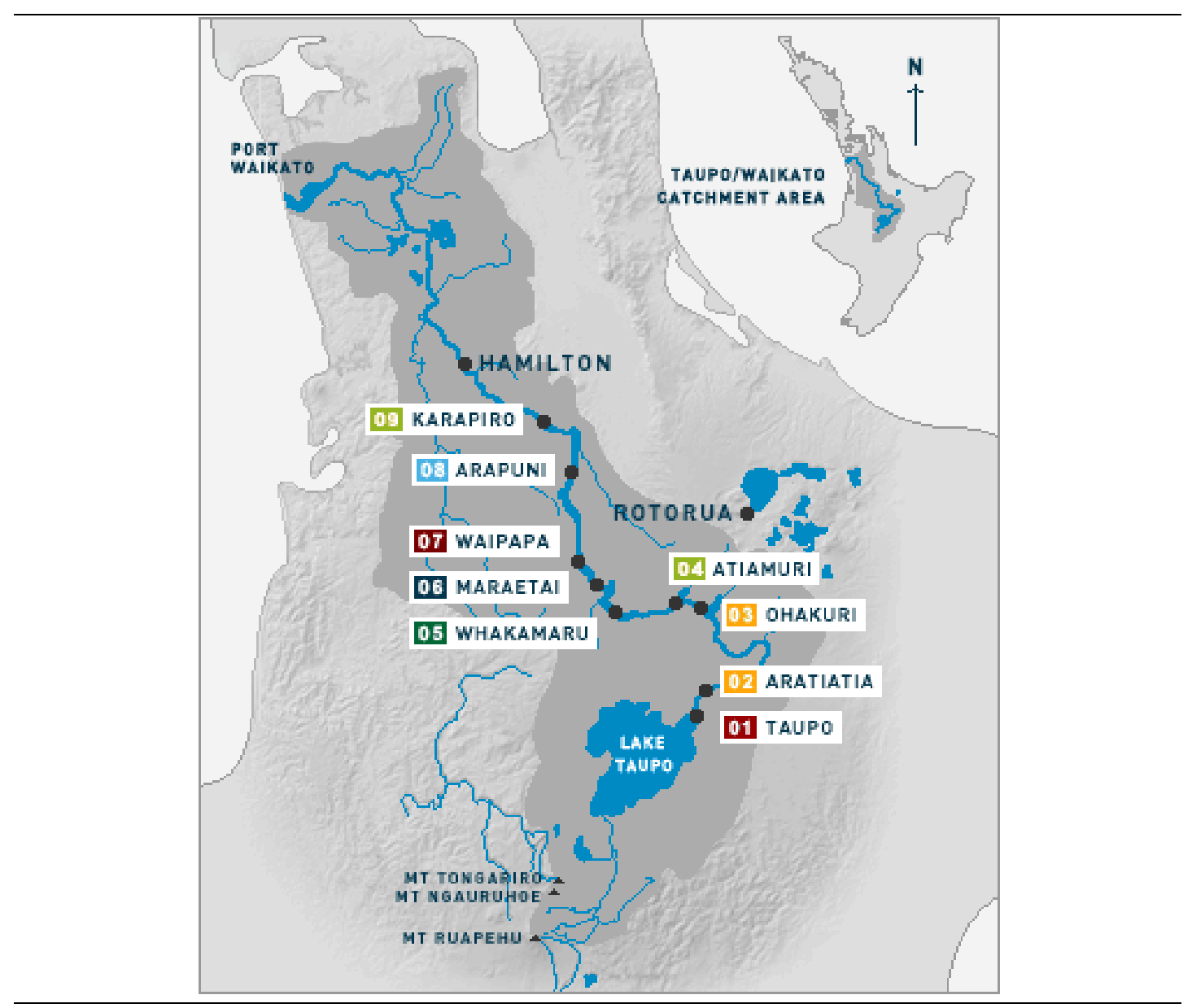

Figure 1.1 The Waikato Power Scheme is located along the Waikato River between the Taupo Control Gates and Karapiro. There are eight dams and nine power stations that make up this scheme. Source: Mighty River Power Ltd

This equates to only one percent of its volume being available for electricity generation. Consequently, although the lake holds a large amount of water, it is the timing and volume of inflows that effectively determine the amount of energy available for power generation.

Despite the importance of Lake Taupo to the Waikato Power Scheme and to New Zealand's electricity generation, inflows to Lake Taupo have not been previously modelled in any detail. The complex nature of the Lake Taupo catchment makes the determination of inflows challenging. Not only are outflows controlled for electricity generation but water is diverted into Lake Taupo from outside of the natural catchment and some natural inflows (approximately 29\%) are also controlled or affected by other hydro power schemes. Over $50 \%$ of the catchment is currently ungauged. 


\subsection{Reservoir inflow forecasting}

Rainfall-runoff models have been widely used to simulate regulated systems for the purpose of deriving reservoir operation policies, improving existing operation procedures, improving historic simulation for impact assessment, assessing the impact on streamflow regimes and for short-term inflow prediction (Amenu and Killingtveit, 2001; Collischonn et al., 2005; Druce, 2001; Hotchkiss et al., 2000; Hughes, 1992; Yang et al., 2005). In catchments where unregulated inflows entering regulated systems are modelled, this is a relatively straightforward task. The problem of reservoir inflow forecasting becomes more complicated when both regulated and unregulated inflows need to be modelled. The success of such applications is often limited by the availability (or lack thereof) of specific operational information.

With or without regulation, one of the challenges of traditional rainfall-runoff models is providing reliable and accurate predictions of streamflow. Model output is inherently uncertain because of simplifications in the model structure, estimated parameters and imperfect data. These sources of uncertainty should be reduced to acceptable levels. Data assimilation is being increasingly recognised as an essential part of any hydrological forecasting application (Liu et al., 2012, in review). Data assimilation via state-updating uses observations to correct for errors in driving data, a major source of uncertainty. When combined with a robust parameter estimation routine and constrained to be consistent with physical laws, it can reliably improve model output for more robust decision making.

\subsection{Specific context of this work}

The overarching aim of this study is to develop a model that can provide quantitative predictions of inflows to Lake Taupo and corresponding forecasts of lake level changes. As a predictive model, it should be computationally efficient and able to produce reliable and accurate forecasts within the lead time of the prediction interval for robust decision making. The highly regulated and complex nature of the Lake Taupo catchment and issues with data quality and availability can make determining and predicting inflows difficult. In this case, a model needs to be able to incorporate data and information relating to the regulation of inflows. However, there is relatively little guidance in the literature about how this regulation can be 
incorporated into traditional model structures, especially where data and information specific to dam operation and scheduling is not easily obtained.

Further, the output from such a model should provide accurate and reliable predictions of inflows to Lake Taupo, particularly if it is to be used operationally. However, models are simplifications of complex real world processes fed by imperfect data and estimated parameter values and as such their output is often subject to considerable uncertainty. If not adequately addressed, relatively large errors can accumulate, even in the short term. If decisions are to be made based on the output from such models it is imperative that this uncertainty is reduced to acceptable levels.

In this study, a semi-distributed conceptual model with an underlying physical basis is developed to forecast inflows to Lake Taupo. Various approaches are adopted to incorporate some of the regulation related to the three power schemes in the catchment. Classic Monte Carlo sampling methods are used for model calibration allowing quantification of parametric uncertainty. In conjunction with data assimilation through state-updating, all sources of uncertainty are addressed, resulting in more accurate model output. Further, it is demonstrated that by constraining the state updates, the reliability of forward predictions is improved. This is essential if model output is to be relied upon in decision making processes.

At present, there are no reported examples in the literature where state-updating is applied in a predictive hydrological model for a highly regulated catchment. Previous research has been largely theoretical or experimental with the aim to further advance the application of data assimilation in hydrology. Of the papers relating to operational examples (He et al., 2012; Komma et al., 2008; Madsen and Skotner, 2005; Seo et al., 2009; Seo et al., 2003; Vrugt et al., 2006), application has not been to highly regulated and complex catchments like Lake Taupo. Further, there are currently only a few examples in the hydrological literature where state constraints are considered (Pan and Wood, 2006; Wang et al., 2009). This study will, therefore, provide a practical application of a constrained state-updating technique. More generally, this body of work will contribute to existing knowledge of the hydrologic behaviour in the Lake Taupo catchment.

It was originally intended that a real-time, continuous predictive model would be developed. However, in April 2011 it was agreed that due to issues with obtaining the necessary input rainfall and flow data in "real time", the model could not be set 
up to operate in real-time. However, it would remain suitable for such operation, and have its capacity for forward prediction evaluated using historical data.

The predictive model used in this study has therefore been developed as a computationally efficient model to allow its use operationally, if desired. It should be relatively straightforward to modify the code to allow use of real-time data, if this can be provided as model input. Recalibration would be required if real-time input data was different to the data used to set up the model (i.e., if different rainfall and/or flow time series were used to drive the model).

\subsection{Aims of the study}

To date, inflows to Lake Taupo have not been explicitly modelled. The predictive model developed in this study is computationally efficient and can be used operationally. Its structure closely represents the hydrological characteristics of the catchment. Determining the model structure requires assessment of the physical and hydrological properties of the catchment and the variation of these properties between different sub-catchments. These structures cannot be determined without this hydrological analysis and may vary from sub-catchment to sub-catchment. Hence, using an existing model with predefined structures and parameters would be inappropriate. With this in mind, the aims of the present research are to:

- Investigate the physical processes controlling the movement of water through the Lake Taupo catchment by undertaking a thorough hydrological assessment of catchment physiographic, climatic and hydrologic characteristics;

- Predict the inflows to Lake Taupo and consequent changes in lake level by developing a rainfall-runoff model that accounts for the data available and modifications to river flows given the extensive hydro power development in the catchment; and

- Quantify the improvement in accuracy and reliability of model output through the use of data assimilation.

These aims are addressed by two distinct, but interacting, sets of objectives - a hydrological component and a modelling component which includes the development of the model and application of a data assimilation routine to reduce predictive uncertainty. 


\subsection{Research questions and objectives}

\subsubsection{Hydrological objectives}

The overall aim of this set of objectives is to provide a thorough hydrological assessment of the physical processes controlling the movement of water through the Lake Taupo catchment. This includes an analysis of each sub-catchment in terms of their specific hydrological regime with respect to catchment physical characteristics. More specifically, the questions to be addressed include:

- Based on the literature and analysis of hydrological data, what are the likely flow pathways in the Lake Taupo catchment and how do these relate to catchment soils, geology and vegetative cover?

- What does the sub-catchment's flow regime suggest about its response to rainfall and potential dominant flow pathways?

- How does groundwater contribute to sub-catchment flow regimes and inflows to Lake Taupo?

- What is the impact of hydro power schemes on river regimes and how do these affect the amount and timing of inflows to Lake Taupo?

- How can the information obtained above be used to guide the development of models predicting inflows from other catchments, both gauged and ungauged?

\subsubsection{Modelling objectives}

The overall aim of this set of objectives is to develop a rainfall-runoff model for the Lake Taupo catchment. For such a model to be useful operationally, it must be computationally efficient whilst producing accurate and reliable predictions. Therefore, as part of this objective an investigation of the sources of model output uncertainty and techniques for addressing these uncertainties is undertaken. Data assimilation is a significant component of this analysis and is used in conjunction with calibration routines to explicitly deal with model structure, parameter and data uncertainty. The performance of the model is evaluated against gauge observations and the accurate prediction of lake level. The questions to be addressed in the modelling component of the study include: 
- Can traditional models be used to represent highly regulated catchments such as Lake Taupo? What modifications may be required to improve their application in these contexts?

- How does parameter uncertainty impact on model output and how does data assimilation improve the accuracy of predictions?

- Can placing constraints on the data assimilation process improve the reliability of model output?

- To what extent can the process of model development provide further information and detail on the dominant flow paths, and hence model structure, within each sub-catchment given available data?

- What is the quality and reliability of the data available to model the catchment and where/how can it be improved?

\subsubsection{Objective interactions}

It is important to note that while the hydrological and modelling objectives are quite distinct in their aims they will also be used interactively to provide a more comprehensive understanding of the physical controls on runoff generation in the Lake Taupo catchment. Using information from existing literature and analysis of hydrological data the potentially significant physical processes will be identified and used to build a perceptual model of the Lake Taupo catchment and develop initial sub-catchment model structures. Conversely, the results from the process of model development and calibration will further inform the understanding of catchment hydrologic function and will provide more detail on the physical processes controlling the movement of water through the catchment.

\subsection{Structure of thesis}

Following on from this introductory chapter, Chapter Two provides a description of the study area. It begins with an overview of the tectonic and volcanic history of the catchment which has had a significant role in forming and shaping the catchment we see today. It also describes the soils and geology that are a result of this activity as well as vegetation and land cover. All of these have an influence on the hydrologic regimes within the catchment. The climatology and hydrology of the catchment is 
also covered in this chapter including a description of the various inflows from surface water (regulated and unregulated) and groundwater, lake level and outflow to the Waikato River. The individual sub-catchments are introduced providing a brief overview of their hydrological and physical characteristics.

Chapter Three provides the theoretical context of this study, providing a review of the relevant findings from the literature and previous research on rainfall-runoff models, uncertainty and data assimilation.

Chapter Four describes the various data available from the Lake Taupo catchment for analysis, model input, calibration and data assimilation. It discusses the strategies used to assess the quality and reliability of this data and some of the specific data issues overcome, in order to identify reliable periods for calibration, analysis and prediction.

Chapter Five provides an assessment of catchment hydrologic function and is the principal chapter for addressing the hydrological objectives. It includes a review of previous research and investigates the relationships between climatic and physical characteristics and a number of hydrologic attributes. The results of the analysis are used to build a perceptual model of the catchment and guide development of initial sub-catchment model structures and parameter estimation.

Chapter Six outlines the conceptual rainfall-runoff model structure used to model sub-catchments and the development of the Lake Taupo Inflow Model (LTIM). Inflow is categorised into four groups according to whether the catchment is regulated or not, and the length and quality of available data. Each group is modelled accordingly. Parametric and model structure uncertainty is addressed. Modelled inflows are then combined to estimate changes in lake level. A constrained Ensemble Kalman Filter approach is used to further improve model predictions by updating states with real-time observations of flow for each catchment for improved inflow and lake level predictions.

The remaining chapters provide an analysis and discussion of the developed model. The results from the calibrations and sensitivity analysis are presented in Chapter Seven. This information provides additional information about catchment hydrologic behaviour. The LTIM and assimilation framework is examined and evaluated in Chapter Eight. This includes a discussion of the model's performance, strengths and limitations, future work (including ways to refine model) and 
implications for hydrologic rainfall-runoff modelling of complex regulated catchments.

The performance of this model is evaluated over a number of events between 1998 and 2011. These results are presented and discussed in Chapter Nine.

The main findings, future research recommendations and research conclusions are provided in Chapter Ten.

\subsection{Terminology}

In this study, 'regulation' and 'regulated' refers to the flow of rivers which have been directly modified by hydro-electric power schemes. 'Unregulated' catchments are those which have not been affected or modified by hydro power schemes. 'Gauged' catchments are those in which the water levels have been monitored and subsequently converted to flow estimates using a stage-discharge rating curve. The terms 'discharge', 'streamflow' and 'flow' are used interchangeably and refer to the volume of water transported per unit of time, as defined in Harding et al. (2004). It may be reported in cumecs $\left(\mathrm{m}^{3} / \mathrm{s}\right)$ or millimetres ( $\mathrm{mm}$ per time step) in which streamflow is normalised by catchment area. Precipitation/rainfall depths are also reported in mm per time step. State volumes and fluxes are reported in millimetres depth and millimetres depth/time step, respectively, so they can be easily compared to rainfall data; actual volumes can be determined by multiplying by the catchment area. The terms 'states' and 'stores' are used to describe the four sub-surface flow pathways in a catchment, namely the soil state or store where water is initially absorbed before draining to the fastflow, interflow or baseflow stores. The term 'reservoir' is reserved for the artificially dammed lakes of hydro power schemes. The study aims to provide reliable predictions of inflows to and lake level of Lake Taupo. 'Reliability' refers to the confidence with which the model output can be used for decision-making purposes, and is primarily concerned with the 'accuracy' and 'precision' of model output. Following the definition presented in Bogner and Kalas (2008), 'accuracy' relates to the correctness of model predictions in relation to the magnitude and timing of flow. 'Precision' refers to the uncertainty associated with the model output. 
10 | Introduction 


\section{Physical setting and hydrology}

The Lake Taupo catchment is a result of a series of tectonic and volcanic events, including some of the most violent volcanic eruptions in the last 30,000 years (Manville and Wilson, 2004; Wilson et al., 1995). As a result most of the geology and soils derive from the region's volcanic origins, influencing sub-catchment hydrological characteristics and runoff response patterns. A comprehensive assessment of these factors is important for creating a robust understanding of the hydrology of the area.

This chapter describes the physical setting and hydrology of the Lake Taupo catchment. Section 2.1 provides an overview of the active tectonic and volcanic history of the catchment that has been pivotal in its formation. It describes the soils and geology of the catchment which result from this history and other factors which contribute to catchment hydrologic response and behaviour. The climatology of the catchment is discussed in Section 2.2 and covers the main factors controlling the amount of water available to runoff. Finally, the hydrological aspects of the catchment are discussed in Section 2.3. This section considers the direct inflows to the lake from surface water and groundwater. Lake level and outflow are also discussed. To aid clarity throughout this chapter, surface waters have been classified as regulated or unregulated. Where the natural river flow has been modified by an upstream hydro power scheme it is considered to be regulated. Natural inflows are referred to as unregulated and may be gauged or ungauged. Groundwater 
contributions to Lake Taupo refer to the direct contribution of groundwater into the lake through the lake bed.

Results from specific analysis of flow records for each sub-catchment are provided. Much of this information provides the basis for further analysis of catchment hydrologic function which informs the development of the perceptual model for the catchment and initial parameter estimates.

\subsection{Physical Setting}

\subsubsection{Location}

The Lake Taupo catchment is situated in the central North Island, New Zealand. The lake has a mean elevation of $356.7 \mathrm{~m}$ a.s.l and has an area of $611 \mathrm{~km}^{2}$. The surrounding natural catchment covers over $2829 \mathrm{~km}^{2}$ (excluding the lake), extending from Taupo, on the northern shores of the lake, south to the northern slopes of Mt Ruapehu (Figure 2.1). It is bounded to the west and east by the Hauhungaroa and Kaimanawa Ranges, respectively. The catchment rises steeply toward the summits of Mt Ruapehu (2797m a.s.l), Mt Ngauruhoe (2291m a.s.l) and Mt Tongariro (1968m a.s.l) in the south and to over $1500 \mathrm{~m}$ in the Kaimanawa ranges. Within this catchment there are over 30 tributaries that drain directly to the lake. In addition, diverted water taken from catchments outside of the natural Lake Taupo catchment also enter Lake Taupo via the TPS located south and south-west of the Lake Taupo catchment adding some $1200 \mathrm{~km}^{2}$ to the catchment's land area (see Section 2.3.1).

\subsubsection{Tectonic setting and volcanic history}

The hydrological characteristics of the Lake Taupo catchment are fundamentally linked to its active tectonic and volcanic history. The catchment is located in the central part of the $300 \mathrm{~km}$ long and $60 \mathrm{~km}$ wide Taupo Volcanic Zone in the central North Island, New Zealand. The TVZ is a broad structural depression formed as a result of back-arc rifting and westward sub-duction of the Pacific Plate in the last two million years (Wilson et al., 1984) and denoted by a SSW-NNE trending zone of volcano-tectonic activity represented by a chain of volcanoes from Ohakune to White Island (Davy and Caldwell, 1998; Houghton et al., 1995; Smith, 1991a; Smith et al., 1993; Wilson et al., 1995). 


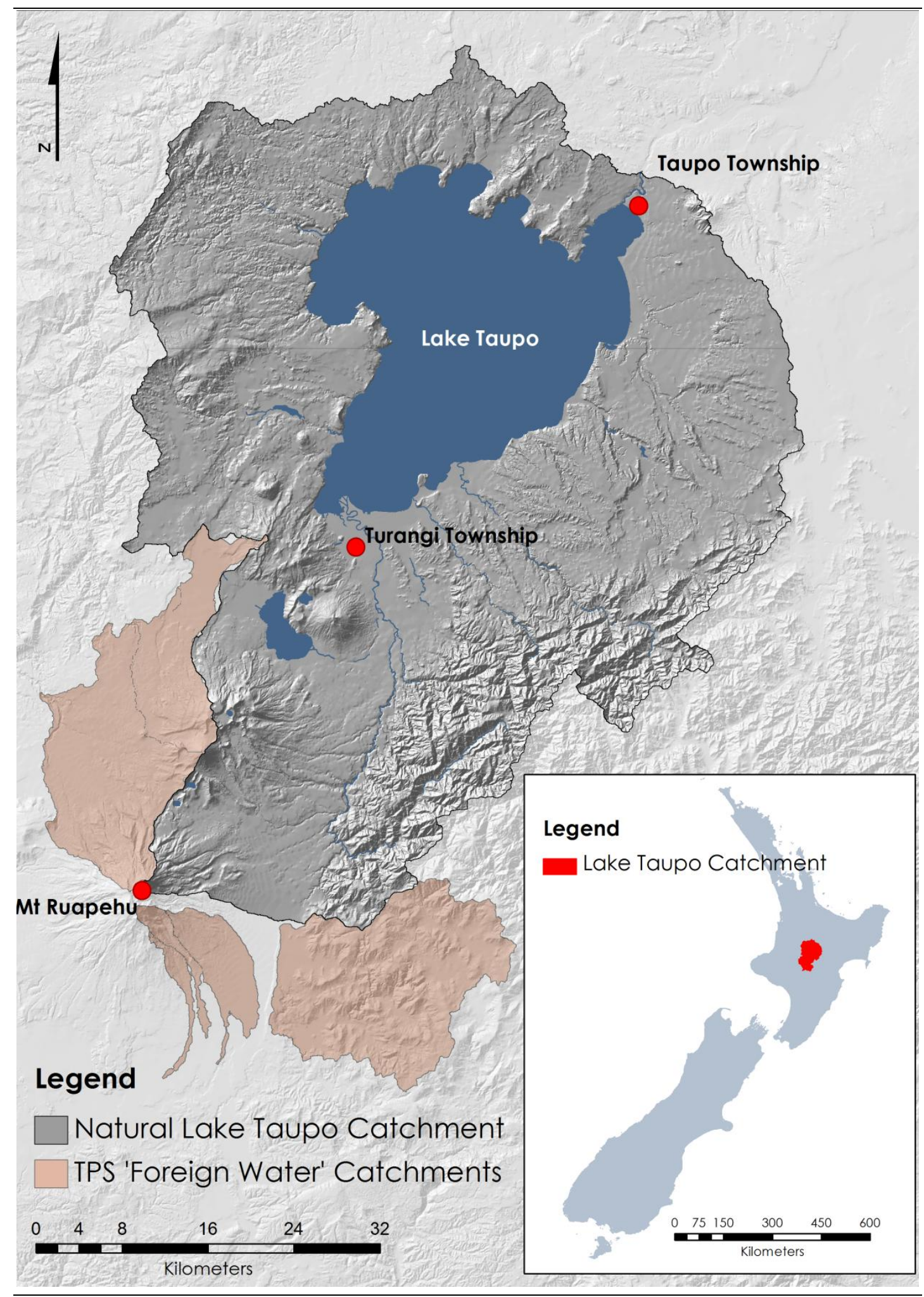

Figure 2.1. The natural Lake Taupo catchment is shown by the darker grey shaded area of the map. The beige areas represent the additional 'foreign water' catchments from which water is diverted into Lake Taupo via the TPS 
The formation and shape of Lake Taupo is a result of a series of volcanic and tectonic events. Tectonic processes of faulting and warping have shaped the catchment to the south and the Waihi fault scarp is visible along the south-western shoreline of Lake Taupo (Wilson et al., 1984). Although, the three andesitic volcanoes of Mt Ruapehu, Mt Ngauruhoe and Mt Tongariro are a prominent feature of the landscape in the south, activity from these volcanoes has not had a major influence on the forming and shaping of the Lake Taupo catchment. Instead it is the violent rhyolitic events of the last 65,000 years that Lake Taupo owes much of its existence (Davy and Caldwell, 1998; Manville and Wilson, 2004; Wilson et al., 1995).

The Oruanui eruption 25,400 years ago (Vandergoes et al., 2012, in review) was the most significant event in the formation of Lake Taupo. It is widely accepted that a large lake filled the Taupo-Reporoa basin for some time before the Oruanui eruption (Grange, 1937; Manville and Wilson, 2004; Smith et al., 1993). During the Oruanui event, a substantial caldera and collapse collar formed and large volumes of volcanic material was emplaced to create a barrier between the northern and southern portions of the pre-existing lake, forming the outline of the modern Lake Taupo. Davy and Caldwell (1998) located this caldera in the northern part of Lake Taupo from seismic reflection, magnetic and gravity surveys of Lake Taupo. Tectonic and volcanic activity continued over the next 25,000 years. Examination of fall deposit stratigraphies by Wilson (1993) have identified 28 eruptions since Oruanui, most of which occurred from vents along the eastern part of the Oruanui caldera. The Taupo eruption, 1800 years ago, was the largest of these and has been described as one of the most violent eruptions of the Holocene (Smith, 1991b; Wilson, 1985; Wilson and Walker, 1985). This event caused further caldera collapse and is responsible for the eastern shoreline of the present Lake Taupo (Davy and Caldwell, 1998; Wilson et al., 1997).

Vast amounts of volcanic material were erupted from both the Oruanui and Taupo eruptions modifying the surrounding catchment substantially. The volume of material erupted during the Oruanui eruption has been calculated by Wilson (2001). Using deposit stratigraphies, Wilson estimates approximately $530 \mathrm{~km}^{3}$ of material (magma equivalent) was generated from this event. Some ignimbrite deposits from this eruption are greater than $200 \mathrm{~m}$ thick in proximal places (Wilson, 2001). On a comparatively smaller scale, but by no means insignificant, the Taupo event radially emplaced $100 \mathrm{~km}^{3}$ volcanic material including $30 \mathrm{~km}^{3}$ of ignimbrite across 20,000 $\mathrm{km}^{2}$, mainly to the east of the vent (Wilson et al., 1995; Wilson and Walker, 1985). 
Vegetation was destroyed and valleys, basins and river networks were filled with up to $70 m$ of unconsolidated pumice material (Wilson, 1985).

On several occasions during its evolution, the lake was enclosed as eruption material emplaced from these eruptions blocked any outlet. The most notable was after the Oruanui eruption when lake levels rose to around 500m above sea level (a.s.l). At this height, the lake overtopped and drained initially through Waihora Bay, north west of the Lake, before a catastrophic outbreak flood established the modern outlet (Manville and Wilson, 2004). Manville \& Wilson (2004) suggest evidence of this lake level height can be seen in the north and west of the catchment by a series of highstand terraces.

During the Taupo eruption, the lake outlet was blocked again. During this event most of the water that filled the lake was expelled (Smith, 1991b; Wilson et al., 1997). Using modern inflow rates, Wilson et al. (1997) estimate it took approximately 15 years for the lake to refill to $390 \mathrm{~m}$ a.s.l $(+34 \mathrm{~m}$ above present lake level) but quickly dropped with another outbreak flood, leaving behind a complex sequence of shoreline terraces and deposits, most obvious along the eastern margin of the lake (Wilson et al., 1997).

Since the Taupo eruption, evolution of the catchment has continued largely though tectonic processes and the reworking and transport of sediment through rivers into the lake and along the shoreline (Hicks et al., 2000).

\subsubsection{Geomorphology}

The geomorphic and sedimentary response of the Lake Taupo catchment to the Oruanui and Taupo eruptions has been documented by Manville and Wilson (2004), Manville et al. (1999), Manville (2002), Smith (1991a) and Smith (1991b).

Large volumes of material were erupted during the Oruanui and Taupo events destroying vegetation and hydrologic networks as valleys, basins and rivers were filled with the unconsolidated material. Intense erosion and deposition is likely to have occurred since the lack of vegetation and erodible nature of the volcanic deposits would have increased sediment yields and surface runoff until hydrologic networks stabilized and vegetation was re-established (Manville, 2002). Consequently, post-eruption erosion and sedimentation activity along with littoral processes played a considerable role in the shaping of the surrounding catchment and shoreline of Lake Taupo. 
Lake Taupo's western bays are dominated by steep cliffs that form the topographic rim of the Oruanui caldera basin. Manville and Wilson (2004) suggest mass wasting and scarp retreat from post-eruption erosion by reforming streams back to more resistant ignimbrite lithologies have created the arcuate embayments characteristic of this area. Along the northern margin, ryholitic domes from pre-Oruanui activity form the headlands of a series of bays which are intersected by NNE-striking faults of the Taupo Fault Belt (Manville and Wilson, 2004).

In contrast, the eastern shoreline is characterised by volcanic sediments, largely from the Taupo eruption, 1.8ka. In a study of the lakeshore geomorphic processes of the Lake Taupo catchment, Hicks et al. (2000) suggest that as a consequence of the abundance of material available to erosion and deposition, there are more sedimentary segments along the eastern shoreline. This material has been transported out of the rivers and into the lake which has been reworked by littoral processes along the eastern shoreline, forming a series of cuspate forelands.

In the south of the catchment, the Tongariro delta is a prominent shoreline feature. The delta has formed from the continued remobilsation and deposition of material into Lake Taupo by the Tongariro River. Hicks et al. (2000) suggest low wave energy in the area has limited dispersion of this sediment further along the coast, allowing the delta to prograde or extend further lakeward. The eastern flank of the delta is fronted by beach ridges due to its exposure to $30 \mathrm{~km}$ of northerly fetch. The western flank is more sheltered and is dominated by fluvial processes (Hicks et al., 2000).

There are also a series of terraces around the catchment reflecting higher lake levels since the Taupo eruption, $1.8 \mathrm{ka}$. Particularly evident in the Waitahanui area is a highstand terrace approximately 35m above current lake levels (Wilson et al., 1997). This level reflects the highest lake level immediately after the Taupo eruption when the outflow to the lake was blocked. Wilson et al. (1997) suggest that drainage was rapid and the level of the lake dropped to around 2-5m above current levels. Lowlevel terraces of this lake level are also evident in the Waitahanui area and in the southeast areas of the Tauranga-Taupo and Waimarino Rivers (for map showing the locations of these rivers, refer to Figure 2.5).

\subsubsection{Geology}

Not surprisingly, most of the soils and geology in the Lake Taupo catchment derive from the region's volcanic origins (Figure 2.2). The geology of the area has been reported by Froggatt (1981), Grange (1937), Grindley (1960), Hadfield et al. (2001) 
and the Institute of Geological and Nuclear Sciences (2008). Ignimbrites from the Oruanui and Taupo events can be found in most areas of the catchment while older Whakamaru ignimbrite is mainly found in the west with rhyolitic pyroclastics and lava domes along the northern margin. In the south, andesitic ashes and lava which mantle Mt Ruapehu, Mt Ngauruhoe and Mt Tongariro are surrounded by postglacial alluvium and lahar deposits. Mesozoic indurated sediments (greywacke) and tertiary marine sediments flank the catchment to the east and west (Hadfield et al., 2001; Houghton et al., 1995; Wilson et al., 1995). Figure 2.2 maps the main geological units across the catchment; each of the main geological lithologies (not shown in Figure 2.2) is briefly described below.

Ignimbrite: The ignimbrite lithologies that are found on the Taupo catchment range in degree of welding and permeability. The oldest ignimbrites are of the Whakamaru group (320-340 ka), found largely found in western areas of the Lake Taupo catchment and forming the topographic rim of the lake itself along the

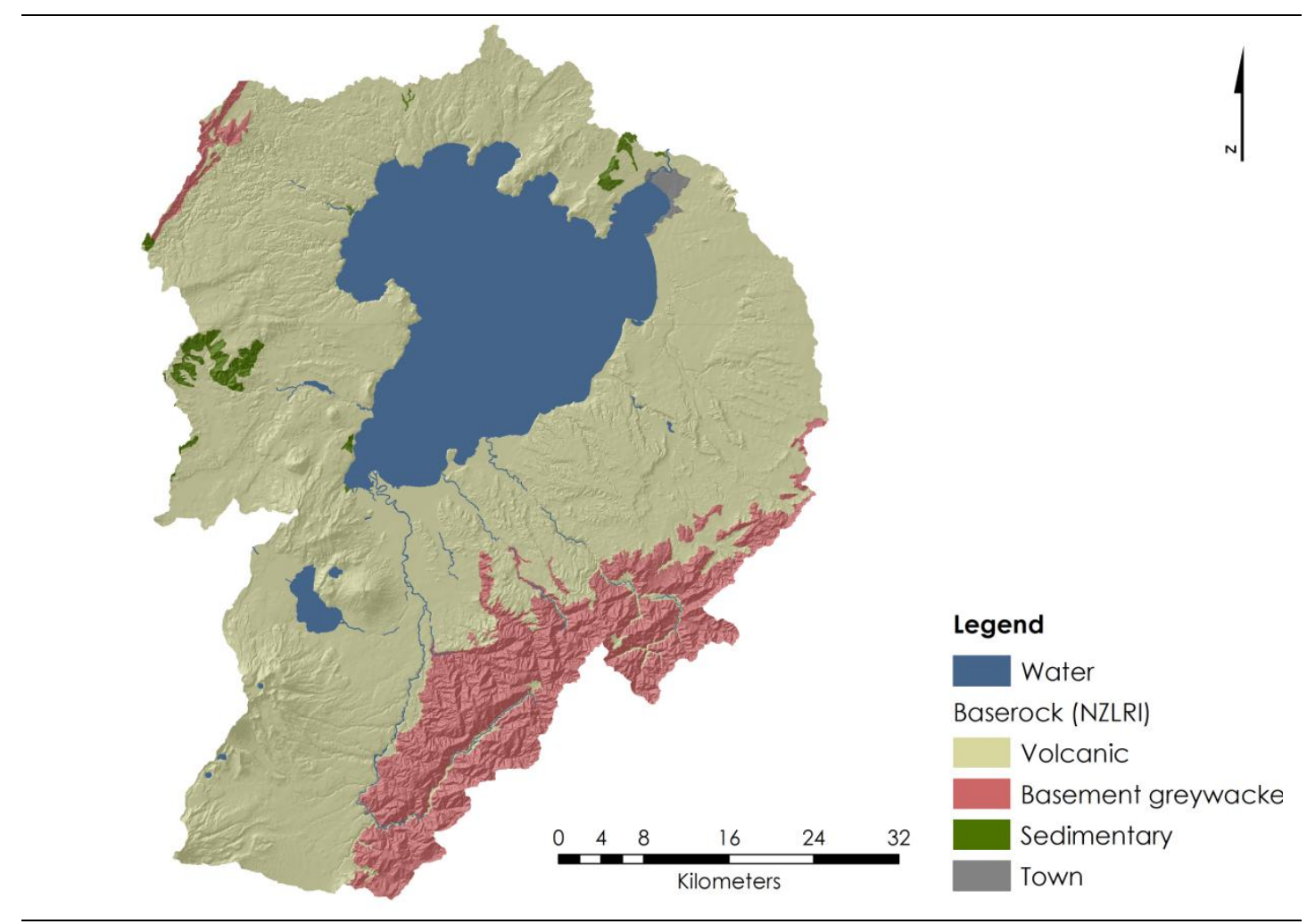

Figure 2.2. The geology of the Lake Taupo catchment is dominated by volcanic lithologies with basement greywacke found in the higher elevation areas of the catchment in the south-east and smaller amounts in the west. Source: New Zealand Land Resource Inventory (Landcare Research - Manaaki Whenua (NZ), 2008). 
western margins. Whakamaru ignimbrite is also found in the north-east of the catchment, north of the Waitahanui River headwaters. Whakamaru ignimbrite is the least permeable and more welded than the younger Oruanui (25.4 ka) and Taupo ignimbrites (1.8 ka) (Hadfield et al., 2001). Oruanui ignimbrite is found in the lowland areas of the western and northern areas of the catchment and in large areas of the east and south-east. Taupo ignimbrite, emplaced during the Taupo eruption, is most prevalent in the eastern parts of the catchment, although is also found in areas of the south west and north. Both of these two lithologies are of an unwelded nature, but it is the Taupo ignimbrite which has the highest permeability as the Oruanui ignimbrite is characterised by much finer grain size (Hadfield et al., 2001).

Rhyolitic domes and pyroclastics flows: Rhyolitic domes (3-320 ka) mainly appear in the north and south-west of the Lake Taupo catchment. Most lie in the age range 100-30oka and some have associated pyroclastics materials (Hadfield et al., 2001). Two groups of rhyolitic pyroclastics are exposed in the northern bays and in the western headland of Tapuaeharuru Bay. The older series (150-320 ka) are more welded and indurated than the younger formations (25.4-320 ka) which are have higher permeability (Hadfield et al., 2001).

Andesites: There are five andesitic volcanoes that make up the Tongariro volcanic centre - Ruapehu, Ngauruhoe, Tongariro, Kakaramea and Pihanga (Grindley, 1960). The volcanoes are surrounded by a ring-plain of lahar material. Vant and Smith (2004) note that these andesites have low water storage. Pre-Quaternary (>1.6 Ma) Hauhungaroa lahars overlay Urewera greywacke in the east of the catchment. Hadfield et al. (2001) state that these formations have lower permeability than the younger formations discussed above.

Greywacke and schist: The oldest of these lithologies is the Kaimanawa Schist (Permian-Mesozoic) which crosses the Kaimanawa Ranges from the south-east in a north-east direction and is flanked by Kaimanawa greywacke (Grindley, 1960). This upthrust greywacke block, fronted by Kaimanawa Fault, is the most extensive in the catchment. Kaweka greywacke extends east and north-east of the Kaimanawa greywacke block to form the headwaters of the Waitahanui River. To the west of the catchment, the Hauhungaroa Fault fronts an upthrusted block of Urewera greywacke to the west. Hadfield et al. (2001) note that these pre-Quaternary rocks are likely to be of lower permeability than any younger formations. 


\subsubsection{Soils}

Most of the soils around the Lake Taupo catchment derive from the tephra and ashes from the Taupo eruption (Gibbs, 1968; Molloy, 1998; Rijkse, 1987). The soils of the catchment have a significant influence on its runoff response to rainfall. The volcanic ash and pumice readily absorb water that falls on them allowing percolation to groundwater which feeds many of the rivers and streams in the catchment (Roper, 2001; White, 2001). A detailed analysis of the soils in the Taupo region was undertaken by the Department of Scientific and Industrial Research (Rijkse, 1987)2 . Pumice soils are most prevalent (Figure 2.3) but are covered by Ngauruhoe and Ruapehu ashes from more recent activity in the south of the catchment. The generally sandy or gravelly texture of pumice soils means they are porous and well-draining, allowing rapid movement of air and water while still capable of storing large amounts of water for plants (Molloy, 1998). Development of soils on the volcanoes of the Tongariro Volcanic Centre is constrained by frequent volcanic eruptions (Schouten et al., 1981) resulting in mostly raw and recent soils in this area. Smaller amounts of podzols and allophonic soils are found predominantly in the south west while organic/gley soils have developed in marsh and wetland areas (for example, around the Tongariro delta). The following is a brief overview of the different soil types (by order) found in the Lake Taupo catchment.

Pumice Soils: These soils mostly derive from the Taupo eruption $1.8 \mathrm{ka}$ and cover most of the Lake Taupo catchment. They are sandy or gravelly soils dominated by pumice, or pumice sand with a high content of natural glass (Hewitt, 1993). Clay contents are generally low (Hewitt, 1998). These soils are highly porous allowing excess water to be drained rapidly while still capable of storing large amounts of water for plants. The potential for erosion by water is high (Hewitt, 1998).

Podzols soils: Found in the higher altitude and higher precipitation areas of the catchment, podzols soils are strongly acidic. They tend to coincide with areas of forest cover which produce an acid litter (Hewitt, 1998). These soils have generally slow permeability (<4 mm per hour (Clayden and Webb, 1994)) and limited root depth (Hewitt, 1993).

Allophanic Soils: These soils are dominated by allophane minerals and generally occur in North Island volcanic ash where rainfall is greater than $1000 \mathrm{~mm} / \mathrm{a}$. They

2 A soils portal is also available online at Landcare Research. This portal provides detailed maps of soil patterns across New Zealand, http://www.landcareresearch.co.nz 


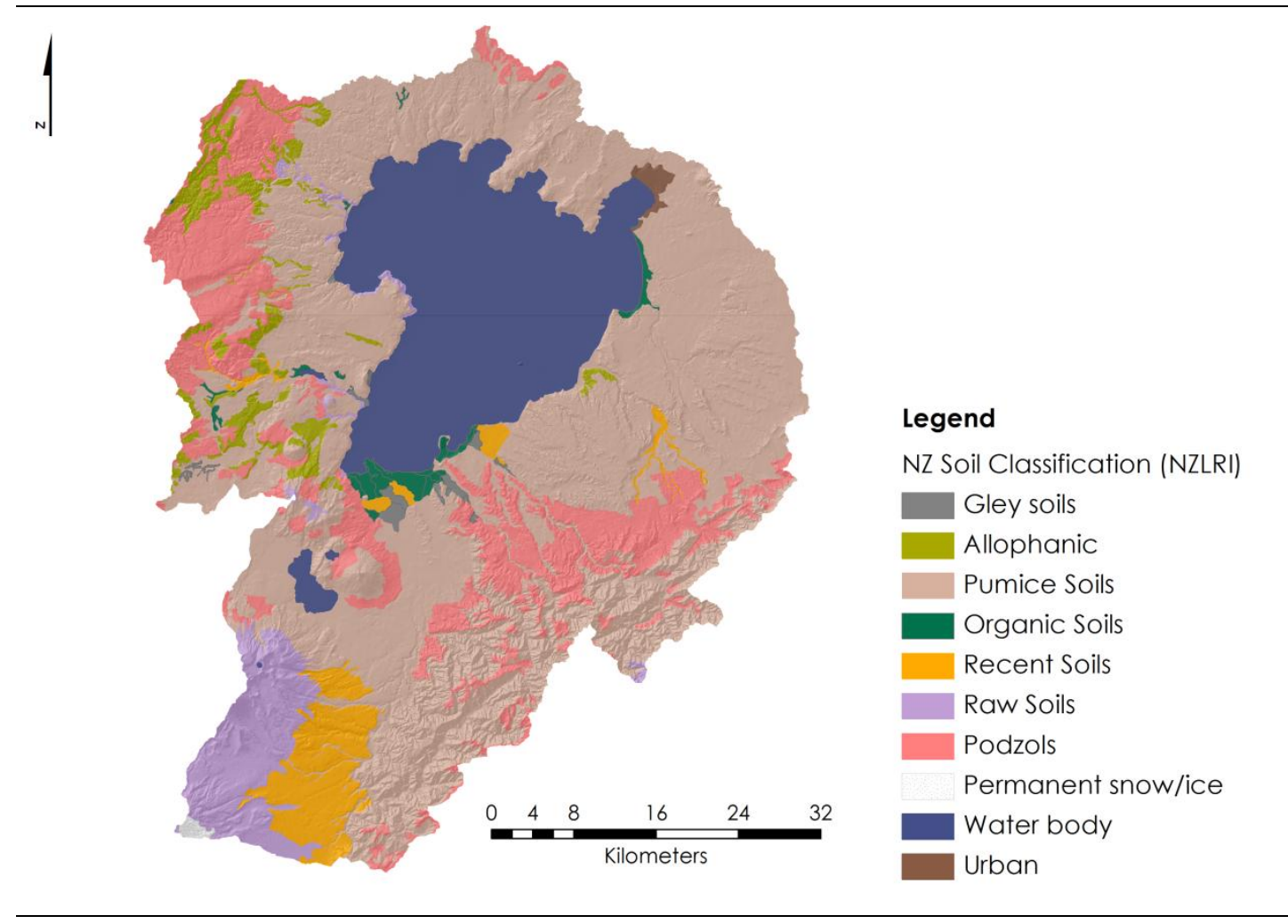

Figure 2.3. Pumice soils are most prevalent in the Lake Taupo catchment although substantial areas of podzols are found in forested areas. In the south recent and raw soils are found on the slopes of the three volcanoes of the Tongariro National Park. Source: New Zealand Land Resource Inventory (Landcare Research - Manaaki Whenua (NZ), 2008)

are characterised by rapid permeability $(72->288 \mathrm{~mm}$ per hour (Clayden and Webb, 1994)) and high water retention and are generally well drained (Rijkse, 1987). Clay content generally ranges between $10 \%$ and $25 \%$ (Hewitt, 1998). There is little resistance to root growth and erosion (Hewitt, 1993).

Raw Soils: Raw soils are predominantly found in the andesitic areas of the Tongariro Volcanic Centre and areas of active erosion or deposition (Rijkse, 1987). This continued activity allows the raw soils in these areas to remain young (Hewitt, 1993). Vegetation cover on these soils is generally sparse due to their low bulk density and water-holding capacity (Molloy, 1998).

Recent Soils: Like pumice soils, recent soils have high plant-available water capacity. However, they are generally weakly developed and occur mainly on young land surfaces such as the lower steep slopes of the three volcanoes of the Tongariro National Park and areas of alluvial floodplains (Hewitt, 1993). They generally have deep rooting depths and good drainage but can be susceptible to flooding or erosion (Rijkse, 1987). 
Organic Soils: Formed in the partly decomposed remains of wetland plants (peat) or forest litter where the water table is permanently high (Gibbs, 1968), organic soils have high total available-water capacity but poor drainage (Hewitt, 1993; Rijkse, 1987).

Gley Soils: These poorly drained soils are strongly affected by waterlogging. They generally occur in areas with high groundwater-tables and can remain saturated for prolonged periods of time (Rijkse, 1987). Together with organic soils, they represent the original extent of New Zealand wetlands (Hewitt, 1993).

\subsubsection{Vegetation and land use}

The Oruanui and Taupo eruptions obliterated vegetation in the area, hence having a substantial impact on catchment hydrologic budgets, sedimentation and erosion. After the Taupo eruption, native vegetation was re-established and by the time the first people arrived 700 years ago, podocarp/hardwood forest was widespread in the Taupo basin (Leathwick et al., 1995).

Maori settled largely around lakes and bush edges (Williams and Walton, 2003). While there was a wide range of local resources at the time, by the $16^{\text {th }}$ century fire was used to clear land for bracken and cultivation. McGlone (1983) argues land clearance also allowed Maori to move more freely around the catchment, allowed expansion of settlements and improved settlement security and also promoted hunting. However, despite modification land cover was still dominated by indigenous species that were able to regenerate, in some cases rapidly, in the absence of subsequent burning. Clearance of natural vegetation accelerated with the arrival of the European settlers in the early to mid $-19^{\text {th }}$ century.

Clearance by Maori is also thought to have increased at this time with the introduction of new crops, tools and animals (Williams and Walton, 2003). However, Leathwick et al. (1995) conclude that the impact of European modifications were more severe with greater intensification and introduction of exotic species. Leathwick et al. (1995) have mapped current and historic (c1840) natural vegetation coverage of the Waikato Region from early aerial photographs and data from a number of historic sources. They found that indigenous forestry was reduced to $25 \%$ of its original area in the Waikato Region by the early 1990 . However, they concluded that the extent of primary forest and scrub in the Taupo basin was still $70 \%$ of its original area over the same period. The amount of secondary forest and scrub was reduced by nearly $85 \%$, probably due the 
widespread conversion to exotic plantation (Leathwick et al., 1995). Figure 2.4 illustrates the vegetative land use in the catchment. The south of the catchment remains largely undeveloped. A large portion of this area is encompassed in the Tongariro National Park, a UNESCO World Heritage site for its cultural and ecological values. Active volcanism still continues. The majority of this area is lightly vegetated with some tussock grassland on the slopes of the three volcanoes that dominate this part of the catchment. Indigenous forestry is present in the eastern side of this area. Most of the active land use is on the rhyolitic lowlands which are permeable and well-draining. Pastoral farming systems were introduced but the Lake Taupo catchment did not become a productive pastoral region until cobalt was added to the nutrient poor pumice soils in the 1930 (McKinnon, 2007). Pasture is widespread in the north and west of the catchment (Schouten et al., 1981). In more recent years concerns are being raised regarding water quality, as farming practices involve the application of nitrogen and other chemicals which could impact Lake Taupo's oligotrophic ${ }^{3}$ status.

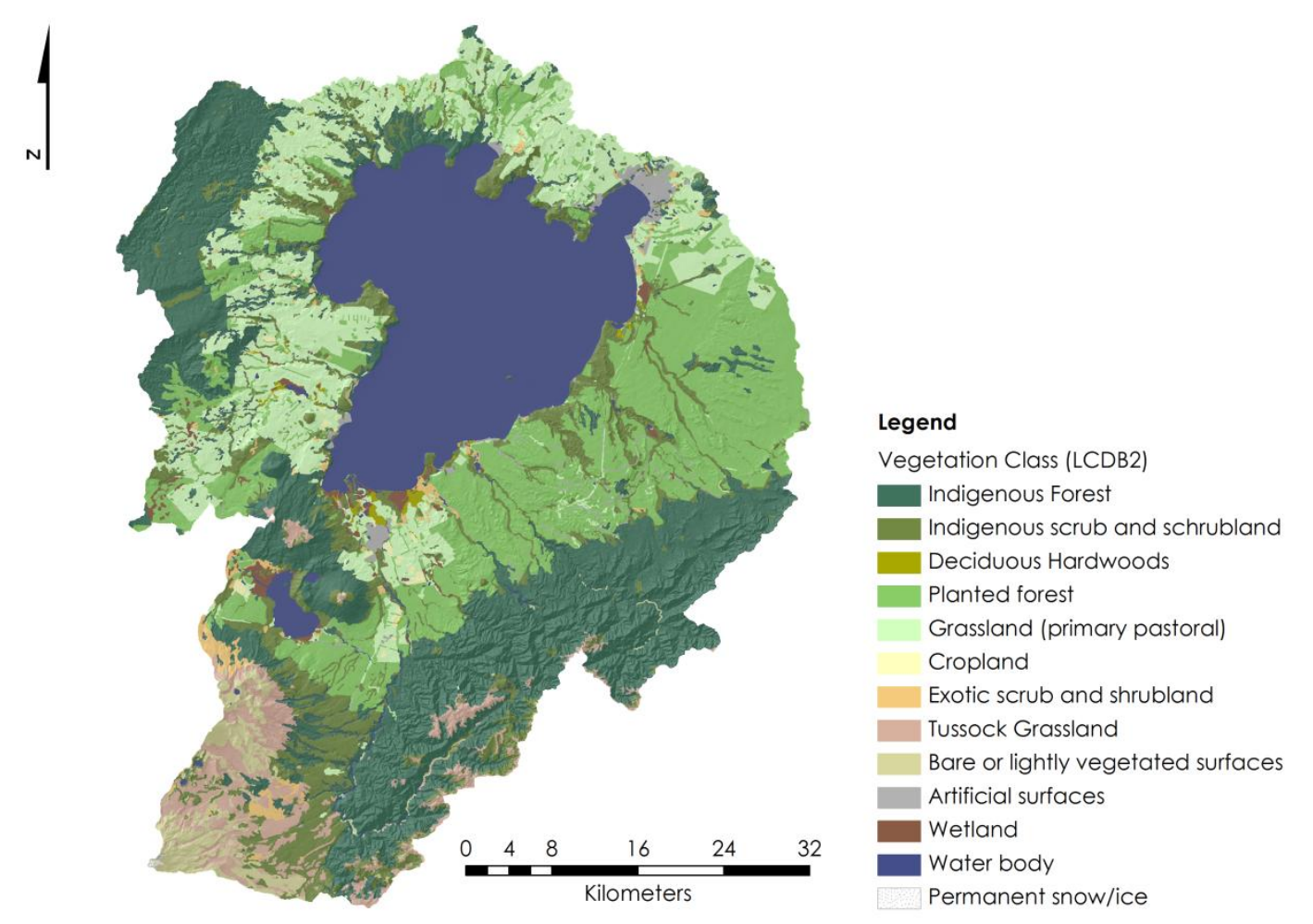

Figure 2.4. Vegetative land use of the Lake Taupo catchment from the New Zealand Land Resource Inventory. Indigenous forests are mainly restricted to higher elevation areas. Pastoral areas are mostly found in the west and east. Exotic forestry is common in the east. Source: New Zealand Land Cover Database 2 (Ministry for the Environment, 2004)

3 'Oligotrophic' is defined as water that is low in nutrients, hence with a relatively low organic productivity (Harding et al., 2004). As a result, Lake Taupo has low algal production, and consequently, very clear water. 
Large tracts of lowland areas of the Lake Taupo catchment, previously covered in scrub or primary forest, have been converted to exotic plantations and pastoral farming. Consequently, native forestry has been confined largely to the higher elevation areas, more specifically, the less permeable greywacke but higher rainfall regions of the Hauhungaroa and Kaimanawa Ranges (Schouten et al., 1981). This transformation from forest to pasture (and vice versa) can have a significant impact on the soils and hydrologic characteristics of catchments.

In pumiceous catchments, like Lake Taupo, the effect can be considerable (Selby, 1972). Some vegetation cover, such as forest and scrub, increases interception, reduces sediment yield and lowers runoff acting to stabilise the landscape. In a study of the relationship between land use and erosion on the pumice soils of the Otutira catchment (a tributary catchment of Lake Taupo), Selby (1972) conducted experiments on the runoff, infiltration and erodibility characteristics from scrub, ungrazed pasture and grazed pasture. Using a purpose-built rainfall-simulating infiltrometer, Selby was able to assess the infiltration of precipitation into the soil over various vegetation covers and on slopes with angles between $0^{\circ}$ and $30^{\circ}$ without disturbance. The analysis highlighted that infiltration was higher for soils that already had high moisture levels at the start of the experiment. Runoff plots in the same catchment were used to determine the surface water runoff characteristics under various vegetation covers. Runoff from pasture was higher than from less developed scrub and ungrazed grass vegetation. In particular, Selby noted that under intense precipitation events, the resistance to infiltration under dry soil moisture conditions can increase surface runoff until the soil is wetted up. Selby (1972) concludes that while plant roots and organic matter can act to inhibit erosion, it is the low density and easy entrainment of soil particles that allows these soils to be eroded.

\subsection{Climatology}

Major influences on the Lake Taupo climate are its location, elevation, and topography. The Hauhungaroa Ranges rise to around 100om a.s.l doing little to block the prevailing westerly wind. As these air masses approach the higher Kaimanawa Range they are forced to ascend and consequently release precipitation to the west of this divide (Thompson, 1984). From the south and east, air masses are blocked by the Kaimanawa Ranges and the volcanoes of Mt Ruapehu, Mt Ngauruhoe and Mt Tongariro. The catchment's inland location and the sheltering conditions of 
the surrounding topography make the lowland areas of the catchment some of the least windy areas of New Zealand, while the existence of the cooler lake surface inhibits convection to descending cold air masses, producing frequent clear, calm conditions (Thompson, 1984).

Rainfall in the catchment is strongly influenced by topography and is consequently unevenly distributed. Rainfall is highest in the mountainous regions to the south and east with an annual average of $>4000 \mathrm{~mm}$ recorded on the flanks of $\mathrm{Mt}$ Ruapehu. Taupo township experiences the least rainfall with an annual average rainfall of less than $1200 \mathrm{~mm}$. Rainfall is, however, fairly uniformly distributed throughout the year, with slightly more (30\%) falling in winter months. It is generally lowest in the summer months and early autumn (January-March) although Thompson (1984) notes this period is also characterised by the highest variability. More frequent and intense rain is experienced in the mountainous regions of the catchment (Thompson, 1984).

Snow is considerable in the higher elevations of the south. Fitzharris et.al. (1999) estimate winter snowlines can be as low as 1400m a.s.l in the North Island. Snow can fall on the mountains at any time during the year but is less common at lower elevations (Thompson, 1984). Most of the snowfall occurs in the Tongariro Catchment.

Potential evapotranspiration rates are calculated by NIWA using the PenmanMonteith potential evapotranspiration (PE) method (see Burman and Pochop (1994), as cited on NIWA's National Climate Database). Annual average PE for Turangi is $852 \mathrm{~mm}(2003-2008)$ and $823 \mathrm{~mm}$ for Taupo (1970-1994). There are obvious seasonal fluctuations in $\mathrm{PE}$ in the catchment. $\mathrm{PE}$ rates are highest in summer and the maximum amount recorded in any one day was $8 \mathrm{~mm}$, recorded at Turangi in January 2006. In winter, PE has been as low as zero and often less than one millimetre per day. Schouten et al. (1981) suggest evapotranspiration rates will be higher for areas of exotic forestry but lower in the cooler mountainous areas of the catchment.

Due to its inland location away from the effects of the Pacific Ocean and Tasman Sea the climate of this catchment is also characterised by large fluctuations in temperature and extremes (Thompson, 1984). Annual average daily temperatures in lowland areas of the catchment are approximately $12^{\circ} \mathrm{C}$, although mean daily temperatures can range between $0^{\circ} \mathrm{C}$ and $24^{\circ} \mathrm{C}$. Temperatures during winter months 
can drop below $-4^{\circ} \mathrm{C}$ and have reached over $30^{\circ} \mathrm{C}$ in summer. At higher elevations average daily temperatures are $7^{\circ} \mathrm{C}$, ranging between $-1^{\circ} \mathrm{C}$ and $20^{\circ} \mathrm{C}$. Cloud cover at higher elevations can dampen temperature ranges (Thompson, 1984).

Sunshine hours have been recorded in the Lake Taupo catchment since 1949, although there is only one station currently operating. The Turangi site records around 2000 bright sunshine hours per annum. Comparatively, Thompson (1984) suggests the mountainous regions of the catchment are exposed to 1600-1700 hours of bright sunshine per annum. Not surprisingly, the summer months record the highest number of bright sunshine hours with over $30 \%$ of bright sunshine hours recorded between December and February. Only 20\% of the annual sunshine hours are recorded in winter months.

\subsection{Hydrology}

\subsubsection{Surface water inflows to Lake Taupo}

Water is received from over 30 rivers and streams (with numerous other smaller tributaries) that enter Lake Taupo (Mighty River Power Ltd, 2007). Most originate in the highlands surrounding the catchment and converge toward Lake Taupo in a centripetal drainage pattern. Despite the importance of Lake Taupo to the Waikato Power Scheme and its reliance on the inflows to the lake, there have been relatively few detailed studies of sub-catchment surface water inputs to Lake Taupo.

The largest body of work was undertaken in the late 1970 s by the Water and Soil Division of the Ministry of Works (Schouten et al., 1981). During this time, 17 rivers directly draining into Lake Taupo (89\% of the land area of the catchment) were gauged for streamflow and water quality. Most of these stations were operated for a short period between 1976 and 1982. Mean streamflow from these catchments totalled $131 \mathrm{~m}^{3} / \mathrm{s}$ or the equivalent of $85 \%$ of outflow from Lake Taupo. Their main aim was to determine water quality and mass sediment transport for Lake Taupo inflows, but the study also provided detailed information of the hydrology of the individual sub-catchments of Lake Taupo. Schouten et al. (1981) characterised the hydrology of each catchment by assessing the flow duration curves and calculating various flow statistics. A variability index based on the standard deviations of the

logarithms of specific discharge values for each sub-catchment was used to illustrate the differences in streamflow variability between major lithologies. Schouten et al. 
(1981) found that catchments with less permeable geology had the highest variability with a variability index of between 0.3 and 0.4 , while the index for those draining volcanic deposits ranged between 0.04 and 0.16. Schouten et al. (1981) also noted that floods produce $30 \%$ of the annual streamflow in rivers draining greywacke geology, with as much as $75 \%$ of the annual runoff taking place in the winter half year. Schouten et al. (1981) defined a flood as any event in which streamflow which exceeds the $5^{\text {th }}$ percentile on the flow duration curve.

Excluding the discharge from the TPS, only six catchments are currently gauged. Of these, three are controlled or affected by hydro power schemes (Hinemaiaia River, Kuratau River and Tongariro River). The inflows from these seven sources are equivalent to $70 \%$ of the lake outflow and $66 \%$ of the catchment's natural land area. The following sections describe the hydrology of the historically gauged regulated and unregulated catchments of Lake Taupo (Figure 2.5). Table 2.1 lists subcatchment information. More detailed information can be found for each subcatchment in Appendix B.

While this section deals with the hydrological inputs to Lake Taupo, another significant source is direct lake rainfall. This is not explicitly dealt with here, but is a considerable inflow - an average input of $22 \mathrm{~m} 3 / \mathrm{s}(1152 \mathrm{~mm} / \mathrm{a})$. The net contribution when direct lake evaporation is accounted for is $5.57 \mathrm{~m} 3 / \mathrm{s}(287 \mathrm{~mm} / \mathrm{a})$.

It is noted that catchment records cover different periods and lengths. Although comparisons are made, it is recognised that more rigorous analysis could be undertaken. Ideally, streamflow records would be 'normalised' to account for climate variability. However, time constraints and other priorities in this study did not allow this to be undertaken. The results should be viewed with this in mind. 


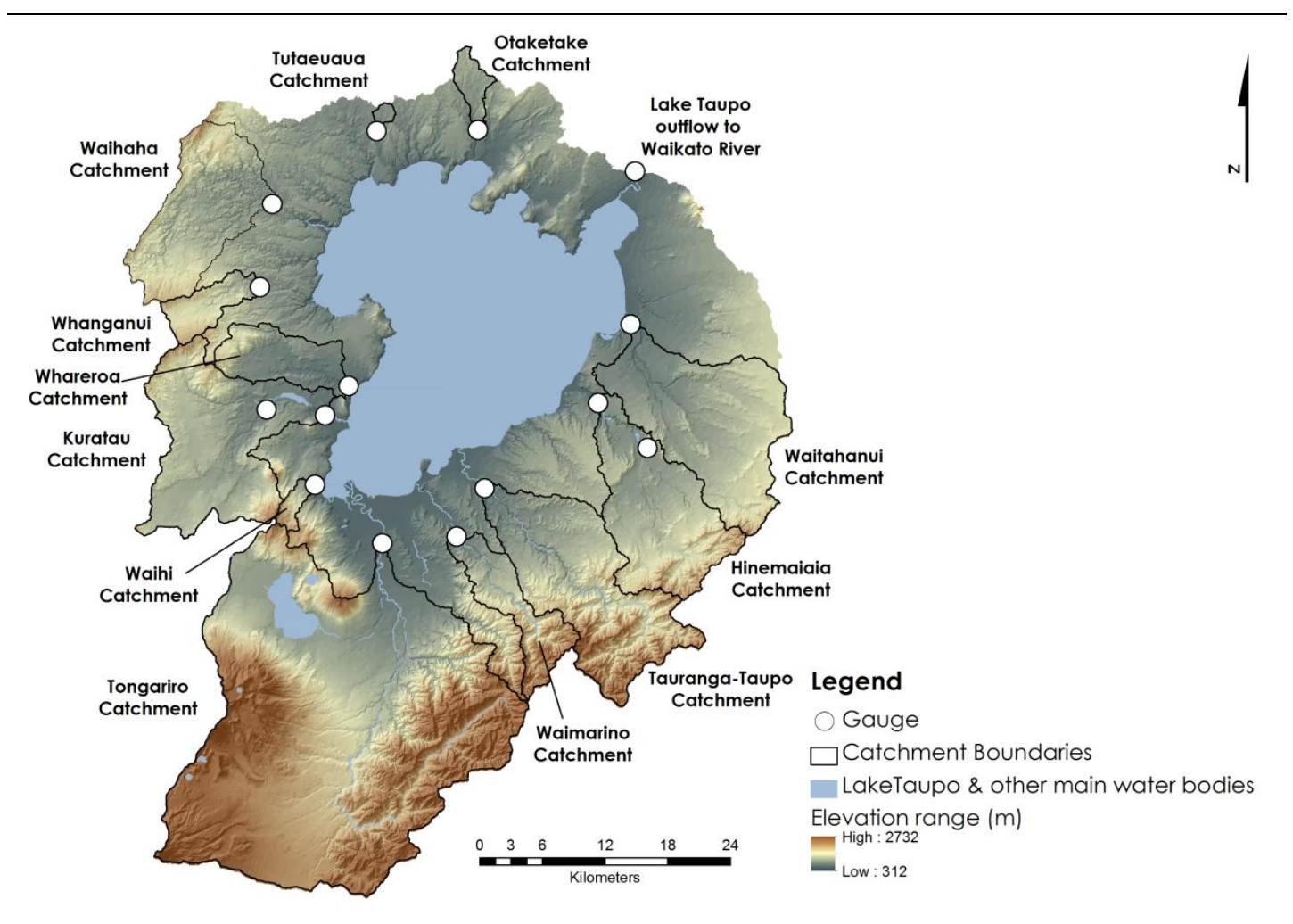

Figure 2.5. The natural Lake Taupo catchment. The individual sub-catchments used for analysis are shown. The map does not include the foreign water catchment areas of the TPS.

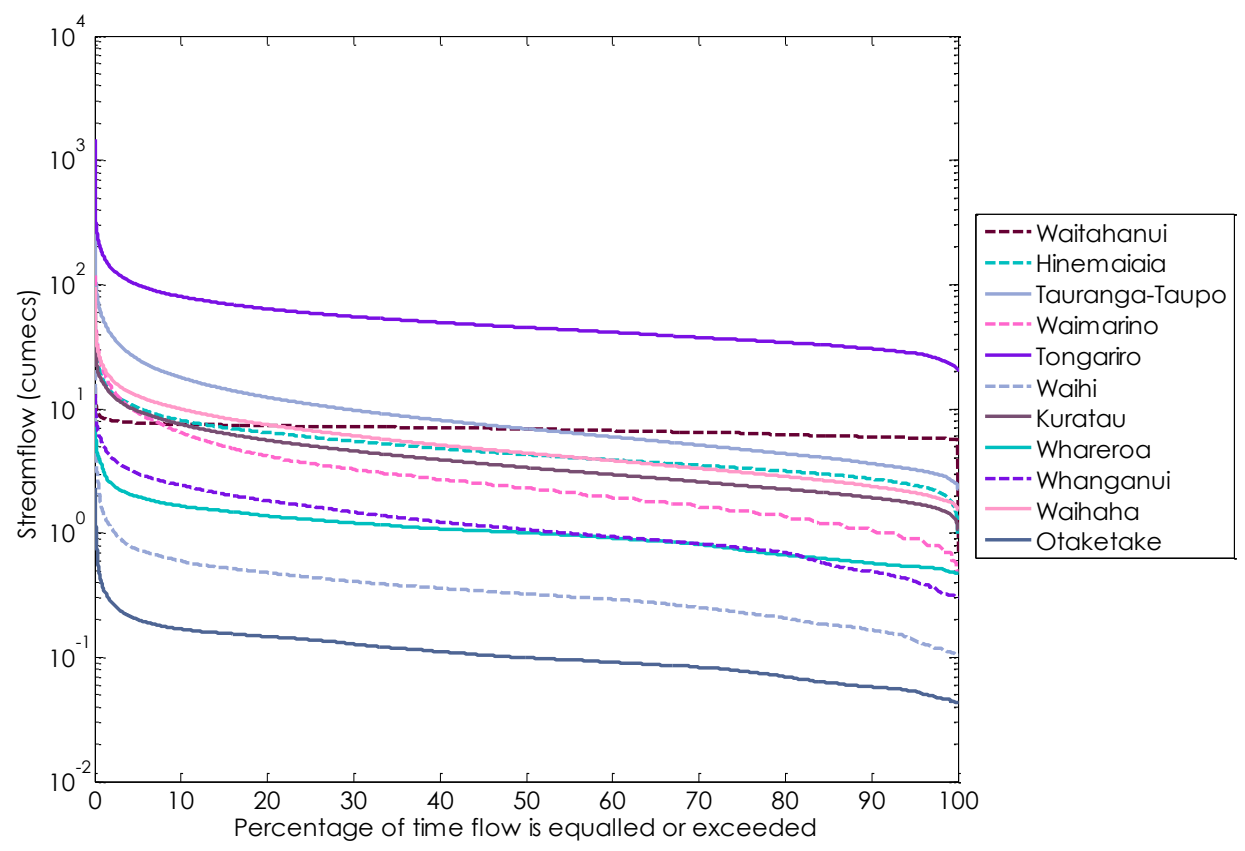

Figure 2.6 Flow duration curves for unregulated catchments. The time series for the Kuratau and Hinemaiaia catchments above the scheme are used. The time series for the Tongariro River prior to the TPS is also included 
Table 2.1. Summary of sub-catchment hydrological data and information

\begin{tabular}{|c|c|c|c|c|c|c|c|c|c|c|c|}
\hline Catchment & Site No. & $\begin{array}{c}\text { Start } \\
\text { (dd/mm/yyyy) }\end{array}$ & $\begin{array}{l}\text { End } \\
\text { (dd/mm/yyyy) }\end{array}$ & $\begin{array}{l}\text { Duration } \\
\text { (years) }\end{array}$ & $\begin{array}{l}\text { Gaps* } \\
(\%)\end{array}$ & $\begin{array}{l}\text { Area } \\
\left(\mathrm{km}^{2}\right)\end{array}$ & $\begin{array}{c}\text { Median Flow } \\
\left(\mathrm{m}^{3} / \mathrm{s}\right)\end{array}$ & $\begin{array}{l}\text { Mean flow } \\
\left(\mathrm{m}^{3} / \mathrm{s}\right)\end{array}$ & $\begin{array}{c}\text { Mean Ann. Runoff } \\
(\mathrm{mm} / \mathrm{a})\end{array}$ & $\begin{array}{l}\text { Spec discharge } \\
\left(\mathrm{m}^{3} / \mathrm{s} \text { per } \mathrm{km}^{2}\right)\end{array}$ & $\begin{array}{l}\text { Outilow } \\
\text { (\%) }\end{array}$ \\
\hline Waitahanui & 1543411 & $21 / 01 / 1976$ & $13 / 01 / 1981$ & 4.98 & 5.6 & 196.07 & 6.90 & 6.82 & 1097 & 0.0348 & 4.5239 \\
\hline Hinemaiaia above dam & 1543412 & $29 / 04 / 1981$ & $12 / 04 / 1987$ & 5.95 & 13.0 & 125.38 & 3.41 & 4.02 & 1012 & 0.0317 & 2.7463 \\
\hline Hinemaiaia above dam & 2743464 & $13 / 04 / 1987$ & $12 / 12 / 2000$ & 13.67 & 0.4 & 125.38 & 4.68 & 5.52 & 1389 & 0.0435 & 3.3896 \\
\hline Hinemaiaia above (combined) & & $29 / 04 / 1981$ & $12 / 12 / 2000$ & 19.63 & 4.2 & 125.38 & 4.29 & 5.11 & 1285 & 0.0407 & 3.2255 \\
\hline Hinemaiaia below dam & 3043471 & $20 / 06 / 2000$ & $24 / 01 / 2009$ & 8.60 & 0.3 & 153.26 & 4.64 & 5.53 & 1139 & 0.0361 & 3.5765 \\
\hline Tauranga-Taupo & 1543413 & $11 / 02 / 1976$ & $18 / 07 / 2008$ & 32.45 & 2.2 & 197.10 & 6.91 & 9.67 & 1547 & 0.0491 & 6.2560 \\
\hline Waimarino & 1543420 & $24 / 09 / 1976$ & $24 / 01 / 2009$ & 32.35 & 31.4 & 63.63 & 2.30 & 3.46 & 1714 & 0.0544 & 2.1877 \\
\hline Waipakihi & 1043461 & $1 / 01 / 1960$ & $1 / 07 / 2008$ & 49.10 & 0.0 & 179.98 & 8.25 & 11.91 & 2087 & 0.0662 & 7.8511 \\
\hline Waihohonu & 1043466 & $1 / 08 / 1961$ & $24 / 01 / 2009$ & 47.51 & 1.8 & 96.06 & 5.77 & 6.30 & 2067 & 0.0655 & 4.2113 \\
\hline Waihi & 3043481 & $12 / 02 / 2003$ & $18 / 01 / 2006$ & 2.93 & 0.0 & 9.84 & 0.33 & 0.39 & 1261 & 0.0400 & 0.2499 \\
\hline Kuratau (above scheme) & 1043468 & $14 / 11 / 1978$ & $21 / 07 / 2008$ & 30.21 & 0.1 & 119.26 & 3.34 & 4.28 & 1132 & 0.0359 & 2.7384 \\
\hline Kuratau (below scheme) & 1543443 & $17 / 06 / 1976$ & 16/02/1979 & 2.67 & 2.9 & 194.18 & 5.48 & 6.58 & 1068 & 0.0339 & 4.9114 \\
\hline Whareroa & 1243461 & $26 / 09 / 1977$ & $20 / 08 / 1980$ & 2.90 & 0.0 & 59.35 & 1.01 & 1.24 & 661 & 0.0209 & 0.7828 \\
\hline Whareroa & 1243461 & $8 / 05 / 2002$ & $18 / 07 / 2008$ & 6.20 & 8.3 & 59.35 & 1.06 & 1.25 & 664 & 0.0210 & 0.8021 \\
\hline Whanganui & 1543427 & $2 / 07 / 1976$ & $29 / 09 / 1980$ & 4.32 & 1.9 & 31.59 & 1.07 & 1.55 & 1546 & 0.0490 & 0.9160 \\
\hline Waihaha & 1543424 & $26 / 05 / 1976$ & $3 / 05 / 1995$ & 18.95 & 4.8 & 133.66 & 4.40 & 5.60 & 1321 & 0.0419 & 3.6927 \\
\hline Tutaevaua & 3043485 & $14 / 10 / 2004$ & $14 / 01 / 2010$ & 5.25 & 15.0 & 3.29 & 0.06 & 0.08 & 723 & 0.0229 & 0.0517 \\
\hline Otaketake & 1543410 & 19/09/1977 & $22 / 09 / 1980$ & 3.01 & 0.0 & 16.31 & 0.10 & 0.12 & 223 & 0.0071 & 0.0815 \\
\hline Tongariro pre 1974 & 1043459 & $2 / 01 / 1957$ & $28 / 12 / 1973$ & 16.99 & 0.0 & 784.15 & 45.13 & 52.59 & 2115 & 0.0671 & 39.5820 \\
\hline Tongariro post 1974 & 1043459 & $2 / 01 / 1975$ & $1 / 04 / 2008$ & 33.27 & 0.0 & 784.15 & 27.83 & 32.13 & 1292 & 0.0410 & 20.7890 \\
\hline Waikato outflow & 1143444 & $23 / 09 / 1969$ & $15 / 07 / 2008$ & 39.56 & 0.7 & 3445 & 151.33 & 150.64 & 1379 & 0.0437 & 100.0000 \\
\hline
\end{tabular}

*This column refers to the percentage of the 15 minute time series record for which there is no data.

28 | Physical setting and hydrology 


\section{Unregulated catchment inflows to Lake Taupo}

Unregulated inflows to Lake Taupo are defined as those natural inflows which have not be modified by hydro power schemes. They are equivalent to approximately $40 \%$ of the average outflow from Lake Taupo and come from over $60 \%$ of the catchment's land area. Historic records exist for 11 unregulated catchments in total, of which only three are currently gauged. Thirty-four percent of the Lake Taupo catchment land area has never been gauged. For comparison, the flow duration curves for all unregulated sub-catchments are shown in Figure 2.6.

\section{Waitahanui River}

The Waitahanui River catchment $\left(196 \mathrm{~km}^{2}\right)$ is located on the eastern side of the catchment, south of Taupo township. The geology of the catchment is predominantly Taupo ignimbrite which is the most permeable of lithologies in the Lake Taupo catchment. This ignimbrite is overlain by pumice soils which are also very permeable. Mean discharge is $6.8 \mathrm{~m}^{3} / \mathrm{s}$ (Site No. 1543411) for the period January 1976 to January 1981. This equates to a specific discharge of $0.03 \mathrm{~m}^{3} / \mathrm{s}$ per $\mathrm{km}^{2}$ or $1097 \mathrm{~mm} / \mathrm{a}$. Discharge for this catchment is evenly dispersed throughout the year despite more precipitation falling in winter months. It is also characterised by low variability and a high baseflow index.

\section{Tauranga-Taupo \& Waimarino Rivers}

The Tauranga-Taupo River and Waimarino River catchments are located on the south-eastern side of Lake Taupo. The catchment of the Tauranga-Taupo River (Site No. 1543413) covers an area of $197 \mathrm{~km}^{2}$. Streamflow has been recorded in the catchment since 1976. Mean flow for the Tauranga-Taupo River is $9.7 \mathrm{~m}^{3} / \mathrm{s}$ which is equivalent to $6 \%$ of the average outflow from Lake Taupo for the corresponding period and $1547 \mathrm{~mm} / \mathrm{a}$. The Waimarino catchment (Site No. 1543420), on the southern side of the Tauranga-Taupo River, has an area of $64 \mathrm{~km}^{2}$. Discharge was recorded between September 1976 and March 1983 and then from December 1993 to the present. Mean flow is $3.5 \mathrm{~m}^{3} / \mathrm{s}(1714 \mathrm{~mm} / \mathrm{a})$

In terms of flow per unit area, the specific discharge for both catchments is 0.05 $\mathrm{m}^{3} / \mathrm{s}$ per $\mathrm{km}^{2}$. Land cover is also similar (largely indigenous and planted forestry). Both catchments are long and narrow and drain the steep and impermeable greywacke areas of the Kaimanawa Ranges. During winter months, some 


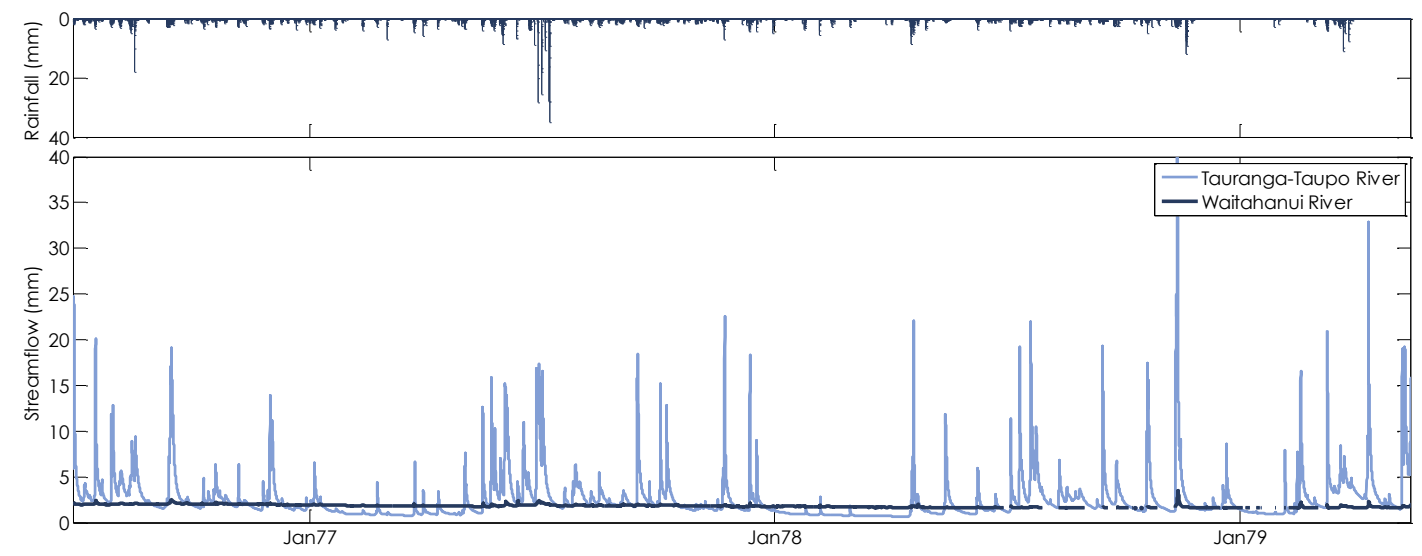

Figure 2.7. Above: Time series of rainfall ( $\mathrm{mm} / 15$ minutes) as measured at Tauranga-Taupo (Site No. 960010). Below: Time series of the Tauranga-Taupo River and Waitahanui River in $\mathrm{mm} / 15$ minutes. The Waitahanui River displays very little flow variability and has a considerable baseflow contribution. The Tauranga-Taupo River has much greater variability as shown by its very flashy response to rainfall events, and lower baseflow volume.

precipitation falls as snow at higher elevations. This snow melts during the warmer spring months. There is evidence of this in the monthly flow pattern for both catchments (see Appendix B).

In contrast to the Waitahanui catchment further north, the Tauranga-Taupo and Waimarino catchments have some of the highest flow variability and lowest baseflow index of the Lake Taupo catchments. Figure 2.7 illustrates the contrasting hydrologic behaviour of the Tauranga-Taupo River catchment with the Waitahanui River catchment further north.

\section{Waihi Stream}

The Waihi Stream catchment $\left(9.8 \mathrm{~km}^{2}\right)$ is located toward the southern end of Lake Taupo. This relatively small catchment drains the slopes of the andesitic Kakaramea volcano. The relief ratio of the catchment is high reflecting the large change in altitude relative to the length of the catchment. The overall contribution of this catchment to Lake Taupo outflow is small but because of its size and steepness it has one of the highest specific discharges in the Lake Taupo catchment. Mean flow for the Waihi Stream (Site No. 3043481) is $1.3 \mathrm{~m}^{3} / \mathrm{s}$ with an annual runoff of 1216 $\mathrm{mm} / \mathrm{a}$ and a specific discharge of $0.13 \mathrm{~m}^{3} / \mathrm{s}$ per $\mathrm{km}^{2}$. The record for the Waihi Stream covers a period of less than three years between February 2003 and January 2006. 


\section{Whareroa Stream}

The Whareroa catchment $\left(59 \mathrm{~km}^{2}\right)$ is located on the south-western side of Lake Taupo. This catchment is covered primarily in pasture and grassland. There are two discharge records for the Whareroa Stream from the same gauging location (Site No. 1243461). The first was recorded over a three year period in the late 1970s. Gauging of this river started again in 2002 and is still operating. Annual runoff from this catchment is approximately $660 \mathrm{~mm}$ per annum, with a mean flow over the two records is $1.2 \mathrm{~m}^{3} / \mathrm{s}\left(0.02 \mathrm{~m}^{3} / \mathrm{s}\right.$ per $\left.\mathrm{km}^{2}\right)$.

\section{Whanganui Stream \& Waihaha River}

The headwaters of the Waihaha River $\left(133.7 \mathrm{~km}^{2}\right)$ and Whanganui Stream (31.6 $\mathrm{km}^{2}$ ) are found in the higher elevation and steeper areas of the Hauhungaroa Ranges. Both catchments drain areas of impermeable basement greywacke but are predominantly volcanic. Whakamaru ignimbrite, which is less permeable than the younger Oruanui and Taupo ignimbrites, make up a considerable proportion of the catchment. Both gauges are located inland from the lake near State Highway 32. Above the gauges the land cover is predominantly forested (mostly native) with pastoral land cover below the gauges.

The Waihaha River (Site No. 1543424) was gauged between May 1976 and May 1995. Mean flow during this period was $5.6 \mathrm{~m}^{3} / \mathrm{s}$ which equates to a specific discharge of $0.04 \mathrm{~m}^{3} / \mathrm{s}$ per $\mathrm{km}^{2}$. Mean annual runoff is over $1320 \mathrm{~mm} / \mathrm{a}$. The Whanganui Stream (Site No. 1543427) has a much shorter record covering a period of just over 4 years between July 1976 and September 1980. Mean flow for this period was $1.5 \mathrm{~m}^{3} / \mathrm{s}\left(0.05 \mathrm{~m}^{3} / \mathrm{s}\right.$ per $\left.\mathrm{km}^{2}\right)$. Mean annual runoff is $1546 \mathrm{~mm} / \mathrm{a}$. These sub-catchments have different physiographic features. The Whanganui catchment is narrow and has the highest drainage density of catchments studied. Conversely, the Waihaha catchment is wider and rounder and is generally steeper. Due to the more impermeable nature of these catchments, baseflow contribution is relatively low and flow variability is moderately high.

\section{Tutaevaua Stream and Otaketake River}

These three catchments are all located in the northern part of the Lake Taupo catchment. The largest of the three catchments is the Otaketake River (Site No. 1543410) which has a catchment area of $16.3 \mathrm{~km}^{2}$. It has mostly pumice soils 
although there is a substantial amount of podzols present. Geology is predominantly Oruanui ignimbrite which is less permeable than the younger Taupo ignimbrite. Mean flow for the Otaketake River was 1.2 m³/s, for the period September 1977 to September 1980. In terms of flow per unit area, the catchment generates $0.07 \mathrm{~m} 3 / \mathrm{s}$ per $\mathrm{km}^{2}$ on average and has a mean annual runoff of only $223 \mathrm{~mm} / \mathrm{a}$. It has moderate flow variability and a relatively high baseflow index.

The Tutaeuaua Stream (Site No. 3043485) is a small catchment with an area of 3.3 $\mathrm{km}^{2}$. It is a predominantly pastoral catchment with a relatively high drainage density. The mean flow for the Tutaeuaua River is $1 \mathrm{~m}^{3} / \mathrm{s}\left(0.3 \mathrm{~m}^{3} / \mathrm{s}\right.$ per $\mathrm{km}^{2}$ and 723 $\mathrm{mm} / \mathrm{a}$ ), for the period October 2004 to January 2010. The site was closed in July 2010.

\section{Ungauged catchments}

Approximately 34\% of the Lake Taupo catchments land area has never been gauged. These ungauged areas are mostly located downstream of gauged catchments and around the northern part of the catchment where very little gauging has occurred. On the western side of the catchment, these ungauged areas are largely pastoral areas, whereas in the east planted exotic forest is widespread. Soils are predominantly pumice soils although there are areas of recent, gley and organic soils toward the south and podzols at upstream parts of ungauged areas.

Although there are historic flow records for approximately $61 \%$ of the catchment's land area, at present $49 \%$ of the catchment is ungauged.

\section{Exclusion of Tokaanu Stream and Otutira Stream}

The Tokaanu Stream catchment (Site No. 2143409) has been historically gauged but the observation record is deemed unreliable due to evidence of physically inconsistent flow responses. This may be largely due to the modifications, interventions and development in the catchment which has affected the natural flow regime (Opus International Consultants Limited, 2012). The Otutira catchment has been used as an experimental basin during the 1970s, with gauging sites located at flumes and weirs. It is uncertain how much of the streamflow has been modified. Examination of streamflow data also indicated some significant water balance issues which also prevented this catchment from being included in any subsequent analysis. 


\section{Regulated inflows to Lake Taupo}

Since the early 1950s, parts of the Lake Taupo catchment have been developed for hydro-electric power generation. There are three schemes in the catchment, varying in size, generation capacity and complexity. The largest and most complex of the three schemes is the TPS. The TPS diverts water from outside the natural Lake Taupo catchment via the western and eastern diversions for generation at Rangipo (120MW) and/or Tokaanu (240MW) Power Stations. The scheme also modifies the natural flow of the Tongariro River. After generation at Tokaanu Power Station, the scheme discharges directly to Lake Taupo. The Hinemaiaia Power Scheme (Hinemaiaia River catchment) generates approximately $30 \mathrm{GWh}$ per annum with an installed capacity of 6.6MW. The Kuratau Power Scheme is the smallest of the three schemes, having a generation capacity of $6 \mathrm{MW}$.

The most significant discharge to Lake Taupo is from the highly regulated and complex TPS. Inflows from three other catchments is also controlled or affected by hydro power schemes - the Hinemaiaia River, Kuratau River and Tongariro River (as part of the TPS). Each of these catchments and the schemes modifying their flow are described below.

\section{Hinemaiaia River}

Located along the eastern side of Lake Taupo, this catchment is made up of mostly volcanic geology with an area of less permeable greywacke in its headwaters. It is covered by indigenous forest in the higher elevation areas and planted exotic forestry elsewhere. Podzols and pumice soils are widespread. Recent soils are found along some river reaches.

This catchment has been developed for power generation since the 1950s. While it is a relatively small hydro scheme it consists of three power stations and three dams with a capacity of $6.6 \mathrm{MW}$ generating around 30GWh per annum (TrustPower Ltd, 2008). The scheme is largely run-of-river with relatively little storage in the three reservoirs. The lake at Hinemaiaia A holds the largest volume of water with just 16.6 hours of storage with average inflow. Hinemaiaia $\mathrm{C}$ is located $2 \mathrm{~km}$ downstream of Hinemaiaia $\mathrm{A}$ and is the smallest of the lakes covering an area of 2 ha and has negligible storage. Hinemaiaia $B$ is located a further $3 \mathrm{~km}$ downstream. The lake at Hinemaiaia B (12.1 ha) has 7 hours of storage with average inflow. A minimum flow of $3 \mathrm{~m}^{3} / \mathrm{s}$ below Hinemaiaia $B$ station is required (where inflows into the 

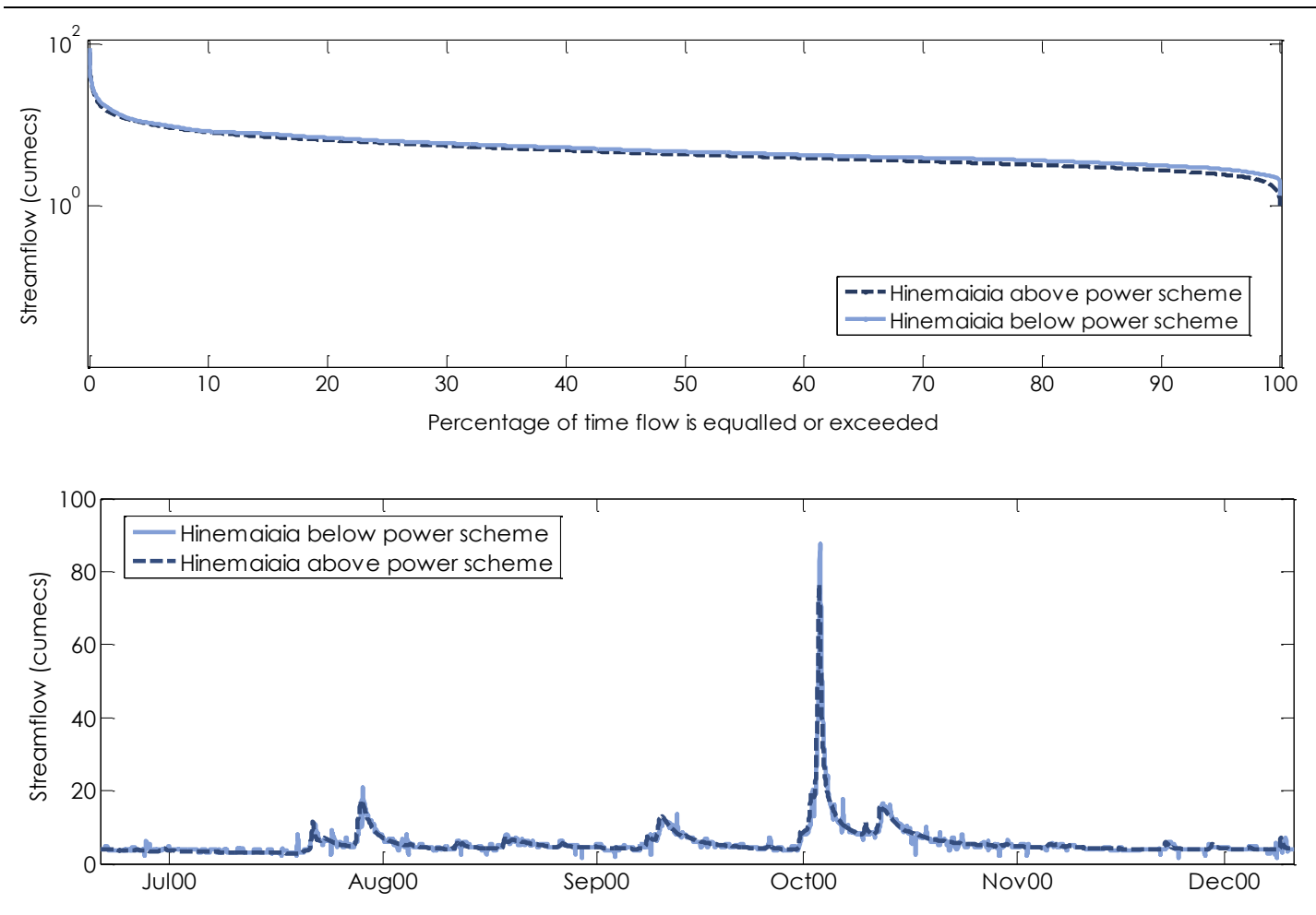

Figure 2.8. Streamflow from the Hinemaiaia River has been modified by the Hinemaiaia Power Scheme since the 1950s. The flow duration curves (upper) shows that the power scheme has had little impact on the natural flow regime of the catchment. The lower figure shows the difference between streamflow above and below the power scheme for an overlapping period of record between June 2000 and December 2000.

Hinemaiaia A Lake permit) to address trout migration and erosion issues (TrustPower Ltd, 2008).

The scheme is operated by TrustPower Ltd. There are two records for locations above the scheme (Site Nos. 1543412 \& 2743464). Because of the close proximity of these sites, the records are combined to provide a long-term record from April 1981 to December 2000. One record has been provided below the scheme (Site No. 3043471, June 2000 - present). The following analysis uses these sites to describe and compare the hydrological characteristics of the catchment.

Between Hinemaiaia A and Hinemaiaia B the catchment is described as a narrow ignimbrite gorge $27 \mathrm{~m}$ deep (TrustPower Ltd, 2008). There are very few additional tributaries along this section so mean flow is not largely modified.

Flow duration curves for both sites are similar (Figure 2.8, upper) and the time series (Figure 2.8, lower) shows very little impact on natural inflows (correlation coefficient of 0.96). For an overlapping period of record (June 2000 to January 
2001) the mean flow above and below the scheme was $5.78 \mathrm{~m}^{3} / \mathrm{s}$, indicating that there is very little additional streamflow added between the two gauging sites. Flow variability and baseflow contribution is similar at both sites. For the corresponding period of record, the discharge from this catchment was equivalent to $3.6 \%$ of outflow from Lake Taupo.

\section{Kuratau River}

The Kuratau River catchment is located in the south-western region of Lake Taupo. It drains an area of mixed volcanic geology. Land use is primarily pastoral but there are also large areas of planted forestry throughout the catchment and pockets of indigenous forestry at higher elevations. There is a wide variety of soil types in the catchment and drainage density is also relatively low.

The Kuratau Hydroelectric Power Scheme was commissioned in 1962 and has a generation capacity of $6 \mathrm{MW}$. The Kuratau River was dammed by an earth dam to form Lake Kuratau and a power station built for electricity generation. Lake levels are maintained between $442.46 \mathrm{~m}$ a.s.l and $445.08 \mathrm{~m}$ a.s.l (Taupo-nui-a-Tia, 2011). The lake covers an area of 100 ha. It has relatively little storage and does little to impede the passage of flood peaks moving downstream (Opus International Consultants Limited, 2011). The maximum discharge from the power station is 16 $\mathrm{m}^{3} / \mathrm{s}$ and sufficient streamflow must be maintained in the river (downstream of the tailrace) to allow for the unimpeded passage of fish at all times (Taupo-nui-a-Tia, 2011).

The scheme is operated by King Country Energy. This analysis uses data from two sites in the catchment - one situated upstream of the power scheme (Site No. 1043468, $119.3 \mathrm{~km}^{2}$ ) and one downstream of the power scheme (Site No. 1543443, $\left.194.2 \mathrm{~km}^{2}\right)$. The mean flow recorded at the upstream gauging site is $4.3 \mathrm{~m}^{3} / \mathrm{s}(0.04$ $\mathrm{m}^{3} / \mathrm{s}$ per $\mathrm{km}^{2}$ or $1132 \mathrm{~mm} / \mathrm{a}$ ) between 1978 and 2011. Over a much shorter time period from 1976 to 1979 , the mean flow downstream from the power station of 6.6 $\mathrm{m}^{3} / \mathrm{s}$, which equates to a specific discharge of $0.03 \mathrm{~m}^{3} / \mathrm{s}$ per $\mathrm{km}^{2}$ and a mean annual runoff of $1068 \mathrm{~mm} / \mathrm{a}$. This catchment accounted for 4.9\% of Lake Taupo outflow for the corresponding period of record. Flow variability and baseflow index were both higher at the downstream location.

The operation of the power station has an effect on downstream flow. While there is relatively little storage in the system, the lake can be used to hold water for 
generation at peak demand times. Although there is little available information about the operation of this scheme, the effect on the pattern of flow below the Kuratau River is evident. Figure 2.9 illustrates the diurnal fluctuations of flow during "normal" operating conditions. There appears to be little effect on streamflow during flood events.

There is a greater impact on flow regimes compared to the Hinemaiaia Scheme. The larger lake and storage of the Kuratau Hydroelectric Power Scheme allows for more regulation as the water is stored overnight to meet peak demand the following day.

Figure 2.10 illustrates the effect of regulation by comparing the time series for a period where records overlap and the flow duration curves for both sites. The correlation between the upstream and downstream sites for this overlapping period is only 0.68. This correlation is improved when mean daily flow is compared (0.97). The power scheme can affect the flow pattern at the upstream site. The daily diurnal fluctuations from the storage of water in Lake Kuratau and its subsequent release to the power scheme can produce a backwater effect (pers comm., NIWA 2010) which can be seen in the hydrograph for this site (Figure 2.11, left). More frequent oscillations (Figure 2.11, right) are thought to be due to the influence of an upstream power generator at Moerangi Station. This generator runs off and on according to demand of the station (pers comm., NIWA 2010).
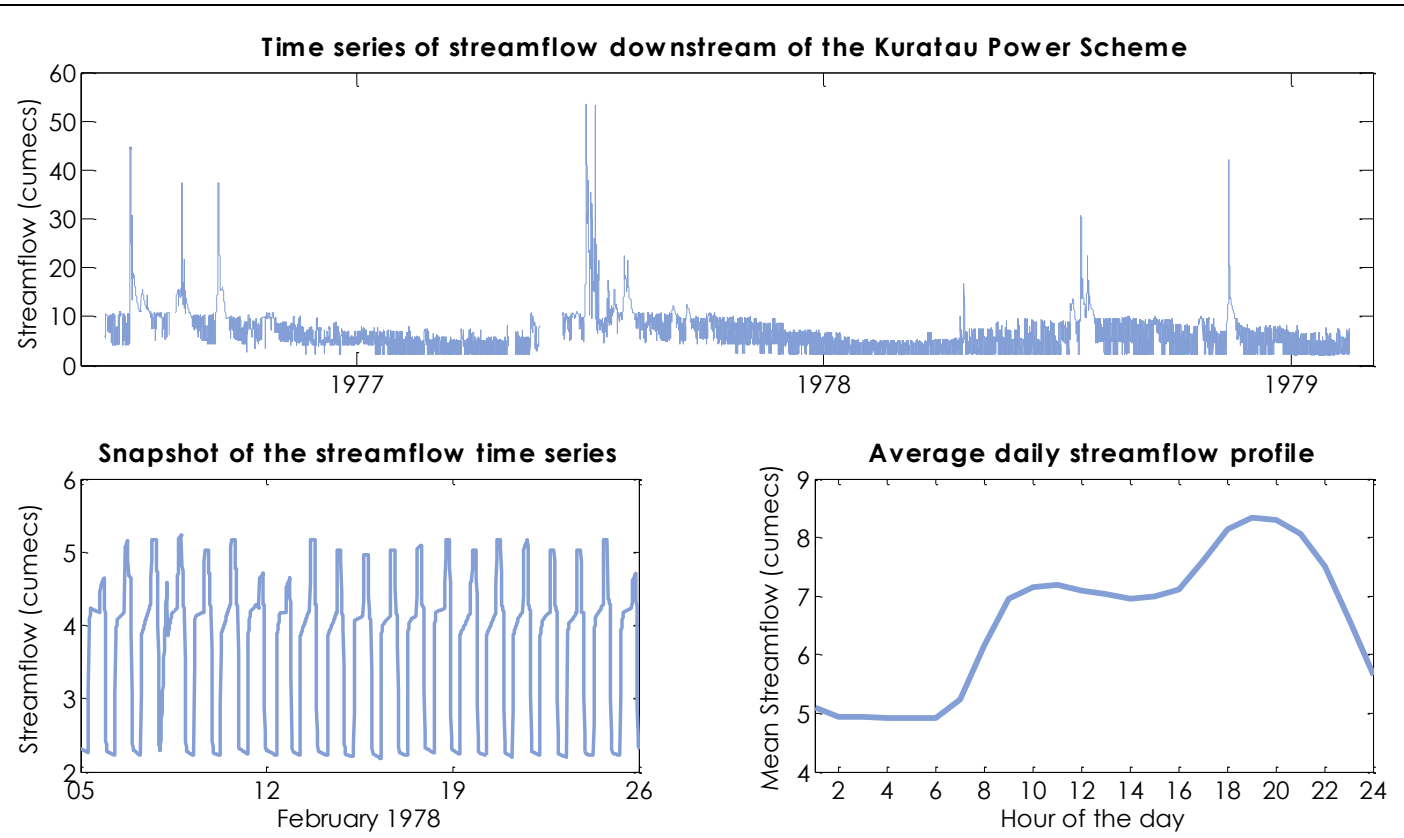

Figure 2.9 Streamflow of the Kuratau River downstream of Kuratau Power Scheme (top) is influenced by the operation of the scheme. The diurnal fluctuations in streamflow (lower left) mimic the typical load profile of daily energy use (lower right). 

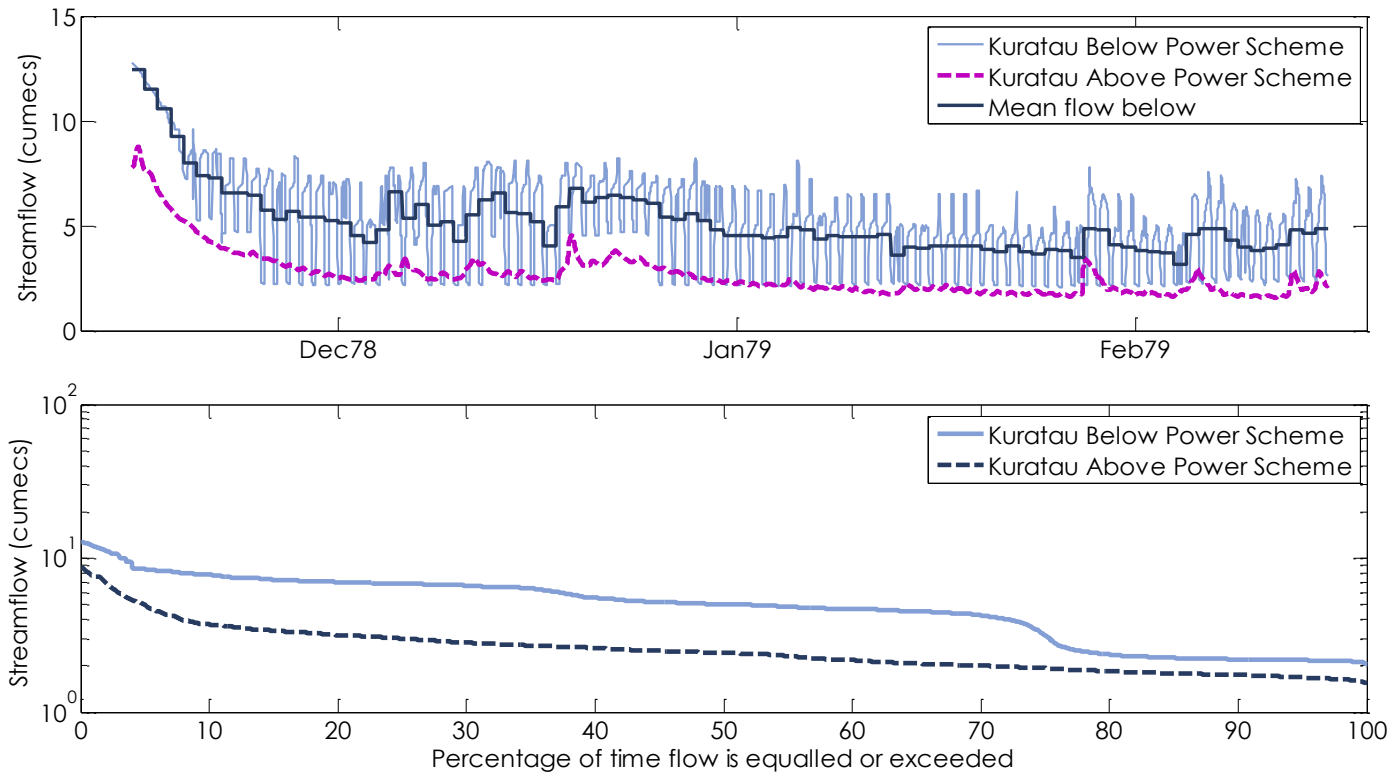

Figure 2.10. Streamflow from the Kuratau River has been modified by the Kuratau Power Scheme since 1962. The top figure shows the difference between streamflow above and below the power scheme for an overlapping period of record between November 1978 and February 1979. The flow duration curves illustrate the effect of the regulation on the natural flow regime.
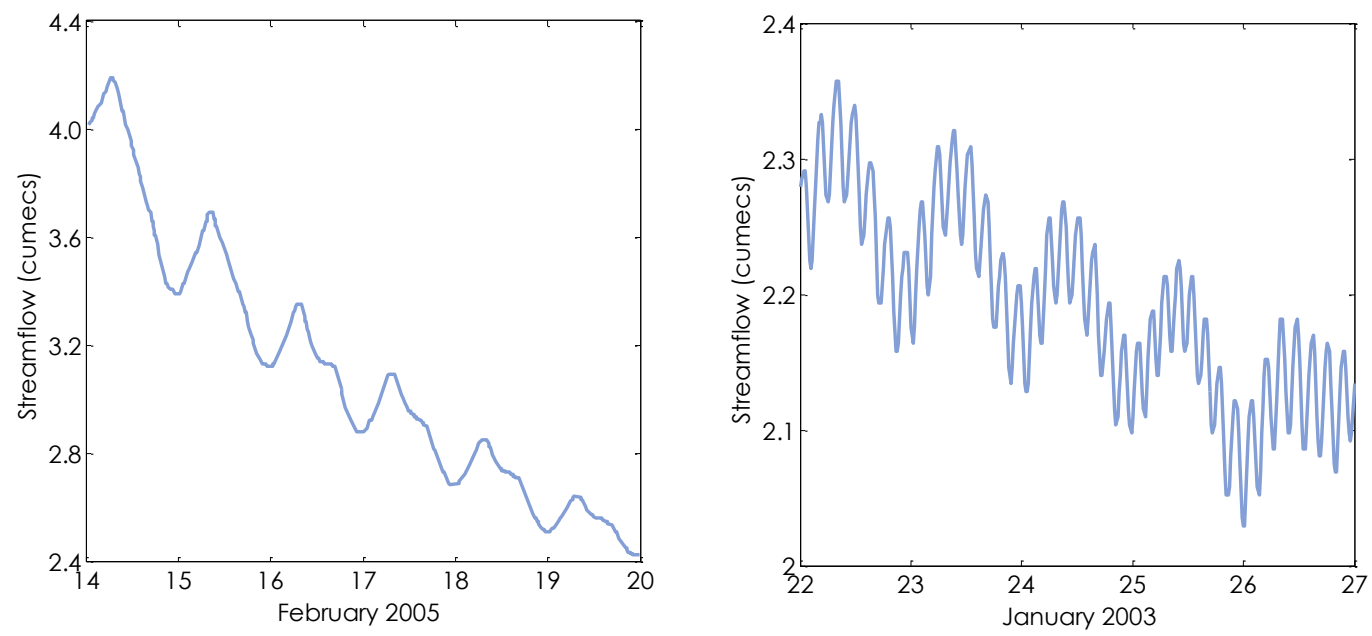

Figure 2.11. Time series of the Kuratau River as recorded above the Kuratau Power Scheme at SH41. The left figure shows the diurnal fluctuations of flow as a result of the backwater effect from Lake Kuratau. More frequent oscillations (right) are likely to be due to an upstream generator at Moerangi Station. 


\section{Tongariro River}

The Tongariro River is the largest natural sub-catchment of Lake Taupo, covering an area of $784 \mathrm{~km}^{2}$. Its headwaters stem from two significant areas. The western part of the Tongariro catchment drains the volcanoes of the Tongariro National Park. This side of the catchment is lightly vegetated with some tussock grassland. Raw or recent soils are prevalent. In the east, the catchment drains the greywacke areas of the Waipakihi catchment located in the Kaimanawa Ranges. Pumice soils are widespread and the catchment is covered by large tracts of indigenous forest. In the lower reaches of the Tongariro River catchment, large areas of planted forest exist on predominantly pumice soils.

Prior to the TPS, streamflow in this river (as recorded at Turangi (Site No. 1043459) between 1957 and 1973) ranged between $20 \mathrm{~m}^{3} / \mathrm{s}$ and $1461 \mathrm{~m}^{3} / \mathrm{s}$. The mean flow was $52.59 \mathrm{~m}^{3} / \mathrm{s}$ which equates to $0.07 \mathrm{~m}^{3} / \mathrm{s}$ per $\mathrm{km}^{2}$ and a mean annual runoff of 2115 $\mathrm{mm} / \mathrm{a}$. Approximately $40 \%$ of the outflow from Lake Taupo could be attributed to the unregulated Tongariro River during this period. As part of the TPS there has been significant modification to the streamflow of the Tongariro River. Since 1973, water has been diverted from the river through the Poutu Intake. From the late 1970s, streamflow has been augmented by water from Lake Moawhango, as part of the eastern diversion. The construction of the Rangipo Dam by 1983 allowed further diversion of water to the Rangipo Power Station (for more detail, refer to the following section). There are two minimum flow restrictions along the Tongariro River. The first is a $0.6 \mathrm{~m}^{3} / \mathrm{s}$ requirement below Rangipo Dam. Further downstream below the Poutu Intake a minimum flow of $16 \mathrm{~m}^{3} / \mathrm{s}$ is required. By the time this reaches the gauging location at Turangi flow is approximately $27 \mathrm{~m}^{3} / \mathrm{s}$, depending on other tributary contributions downstream (pers comm. Genesis Energy Ltd, 2010). The purpose of these minimum flows is for aquatic habitat, recreation and to enhance natural character (Genesis Energy Ltd, 2008). The regulation of the Tongariro River (as part of the TPS) is controlled by Genesis Energy Ltd.

Figure 2.12 shows the flow duration curves and time series for the Tongariro River before and after the diversions were started. The range of streamflow at the Turangi gauging site has not been greatly affected since the principal effect of the TPS on the Tongariro River has been during normal streamflow conditions (Stephens, 1989). Natural flow conditions prevail during natural low flow $\left(<16.3 \mathrm{~m}^{3} / \mathrm{s}\right)$ and flood conditions $\left(>160 \mathrm{~m}^{3} / \mathrm{s}\right)$, as recorded downstream of Poutu Intake. Between these 

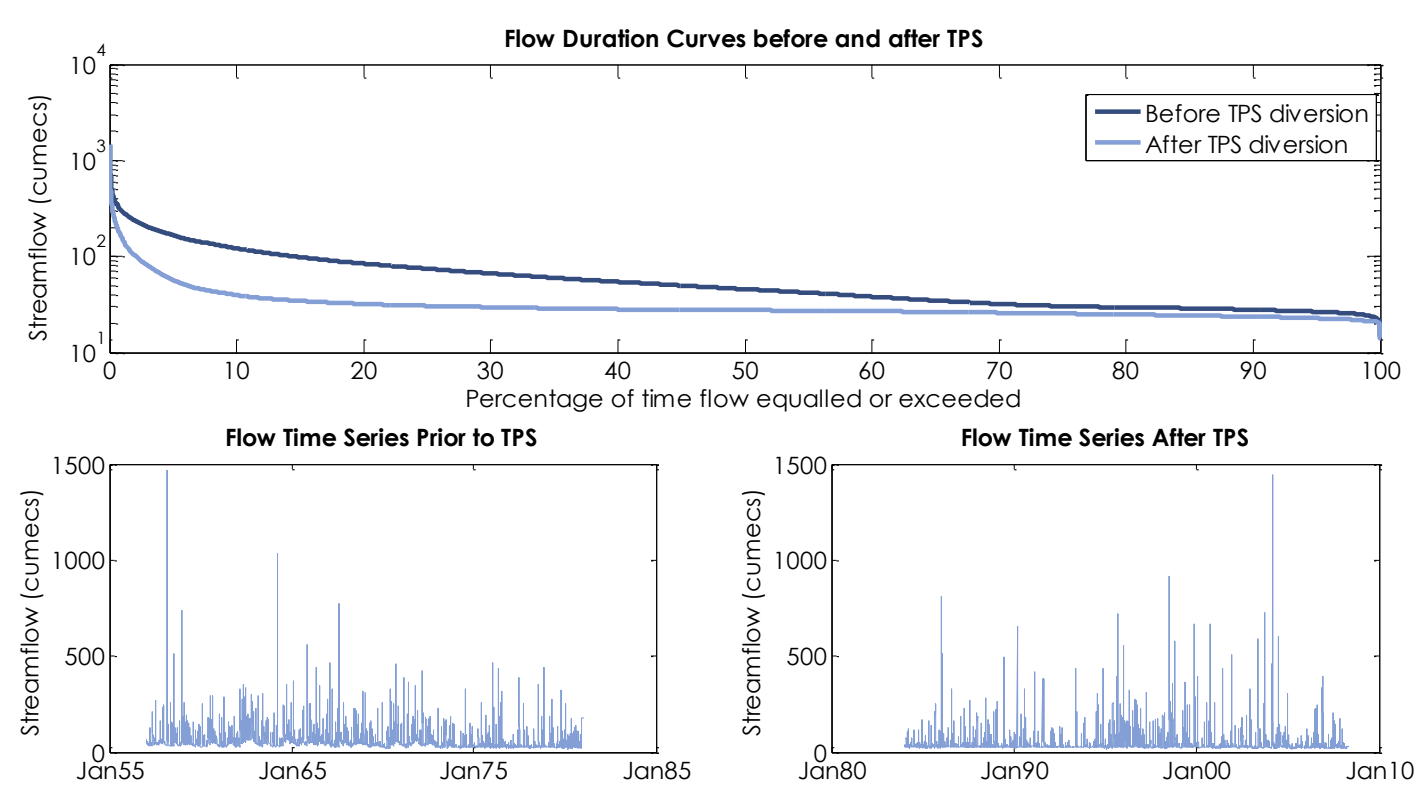

Figure 2.12. The impact of the TPS on flow regime. The flow duration curve (top) illustrates the effect of the diversions on the Tongariro River. The range of flows has not been greatly affected (lower figures).

two flow rates up to $80 \mathrm{~m}^{3} / \mathrm{s}$ can be taken from the river via the Poutu Intake for power generation.

Mean flow at Turangi since the development of the TPS is $32.13 \mathrm{~m}^{3} / \mathrm{s}$ (reduced from $52.7 \mathrm{~m}^{3} / \mathrm{s}$ prior to the development of the TPS) with a corresponding drop in the catchment's specific discharge and mean annual runoff to $0.04 \mathrm{~m}^{3} / \mathrm{s}$ per $\mathrm{km}^{2}$ and $1292 \mathrm{~mm} / \mathrm{a}$, respectively. As a result of the regulation, the variability of flow has been reduced. All of the water from the Tongariro River eventually ends up in Lake Taupo either directly or indirectly via the TPS.

\section{The Tongariro Power Scheme}

The TPS draws water from the mountains of the central volcanic plateau, diverting water from outside of the natural Lake Taupo catchment area for generation at Rangipo (120MW) and/or Tokaanu (240MW) Power Stations. There are four sections to the TPS which are described in more detail below and illustrated in Figure 2.13. On average the Tongariro Power Scheme generates approximately 3.5\% of New Zealand electricity generation (Genesis Energy Ltd, 2010).

Western Diversion: The western diversion diverts water from the Whakapapa River, Whanganui River and four other smaller tributaries into Lake Te Whaiau and 
Lake Otamangakau before being routed into Lake Rotoaira via the Wairehu Canal (Genesis Energy Ltd, 2011). There are six intakes along the diversion. The largest of these intakes is from the Whakapapa River which has a maximum intake of is 35 $\mathrm{m}^{3} / \mathrm{s}$. Any flow above the maximum continues down its natural course. This diversion accounts for a significant proportion of the $42 \mathrm{~m}^{3} / \mathrm{s}$ capacity of the Wairehu canal (Genesis Energy Ltd, 2011). Downstream of the intake there is a minimum flow requirement set to $3 \mathrm{~m}^{3} / \mathrm{s}$ although there are also periodic recreational flow releases from the intake. Further downstream at Te Maire a minimum flow for the Whanganui River is $29 \mathrm{~m}^{3} / \mathrm{s}$ is required (Genesis Energy Ltd, 2011). To meet this requirement typically means that for two months during summer/autumn no water is diverted from this segment of the scheme (Genesis Energy Ltd, 2008).

Eastern Diversion: The eastern diversion diverts water via the Wahianoa Aqueduct on the southern flanks of Mt Ruapehu, eastward to the Moawhango Dam, a man-made storage lake (Genesis Energy Ltd, 2011). Lake Moawhango has a $15 \mathrm{~m}$ operating range. Water is routed through the Moawhango Tunnel north to Rangipo Dam on the Tongariro River. The eastern diversion has a maximum capacity of 22 m³ s to Rangipo Dam.

The volume of 'foreign' water diverted (from both western and eastern diversions equates to approximately 20\% of the outflow from Lake Taupo (Mighty River Power Ltd, 2007).

Tongariro Section: Water from the eastern diversion is discharged into Rangipo dam where streamflow from the Waihohonu Stream is also diverted, before being transported to the Rangipo Power Station (Genesis Energy Ltd, 2011). Rangipo Power Station is located south of Turangi $63 \mathrm{~m}$ underground and has an operating capacity of 120MW. After generation at Rangipo, water is released back into the Tongariro River before the Poutu Intake routes water through the Poutu Canal to the Poutu Dam. The Poutu Intake has a capacity of $80 \mathrm{~m}^{3} / \mathrm{s}$ (Smart, 2005). Once flow reaches $160 \mathrm{~m}^{3} / \mathrm{s}$ no water is diverted via the Poutu Intake due to turbidity (pers comm. Genesis Energy Ltd, 2009).

Below the Rangipo dam, consent conditions require a minimum flow of $0.6 \mathrm{~m}^{3} / \mathrm{s}$ for ecological reasons (Genesis Energy Ltd, 2011). The minimum flow of the Tongariro River below the Poutu Intake in 1973 was $11.3 \mathrm{~m}^{3} / \mathrm{s}$; this was revised to its current rate of $16 \mathrm{~m}^{3} / \mathrm{s}$ in 1994 (Smart, 2005). By the time it enters Lake Taupo it is over 


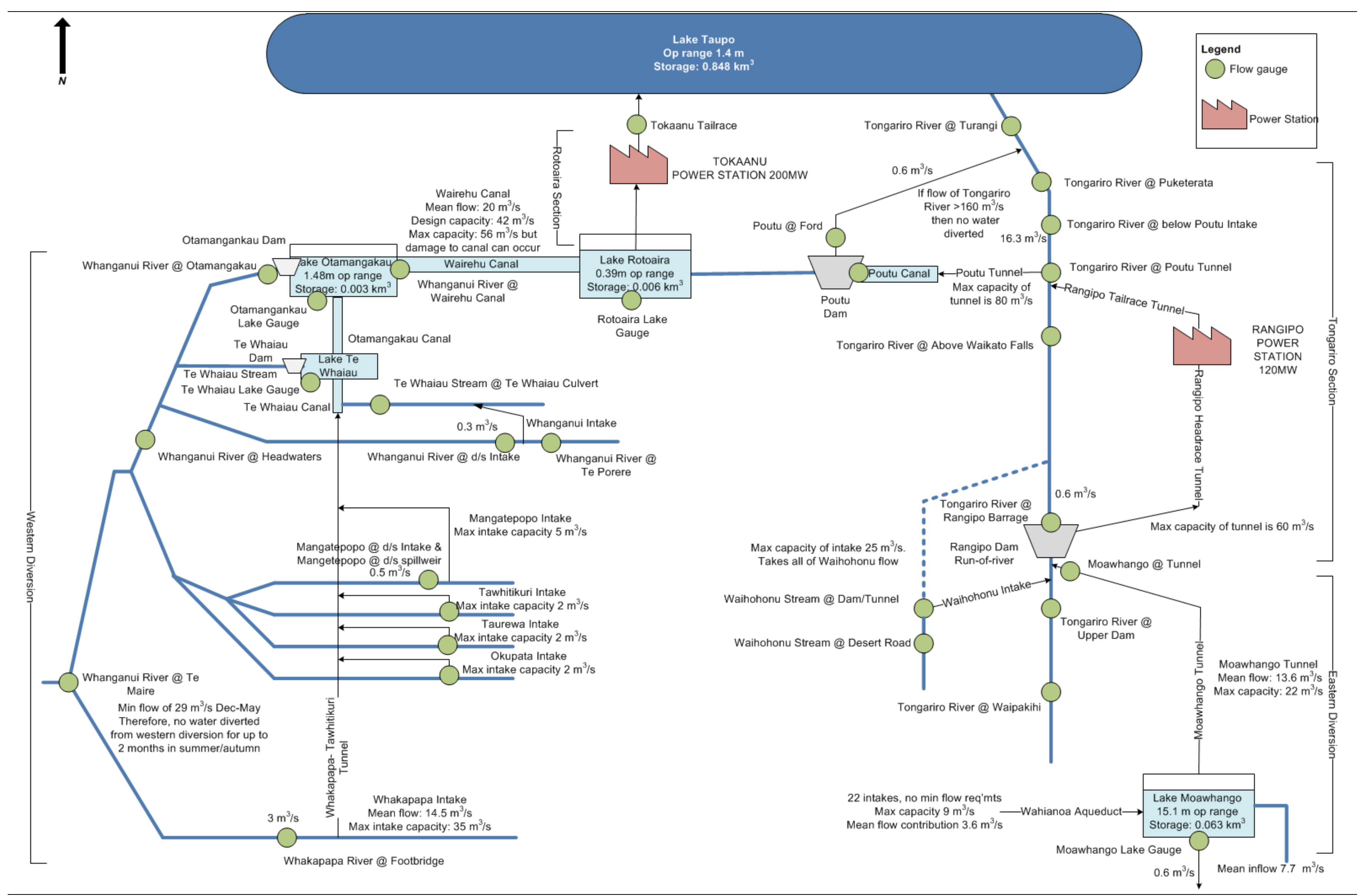

Figure 2.13. Schematic diagram of the Tongariro Power Scheme. 
$27 \mathrm{~m}^{3} / \mathrm{s}$, depending on the contribution from other tributaries (pers comm. Genesis Energy Ltd, 2010). Recreational releases of $30 \mathrm{~m}^{3} / \mathrm{s}$ in the Tongariro River are also part of consent conditions for the scheme (Genesis Energy Ltd, 2008).

Rotoaira Section: Once the water has passed through the Wairehu and Poutu canals it is discharged into Lake Rotoaira which is the storage lake for the Tokaanu Power Station. The natural outflow from Lake Rotoaira is at the eastern end of the lake via the Poutu Stream (Stephens, 1989). Since the development of the TPS, the lake now discharges through a $6 \mathrm{~km}$ tunnel through Mt Tihia to the Tokaanu Power Station which has an operating capacity of 240MW. After generation at Tokaanu, the water is discharged directly to Lake Taupo. On average, the TPS generates approximately 3.5\% of New Zealand's electricity generation (Genesis Energy Ltd, 2010). A minimum compensation flow is provided for the Poutu Stream of $0.6 \mathrm{~m} 3 / \mathrm{s}$ (Stephens, 1989).

Data for the discharge from the Tokaanu Station has been made available by Genesis Energy Ltd. For the period January 1998 to November 2008, the average discharge from the Tokaanu Power Station was $46.6 \mathrm{~m}^{3} / \mathrm{s}$. This equates to approximately 0.03 $\mathrm{m}^{3} / \mathrm{s}$ per $\mathrm{km}^{2}$ based on a catchment area of $1364 \mathrm{~km}^{2}$. However, it should be noted that Tokaanu Power Station is a peaking plant, only generating electricity during New Zealand's peak demand periods (pers comm. Genesis Energy Ltd, 2009). Hence, there are often zero discharges to Lake Taupo. When there is flow from the station, it averages $65 \mathrm{~m}^{3} / \mathrm{s}$. In addition, during periods when the level of Lake Taupo enters its flood storage range, generation at (and therefore discharges from) Tokaanu Power Station ceases (Genesis Energy Ltd, 2008).

\subsubsection{Groundwater}

The unwelded and fractured nature of volcanic deposits is favourable to the movement of water through the subsurface and the development of a considerable groundwater resource. The presence of significant groundwater in the catchment is evidenced by the sustained, moderated baseflows throughout the year. Assessing the flow duration curves of 17 sub-catchments of Lake Taupo, Schouten et al., (1981) estimated that as much as $95 \%$ of annual discharge from the rivers draining the permeable areas of the Lake Taupo could be derived from groundwater. Their estimated baseflow proportion of annual runoff from catchments draining less permeable lithologies was as low as $74 \%$. 
Although groundwater and surface water catchments do not always coincide (Gusyev et al., 2012), groundwater in the Lake Taupo catchment generally flows in the direction of the lake and is recharged by rainfall (Hadfield et al., 2001). The time it takes to move through the groundwater system is described by its residence time and largely influenced by catchment soils and geology. Residence times provide an insight into surface and groundwater interaction, the vulnerability of the resource to contamination, flow rates and paths, buffering against drought and resource sustainability (Stewart and Morgenstern, 2001). Residence times in the northern (Mapara, Whangamata, Kawakawa, Otaketake and Omoho) and western (Waihora, Waihaha, Whanganui, Whareroa, Kuratau and Omori) catchments of Lake Taupo have been estimated using tritium dating techniques by Hadfield et al. (2001), Morgenstern (2008), Piper (2004), and Vant and Smith (2004). All four studies found mean residence times ranged between 20-35 years up to 75-87 years. Mean residence times were greatest in the northern catchments where the Oruanui and rhyolitic pyroclastics predominate. These lithologies are more permeable and capable of storing more water deep in the groundwater system than the older Whakamaru ignimbrites of the western catchments which contribute more rapidly to surface water flow (Hadfield, 2007; Morgenstern, 2008). The youngest water (lowest mean residence times) was found in the Kuratau and Omori catchments by Vant and Smith (2004) who note that these catchments drain largely andesitic geology which has lower water storage. Tritium analyses undertaken by Morgenstern (2008) indicated that the western catchments streams largely have very young water of less than three years.

Most water held in the groundwater system exits either directly to the stream or directly to the lake. The volume of groundwater discharging directly to Lake Taupo has been estimated in a number of ways but still remains a relatively unknown quantity. White and Downes (1977) arbitrarily rated the groundwater contribution to be $1 \%$ of total inflows $\left(1.2 \mathrm{~m}^{3} / \mathrm{s}\right)$. Schouten (1983) was able to further deduce the direct groundwater contribution by substituting all of the measured and estimated components of the water balance resulting in an average groundwater contribution of $8 \mathrm{~m}^{3} / \mathrm{s}$, although the error margin was $\pm 5 \mathrm{~m}^{3} / \mathrm{s}$.

Many studies relating to the groundwater resource have been undertaken in the western and northern catchments, since these areas have the greatest potential for agricultural intensification (Hadfield, 2007). Using a water balance approach, where the groundwater contribution is determined by the difference between net recharge (residual precipitation after evapotranspiration and surface runoff) and annual 
mean streamflow, Piper (2004) estimated the groundwater discharge from nine sub-catchments in northern (Mapara, Whangamata, Otaketake and Tutaeuaua) and western (Waihora, Waihaha, Whanganui, Whareroa and Omori) areas of Lake Taupo. The groundwater contribution from these sites ranged between $0.105 \mathrm{~m}^{3} / \mathrm{s}$ and $0.835 \mathrm{~m}^{3} / \mathrm{s}$ with direct groundwater discharge to the lake from northern catchments generally considerably greater than from catchments along the western bays. The Waihora and Omori catchments, however, were not consistent with this finding. Morgenstern (2008) notes the Waihora catchment (north-western margin) is located in the boundary zone of the different lithologies which separate the two regions. This may result in similar discharge patterns to the northern catchments. The Omori catchment, south of Kuratau, has more permeable Taupo ignimbrite close to the lake which may allow greater direct groundwater seepage to the lake than other western areas (Morgenstern, 2008).

Direct seepage of groundwater to Lake Taupo in the northern catchments of Whangamata Bay and Whakaipo Bay has been investigated by Gibbs et al. (2005). Building on the results of an MSc thesis by Ross Hector in 2004, they surveyed water temperature to a depth of $10 \mathrm{~m}$ and found that groundwater enters Lake Taupo through the bed down to a depth of $6.5 \mathrm{~m}$. The majority of this inflow is between 2$6 \mathrm{~m}$ depth. These seepages totalled approximately $0.50 \mathrm{~m}^{3} / \mathrm{s}$ and $0.25 \mathrm{~m}^{3} / \mathrm{s}$ in Whangamata Bay and Whakaipo Bay, respectively, although the authors noted these estimates may potentially have considerable uncertainty due to the variability of seepage within the groundwater zone and the extrapolation of data from four sites of $0.25 \mathrm{~m}^{2}$ to a wider lake bed area of $200,000 \mathrm{~m}^{2}$.

These estimates are less than those determined by Piper (2004). For the Whangamata Bay, Piper (2004) estimated the direct groundwater contribution from the Otaketake Stream and Whangamata Stream were $0.835 \mathrm{~m}^{3} / \mathrm{s}$ and $0.413 \mathrm{~m}^{3} / \mathrm{s}$, respectively. In Whakaipo Bay, Piper (2004) estimated a groundwater discharge to the lake of $0.320 \mathrm{~m}^{3} / \mathrm{s}$ from the Mapara Stream alone. It should be noted that the work of Gibbs et al. (2005) was undertaken after a long dry period before the survey which may account for the lower discharge rates.

Fewer studies have been undertaken in the eastern catchments. Murphy (2006) used a water balance approach (similar to Piper (2004)) to estimate the groundwater contribution from the Tauranga-Taupo River catchment. The contribution from this catchment was estimated to be $4.4 \mathrm{~m}^{3} / \mathrm{s}$. Exchanges between surface and groundwater in the eastern catchments of Lake Taupo were modelled 
using a three-dimensional finite-element groundwater model by Bou (2007). Preliminary results indicate that the groundwater contribution to Lake Taupo from catchments draining from the eastern side of Lake Taupo totalled $15.4 \mathrm{~m}^{3} / \mathrm{s}$, with individual sub-catchment contributions ranging between $0 \mathrm{~m}^{3} / \mathrm{s}$ and $2.72 \mathrm{~m}^{3} / \mathrm{s}$. Calibration of the model is based on four of the ten sub-catchments representing $83 \%$ of the baseflow discharge. The groundwater contribution from the TaurangaTaupo catchment was $0.38 \mathrm{~m}^{3} / \mathrm{s}$, significantly less than estimate provided by Murphy (2006). Results should be used with caution as Bou (2007) notes further work is required to improve the correspondence of modelled streamflow to observed streamflow.

Based on the findings of Piper (2004) and Bou (2007) eastern areas appear to have, on average, a greater direct contribution to Lake Taupo per unit area than northern and western catchments. The total direct groundwater contribution to Lake Taupo from all study catchments is over $18 \mathrm{~m}^{3} / \mathrm{s}$, although neither paper provides a margin of error. This figure, which represents the contribution from $50 \%$ of the catchment's land area, is significantly greater than the estimates from both White and Downes (1977) and Schouten (1983). Excluding the average foreign water input to Lake Taupo of $29 \mathrm{~m}^{3} / \mathrm{s}$, the estimate indicates that the total direct groundwater contribution could be as much as $20 \%$ of total inflow to Lake Taupo.

\subsubsection{Outflow}

While there are many rivers directly entering Lake Taupo, the Waikato River is its only outflow. This lakes outflow has been recorded since 1969 (Site No. 1143444). Mean discharge from the lake to the Waikato River is $150.6 \mathrm{~m}^{3} / \mathrm{s}$. Since 1941 when the Taupo Control Gates were constructed the outflow from Lake Taupo has been controlled. This control is a balance between lake level operating ranges, energy generation demands and also flow requirements downstream through the Waikato Power Scheme.

Current flood rules include a minimum outflow of $50 \mathrm{~m}^{3} / \mathrm{s}$ (Opus International Consultants Limited, 2009). In drought conditions, if lake level drops below the minimum control level outflow from Lake Taupo must equal the inflows to the Lake, so outflow could be below $50 \mathrm{~m}^{3} / \mathrm{s}$. This situation has not yet occurred (pers comm. MRP 2011).

During flood events, Environment Waikato can request the outflow from Lake Taupo to be at or below this minimum to prevent flooding of settlements along the 
Waikato River. In July 1998, severe flooding and intense rainfall in the region resulted in Environment Waikato requesting Mighty River Power to reduce outflow to $33 \mathrm{~m}^{3} / \mathrm{s}^{4}$ to prevent flooding down the Waikato River (Freestone et al., 1998). Lake levels rose above the consented operating range during this period (as is allowed under these conditions).

The maximum consented outflow from Lake Taupo is related to the lake level height and ranges between $305 \mathrm{~m}^{3} / \mathrm{s}$ (at $357.3 \mathrm{~m}$ a.s.l) up to $343 \mathrm{~m}^{3} / \mathrm{s}$ (at $357.8 \mathrm{~m}$ a.s.l). During the 1998 flood event, when the requirement to reduce outflow was lifted the Taupo Control gates were fully opened, releasing an outflow of $312 \mathrm{~m}^{3} / \mathrm{s}$ to reduce lake level to normal operating conditions. The highest outflow recorded from Lake Taupo since September 1969 was in September 2010 when an outflow of $321.2 \mathrm{~m} 3 / \mathrm{s}$ was recorded.

\subsubsection{Lake level}

The level of Lake Taupo has been recorded since 1905. The installation of the Taupo Control Gates by 1941 allowed the outflow from the lake to be regulated. Lake Taupo is currently managed over a $1.4 \mathrm{~m}$ operating range $(355.85-357.25 \mathrm{~m}$ a.s.l) in order to mimic natural fluctuations. On average, Lake Taupo has a storage capacity of 8-9 weeks (Mighty River Power Ltd, 2007).

Historically, lake level has been recorded at four sites on Lake Taupo. There are currently two lake level recording sites on Lake Taupo, located at opposite ends of the lake. The gauge at Acacia Bay (Site No. 1543478) is located in the northern region of the lake toward Taupo township. The second gauge is located toward the southern end on the lake near Tokaanu (Site No. 1143420). Figure 2.14 shows the time series of lake level for both sites. Between December 1978 and July 2008 the highest level recorded for Lake Taupo at Acacia Bay was 357.5m a.s.l in July 1998 and the lowest was $355.9 \mathrm{~m}$ a.s.l in May 2010. However, the lake level was reported to drop as low as $355.7 \mathrm{~m}$ a.s.l in July 1946 while the highest lake level was $357.72 \mathrm{~m}$ a.s.l recorded in October 1909 (Mighty River Power Ltd, 2007).

Time series data of Lake Taupo level as recorded at Acacia Bay (Site No. 1543478) displays significant fluctuations not only from the direct input of rainfall from the passage of weather systems across the catchment but also from various natural oscillations caused by tectonic, wind and barometric effects. Taupo is a tectonically

${ }^{4}$ Flood rules in 2004 included a minimum outflow of $30 \mathrm{~m}^{3} / \mathrm{s}$. 


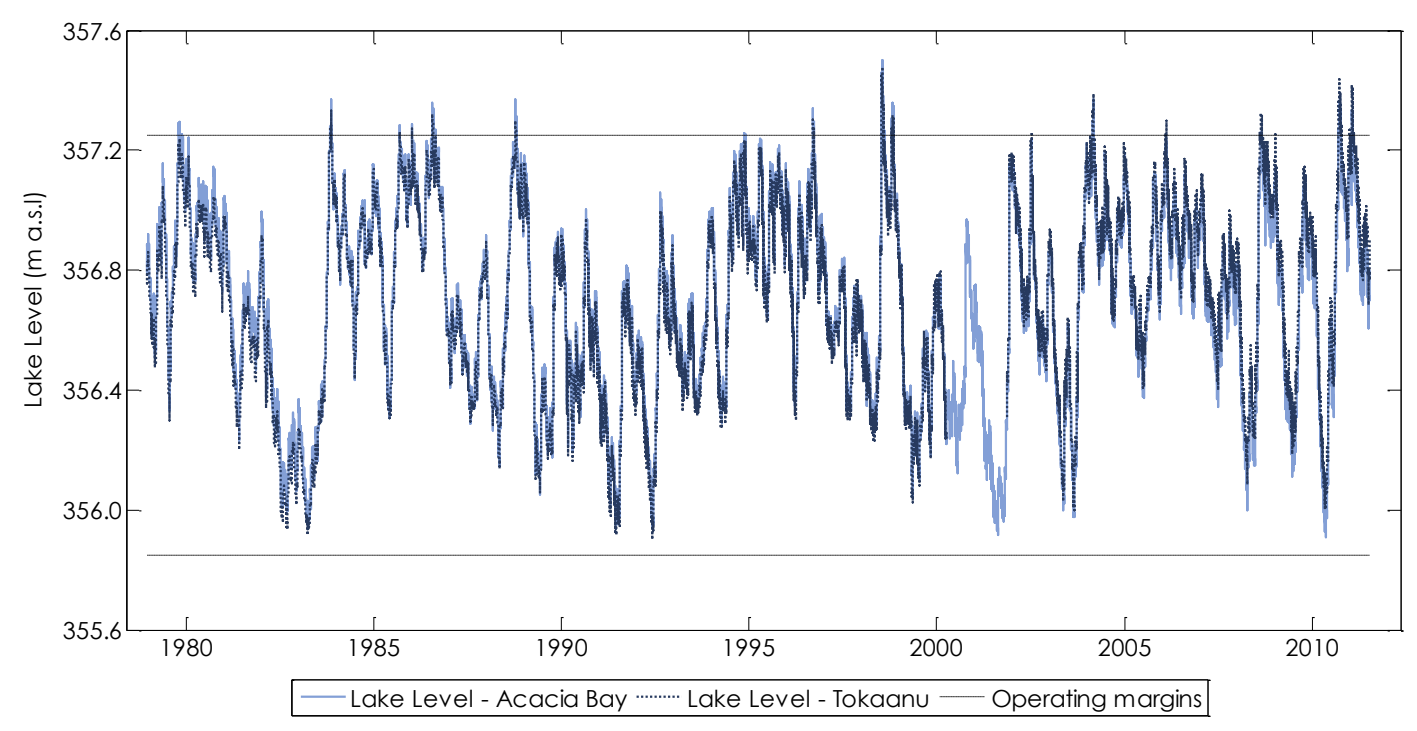

Figure 2.14. Lake levels as recorded at Acacia Bay (light blue) and Tokaanu (dashed dark blue). Lake level operating margins are indicated by the black dashed horizontal lines at $355.85 \mathrm{~m}$ a.s.l and $357.25 \mathrm{~m}$ a.s.l. The two time series fluctuations follow a similar pattern. The correlation between the two sites is 0.9925 .

active area and as such the accuracy of lake levels can be affected by earth movements of downwarping and upthrusting. Otway (1986) investigated the deformation associated with an earthquake swarm in 1983 and found there was up to up 50mm of upward movement of the land at the northern end of the lake. Lake level observation points, therefore, need to be frequently checked and calibrated.

Seiche effects cause the surface of the lake to be higher at one end than another and are largely due to wind or barometric pressure exerting a force over the water (ECNZ, unknown). When the force ceases, the pressure is released and results in the water slopping back and forth. The seiche characteristics of Lake Taupo have been reported by Gilmour (1991), Gilmour and Butcher (1987), and Gilmour and Heath (1989). There are several seiches in effect on Lake Taupo with periods of 30 minutes (wind seiche) up to several hours (barometric seiche) (Gilmour and Butcher, 1987; Gilmour and Heath, 1989), the combined effect of which can be several centimetres (ECNZ, unknown).

\subsection{Summary}

A description of the Lake Taupo catchment in terms of its physical setting is outlined in this chapter. The catchment covers $3445 \mathrm{~km}^{2}$ plus additional catchment 
areas associated with the TPS. It is New Zealand's largest lake $\left(611 \mathrm{~km}^{2}\right)$ and the effective source of the Waikato River.

Climatic and physiographic characteristics are the major influences on catchment flow regimes, controlling how much water enters the catchment and the movement of this water once it reaches the ground (Duncan and Woods, 2004). The climate of the Lake Taupo catchment is influenced by its location, elevation and topography. Rainfall and evapotranspiration are particularly important, in terms of rainfallrunoff modelling, as they determine the amount of water made available for catchment water storage and runoff. Rainfall is unevenly distributed throughout the catchment and snow can be considerable in the higher elevations of the south. There are obvious seasonal fluctuations in evapotranspiration in the catchment. Rates of evapotranspiration and calm weather typical of Taupo result in a generally humid climate for the Lake Taupo catchment (Timperley, 1983).

The hydrological characteristics of the Lake Taupo catchment are fundamentally linked to its active tectonic and volcanic history. The lake is a result of a series of tectonic and violent volcanic events. Not surprisingly the geology and soils of the catchment derive from the volcanic material produced from these major events and have a significant influence on the catchment's runoff response to rainfall. Land use in the catchment is a mixture of both exotic and native forestry in the east with pastoral activities in lowland areas of the west. In the south, active volcanism as well as its National Park and UNESCO World Heritage status leaves this large area relatively undeveloped. Development of three hydro power schemes in the catchment have further modified catchment physiographic attributes and have also altered catchment flow regimes.

In terms of catchment hydrology, inflows to Lake Taupo are sourced from regulated, unregulated, gauged and ungauged basins. Streamflow has been recorded in many catchments historically but only six catchments are currently gauged plus the discharge from the Tokaanu Power Stations. Streamflow in three of these gauged catchments is modified by hydro power schemes. The largest direct inflow is from the TPS ( $46 \mathrm{~m}^{3} / \mathrm{s}$ ) which, combined with the Tongariro River (which is modified as part of the TPS) is equivalent to over $50 \%$ of the outflow from Lake Taupo.

Direct groundwater contribution to the lake may be significant, but no robust quantification of the total direct contribution has been achieved. Based on the findings from various reports, the direct groundwater contribution to Lake Taupo is 
estimated at $18 \mathrm{~m}^{3} / \mathrm{s}$ from $50 \%$ of the catchment's land area. Total groundwater input could be in the order of $20 \%$ of outflow from Lake Taupo.

Knowledge of the amount and timing of inflows to Lake Taupo are important for the operation of the Taupo Control Gates and the Waikato Power Scheme. Lake level has been managed between a $1.4 \mathrm{~m}$ operating to mimic natural fluctuations. The lake holds $93 \%$ of the storage for the scheme and is used to moderate flows throughout the year and for reducing the effects downstream of flooding and drought.

This information gathered in this chapter provides the basis for further analysis of catchment hydrologic function which, in turn, informs the development of the perceptual model for the catchment and initial parameter estimates. 


\section{Rainfall-runoff modelling for reservoir inflow forecasting}

This chapter begins with an overview of rainfall-runoff modelling (Section 3.1). This is followed by a discussion of modelling approaches with respect to reservoir inflow forecasting, commenting on their suitability for adoption in this study (Section 3.2). Section 3.3 summarises the sources of uncertainty and reviews the development of various techniques to reduce this uncertainty to within reasonable limits. Particular attention is paid to data assimilation (via state updating) as a general framework for dealing with uncertainty. This section also discusses the implications of traditional unconstrained state updating for producing reliable model predictions.

\subsection{General overview of rainfall-runoff models}

Hydrological (rainfall-runoff) models have evolved as our understanding of hydrological processes has increased and as computers have been able to handle more complex model structures (Beven, 2001). Today, computer-based rainfallrunoff models allow relatively quick predictions to be made about a catchment's response to a given input of rainfall given specific antecedent conditions. These predictions are based on various sources of information, including field data and 
observations as well as detail about the interactions and processes of the rainfallrunoff relationship (Mulligan and Wainwright, 2004). The output from such models is widely used in decision-making processes, whether for hydro-electricity generation, erosion control, flood management or reservoir design (Moradkhani and Sorooshian, 2008; Todini, 1988; Wagener et al., 2004b).

There are several ways to classify rainfall-runoff models (Becker and Serban, 1990; Kampf and Burges, 2007; Mulligan and Wainwright, 2004). Becker and Serban (1990) categorise rainfall-runoff models according to their degree of spatial resolution (lumped/semi-distributed/ distributed) and by the degree to which they represent real world processes (empirical/conceptual/physics-based). A lumped model assumes spatial homogeneity, ignoring spatial variation of the rainfall-runoff response by using average or single point data to represent the whole of the catchment (Wagener et al., 2004b). Semi-distributed models allow for some spatial variation, delineating the larger lumped catchment by smaller units such as subcatchment boundaries. Distributed models aim to more fully represent the heterogeneity of the catchment accounting for the spatial variation of processes and properties over the entire area (Mulligan and Wainwright, 2004).

How well a model represents real world processes will depend on the approach. Empirical (or metric) models are strongly observation oriented, extracting information from existing data to determine the response of a catchment to rainfall inputs (Kokkonen and Jakeman, 2001). The foundation of empirical models is the unit hydrograph approach developed by Sherman in 1932 (Beven, 2001; Kokkonen and Jakeman, 2001; Todini, 1988). Other examples include the IHACRES model (Jakeman et al., 1990) and artificial neural network models (Dawson and Wilby, 2001; Minns and Hall, 2005).

In contrast to empirical models, physics-based models aim to represent all significant physical processes of the hydrological cycle relevant to the problem of interest using mathematical partial differential equations (Moradkhani and Sorooshian, 2008; Young, 2001). These models are commensurate with a high degree of discretisation. One of the most widely known models of this type is the Système Hydrologique Europèen (SHE) model, developed as a joint project between the Institute of Hydrology (UK), the Danish Hydraulics Institute and SOGREAH in 
France. Others include HILLFLOW (Bronstert and Plate, 1997), IHDM5 (Calver and Wood, 1995) and Topog (Vertessy et al., 1993).

Conceptual models provide a balance between the 'top-down' empirical and 'bottom-up' physics-based models and can be applied at lumped or distributed spatial scales. Conceptual models incorporate knowledge and theory of hydrological processes but generally approximate these processes into a simpler model structure. The rainfall-runoff relationship is often represented by a number of internal stores connected by a series of component processes controlling their recharge and depletion (Beven, 2001; Kitanidis and Bras, 1980; Kokkonen and Jakeman, 2001; Young, 2001). The model structure is generally determined a priori based on the perceived importance of the rainfall-runoff mechanisms. Determining the boundaries and interactions between reservoirs is, therefore, a subjective process and calibration is required to ensure the simulations closely match the observed response (Beven, 2001). Numerous conceptual models have been developed that vary in the number of storage elements, exchanges between these elements and model parameters reflecting the modeller's perception of the relative importance of the rainfall-runoff mechanisms in the system. The Sacramento Soil Moisture Accounting Model (Burnash, 1995), ARNO model (Todini, 1996) and the HBV ${ }^{6}$ model (Bergström, 1995) are examples of conceptual type models.

While physically-based conceptual models should, in theory, incorporate the important hydrological components of the rainfall-runoff process, these processes are generally only represented by approximations rather than actual physical representations of the processes themselves (Todini, 1988). The parameters of some conceptual models can, consequently, lack any physical meaning. Hybrid conceptual/physics-based models combine the simplicity of the conceptual approach with the physical interpretation of the 'bottom-up' physics-based approaches. These models provide a balance between the detail of physical catchment processes and data and computational requirements. TOPMODEL (Beven and Kirkby, 1979) is an example of a hybrid model which identifies units with similar soils and topography that will have a corresponding hydrological response. The model structure is simplified while retaining the physical meaning of parameters within a distributed parameter space. One of the limitations of TOPMODEL is that it has been developed for small watersheds (Bandaragoda et al., 2004). To counter this limitation, the National Institute of Water and Atmospheric

5 Institute of Hydrology distributed model, United Kingdom

${ }^{6}$ Hydrologiska Byråns Vattenbalansavdelning model 
Research (NIWA), New Zealand, developed TopNet (Ibbitt and Woods, 2004), a rainfall-runoff model which combines TOPMODEL with a kinematic wave channel routing algorithm which allows larger watersheds to be modelled using smaller subcatchments as elements (Bandaragoda et al., 2004). NIWA have applied TopNet to a number of New Zealand catchments of various sizes and climate regimes (Clark et al., 2008a; Ibbitt et al., 2005; Poyck et al., 2011). It's structure, however, does not allow for catchments where there are multiple runoff-generating stores (McMillan et al., 2010).

The models outlined above can be classified further into deterministic or stochastic. Deterministic models take a given a set of inputs and parameter values and generate a single possible response or outcome for a corresponding point in time and space from a simulation (Beven, 2001). Stochastic models, on the other hand, require the uncertainty to be quantified in some manner as part of the modelling process (Young, 2001). Stochastic models are particularly useful where inadequate data prevents actual (deterministic) estimates of flow from being obtained. For example, where only streamflow data exists (or is available) probabilistic approaches can be used to consider all possible flow values and to assign a probability to each of them being the right one (Maidment, 1993).

The distinction between deterministic and stochastic models is not always clear cut. Some deterministic models, such as the probability distributed model (PDM) of Moore (2007), will characterise a particular aspect of the hydrological system using a stochastic approach. The PDM groups the catchment into a series of stores with different storage capacities. Each store represents a dynamic contributing area for runoff generation, and the response of each store to rainfall is represented by a probability distribution function (Moore, 2007). As is common with empirical models, the distribution of responses has been determined with little consideration to the physical processes and characteristics of the store's response.

\subsection{Rainfall-runoff modelling for reservoir inflow forecasting}

The type of model suitable for any given application will depend on the desired outcome of the project, model assumptions and resource constraints (Beven, 2001). In reservoir inflow forecasting applications, where short-term predictions are the main aim, computational efficiency is imperative as well as the accuracy and reliability of model output. 
Although physics-based models are of value to the understanding of catchment hydrological processes, their application to forecasting problems has been limited due to their heavy data and computational requirements (Daniel et al., 2011; Graham and Butts, 2005). To run such models at the appropriate resolution requires considerable computational resources, and in some cases even modern computers (and supercomputers) are unable to meet these requirements. Large amounts of data are required which can also be prohibitively costly (Pechlivanidis et al., 2011).

There are numerous data driven techniques which have been applied to reservoir inflow forecasting including empirical regression, fuzzy-rule based systems and artificial neural network models (Coulibaly et al., 2000; Harte and Thomson, 2007; Lohani et al., 2012; Taghi Sattari et al., 2012; Xu and Li, 2002). Empirical models can be parametrically efficient, but in their development they give little consideration to the physical processes that generate the system's runoff response (Kokkonen and Jakeman, 2001; $\mathrm{Xu}$ and $\mathrm{Li}, 2002$ ). This can restrict their utility when seeking further understanding of catchment hydrological processes and extrapolating beyond the observation set or to other catchments.

Conceptual models provide the necessary computational efficiency while maintaining an underlying physical basis. For this reason, they have been extensively applied for reservoir inflow forecasting to derive reservoir operation policies, improve existing operational procedures, simulate climate change, assess the impact on flow regimes, and predict short-term inflows (Amenu and Killingtveit, 2001; Collischonn et al., 2007; Druce, 2001; Hotchkiss et al., 2000; Welsh et al., 2012, in review; Yang et al., 2005). They can also be applied at a range of spatial (lumped/semi-distributed/distributed) and temporal scales and are suitable for estimating inflows from ungauged basins. Wagener et al. (2004b) state that conceptual models are likely to perform just as well as physics-based models without the intensive data and computational requirements.

The HBV hydrological model (Bergström, 1995; Lindström et al., 1997), was originally developed to forecast streamflow in hydro-power generation regions of Scandinavia and has since been applied in numerous countries world-wide (Amenu and Killingtveit, 2001; Yang et al., 2005). In another example, the conceptual UBC watershed model has been used to forecast seasonal inflows to Kinbasket Lake (storage capacity: $14.8 \mathrm{~km}^{3}$ ) and Mica Dam (drainage basin area: $21500 \mathrm{~km}^{2}$ ) on the Columbia River for more than 20 years (Druce, 2001). Outflow from the Mica Dam 
is regulated based on these forecasts. Collischonn et al. (2005) also used a conceptual model to forecast hourly inflows to the Machadinho dam and reservoir located on the Uruguay River, southern Brazil. This same model was also used to model daily inflows between Itumbiara and Sāo Simāo power plants (drainage basin between the two power plants: $76,746 \mathrm{~km}^{2}$ ) on the Paranaíba River basin in Brazil (Collischonn et al., 2007).

In the majority of examples found in the literature, it is principally the unregulated inflows to regulated systems that are simulated. The problem of reservoir inflow forecasting is more complicated when regulated inflows need to be modelled. This requires the incorporation of specific reservoir operational information into the traditional model structure.

Although there are numerous examples where regulated catchments have been modelled, (Bulygina et al., 2012; Hotchkiss et al., 2000; Sayama et al., 2006; Zhang et al., 2011, amongst others) the success of these applications relies on obtaining extensive data and information pertinent to the schemes operation. In the Lake Taupo catchment, three competing power companies control approximately $60 \%$ of the inflows through three hydro power schemes, while Mighty River Power Ltd manages lake level and outflow. Although some streamflow data is available, there is little information relating to the control of water storage and release for the respective power schemes. The challenge is, therefore, to find alternative ways in which this regulation can be quantified. This thesis, therefore, sets out to provide some guidance on how some of this regulation (using various physical and legislative constraints) can be incorporated into a conceptual model structure in the absence of direct operational information.

\subsection{Reducing uncertainty for more accurate and reliable model output}

Predictive models require adequate characterisation of the underlying system, accurate parameter estimations and sound state variables. However, since models are simplifications of real world processes, fed by imperfect data and estimated parameter values, their output can be subject to considerable uncertainty (Kitanidis and Bras, 1980; Wagener and Gupta, 2005). Uncertainty arises from natural randomness (which cannot be corrected for (Melching, 1995)), subjective interpretation of the relative importance of physical processes, simplifications and 
approximations in the model structure, estimation of parameter values and collection and interpretation of data for input (Wagener and Gupta, 2005). Therefore, the key to providing more accurate model predictions is to reduce the uncertainties associated with the model structure, parameterisation and data issues to within acceptable ranges for more reliable and robust decision-making.

Model structure uncertainties stem from the inability of models to truly represent the complex reality of a hydrological system (Liu and Gupta, 2007). Rainfall-runoff models are an assembly of simplifications and approximations of the real world. For these approximations to be made correctly, sufficient data and computer resources are required. In addition, the modeller is required to have knowledge of the important rainfall-runoff generating mechanisms and processes within the catchment. This is particularly relevant in conceptual models in which the model structure is based on the modeller's perceived understanding of catchment hydrologic processes. Key processes may be mistakenly omitted or given less consideration than some less influential components on the system, resulting in uncertainty in model output (Liu and Gupta, 2007; Wagener and Gupta, 2005). Defining the model structure, therefore, involves selecting appropriate and accurate representations of the hydrological processes and the relationship between model inputs, parameters, states and outputs (Liu and Gupta, 2007).

Attempts to reduce the effects of model structure uncertainty have generally involved multi-model approaches in which a suite of plausible and independent model structures are employed to provide a more realistic approximation of the underlying system (Beven and Binley, 1992; Duan et al., 2007; Neuman, 2003; Vrugt and Robinson, 2007). More recently, research has also focussed on diagnosing differences in hydrological behaviour between model structures (Clark et al., 2008b). Neuman (2003) states that hydrological analysis derived from a single hydrologic model (as is common in hydrologic modelling) can lead to statistical bias and underestimation of uncertainty. Multi-model approaches, however, can be computationally demanding (Liu and Gupta, 2007).

Parameter estimation has received much attention in the last few decades in relation to reducing uncertainty, but generally assumes the model itself is true and correct and ignores state conditions (Liu and Gupta, 2007; Vrugt et al., 2005). Parameters characterise the real world properties of a hydrologic system (Liu and Gupta, 2007; Wagener and Gupta, 2005). However, they are often aggregated in space and time and applied at scales much different to those they represent. In addition, they are 
often approximated if corresponding field observations are unavailable. These parameters therefore can lose a degree of spatial representativeness and direct physical interpretation. A lack of correlation between model parameters and the real world can often result in predictive uncertainty (Wagener and Gupta, 2005).

Calibration (manual and automatic) essentially aims to improve this correlation by optimising the parameter set in order to effect a closer matched simulation of the real world. The subjective and time-consuming nature of manual methods led to the development of automatic calibration procedures with the aim of speeding up the calibration process and providing an objective strategy for parameter estimation and optimisation (Boyle et al., 2000; Wagener et al., 2001). Multi-criteria routines were borne out of the inability of early automatic methods to evaluate the performance on more than one aspect of the hydrograph (Boyle et al., 2000; Gupta et al., 2009; Gupta et al., 1998; Kavetski et al., 2002; Wagener et al., 2003).

Monte Carlo methods offer a flexible and robust method for estimating parametric uncertainty by being able to efficiently sample across a wide parameter space and provide an objective assessment of model performance (Pechlivanidis et al., 2011). Numerous parameter sets are generated from which optimal parameter sets can be found (Beven, 1993). An objective function is used to describe the correspondence between the simulation and observed system behaviour. Depending on the computing resources available, many thousands of calibration runs can be achieved in a much shorter time than traditional manual calibration routines. In the absence of sufficient computational resources, optimisation methods can be used alongside Monte Carlo methods to fine tune parameter sets (Duan et al., 1992). The Generalised Likelihood Uncertainty Estimation (GLUE) method of Beven and Binley (1992) is an example of a method that uses Monte Carlo simulations to identify behavioural parameter sets; it can also be used to identify behavioural model structures.

Adequate characterisation of this parametric uncertainty is essential for robust decision making, but does not overcome the problem of biases in the model states where cumulative effects of data errors and/or incorrect model assumptions lead to internal discrepancies (e.g. in groundwater levels, soil moisture) that then cause large errors in predicted water fluxes and other essential model outputs.

Data assimilation is a method that has been used to address uncertainties of data and model output, by updating state conditions with real-time or near real-time 
observations. State conditions are used as a proxy to storage in the catchment which is a major moderator of flows. Data uncertainty arises not only directly from its measurement but also from its interpretation, data processing and spatial representativeness (Bulygina, 2007; Kitanidis and Bras, 1980; Liu and Gupta, 2007; Moradkhani and Sorooshian, 2008; Wagener and Gupta, 2005). Methods for collecting data may not be perfect and can result in measurement uncertainty. An example is if the instrumentation has not been calibrated appropriately. The human component of data uncertainty is introduced in the interpretation of the observations, for example, radar rainfall estimates and the conversion of stage data to flow data. In addition, observed data is often applied at scales very different to those they directly represent in the field (Blöschl and Sivapalan, 1995; Wagener et al., 2004a). Soil hydraulic conductivity, for example, can vary within metres of a measurement (Hopmans and Schoups, 2005) but a single observation may be applied to a much wider area.

Data assimilation assumes that neither the model output nor the field observations are perfect and instead aims for consistency with real world processes by merging models and data (Reichle, 2008). Observations are used to correct for errors in driving data by updating states to better characterise catchment water storage. These updated states are then used to forecast streamflow over the next prediction interval. Consequently, the short-term biases associated with this source of uncertainty can be reduced (McLaughlin, 2002; Reichle, 2008; Wagener and Gupta, 2005). This is particularly relevant in operational modelling when short-term predictions are the main aim and a balance needs to be achieved between computational efficiency and predictive accuracy.

Model states can be updated directly using remote sensing or satellite information and field data such as snowpack water equivalent. The successful assimilation of remote sensing data into land surface models has been widely reported (Aubert et al., 2003; Dunne and Entekhabi, 2005; McLaughlin, 2002; Reichle, 2008; Reichle et al., 2002). However, there are some significant drawbacks. The temporal and spatial resolution of remotely sensed data is often very coarse compared to the model which they are used to inform and they can have inherently more uncertainty than in situ observations (Liu et al., 2012; Pauwels and De Lannoy, 2006).

Streamflow can also be used to update states. Streamflow represents an integrated catchment response to rainfall and is an indicator of catchment water storage (Kirchner, 2009; Pauwels and De Lannoy, 2006). This data is generally available at 
high temporal resolution and across different spatial scales (Pauwels and De Lannoy, 2006). As such, the assimilation of discharge observations to update states in rainfall-runoff models has been the focus of a number of studies in the last decade (Clark et al., 2008a; DeChant and Moradkhani, 2012; Pauwels and De Lannoy, 2009; Seo et al., 2009; Vrugt et al., 2006; Weerts and El Serafy, 2006; Xie and Zhang, 2010) and is also a focus of this research.

Increasingly, the use of data assimilation through state-correction is being recognised as an essential part of any forecasting application (Liu et al., 2012, in review). Without it, relatively large errors can accumulate in the model output, even over the short term (Collischonn et al., 2007). However, the success of stateupdating in terms of improving predictive accuracy is dependent on obtaining accurate parameter estimates. The inclusion of an (unbiased) error term in the model transition equation allows input, output and model structure error to be explicitly dealt with in the update procedure, but parameter uncertainty is largely ignored (Liu and Gupta, 2007; Moradkhani et al., 2005a; Vrugt et al., 2005).

To overcome this problem, Moradkhani et al. (2005b) proposed a dual stateparameter assimilation method which allows parameters to vary over time. States and parameters are updated simultaneously at each update step. However, Liu and Gupta (2007) point out that while parameters may vary over time they will generally vary at a much slower rate than state variables. They note that problems of instability could arise from both values being updated in the same time step and conclude that careful consideration should be given to identifying appropriate timescales which should be integrated into the data assimilation procedure. In another example, Vrugt et al. (2005) combine a data assimilation routine in a batch calibration method (Simultaneous Optimization and Data Assimilation (SODA)) to improve not only the predictive capabilities but also to more explicitly account for all sources of uncertainty. They note that the parameter values found will only have meaning in combination with a data assimilation method. In the absence of statecorrection, these parameters will not provide the best forecasts. This has implications for periods when observations may not be available to assimilate.

These two state-parameter assimilation methods are based on adjusting a single optimal parameter set to ascertain the uncertainty bounds associated with the parameter set. While effective, the computational burden of these approaches can be limiting (Liu and Gupta, 2007; Xie and Zhang, 2010). Alternatively, Monte Carlo routines (described above) can account for the parametric and model structure 
uncertainty by sampling the entire feasible parameter set and allowing more than one optimal parameter set to be identified. State updating applied to each time step for each parameter set can account explicitly for some of this parametric uncertainty. The model output for each parameter set reflects the range of potential outcomes and hence the uncertainty in the estimated parameters.

With all sources of uncertainty accounted for, state-updating can significantly improve the accuracy of model predictions. However, although parameter and states are generally constrained either physically or mathematically in hydrological modelling, they are generally not constrained in the state updating process. In conceptual hydrological modelling, parameter ranges are usually determined $a$ priori. State volumes are required to be non-negative and changes to states between time steps are based on mathematical representations of the interactions between stores and the processes controlling their recharge and depletion (Beven, 2001; Kitanidis and Bras, 1980; Kokkonen and Jakeman, 2001; Young, 2001). Conversely, the aim of state updating is to minimise the mean square error, irrespective of physical laws (Simon and Tien Li, 2002; Wang et al., 2009). While this can increase the possibility of successful forecasting (Weerts and El Serafy, 2006), it can also result in erratic streamflow simulations (Clark et al., 2008a). Pan and Wood (2006) found that although standard operation of a land surface model satisfied the requirement for closure of the water balance when state and flux observations were assimilated, the water balance was often broken because updates made to the various states were done without constraint. Clark et al. (2008a) note that in situations where the difference between the modelled streamflow and observed streamflow is large, state updates can be exceptionally large, resulting in unrealistic streamflow simulations. By constraining states to be consistent with physical laws the accuracy and reliability of model output can be improved (Wang et al., 2009).

There are few examples in the hydrological literature where constraints have been applied. Reportedly, this is because of difficulties in incorporating them into the assimilation framework (Simon and Tien Li, 2002; Wang et al., 2009). However, Pan and Wood (2006) applied constraints to assure closure of the water balance in a land-surface model with relative ease. In another example, Wang et al. (2009) compared three approaches to constrain simultaneous state correction and parameter updating in a conceptual hydrologic model. To the best of the author's knowledge, constraints have not been applied in an operational forecasting context. Nevertheless, it should be considered an integral part of any state-updating 
procedure, especially if the model output is being relied upon in decision making processes.

\subsection{Summary}

The purpose of this study is to develop a predictive rainfall-runoff model specifically for the Lake Taupo catchment. Inflow data are combined to provide accurate and reliable short-term predictions of lake level for robust decision making relating to the operation of the Waikato Power Scheme. Such a model needs to be computationally efficient and able to incorporate the complexities of the Lake Taupo catchment pertaining to the various regulated inflows and data/information issues. In addition, it is desirable that the model will provide enough information to contribute to the overall understanding of catchment hydrologic function.

Internationally, empirical neural network models have received considerable attention for inflow applications in the last decade (Coulibaly et al., 2000; Dawson and Wilby, 2001; Jain et al., 1999; $\mathrm{Xu}$ and Li, 2002). Although operationally efficient, they can lack a physical basis. Extrapolation of the model beyond the range of hydrological conditions contained in the calibration data, or to other catchments, is therefore inappropriate. Physics-based models can provide a more detailed and accurate description of the hydrological processes within a catchment but their heavy data and computational requirements limit their usefulness.

Physically-based conceptual models provide sufficient information about the catchment's response to rainfall as well as generate inflow predictions (model output) without necessarily being computationally demanding. They have been widely applied to reservoir inflow forecasting and are also suitable for extrapolation to ungauged areas. Conceptual models are also capable of incorporating regulation into the model structure, although there is little guidance in the literature as to how this can be achieved in the absence of direct operational information.

To produce accurate and reliable model output, predictive models require adequate representation of the underlying system and accurate estimates of parameters and state variables. Errors associated with these sources of uncertainty need to be reduced to acceptable levels. Model calibration routines can deal with some of the uncertainty associated with the model structure and estimated parameters, but data errors (which determine state variables) are more difficult to assess. Data assimilation through state updating can deal with data uncertainties and, when used 
in conjunction with Monte Carlo methods to explicitly address parameter uncertainty, can also be used as a general framework to address uncertainty from all sources. Because of this, state-updating is starting to be recognised as an integral part of any forecasting application.

However, state-updating usually takes place with little, if any, consideration of physical laws. Without constraints, updated states may compromise the integrity and reliability of model output. This issue has received relatively little consideration in the hydrologic literature, but is an area that deserves further attention, particularly if model output is to be relied upon in decision making processes.

In this dissertation, Monte Carlo sampling is used in conjunction with a constrained state updating approach to address all sources of uncertainty. State-updating is applied to catchments for which streamflow observations are available. Perturbations to states are constrained to improve the reliability of model output to enable more robust decision-making in the Lake Taupo catchment. 


\section{Data availability, processing and preparation}

The value of any model is dependent on the quality of the data that goes into it. This chapter summarises the data collected, analysed and used in the development and calibration of the conceptual rainfall-runoff model and subsequent data assimilation and prediction of lake level. Section 4.1 discusses the rainfall data available, the quality of that data and describes how gaps are infilled and catchment areal estimates are obtained. Section 4.2 explains the process for obtaining a long-term continuous record of potential evapotranspiration (PE), and lake evaporation, from the few observation points in and around Taupo. The availability and reliability of streamflow observations are discussed in Section 4.3 and includes the outflow from Lake Taupo. In the final section, seiche effects on lake level time series are described and the method used to reduce these effects explained.

\subsection{Rainfall}

Seventeen rainfall records are used in this study. These were selected based on temporal resolution, availability and proximity to catchments for model calibration and suitability as model driving data. Only eight of these gauging stations are currently operational (Figure 4.1). The location of these gauges is shown in Figure 
4.2. Table 4.1 lists the rainfall gauges used, their respective locations, elevation and mean annual rainfall. Rainfall stations are located at elevations ranging between $350 \mathrm{~m}$ a.s.l and over $1360 \mathrm{~m}$ a.s.l. The shortest record covers just 2.5 years at Turangi (Site No. 12432) followed by 3.5 years for Waitahanui (Site No. 869210). The longest record covers the period 1976-2001 (Tauranga-Taupo catchment, Site No. 960010).

Errors and gaps in the data associated with rainfall records are generated from a number of sources including its measurement artefacts, transfer problems and processing issues. The majority of these rainfall records have been maintained by NIWA. The quality of these records is generally good, with gaps commented and files available that record where issues have been identified and/or resolved. Records provided by Environment Waikato have been quality checked and the reliability of the data given a code. Periods of data which are not considered of good quality from either the comment files or quality codes have been removed from the analysis. For the purpose of this study, rainfall data is interpolated to 15 minute time steps.

\subsubsection{Infilling missing data}

Rainfall data is an important input to hydrological models. Gaps sometimes occur in these records which may need to be infilled in order to generate a continuous long term record. These gaps may be isolated occurrences or cover lengthy periods. Approaches to infill these gaps include station-average, normal-ratio, inverse distance weighted and isohyetal methods. These methods all use observations from multiple nearby gauges to infill the missing data. The choice of method suitable for application in the Lake Taupo catchment is limited due to the sparse network of gauges and, in many cases, a lack of overlapping data between sites. Gauges are often located several kilometres (or more) apart and show only a small degree of correlation. As a result, finding more than one gauge to estimate a missing data point can be difficult.

In this study, gaps in rainfall records are infilled using the normal-ratio method. The normal-ratio method weights the observations by their respective annual average volumes. It is suitable for use where differences between the annual catch at the gauge with the missing data and the gauge being used to infill the gap is greater than $10 \%$, which is a limitation of the station-average method (McCuen, 1998). 


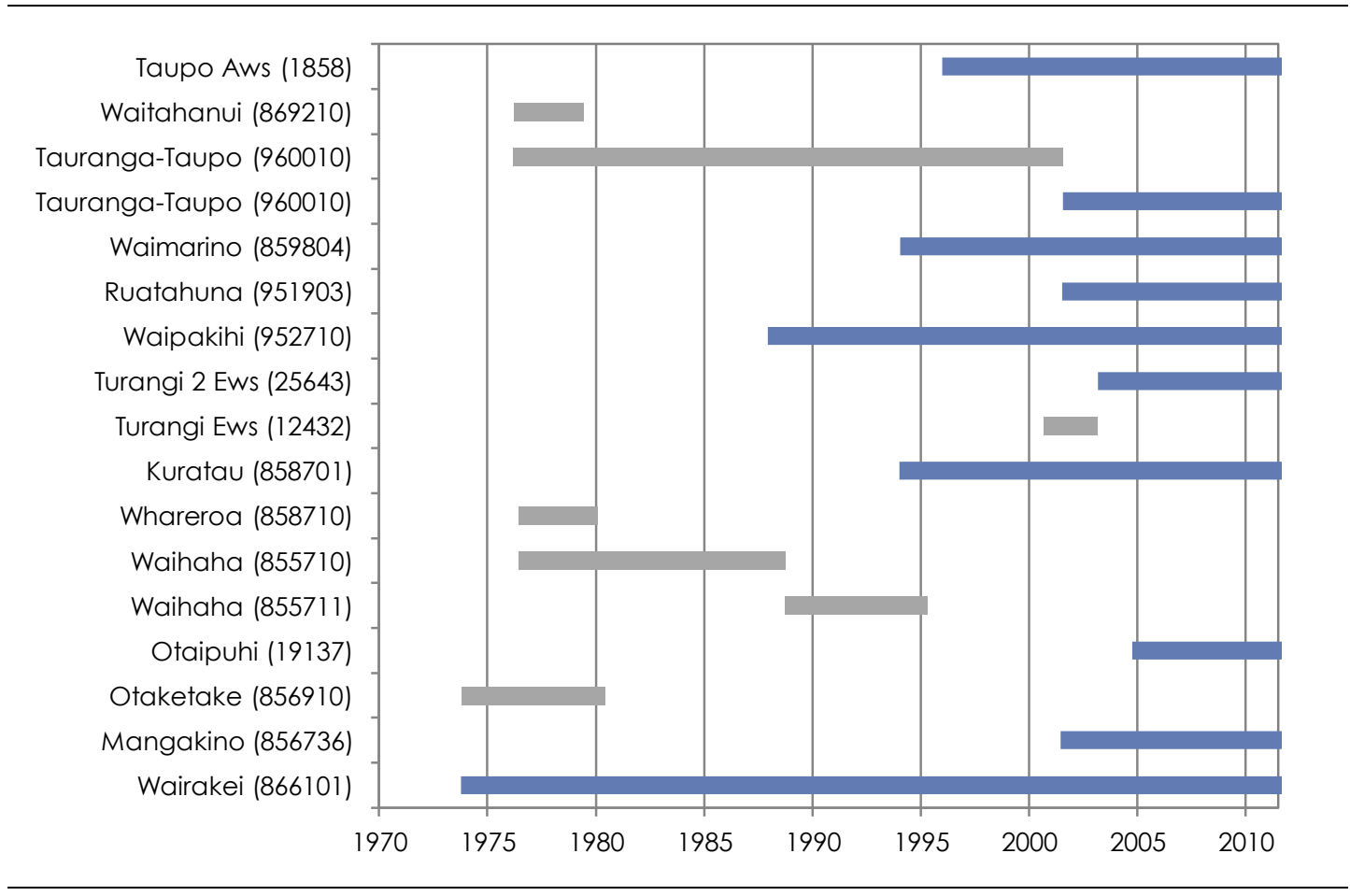

Figure 4.1 The duration and timing of rainfall records for the Lake Taupo catchment vary. The light blue bars indicate records stations which are closed. The dark blue bars represent currently operational gauge stations.

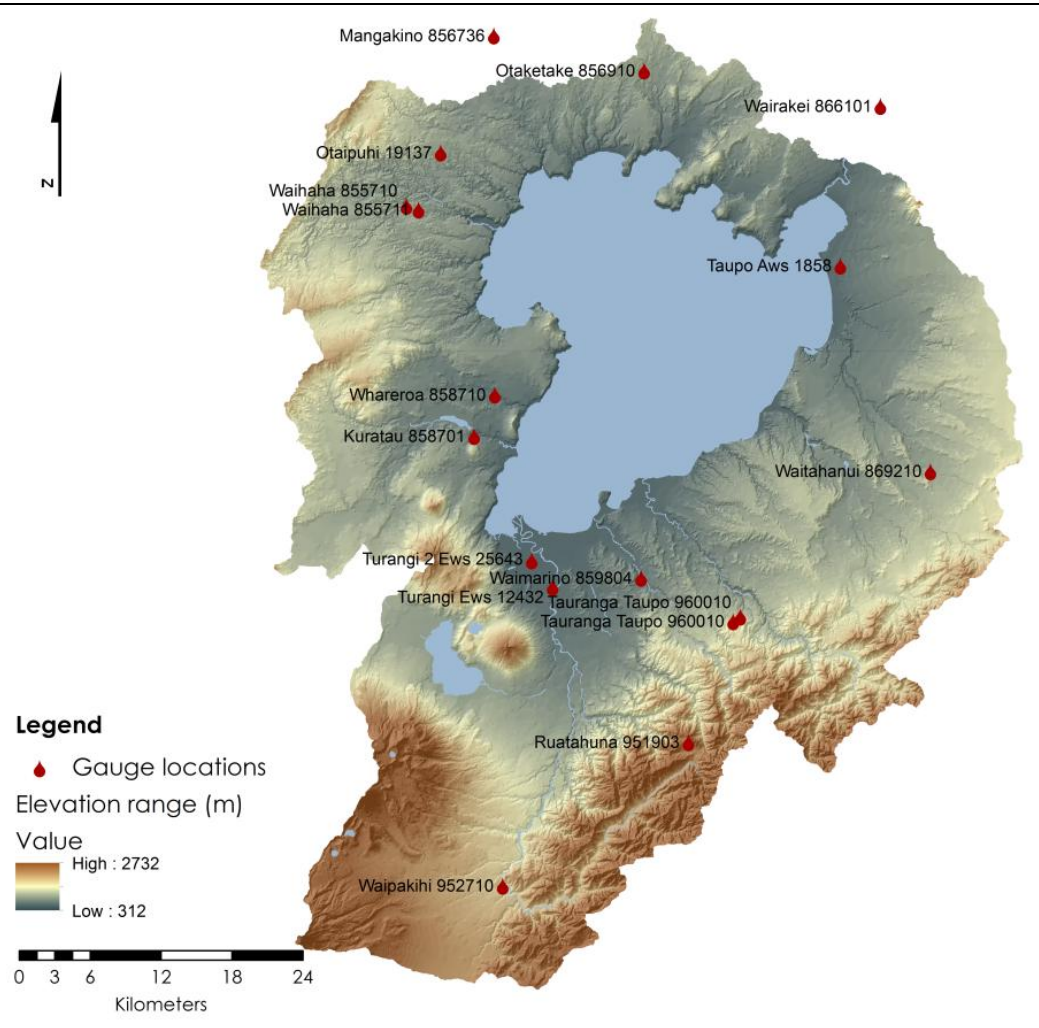

Figure 4.2 Location of rainfall gauges used in this dissertation 
Table 4.1 Rainfall gauging sites in the Lake Taupo catchment used in this study

\begin{tabular}{|c|c|c|c|c|c|c|c|c|c|}
\hline Agent & Station Name & Start Date & End Date & $\begin{array}{l}\text { Mean Annual } \\
\text { Rain (mm/a) }\end{array}$ & $\begin{array}{l}\text { Elevation } \\
\text { (m a.s.l) }\end{array}$ & Easting & Northing & Status & Source \\
\hline 1858 & Taupo AWS & 26-Jan-1996 & 24-Aug-2011 & 779 & 400 & 2778000 & 6269000 & Open & NIWA \\
\hline 869210 & Waitahanui at Collins Farm & 9-Mar-1976 & 1-Jun-1979 & 1230 & 589 & 2785595 & 6251595 & Closed & NIWA \\
\hline 960010 & Tauranga-Taupo at Kiko Rd & 9-Mar-1976 & 25-Jul-2001 & 1923 & 671 & 2769500 & 6239320 & Open & Waikato Regional Council \\
\hline 960010 & Tauranga-Taupo at Kiko Rd & 29-Jul-2001 & 1-Aug-2011 & 1800 & 720 & 2768900 & 6238925 & Open & Genesis Energy Ltd \\
\hline 859804 & Waimarino at Kepa Rd & 20-Jan-1994 & 1-Sep-2011 & 1469 & 418 & 2761104 & 6242603 & Open & Genesis Energy Ltd \\
\hline 951903 & Ruatahuna & 15-Jul-2001 & 15-Oct-2009 & 1817 & 1360 & 2765100 & 6228690 & Open & Genesis Energy Ltd \\
\hline 952710 & Tongariro R. at Waipakihi & 12-Dec-1987 & 1-Aug-2011 & 2386 & 880 & 2749375 & 6216555 & Open & Genesis Energy Ltd \\
\hline 25643 & Turangi 2 EWS & 7-Mar-2003 & $1-J u n-2011$ & 1397 & 350 & 2751859 & 6244085 & Open & NIWA \\
\hline 12432 & Turangi EWS & 14-Sep-2000 & 1-Aug-2003 & 1449 & 375 & 2753626 & 6241844 & Closed & NIWA \\
\hline 858701 & Kuratau SH4 1 & 2-Jan-1994 & $1-A u g-2011$ & 1475 & 500 & 2742650 & 6254700 & Open & King Country Energy Ltd \\
\hline 855710 & Waihaha at Forest Boundary & 31-May-1976 & 21-Sep-1988 & 1502 & 540 & 2741290 & 6274100 & Closed & Waikato Regional Council \\
\hline 855711 & Waihaha at Farm House & 22-Sep-1988 & 25-Apr-1995 & 1605 & 549 & 2742310 & 6273780 & Closed & Waikato Regional Council \\
\hline 19137 & Otupoto at Otaipuhi & 14-Oct-2004 & 29-Nov-2011 & 1495 & 575 & 2744200 & 6278600 & Open & Waikato Regional Council \\
\hline 856910 & Otaketake at Otake Rd & 18-Oct-1973 & 3-Jun-1980 & 1398 & 580 & 2761410 & 6285520 & Closed & NIWA \\
\hline 866101 & Wairakei & 1-Jul-1998 & 1-Jul-12001 & 1319 & 340 & 2781400 & 6281500 & Open & Contact Energy Ltd \\
\hline 856736 & Mangakino at Kakaho Rd & 20-Jun-2001 & 3-Feb-2011 & 1635 & 470 & 2748700 & 6288500 & Closed & NIWA \\
\hline
\end{tabular}

68 | Data availability, processing and preparation 
Following Dingman (2008) and McCuen (1998), the normal-ratio method is formulated as follows:

$$
\dot{P}=\sum_{g=1}^{n} w_{g} P_{g}
$$

where $\dot{P}$ is the missing point rainfall estimated by the weight, $w_{g}$, given to the depth of rainfall $P_{g}$ at station $g$. The sum of the weighted rainfall calculated for $n$ gauges is used to infill the missing data point. The weight for each station $g$ is given by

$$
w_{g}=\frac{1}{n}\left(\frac{A_{\widehat{g}}}{A_{g}}\right)
$$

in which $A_{\hat{g}}$ is the average annual rainfall at the station with the missing data point, $A_{g}$ is the average annual rainfall of the 'donor' station and where $n$ is the number of gauges used in the estimation of the missing data point. While average annual rainfall is used here to determine the relative weights, it would also be possible to define these weights using climatological monthly rainfall to account for the temporal variability of rainfall throughout the year. Data and time constraints prevented from this approach being used in this study.

Where only one gauge in used to infill the missing data point, Eqn 4.2 simply becomes

$$
w_{g}=\frac{A_{\hat{g}}}{A_{g}}
$$

Eqn 4.3

Correlation analysis is used to identify gauges suitable for estimating the missing data point. Correlations of daily and hourly rainfall depths are used in this process. Over a longer period a number of different rain gauges may be used to infill missing data points over different periods of the record.

Infilled data will have greater uncertainty associated with it, especially if infilling is required over extended periods. For the purpose of model evaluation, gaps are infilled irrespective of length in order to obtain an uninterrupted data set for the period 1998-2011. Outside of this period, missing data is infilled only where necessary to achieve a suitable amount of time for model calibration and validation, avoiding periods of extensive missing data. Table 4.2 lists the percentage of rainfall records which have been infilled over calibration and evaluation periods as well as the 1998-2010 period. 
Table 4.2. Percentage of rainfall records infilled

\begin{tabular}{|ccccc|}
\hline Catchment & Rain gauge & Calibration period & Evaluation period & $\mathbf{1 9 9 8 - 2 0 1 0}$ \\
\hline Waitahanui & Waitahanui & $0.00 \%$ & - & - \\
Hinemaiaia & Tauranga-Taupo & $0.00 \%$ & $0.00 \%$ & $4.07 \%$ \\
\hline Tauranga-Taupo & Tauranga-Taupo & $0.00 \%$ & $0.00 \%$ & $4.07 \%$ \\
Waimarino & Waimarino & $0.00 \%$ & $0.00 \%$ & $2.34 \%$ \\
Lower Tongariro & Waipakihi & $0.00 \%$ & $0.00 \%$ & $0.00 \%$ \\
Poutu & Waipakihi & $0.00 \%$ & $0.00 \%$ & $0.00 \%$ \\
Waipakihi & Waipakihi & $0.00 \%$ & $0.00 \%$ & $0.00 \%$ \\
Waihohonu & Waipakihi & $0.00 \%$ & $0.00 \%$ & $0.00 \%$ \\
Waihi & Turangi & $0.00 \%$ & - & - \\
Kuratau & Kuratau & $0.03 \%$ & $0.00 \%$ & $2.51 \%$ \\
Whareroa & Kuratau & $0.00 \%$ & - & - \\
Whanganui & Waihaha & $0.00 \%$ & $0.87 \%$ & - \\
Waihaha & Waihaha & $0.00 \%$ & $0.00 \%$ & - \\
Tutaeuaua & Mangakino & $0.00 \%$ & - & - \\
\hline
\end{tabular}

\subsubsection{Estimation of catchment areal rainfall}

Gauge data provides point values of rainfall only. Hydrological models require estimates of catchment areal volumes. There are several methods available to extend this point information to the area being modelled, the most common being areaweighted and surface fitting methods.

Area weighted methods (such as Thiessen polygons and inverse distance weighting) are suited to catchments in which the gauge network is well distributed and where topography does not have a strong influence on precipitation (Dingman, 2008). They are not used for the gauged sub-catchments of Lake Taupo since there is often only one gauge located in or near a catchment in question and there are few at elevation. Using the Thiessen polygons method in four sub-catchments of Lake Taupo did little to improve the error in estimation of catchment water balances compared to the single gauge observation (Table 4.3) since it does not take into account increased rainfall with elevation.

The Thiessen polygons method, however, is used to estimate rainfall for ungauged areas which are spread around the lowland parts of the catchment because there would be no similarly simple method that would do better. Similarly, it is also used for estimating direct lake rainfall.

Surface fitting methods use observations to derive a precipitation surface representative of the area of interest but can require significant computational resources (Dingman, 2008). Such a surface has been developed for New Zealand 
(including Taupo) by Tait et al. (2006) who used a thin plate smoothing spline interpolation approach using latitude, longitude, and a mean annual precipitation surface (1951-1980) to estimate daily rainfall for the period 1960-2004. Woods et al. (2006) found that there were regional discrepancies in this surface. Runoff was underestimated in catchments where flow was less than $400 \mathrm{~mm} / \mathrm{a}$ and overestimated in catchments where flow was greater than $1200 \mathrm{~mm} / \mathrm{a}$. They proposed a bias correction surface to improve mean flow predictions (Woods et al., 2006). It can be used to either adjust modelled flow volumes or improve rainfall estimation, if it is thought most of the error is in catchment rainfall estimation (pers comm. Woods 2009).

While the generated time series provides daily gridded rainfall from 1960, this study requires high resolution data for the 1998 to 2011 period. Therefore, estimates of input rainfall are determined by relating gauge volumes to estimates of total catchment rainfall at each time step. This relationship is based on annual average rainfall estimates for the observation point and the catchment as a whole. To determine a suitable estimate of catchment rainfall, annual average rainfall based on gauge observations, Theissen polygons, the surface derived by Tait et al. (2006) and corrected (for rainfall) by Woods et al. (2006) are compared using a simple water balance approach,

$$
P=Q+A E
$$

Eqn 4.4

where $P$ is annual average precipitation ( $\mathrm{mm} / \mathrm{a}), Q$ is mean annual runoff $(\mathrm{mm} / \mathrm{a})$ and $A E$ is actual evapotranspiration (mm/a). Since $A E$ is not easily determined, it is calculated as the residual between rainfall and potential evapotranspiration (mean annual average as calculated for Turangi). Using the Budyko curve (Figure 4.3) to assess the expected partitioning between $P, Q$ and $A E$, ratios of $A E$ to potential evapotranspiration ( $P E$ ) and $Q$ to $P$ are used to evaluate the performance of each method for providing sensible estimates of catchment areal rainfall.

Assuming $P E$ is correct, or has less uncertainty associated with it than the rainfall estimates, the ratios indicate that catchment rainfall is under-estimated in all subcatchments. Although the bias corrected rainfall from Woods et al. (2006) provides the most sensible results, these estimates are generally too low for the subcatchments of Lake Taupo. All methods are based on the observations from gauge locations and, therefore, may not be able to adequately account for all of the temporal and spatial variability of rainfall in areas (like Lake Taupo) where the network is sparse and rainfall gauges are located several kilometres apart. 
As a result, in this study the amount by which the observations are scaled is included as a parameter for calibration. Initial parameter ranges are based on equalising catchment water balances for the calibration period.

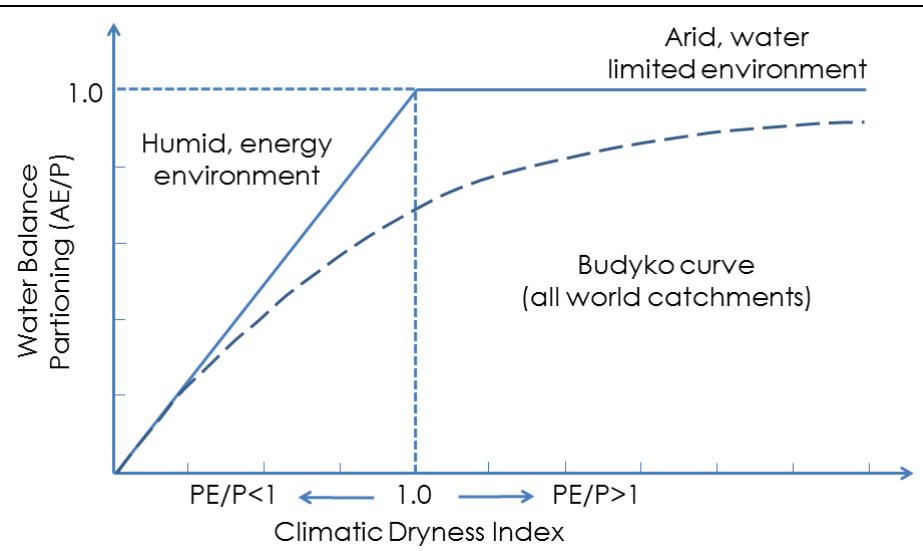

Figure 4.3 Budyko curve, adapted from Sivapalan (2005). In humid environments (such as Lake Taupo and New Zealand catchments, in general), evaporative demand is greater than can be satisfied by the energy limited environment. In the Lake Taupo catchments and climatic dryness index of between 0.4-0.6 would suggest that $40-50 \%$ of rainfall is actually lost to evapotranspiration.

Table 4.3. Annual Average Catchment Water Balance Analysis

\begin{tabular}{|c|c|c|c|c|c|c|}
\hline Tauranga-Taupo & $\mathrm{mm} / \mathrm{a}$ & $\mathrm{PE} / \mathrm{P}$ & WB AE & $\mathrm{AE} / \mathrm{PE}$ & Q/P & $\mathrm{AE} / \mathrm{P}$ \\
\hline Flow & 1558 & & & & & \\
\hline PE & 892 & & & & & \\
\hline Rain Observed & 1908 & 0.47 & 350 & 0.39 & 0.82 & 0.18 \\
\hline Rain Thiessen & 1861 & 0.48 & 303 & 0.34 & 0.84 & 0.16 \\
\hline Rain Tait & 1883 & 0.47 & 325 & 0.36 & 0.83 & 0.17 \\
\hline Rain Woods & 2274 & 0.39 & 716 & 0.80 & 0.69 & 0.31 \\
\hline Waimarino & $\mathrm{mm} / \mathrm{a}$ & $\mathrm{PE} / \mathrm{P}$ & WB AE & $\mathrm{AE} / \mathrm{PE}$ & $Q / P$ & $\mathrm{AE} / \mathrm{P}$ \\
\hline Flow & 1706 & & & & & \\
\hline PE & 892 & & & & & \\
\hline Rain Observed & 1474 & 0.61 & -232 & -0.26 & 1.16 & -0.16 \\
\hline Rain Thiessen & 1853 & 0.48 & 147 & 0.16 & 0.92 & 0.08 \\
\hline Rain Tait & 1828 & 0.49 & 122 & 0.14 & 0.93 & 0.07 \\
\hline Rain Woods & 2139 & 0.42 & 433 & 0.49 & 0.80 & 0.20 \\
\hline Kuratau & $\mathrm{mm} / \mathrm{a}$ & $\mathrm{PE} / \mathrm{P}$ & WB AE & $\mathrm{AE} / \mathrm{PE}$ & $Q / P$ & $\mathrm{AE} / \mathrm{P}$ \\
\hline Flow & 1175 & & & & & \\
\hline PE & 892 & & & & & \\
\hline Rain Observed & 1481 & 0.60 & 306 & 0.34 & 0.79 & 0.21 \\
\hline Rain Thiessen & 1784 & 0.50 & 609 & 0.68 & 0.66 & 0.34 \\
\hline Rain Tait & 1734 & 0.51 & 559 & 0.63 & 0.68 & 0.32 \\
\hline Rain Woods & 2139 & 0.42 & 964 & 1.08 & 0.55 & 0.45 \\
\hline Waihaha & $\mathrm{mm} / \mathrm{a}$ & $\mathrm{PE} / \mathrm{P}$ & WB AE & $\mathrm{AE} / \mathrm{PE}$ & $Q / P$ & $\mathrm{AE} / \mathrm{P}$ \\
\hline Flow & 1321 & & & & & \\
\hline PE & 892 & & & & & \\
\hline Rain Observed & 1552 & 0.57 & 231 & 0.26 & 0.85 & 0.15 \\
\hline Rain Thiessen & 1492 & 0.60 & 171 & 0.19 & 0.89 & 0.11 \\
\hline Rain Tait & 1599 & 0.56 & 278 & 0.31 & 0.83 & 0.17 \\
\hline
\end{tabular}




\subsection{Evapotranspiration}

Daily PE data is obtained from NIWA's National Climate Database ${ }^{7}$ which is calculated using the Penman-Monteith potential evapotranspiration (PE) method (see Burman and Pochop (1994), as cited on NIWA's National Climate Database). PE has been recorded at three sites within the Lake Taupo catchment. PE recorded at Taupo (Site No, 1841) was calculated between 1972 and 1993. Annual average PE for this record is $815 \mathrm{~mm} / \mathrm{yr}$. There are two records at Turangi. The first (Site No. 12432) covers a short period between April 2002 and September 2002 and is therefore not considered in this analysis. Since March 2004, PE has been calculated in Turangi (Site No. 25643). Annual average PE at this site is $889 \mathrm{~mm} / \mathrm{yr}$. Outside of the Lake Taupo catchment, there are a number of other locations calculating PE. The Taumaranui site (Site No. 2250) is most proximal to the Lake Taupo catchment and has an annual average $\mathrm{PE}$ rate of $735 \mathrm{~mm} / \mathrm{yr}$.

To obtain a long-term PE record for the Lake Taupo catchment, a combination of records are used to extend the Turangi PE time series back further in time. Since there is no overlapping record between the Taupo and Turangi sites it is difficult to ascertain the relationship between these two datasets. However, there is a high correlation (Table 4.4) between the daily Taupo and Turangi records with the Taumaranui site. Prior to March 2003, the Taumaranui PE record is used to extend the $\mathrm{PE}$ record at Turangi back to 1975 (the earliest data requirement for subcatchment model calibration). A multiplier is determined by the relative difference between the annual average PE rates for both sites and the Taumaranui values adjusted accordingly.

Table 4.4. Correlation coefficients of daily PE rates between the Taumaranui station and the two records from the Taupo and Turangi stations.

\begin{tabular}{cc}
\hline Station Name & Correlation Coefficient (to Taumaranui (2250) \\
Taupo (1841) & 0.943 \\
Turangi (25643) & 0.925 \\
\hline
\end{tabular}

The record provides an extended daily PE record from 1975 to present. However, finer temporal resolution data is needed to drive the model. This requires some form of data disaggregation. Evapotranspiration rates are a function of energy (e.g. direct

7 The National Climate Database: http://cliflo.niwa.co.nz/ 
radiation) and will typically follow a diurnal cycle. Approximations of this diurnal cycle are used by Liu (2005) and Van Den Bos et al. (2006). In their studies a simple sinusoidal function between sunrise and sunset is applied to approximate the daily temperature pattern. In other studies, this diurnal cycle is more directly estimated using sunshine duration (Drogue et al., 2002).

This dissertation also approximates this diurnal cycle by fitting a sinusoidal function based on hourly mean global radiation as measured at Turangi, corrected for periods with high (>90\%) humidity and minimal mean global radiation. The daily $\mathrm{PE}$ volume is then disaggregated accordingly. Missing daily data are replaced with the mean daily $\mathrm{PE}$ for the month in question. Hourly values are uniformly disaggregated to 15 minute intervals.

Direct lake evaporation is obtained from NIWA's Climate Database using the open water evaporation time series recorded at Turangi. Using this method to estimate evaporation from large expanses of water like Lake Taupo may over-estimate evaporation by approximately 10-15 percent (Shuttleworth, 1993). Disaggregation of this time series was also undertaken using the same method described above.

\subsection{Streamflow and Outflow}

Historical discharge records have been obtained for 17 sub-catchments of Lake Taupo including the discharge time series for the TPS. Many of the records for these catchments are not publically available and have been obtained with permission from respective companies, including King Country Energy Ltd, Trustpower Ltd and Genesis Energy Ltd.

Table 4.5 lists the time series data used in this study. All records are interpolated to 15 minute time step resolution. These historical time series are of varying quality and length. Many catchments were gauged for a short period in the late 1970 s as part of a study on the inflows to Lake Taupo (Schouten et al., 1981). Figure 4.4 shows the timing and duration discharge records for the sub-catchments of this study and indicates which sites are still currently open. The location of these gauges is shown in Figure 4.5. During the 1970s and 1980s, the average time step length was several hours. As a result, flood peaks may be missed, leading to misrepresentation of the catchment's rainfall-runoff response. Today, automatic gauging stations have improved data collection; average time step lengths since 2000 are in the order of several minutes. 
Errors in the observed streamflow records arise from the interpretation, measurement and processing of river flow data. For example, rating curves are used to relate stage (river height) and flow. However, if rating curves are not reviewed frequently enough changes in bed form can alter the stage-flow relationship. For some records, quality codes have been assigned to each observation, providing an indication of the reliability of the records. For other records, comment files indicate gaps in the record and ratings measurements. Observations that are deemed to be of poor quality are removed from the analysis. In the case of streamflow data, missing values are not infilled since calibration and evaluation can occur on available observations. In terms of data assimilation, state-updating does not occur where observations do not exist.

Outflow from Lake Taupo has been recorded directly since 1969, and has been indirectly inferred from lake level records since 1905. Streamflow downstream of the Taupo Control Gates (as recorded at Reid's Farm, Site No. 1143444), has been supplied by NIWA for the period September 1969 to July 2011. Although discharge from the Taupo Control Gates is available, it is considered less accurate than the Reid's Farm site to which it is calibrated (pers Comm., Mighty River Power 2013).

The information from this gauge is used as the estimate of outflow from the Taupo Control Gates between 1998 and 2010. Fortunately, over this period the record is complete. Outside of this period, gaps could be infilled using the inflow data to the Wairakei Power Station downstream. 
Table 4.5 Hydrological gauging sites in the Lake Taupo catchment used in this study

\begin{tabular}{|c|c|c|c|c|c|c|c|c|c|c|c|c|}
\hline Catchment & Site No. & Start date & End date & $\begin{array}{l}\text { Area } \\
\left(\mathrm{km}^{2}\right)\end{array}$ & $\begin{array}{l}\text { Duration } \\
\text { (years) }\end{array}$ & $\begin{array}{c}\text { Median } \\
\text { Flow } \\
\left(\mathrm{m}^{3} / \mathrm{s}\right)\end{array}$ & $\begin{array}{l}\text { Mean } \\
\text { Flow } \\
\left(\mathrm{m}^{3} / \mathrm{s}\right)\end{array}$ & $\begin{array}{l}\text { Mean Ann } \\
\text { Runoff } \\
(\mathrm{mm} / \mathrm{a})\end{array}$ & Easting & Northing & Status & Source \\
\hline Waitahanui & 1543411 & 21-Jan-1976 & 13-Jan-1981 & 196.1 & 4.98 & 6.90 & 6.82 & 1097 & 2777854 & 6262966 & Closed & Waikato Regional Council \\
\hline Hinemaiaia above scheme & 1543412 & 29-Apr-1981 & 12-Apr-1987 & 125.4 & 5.95 & 3.41 & 4.02 & 1012 & 2779618 & 6250935 & Closed & Waikato Regional Council \\
\hline Hinemaiaia above scheme & 2743464 & 13-Apr-1987 & 12-Dec-2000 & 125.4 & 13.67 & 4.68 & 5.52 & 1389 & 2779600 & 6250900 & Closed & Trustpower Ltd \\
\hline Hinemaiaia below scheme & 3043471 & 20-Jun-2000 & 24-Jan-2009 & 153.3 & 8.60 & 4.64 & 5.53 & 1139 & 2774800 & 6255600 & Open & Trustpower Ltd \\
\hline Tauranga-Taupo & 1543413 & 11-Feb-1976 & 18-Jul-2008 & 197.1 & 32.45 & 6.91 & 9.67 & 1547 & 2763601 & 6247272 & Open & Waikato Regional Council \\
\hline Waimarino & 1543420 & 24-Sep-976 & 24-Jan-2009 & 63.6 & 32.35 & 2.30 & 3.46 & 1714 & 2761088 & 6242496 & Open & SCION \\
\hline Waipakihi & 1043461 & 1-Jan-1960 & 1-Jul-2008 & 180.0 & 49.10 & 8.25 & 11.91 & 2087 & 2749288 & 6216582 & Open & NIWA \\
\hline Waihohonu & 1043466 & 1-Aug-1961 & 24-Jan-2009 & 96.1 & 47.51 & 5.77 & 6.30 & 2067 & 2746291 & 6217307 & Open & NIWA \\
\hline Waihi & 3043481 & 12-Feb-2003 & 18-Jan-2006 & 9.8 & 2.93 & 0.33 & 0.39 & 1261 & 2747400 & 6247500 & Closed & NIWA \\
\hline Kuratau above scheme & 1043468 & 14-Nov-1978 & $21-J u l-2008$ & 119.3 & 30.21 & 3.34 & 4.28 & 1132 & 2742682 & 6254632 & Open & King Country Energy Ltd \\
\hline Kuratau below scheme & 1543443 & 17-Jun-1976 & 16-Feb-1979 & 194.2 & 2.67 & 5.48 & 6.58 & 1068 & 2748343 & 6254288 & Closed & King Country Energy Ltd \\
\hline Whareroa & 1243461 & 26-Sep-1977 & 20-Aug-1980 & 59.4 & 2.90 & 1.01 & 1.24 & 661 & 2750708 & 6257057 & Closed & Waikato Regional Council \\
\hline Whareroa & 1243461 & 8-May-2002 & 18-Jul-2008 & 59.4 & 6.20 & 1.06 & 1.25 & 664 & 2750708 & 6257057 & Open & Waikato Regional Council \\
\hline Whanganui & 1543427 & 2-Jul-1976 & 29-Sep-1980 & 31.6 & 4.33 & 1.07 & 1.55 & 1546 & 2742196 & 6266535 & Closed & Waikato Regional Council \\
\hline Waihaha & 1543424 & 26-May-1976 & 3-May-1995 & 133.7 & 18.95 & 4.40 & 5.60 & 1321 & 2743434 & 6274731 & Closed & Waikato Regional Council \\
\hline Tutaevaua & 3043485 & 14-Oct-2004 & 14-Jan-2010 & 3.3 & 5.25 & 0.06 & 0.08 & 723 & 2753600 & 6280700 & Closed & NIWA \\
\hline Otaketake & 1543410 & 19-Sep-1977 & 22-Sep-1980 & 16.3 & 3.01 & 0.10 & 0.12 & 223 & 2763110 & 6281674 & Closed & NIWA \\
\hline Tongariro d/s Poutu Intake & 1643445 & 15-Dec-1987 & 23-Mar-2009 & 442.6 & 21.29 & 16.26 & 19.2 & 1369 & 2754061 & 6226873 & Open & Genesis Energy Ltd \\
\hline Tongariro pre 1974 & 1043459 & 2-Jan-1957 & 28-Dec-1973 & 784.2 & 17.00 & 45.13 & 52.59 & 2115 & 2753749 & 6241697 & - & Genesis Energy Ltd \\
\hline Tongariro post 1974 & 1043459 & 2-Jan-1975 & 1-Apr-2008 & 784.2 & 33.27 & 27.83 & 32.13 & 1292 & 2753749 & 6241697 & Open & Genesis Energy Ltd \\
\hline TPS & & 2-Jan-1998 & 30-Jun-2011 & - & 13.49 & & 46.64 & - & - & - & Open & Genesis Energy Ltd \\
\hline Waikato outflow & 1143444 & $23 / 09 / 1969$ & $15-J u l-2008$ & 3445 & 39.56 & 151.33 & 150.64 & 1379 & 2778271 & 6277678 & Open & Mighty River Power Ltd \\
\hline
\end{tabular}

$\mathbf{7 6}$ | Data availability, processing and preparation 


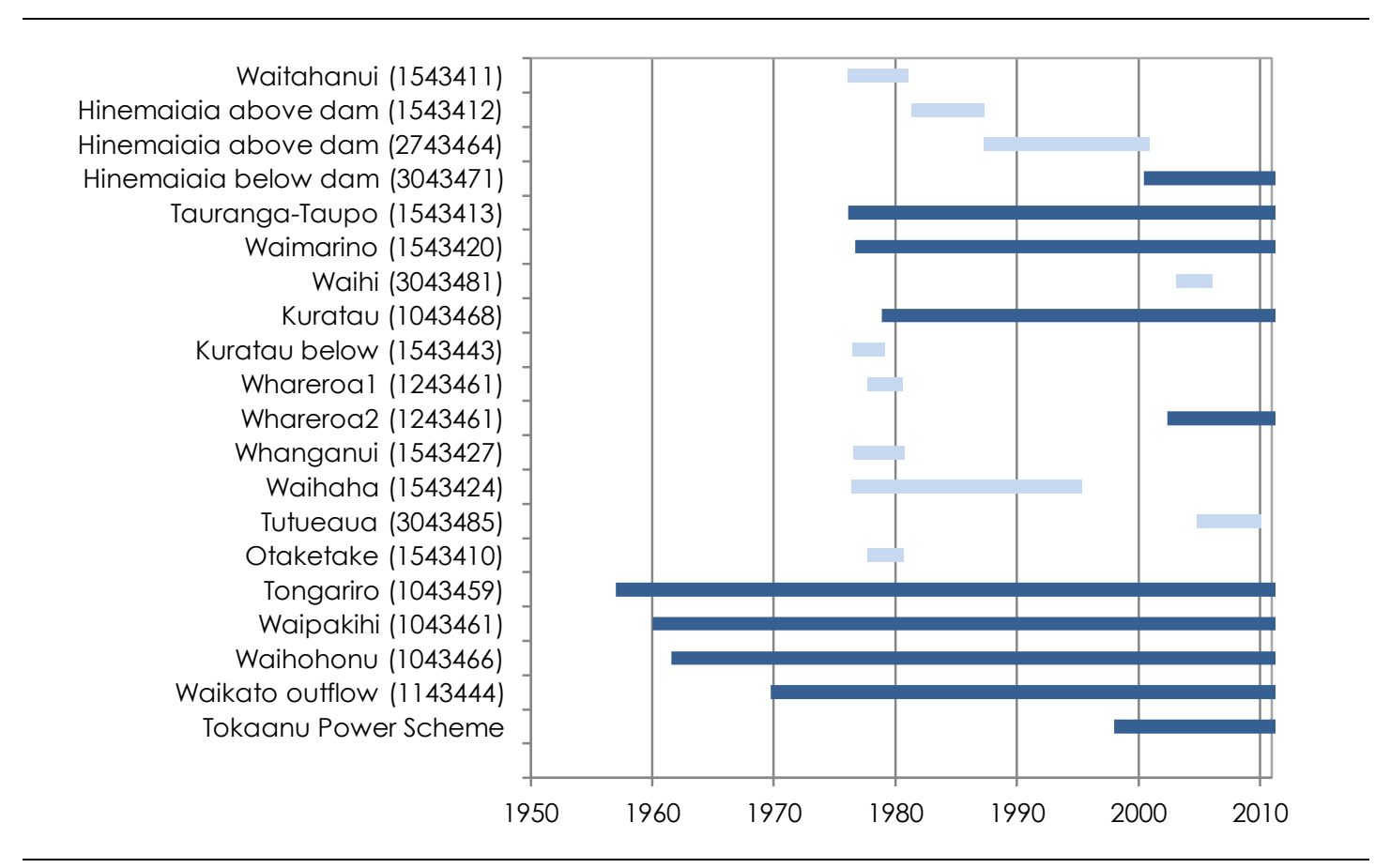

Figure 4.4 The duration and timing of river discharge records for the Lake Taupo catchment vary. The light blue bars indicate records stations which are closed. The dark blue bars represent currently operational gauge stations.

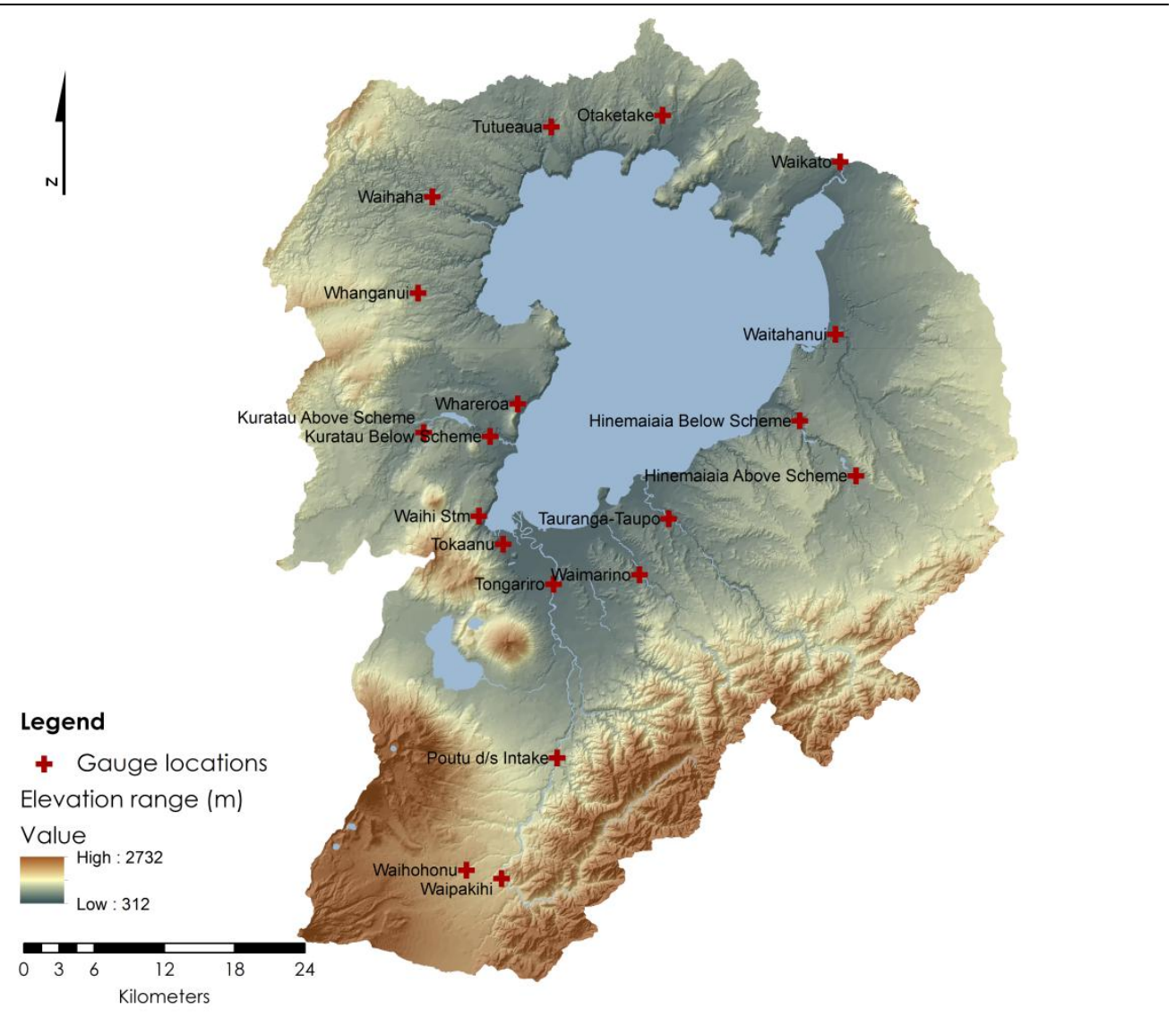

Figure 4.5 Location of streamflow gauges used in this dissertation. 


\subsection{Lake level}

There are two lake level gauging sites- Tokaanu (Site No. 1143420) and Acacia Bay (Site No. 1543478) - located at opposites ends of the Lake Taupo (Figure 4.6). The average of these two records is used to provide lake level time series. Where there are gaps, the station with the data is the sole contributor.

As discussed in Section 2.3.4, Lake Taupo is affected by a number of seiche and other oscillatory fluctuations that can at times be several centimetres. There are several seiches in effect on Lake Taupo with periods of 30 minutes (wind seiche) up to several hours (baroclinic seiche) (Gilmour and Butcher, 1987; Gilmour and Heath, 1989). These effects make measuring the level of Lake Taupo difficult. Removal of these seiche effects allows the genuine lake level response to be identified for easier assessment of the Lake Taupo Inflow Model performance and more accurate determination of inflows from ungauged areas.

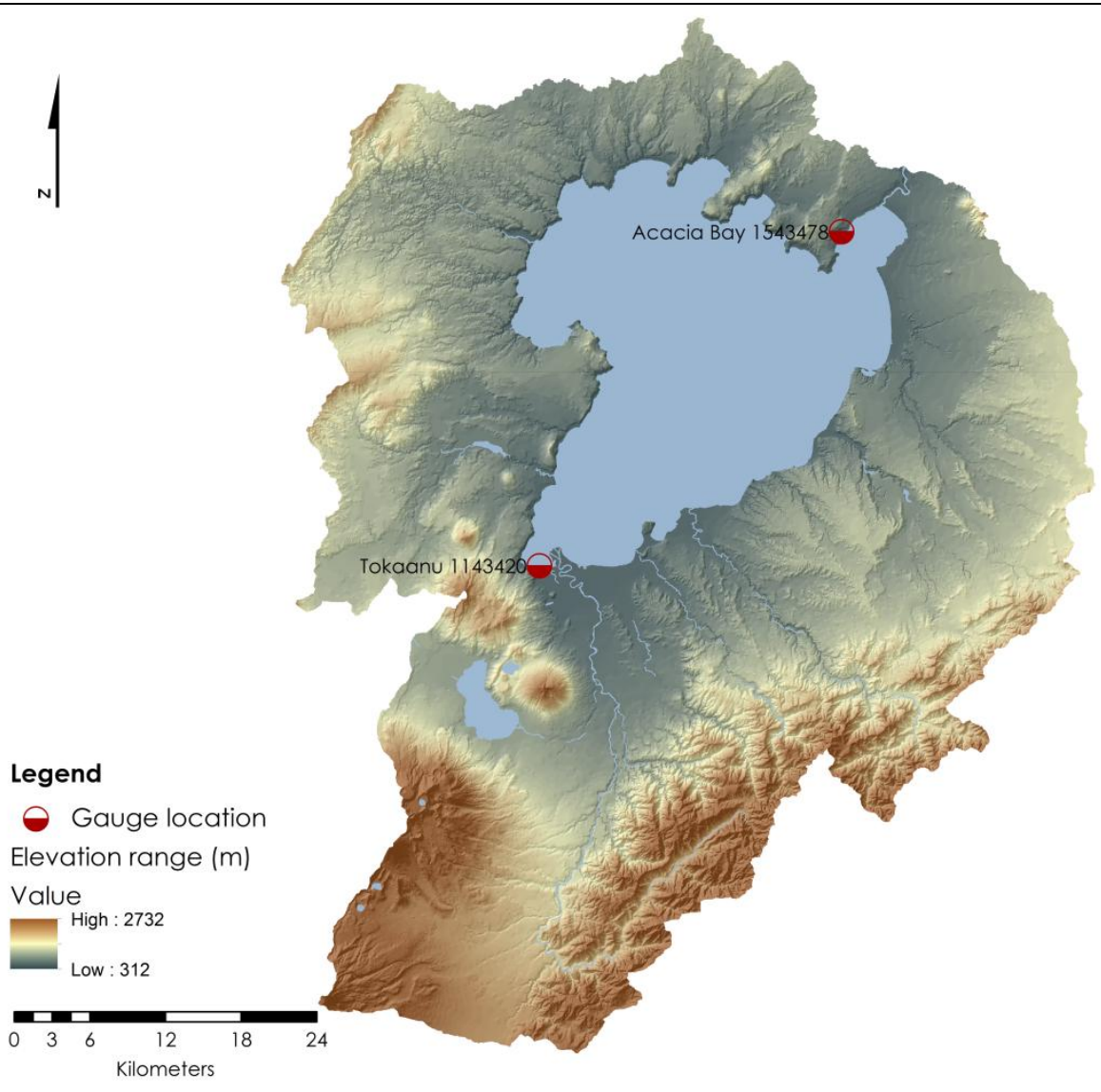

Figure 4.6 Location of lake gauges used in this dissertation. 
Early attempts to address this issue are based on averaging lake level over a suitable interval. For example, Thompson and Ibbitt (1978) concluded that a smoothing interval of 3 hours is required to remove the effect of wind seiches on Lake Tekapo. Gilbert (1978) found that this method often 'blurred' too much detail in the time series and proposed a method based on an exponential decay function for lake inflows. Inflow is calculated for each time step based on knowledge the current and previous days inflow, with a minimum inflow value for the lake. Similarly, NIWA use a method based on the conservation of volumes in which data is smoothed and inflow/outflow volumes are adjusted for physically consistent lake level recessions. Inflows are allowed to rise rapidly, but the rate of recession is limited. These smoothing methods often mean that the inflow data set generated may not be consistent with actual measured inflows.

In this dissertation, a low-pass Butterworth filter is used to remove the high frequency oscillations while preserving the lower frequency rise and fall of the lake. Butterworth filters have their origins in signal processing applications. The filter is created in Matlab using the butter function, which requires two parameters to be specified - the order number and the normalised cutoff frequency. The higher the filter order, the longer the passband flatness and the wider the transition between signals that are accepted and rejected (Narasimhan and Veena, 2005). The passband is the range of frequencies or wavelengths that are allowed to pass through a filter (Lyons, 2001). A low-pass filter passes low frequency signals, and rejects signals at higher frequencies.

The second parameter is the normalised cutoff frequency. This parameter is related to the period of the oscillations and while it is precise, because discrete data is used some of the slightly higher frequencies will remain in the filter signal. In this study the normalised cutoff frequency is determined by dividing the resolution of the data (i.e. 15 minutes) by the length of the period below which the filter will aim to remove. For example, a normalised cutoff of half an hour (2 time steps) results in a cutoff frequency of $0.5(1 / 2)$. Similarly, a cutoff of 1 hour ( 4 time steps) results in a cutoff frequency of 0.25 hours (1/4). Figure 4.7 shows the effect of different cutoff frequencies on lake level for Lake Taupo. Taking a cutoff frequency of 6 hours (Figure 4.7a) removes too much of the frequency domain while with a cutoff of 0.5 hour (Figure $4.7 \mathrm{~b}$ ) too much of the noise remains. In this study, a $4^{\text {th }}$ order Butterworth filter is applied with a cut-off frequency of 2.5 hours (Figure 4.7c). This cutoff value removes a large amount of the high frequency oscillations while preserving the rise and fall of the lake. Oscillations with lower frequency, such as 

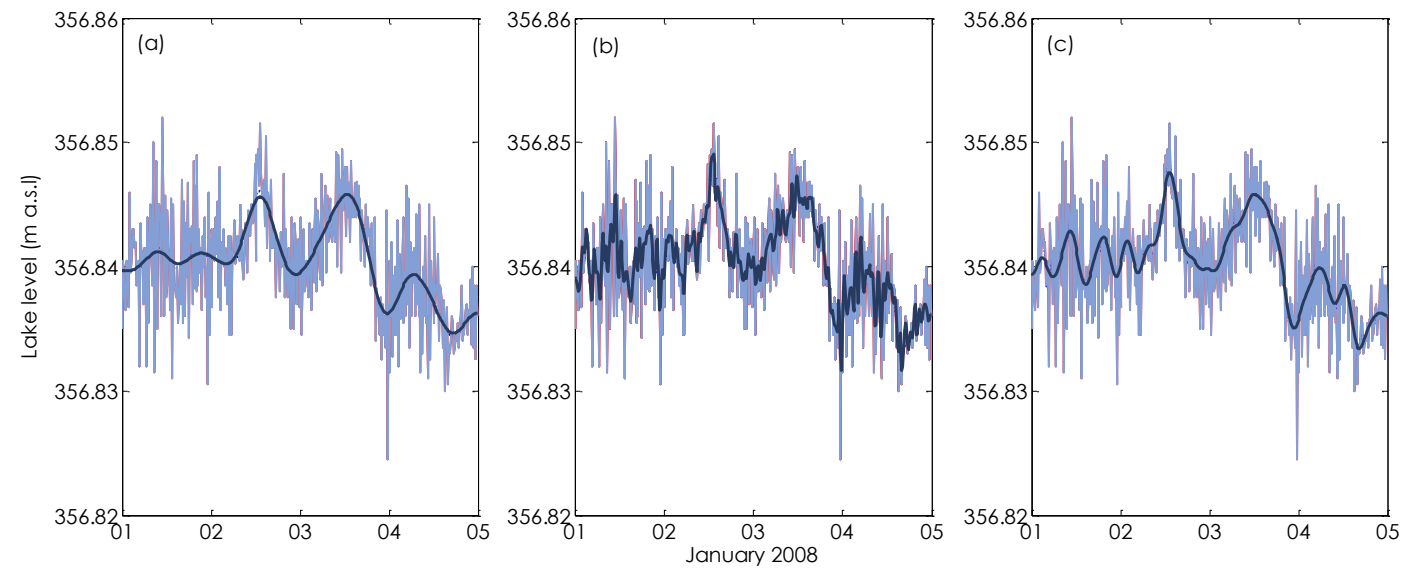

Figure 4.7. The effect of different cutoff frequency values on reducing high frequency oscillations in the lake level time series for Lake Taupo. A 6 hour cutoff frequency (a) removes too much of the frequency domain. Not enough of the high frequency oscillations are removed with a cutoff frequency of 0.5 hours. A cutoff frequency of 2.5 hours (c) appears to remove most of the high frequency oscillations while preserving the more natural rise and fall of the lake.

barometric seiches, would remain. Removing these longer period effects may also remove some of the genuine lake level change. The time series is run through the filter twice (forwards and backwards) to ensure any phase distortions are removed (de Goffau, 2006).

\subsection{Data uncertainty}

The methods described in the previous sections relating to creating serially complete records, estimation of catchment volumes and addressing lake seiche effects, generate some uncertainty in the data sets which can have flow-on effects to modelled output. In this study, no attempt is made to rigorously analyse this uncertainty from the various data sources. While a synthetic study comparing 'raw' and 'synthetic' data to show their effect on model simulation may have been useful, time constraints prevented this from being undertaken. Fortunately, the data assimilation routine used later in this dissertation does account for all sources of uncertainty (and specifically the uncertainty associated with data), although does not separate these errors out (refer Section 6.5). 


\subsection{Summary}

A model is only as good as the data used to drive it. Rainfall, evapotranspiration, streamflow, TPS discharge data, outflow and lake level data have been made available from a number of sources for the purpose of this study. The data has been collected and assessed for quality, gaps and inconsistencies.

Gaps in rainfall are infilled using the normal-ratio method. Although other methods (e.g. isohyetal and inverse distance weighted methods) may provide more reliable estimates of missing rainfall (McCuen, 1998), the low density of rain gauges and a lack of overlapping data sets limited their application. Approaches to extend these point estimates to catchment volumes are compared in terms of their ability to close the water balance. While the precipitation surface of Tait et al. (2006), and subsequent bias corrected surface of Woods et al. (2006), improved water balances there is still some discrepancy. Estimation of catchment areal volumes are therefore left as a parameter for calibration. Thiessen polygons are used to derive catchment rainfall for ungauged areas and direct lake rainfall.

A long-term continuous PE record is obtained for the Lake Taupo catchment through back-filling gaps with a highly correlated record. This time series of daily $\mathrm{PE}$ is disaggregated using a sinusoidal function based on mean global radiation and corrected for periods of high humidity and minimal mean global radiation. A similar process is used to obtain a long-term continuous time series for lake evaporation.

Streamflow data is obtained for 17 sub-catchments. The length and quality of records vary. Missing data is ignored as model calibration and state-updating occur only where observations are available. Outflow from Lake Taupo is available from September 1969. This time series is continuous over the period 1998-2010 in which it is used in the Lake Taupo Inflow Model to predict lake level and derive residual inflow for ungauged areas.

Finally, the lake level time series for Lake Taupo presents significant oscillations resulting from various seiches. Removal of the high frequency oscillations (wind seiches) while maintaining the genuine rise and fall of the lake is achieved by using a Butterworth filter. Some of the longer period (barometric seiche) oscillations remain and may be difficult to remove without losing some information about actual lake level change. 
The rigorous analysis undertaken allows selection of suitable data sets and data periods for model calibration and evaluation, providing valuable information about the reliability of the data used to drive the conceptual rainfall-runoff model. 


\section{Catchment hydrologic behaviour}

Conceptual model structures simplify the complex rainfall-runoff relationship (refer Chapter 3). The model structure is generally determined a priori based on the perceived importance of the rainfall-runoff mechanisms by the modeller (Beven, 2001). Development of a suitable conceptual model, therefore, entails identification of the main factors relevant to the rainfall-runoff response in the catchment. This requires some understanding of catchment hydrologic function, particularly with respect to the climatic and physiographic attributes which control how much water enters the catchment and the movement of this water once it reaches the ground (Duncan and Woods, 2004). Quantification of the relative importance of each of these factors is useful for determining the dominance of a process or attribute in terms of the catchment's hydrologic response.

The objective of this chapter is to examine the rainfall-runoff relationships in the Lake Taupo catchment. These relationships are used, along with a fundamental understanding of hydrologic principles, to build a perceptual model of the catchment ${ }^{8}$ and guide development of initial sub-catchment model structures and parameter estimation. It is the principal chapter for addressing the hydrological objectives of the study. Section 5.1 provides a review of the effect of climatic and physiographic attributes on catchment hydrologic response. Section 5.2 outlines the

8 A perceptual model is defined by Beven (2001) as "a qualitative description of the processes thought to be controlling the hydrological response of an area' (Beven, K.J., 2001. Rainfall-Runoff Modelling: The Primer. John Wiley \& Sons.). 
indices and method used in this dissertation to examine these relationships while Section 5.3 discusses the results from this analysis. Finally, Section 5.4 presents a summary of the key findings and implications for model development. Detailed catchment data analysis can be found in Appendix B.

\subsection{Catchment hydrologic response and behaviour}

Flow represents the catchment integrated response to a rainfall event and to the catchment antecedent conditions (or soil moisture conditions) just prior to that rainfall event (Kirchner, 2009; Pauwels and De Lannoy, 2006). The way in which this response changes over time is known as a river's flow (or hydrological) regime. Examination of flow regimes can provide information about the likely response of a catchment to a rainfall event, susceptibility to low flows and flood flows, monthly, seasonal and annual patterns of flow, impact assessment and whether it is potentially useful (Duncan and Woods, 2004). Climatic and physiographic attributes specific to the catchment are major influences shaping this flow regime, providing an insight to the dominant processes that may control the catchment's runoff response.

\subsubsection{Effect of climatic attributes on catchment flow regimes}

The climatic attributes of a catchment influence the amount of water entering the catchment. Runoff generally follows the seasonal distribution of rainfall unless snow accumulates in large enough quantities to affect runoff regimes (Riggs, 1985). At shorter timescales, catchment-to-catchment variations in precipitation and $\mathrm{PE}$ influence the amount of water available at the surface for runoff. Along with topography and other catchment attributes, climatic attributes broadly control the frequency of flood flows and low flows (Snelder and Biggs, 2002).

Rainfall depths depend on the size, location and topographic characteristics of the catchment, the interaction of the catchment with the passage of weather systems over the area and the precipitation-generating mechanisms of these systems. In the Lake Taupo catchment, the temporal and spatial variability of rainfall is considerable. In mountainous areas (i.e., the Kaimanawa Ranges and the volcanoes of the Tongariro National Park), precipitation is generally greater ( $>2000 \mathrm{~mm} / \mathrm{a})$ than in lowland parts of the catchment (i.e. Taupo and Turangi, $<1200 \mathrm{~mm} / \mathrm{a}$ ). In 
addition, at higher elevations lower temperatures result in more of this precipitation falling as snow and lower evapotranspiration rates (Snelder and Biggs, 2002).

\subsubsection{Effect of physiographic attributes on catchment flow regimes}

The transformation from precipitation to streamflow is dependent on many variables (Riggs, 1985). Catchment physical attributes influence the ability of a catchment to store water and the timing and magnitude of the runoff response. The relative importance of each of the physiographic attributes in the estimation of hydrological behaviour varies from catchment to catchment, and is reflected in the hydrographs from which two principal components can be identified - the fastflow response and the baseflow (groundwater) response (Duncan and Woods, 2004). The hydrological response in terms of the timing and volume of the flood flow and baseflow response is strongly influenced by catchment physical properties which control the movement of water once it reaches the ground (Duncan and Woods, 2004; Snelder and Biggs, 2002)

The type of vegetative cover influences water yield, surface interception of rainfall and evaporation rates. Consequently, vegetative cover influences the amount of water available to reach the river and the frequency and duration of low flow periods (Snelder and Biggs, 2002). Over 55 \% of the Lake Taupo catchment (by land area) is forested. Forested areas tend to have higher interception rates (Kelliher et al., 1993) and lower annual water yields (Fahey et al., 2004) relative to grassland and pasture. Conversely, pastoral catchments (19\% of catchments land area) generally have higher annual yields and peak flows and can be more responsive (higher quickflows) than comparable forested catchments (Fahey et al., 2004).

Water retention and conductivity characteristics of soils determine soil water storage and movement (Kelliher and Scotter, 1992), acting as a buffer in the hydrological cycle. These characteristics vary depending on the type of soil in a catchment and are important because they affect evaporation, surface runoff, groundwater recharge and stream flow through infiltration, redistribution and drainage processes (Kelliher and Scotter, 1992). Most of the soils around the Lake Taupo catchment derive from the tephra and ashes from the Taupo eruption (Gibbs, 1968; Molloy, 1998; Rijkse, 1987). Pumice soils are most prevalent (Rijkse, 1987). The generally sandy or gravelly texture of pumice soils means they are porous and well-draining, allowing rapid movement of air and water while still capable of storing large amounts of water for plants (Molloy, 1998). 
The presence of groundwater is related to catchment geology, controlling storage and transmissivity (Snelder and Biggs, 2002) and significantly influences patterns of discharge, variability and flashiness (Rosen and Coshell, 1998). The volcanic ash, pumice and ignimbrite found in the Lake Taupo catchment readily absorb water that falls on them allowing percolation to groundwater which feeds many of the rivers and streams in the catchment (Roper, 2001; White, 2001). Groundwater acts as a buffer between the rainfall event and streamflow response by dampening flood response and reducing overall flow variability. Areas of more permeable lithologies (Oruanui and Taupo ignimbrite, and rhyolitic pyroclastics) generally have lower mean flows and specific discharges (Morgenstern, 2008). These types of catchments tend to have higher and more persistent baseflows, more groundwater storage and respond less rapidly to rainfall (Duncan and Woods, 2004). Schouten et al., (1981) estimate that as much as $95 \%$ of annual discharge from the rivers draining the permeable areas of the Lake Taupo could be derived from groundwater. In less permeable areas (Whakamaru ignimbrite) specific discharge and mean flows are comparatively higher. These catchments respond more quickly to rainfall events with steep recessions and lower baseflow volumes (Duncan and Woods, 2004). The baseflow proportion of annual runoff from catchments draining less permeable lithologies is less than 80\% (Schouten et al., 1981).

The time it takes for water to reach the river and be transported from the catchment is influenced by geomorphic characteristics including the catchment's size, shape, slope and drainage density (Chow, 1964; Post and Jakeman, 1996; Schumm, 1956). It is widely accepted that streamflow is directly related to the size of the catchment (Beven, 2001; Chow, 1964). In larger catchments, more water can be captured and discharged. In terms of shape, a long narrow basin is more likely to have a more rapid response to rainfall events, shorter recessions and larger peak flows than a catchment which is rounder (Chow, 1964). In a study of 17 small mountain catchments (0.04-0.65 km²), Post and Jakeman (1996) conclude that wider catchments drain more slowly and have longer quickflow recession time constants. Gently sloping catchments tend to have more subdued and delayed flow response (longer baseflow recessions) than catchments with higher gradients and steeper slopes because it takes longer for precipitation to reach drainage channels. Catchments with higher drainage densities showed more attenuated quickflow response periods, since water is able to reach drainage channels more quickly. In catchments with lower drainage density, water needs to travel through a larger area of the catchment before it reaches the river, reducing catchment response times. 


\subsubsection{Effect of regulation on natural flow regimes}

Hydro power schemes and the dams associated with them can alter natural flow regimes by physically blocking the river, storing excess runoff, or releasing water according to human needs. Effectively, hydro power schemes and dams modify the magnitude and timing of catchment runoff (Poff and Hart, 2002). This can result in flood responses downstream of infrastructures being dampened and flood peaks attenuated (Bednarek, 2001). Stored water can be released to augment low flows and can provide more uniform monthly flow distributions (Duncan and Woods, 2004). While the variability of flow over longer periods is often less, over shorter time frames fluctuations can be significant in response to electricity spot prices and electricity demands (Bednarek, 2001; Young et al., 2004).

The TPS is the largest and most complex of hydro schemes in the Lake Taupo catchment. The impact on the flow regime of the Tongariro catchment is significant. Streamflow during 'normal' conditions is most affected. Up to $80 \mathrm{~m}^{3} / \mathrm{s}$ can be diverted from the river for generation at Tokaanu Power Station, between $16 \mathrm{~m}^{3} / \mathrm{s}$ (minimum flow condition) and $160 \mathrm{~m}^{3} / \mathrm{s}$ (maximum turbidity level). Stephens (1989) reports the operation of the scheme has resulted in reduced normal flow, less seasonal variations in normal flow, reduced frequency of small flood ('freshes'), truncated recessions and minimum flows soon after rain, higher flows during drought and artificially induced surges (for example, those associated with required recreational releases).

In the Kuratau catchment, the release of water follows the typical diurnal energy demand profile (Figure 5.1) and water is held back in the lake for generation at peak times. Peak demand periods are during early morning and evening; demand is less overnight. Short term flow variability is increased. The Hinemaiaia Power Scheme is largely run-of-river which means it has relatively limited storage volume and short residence time (EPA, 2010). Although there is some fluctuation related to the daily energy demand profile, there is relatively little modification to the unmodified streamflow entering the system above the scheme (refer Figure 2.8). 


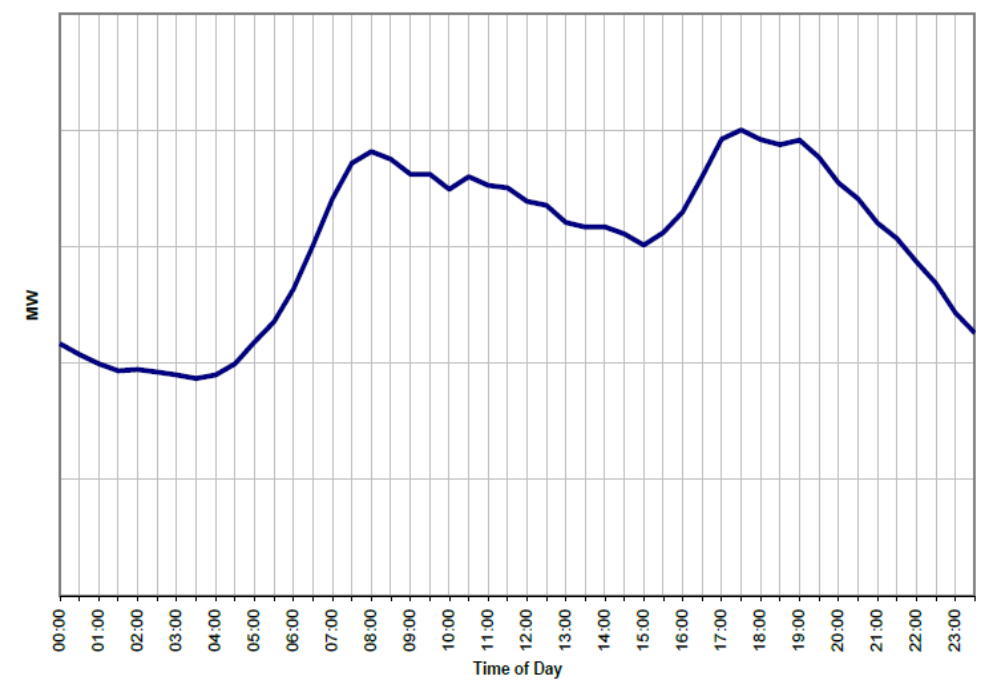

Figure 5.1. Typical load profile of daily energy use. Note the two peak demand periods during day and lower demand overnight. Source: Transpower New Zealand Ltd (2010)

\subsubsection{Summary}

The assessment of the climatic physiographic and hydrologic attributes can provide some insight into the important processes and mechanisms for the rainfall-runoff response in the Lake Taupo catchment. The seasonality of streamflow (including high and low flow regimes) is largely controlled by climatic attributes (Snelder and Biggs, 2002) while physiographic attributes mainly influence the movement of water once it reaches the ground. The type of vegetation affects surface interception of rainfall and evapotranspiration and can consequently affect catchment water yield. Of the water that reaches the ground, the transmissivity of the soils and geology of the groundwater system play a significant role in determining the rate at which water passes through the catchment. Geomorphic attributes are also important factors controlling the speed at which water reaches the river and is transported out of the catchment. The development of hydro power schemes has modified the downstream magnitude and timing of flow. In the following sections, the relationships between these physical attributes and various hydrologic characteristics are investigated for a number of sub-catchments of Lake Taupo. Further, the effects of hydro power schemes on natural flow regimes are identified. 


\subsection{Assessment of catchment physical attributes in relation to hydrologic characteristics}

Based on the information above, a number of indices are selected to describe the various attributes of the catchment. These attributes have been categorised into hydrologic, climatic and physiographic. A list of the indices used is provided in Table 5.1.

Table 5.1. Hydrologic, climatic and physiographic attributes used for analysis

\begin{tabular}{|c|c|c|c|}
\hline Category & Attributes & Method of measurement & units \\
\hline \multicolumn{4}{|l|}{ Hydrologic } \\
\hline & Mean Annual Flow & Average annual flow & $\mathrm{m}^{3} / \mathrm{s}$ \\
\hline & Specific discharge & Mean flow per unit area & $\mathrm{m}^{3} / \mathrm{s}$ per $\mathrm{km}^{2}$ \\
\hline & Baseflow index & Chapman (1991) & - \\
\hline & Variability Index & Lane and Lei (1950) & - \\
\hline & Low flows & Q50/Q95 (Davie 2003) & - \\
\hline & Flood flows & Q10/Q30 (Davie 2003) & \\
\hline \multicolumn{4}{|l|}{ Climatic } \\
\hline & Wetness Ratio & $\mathrm{P} / \mathrm{PE}$ & $\mathrm{mm} / \mathrm{a}$ \\
\hline & Runoff Coefficient & $P / Q$ & $\mathrm{~mm} / \mathrm{a}$ \\
\hline \multicolumn{4}{|c|}{ Physiographic } \\
\hline & Volcanic geology & Proportion of catchment & $\%$ \\
\hline & Basement geology & Proportion of catchment & $\%$ \\
\hline & Pumice soils & Proportion of catchment & $\%$ \\
\hline & Forest cover & Proportion of catchment & $\%$ \\
\hline & Area & NIWA & $\mathrm{km}^{2}$ \\
\hline & Elongation Ratio & Circle diametert/catchment length $\ddagger$ & - \\
\hline & Relief Ratio & Relief $/$ catchment length $\ddagger$ & - \\
\hline & Mean Slope & Average slope & degrees \\
\hline & Slopes $>26^{\circ}$ & Proportion of catchment & $\%$ \\
\hline & Drainage density & Total channel length/catchment area & $\mathrm{km} / \mathrm{km}^{2}$ \\
\hline
\end{tabular}




\subsubsection{Hydrologic indices}

In this study, six hydrological indices have been selected for analysis: mean flow, specific discharge, baseflow contribution, flow variability and indices of flood flows and low flows. These have been selected because together they represent a wide range of hydrological aspects of catchment flow regimes. Each of these attributes is described in the following sections.

\section{Mean flow and specific discharge}

Mean flow is defined as the arithmetic mean of all the individual average annual discharge over the length of the record. Specific discharge describes flow generated per unit area. It can be used for individual hydrograph response analysis or as an average over the entire hydrologic time series. Unlike mean flow, the use of specific discharge allows for more direct comparisons between catchments of different sizes and can be easily converted into depth of runoff in millimetres for comparison to rainfall and evapotranspiration (Duncan and Woods, 2004).

\section{Baseflow contribution}

The analysis of baseflows and flood flows requires some form of separation between these two flow components of the hydrograph. Graphical techniques such as that of Hewlett and Hibbert (1967) generally aim to separate the baseflow and quickflow proportion of individual event hydrographs. These techniques are less convenient when separations are required over long continuous time series (Chapman and Maxwell, 1996). This has led to the use of numerical algorithms for baseflow separation.

Two common continuous separation techniques include the Institute of Hydrology (UK) smoothed minima method and those based on Lynne and Hollick's recursive digital filter, both described in Nathan and McMahon (1990). The smoothed minima technique finds the minima over five day non-overlapping periods over the entire record. The minima values which are less than a defined threshold are connected to produce the baseflow hydrograph. The recursive digital filter separates the low frequency, high magnitude flood flow signal in the time series from the high frequency, low magnitude baseflow signal. These approaches aim to derive an objective index of baseflow response rather than simulate actual baseflow conditions and can, therefore, lack a physical basis (Szilagyi, 2004). Nathan and McMahon 
(1990) argue that the approach is no more unrealistic than approaches based on a series of straight lines.

In a comparison of the two approaches, Nathan and McMahon (1990) found that the smoothed minima technique did not perform as well as the recursive digital filter, particularly during periods of negligible baseflow contribution. Output statistics suggest the digital filter is also less variable; it is also more strongly correlated to other low flow indices.

The recursive digital filter can be written

$$
q_{f(t)}=\omega q_{f(t-1)}+\frac{(1+\omega)}{2}\left(q_{(t)}-q_{(t-1)}\right)
$$

where $q_{\omega(t)}$ is the filtered quickflow response at time step $t$ or the previous time step $t-1, q_{(t)}$ is the total streamflow at time step $t$, and $\omega$ is the filter parameter. Nathan and McMahon (1990) suggest that $\omega$ should be between 0.9 and 0.95 . They also note that the filter should be passed through more than once. The filter parameter affects the degree of attenuation but the number of passes of the filter determines the degree of smoothing. Nathan and McMahon (1990) recommend three passes (forward, backward and forward again). Arnold et al. (1995) show that when applied to 11 catchments in the USA, the baseflow proportion decreased with each pass of the filter. The second pass reduced baseflow by $17 \%$ and a further $10 \%$ for the third pass. The greater the number of iterations the more smoothing of the data resulting in lower baseflow estimates. Chapman (1991) notes that plausible results could be achieved with just two passes of the filter.

There is another effect of passing the filter through more than once that is not discussed in the original papers. A single pass of the filter can add a phase distortion to the data affecting the timing of the baseflow response. Spongberg (2000) concludes that the filter should be passed an even number of times to minimise any phase distortion of the data due to the forward (odd numbered) pass of the filter. A subsequent third pass would smooth the baseflow response further but any phase distortion would also reappear.

The filter in the form of Eqn 5.1 assumes that baseflow remains constant during periods of no direct runoff, which is generally not the case (Chapman, 1991). Chapman (1991) reformulated the approach to be consistent with conventional recession theory, so that: 


$$
q_{f(t)}=\left(\frac{3 \omega-1}{3-\omega}\right) q_{f(t-1)}+\left(\frac{2}{3-\omega}\right)\left(q_{(t)}+\omega q_{(t-1)}\right)
$$

where $\omega$ now becomes a recession constant, the ratio of flow to the preceding flow during a period of no direct runoff (Chapman, 1991). Eqn 5.2 can be rewritten in terms of baseflow and simplified so that,

$$
q_{b(t)}=\left(\frac{\omega}{2-\omega}\right) q_{b(t-1)}+\left(\frac{1-\omega}{2-\omega}\right) q_{(t)}
$$

The baseflow index represents the proportion of the total stream volume over the length of the time series. A further development of this filter is proposed by Eckhardt (2005) in which an additional parameter, $B F I_{\max }$, constrains the maximum value of the baseflow index, which will change depending on the permeability of the catchment. This filter is written

$$
q_{b(t)}=\frac{\left(1-B F I_{\max }\right) \omega q_{b(t-1)}+(1-\omega) B F I_{\max } q_{(t)}}{\left(1-\omega B F I_{\max }\right)}
$$

Eqn 5.4

where $q_{b(t)} \leq q_{t}$. The value of $B F I_{\max }$ varies depending on the hydrological and hydro-geological conditions of the catchment (Eckhardt, 2008), reflecting the assumption that baseflow is linearly proportional to storage (Partington et al., 2012). Since $B F I_{\max }$ is not measureable, it adds some subjectivity to the process (Eckhardt, 2005).

There are a number of assumptions involved in using digital filters that may not hold in hydrological applications. These filters generally assume that the low frequency (baseflow) signal and the higher frequency (direct runoff) signal can be isolated. In a review of the use of digital filters for baseflow separation, Spongberg (2000) concludes that perfect separation cannot be achieved because of overlapping frequency content. Some information may, therefore, be lost in the filtering processes that may affect the reliability of filter results (Spongberg, 2000).

Further, time series based algorithms such as the filters described above generally assume stationarity in the data. That is, the statistical parameters of the data set such as the mean and variance remain constant through time (Chow, 1964; Maidment, 1993). Over timescales less than a year, a time series is non-stationary due to seasonality. On an annual scale hydrologic time series will generally be stationary where there have been no significant changes (for example, extensive changes to vegetation cover, human-induced modification such as hydro power development etc.). Removing non-stationarity for data series can be complex, and in most cases stationarity is assumed (Chow, 1964). 
In this study, the approach of Chapman (1991) is selected to provide an index of baseflow contribution to streamflow using two passes of the filter to minimise any phase distortion. The recession constant is determined by evaluating consecutive flow values in recession periods (defined as flow values between $Q_{95}$ and $Q_{30}$ of the flow duration curve) and taking the average of these ratios. This approach is selected for its simplicity, and is deemed sufficient to detect the relative differences between catchments.

\section{Variability}

Flow duration curves are a convenient and informative way of displaying the range of flow for a catchment by presenting the relationship between streamflow and the percentage of time it is exceeded (Gordon et al., 2004). They can be used to understand catchment runoff response characteristics by assessing the shape of the curve, which is influenced by catchment climatic and physical attributes (Peters, 1994). Flow duration curves are particularly useful when comparing the runoff response between catchments or the effect of, for example, climatic changes, land use modifications and the effect of regulation from hydro power schemes.

In this study, flow duration curves of mean hourly flow are used to ascertain an overall measure of variability. Following Lane and Lei (1950), the standard deviations of the logarithmic values of flow at $10 \%$ intervals of the flow duration curve (between the $5^{\text {th }}$ and $95^{\text {th }}$ percentile) are computed. This is done by taking the mean of the logarithms and computing the difference of each of the ten logarithms from the mean. These differences are then squared, summed together, then divided by 9 . The square root of this value is the variability index. Using this approach Schouten et al. (1981) determined the variability index for sub-catchments of Lake Taupo based on mean daily flow. Index values ranged between 0.04 and 0.40 with higher index values coinciding with areas of less permeable geology.

\section{Flood flows and low flows}

Indices of flood flow and low flows are also examined. A useful statistic for low flow analysis is value of flow exceeded 95\% of the time (Davie, 2003). The ratio of the median flow and this value $\left(\mathrm{Q}_{50} / \mathrm{Q}_{95}\right)$ provides an index of the slope (steepness) of the flow duration curve over this range, and can essentially be considered as an alternative index of baseflow contribution (Gordon et al., 2004). The ratio also allows direct comparison between catchments (Davie, 2003). It can also be used to 
interpret the effect of the underlying geology on groundwater storage and release (Peters, 1994). A high index value would be reflected in the curve dropping off quickly toward the end of the low flow range. Groundwater storage is less likely to be influential in this context than a catchment which has a very flat slope over the same flow range (Gordon et al., 2004).

The flow value which is exceeded only $10 \%$ of the time $\left(\mathrm{Q}_{10}\right)$, is an index of high flows and flooding (Davie, 2003). The shape and steepness of the flow duration curve between this value and $Q_{30}$ reflects the variability over this range of high flow. A low index value would be illustrated by a flatter slope at the higher end of the curve and may indicate the effect of lakes that may be present in the catchment (Gordon et al., 2004).

\subsubsection{Climatic indices}

Two climatic indices are used to describe the climatic attributes of the subcatchments. The annual wetness ratio is a measure of the potential runoff for a catchment. It is a measure of atmospheric supply and demand of moisture and represents the moisture available at the surface for evaporation and runoff (Berger and Entekhabi, 2001). It is defined by the ratio of annual rainfall to annual potential evapotranspiration. Essentially, the higher the index the more water there is potentially available to reach rivers as runoff. Analysed on a month-to-month basis, the wetness index is likely to be highest during the winter months when evaporative demand is less and rainfall is generally higher.

The second climatic index is the runoff coefficient which is a measure of how much catchment precipitation is converted to runoff given evaporative efficiency and catchment physiographic features (Berger and Entekhabi, 2001). As an annual index, physiographic attributes would be less influential as catchment storage changes would balance out. Discharge and evapotranspiration outputs would also be expected to largely balance with precipitation inputs.

Since over the course of a year the change in storage is essentially zero, annual catchment rainfall is estimated using a water balance approach so that it is equal to the sum of mean annual flow and mean annual potential evapotranspiration. 


\subsubsection{Catchment physiographic indices}

Based on the literature review, ten physiographic indices are determined for each sub-catchment in this study. Catchment geology and soils is obtained from the New Zealand Land Resource Inventory (Landcare Research - Manaaki Whenua (NZ), 2008), while land use is based on the New Zealand Land Cover Database 2 (Ministry for the Environment, 2004).

The lithologies present in the catchment, and individual sub-catchments are numerous, each having a different influence on catchment hydrologic response. For the purpose of this study, the geologies are divided into two main types: volcanic and basement. The proportion of each within sub-catchment is ascertained. Similarly, there are several soil types (orders) covering the Lake Taupo catchment, although pumice soils are the most common soils in the catchment. Pumice soils are also the most permeable and well-draining and are, therefore, assumed to be indicative of overall soil permeability. The percentage of pumice soils in each catchment is used as a physiographic index.

The sub-catchments of Lake Taupo are predominantly covered by forest. Tussock grasslands and shrub are common in the Tongariro catchment, on the slopes of the three volcanoes. Areas of pastoral grassland are also common but are largely found on lowland areas of western Lake Taupo catchment below most gauge locations. For simplicity, the proportion of the catchment covered by forest is assumed to be indicative of vegetative influence in sub-catchments.

The size of a catchment as measured by the catchment area $\left(\mathrm{km}^{2}\right)$ has been provided by NIWA. To describe catchment shape, the elongation ratio is used. While caution should be used with quantitative indices that are referenced to a particular form or shape (in this case, a circle), the elongation ratio is widely used (Goudie, 1994). The elongation ratio is defined by Schumm (1956) as the ratio between the diameter of a circle with the same area as the catchment and the maximum length of the catchment. The length of the catchment can be defined as the horizontal distance between the outlet to the highest point; the distance along the longest dimension of the basin parallel to the principal drainage line; or distance to the most distant point in the catchment (Chow, 1964; Maidment, 1993; Schumm, 1956). Given the unusual shape of many catchments, McCuen (1998) suggests a more appropriate measure would be the length of main drainage line extended to catchment boundary. This definition by McCuen (1998) is used in this study. 
The slope of the catchment influences the speed at which water reaches a stream network and can also affect the energy of the stream with implications for erosion and sedimentation. While some parts of the catchment will have much steeper slopes than others, the mean slope can provide a good indication of the overall influence of this catchment characteristic. Another measure of slope used is the proportion of the catchment with steep slopes $\left(>26^{\circ}\right.$, Landcare Research - Manaaki Whenua Ltd, (2008)). Alternatively, the relief ratio, defined by the ratio of relief (elevation difference between the highest point and lowest (or outlet) point in the catchment) to catchment length, measures the overall steepness or gradient of the catchment and can provide an indication of the potential energy of a drainage system (Chow, 1964). The relief ratio also allows comparison of the relative relief of any basin regardless of topography. The final physiographic attribute is the density of the drainage network which is defined as the ratio of total stream length to total catchment area (Schumm, 1956).

It is noted that the single value assigned to each attribute for each sub-catchment does not necessarily reflect the spatial variability of the attribute. As a result, its influence on catchment runoff response may be affected. For example, a catchment may be covered in forest but its canopy may not be continuous. Cyclical rotation of exotic forestry means different parts of the forest will be at different stages of planting (Fahey et al., 2004) so that a single descriptor of forest cover at a point in time may not be representative for another period. This non-uniformity affects how much rainfall is intercepted and, consequently, how much water reaches the surface. While soil permeability is measured by its hydraulic conductivity, this value is spatially variable. Soil attributes may also be affected by land use activities. For example, soil compaction from livestock can affect the drainage characteristics of a soil and hence influence direct runoff to streams (Selby, 1972).

\subsubsection{Statistical analysis of relationships}

Regression analysis and correlation coefficients have been widely used in the literature to relate catchment physical characteristics to hydrological response (Berger and Entekhabi, 2001; Post and Jakeman, 1996; Sefton and Howarth, 1998). Conclusions generated from regression analysis should be treated with caution where there are cross-correlations between variables (Zecharias and Brutsaert, 1988). This is often not the case with geomorphic attributes. Higher elevation areas, for example, are often steeper. Schumm (1956) also found that as drainage density 
increases so too does relief ratio. Similarly, as the relief ratio increases catchments become more elongated.

Zecharias and Brutsaert (1988) overcame this problem by applying principal components analysis to determine the relationship between catchment physical properties and groundwater response characteristics. The above two approaches are commonly used in applications of prediction from ungauged basins or to determine the casual relationship between attributes.

For the purpose of simply relating catchment climatic and physiographic attributes to hydrological response characteristics, correlation coefficients provide an easy and convenient way to describe strength of the relationship between two variables. $(X$ and $Y$ ). The resulting coefficients describe the covariability between variables but do not imply a causal relationship (Gordon et al., 2004).

The correlation coefficients $\left(r_{X, Y}\right)$ are calculated as

$$
r_{X, Y}=\frac{\sum X Y-\left(\sum X\right)\left(\sum Y\right)}{\sqrt{\sum X^{2}-\left(\sum X\right)^{2}} \sqrt{\sum Y^{2}-\left(\sum Y\right)^{2}}}
$$

Eqn 5.5

The coefficients have a significance level associated with them. Unless otherwise stated, any relationships identified are treated as significant at the $95 \%$ confidence level. Following Devore (1982), a correlation is considered strong if $0.8 \leq|r| \leq 1$ and moderate if $0.5<|r|<0.8$. Between \pm 0.5 the correlation is considered weak.

\subsubsection{Impacts of regulation}

In terms of assessing the impact of regulation on natural flow regimes, flow duration curves for overlapping records above and below the schemes of the Kuratau and Hinemaiaia sub-catchments are compared. For the Tongariro River, observations at Turangi extend back to 1957, prior to the development of the TPS. In this catchment the data set is separated into two periods. 'Before diversions' covers the period 1957 to 1973 and 'After diversions' covers the period from 1975 to present. As a separate assessment the hydrological indices for the modified sub-catchments are also compared to the corresponding unmodified sub-catchment, although it is noted that different data periods may be affected by different climatological regime which may influence results. 


\subsection{Hydrological behaviour and response of the Lake Taupo catchment}

As discussed in previous sections, a range of indices have been selected to describe the hydrologic, climatic and physiographic attributes of 14 sub-catchments of Lake Taupo. These sub-catchments range in size from $3.3 \mathrm{~km}^{2}$ to $784.2 \mathrm{~km}^{2}$. Six hydrological descriptors are used in this study, including mean flow, specific discharge, baseflow index (Chapman, 1991), variability index (following Lane and Lei (1950)), and indices of flood flows and low flows. Fifteen minute interpolated time series data is used for hydrological and climatic descriptors, except for the baseflow index in which hourly flow is used. Climatic descriptors include the runoff coefficient (the ratio of annual runoff to annual precipitation) and wetness ratio (the ratio of annual precipitation to annual potential evapotranspiration). Physiographic descriptors include area, relief ratio and elongation ratio (where catchment length is defined as the length of main drainage line extended to catchment boundary), mean slope, proportion of catchment with steep slopes, drainage density, percentage of catchment covered by forest, pumice (well-draining) soils, basement (impermeable) geology and volcanic geology.

\subsubsection{Natural flow regimes}

The distribution of precipitation and flow throughout the year for each catchment is shown in Figure 5.2. Streamflow in all catchments generally follows a similar pattern to rainfall over the year, except for a few notable exceptions. The Waitahanui catchment shows a consistent flow throughout the year despite fluctuations in rainfall. Streamflow in this catchment is spring-fed providing even flow throughout the year. In the Waimarino catchment, a rise in flow which does not correspond with a sharp rise in rainfall during October may be indicative of meltwater from winter snow accumulation in higher elevation areas of the catchment. Evidence of this possible meltwater response is less evident in the Tauranga-Taupo catchment which is located next to the Waimarino catchment. The headwaters of both catchments are also in the same general area of high elevation. The two catchments in the northern region also do not show a strong correlation between flow and rainfall. The rainfall record used for the Tutaeuaua catchment is from a gauge located several kilometres away and may not be representative of the rainfall over this small catchment. A significant number of gaps in the Otaketake rainfall record have, for some months, reduced the number of monthly rainfall values to only a few observations, making these monthly averages unreliable. 

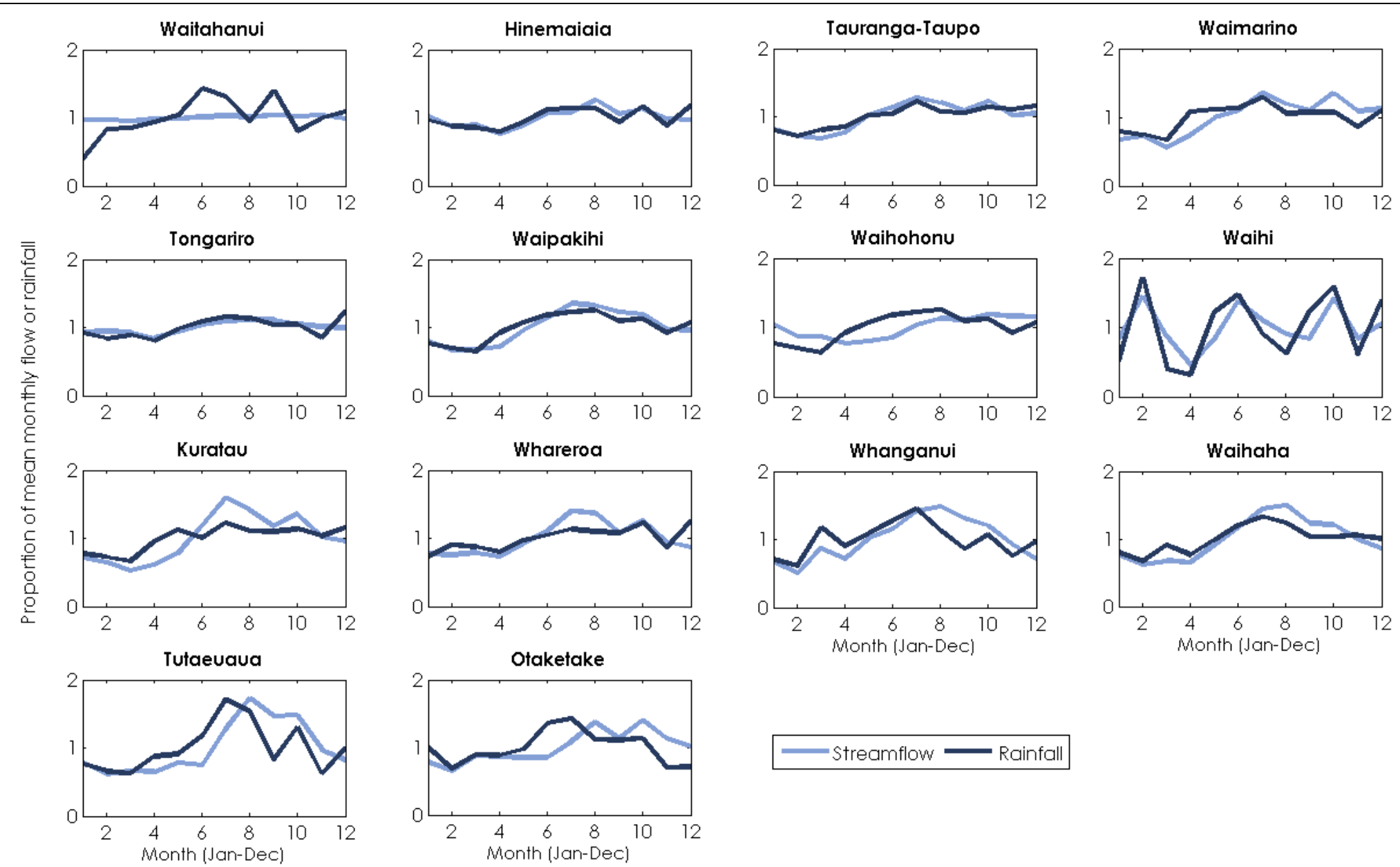

-Streamflow $=$ Rainfall

Figure 5.2 Distribution of flow and rainfall over the year for each catchment based on monthly averages. 
Rainfall and streamflow in many of the sub-catchments appear to diverge in December. Mean monthly rainfall appears to increase while mean monthly streamflow decreases. This may be due to a combination of factors. Warmer temperatures during this time increase evaporative demand and the drier catchment conditions may result in more of the precipitation being soaked up by the soil and sub-surface rather than reaching the waterway.

Not surprisingly, mean flow is strongly positively correlated to catchment size $(r=$ 0.9897). It is also positively correlated to relief $(r=0.7917)$ and negatively correlated to elongation ratio $(r=-0.6057)$. Smaller catchments of Lake Taupo tend to be more elongated than larger catchments and generally have lower relief. However, it is noted that if the Tongariro catchment is removed there appears to be little relationship between the shape of the catchment and mean flow. Figure 5.3 shows the relationship between mean flow and catchment size and relief. It should be noted that the relationship between mean flow and relief is skewed by the Tongariro catchment. If this catchment is not included, the coefficient would be considerably less $(r=0.5502)$.

Specific discharges in the Lake Taupo catchment range between $0.007 \mathrm{~m}^{3} / \mathrm{s}^{\mathrm{per} \mathrm{km}^{2}}$ to $0.067 \mathrm{~m}^{3} / \mathrm{s}$ per $\mathrm{km}^{2}$. Specific discharge is positively correlated to catchment size ( $r=0.5417)$, average slope ( $r=0.7178)$, steepness of the catchment (\% steep slopes: $r=0.6843$ ) and geology (volcanic: $r=-0.5487$; basement: $r=0.5962$ ). It is also strongly correlated to both climatic indices (wetness ratio: $r=0.9577$; runoff coefficient: $r=0.9306$ ), as shown in Figure 5.4. This is not surprising since these attributes are measures of the amount of water available for runoff generation. The Tongariro River has the highest specific discharge with similar values at the higher end for the Waipakihi and Waihohonu Rivers.

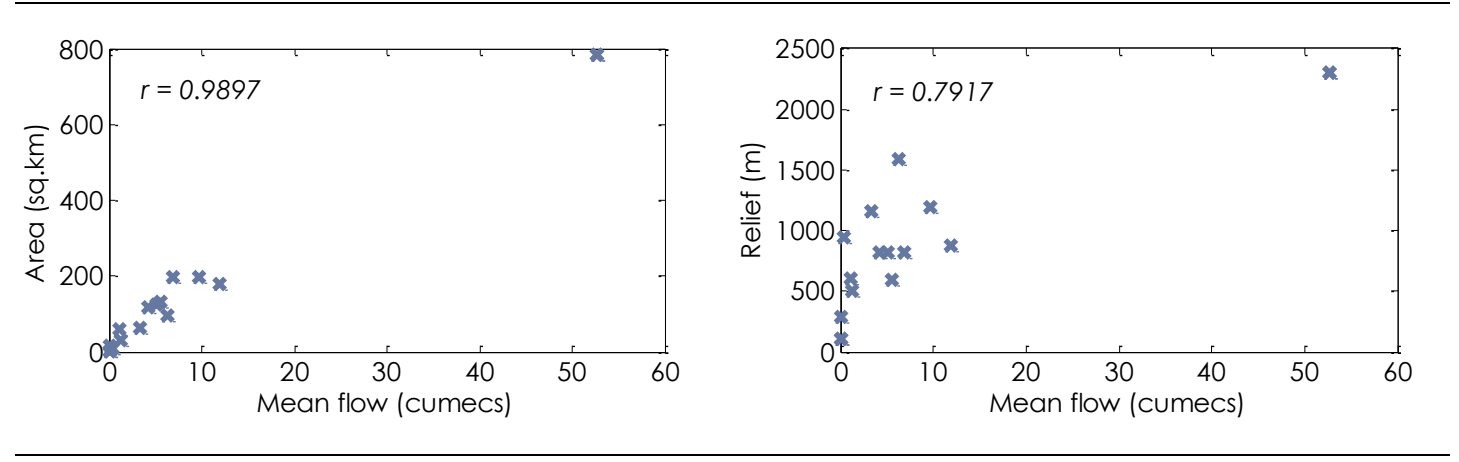

Figure 5.3 Mean flow versus catchment size (left) and relief (right). 

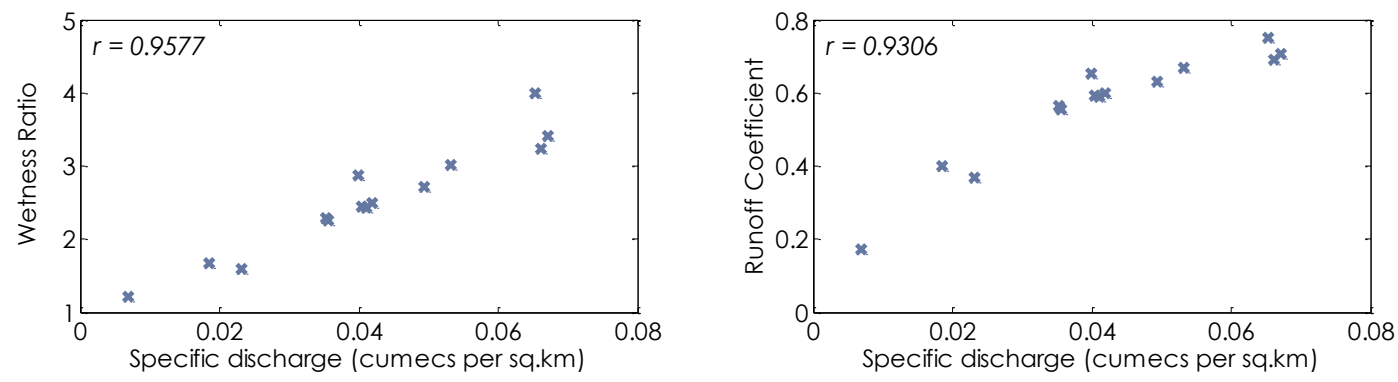

Figure 5.4 Relationship between climatic indices and specific discharge.

The Otaketake River has the lowest specific discharge and is considerably lower than all other catchments. This catchment is relatively small $\left(16.3 \mathrm{~km}^{2}\right)$, long and narrow with around $1.9 \%$ of slopes classified as steep and is primarily covered in pastoral grassland. With these features combined a higher specific discharge may be expected. This catchment, however, also has the lowest wetness ratio (1.21) and runoff coefficient (0.17) of all catchments studied.

Catchment wetness ratio values and runoff coefficients are strongly correlated to each other $(r=0.9334)$ and to catchment relief with $r$ values of 0.8018 and 0.7112 , respectively (Figure 5.5, top). These areas with higher climatic indices tend to be in areas that are generally steeper. Both mean slope and steep slopes were significantly correlated to wetness index $(r=0.6201$ and $r=0.5519$, respectively) and runoff coefficients ( $r=0.6203$ and $r=0.5380$, respectively) as shown in Figure 5.5.
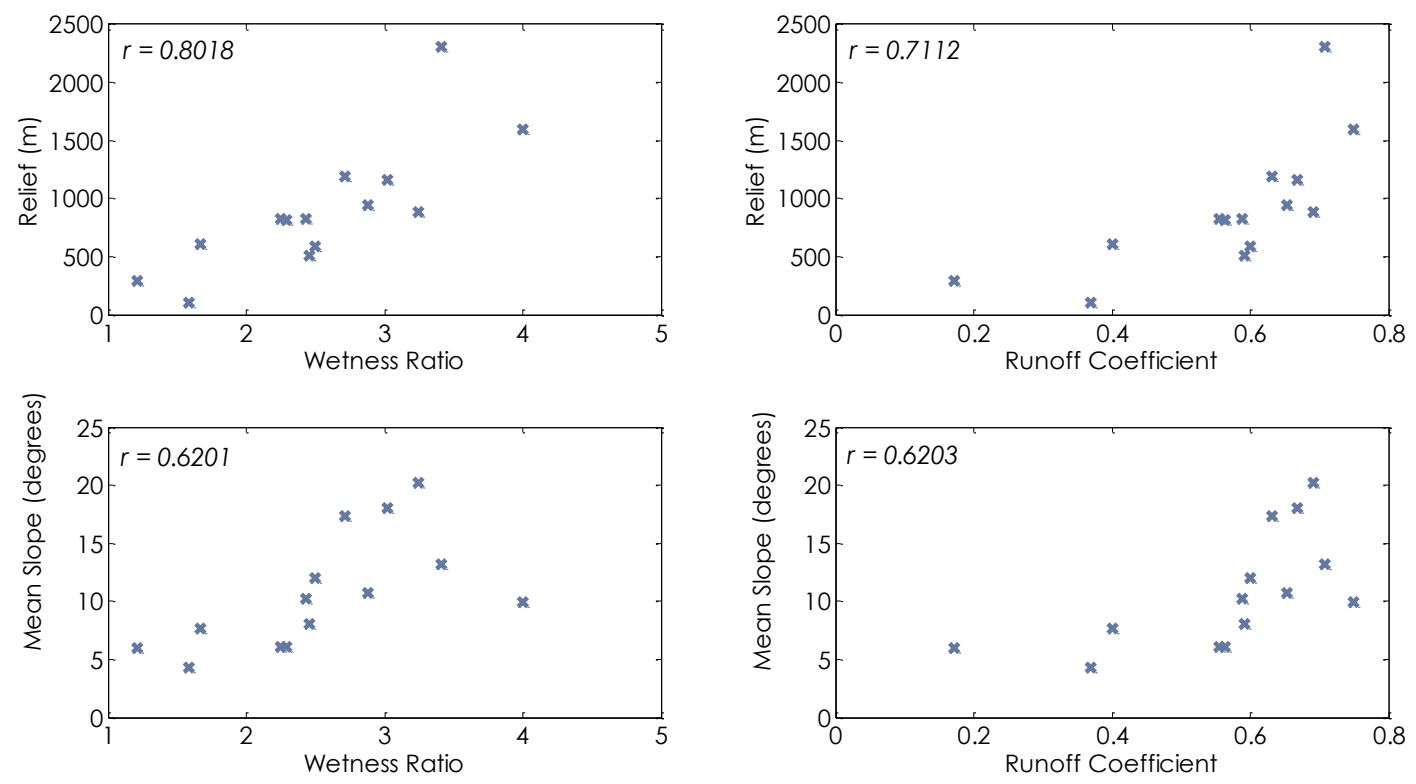

Figure 5.5 Climatic indices are positively correlated to catchment relief (upper) and mean slope (lower). 
Areas of steeper slopes coincide with some of the highest elevation areas of the Lake Taupo catchment. Elevation can affect how much precipitation falls in the catchment and hence the water available for runoff generation. In the Lake Taupo catchment, the higher (and steeper) elevations of the eastern areas tend to block the passage of weather systems forcing more precipitation to fall within catchment boundaries (Thompson, 1984). With increasing slope steepness, this water is able to reach the river more quickly.

The presence of groundwater is related to catchment geology (Figure 5.6). Catchments underlain by more permeable volcanic lithologies tend to have greater baseflow volumes $(r=0.8310)$ and be less variable $(r=-0.6620)$. With increasing basement greywacke geology variability is increased $(r=0.6410)$ and baseflow contribution reduced $(r=-0.8158)$. This is consistent with Schouten et al. (1981) who found that flow variability is higher in areas of less permeable geology.

Baseflow contribution and flow variability are strongly negatively correlated with an $r$ value of -0.8520 . Flow variability in the 14 catchments studied range between 0.24 for the Waitahanui catchment and 0.70 for the Waimarino catchment. These two catchments also have the lowest and highest baseflow index values, respectively.
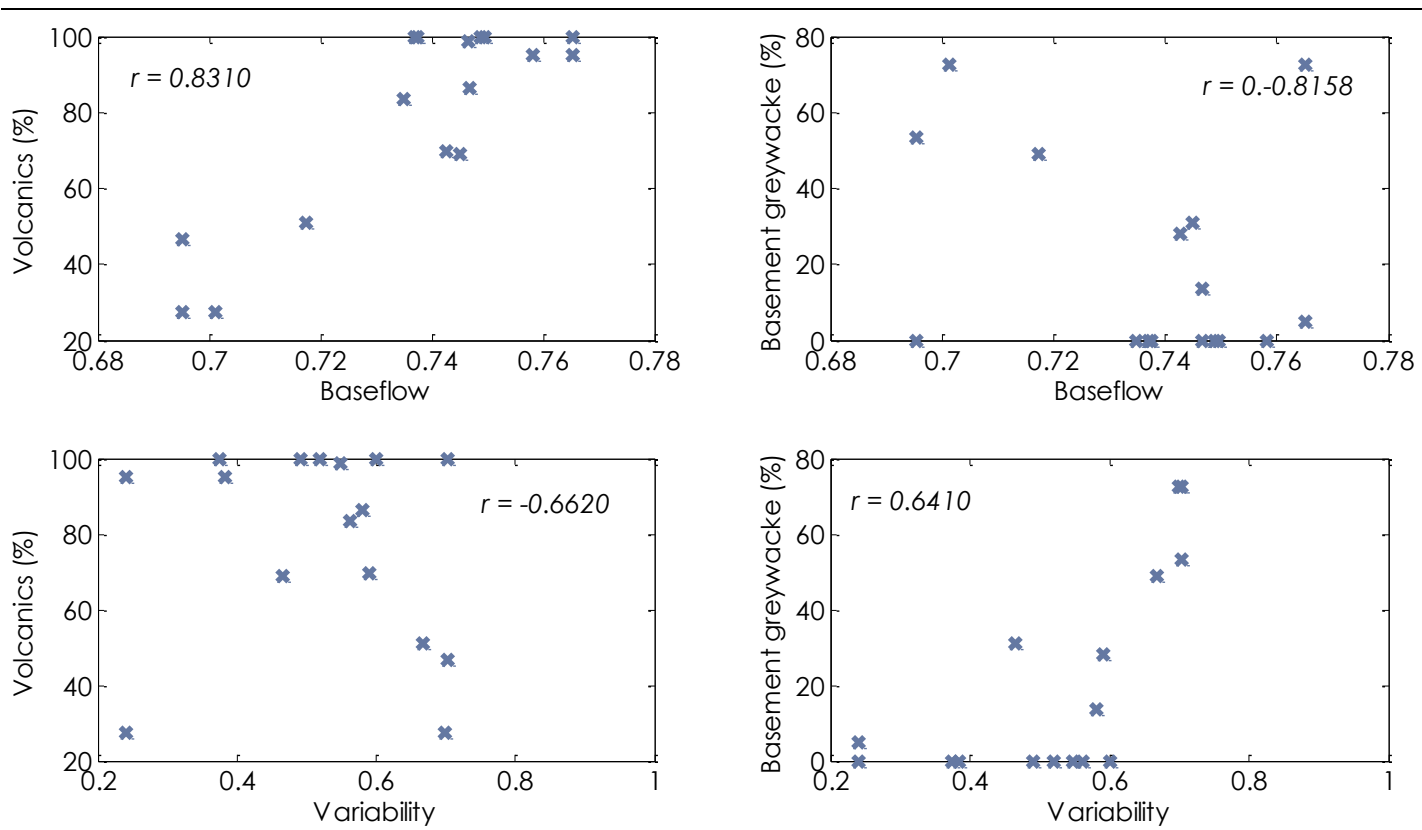

Figure 5.6. With increasing amount of volcanic geology baseflow contribution tends to increase and variability decreases (left). The presence of basement greywacke geology decrease baseflow contribution and increases variability (right). 
This is not unexpected since groundwater (baseflow) acts as a buffer to rainfall events dampening flood response, moderating and sustaining river flows throughout the year and reducing flow variability.

In the Lake Taupo catchment, baseflow index values range between 0.695 and 0.765. The highest baseflow proportion is in the Waitahanui River. This figure may, however, be under-estimated. Visual inspection of the time series reveals there is evidence of some non-stationarity in the data. Although this can be explicitly tested, this record is of short duration and has many gaps. Only two years had complete data. The lack of any strong correlations to any other catchment prevented these gaps from being infilled.

Although there is a significant correlation between catchment geology and baseflow index, over the range of low flows this correlation is weaker. In addition, the low flow index is only weakly correlated to other physiographic attributes. This suggests that groundwater is likely to be a significant presence in the flow for all of the Lake Taupo catchments.

A moderate correlation is found between volcanic geology with variability index $(r=$ -0.6620). Some catchments of predominantly volcanic geology have relatively high variability. Flow variability in the Whanganui and Waihaha catchments is generally high (0.600 and 0.580 , respectively) despite consisting of predominantly volcanic lithologies. The type of volcanic geology may be important. The volcanic geology in these catchments is largely made up of older Whakamaru ignimbrite which is more welded and less permeable than the younger Oruanui and Taupo ignimbrites which are also common around the Lake Taupo catchment (Hadfield et al., 2001). More definitive relationships may be realised by using a better index of geologic influence which can account for the varying permeabilities of the volcanic lithologies in the catchment.

Other factors are also influential. Positive correlations are found between flood flow regime (the part of the flow duration curve which is more likely to contain most of the direct runoff portion of the hydrograph) and catchment steepness (mean slope ( $r=0.6085)$ and steep slopes $(r=0.5827)$. Mean slope and the proportion of steep slopes are higher in areas of basement greywacke geology, with correlations of 0.9165 and 0.9664, respectively. These areas include the headwaters of the Waihaha catchment in the west and Tauranga-Taupo, Waimarino, Waipakihi catchments in 
the south-east. With increasing steepness, more water is able to find its way to streams more directly. These relationships are illustrated in Figure 5.7.

In the Whanganui catchment, while overall variability is high (0.600) the catchment is less steep than the Waihaha catchment with only $2.2 \%$ of slopes greater than $26^{\circ}$ and an average slope of $8^{\circ}$. This higher variability may be influenced by the shape of the catchment. The elongation ratio is positively correlated to the variability of low flows and negatively correlated to catchment area. The Whanganui catchment is relatively small $\left(31.6 \mathrm{~km}^{2}\right)$ but is relatively long and narrow. It also has one of the highest drainage densities allowing water to reach drainage channels more quickly, increasing direct runoff volumes.

The Kuratau catchment (above the scheme) also has relatively high variability (0.548) and baseflow index (0.747), despite being underlain by predominantly volcanic geology. Like the Whanganui catchment it has a low average slope $\left(6^{\circ}\right)$ and only $2 \%$ of the catchment is classified as steep. Over $47 \%$ of the catchment is covered in pastoral grasslands, reducing interception and increasing water yields. In addition, although the catchment has a relatively high elongation ratio, its unusual shape gives way to three main branches allowing water to reach main drainage channels more quickly.
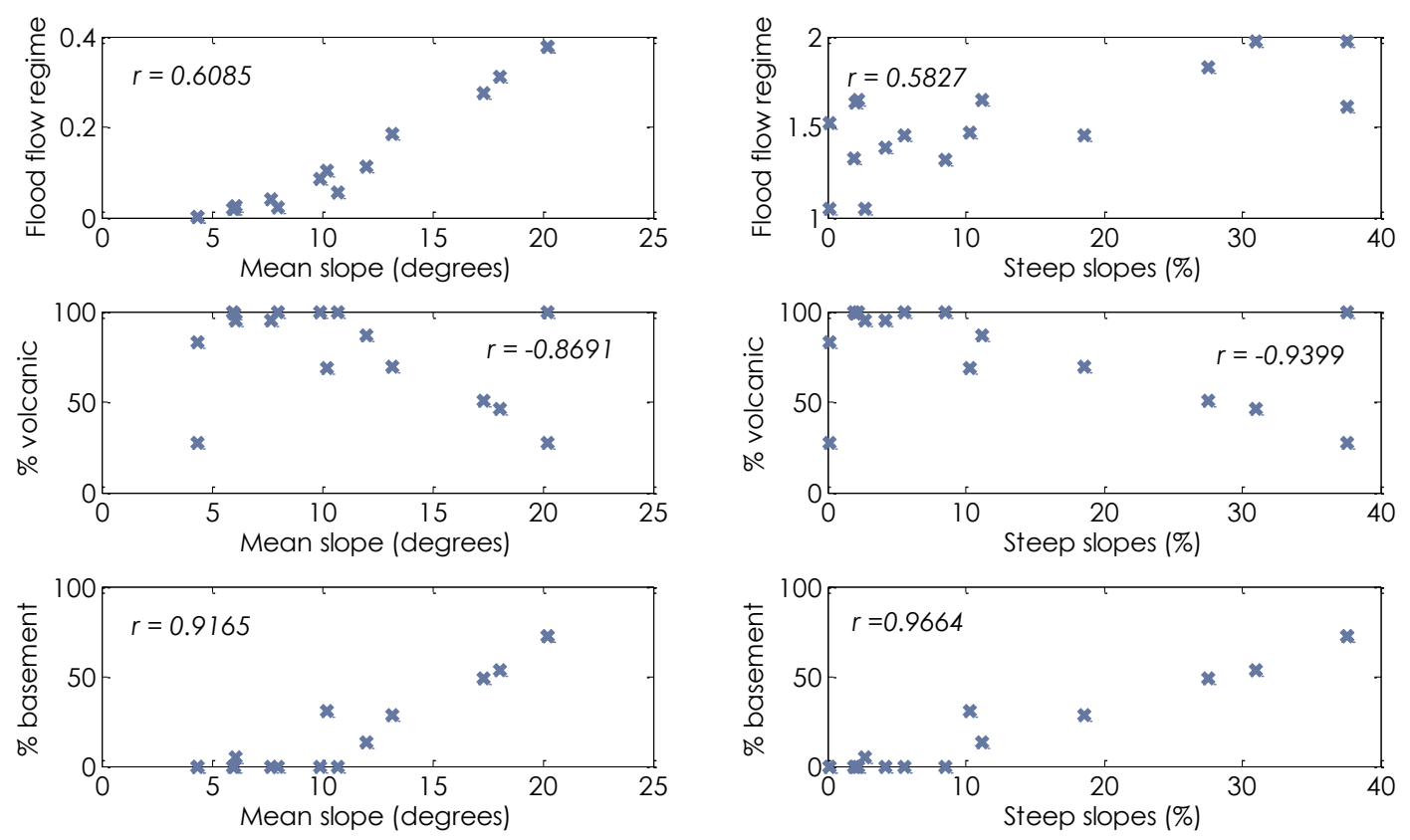

Figure 5.7 Catchment steepness is positively correlated to the variability of flow in the high (flood flow) portion of the flow duration curve (upper). It is also strongly correlated to the type of underlying geology (middle and lower). 
In the sub-catchments studied, forest cover has very little influence on catchment hydrologic behaviour with only weak correlations found between this descriptor and hydrologic attributes. A correlation of $r=0.3620$ is found between forest cover and specific discharge, which is contrary to Fahey et al. (2004) who states that forested areas tend to reduce water yields. Forest cover is common in most of the subcatchments analysed. It is, however, most prevalent in high elevation (and often steeper) areas of Lake Taupo catchment which coincide with areas which are generally steeper (mean slope: $r=0.5011$ ) and have higher runoff coefficients $(r=0.5161)$. These factors would therefore result in higher specific discharges.

The amount of permeable pumice soil in a catchment seemed to have very little influence on catchment hydrologic response, although drainage density appeared to decrease with increasing coverage of pumice soils. Stronger relationships may be found if a better index of soil permeability is used.

\subsubsection{Impact of regulation on catchment runoff response}

The impact of regulation on catchment flow regimes and runoff response characteristics varied between catchments due to the difference in catchment areas, amount of storage and the type of regulation involved.

In the Hinemaiaia catchment, the effect of the hydro power scheme is assessed by analysing data from above the scheme (1981-2001) and data below the scheme (2000-2009). Variability (below: 0.4653 and above: 0.4399) and baseflow (below: 0.7450 and above: 0.7449 ) over these periods are similar between locations. There is also little difference between high flow and low flow regimes. Comparison of flow duration curves for the Hinemaiaia catchment (June-December 2000) show that the largest effect is in the lower flow range of the flow duration curve (Figure 5.8, top).

In the Kuratau catchment (Figure 5.8, middle), regulation has increased the baseflow index to 0.8249. Flow variability, however, has also increased (above: 0.5479 and below: 0.6078 ) and is likely to be due to the short term fluctuations that coincide with peak generation demand (refer to Section 2.3.1). These results may also be affected by the length of records being compared (3 years (below) versus 32 years (above)) and the possible climatological differences of the two periods. 

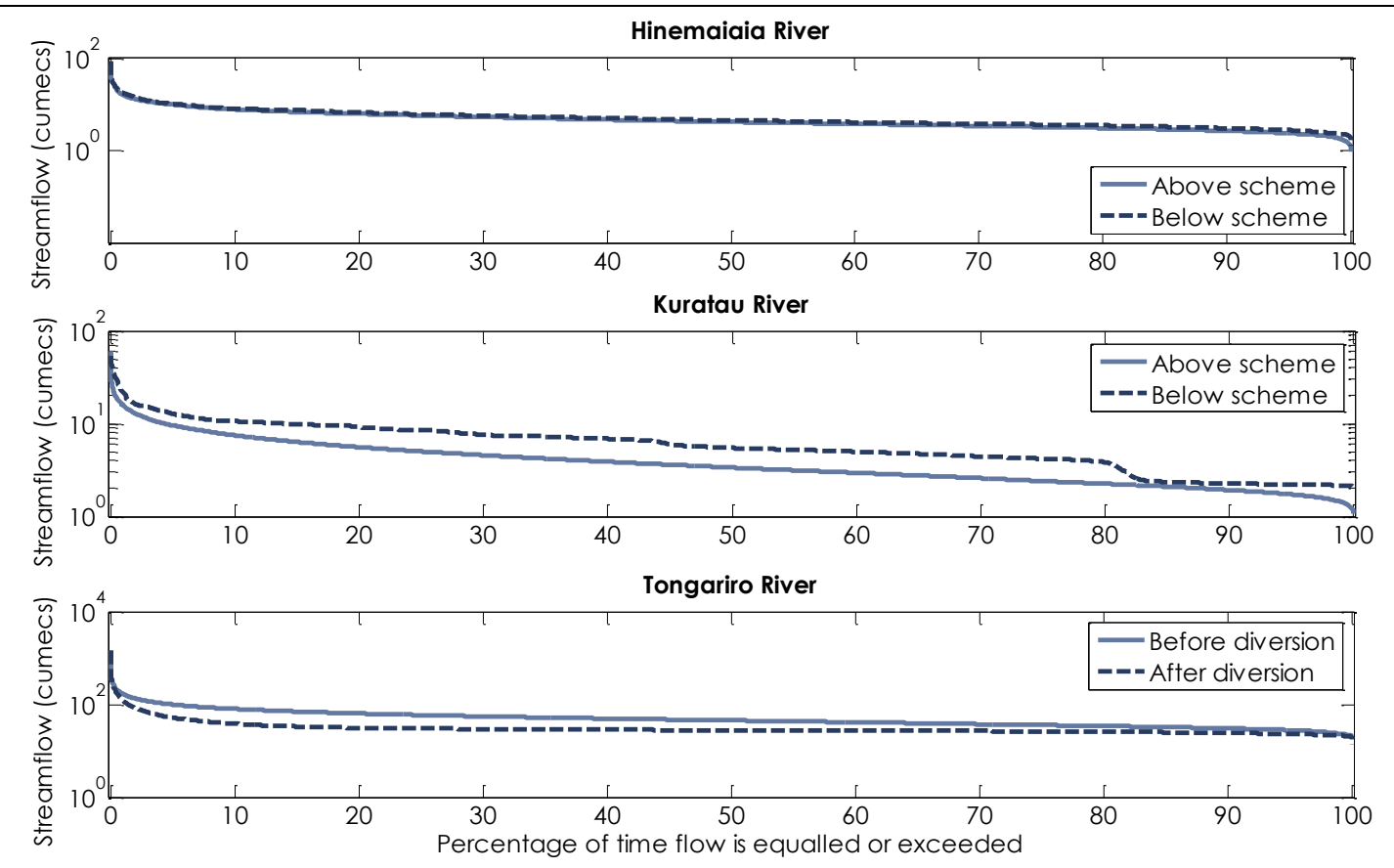

Figure 5.8. Flow duration curves for the three regulated sub-catchments of Lake Taupo. The light blue lines show the natural flow regime without modification. The dark blue line shows the flow regime after regulation.

Regulation of the Tongariro River largely affects normal flow conditions. As such, the variability index is reduced (before: 0.5908 and after: 0.4547) and baseflow index values remain largely unchanged. While high flows $\left(>160 \mathrm{~m}^{3} / \mathrm{s}\right)$ remain unmodified by the scheme flow below this value is affected by the various diversions. Over the range of low flows the slope of the flow duration curve is flatter indicating more constant low flows (Figure 5.8, lower). The index of flood flows has decreased from 1.4533 to 1.2915 , indicating that the amount of time the catchment experiences larger floods is less. This is largely a result of the diversions which takes up to $80 \mathrm{~m}^{3} / \mathrm{s}$ out of the Tongariro River, extending the length of time at which flow is in its lower range. The flow duration curve shows a flatter slope after the diversions for the majority of the time.

\subsection{Conclusions}

Hydrologic function is a response to the climatic inputs (precipitation) and outputs (evapotranspiration) to the catchment as well as the physical factors controlling the movement of water once it reaches the ground. Analysis of these catchment specific physical attributes is undertaken and compared to catchment hydrologic characteristics. The relationships between the various indices not only provide an 
overview of catchment hydrologic behaviour but also contribute to the development of the perceptual model of the catchment and guidance on initial sub-catchment model structures and parameter estimation.

Groundwater is a significant contributor to flow in all catchments of Lake Taupo and as such initial parameter ranges should reflect this. Variability is highest in areas of basement greywacke which also tend to coincide with the higher elevation and steeper parts of Lake Taupo. These catchments also appear to be more elongated. As such, water is able to reach the stream network more quickly. In addition, these steeper catchments are also in the higher elevation areas of the catchment which receive greater precipitation volumes and therefore more water is available for runoff. The analysis could be further improved if more descriptive indices of catchment geology and soils are used.

In the Lake Taupo catchment, the effect of regulation on natural flow regimes depends on the amount of storage within the scheme, its operation (i.e. the storage and release of water) and any resource consent conditions under which it is required to operate. The Hinemaiaia catchment has little storage and therefore the impact on natural flow regimes has been limited. The operation of the Kuratau Power Schemes has increased baseflow and variability in the upper range of flows, although the limited data available for below the scheme may influence this result. Streamflow in the modified Tongariro River is largely affected during normal operating conditions, reducing flow variability overall.

This information has confirmed the significance of groundwater in all catchments of Lake Taupo and provides some indication of parameter ranges suitable for each catchment. Initial parameter ranges reflect these results. Parameter ranges for the proportion of flow draining to the baseflow store should be highest for baseflow dominated catchments such as the Waitahanui and Waihohonu catchments. In terms of the fastflow response, the ability of water to reach the stream quickly is important. Quick flow residence times are therefore likely to be shorter in steeper catchments than those which are more gently sloping, rounder and more permeable. 
Table 5.2. Sub-catchment hydrologic, climatic and physiographic information

\begin{tabular}{|c|c|c|c|c|c|c|c|c|c|c|c|c|c|c|c|c|c|c|c|}
\hline Catchment & ठ 즈 है & 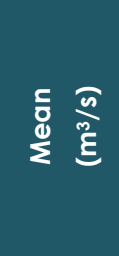 & 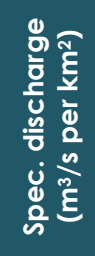 & $\begin{array}{l}5 \\
0 \\
\frac{0}{14} \\
3 \\
0\end{array}$ & 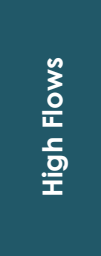 & $\begin{array}{l}\text { 줄 } \\
\frac{0}{0} \\
\text { 음 } \\
\text { > }\end{array}$ & $\begin{array}{l}3 \\
0 \\
\overline{0} \\
\overline{0} \\
0 \\
0\end{array}$ & 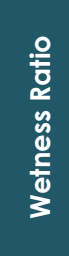 & 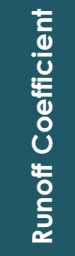 & $\stackrel{\bar{\Phi}}{\bar{\Phi}} \bar{\xi}$ & 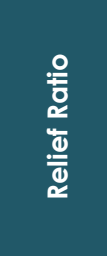 & 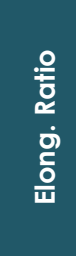 & 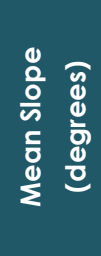 & $\begin{array}{l}\stackrel{\hat{N}}{\$} \\
\stackrel{\circ}{\circ} \\
\frac{0}{5}\end{array}$ & 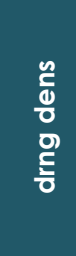 & $\begin{array}{l}\stackrel{d}{0} \\
\frac{.}{5} \\
\frac{0}{\circ} \\
\frac{0}{\circ}\end{array}$ & 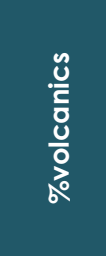 & 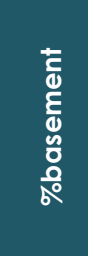 & $\begin{array}{l}\overline{5} \\
\overline{0} \\
\frac{0}{0}\end{array}$ \\
\hline Waitahanui & 196.07 & 6.9135 & 0.035 & 1.182 & 1.048 & 0.241 & 0.7652 & 2.29 & 0.56 & 818 & 31.71 & 1.63 & 6.08 & $2.7 \%$ & 1.70 & 70.30 & 95.00 & 5.00 & 99.00 \\
\hline Hinemaiaia & 125.38 & 5.1407 & 0.041 & 1.766 & 1.469 & 0.465 & 0.7450 & 2.43 & 0.59 & 824 & 41.54 & 1.57 & 10.23 & $10.3 \%$ & 2.23 & 53.30 & 69.00 & 31.00 & 98.60 \\
\hline Taur-Taupo & 197.1 & 9.7391 & 0.049 & 2.131 & 1.834 & 0.667 & 0.7173 & 2.71 & 0.63 & 1191 & 35.40 & 2.12 & 17.33 & $27.5 \%$ & 2.34 & 66.20 & 51.00 & 49.00 & 97.60 \\
\hline Waimarino & 63.63 & 3.3872 & 0.053 & 2.556 & 1.974 & 0.703 & 0.6953 & 3.02 & 0.67 & 1159 & 56.79 & 2.27 & 18.07 & $31.0 \%$ & 1.81 & 47.40 & 46.60 & 53.40 & 98.50 \\
\hline Tongariro pre 1974 & 784.15 & 52.6731 & 0.067 & 1.612 & 1.453 & 0.591 & 0.7427 & 3.41 & 0.71 & 2304 & 80.19 & 0.91 & 13.20 & $18.6 \%$ & 2.19 & 56.20 & 69.80 & 28.10 & 67.30 \\
\hline Waipakihi & 179.98 & 11.9023 & 0.066 & 2.291 & 1.612 & 0.699 & 0.7012 & 3.24 & 0.69 & 881 & 31.37 & 1.86 & 20.19 & $37.6 \%$ & 2.44 & 70.30 & 27.30 & 72.70 & 78.50 \\
\hline Waihohonu & 96.06 & 6.2808 & 0.065 & 1.546 & 1.317 & 0.374 & 0.7496 & 4.00 & 0.75 & 1592 & 112.83 & 1.28 & 9.93 & $8.5 \%$ & 3.08 & 0.10 & 100.00 & 0.00 & 14.00 \\
\hline Waihi & 9.84 & 0.3934 & 0.040 & 2.390 & 1.458 & 0.520 & 0.7375 & 2.88 & 0.65 & 942 & 133.86 & 1.99 & 10.69 & $5.6 \%$ & 1.75 & 43.30 & 100.00 & 0.00 & 92.20 \\
\hline Kuratau & 119.26 & 4.2428 & 0.036 & 1.944 & 1.638 & 0.548 & 0.7466 & 2.25 & 0.56 & 824 & 36.54 & 1.83 & 6.03 & $2.0 \%$ & 1.70 & 59.40 & 98.60 & 0.00 & 52.80 \\
\hline Whareroa & 59.35 & 1.0971 & 0.018 & 1.717 & 1.388 & 0.383 & 0.7582 & 1.67 & 0.40 & 609 & 35.07 & 2.00 & 7.69 & $4.2 \%$ & 1.51 & 78.40 & 95.00 & 0.00 & 24.90 \\
\hline Whanganui & 31.59 & 1.2748 & 0.040 & 2.608 & 1.652 & 0.600 & 0.7369 & 2.45 & 0.59 & 507 & 35.38 & 2.26 & 8.02 & $2.2 \%$ & 3.79 & 13.90 & 100.00 & 0.00 & 99.80 \\
\hline Waihaha & 133.66 & 5.6103 & 0.042 & 2.084 & 1.652 & 0.580 & 0.7467 & 2.50 & 0.60 & 590 & 29.35 & 1.54 & 12.02 & $11.2 \%$ & 2.40 & 4.20 & 86.50 & 13.50 & 91.50 \\
\hline Tutaevaua & 3.29 & 0.0761 & 0.023 & 1.848 & 1.526 & 0.562 & 0.7349 & 1.59 & 0.37 & 102 & 37.72 & 1.32 & 4.33 & $0.1 \%$ & 2.32 & 16.60 & 83.40 & 0.00 & 2.10 \\
\hline Otaketake & 16.31 & 0.1134 & 0.007 & 1.838 & 1.324 & 0.491 & 0.7488 & 1.21 & 0.17 & 292 & 32.57 & 1.97 & 5.96 & $1.9 \%$ & 1.83 & 56.60 & 100.00 & 0.00 & 24.60 \\
\hline
\end{tabular}

$\mathbf{1 0 8}$ | Catchment hydrologic behaviour 
Table 5.3. Correlation coefficients relating hydrologic, climatic and physiographic attributes

\begin{tabular}{|c|c|c|c|c|c|c|c|c|c|c|c|c|c|c|c|c|c|c|c|}
\hline & 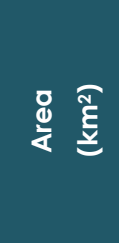 & 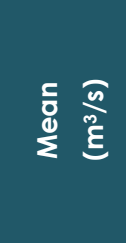 & 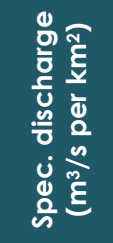 & $\begin{array}{l}\frac{0}{3} \\
\frac{0}{14} \\
3 \\
0\end{array}$ & 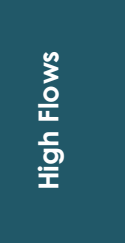 & $\begin{array}{l}\frac{7}{0} \\
\frac{0}{0} \\
\text { 흫 } \\
\text { > }\end{array}$ & $\begin{array}{l}3 \\
\frac{3}{0} \\
\overline{0} \\
0 \\
0 \\
0\end{array}$ & 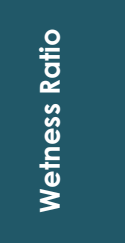 & 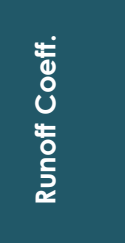 & 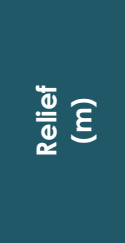 & 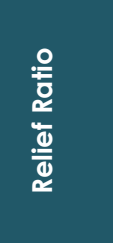 & 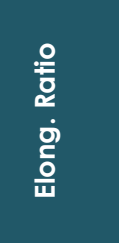 & 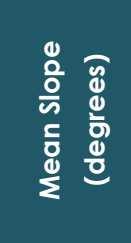 & 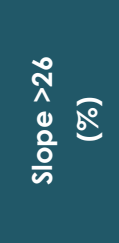 & 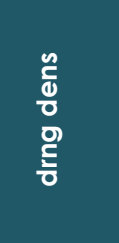 & 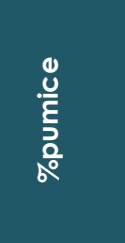 & \begin{tabular}{l}
$\frac{\tilde{U}}{Z}$ \\
$\overline{0}$ \\
$\frac{0}{0}$ \\
\multirow{2}{0}{}
\end{tabular} & 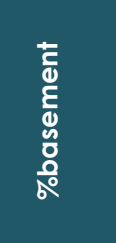 & $\begin{array}{l}\bar{y} \\
\frac{5}{00}\end{array}$ \\
\hline Area $\left(\mathbf{k m}^{2}\right)$ & 1 & & & & & & & & & & & & & & & & & & \\
\hline Mean $\left(m^{3} / s\right)$ & 0.9897 & 1 & & & & & & & & & & & & & & & & & \\
\hline $\begin{array}{l}\text { Spec yield } \\
\left(\mathrm{m}^{3} / \mathrm{s} \text { per } \mathrm{km}^{2}\right)\end{array}$ & 0.5417 & 0.5717 & 1 & & & & & & & & & & & & & & & & \\
\hline Low flows & -0.3349 & -0.2674 & 0.1402 & 1 & & & & & & & & & & & & & & & \\
\hline Flood flows & -0.0828 & -0.0478 & 0.2878 & 0.7956 & 1 & & & & & & & & & & & & & & \\
\hline Variability & 0.1114 & 0.1772 & 0.3569 & 0.7893 & 0.8875 & 1 & & & & & & & & & & & & & \\
\hline Baseflow & 0.0387 & -0.0244 & -0.4645 & -0.7184 & -0.7950 & -0.8520 & 1 & & & & & & & & & & & & \\
\hline Wetness Ratio & 0.4289 & 0.4657 & 0.9577 & 0.1057 & 0.1768 & 0.2022 & -0.3465 & 1 & & & & & & & & & & & \\
\hline Runoff Coeff. & 0.3975 & 0.4041 & 0.9306 & 0.1883 & 0.2797 & 0.2354 & -0.3517 & 0.9334 & 1 & & & & & & & & & & \\
\hline Relief (m) & 0.7917 & 0.8049 & 0.7855 & -0.1851 & 0.0383 & 0.0882 & -0.1209 & 0.8018 & 0.7112 & 1 & & & & & & & & & \\
\hline Relief Ratio & 0.1143 & 0.1829 & 0.3908 & 0.0341 & -0.1525 & -0.1197 & 0.0291 & 0.5955 & 0.4629 & 0.5337 & 1 & & & & & & & & \\
\hline Elong. Ratio & -0.6057 & -0.6123 & -0.2936 & 0.6639 & 0.4484 & 0.2835 & -0.3940 & -0.2725 & -0.1673 & -0.4328 & -0.2420 & 1 & & & & & & & \\
\hline $\begin{array}{l}\text { Mean Slope } \\
\text { (degrees) }\end{array}$ & 0.2901 & 0.3179 & 0.7178 & 0.4716 & 0.6085 & 0.6652 & -0.8082 & 0.6201 & 0.6203 & 0.4746 & 0.0802 & 0.2009 & 1 & & & & & & \\
\hline Slope > 26 (\%) & 0.3207 & 0.3450 & 0.6843 & 0.3821 & 0.5827 & 0.6599 & -0.8340 & 0.5519 & 0.5380 & 0.4466 & -0.0387 & 0.1543 & 0.9746 & 1 & & & & & \\
\hline Drng. density & -0.0322 & 0.0205 & 0.3810 & 0.2988 & 0.1716 & 0.2236 & -0.1295 & 0.3700 & 0.3309 & 0.0517 & 0.0429 & -0.0481 & 0.0840 & 0.0229 & 1 & & & & \\
\hline \%pumice & 0.2376 & 0.1803 & -0.1388 & -0.1872 & -0.1086 & -0.0631 & -0.0734 & -0.2281 & -0.1654 & 0.0953 & -0.2829 & 0.2639 & 0.1949 & 0.2824 & -0.6673 & 1 & & & \\
\hline \%volcanics & -0.2795 & -0.2969 & -0.5487 & -0.3258 & -0.5648 & -0.6620 & 0.8310 & -0.3579 & -0.3871 & -0.2723 & 0.2258 & -0.1033 & -0.8691 & -0.9399 & 0.0197 & -0.3423 & 1 & & \\
\hline \%basement & 0.2930 & 0.3035 & 0.5962 & 0.3452 & 0.5545 & 0.6410 & -0.8158 & 0.4241 & 0.4508 & 0.3303 & -0.1911 & 0.1595 & 0.9165 & 0.9664 & -0.0056 & 0.3632 & -0.9835 & 1 & \\
\hline \%forest & 0.1559 & 0.1032 & 0.3620 & 0.4000 & 0.3371 & 0.2788 & -0.3149 & 0.2905 & 0.5161 & 0.1802 & -0.0729 & 0.3651 & 0.5011 & 0.4107 & 0.0776 & 0.1742 & -0.3653 & 0.4654 & \\
\hline
\end{tabular}

109 | Catchment hydrologic behaviour 
110 | Catchment hydrologic behaviour 


\section{A rainfall-runoff model for the Lake Taupo catchment}

The development of a rainfall-runoff model specifically for the Lake Taupo catchment is described in this chapter. Section 6.1 outlines the model, its inputs, structure and outputs. The semi-distributed conceptual model is used for the purpose of adding to the existing knowledge of catchment hydrologic function through calibration of historically gauged catchments. The process for identifying suitable periods of data for calibration and evaluation is discussed in Section 6.2, with model identification (parameter estimation and sensitivity analysis) described in Section 6.3.

The conceptual model described in Section 6.1 is also the basis for the Lake Taupo Inflow Model (Section 6.4) from which lake level predictions are made. It is applied to five currently gauged catchments and ungauged areas of Lake Taupo. For the complex TPS, a statistical probability analysis is used to estimate discharge due to availability of data and complexity of the scheme. Section 6.5 outlines the data assimilation approach used in the study and the constraints applied. The combined model output provides quantitative predictions of inflow to Lake Taupo (Section 6.6). This inflow is then used to predict lake level changes out to 15 days. The process for model evaluation is described in Section 6.7. The model is computationally efficient to allow its use operationally when coupled with 
meteorological forecasts. The information obtained as a result of the modelling approach adds to the current understanding of the physical processes that control the movement of water within the catchment.

\subsection{Conceptual model structure}

In this dissertation, a conceptual model structure is selected to simulate the rainfallrunoff response in the Lake Taupo catchment because it provides the necessary computational efficiency while maintaining some underlying physical basis. Rather than use an existing 'off-the-shelf' model, which would have a predefined structure and parameters, the model developed is specific to the physical and hydrological properties for the Lake Taupo catchment.

The structure is typical of most conceptual models (Beven, 2001; Clark et al., 2008a; Moore, 2007). It uses a number of storage elements representing important flowpaths in the catchment. Each of these stores is connected by mathematical functions describing their respective storage and depletion. The time delay between system inputs and the timing of the response observed at the gauge is accounted for.

The aim in model development is to be parametrically parsimonious while still retaining some physical meaning. A number of alternative structures were tested during the formulation of the model structure. Initially, the model structure included two (fastflow and baseflow) linear stores and drainage to the sub-surface occurred only once the whole catchment reached field capacity. Simulations based on this structure indicated that better characterisation of rising and recession limbs was required. A third store was added. Since it is uncommon for there to be more than three sub-surface stores in hydrological models, more attention was given to achieving appropriate thresholds and release functions such as the variable source area and relationship between potential and actual evapotranspiration.

The following sections describe the final conceptual model structure used in this dissertation, although in subsequent chapters (Chapters 7 to 9), potential areas of improvement are suggested. Figure 6.1 illustrates the basic conceptual model structure, based on effective rainfall infiltrating the soil layer before draining to three (fastflow, interflow and baseflow) linear stores before entering the river or stream. Accounting for the concept of a variable source area, where soil becomes saturated at different times across the catchment (Dunne and Black, 1970; Steenhuis et al., 1995), some drainage is allowed to occur between a minimum soil 


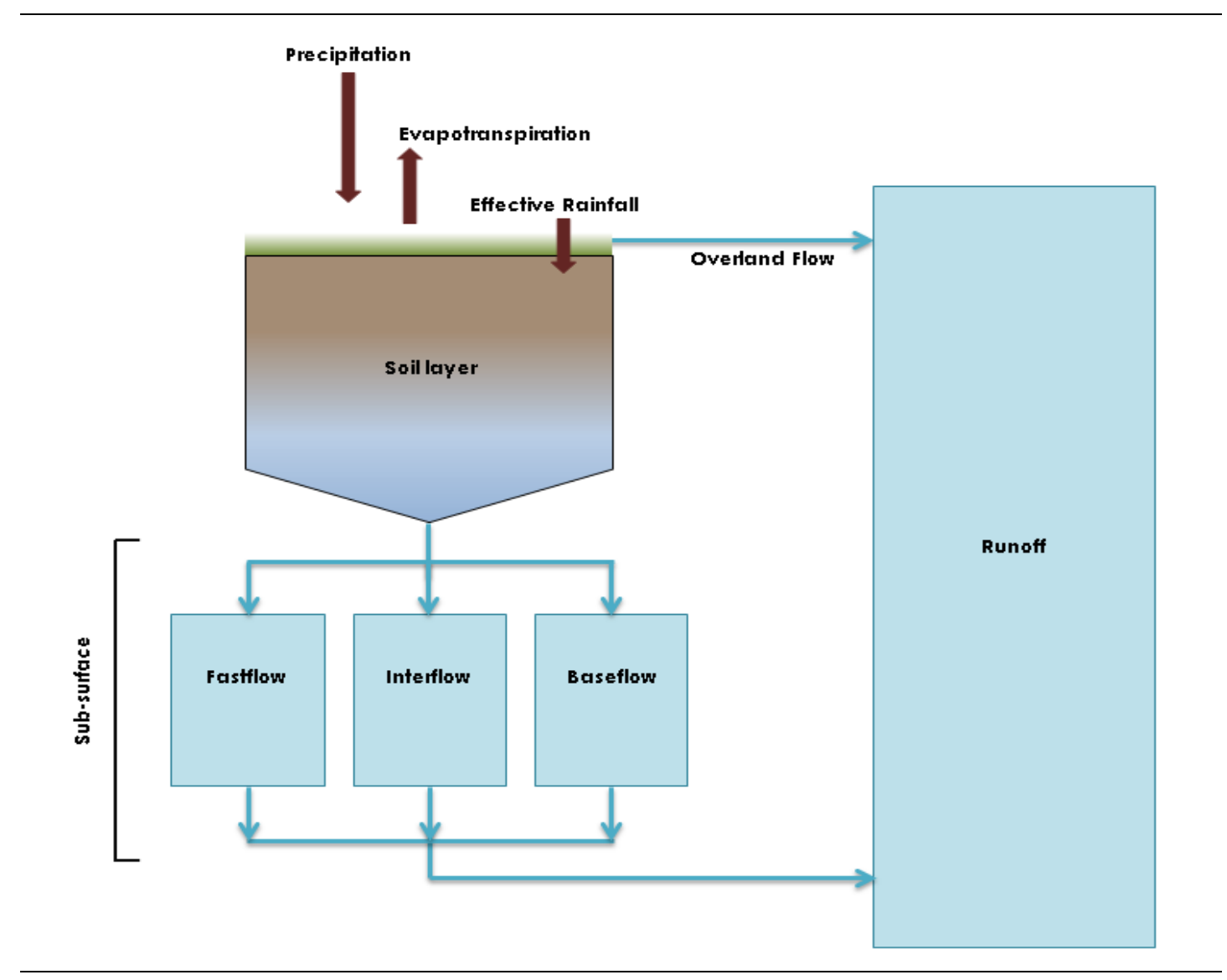

Figure 6.1. Simple conceptual model structure of the Taupo Rainfall-Runoff Model. Effective rainfall infiltrates the soil layer and drains to three linear stores before discharging to the river. Overland flow occurs if the infiltration rate is exceeded or if the soil layer becomes saturated.

water content threshold and field capacity. The relationship between the amount of water draining to the stores and soil water content is defined by a power law relationship. Table 6.1 lists the main parameters/variables used in the model, their associated symbol and unit dimensions.

\subsubsection{Model Inputs}

Precipitation $(P)$ and potential evapotranspiration $(P E)$ are the two inputs used to drive the model. As stated in Section 1.7, the units for these two variables are $\mathrm{mm}$ depth per time step (mm/15 minutes). The surface water flux, denoted by $S$ (mm/15 minutes), is the difference between these two inputs and is written

$$
S=P-P E
$$

Eqn 6.1

$P$ is estimated catchment areal precipitation based on observed rainfall (see Section 4.1.2). Potential evapotranspiration $(P E)$ is the demand for water from the 
Table 6.1 List of model parameters/variables, associated symbol and unit dimension

\begin{tabular}{|c|c|c|}
\hline Parameter/Variable & Symbol & Unit \\
\hline \multicolumn{3}{|l|}{ Model state variables } \\
\hline Soil water volume & $V_{\text {soil }}$ & $\mathrm{mm}$ \\
\hline Baseflow store volume & $V_{\text {base }}$ & $\mathrm{mm}$ \\
\hline Interflow store volume & $V_{\text {inter }}$ & $\mathrm{mm}$ \\
\hline Throughflow/fastflow store volume & $V_{\text {fast }}$ & $\mathrm{mm}$ \\
\hline Total runoff & $Q$ & $\mathrm{~mm} / 15 \mathrm{~min}$ \\
\hline Baseflow runoff & $q_{\text {base }}$ & $\mathrm{mm} / 15 \mathrm{~min}$ \\
\hline Interflow runoff & $q_{\text {inter }}$ & $\mathrm{mm} / 15 \mathrm{~min}$ \\
\hline Throughflow/fastflow runoff & $q_{\text {fast }}$ & $\mathrm{mm} / 15 \mathrm{~min}$ \\
\hline Overland flow & $q_{\text {overland }}$ & $\mathrm{mm} / 15 \mathrm{~min}$ \\
\hline Hortonian overland flow & $q_{\text {ohort }}$ & $\mathrm{mm} / 15 \mathrm{~min}$ \\
\hline Saturation excess overland flow & $q_{\text {osatexcess }}$ & $\mathrm{mm} / 15 \mathrm{~min}$ \\
\hline Saturation zone & $S Z$ & - \\
\hline \multicolumn{3}{|l|}{ Model Fluxes and Inputs } \\
\hline Precipitation & $P$ & $\mathrm{~mm} / 15 \mathrm{~min}$ \\
\hline Potential Evapotranspiration & PET & $\mathrm{mm} / 15 \mathrm{~min}$ \\
\hline Actual Evapotranspiration & AET & $\mathrm{mm} / 15 \mathrm{~min}$ \\
\hline Surface water flux & $S$ & $\mathrm{~mm} / 15 \mathrm{~min}$ \\
\hline Maximum infiltration rate & $\lambda_{\max }$ & $\mathrm{mm} / 15 \mathrm{~min}$ \\
\hline Drainage & $\delta$ & $\mathrm{mm} / 15 \mathrm{~min}$ \\
\hline Maximum drainage rate to subsurface & $\delta_{\max }$ & $\mathrm{mm} / 15 \mathrm{~min}$ \\
\hline \multicolumn{3}{|l|}{ Model parameters } \\
\hline Baseflow & base & - \\
\hline Interflow & inter & - \\
\hline Throughflow/fastflow & fast & - \\
\hline Interflow proportion & $\rho_{\text {inter }}$ & - \\
\hline Baseflow proportion & $\rho_{\text {base }}$ & - \\
\hline Throughflow/fastflow proportion & $\rho_{\text {fast }}$ & - \\
\hline Interflow residence time & $T_{\text {inter }}$ & days \\
\hline Baseflow residence time & $T_{\text {base }}$ & days \\
\hline Throughflow/fastflow residence time & $T_{\text {fast }}$ & days \\
\hline Field capacity & $V_{F C}$ & $\mathrm{~mm}$ \\
\hline Maximum saturation capacity & $V_{\text {satmax }}$ & $\mathrm{mm}$ \\
\hline Critical point & $c$ & $\mathrm{~mm}$ \\
\hline Minimum release threshold & $V_{\min }$ & $\mathrm{mm}$ \\
\hline Power function for contributing area & $\varphi$ & - \\
\hline Lag time & lag & \# time steps \\
\hline
\end{tabular}


atmosphere and plants, assuming ample water supply. The loss of water to evapotranspiration is a function of the water available in the system to meet this evaporative demand. When $P$ exceeds $P E$ the surface flux is positive. That is, infiltration through the soil layer occurs. A negative surface flux occurs when evaporative loss is greater than $P$. The model uses the surface flux to determine actual evapotranspiration $(A E)$. When $P$ is greater than $P E$, the demand from $P E$ can be satisfied entirely by $P$ and, therefore, $A E$ equals $P E$. When $P E$ is greater than $P$, moisture is extracted from $P$ and the soil layer in order to satisfy $P E$.

\subsubsection{Surface soil layer}

How easily water is extracted from the soil by plants and the atmosphere is dependent on the availability of water in the soil (Hillel, 2004). As soil water content $\left(V_{\text {soil }}, \mathrm{mm}\right)$ decreases water becomes more tightly bound in the soil particles and more difficult to extract (Davie, 2004). In this study, it is assumed that water is readily available (easily extracted) below field capacity ${ }^{9}(\mathrm{~mm})$ to a critical point (Figure 6.2). Beyond this point the availability of water is not as easily extracted. The level at which this critical point ( $c$ ) occurs varies between and within soils and crops. It is commonly represented as a fraction of total available water and is generally between 0.3 and 0.7 , depending on depth of rooting (Allen et al., 1998). A value of 0.5 is commonly used. In the absence of information on specific soil hydraulic properties and since it is not considered a vital model parameter, $c$ is also defined in this application to be as a proportion (50\%) of field capacity $\left(V_{F C}\right)$, that is,

$$
c=0.5 \times V_{F C}
$$

Eqn 6.2

Following Rushton et al. (2006), if $V_{\text {soil }}$ is greater than $c$ then the water in the soil is sufficient to meet the demand of $P E$, and $A E$, therefore, equals $P E$. However, when $V_{\text {soil }}$ is not enough to meet the demand from $P E$ (i.e. $V_{\text {soil }}<c$ ), $A E$ is only a proportion of $P E$, as determined by

$$
\begin{gathered}
A E=\frac{V_{\text {soil }}}{c} \times P E, \text { where } V_{\text {soil }}<P E \text { and, } \\
A E=P E, \text { where } V_{\text {soil }} \geq P E
\end{gathered}
$$

Eqn 6.3

\footnotetext{
9 Field capacity is defined as the amount of water held in the soil after water has drained away by gravity Harding, J., Mosley, P., Pearson, C., Sorrell, B., 2004. Freshwaters of New Zealand. New Zealand Hydrological Society and New Zealand Limnological Society, Christchurch.
} 


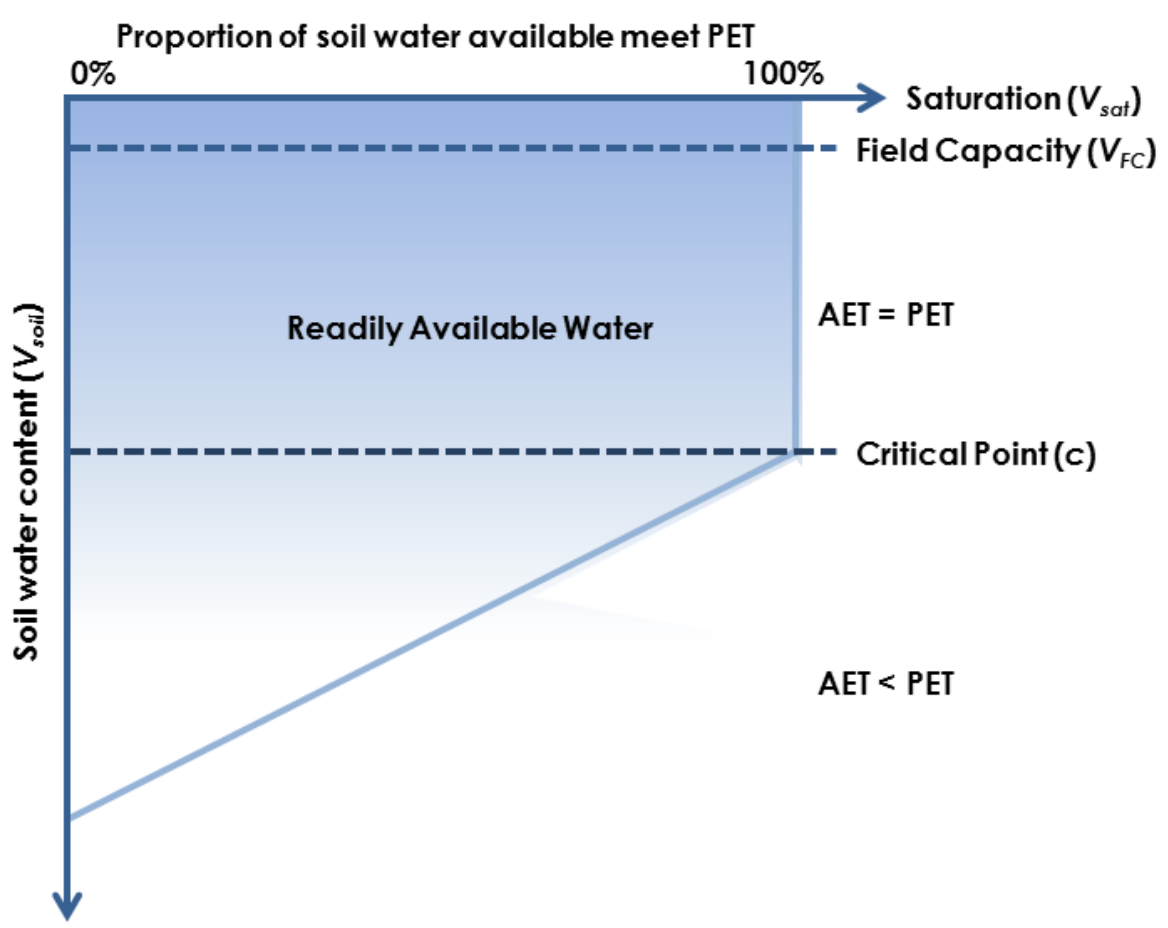

Figure 6.2. Schematic diagram of the soil layer with regard to moisture available for evapotranspiration. The availability of water to plants and the atmosphere in the soil is illustrated. Water above a critical point is readily available and easily extracted. There is enough water readily available in the system to meet evaporative demand. Below the critical point, only a proportion of the evaporative demand is can be met.

The rate at which $S^{+}$can infiltrate the surface and enter the soil layer is limited by a maximum infiltration rate denoted by $\lambda_{\max }(\mathrm{mm} / 15 \mathrm{~min})$. In the pumice soils of the Otutira catchment, northern Lake Taupo catchment, Selby (1972) found infiltration rates ranged widely between $60-600 \mathrm{~mm}$ per hour. In situations where $\lambda_{\max }$ is exceeded or the soils maximum saturation capacity $\left(V_{\text {sat }}, \mathrm{mm}\right)$ is exceeded, overland flow ( $q_{\text {over }}, \mathrm{mm}$ per timestep) is generated. Under the first scenario Hortonian overland flow ( $q_{\text {ohort }}, \mathrm{mm} / 15$ minutes) is determined as

$$
q_{\text {ohort }}=S^{+}-\lambda_{\max }
$$

Eqn 6.4

If the volume of water in the soil reaches saturation and $S^{+}$exceeds the maximum rate of drainage from the soil ( $\delta_{\max }, \mathrm{mm} / 15$ minutes) then saturation excess overland flow ( $q_{\text {osat }}, \mathrm{mm} / 15$ minutes) occurs, where

$$
q_{\text {osat }}=S^{+}-\delta_{\max }-\left(V_{s}-V_{\text {sat }}\right)
$$

and

$$
q_{\text {over }}=q_{\text {ohort }}+q_{\text {osat }}
$$




\subsubsection{Drainage to subsurface}

The amount and timing of water released from the soil layer into the subsurface stores is also controlled by the volume of water in the soil. In this conceptual model, the soil layer is lumped as a single homogeneous layer throughout the whole catchment.

Drainage from the soil layer to the subsurface (Figure 6.1) occurs when field capacity is reached. This is likely to occur at different times for different parts of the catchment. Following Steenhuis et al. (1995) the rate of subsurface runoff generation is proportional to the fraction of the catchment under saturation ( $S Z)$ assuming that in the unsaturated zone, all rain is able to infiltrate the soil and that once the soil profile becomes saturated any additional rain contributes to runoff via overland flow or subsurface flow. Valley bottoms and riparian zones, for example, are more likely to saturate sooner than areas further away from the waterway (Dunne and Black, 1970; Steenhuis et al., 1995). Consequently, these parts of the catchment start contributing to runoff earlier than other areas. These saturated zones are likely to expand and contract with rainfall (Dunne and Black, 1970). This is the basis for the variable source area or contributing area concepts of Hewlett and Hibbert (1967), Dunne and Black (1970) and references therein.

There are a number of approaches for incorporating the variable source area into hydrological models reported in the literature. Some of these are topographicallydriven (Beven and Kirkby, 1979; Clark et al., 2008a; Pradhan and Ogden, 2010), while others consider the catchment as a set of partial areas of different capacities from which runoff is generated as each capacity is met (Boughton, 2004; Moore, 2007). For simplicity, the lumped soil layer approach of this model uses the increase in $V_{\text {soil }}$ to represent the expansion of the $S Z$. This is because $V_{\text {soil }}$ is the average soil water content in the catchment and includes areas which have reached saturation earlier than other areas. This relationship is described by the following equation:

$$
S Z=\left(V_{\text {soil }}-V_{\text {min }}\right) /\left(V_{F C}-V_{\text {min }}\right)
$$

Eqn 6.7

where $V_{\min }$ is a minimum threshold ( $\mathrm{mm}$ ) below which saturation, and contributing area, is assumed negligible. From this it can be seen that as $V_{\text {soil }} \rightarrow V_{F C}, S Z \rightarrow 1$. That is, at field capacity it is assumed all flow pathways are activated and all soil water is moving toward the stream. $S Z$ is then used to calculate drainage to the subsurface. Drainage is calculated as a fraction of the infiltrated rainfall $\left(S^{+}\right)$given the proportion of the catchment under saturation, so that 
where $\varphi$ is the exponent of a power law function relating $S Z$ to drainage volumes and is specific to the physical properties and characteristics of each catchment. It is included as a parameter for calibration in this study. The effect of this power law function is illustrated in Figure 6.3.

\subsubsection{Subsurface stores}

Water from the soil layer is released into three linear stores - fastflow $\left(V_{\text {fast }}\right)$, interflow $\left(V_{\text {inter }}\right)$, and baseflow ( $\left.V_{\text {base }}\right)$, as shown in (Figure 6.1). These stores represent different pathways in which water can move through the subsurface. Each store has a specific residence time associated with it; fastflow is the quickest pathway and baseflow the slowest. Interflow is somewhere in between these two stores. The relative proportions $(\rho)$ draining to each store is determined as follows:

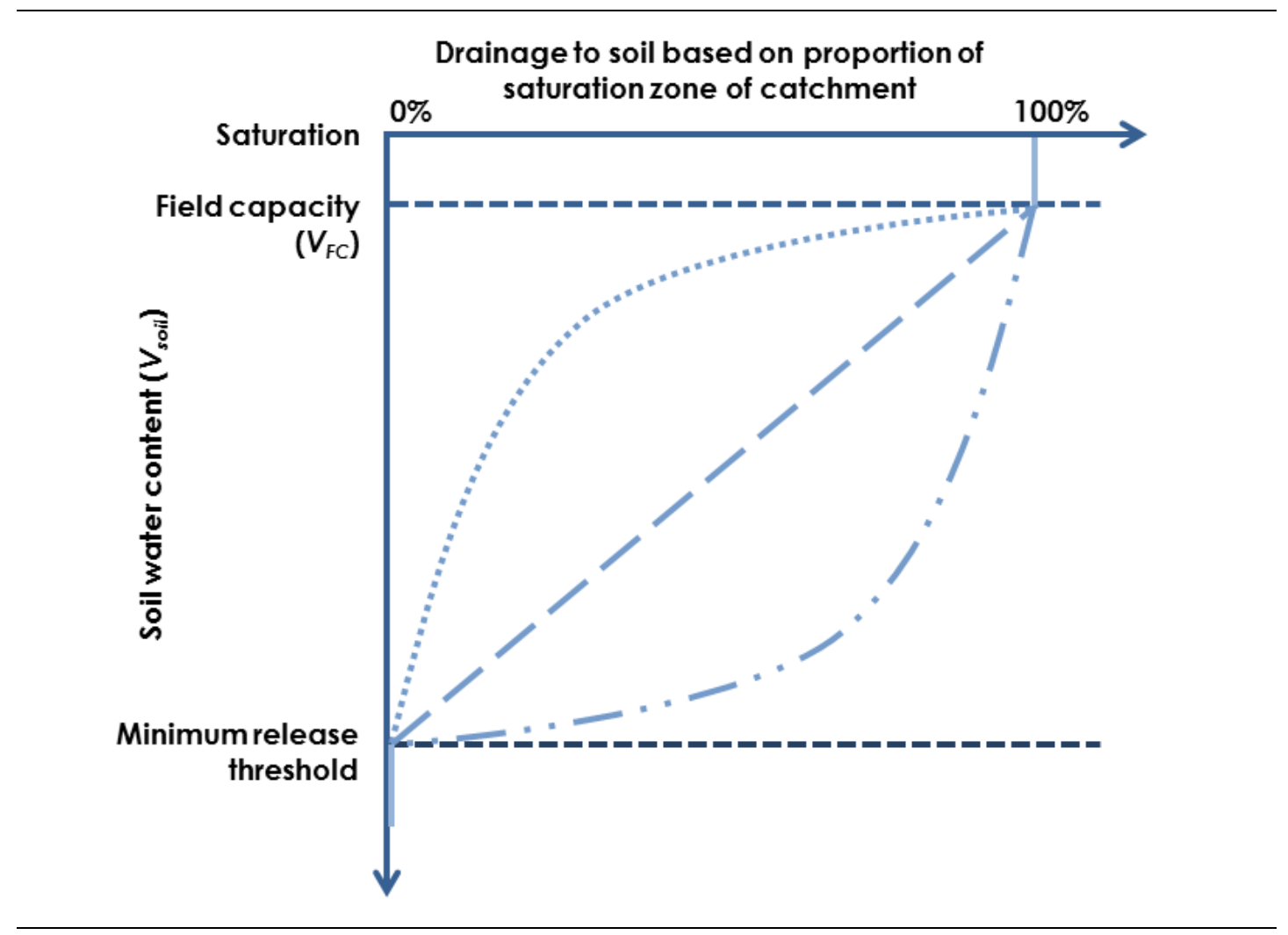

Figure 6.3 Relationship between volume of water in the soil (y-axis) and the proportion of rainfall draining to the subsurface (x-axis). The dashed line shows a linear relationship; a power law relationship of 1 . The dotted line shows a power law relationship of 0.5 and the third line represents a power law relationship of 2. 


$$
\begin{gathered}
0 \leq \rho_{\text {base }} \leq 1 \\
0 \leq \rho_{\text {inter }} \leq\left(1-\rho_{\text {base }}\right) \\
\rho_{\text {fast }}=1-\rho_{\text {inter }}-\rho_{\text {base }}
\end{gathered}
$$

and where the following condition must be satisfied,

$$
\rho_{\text {base }}+\rho_{\text {inter }}+\rho_{\text {fast }}=1
$$

Eqn 6.12

The volume of water entering each store is determined by multiplying the amount of water draining the soil layer by the relative proportion for each store. The new volume of water $(\mathrm{mm})$ in the soil and the three sub-surface stores are calculated by adding the amount of water draining into the store at time $t$ to the store volume at the previous time step $(t-1)$ and subtracting any 'losses' to runoff. These 'losses' are determined by dividing the store volume $(\mathrm{mm})$, at time $t$, by the respective store residence times, denoted by $T_{\text {base }}, T_{\text {inter }}$ and $T_{\text {fast }}$, so that

$$
\begin{aligned}
q_{\text {base }(t)} & =\frac{V_{\text {base }(t)}}{T_{\text {base }}} \\
q_{\text {inter }(t)} & =\frac{V_{\text {inter }(t)}}{T_{\text {inter }}} \\
q_{\text {fast }(t)} & =\frac{V_{\text {fast }(t)}}{T_{\text {fast }}}
\end{aligned}
$$

Eqn 6.15

where $q_{\text {base(t) }}$ is the runoff ( $\mathrm{mm} / 15$ minutes) from the baseflow store at time $t, q_{\text {inter }(t)}$ is the runoff $(\mathrm{mm})$ from the interflow store at time $t$, and $q_{f a s t(t)}$ is the runoff (mm) from the fastflow store at time $t$.

The new volumes of each store are then calculated by the following:

$$
\begin{aligned}
& V_{\text {base }(t)}=V_{\text {base }(t-1)}+\rho_{\text {base }} \delta_{(t)}-q_{\text {base }(t)}, \\
& V_{\text {inter }(t)}=V_{\text {inter }(t-1)}+\rho_{\text {inter }} \delta_{(t)}-q_{\text {inter }(t)} \text {, } \\
& V_{\text {fast }(t)}=V_{\text {fast }(t-1)}+\rho_{\text {fast }} \delta_{(t)}-q_{\text {fast }(t)} .
\end{aligned}
$$

\subsubsection{Model Output}

Runoff $(Q)$ is determined by the relative contributions of flow from the respective stores and any overland flow that may have occurred, that is

$$
Q_{(t)}=q_{\text {base }(t)}+q_{\text {inter }(t)}+q_{\text {fast }(t)}+q_{\text {overland }(t)}
$$


Direct rainfall to and evaporative losses from the river itself are assumed negligible. Abstractions from the lake for municipal supply are relatively small (based on monthly figures received from the Taupo District Council) and not included in the model. The data assimilation approach described in Section 6.5 is able to address some of the errors associated with these assumptions.

\subsubsection{Numerical implementation}

Numerical implementation refers to the discretisation method used to solve the governing equations of the model. While this is not a new area of research, with many excellent mathematical texts on the subject (see for example, Burden and Faires (1993)), best practice has been often overlooked in past hydrological applications, as recently highlighted in the literature by Kavetski and Clark (2010, 2011). It is acknowledged that this dissertation does not utilise a robust integration approach; the model is implemented using a fixed step (15 minutes) numerical integration method, driven by the time step of the information available. It is recognised that this may degrade the reliability of model predictions because of numerical approximation errors (Kavetski and Clark, 2011). These numerical errors can lead to sub-optimal parameter estimation and inconsistent inference of model states (Kavetski and Clark, 2010). Recent studies have shown that adaptive explicit time-stepping routines constrain numerical approximation errors for more robust model output (Kavetski and Clark, 2011) and is recommended in future development of the model. It has not been used here due to time constraints and the importance of other areas of this research.

\subsubsection{Summary}

The conceptual rainfall-runoff model described above is developed specifically for sub-catchments within the Lake Taupo catchment. It consists of three linear stores - fastflow, interflow and baseflow - and a soil store for water held below field capacity. The amount of water draining to these reservoirs is related to the size of the catchment area under saturation, following the variable source area concept. The model is computationally efficient to allow its use operationally when coupled with meteorological forecasts. It can easily accommodate regulation and is suitable for estimating inflows from ungauged basins because of its underlying physical basis. The application of this model in terms of the different types of inflows to Lake Taupo is described in the following section. 


\subsection{Calibration and evaluation data selection}

Model calibration is the process of adjusting parameter values to effect a closer matched simulation of the real world. Model performance is evaluated by how well it provides acceptable representations of the real world (Refsgaard and Henriksen, 2004; Wagener, 2003). The term 'evaluation' is used in this study since the commonly used term 'validation' implies some degree of 'truth' or legitimacy in the model (Oreskes et al., 1994), which is difficult to achieve with models which are made up of simplified representations of the complex reality (Beven, 2009).

Past observations of discharge, precipitation and potential evapotranspiration are used for calibration of this hydrological model. Successful calibration requires the identification of model parameters that can reliably simulate the catchment's hydrological response over a range of conditions (Singh and Bárdossy, 2012). The data is often split for calibration and evaluation periods, with the location of the split between the two selected subjectively. Although there have been a number of attempts to quantify a suitable length of time for model calibration, it is commonly accepted that it is the information content of the data used rather than the length of data that is more important for parameter identification (Gupta and Sorooshian, 1985; Liu and Han, 2010; Singh and Bárdossy, 2012). The information content of hydrological data is, however, largely unknown (Singh and Bárdossy, 2012)

The calibration period should ideally represent the range of phenomena experienced in the catchment including periods of floods, drought and normal flow conditions (Gupta and Sorooshian, 1985; Singh and Bárdossy, 2012). In the Lake Taupo catchment, however, many of the records for the sub-catchments are over relatively short periods (often less than five years). The corresponding rainfall record may be, in some cases, longer but may have lengthy gaps in the record limiting the selection of suitable calibration periods. Where data permits, calibration periods are selected from the longest continuous period of rainfall data for which there is a corresponding flow record. One third of the calibration data length up to a maximum of one year is used for model warm-up, to minimise effect of initial conditions (Madsen, 2003). At least one year is kept for model evaluation. In catchments for which suitable calibration and evaluation data is limited, calibration is undertaken on as much information as possible to identify model parameters (Singh and Bárdossy, 2012). Evaluation is not performed. 
For those catchments used in the Lake Taupo Inflow Model (LTIM), the periods selected have undergone extensive analysis in terms of their suitability for model calibration. The periods are assessed in terms of the range of hydrological responses represented in the period selected and the consistency between the rainfall and discharge records. Four separate analyses of the data are undertaken. First, periods of no rainfall (and evapotranspiration) are plotted and negative recessions (rising streamflow) highlighted with the aim of ascertaining the representative of the rainfall gauges for capturing the majority of events in the hydrograph.

Secondly, flow duration curves for the calibration data and the entire record are compared. Thirdly, residual mass curves are used to identify periods where there is consistency between the period in terms of the cumulative departure of rainfall and flow from their respective means. Finally, the rainfall data for the period is assessed for catchment representativeness in terms of how adequately it captures the events that are observed in the hydrograph.

Optimal parameters are evaluated on a separate and non-overlapping set of data. They are also evaluated over the 1998-2011 period as this is the critical period for evaluating the performance of the model in terms of predicting lake level over certain events. This 14 year period overlaps with many of the calibration data periods; any gaps are infilled irrespective of length.

\section{Identifying negative recessions}

The consistency between the rainfall and streamflow records is undertaken by identifying periods of no rainfall and or evapotranspiration and highlighting where streamflow is significantly rising during these recession periods (Figure 6.4). This assessment aims to show how representative the selected rainfall gauge is by illustrating how adequately it captures the events that are observed in the hydrograph. This analysis helps to identify suitable periods of data for calibration and evaluation purposes.

\section{Representativeness of calibration period}

To compare the representativeness of the calibration period selected, flow duration curves are compared of the calibration data and the entire record. Ideally the calibration period would reasonably cover the main range of flows that are seen in the whole record, as shown in Figure 6.5, although it is noted that depending on the 


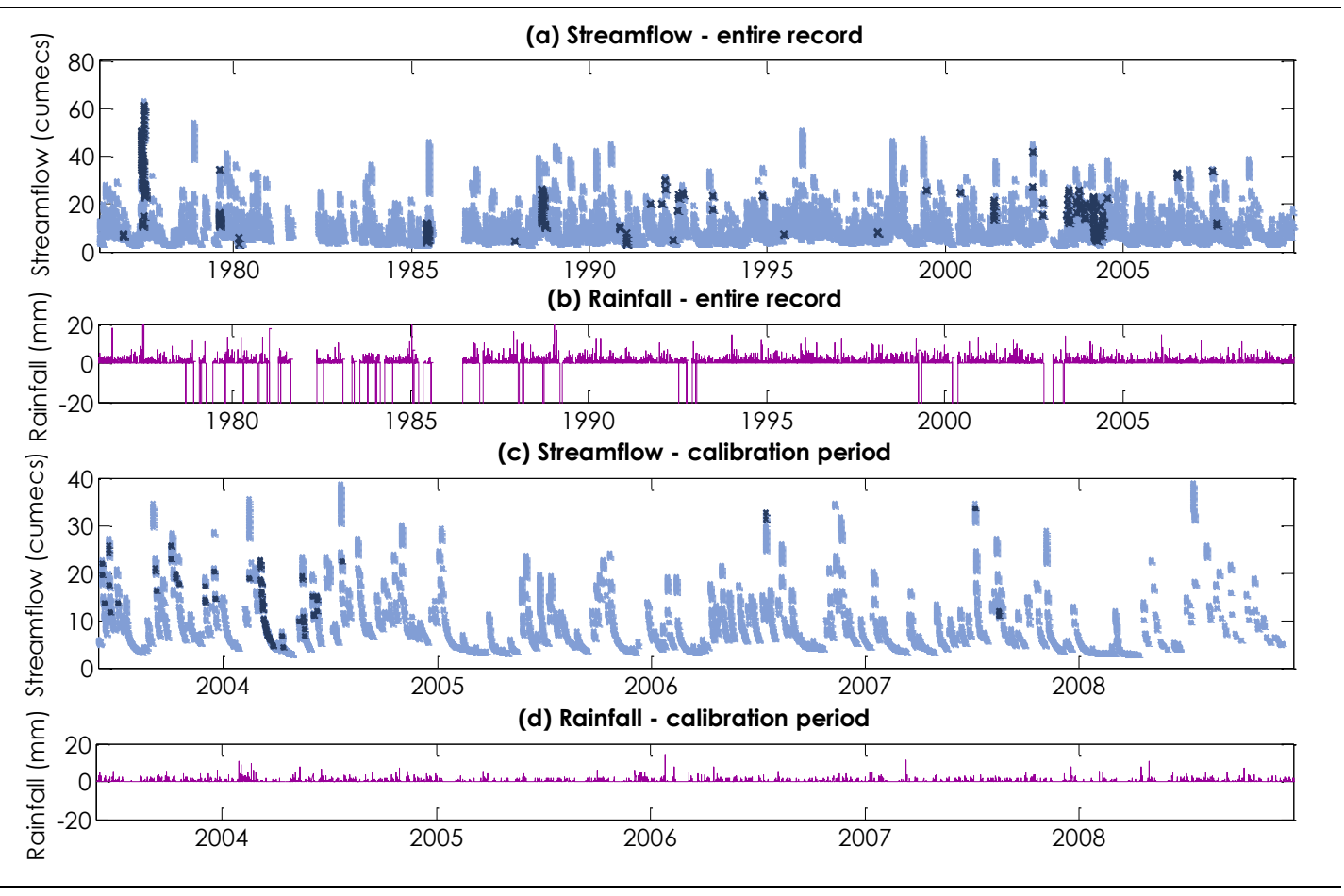

Figure 6.4. Plot of recession periods (light blue dots). Negative recessions (rising streamflow during periods of no rain or evapotranspiration) are highlighted (dark blue dots) (a) Entire record and (b) corresponding rainfall (mm/15 minutes). (c) Calibration period and (d) corresponding rainfall.

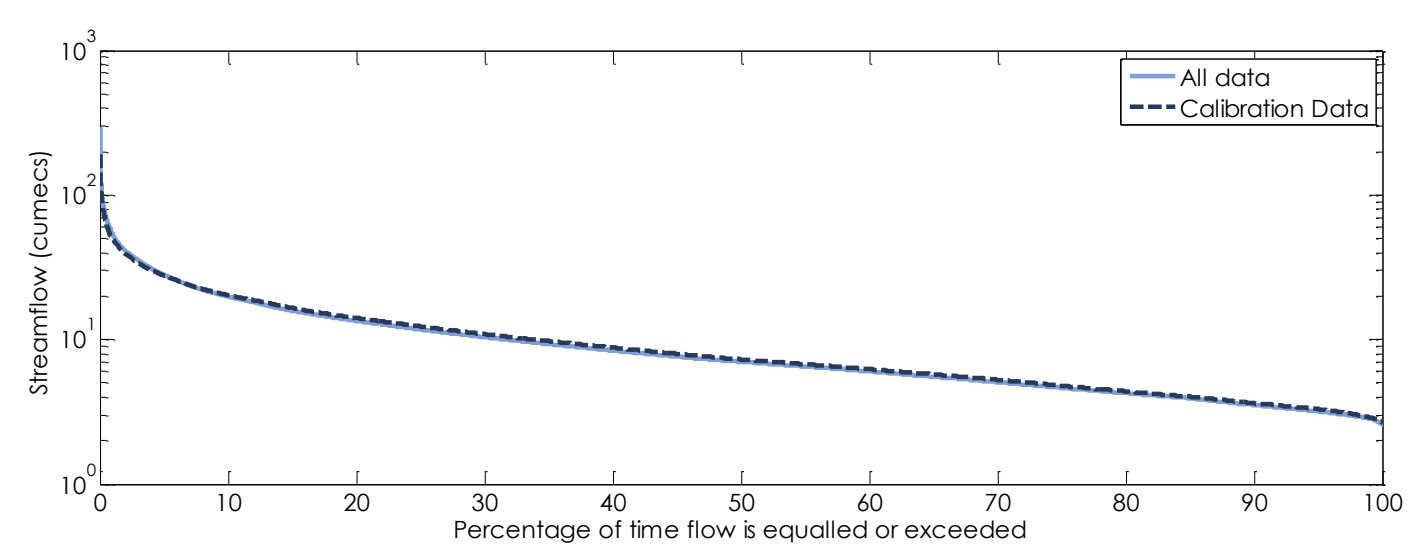

Figure 6.5 Comparison of flow duration curves for calibration period and entire record. This calibration period represents the range of hydrological responses reasonably across the entire range of flow. 
length of the record there may be more extreme responses that have not been observed.

\section{Residual mass curves}

Residual mass curves are used to identify abnormalities in the monthly and annual records of individual rainfall and runoff records. They show the departure of the monthly (and annual) values to the mean. Comparison of residual mass curves for both rainfall and flow may indicate if a rainfall record is suitable for input to the model for a particular sub-catchment. Ideally both would follow a similar pattern. In Figure 6.6 (top), the monthly rainfall and stream flow show significant differences in the residual mass plots, indicating that the rainfall record is not suitable as model input for this catchment. Conversely, in Figure 6.6 (lower) the residual mass plots show little difference between the monthly rainfall and streamflow curves, suggesting this rainfall record is appropriate for model calibration for this particular catchment. It should be noted that in catchments where precipitation falls as snow there may be some discrepancies in the rain and flow residual mass curves during periods of snowfall and subsequent snowmelt.
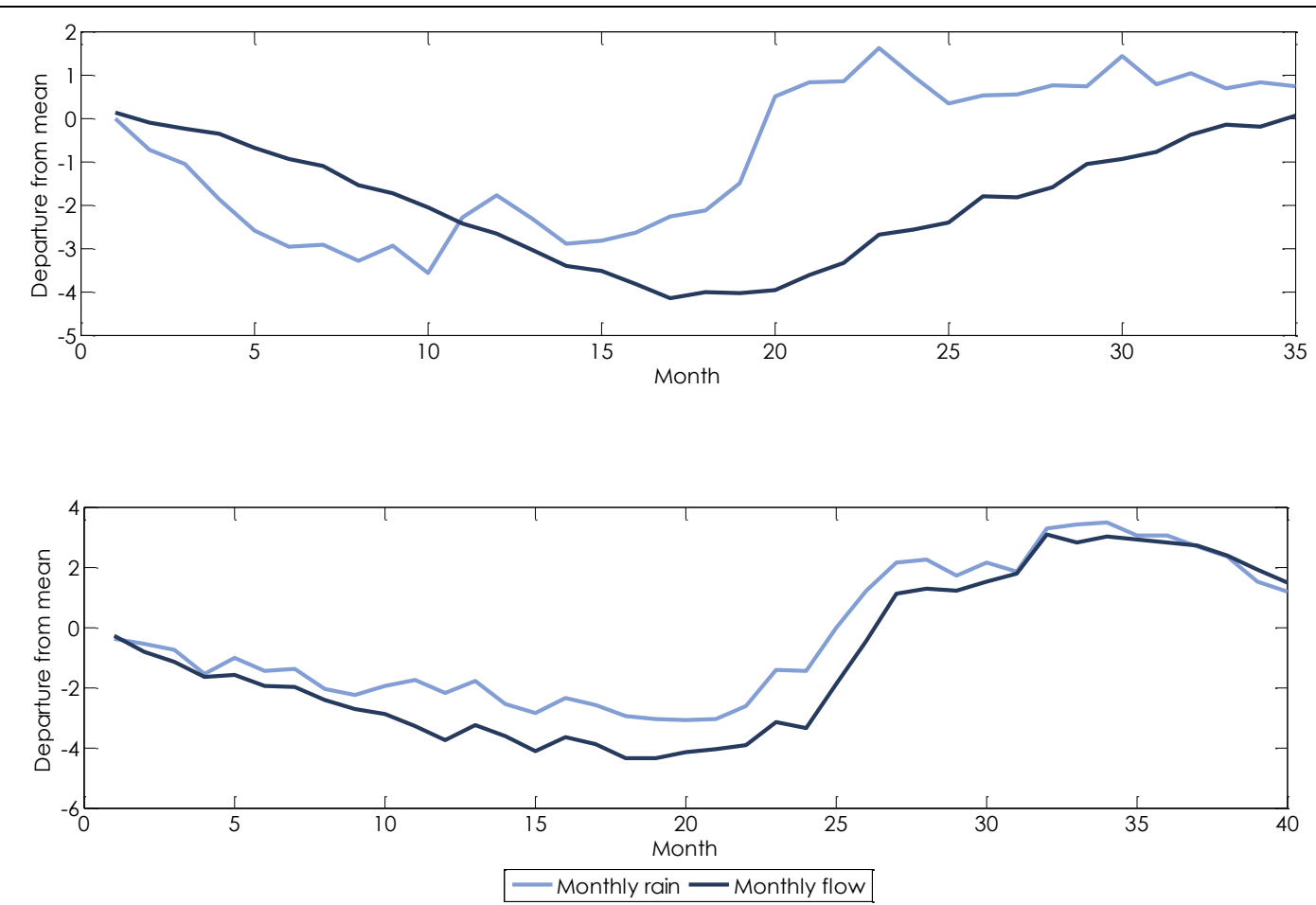

Figure 6.6 Residual mass curves compare monthly rainfall and streamflow data to provide an indication of suitability for rainfall-runoff modelling. The top chart shows a catchment where there is considerable divergence between the time series indicating that the rainfall record should not be used for calibrating this catchment. Conversely, in the lower chart both time series show consistency in the curves suggesting that this catchment can be calibrated using this rainfall time series as input. 


\section{Rainfall-runoff event analysis}

Residual mass curves can identify periods of record which are suitable for model calibration in general. The next stage is to assess whether the rainfall record over the period is able to capture the majority of events in the catchment. Corresponding event rainfall and flow observations are reviewed to find inconsistencies between event rainfall and runoff. For example, small scale intense convective events may occur over the gauge itself, resulting in observed rainfall but only a small (if any) response in the hydrograph. Similarly, rainfall in areas away from the gauge would result in a hydrograph response but no observed rainfall. Figure 6.7 shows an example of such an occurrence which has resulted in a hydrograph in the flow time series for the event but no corresponding rainfall for the period. If numerous instances of such inconsistencies are evident, then the rainfall record may not be suitable for representing the spatial and temporal rainfall over the catchment.
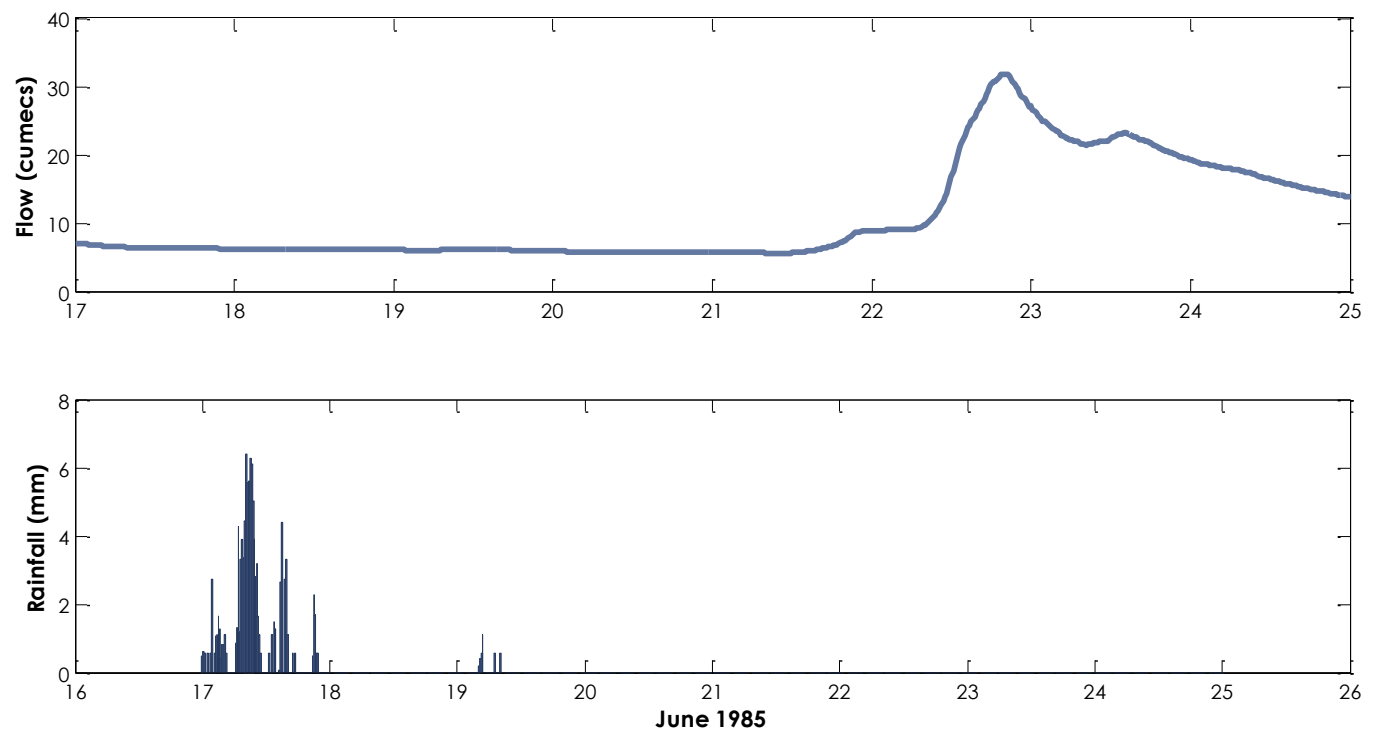

Figure 6.7 A rainfall event is observed a number of days before the response is seen at the outlet of the catchment. This is unlikely to be a lag time issue. The rainfall event recorded may not be representative of catchment areal rainfall. In addition, the response in the hydrograph suggests that there may have been a significant event in the catchment which was not adequately captured at the rainfall gauge site. Many occurrences of these may render the rainfall record unsuitable for model calibration in this catchment. 


\subsection{Model identification and calibration}

Following Wagener and Kollat (2007), model identification is defined as

“...the identification of all models (parameter sets) within a given model structure, that can be considered feasible (behavioral) representations of the natural system under study."

In this study, model identification has two components - parameter estimation and sensitivity analysis. These two aspects of model identification are performed together as an iterative process. Parameter estimation is undertaken through classic Monte Carlo simulations from which optimal parameter sets are obtained. These simulations are also the basis for sensitivity analysis from which the most sensitive parameters are identified, allowing more focus to be given to refining these parameters for improved model identifiability. This process also provides insights into the dominant processes controlling runoff response and hence may provide further information about the catchment's hydrologic function.

Model identification and calibration is undertaken for all modelled catchments excluding the TPS. Stochastic models such as the one used to predict the discharge from the TPS require the uncertainty to be quantified in some manner as part of the modelling process (Young, 2001). There are no parameters in this model and, therefore, calibration is not required.

\subsubsection{Monte Carlo simulations}

Using the Victoria University Science Faculty High-Performance Computing Facility, classic Monte Carlo sampling is used to randomly generate parameter sets from a feasible and pre-defined parameter space. The parameter space is sampled using a uniform distribution so that the entire range of the parameter space is given equal priority or weighting. Each simulation generates a parameter set, the performance of which is described by an objective function or goodness-of-fit measure (see following section).

Parameter ranges are formed by selecting minimum and maximum parameter values based on the relationships between catchment physical and hydrologic attributes obtained in Chapter 5 and empirical information from previous studies. Table 6.2 lists the ranges for each of the parameters used in this study. Typically, at least one million calibrations are obtained for each catchment (although for various 
Table 6.2 Initial parameter ranges for each of the sub-catchments for model calibration

\begin{tabular}{|c|c|c|c|c|c|c|c|c|c|c|c|c|c|c|}
\hline $\begin{array}{l}\text { t⿱ } \\
\text { g } \\
\frac{5}{0} \\
\frac{0}{0} \\
0\end{array}$ & 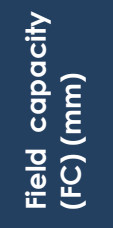 & 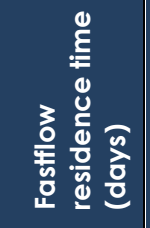 & 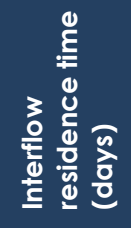 & 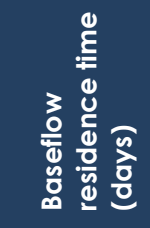 & 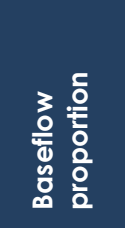 & 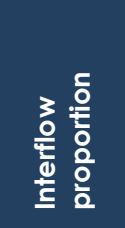 & 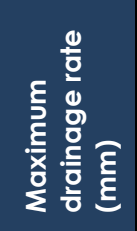 & 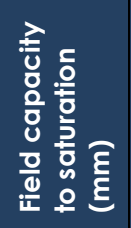 & 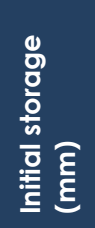 & 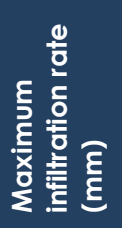 & 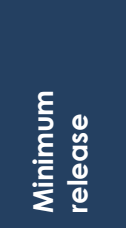 & 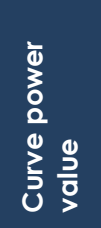 & 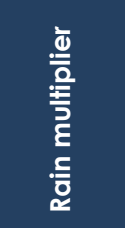 & 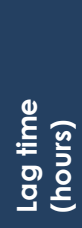 \\
\hline Waitahanui & $50-500$ & $0.2-2.5$ & $4-30$ & $500-2500$ & $0.8-1$ & $0-0.2$ & $10-100$ & $2-20$ & $0-\mathrm{FC}$ & $10-150$ & $0.1-0.9$ & $0.01-6$ & $1.4-1.5$ & $1-24$ \\
\hline TaurTaupo & $10-80$ & $0.05-1.5$ & $2-20$ & $50-250$ & $0.1-0.5$ & $0.15-0.5$ & $10-100$ & $2-20$ & $0-\mathrm{FC}$ & $10-150$ & $0.1-0.9$ & $0.01-6$ & $1.15-1.5$ & $1-24$ \\
\hline Waimarino & $20-150$ & $0.05-0.9$ & $1.1-15$ & $50-250$ & $0.1-0.5$ & $0.15-0.7$ & $10-100$ & $2-20$ & $0-\mathrm{FC}$ & $10-150$ & $0.1-0.9$ & $0.01-6$ & $1.5-2$ & $1-24$ \\
\hline L. Tongariro & $10-500$ & $0.2-2.5$ & $3-50$ & 50-1200 & $0.05-0.8$ & $0-0.4$ & $10-100$ & $2-20$ & $0-\mathrm{FC}$ & $10-150$ & $0.1-0.9$ & $0.01-6$ & $0.5-3$ & $1-24$ \\
\hline Poutu & $20-150$ & $0.2-2.5$ & 3-35 & $50-250$ & $0.2-0.8$ & $0-0.5$ & $10-100$ & $2-20$ & $0-\mathrm{FC}$ & $10-150$ & $0.1-0.9$ & $0.01-6$ & $0.8-1.3$ & $1-24$ \\
\hline Waipakihi & $20-150$ & $0.2-2.5$ & $3-35$ & $50-250$ & $0.2-0.8$ & $0-0.5$ & $10-100$ & $2-20$ & $0-\mathrm{FC}$ & $10-150$ & $0.1-0.9$ & $0.01-6$ & $0.8-1.3$ & $1-24$ \\
\hline Waihohonu & $10-300$ & $0.2-2.5$ & $3-30$ & $200-1200$ & $0.6-1$ & $0-0.4$ & $10-100$ & $2-20$ & $0-F C$ & $10-150$ & $0.1-0.9$ & $0.01-6$ & $0.8-1.45$ & $1-24$ \\
\hline Kuratau & $40-350$ & $0.2-2.99$ & 3-35 & $50-250$ & $0.2-0.7$ & $0-0.5$ & $10-100$ & $2-20$ & $0-\mathrm{FC}$ & $10-150$ & $0.1-0.9$ & $0.01-6$ & $1.25-1.5$ & $1-24$ \\
\hline Waihi & $10-200$ & $0.2-2.5$ & 3-35 & $50-500$ & $0.1-0.8$ & $0-0.5$ & $10-100$ & $2-20$ & $0-\mathrm{FC}$ & $10-150$ & $0.1-0.9$ & $0.01-6$ & $0.5-2$ & $1-24$ \\
\hline Whareroa & $10-200$ & $0.2-2.5$ & 3-35 & $50-500$ & $0.1-0.8$ & $0-0.5$ & $10-100$ & $2-20$ & $0-\mathrm{FC}$ & $10-150$ & $0.1-0.9$ & $0.01-6$ & $0.5-2$ & $1-24$ \\
\hline Whanganui & $10-200$ & $0.2-2.5$ & 3-35 & $50-500$ & $0.1-0.8$ & $0-0.5$ & $10-100$ & $2-20$ & $0-\mathrm{FC}$ & $10-150$ & $0.1-0.9$ & $0.01-6$ & $0.5-2$ & $1-24$ \\
\hline Waihaha & $10-100$ & $0.2-2.5$ & 3-35 & $50-250$ & $0.2-0.8$ & $0-0.5$ & $10-100$ & $2-20$ & $0-\mathrm{FC}$ & $10-150$ & $0.05-0.9$ & $0.01-6$ & $1-1.4$ & $1-24$ \\
\hline Tutaeuaua & $10-200$ & $0.2-2.5$ & 3-35 & $50-500$ & $0.1-0.8$ & $0-0.5$ & $10-100$ & $2-20$ & $0-\mathrm{FC}$ & $10-150$ & $0.1-0.9$ & $0.01-6$ & $0.5-2$ & $1-24$ \\
\hline Ungauged & $10-500$ & $0.2-2.99$ & $3-45$ & $50-1500$ & $0.1-0.8$ & $0-0.5$ & $10-100$ & $2-20$ & $0-\mathrm{FC}$ & $10-150$ & $0.1-0.9$ & $0.01-6$ & $0.25-2$ & $1-24$ \\
\hline
\end{tabular}


Table 6.3 Final parameter ranges for each of the sub-catchments for model calibration

\begin{tabular}{|c|c|c|c|c|c|c|c|c|c|c|c|c|c|c|}
\hline 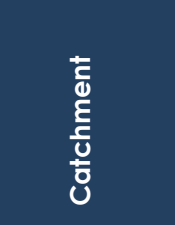 & 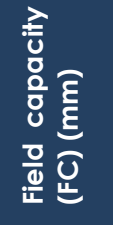 & 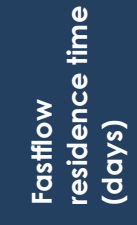 & 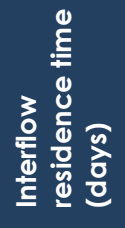 & 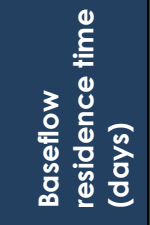 & 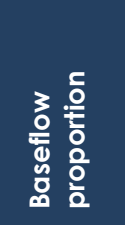 & 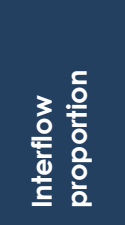 & 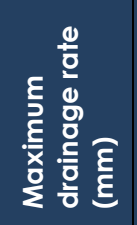 & 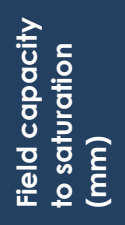 & 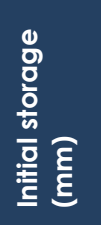 & 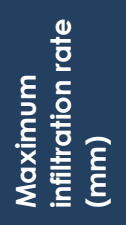 & 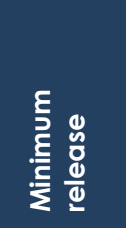 & 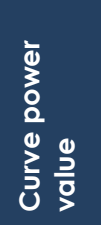 & 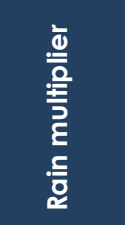 & 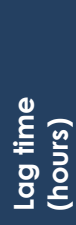 \\
\hline Waitahanui & $50-800$ & $0.2-2.5$ & $2-30$ & $500-2500$ & $0.8-1$ & $0-0.2$ & $10-100$ & $2-20$ & $0-F C$ & $10-150$ & $0.1-0.9$ & $0.01-6$ & $0.8-1.5$ & $1-24$ \\
\hline Hinemaiaia & $10-200$ & $0.2-2.5$ & 3-35 & $50-500$ & $0.1-0.8$ & $0-0.5$ & $10-100$ & $2-20$ & $0-F C$ & $10-150$ & $0.1-0.9$ & $0.01-6$ & $0.5-2$ & $1-24$ \\
\hline TaurTaupo & $10-80$ & $0.05-1.5$ & $2-20$ & $50-250$ & $0.1-0.5$ & $0.15-0.5$ & $10-100$ & $2-20$ & $0-F C$ & $10-150$ & $0.1-0.9$ & $0.01-6$ & $1.15-1.5$ & $1-24$ \\
\hline Waimarino & $20-200$ & $0.05-0.9$ & $1.1-15$ & $50-250$ & $0.1-0.5$ & $0.15-0.7$ & $10-100$ & $2-20$ & $0-F C$ & $10-150$ & $0.1-0.9$ & $0.01-6$ & $1.5-2$ & $1-24$ \\
\hline L. Tongariro & $10-600$ & $0.2-2.5$ & 3-39 & $40-1200$ & $0.05-0.8$ & $0-0.4$ & $10-100$ & $2-20$ & $0-F C$ & $10-150$ & $0.1-0.9$ & $0.01-6$ & $0.25-3$ & $1-24$ \\
\hline Poutu & $20-300$ & $0.2-2.5$ & 2.5-35 & $50-250$ & $0.5-0.8$ & $0-0.5$ & $10-100$ & $2-20$ & $0-\mathrm{FC}$ & $10-150$ & $0.1-0.9$ & $0.01-6$ & $0.8-1.3$ & $1-24$ \\
\hline Waipakihi & $20-150$ & $0-1$ & $1-35$ & $50-250$ & $0.05-0.6$ & $0-0.5$ & $10-100$ & $2-20$ & $0-\mathrm{FC}$ & $10-150$ & $0.1-0.9$ & $0.01-6$ & $0.8-1.3$ & $1-24$ \\
\hline Waihohonv & $10-300$ & $0-0.5$ & $3-30$ & $50-200$ & 0.6-1 & $0-0.4$ & $10-100$ & $2-20$ & $0-F C$ & $10-150$ & $0.1-0.9$ & $0.01-6$ & $0.8-1.45$ & $1-24$ \\
\hline Waihi & $10-200$ & $0.2-2.5$ & 3-35 & $50-500$ & $0.1-0.8$ & $0-0.5$ & $10-100$ & $2-20$ & $0-F C$ & $10-150$ & $0.1-0.9$ & $0.01-6$ & $0.5-2$ & $1-24$ \\
\hline Kuratau & $40-600$ & $0.2-3.5$ & 3.6-35 & $50-250$ & $0.2-0.7$ & $0-0.5$ & $10-100$ & $2-20$ & $0-F C$ & $10-150$ & $0.05-0.9$ & $0.01-6$ & $1.25-1.5$ & $1-24$ \\
\hline Whareroa & $10-200$ & $0.2-2.5$ & 3-35 & $50-500$ & $0.1-0.95$ & $0-0.5$ & $10-100$ & $2-20$ & $0-F C$ & $10-150$ & $0.1-0.9$ & $0.01-6$ & $0.5-2$ & $1-24$ \\
\hline Whanganui & $10-200$ & $0.2-2.5$ & $3-35$ & $50-500$ & $0.1-0.8$ & $0-0.5$ & $10-100$ & $2-20$ & $0-F C$ & $10-150$ & $0.1-0.9$ & $0.01-6$ & $0.5-2$ & $1-24$ \\
\hline Waihaha & $10-150$ & $0.2-2.5$ & 3-35 & $50-250$ & $0.1-0.8$ & $0-0.65$ & $10-100$ & $2-20$ & $0-F C$ & $10-150$ & $0.1-0.9$ & $0.01-6$ & $1-1.4$ & $1-24$ \\
\hline Tutaeuaua & $10-200$ & $0.2-2.5$ & 3-35 & $50-500$ & $0.1-0.8$ & $0-0.5$ & $10-100$ & $2-20$ & $0-\mathrm{FC}$ & $10-150$ & $0.1-0.9$ & $0.01-6$ & $0.5-2$ & $1-24$ \\
\hline Otaketake & $10-200$ & $0.2-2.5$ & 3-35 & $50-500$ & $0.1-0.8$ & $0-0.5$ & $10-100$ & $2-20$ & $0-F C$ & $10-150$ & $0.1-0.9$ & $0.01-6$ & $0.5-2$ & $1-24$ \\
\hline Ungauged & $10-500$ & $0.2-2.99$ & $3-45$ & $50-1500$ & $0.1-0.8$ & $0-0.5$ & $10-100$ & $2-20$ & $0-F C$ & $10-150$ & $0.1-0.9$ & $0.01-6$ & $0.25-2$ & $1-24$ \\
\hline
\end{tabular}

$\mathbf{1 2 8}$ | A rainfall-runoff model for the Lake Taupo catchment 
reasons, four catchments had fewer (see Section 7.1). Although this is extensive, it cannot comprehensively sample the entire parameter space given the number of parameters (13) to be calibrated. However, this number of calibrations does provide a balance between statistical accuracy and computational constraints.

From the results of the Monte Carlo simulations, scatterplots of parameter values against their corresponding objective function value are generated for each calibrated parameter. The top 1000 parameter sets are plotted, with the five highest highlighted (Figure 6.8, left). A parameter with high identifiability would show a clear relationship between objective function value and parameter value. Low identifiability is characterised by similar objective function values across the entire parameter range.

These plots not only provide information on how well a particular parameter can be identified based on the selected performance index but can also be used to refine parameter ranges if it appears these ranges may not have been adequately defined.

\subsubsection{Objective function}

Model performance is evaluated by how well it provides acceptable representations of the real world (Refsgaard and Henriksen, 2004; Wagener, 2003). Automatic calibration routines make use of a goodness-of-fit measure (also referred to as performance measure, objective function, or likelihood measure) to determine the performance of the model compared to the observations (Boyle et al., 2000; Wagener et al., 2001).

The choice of objective function is subjective. However, selection of an appropriate objective function for application is imperative since this is what reflects the intended hydrologic characteristics (McCuen, 1973). Many objective functions emphasise fitting to a specific region of the hydrograph, preferentially reducing the errors in these areas at the expense of other parts of the hydrograph. This may result in an inappropriate solution (Boyle et al., 2000; Jain and Sudheer, 2008).

The Nash Sutcliffe Efficiency (NSE) index is one of the most common criterion used in hydrological modelling (Gupta et al., 2009; Jain and Sudheer, 2008; Schaefli and Gupta, 2007). It is based on a normalisation of the summation of squared errors, and can be written (following Gupta et al. (2009)) 

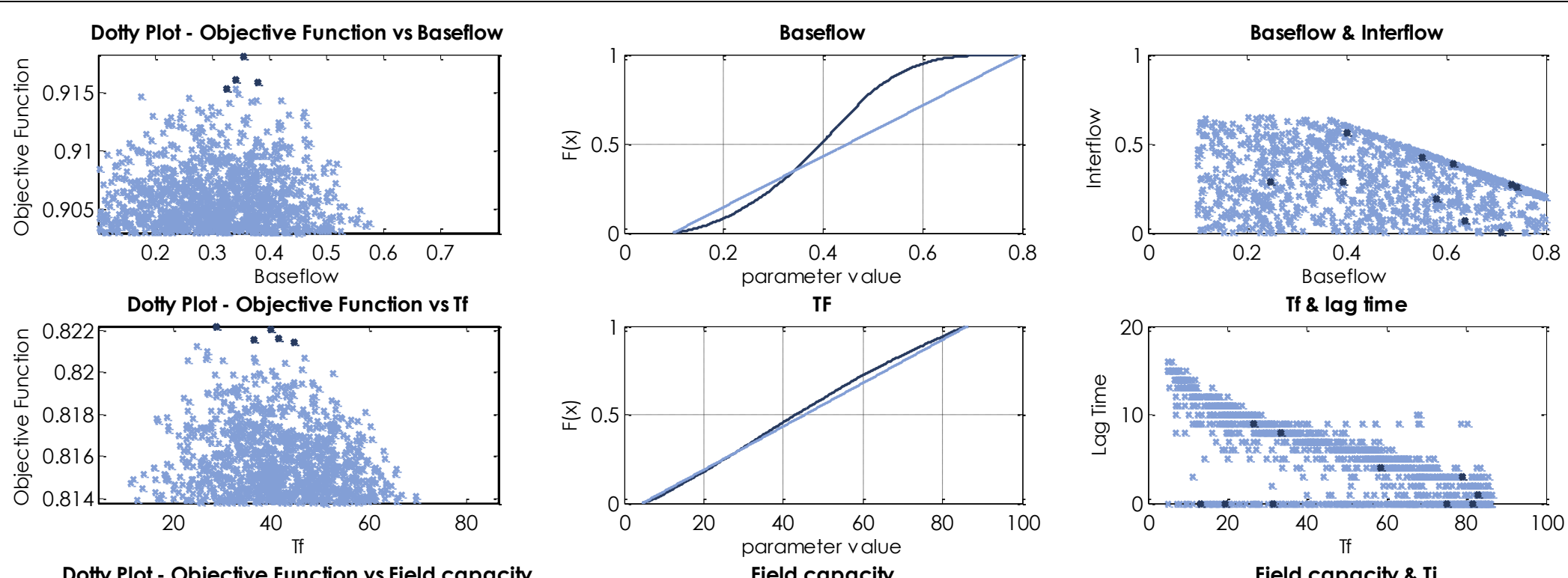

Dotty Plot - Objective Function vs Field capacity
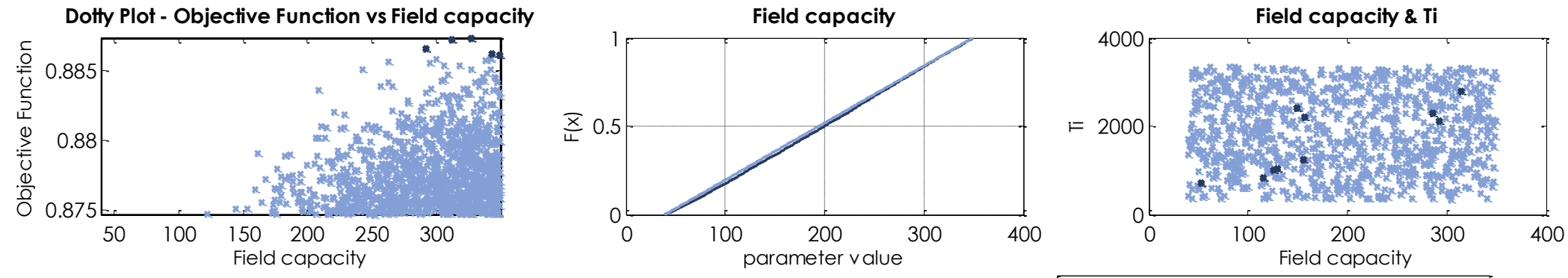

- parameter space * top 1000 par sets $=$ top 5 par sets

- behavioural - non-behavioural

Figure 6.8. Three types of visualisation tools are used for parameter estimation and sensitivity analysis in this study. Scatterplots of parameter values versus objective function (a) show how well a parameter can be identified. Regionalised sensitivity analysis identifies the most influential parameters which can then be the focus of refining parameter ranges and can provide further information on catchment hydrologic behaviour. Scatterplots are again used to identify two-way parameter interactions which may not be identified in the regionalised sensitivity analysis.

130 | A rainfall-runoff model for the Lake Taupo catchment 


$$
N S E=1-\frac{\sum_{t=1}^{n}\left(q_{x, t}-q_{y, t}\right)^{2}}{\sum_{t=1}^{n}\left(q_{y, t}-\overline{q_{y}}\right)^{2}},
$$

where $n$ is the total number of time steps, $q_{x, t}$ is the simulated value at time step $t$, $q_{y, t}$ is the observed value at time step $t$, and $\overline{q_{y}}$ is the mean of the observed values. The numerator is equivalent to the mean squared error (MSE) and the denominator is essentially the standard deviation of the observed values. The index is sensitive to extreme values since the values of paired differences between the observation and the baseline mean $\left(\overline{q_{y}}\right)$ are squared (Harmel and Smith, 2007; Schaefli and Gupta, 2007). This can result in over-estimation of model performance for highly seasonal time series (Gupta et al., 2009).

Although the NSE has generally been viewed as a single criterion approach to calibration, it can be applied within a multi-criteria framework by computing the NSE for different aspects of the simulated response. Weglarczyk (1998) notes, however, that the selection of evaluation criteria and their interrelations and consequences should be carefully considered. Murphy (1988) and Weglarczyk (1998) were able to show that the NSE is made up of three distinct components. These three components are represented by the correlation, a measure of relative variability and a bias. The NSE in a decomposed form (as outlined by Gupta et al. (2009) is written

$$
N S E=2 \alpha r-\alpha^{2}-\hat{\beta}^{2},
$$

where $\alpha$ is a measure of relative variability in the simulated and observed values, defined as

$$
\alpha=\frac{\sigma_{x}}{\sigma_{y}}
$$

where $\sigma_{x}$ and $\sigma_{y}$ are the standard deviations of the simulated and observed values, respectively. The linear correlation coefficient between simulated $\left(q_{x}\right)$ and observed $\left(q_{y}\right)$ values is denoted by $r . \hat{\beta}$ is equal to the bias normalized by $\sigma_{y}$, and is written

$$
\hat{\beta}=\frac{\left(\mu_{x}-\mu_{y}\right)}{\sigma_{y}},
$$

where $\mu_{x}$ (i.e. $\overline{q_{x}}$ ) and $\mu_{y}$ (i.e. $\overline{q_{y}}$ ) are the respective means of the simulated and observed values. 
The three components of the decomposed NSE effectively represent the overall volume of flow $(\beta)$, the variability or spread of flows $(\alpha)$ and the timing and shape of the hydrograph ( $r$ ) (Gupta et al., 2009). It also allows for further diagnoses of where the weaknesses of this index lie. However, using $\sigma_{o}$ to normalise the bias can lead to an imbalance of this component in highly variable time series, essentially giving less weight to the bias component in the overall model performance (Gupta et al., 2009). Gupta et al. (2009) also suggest that the NSE will give a higher performance index for parameter sets which under-estimate the variability of flows due to the interplay between $r$ and $\alpha$.

To overcome these issues, Gupta et al. (2009) propose the Kling-Gupta Efficiency (KGE) index - a reformulation of the decomposed NSE giving equal weighting to the individual components of the criterion. The KGE is written

$$
K G E=\sqrt{(r-1)^{2}+(\alpha-1)^{2}+(\beta-1)^{2}},
$$

Eqn 6.24

where $\beta$ represents the bias and is defined as

$$
\beta=\frac{\mu_{x}}{\mu_{y}}
$$

Ideally, an optimal parameter set would be able to achieve a good fit to all three components of the index. However, given the simplifications of complex hydrological processes that are made in conceptual models and the uncertainty resulting from the model structure, parameter estimation and input data, there is still likely to be trade-offs between some parts of the hydrograph.

Initial applications of the KGE are promising. Gupta et al. (2009) found that the KGE improved the bias and variability components with only a small decrease in the correlation when used to assess the performance of a simple conceptual rainfallrunoff model applied to 49 Austrian catchments. Pechlivanidis et al. (2010) compared the performance of the NSE and KGE for the $46.6 \mathrm{~km}^{2}$ Mahurangi catchment, New Zealand. They found that the KGE was able to match variability and mean flows better than the NSE while still maintaining a high correlation coefficient and decreasing errors in mass balance and peak runoff volumes. However, they also note that while the KGE is able to better represent high and low flows, the fit to medium flows is less satisfactory. Conversely, the NSE is able to match medium flows better at the expense of high and low flow regions of the flow regime. Given questions around the suitability of the NSE index and limited application of the 
KGE, both of these indices were investigated for appropriateness for application in this study.

As a result of the analysis undertaken in Appendix A, the KGE index is selected for this application in this study. It is chosen based on its performance in two subcatchments of Lake Taupo, identifying parameter sets which provided a better overall fit to the observations than the NSE. A multi-criteria approach is used optimal parameters must fit well to both the time series and flow duration curves. KGE performance values can range between $-\infty$ and 1 , with a perfect simulation having a KGE value of 1 .

\subsubsection{Sensitivity Analysis}

A regionalised sensitivity analysis, based to the Hornberger-Spear-Young (HSY) method (Hornberger and Spear, 1981), is used to search the entire feasible parameter space because of its ease of implementation and low computational demand. This approach is a form of global sensitivity analysis which partitions model simulations into behavioural (defined by Beven (2001) as simulations which provide an acceptable reproduction of the observed system) and non-behavioural according to the given criterion. The similarity (or dissimilarity) between the distributions of the two sub-samples indicates the sensitivity of the parameter in question (Yang, 2011).

The results of the Monte Carlo simulations are used for this process. Parameter sets are categorised according to whether they are deemed behavioural or nonbehavioural with regard to the objective function. The definition of bins is subjective. For the purpose of this study, behavioural parameter sets are considered to be those that generate an objective function (KGE) greater than or equal to 0.7 , while non-behavioural parameters are those below 0.7. Taking the values of the parameters within each of the bins, a comparison of the corresponding cumulative distributions provides an indication of the sensitivity of each of the parameters. Insensitive parameters would show little difference between the two classes. Sensitive parameters would show some difference.

To quantify the sensitivity of the binned parameters, the Kolmogorov-Smirnov (KS) test is used as a measure of sensitivity. This test compares the empirical cumulative distribution functions of behavioural $(B)$ and non-behavioural $(\bar{B})$ samples (Figure 6.8 , middle). The maximum distance, $D$, between the two distributions essentially measures the sensitivity of a parameter $j$ (Massey, 1951). The formula for $D$ is: 


$$
D=\max (|B(j)-\bar{B}(j)|)
$$

The KS $D$ statistic has associated with it a significance level which can be used to rank the parameters providing an indication of the relative importance of the parameter on model output (Saltelli et al., 2004). This approach should be used with caution, however, since when there are many samples the power of the KS test can begin to degenerate (Beven, 2009; Saltelli et al., 2004) and may suggest small differences in distributions may be significant (Beven, 2001).

Despite this, the value of the $D$ statistic still provides a relative measure of global sensitivity for parameters (Hornberger and Spear, 1981). Harlin and Kung (1992) classify the parameter sets by their $D$ value, where

$$
\begin{array}{cc}
\text { sensitive }(D \geq 0.2) & \text { Eqn } 6.27 \\
\text { moderately sensitive }(0.1<D<0.2) & \text { Eqn } 6.28 \\
\text { insensitive }(D \leq 0.1) & \text { Eqn } 6.29
\end{array}
$$

Fenicia et al. (2008) notes that a lack of sensitivity can indicate model overparameterisation; this can lead to a lack of confidence that the model is suitably describing catchment hydrologic processes. The problem of over-parameterisation can be overcome somewhat by the elimination of insignificant parameters from the final model (Chan et al., 1997) or by reducing them to constant values, improving calibration efficiency. However, some sensitivity analyses (including the analysis used here) are unable to identify parametric interdependence or interaction. This can result in non-identification of an influential parameter (Wagener and Kollat, 2007). In addition, Seibert (Seibert, 2000) notes that reducing the number of model parameters can transform conceptual models toward more black-box empirical descriptions. Some physical meaning can, therefore, be lost.

In this study, insensitive parameters are not eliminated from the calibration process. Further investigation of parameter sensitivity and parameter interaction is undertaken. Scatterplots are again used to identify the two-way parameter response surface with respect to the performance measure used (Figure 6.8, right). The values of two selected parameters are plotted against each other. The top 1000 (unless fewer are obtained) behavioural parameter sets are plotted with the five highest highlighted. If these behavioural parameter sets are observed across the entire parameter space then there is little, if any, interaction between the two parameters. 
If the plots show some (positive or negative) relationship between the corresponding parameter sets, some form of parameter interaction can be assumed.

\subsection{Lake Taupo Inflow Model}

The LTIM is used to predict inflows to Lake Taupo as well as subsequent lake level change. In the following sections, the LTIM is described in terms of the various components which make up the inflow predictions. Five currently gauged catchments are explicitly modelled using optimal parameter sets based on the conceptual model structure and model identification/calibration routines described above. These include both unregulated (Section 6.4.1) and regulated (Section 6.4.2) catchments. Statistical probability analysis is used to determine the possible range of discharge from the Tongariro Power Scheme (Section 6.4.3). Regionalisation is used to estimate the inflow from ungauged areas (Section 6.4.4). Inflow from each of these areas is combined to generate a single inflow volume to Lake Taupo.

Table 6.4 lists each of the areas included in the LTIM, classifying them according to whether the catchment is regulated, gauged, and data availability. While there are numerous other unregulated catchments which have been historically gauged, for the purpose of the LTIM they are included in the 'Ungauged' category. These catchments include the Waitahanui, Waihi, Whanganui, Waihaha, Tutaeuaua and Otaketake.

\subsubsection{Unregulated Gauged Catchments}

Unregulated gauged catchments include those catchments whose flow are not modified by any hydro power scheme and are currently gauged. Only two catchments under this category are currently operational and used directly to predict inflows to Lake Taupo. The combined mean flow of these two catchments (Tauranga-Taupo and Waimarino) is equivalent to $8.7 \%$ of the mean outflow from Lake Taupo. The location of these catchments is illustrated in Figure 6.9. It should

Table 6.4. Classification of sub-catchments based on whether flow is modified by hydro power schemes and the availability of relevant data and information.

\begin{tabular}{cccc}
\hline Unregulated Gauged & Regulated Gauged & TPS & Ungauged \\
Tauranga-Taupo & Kuratau & TPS & All other areas \\
Waimarino & Tongariro & & \\
& Hinemaiaia & & \\
\hline
\end{tabular}


be noted that although the Whareroa catchment is currently gauged it has not been included in this operational model because gauging only began again in 2002 (after it was stopped in 1980) and due to the large number of gaps in the record complicating model calibration. A suitable rainfall record has also not been identified.

\subsubsection{Regulated Gauged catchments}

Regulated catchments are defined as those which are directly affected by hydro power schemes and include the modified flows of the Hinemaiaia, Kuratau and Tongariro Rivers (Figure 6.10). The effect of hydro generation on these inflows is influenced by specific decision-making criteria based around system storage, predicted inflows, forecast rainfall, electricity demand profile and price. While some data is available downstream of each system much of the dam operation and scheduling information is unavailable given the competitive nature of the hydroschemes within the Lake Taupo catchment. The Hinemaiaia Power Scheme has very little storage and is largely run-of-river. A minimum flow below the lower dam is in place. In terms of the Kuratau River very little information is available although some operational information can be obtained from inspection of streamflow time series below the scheme. With regard to the TPS resource consent conditions provide some information relating to operating constraints (such as minimum flows) and relevant design capacities of the hydro power scheme that directly affect the Tongariro River. This information supplies some boundary conditions under which the scheme is operated and can be easily incorporated in the traditional conceptual model structure.

\section{Hinemaiaia River}

Flow is gauged on the Hinemaiaia River above and below the Hinemaiaia Power Scheme. Streamflow time series below the scheme has been provided by NIWA with permission from Trustpower Ltd who operates the scheme. Two records are available above the scheme and have been provided by Environment Waikato.

Daily rainfall was recorded in the catchment between 1965 and 2005. An attempt to disaggregate this record into hourly volumes by using the temporal pattern from a nearby gauge was unsuccessful. Instead, the nearby Tauranga-Taupo rainfall gauge, which showed a good correlation $(r=0.7015)$ to the Hinemaiaia rainfall gauge at daily resolution was used as model input for this catchment. 


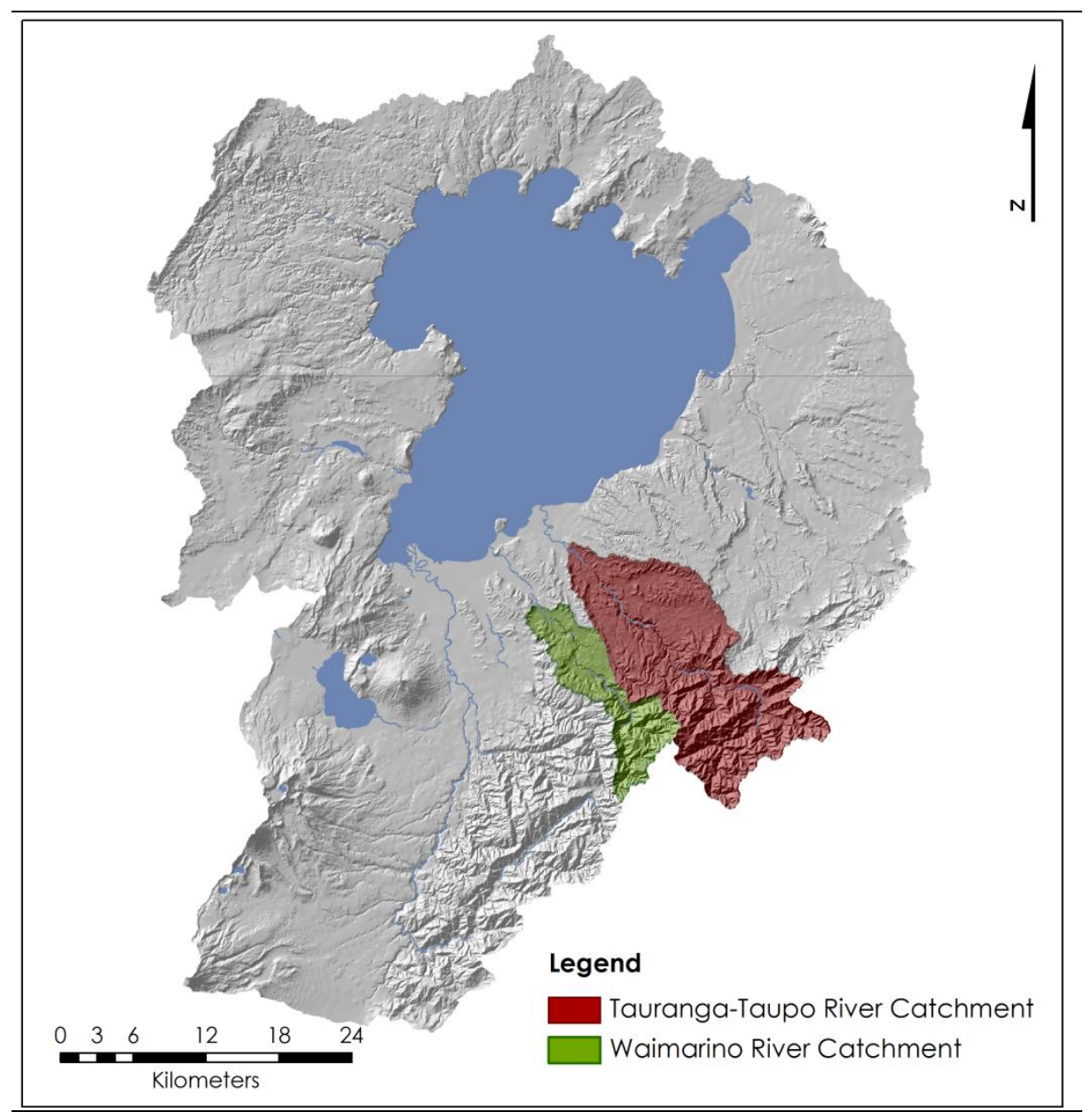

Figure 6.9. Unregulated catchments explicitly modelled as part of the LTIM

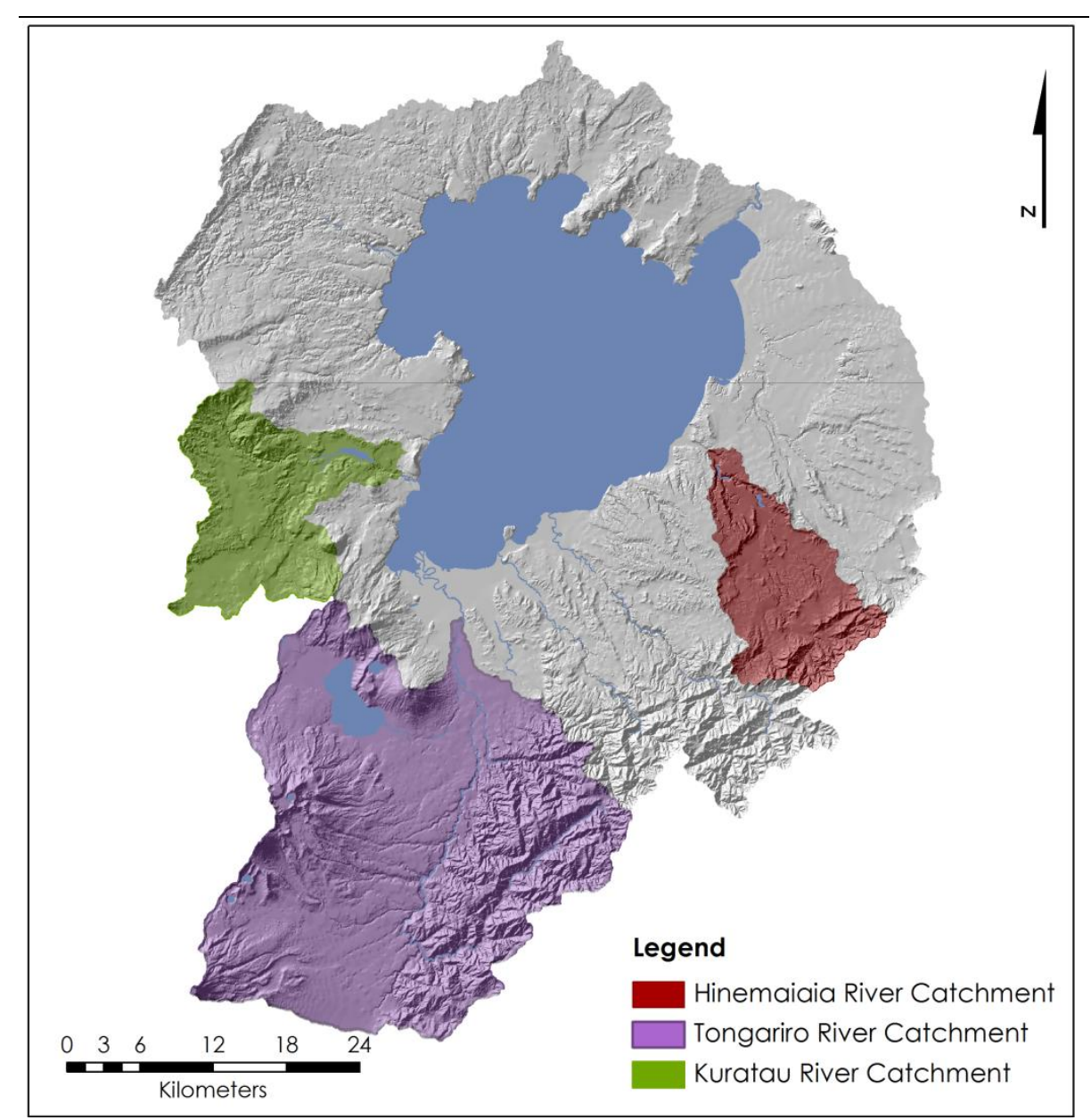

Figure 6.10 Regulated catchments explicitly modelled as part of the LTIM. 


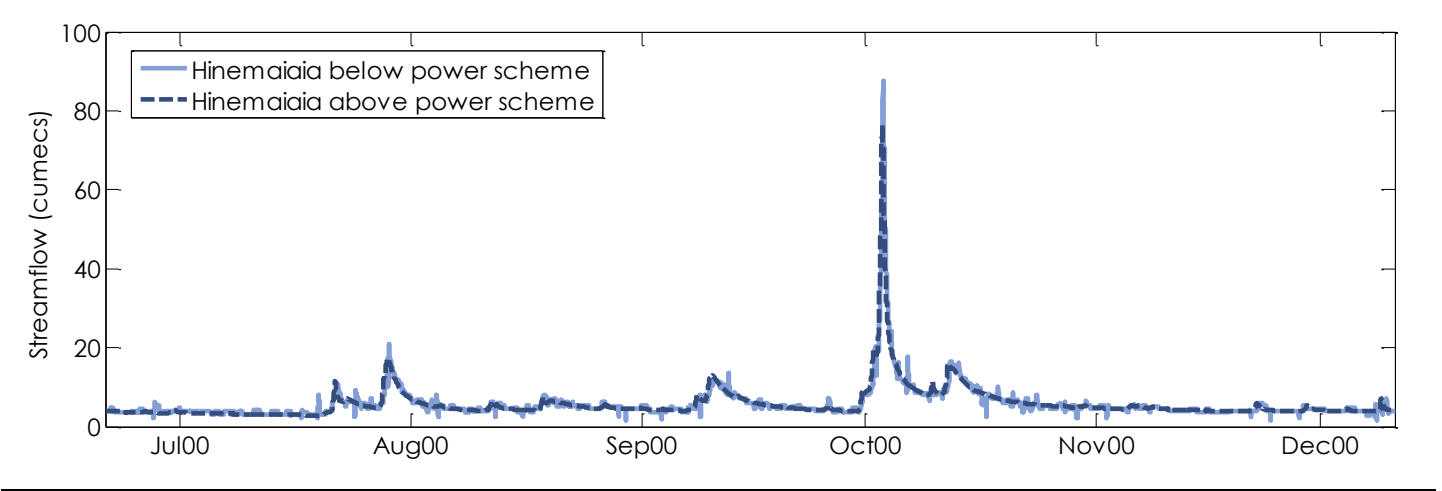

Figure 6.11 Comparison of streamflow above and below the Hinemaiaia Power Scheme

There is relatively little regulation from the scheme, due the limited storage in the three reservoirs. The only known regulation is a minimum flow of $3 \mathrm{~m}^{3} / \mathrm{s}$ below the scheme, where inflows into the Hinemaiaia A Lake permit (TrustPower Ltd, 2008). Mean flow below the scheme is $5.53 \mathrm{~m}^{3} / \mathrm{s}$ which is only slightly higher than the mean flow above the scheme $\left(5.11 \mathrm{~m}^{3} / \mathrm{s}\right)$ indicating that there is very little additional flow added to the river between the two gauging sites. A comparison of these two records over a short overlapping period of data is shown in Figure 6.11. For this period, the correlation between the two sites is high $(r=0.9622)$. Since little is known of the storage and release of water from the scheme, and the fact that it is essentially run-of-river, streamflow is modelled without regulation. The minimum flow is not enforced since a low inflow above the scheme would correspond to a naturally low flow below the scheme as well.

\section{Kuratau River}

Flow is gauged on the Kuratau River above and below the Kuratau Power Scheme with a rainfall gauge located near the flow gauging site above the scheme. Streamflow time series for both locations have been provided by NIWA with permission from King Country Energy Ltd who operates the scheme.

There is little guidance available about specific operation of the scheme except that the maximum discharge from the scheme is $16 \mathrm{~m}^{3} / \mathrm{s}$ and that lake level should be maintained between $442.46 \mathrm{~m}$ a.s.l and $445.08 \mathrm{~m}$ a.s.l (Taupo-nui-a-Tia, 2011). However, analysis of the time series from below the scheme (June 1976 to February 1979) shows evidence of a diurnal flow pattern that is consistent with typical energy demand profiles for New Zealand (refer Figure 5.1). This diurnal pattern is less apparent for flows greater than $10 \mathrm{~m}^{3} / \mathrm{s}$. 
Based on this information, regulation is incorporated into the model in the following way. The unmodified inflow as observed above the scheme (Site No. 1043468) is modelled using the conceptual model described in Section 6.1. This output is scaled to account for the increase in flow downstream by comparing the mean flow above and below the scheme for all flow values. Depending on the hour of the day a multiplier is applied to the modelled output to reflect the diurnal pattern of flow to be consistent with the regulated discharge from the scheme. This multiplier is calculated by taking mean hourly flow values up to $10 \mathrm{~m}^{3} / \mathrm{s}$ (above which the diurnal profile is less evident) and dividing these values by mean daily flow. This relationship is plotted in Figure 6.12 (a). Natural conditions are assumed above 10 $\mathrm{m}^{3} / \mathrm{s}$. A comparison of the modelled output and observed flow downstream of the power station is shown in Figure 6.12 (b) for a short overlapping period of data. Over this period, the modelled output was able to predict the diurnal pattern well but underestimated maximum river flow and overestimated minimum flows in the earlier part of the time series. This period, however, is characterised by greater variability of flow than earlier in the record.
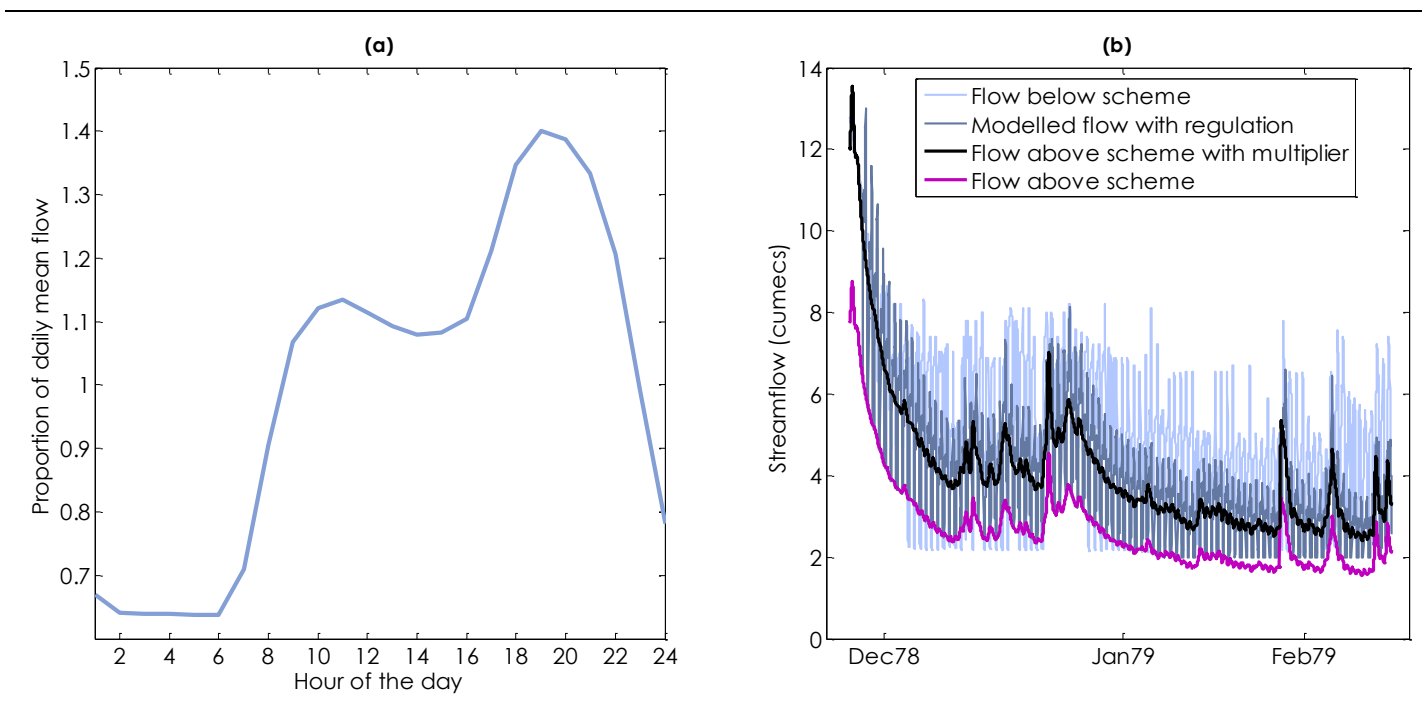

Figure 6.12 (a) The diurnal flow profile as a proportion of mean daily flow shows that there are two discharge peaks during the day which coincides with peak energy demand. (b) This diurnal profile is imposed on the natural inflow as observed above the power scheme to predict flow downstream of the station. 


\section{Tongariro River}

The Tongariro River is modified as part of the TPS. It is a significant contributor (>20\%) to inflows (Mighty River Power Ltd, 2008). For the Tongariro River, the catchment can be divided into two parts. Above the Poutu Intake is the modified Tongariro River flow. Below the Poutu Intake natural inflows are received from a largely unmodified part of the catchment. The only modified inflow to this section is the release of water from the Poutu Dam to the Poutu Stream, formerly the outlet to Lake Rotoaira. A minimum compensation flow of $0.6 \mathrm{~m}^{3} / \mathrm{s}$ has been provided for this stream. Both parts of the catchment have been modelled separately.

The lower section of the Tongariro River is modelled using the conceptual model, with no regulation. The modelled flow is calibrated to the Tongariro record at Turangi minus the observations from below the Poutu Intake. The lag time between the two sites is estimated by comparing the two time series and calibrating for the lag time only.

In terms of the modified section, resource consent conditions require a minimum flow downstream of the Poutu Intake of $16 \mathrm{~m}^{3} / \mathrm{s}$, unless natural flow conditions fall below this level. In these periods natural flow conditions prevail. However, there are few instances of this occurring. This may possibly be due to the effect of the Rangipo Power Station which discharges to the Tongariro River immediately upstream of the Poutu Intake. This additional water may obscure the natural low flow condition in the observations downstream of the intake. As such, in this model a blanket minimum flow condition of $16 \mathrm{~m}^{3} / \mathrm{s}$ is applied to the modelled output.

A second constraint is related to the design capacity of the Poutu Intake itself which has a maximum capacity of $80 \mathrm{~m}^{3} / \mathrm{s}$. To account for this, any flow between $16 \mathrm{~m}^{3} / \mathrm{s}$ and $96 \mathrm{~m}^{3} / \mathrm{s}$ is diverted. Above $96 \mathrm{~m}^{3} / \mathrm{s}$ it is assumed the full $80 \mathrm{~m}^{3} / \mathrm{s}$ is taken from the river, up to $160 \mathrm{~m}^{3} / \mathrm{s}$. Once streamflow reaches $160 \mathrm{~m}^{3} / \mathrm{s}$, no water is diverted due to turbidity.

There is an additional element in the operation of the scheme that is not accounted for in the model. Resource consent conditions require continuous releases of 30 m³ s from both Rangipo Dam and Poutu Intake for periods of 6-8 hours (Genesis Energy Ltd, 2011) to be provided periodically for recreational purposes. If these recreational release schedules are known in advance, they can be incorporated into the model structure. 
The modelled output from both the Poutu and lower Tongariro catchments is combined to provide an overall streamflow prediction at Turangi.

\subsubsection{Tongariro Power Scheme}

The TPS (Figure 6.13) is the single most important inflow to Lake Taupo as it accounts for over $30 \%$ of the inflows to the lake. However, while a discharge time series from the scheme has been provided (1998-2011), there is limited information and data available in relation to the various diversions, system regulations and storage which influence discharge from the scheme. The conceptual model above is, therefore, not suitable for estimating flow for this catchment. Instead a stochastic modelling approach is used to estimate the discharge from the station.

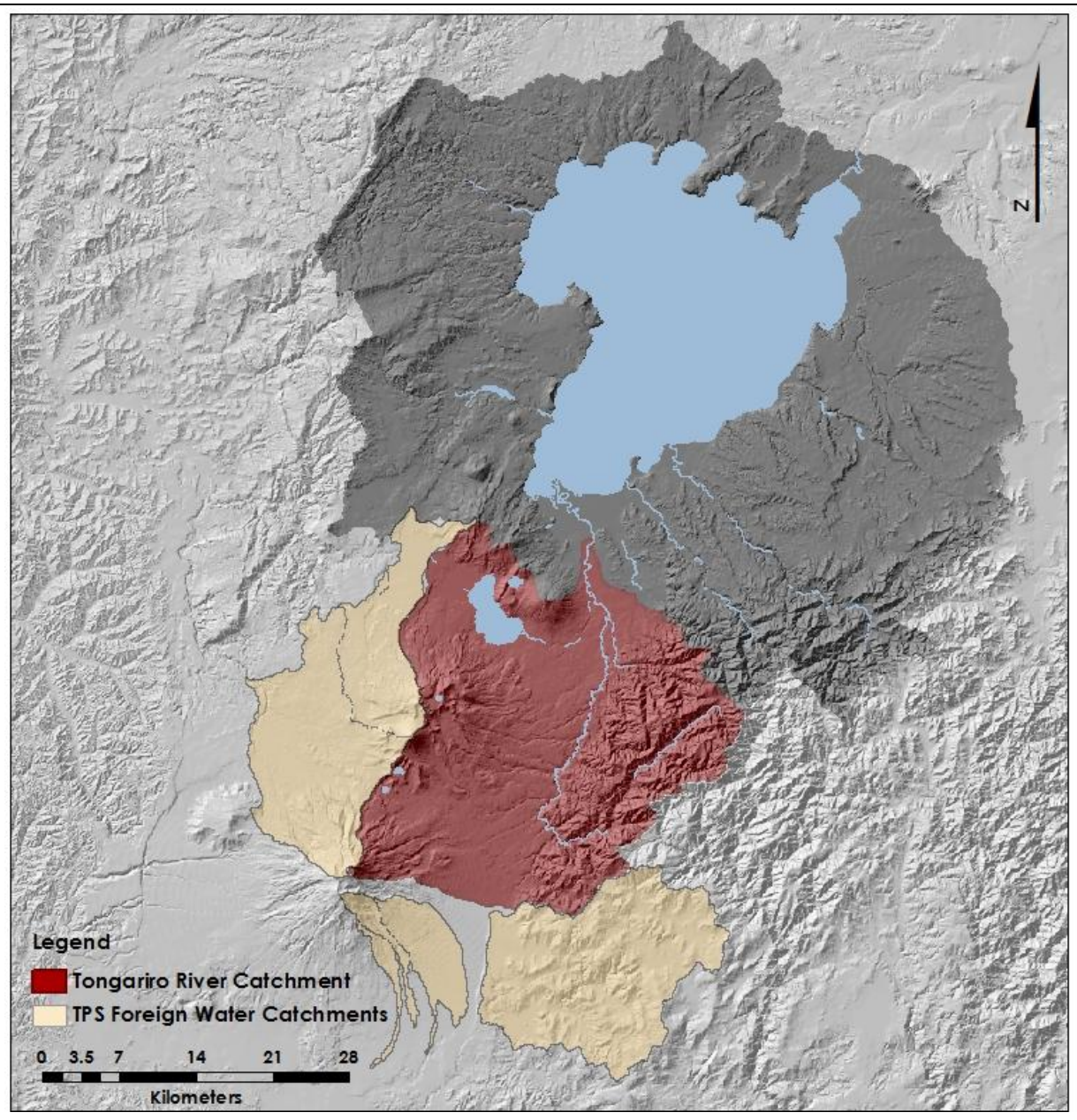

Figure 6.13 The TPS includes areas outside of the natural Lake Taupo catchment from which water is diverted to Lake Taupo via the eastern and western diversion. 
Aside from Lake Moawhango (eastern diversion), there is very little storage available in the TPS and it essentially operates as a run-of-river scheme. As a result the pattern of discharge throughout the day generally follows the typical daily load profiles of electricity demand (refer Section 5.1.3). Peak demand periods are during early morning and evening. Demand is less overnight. The day-to-day demand profiles vary depending on the weather (for example, temperature), day of the week (weekend demand differs from working week days) and as the seasonal climatic pattern evolves throughout the year.

Discharge from the TPS has been made available for the period 1998-2011, with a resolution of 30 minute intervals. This data is used to assess the probability or likelihood of a discharge volume $(q)$ given the time of the year $(m)$, day of the week $(d)$ and time of day $(h)$. Two probability scenarios are generated, as shown in Figure 6.14. The TPS is operated mainly to meet peak demand periods so discharge is often not continuous and zero discharge may occur at any time throughout the year. The
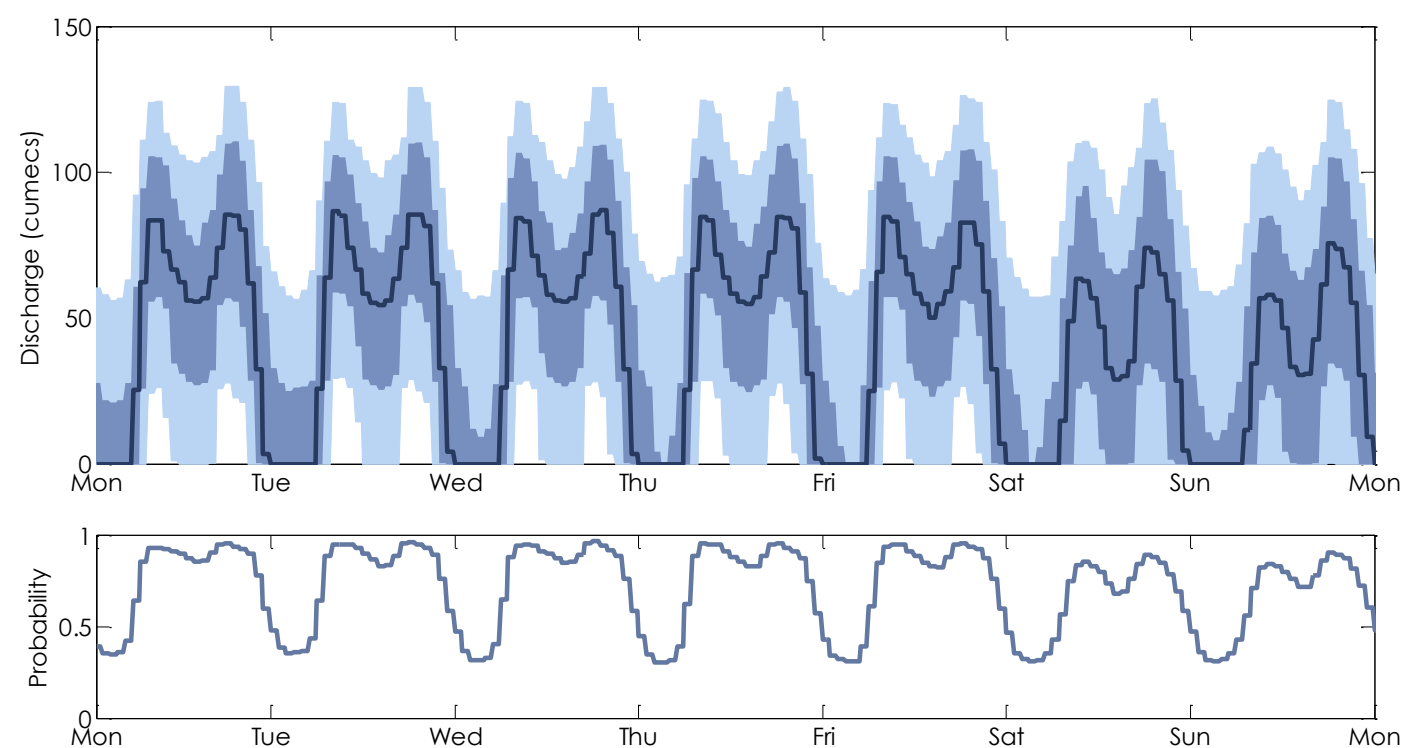

Figure 6.14 Example of the results from the statistical probability for a week in July. (upper) The probability of a particular discharge depends on the time of the day as well as day of the week and month of the year. Note the difference in discharge profile between week days and weekends. The lighter shaded regions represent the range of flow between the 10th and 90th percentile with the 25th and 75th percentiles show in the darker shaded areas. The median flow (50th percentile) is represented by the dark blue line. (lower) The TPS is a peaking plant and will often have zero discharge generally coinciding with periods of lower demand. The probability that there is flow for the corresponding period is represented by the blue line. 
likelihood that flow is being discharged from the scheme is determined by the following:

$$
p\left(q_{m, d, h}>q_{o}\right)=\frac{n}{N}
$$

where $q_{m, d, h}$ is the observed discharge values for the time in question, $n$ is the number of observations of non-zero discharge, $q_{0}$, and $N$ is the total number of observations of $q_{m, d, h}$. When there is discharge, a cumulative distribution function of

$q_{m, d, h}$ (where $q_{m, d, h}>0$ ) is used to determine the likelihood of flow at selected percentile levels, $q_{\%}$. For example, the discharge value at $q_{50}$ represents the $50^{\text {th }}$ percentile at which there is a 50\% likelihood discharge is above or below this value. The range of flow between $q_{10}$ and $q_{90}$ provide an indication of uncertainty in the estimation and reflects the range of potential operational decisions of the scheme.

\subsubsection{Ungauged catchments}

The remaining areas are considered ungauged (Figure 6.15). This large area is made up of catchments which have been gauged historically but are currently not gauged and areas which have never been gauged (Figure 6.15). Regionalisation is used to estimate the inflow from these areas. Regionalisation essentially applies calibrated parameter sets from gauged catchments to ungauged areas. The selection of an appropriate catchment is generally achieved by determining a relationship between the physical characteristics of the gauged catchment to the ungauged areas (Croke and Norton, 2004; Seibert, 1999). Parameter values can be adjusted based on the relationships found. If the gauged catchment is too dissimilar to the ungauged area then the modelled output will be prone to error (Blöschl and Sivapalan, 1995).

As a first step, streamflow time series for all historically gauged catchments are correlated. Catchments which show significantly strong relationships ( $r \geq 0.8$ ) are assessed for their hydrologic and physical similarities. This provides an indication of possible suitable parameter sets for estimation of streamflow in currently ungauged areas.

Significantly high streamflow cross-correlations (Table 6.5) are found between the four catchments of the western bays. Despite high streamflow correlations, the Whareroa displayed some hydrologic dissimilarity to the other three catchments. The Whareroa catchment had lower variability, lower climatic indices and specific discharge. The Kuratau, Whanganui and Waihaha catchments, on the other hand, show some hydrological similarity in terms of wetness ratio, runoff coefficients and 


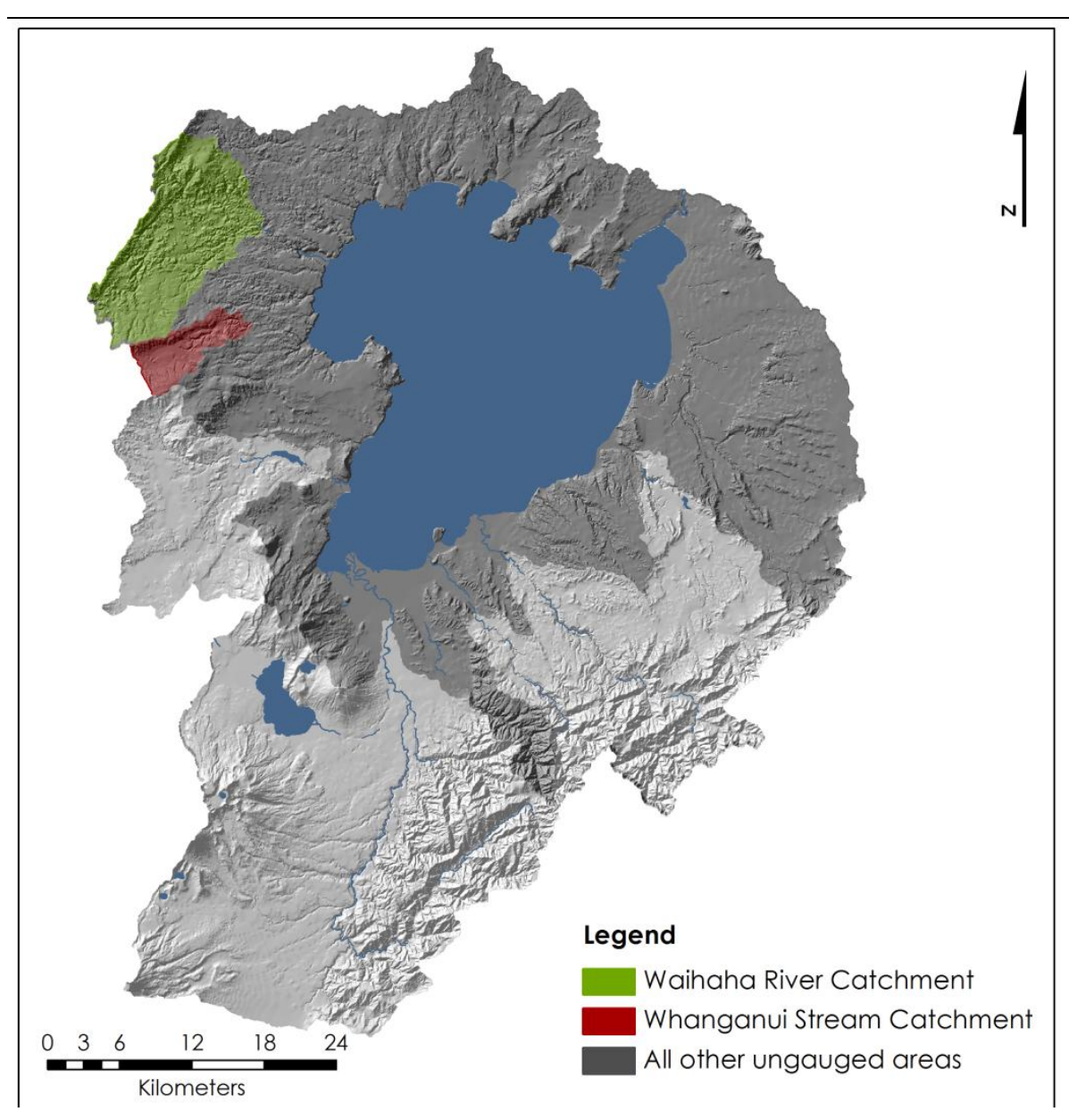

Figure 6.15 Ungauged areas of the Lake Taupo catchment. The Waihaha and Whanganui catchments are estimated directly using the parameters of the Kuratau catchment.

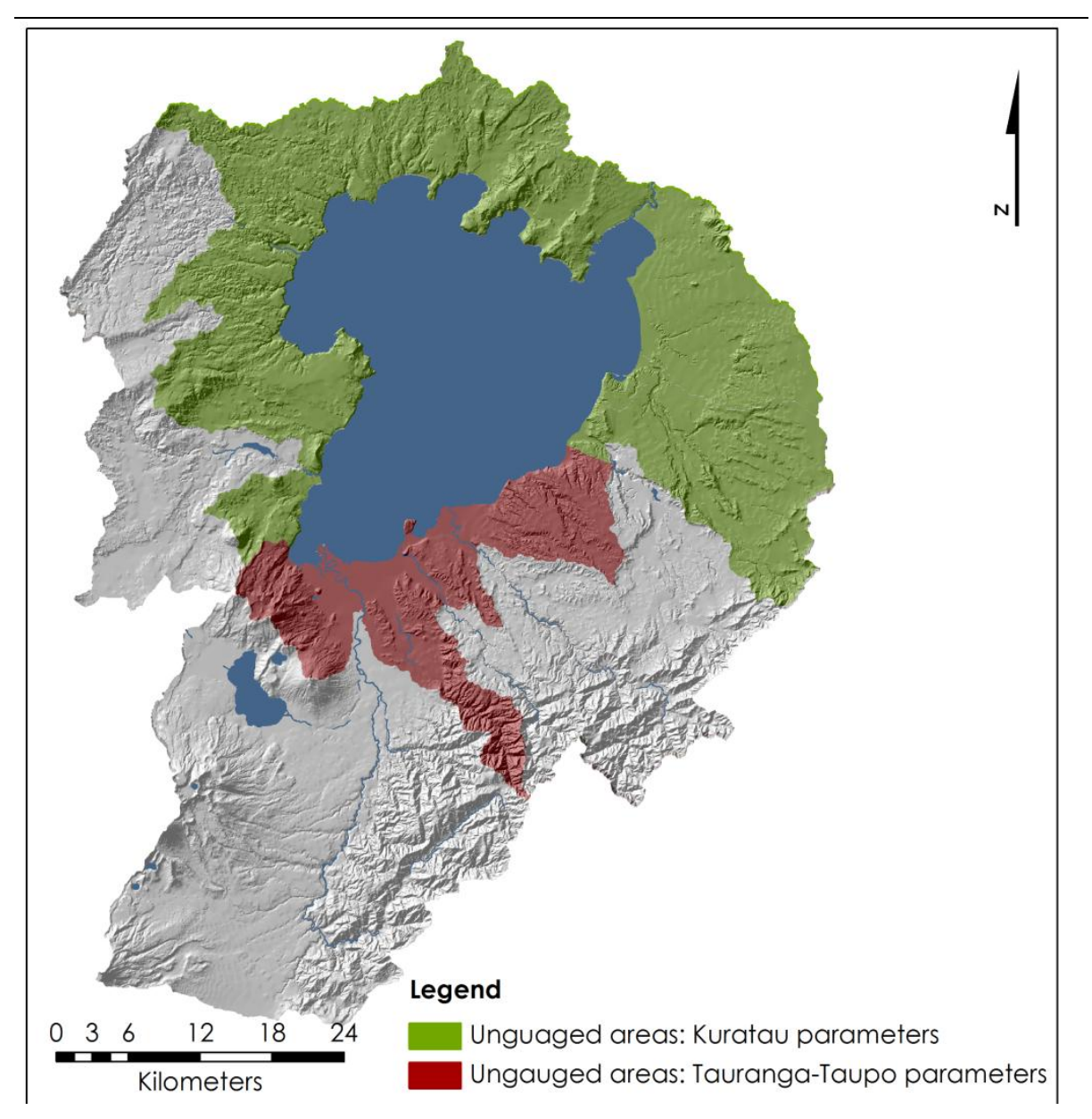

Figure 6.16 Ungauged areas estimated using the regionalised Kuratau parameters and regionalised Tauranga-Taupo parameters.

144 | A rainfall-runoff model for the Lake Taupo catchment 
Table 6.5 Cross-correlations of streamflow data between the Kuratau, Whareroa, Whanganui and Waihaha catchments.

$\begin{array}{ccccc} & \text { Kuratau } & \text { Whareroa } & \text { Whanganui } & \text { Waihaha } \\ \text { Kuratau } & 1 & & & \\ \text { Whareroa } & 0.8661 & 1 & 1 & \\ \text { Whanganui } & 0.9542 & 0.8839 & 0.9684 & 1 \\ \text { Waihaha } & 0.8589 & 0.7947 & \end{array}$

specific discharges. Flow variability is also similar between the three but over the low flow conditions, the Kuratau is less variable. For these reasons, the parameters of the Kuratau catchment are used to estimate inflow from the currently ungauged Whanganui and Waihaha catchments. The Whareroa catchment is included in the larger ungauged area of Lake Taupo.

Streamflow from the remaining ungauged areas $\left(1287 \mathrm{~km}^{2}\right.$, Figure 6.16$)$ is estimated from regionalised parameters of calibrated catchments which are the most physically similar to the ungauged areas. Based on this, the ungauged areas are divided into two sub-areas. The first area includes the northern bays and the remaining ungauged section of western areas. The area south of Taupo township and the Waitahanui catchment are included in this area. This accounts for approximately $75 \%\left(1003 \mathrm{~km}^{2}\right)$ of the remaining ungauged areas. The parameters of the Kuratau catchment are regionalised for this area. The Kuratau parameters are chosen because this catchment is quite representative of the diverse land cover and soils across this area. For the area south of the Hinemaiaia catchment around to and including the Waihi catchment, the parameters of the Tauranga-Taupo catchment are selected for regionalisation. This ungauged area $\left(284 \mathrm{~km}^{2}\right)$ drains some of the steep slopes of the Kaimanawa Ranges and smaller volcanoes (e.g. Pihanga) near Turangi. The geology of the area is very similar to the Tauranga-Taupo catchment, which is considered a significant influence on runoff generation (see Chapter 5).

While these parameter sets would normally be adjusted to account for differences between the sub-catchments, it is assumed that the parameter sets used are adequate for the purpose of this study, although this is an area that could benefit from further study. The only parameters that are calibrated are the rainfall multiplier and lag times. Calibration, however, requires a streamflow time series. In this study, this time series is derived from the residual between the change in lake 
level $(\Delta l a k e)$, outflow $\left(q_{\text {outflow }}\right)$, gauged inflows $\left(q_{\text {gauged }}\right)$, lake evaporation $\left(E_{\text {lake }}\right)$ and direct lake rainfall $\left(P_{\text {lake }}\right)$ so that

$$
q_{\text {ungauged }}=\Delta \text { lake }+q_{\text {outflow }}-q_{\text {gauged }}-E_{\text {lake }}+P_{\text {lake }},
$$

where $\Delta$ lake is derived from the lake level time series generated using a Butterworth filter to remove unwanted seiche and other oscillatory effects, as described in Section 4.4. However, while the filter has removed many of the high frequency oscillations, many other longer period oscillations still exist. As a result, the filtered lake level still shows some considerable fluctuations in lake level which correspond to considerable negative fluxes that are not physically realistic. This is reflected in the derived ungauged time series illustrated in Figure 6.17 (top).

Closer inspection of the filtered average lake level time series show that these oscillations generally balance out over time. These 'see-saw' oscillations (Thompson and Ibbitt, 1978) are a result of changes in the driving force of the seiches (Figure 6.17 , lower). For example, a change in wind direction will release water which has been pushed toward a certain direction causing some 'sloshing' back and forth. Similarly, barometric changes alter lake levels as the pressure gradient passes over the lake, after which normal levels return (Thompson and Ibbitt, 1978).
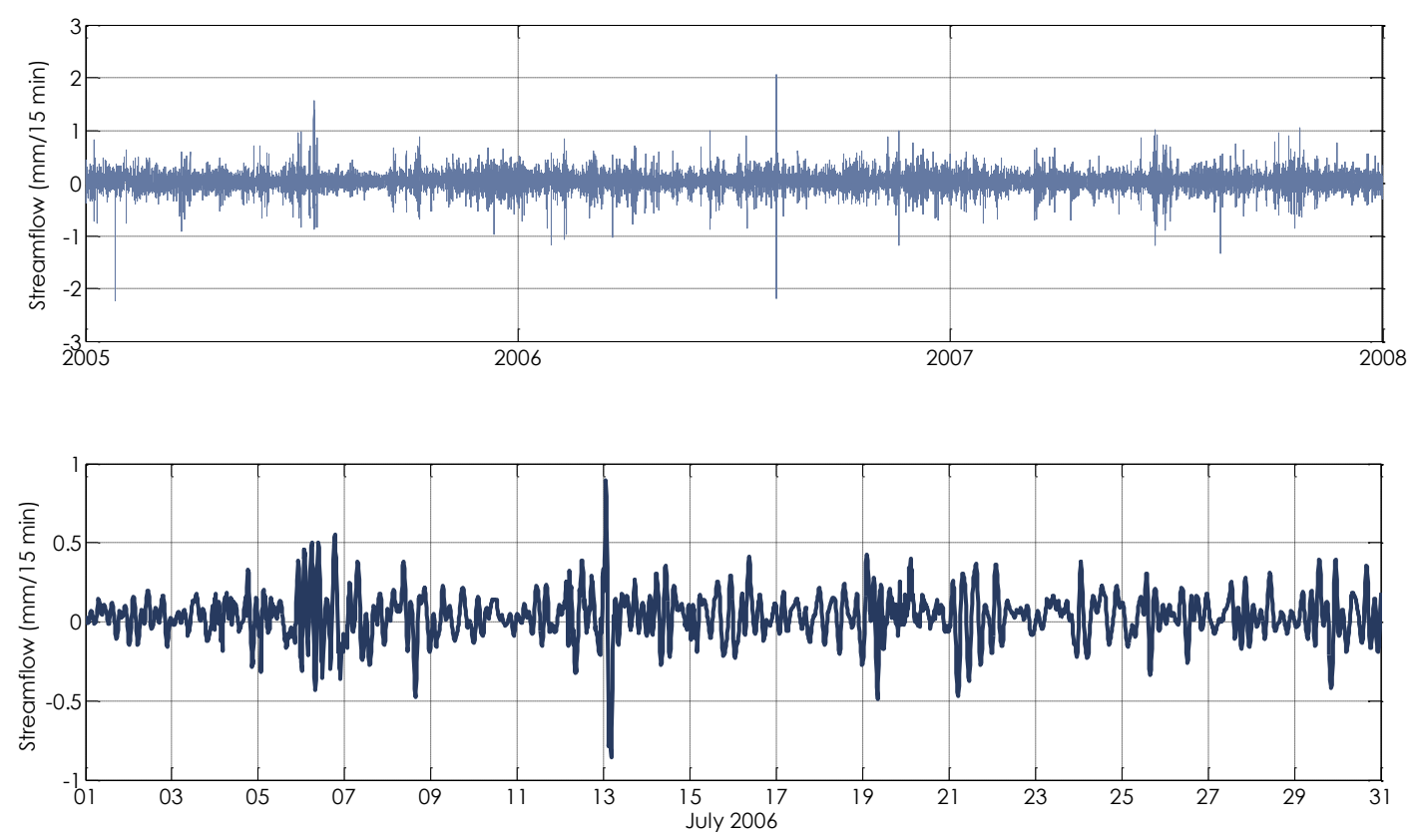

Figure 6.17 Upper: Ungauged inflow time series derived from known inflows, outflow, lake level change and direct precipitation and potential evapotranspiration. Lower: these oscillations generally balance out as a flux in one direction is often followed by a corresponding flux in the opposite direction. Most oscillations are within $\pm 0.5 \mathrm{~mm}$. 
Since the model in this study is not permitted to predict negative inflow to Lake Taupo there will be some discrepancy between simulated and 'observed' inflow from ungauged areas. Calibration is undertaken on the cumulative distribution of modelled and observed time series to ensure the overall mass balance is achieved. Since these ungauged areas cover some considerable distances, rainfall is based on area averaged volumes using Thiessen polygons.

\subsection{Hydrologic state-updating}

Hydrologic state-updating uses state conditions as a proxy to catchment water storage, which is a major moderator of streamflow. Updating state variables with real-time observations reduces errors in determining catchment water content. Model states can be updated directly using remote sensing or satellite information, field data (such as snowpack water equivalent) and streamflow. Streamflow represents an integrated catchment response to rainfall and is an indicator or catchment water storage (Kirchner, 2009; Pauwels and De Lannoy, 2006). The assimilation of discharge observations to update states in rainfall-runoff models has been the focus of a number of studies in the last decade (Aubert et al., 2003; Clark et al., 2008a; Moradkhani et al., 2005b; Pauwels and De Lannoy, 2009; Seo et al., 2009; Seo et al., 2003; Weerts and El Serafy, 2006) and is also a focus of this research.

There are three main approaches used to update states in real-time hydrologic forecasting applications: variational data assimilation (VAR), Kalman filter (and its variants) and particle filtering. VAR methods are applied widely in atmospheric applications because they can be applied to large scale processes at relatively little cost (Liu and Gupta, 2007). VAR methods operate in batch processing manner over a given assimilation window, but do not explicitly consider model errors (Clark et al., 2008a; Liu and Gupta, 2007; Seo et al., 2003). VAR is less appropriate for hydrological applications due the continual expansion of the observation vector as new data arrives (Liu and Gupta, 2007; McLaughlin, 2002). Despite this, Seo et al. (2009; 2003) assimilated streamflow, precipitation and potential evapotranspiration to update soil moisture states of the conceptual Sacramento soil moisture accounting model using VAR with some success.

The Kalman Filter and its variants are the most commonly applied method in hydrologic data assimilation. The Kalman filter (KF) was developed in the 1960 s for 
linear systems and became popular in hydrology during the 1970s and $1980 \mathrm{~s}$ (Weerts and El Serafy, 2006). The KF was easy to implement and effective in the case of linear hydrologic systems, but since hydrologic systems are generally nonlinear its use is limited. The extended Kalman filter (EKF) was designed to deal with this problem by requiring a linearisation of the forecast variance around the nonlinear model predictions (Beven, 2009). However, its application is not widespread due to update instability issues in strongly non-linear systems and additional computational requirements (McLaughlin, 2002; Moradkhani et al., 2005b; Reichle et al., 2002; Vrugt et al., 2005).

Ensemble methods offer a solution to the problems of non-linearity. Particle filtering methods assign an importance weight to ensemble (particle) members which are then used to produce a probability distribution of model predictions. The particle weights are updated as new observations become available. Complications arise when particles are found to have negligible weights in subsequent iterations, making little contribution to the final representation of the probability distribution (Liu and Gupta, 2007). One of the advantages of the approach is that Gaussian model errors are not required (Clark et al., 2008a). Assuming non-Gaussian errors can improve model accuracy but increase computational run times. Examples of particle filters include sequential importance resampling (Moradkhani et al., 2005a; Weerts and El Serafy, 2006) and residual resampling (Weerts and El Serafy, 2006).

The Ensemble Kalman Filter (EnKF) developed by Evensen (1994) is another extension of the Kalman Filter. Monte Carlo methods are utilised to generate an ensemble of model trajectories. State variables are updated taking into account the relative error in both the observation and the model (Clark et al., 2008a; Reichle, 2008; Salamon and Feyen, 2009; Vrugt et al., 2005). The EnKF is easy to implement and feasible in an operational short-term forecasting context. Examples of applications of the EnKF can be found in Reichle et al. (2002) and Vrugt and Robinson (2007). The EnKF has also been applied to New Zealand river catchments by NIWA using the TopNet model (Clark et al, 2008a). One of the drawbacks with the $\mathrm{KF}$ approaches is that Gaussian model errors are assumed. Clark et al. (2008a) note that this rarely holds in hydrological systems and has the potential to reduce the accuracy of model output. Despite this assumption, most applications report success. McLaughlin (2002) suggests this may be in part due to the error covariances used to update the model states reflecting the effects of non-linearities in the state and measurement equations. 
The performance of two particle filters and the EnKF are compared by Weerts and El Serafy (2006). Applied to the Nahe River, Germany, the EnKF outperformed the particle filters, particularly during low flows. They argue that the EnKF is less sensitive to misspecification of the model and input uncertainties, concluding that it was more robust than the particle filter. The particle filter method was, however, more accurate in terms of the root-mean-square error (RMSE). Weerts and El Serafy (2006) also note that in an operational context the EnKF may be preferred since it is computationally less demanding.

In this study, a constrained EnKF is used to assimilate streamflow observations and update model states to be consistent with the physical reality. The filter is applied to modelled catchments of the operational model (Tauranga-Taupo, Waimarino and Whareroa catchments) and the modelled inflows of regulated catchments (Kuratau and Tongariro catchments). For the TPS, modelled predictions of flow are corrected with observations directly.

\subsubsection{The Ensemble Kalman Filter}

The EnKF is a two-step sequential data assimilation routine which uses Monte Carlo methods to generate an ensemble of model states. Errors in both the model states and observations are quantified and used to update model states. The EnKF formalised below broadly follows the notation presented in Clark et al. (2008a) and Gillijns et al. (2006). In the forecast step, an ensemble of model states is propogated forward in time,

$$
\chi^{b}=\left[x_{1}^{b}, \ldots, x_{n e n s}^{b}\right]
$$

where $\chi^{b}$ is a background matrix of model states $(b)$ of size nstate $\mathrm{x} n e n s$, where nstate is the number of states, nens is the number of ensemble members and $x_{1}^{b}, \ldots, x_{\text {nens }}^{b}$ are the vectors of all model states. As a balance between statistical robustness and computational efficiency, an ensemble size of 100 is selected. Since the true state is not known, the mean of the ensemble $(\bar{x})$ is used as a best estimate of the actual state ('truth'), where

$$
\bar{x}^{b}=\frac{1}{n e n s} \sum_{i=1}^{n e n s} x_{i}^{b}
$$

Eqn 6.32

where $i$ is the $i$ th ensemble member and the spread of the ensemble members around the mean representing the error variance is 


$$
E_{X}^{b}=\left[x_{1}^{b}-\bar{x}_{1}^{b}, \ldots, x_{\text {nens }}^{b}-\bar{x}_{\text {nens }}^{b}\right]
$$

The output from the model, given the ensemble of model states, is the model equivalent of the observation with a mean of $\bar{y}$ and forecast error statistics $\left(E_{y}^{b}\right)$.

$$
\begin{gathered}
\bar{y}^{b}=\frac{1}{n e n s} \sum_{i=1}^{n e n s} y_{i}^{b} \\
E_{y}^{b}=\left[y_{1}^{b}-\bar{y}_{1}^{b}, \ldots, Y_{\text {nens }}^{b}-\bar{y}_{\text {nens }}^{b}\right] .
\end{gathered}
$$

Eqn 6.34

Eqn 6.35

The relationship between the relative uncertainties between the model states and model output is described by error covariances. The model error covariance is computed directly so that

$$
\begin{aligned}
& C_{x y}^{b}=\frac{1}{n e n s-1} E_{x}^{b}\left(E_{y}^{b}\right)^{T} \\
& C_{y y}^{b}=\frac{1}{n e n s-1} \quad E_{y}^{b}\left(E_{y}^{b}\right)^{T}
\end{aligned}
$$

Eqn 6.36

Eqn 6.37

where $T$ denotes the matrix transposition, $C_{x y}^{b}$ is the forecasted cross-covariance of modelled states and modelled streamflow and $C_{y y}^{b}$ is the forecasted output error covariance.

In the analysis step, the Kalman gain $(\kappa)$ is used to determine the amount of update made to the states, given the error (difference) between the observations and model output. The Kalman gain is a weight matrix describing the relative uncertainties in model states determined by the forecast error covariances obtained in the forecast step,

$$
\kappa=C_{x y}^{b}\left(C_{y y}^{b}\right)^{-1}
$$

Eqn 6.38

The update step then becomes

$$
x_{i}=x_{i}^{b}+\kappa\left[y_{i}-\mathcal{H}\left(x_{i}^{b}\right)\right]
$$

Eqn 6.39

where $\mathcal{H}$ is the forward model which is used to equate the model equivalent of the observations. Since it is the hydrological model which is used the forward model in this application, this term essentially becomes the model output given the ensemble of states. That is,

$$
\mathcal{H}\left(x_{i}^{b}\right)=y_{i}^{b} .
$$

Eqn 6.40

To map the observations (y) into state-space, the modelled unrouted discharge is compared to the observation a number of time steps ahead, allowing for the time it 


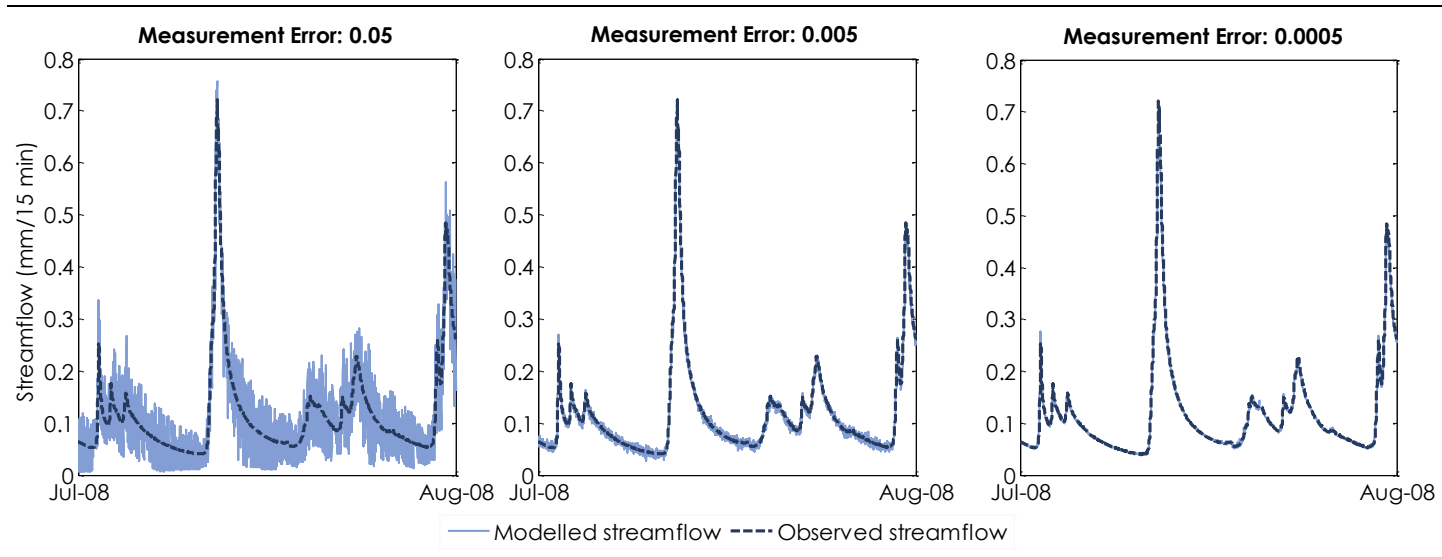

Figure 6.18 Comparison of the effect of different levels of measurement error on model output.

takes for the input to the system to reach the outlet. In this application, catchment lag times are used for this comparison. The observations are not considered perfect and are treated as random variables with a mean of the actual observation and the variance $(\varepsilon)$ representing the measurement error. This measurement error is often unknown, so a parallel assimilation cycle is run where $i$ is the number of ensembles, so that

$$
y_{i}=y+\varepsilon_{i}
$$

where the measurement error is generated as a random variable with a zero-mean normal distribution. In this study, the standard deviation is defined as $0.005 \mathrm{~mm}$ as it provided a realistic amount of error around the observations. It was obtained by comparing the effect of different error levels on model output (Figure 6.18). A standard deviation of $0.05 \mathrm{~mm}$ would generate too much uncertainty, while a lower standard deviation of $0.0005 \mathrm{~mm}$ generates too little. However, if the measurement error of streamflow is known or obtained then it can be easily included in the assimilation code.

\subsubsection{Perturbations to model states}

The final part is the quantification of error statistics in the forecast step based on the error variance between multiple ensemble members. These ensembles are generated by stochastically perturbing model states $(b)$ so that

$$
x_{i, t+1}^{b}=\bar{x}_{t}^{b}+\varepsilon_{i}^{b}
$$

Eqn 6.42 
where for each state $\left(x^{b}\right)$, the mean of the perturbed states $\left(\bar{x}^{b}\right)$ from the previous time step is considered 'truth' and model error $\left(\varepsilon_{i}^{b}\right)$ is generated as a random number with a zero mean normal distribution with covariance of the ensemble members, to produce the ensemble forecast at the next time step. In the following section, constraints are placed on these perturbations to ensure physically consistent updating.

\subsubsection{Constraints}

The above formulation (Eqn 6.42) places no restrictions on the amount a state is perturbed by and as a result allows the filter to adjust state values to beyond what is physically possible. To overcome this, some simple constraints are placed on the filter to encourage more realistic state updating. Approaches for incorporating constraints into data assimilation routines can be found in Julier and LaViola (2007), Han et al. (2012), Pan and Wood (2006), Simon and Simon (2006), Simon and Tien Li (2002), and Thacker (2007). Many of these applications have been in areas outside of hydrology.

Wang et al. (2009) provide the only comprehensive assessment of constraint techniques related to hydrological modelling. They test three methods for constraining state (and parameter) updating in an EnKF framework. Catchment runoff is simulated with the HyMOD conceptual model which has five state variables and five parameters. Linear inequality constraints are applied to both states (non-negativity) and parameters (bound by parameter ranges). A non-linear inequality constraint is also applied to soil water content.

The naïve, projection and accept/reject methods for constraining the filter are compared. Ensemble members are constrained after applying the unconstrained EnKF. The naïve method treats constraints in a simple way. If the constraint is violated then the ensemble member value is replaced to ensure it conforms to the feasible space. For example, if an ensemble member has a negative value it can be replaced with zero in order to satisfy a non-negativity constraint. In the projection method, the updated states which violate constraints are projected into the feasible space through a projection operator. The third approach is the accept/reject method, which checks for violation of the forecasted and updated states and regenerates the model error until the states obey the specified constraints. This approach may require a large number of samples which can be computationally demanding (Wang et al., 2009). To overcome this, a stopping threshold of the 
maximum number of rejections is set to each possible ensemble member at each time step. If this threshold is reached and the updated states still violate the constraints, the soft inequality constraints are skipped and hard (non-negativity) constraints enforced.

Wang et al. (2009) conclude that while the naïve method performs reasonably well, the projection and accept/reject methods show a general improvement in performance. The trade-off is an increase in computational burden. Although it is noted that this application has been for dual state and parameter updating, the computational efficiency and satisfactory performance of the naïve method indicates that it is suited to high-resolution forecasting applications. For these reasons the naïve method is used in this dissertation in which both mass and flux constraints are applied.

The four mass and flux constraints are described in the following sections. They are relatively simple and straightforward to implement but allow state-updating to be consistent with physical laws.

\section{Mass constraints}

- Non-negativity of state variables. If this constraint is violated the ensemble member value is replaced with a zero, so that

$$
\begin{aligned}
V_{\text {soil }} & \geq 0 \\
V_{\text {fast }} & \geq 0 \\
V_{\text {inter }} & \geq 0 \\
V_{\text {base }} & \geq 0
\end{aligned}
$$

- In addition, the soil state is constrained to a maximum volume based on field capacity, so that

$$
0 \leq V_{\text {soil }} \leq V_{F C}
$$

\section{Flux constraints}

- If there has been no rain in 12 hours, no updates can be made to $V_{\text {soil }}$ or $V_{\text {fast }}$.

- State perturbations are constrained to be within the maximum state volume change simulated in the unfiltered model output over the 1998-2010 
evaluation period. This will vary between catchments and each of the four states.

During the analysis step, the Kalman gain is used to update the ensemble of model states, the mean of which is used as the state value at the next time step. However, depending on the covariance between the modelled states and output this can sometimes result in negative state values leading to unreliable state estimates. In this study, only those ensembles where all state values are non-negative are used for estimating the state at the next time step. Where there are few or no acceptable state ensembles, then all negative values are replaced with zero and included in state forecasting. In this study, a minimum of 20 ensembles are deemed necessary for state forecasting. For the period 2008-2010 (104,673 time steps) this threshold is achieved at least $85 \%$ of the time (Table 6.6). In the Tauranga-Taupo and Waimarino catchments, at least 90 accepted ensembles were obtained $90 \%$ of the time. In the Kuratau and lower Tongariro catchments at least 90 ensemble members were achieved $84 \%$ and $81 \%$ of the time, respectively.

\subsection{Prediction of lake level changes}

The model output from the various sub-catchments, the TPS and the ungauged areas are combined and the total inflow converted into a corresponding lake level change given direct rainfall to and evaporation from the lake itself. Sub-catchment inflows are treated instantaneously. That is, it is assumed there is no lag

Table 6.6 Percentage of time number of acceptable ensemble members was reached for the period 2008-2010.

\begin{tabular}{|cccccc|}
\hline Catchment & \multicolumn{5}{c|}{ Parameter sets } \\
\hline$>90$ members & $\mathbf{1}$ & $\mathbf{2}$ & $\mathbf{3}$ & $\mathbf{4}$ & $\mathbf{5}$ \\
\hline Tauranga-Taupo & $90.8 \%$ & $90.8 \%$ & $90.8 \%$ & $90.7 \%$ & $90.9 \%$ \\
Waimarino & $90.2 \%$ & $90.3 \%$ & $90.1 \%$ & $90.2 \%$ & $90.3 \%$ \\
Kuratau & $84.0 \%$ & $84.0 \%$ & $83.9 \%$ & $83.8 \%$ & $83.8 \%$ \\
Lower Tongariro & $81.5 \%$ & $81.5 \%$ & $81.5 \%$ & $81.4 \%$ & $81.5 \%$ \\
\hline $\mathbf{2 0}$ members & $\mathbf{1}$ & $\mathbf{2}$ & $\mathbf{3}$ & $\mathbf{4}$ & $\mathbf{5}$ \\
\hline Tauranga-Taupo & $2.0 \%$ & $2.1 \%$ & $2.1 \%$ & $2.1 \%$ & $2.0 \%$ \\
Waimarino & $2.7 \%$ & $2.7 \%$ & $2.7 \%$ & $2.7 \%$ & $2.6 \%$ \\
Kuratau & $10.3 \%$ & $10.2 \%$ & $10.3 \%$ & $10.5 \%$ & $10.4 \%$ \\
Lower Tongariro & $14.3 \%$ & $14.4 \%$ & $14.3 \%$ & $14.4 \%$ & $14.3 \%$ \\
\hline
\end{tabular}


between the gauge and the river mouth at the lake. The implications of this are discussed in Section 9.4. Outflow from the lake is also required. Three scenarios are presented which relate to various outflow rates from Lake Taupo and include maximum outflow $\left(320 \mathrm{~m}^{3} / \mathrm{s}\right)$, minimum outflow $\left(30-50 \mathrm{~m}^{3} / \mathrm{s}\right)$ and mean outflow $\left(150 \mathrm{~m}^{3} / \mathrm{s}\right)$ scenarios. In addition, observed outflow is also compared.

It was originally intended that a real-time, continuous predictive model would be developed. However, in April 2011 it was agreed that due to issues with obtaining the necessary input rainfall and flow data in "real time", the model could not be set up to operate in real-time. However, it would remain suitable for such operation, and have its capacity for forward prediction evaluated using historical data.

The predictive model used in this study has therefore been developed as a computationally efficient model to allow its use operationally, if desired. It should be relatively straightforward to modify the code to allow use of real-time data, if this can be provided as model input. However, it is note that recalibration would be required if real-time input data was different to the data used to set up the model (i.e., if different rainfall and/or flow time series were used to drive the model).

As discussed previously, the filtered time series of observed lake level change shows some considerable fluctuations (Figure 6.19, top) which balance out over time (see Section 6.4.4). Most of the oscillations are within $\pm 1 \mathrm{~mm}$. To close the water balance, negative inflow fluxes would be required, which is physically inconsistent and not permitted in the model. As a result, there is some error between simulated and observed lake level, which can accumulate. This error is accounted for by setting a tolerance limit. When modelled lake level deviates by more than $2 \mathrm{~mm}( \pm 1 \mathrm{~mm})$ from the observation, the modelled value is replaced with the observed lake level for more reliable lake level predictions. While $2 \mathrm{~mm}$ may not seem a large deviation, it corresponds to over 1.2 million $\mathrm{m}^{3}$ of water. A lower tolerance would allow seiche effects to be assimilated which do not represent the genuine lake level fluctuations.

\subsection{Model evaluation}

The combined model is evaluated in terms of its ability to predict changes in the level of Lake Taupo during eight events between 1998 and 2011. The events are listed in Table 6.7. The events selected provide a range of meteorological, 

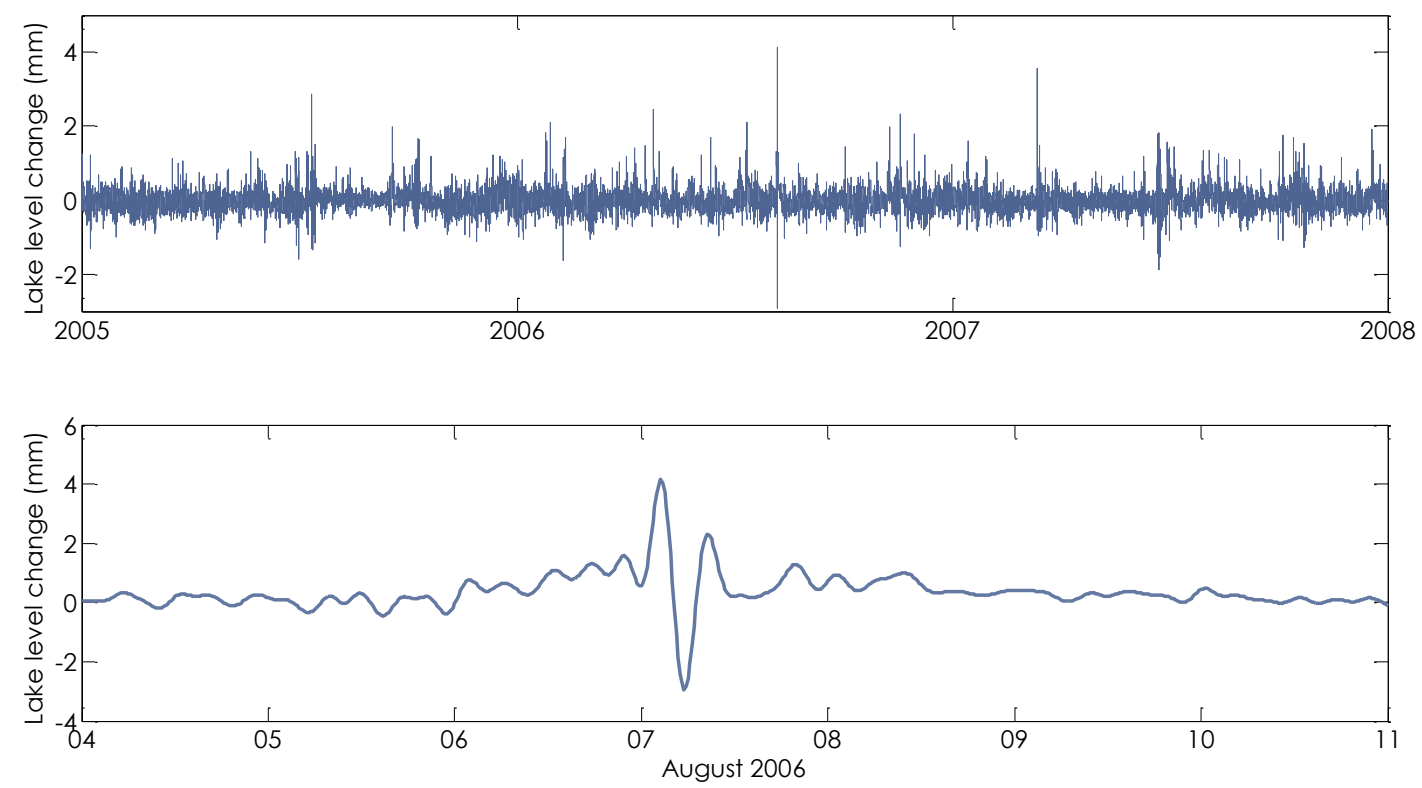

Figure 6.19 Upper: Lake level change in mm/15 minutes. Lower: these oscillations generally balance out as a flux in one direction is often followed by a corresponding flux in the opposite direction. Most oscillations are within $\pm 1 \mathrm{~mm}$.

hydrological and operating conditions in the catchment including dry/drought conditions when lake levels were nearing minimum operating levels, 'normal' operating conditions, and flood conditions during which lake levels exceeded operating levels.

For each event the model is run historically. Lake level is forecasted at various times before, during and after the event to show the progression of the predictions and the improvement in the model output when observations are assimilated as part of the modelling procedure. At each point in time, lake level is projected forward 15 days. Model performance over these specific events is evaluated given known lake outflow. To understand the various sources of uncertainty in the modelled response, the individual components that make up this modelled response are analysed and include the uncertainty associated with the TPS and modelled inflows from gauged and ungauged areas.

Table 6.7 Events over which the model is evaluated in terms of predicting lake level

$\begin{array}{ccc}\text { Dry/drought periods } & \text { 'Normal' conditions } & \text { Flood Events } \\ \text { August } 2001 & \text { November } 2006 & \text { July } 1998 \\ \text { August } 2003 & \text { March } 2007 & \text { February } 2004 \\ \text { May } 2010 & & \text { September } 2010\end{array}$


In the final analysis, model output is presented for each event given different operational scenarios. These scenarios are based on outflow rates from the lake and display the output from the model for decision making purposes. These scenarios are also compared against observed lake outflow for the event.

\subsection{Summary}

The Lake Taupo catchment is a complex regulated catchment in which both regulated and unregulated inflows discharge directly to the lake. Unregulated flows may be gauged or ungauged. Regulated flows may be from modified or highly modified systems. Modelling these inflows requires a model that is computationally efficient while still being physically realistic and capable of incorporating aspects of regulation as well as the varying amounts of data and information.

A physically consistent semi-distributed conceptual rainfall-runoff model is developed and used for modelling both unregulated gauged catchments and regulated catchments (excluding the TPS). The structure of this conceptual model is relatively simple. Rainfall infiltrating the soil layer drains to three linear stores, based on the assumption of a variable source area, before discharging to the river. Overland flow occurs if the infiltration rate is exceeded or if the soil layer becomes saturated. This structure is modified to incorporate physical and legislative constraints relating to the regulation of some catchments. Due to insufficient data and information to apply the conceptual model, a statistical probability analysis is undertaken to estimate inflow from the TPS. Regionalisation is used to estimate inflows from ungauged areas.

Parameter estimation and sensitivity analysis are undertaken as an iterative process using the results of Monte Carlo simulations. Model performance is evaluated using the Kling-Gupta Efficiency index. To improve the accuracy and reliability of model output, real-time observations of streamflow are used to update model states using the EnKF. Mass and flux constraints are applied to the filter. States volumes must be non-negative and the soil storage state must not exceed field capacity. Perturbations to states are constrained to be within reasonable ranges. State-updates are not allowed to the soil storage and fastflow stores after a period of no rainfall.

Predicted inflows are combined and converted into a corresponding lake level rise. The model is evaluated for its ability to accurately and reliably predict lake level over a number of events between 1998 and 2011. 
$\mathbf{1 5 8}$ | A rainfall-runoff model for the Lake Taupo catchment 


\section{Model calibration and sensitivity analysis}

This chapter presents the results of the sensitivity analysis and sub-catchment model calibration. Fourteen sub-catchments of Lake Taupo are modelled. The Otaketake catchment is not included due to a lack of suitable rainfall data for calibration. A regionalised sensitivity analysis (Section 7.1) is used for refinement of parameter ranges and for identifying dominant flow pathways. Model calibration results for both regulated and unregulated sub-catchments are presented and discussed in Section 7.2. The complete results for all sub-catchments can be found in Appendix C.

\subsection{Sensitivity analysis}

In this study, sensitivity analysis is used to identify which parameters are most influential in determining catchment hydrologic response, and therefore which ones should receive more attention in parameter refinement.

Adjustments were made to some parameter ranges to improve model calibrations. For example, in the Waitahanui catchment the range of values for field capacity were widened from a maximum of $800 \mathrm{~mm}$ and the rainfall multiplier was reduced 
to 0.4. KGE values for the fit to the time series increased from 0.88 to over 0.91 (an improvement of $4 \%)$.

Identifiable parameters present a clear relationship between objective function value and parameter value. Those that are well-defined (in the parameter space, refer Section 6.3.1) converge toward a narrow range of values for which the highest objective function values are found. The most identifiable parameters also tend to be the most sensitive in each of the sub-catchments. Table 7.1 lists sensitive parameters in order of importance for each of the modelled sub-catchments. The four most sensitive and identifiable parameters are the rainfall multiplier, lag time, fastflow proportion and baseflow proportion. Scatterplots (Figure 7.1 to Figure 7.4) of the respective parameters demonstrate that these four parameters are well defined within the parameter space for most catchments. It is not unexpected that the catchment lag time and rainfall multiplier are sensitive. The rainfall multiplier converts the observed rainfall into a catchment areal estimate. This is based on achieving mass balance (minimising the overall bias) in each sub-catchment. The fact that such high calibration values have been obtained in a number of catchments suggests that the inputs to the system are representative of overall dynamics, if not the magnitude of catchment rainfall which the rainfall multiplier accounts for.

Although sensitive, the rainfall multiplier parameter is less identifiable in the lower Tongariro, Whanganui, Tutaeuaua and Poutu catchments. The first three catchments use observations from gauges several kilometres away which may lack some representativeness. In terms of the lower Tongariro catchment the rainfall multiplier is not only used to adjust for mass balance and areal rainfall estimates but also for the area of the catchment which now drains through the Tokaanu Power Station rather than to the Tongariro River. A lack of identifiability for this parameter in the Poutu catchment is most likely to be a result of the complex regulation which is difficult to model. More information on the regulation of the catchment, particularly in regard to the discharge from the Rangipo Station would improve overall performance.

It is not surprising that catchment lag times are also generally well-defined and sensitive, particularly in some of the more flashy catchments. Catchment lag times account for the time it takes for input rainfall to move through the catchment and be measured at the gauge. Adjusting the timing of the modelled output for this time difference allows a closer fit to the observations. 
Table 7.1 Results of sub-catchment sensitivity analyses. Parameters are in order of descending $D$ statistic value. The darker shading indicates parameters which are classified as sensitive and lighter shading for moderately sensitive parameters. Insensitive parameters are not shaded. Insensitive parameters that are still significant (at the $5 \%$ level) are in italics.

\begin{tabular}{|c|c|c|c|c|c|c|c|c|c|c|c|c|c|}
\hline Waitahanui & Hinemaiaia & TaurTaupo & Waimarino & L. Tongariro & Poutu & Waipakihi & Waihohonu & Waihi & Kuratau & Whareroa & Whanganui & Waihaha & Tutaevaua \\
\hline Baseflow & Rain mult. & Rain mult. & Rain mult. & Rain mult. & Baseflow & Lag time & TB & Tf & Rain mult. & Lag time & Rain mult. & Rain mult. & rain mult \\
\hline Rain mult. & Lagtime & Fastflow & Fastflow & Lag time & Rain mult. & Tf & Tf & Fastflow & Lag time & Rain mult. & Fastflow & Lag time & Tf \\
\hline Lag time & Baseflow & Baseflow & Lag time & Fastflow & Fastflow & Rain mult. & rain mult & Rain mult. & Baseflow & Fastflow & Lag time & Fastflow & lagtime \\
\hline Interflow & Fastflow & Lag time & Interflow & Baseflow & Tf & Fastflow & baseflow & Baseflow & Fastflow & Baseflow & Baseflow & Baseflow & fastflow \\
\hline TB & Interflow & Tf & Baseflow & Tf & Interflow & Baseflow & fastflow & Field cap & TB & Interflow & TB & Interflow & baseflow \\
\hline Fastflow & Tf & Field cap & Tf & TB & Lag time & Interflow & interflow & Curve & Interflow & Tf & Ti & Tf & Field cap. \\
\hline Field cap & TB & Interflow & $\mathrm{Ti}$ & Field cap & $\mathrm{Ti}$ & Min. release & lagtime & Interflow & Tf & TB & Tf & TB & Curve \\
\hline $\mathrm{Ti}$ & $\mathrm{Ti}$ & $\mathrm{Ti}$ & Curve & Interflow & Field cap & Field cap & Field cap. & Lag time & Field cap & Curve & Interflow & Min. release & Min. release \\
\hline Curve & Field cap & Curve & Min. release & Min. release & Min. release & FC to sat & $\mathrm{Ti}$ & $\mathrm{Ti}$ & Curve & Max. infiltr. & Max. infiltr. & Curve & Ti \\
\hline Min. release & FC 2 sat & FC to sat & TB & Curve & Curve & Curve & Max. infiltr. & Min. release & Min. release & Min. release & Field cap & Field cap & interflow \\
\hline Max. infiltr. & Max. drain. & Max. infiltr. & Max. infiltr. & FC to sat & Max. infiltr. & Max. infiltr. & Min. release & TB & $\mathrm{Ti}$ & Field cap & Curve & $\mathrm{Ti}$ & TB \\
\hline Max. drain. & Max. infiltr. & Min. release & FC to sat & Max. infiltr. & TB & Max. drain. & Curve & FC to sat & Max. drain. & $\mathrm{Ti}$ & Min. release & FC to sat & Max. drain \\
\hline $\begin{array}{c}\text { Tf } \\
\text { FC to sat }\end{array}$ & $\begin{array}{c}\text { Curve } \\
\text { Min. release }\end{array}$ & $\begin{array}{l}\text { Max. drain. } \\
\text { TB }\end{array}$ & $\begin{array}{l}\text { Field cap } \\
\text { Max. drain. }\end{array}$ & $\begin{array}{c}\text { Max. drain. } \\
\qquad \mathrm{Ti}\end{array}$ & $\begin{array}{l}\text { FC to sat } \\
\text { Max. drain. }\end{array}$ & $\begin{array}{l}\mathrm{TB} \\
\mathrm{Ti} \\
\end{array}$ & $\begin{array}{l}\text { Max. drain } \\
\text { FC to sat }\end{array}$ & $\begin{array}{l}\text { Max. drain. } \\
\text { Max. infiltr. }\end{array}$ & $\begin{array}{c}\text { Max. infiltr. } \\
\text { FC to sat }\end{array}$ & $\begin{array}{l}\text { Max. drain. } \\
\text { FC to sat }\end{array}$ & $\begin{array}{l}\text { FC to sat } \\
\text { Max. drain. }\end{array}$ & $\begin{array}{l}\text { Max. drain. } \\
\text { Max. infiltr. }\end{array}$ & $\begin{array}{l}\text { Max. infiltr. } \\
\text { FC to sat }\end{array}$ \\
\hline
\end{tabular}



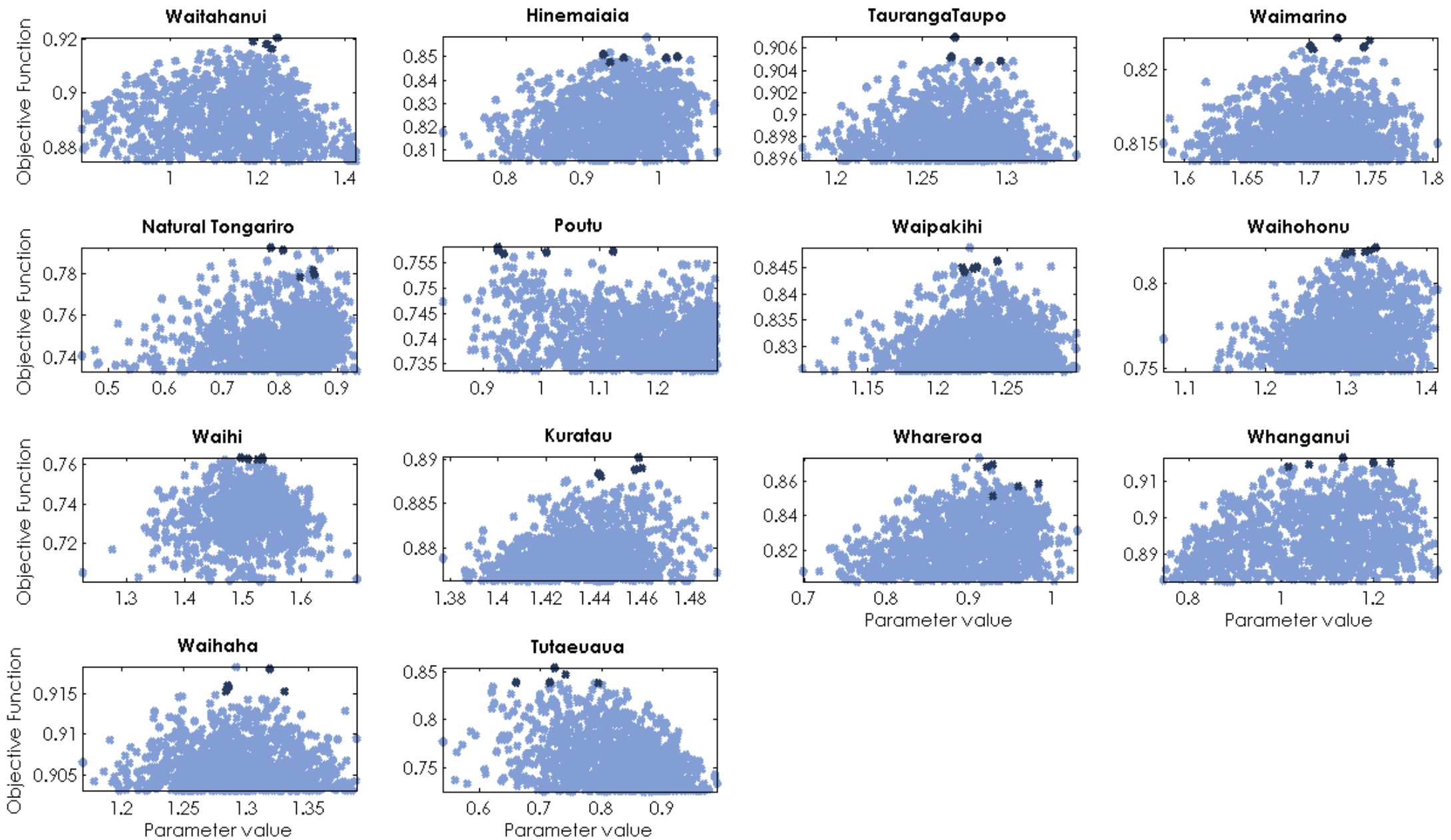

Figure 7.1 Scatterplot of rainfall parameter - most sensitive parameter over all 

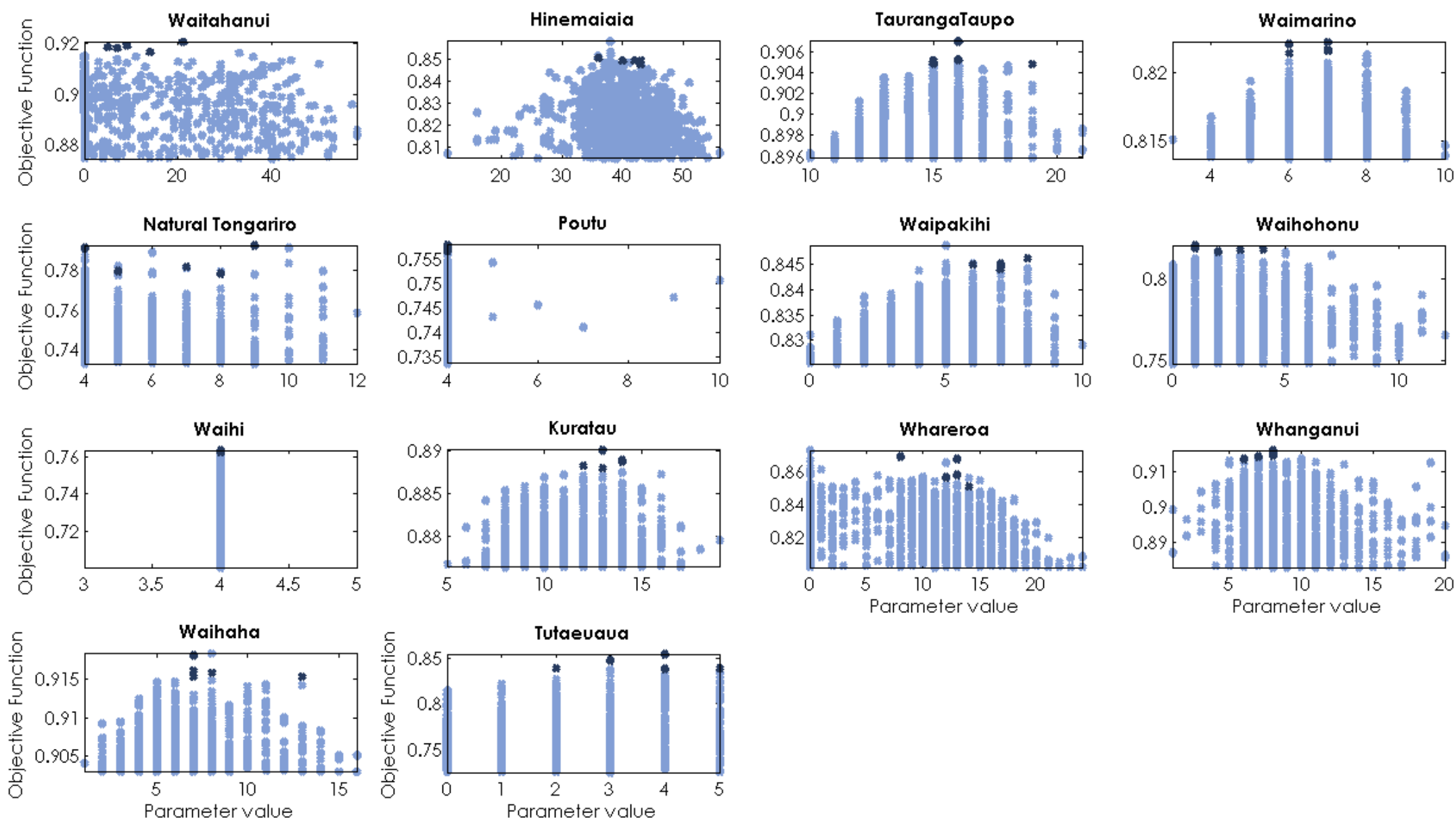

Figure 7.2 Scatterplot of lag parameter - most sensitive parameter over all 

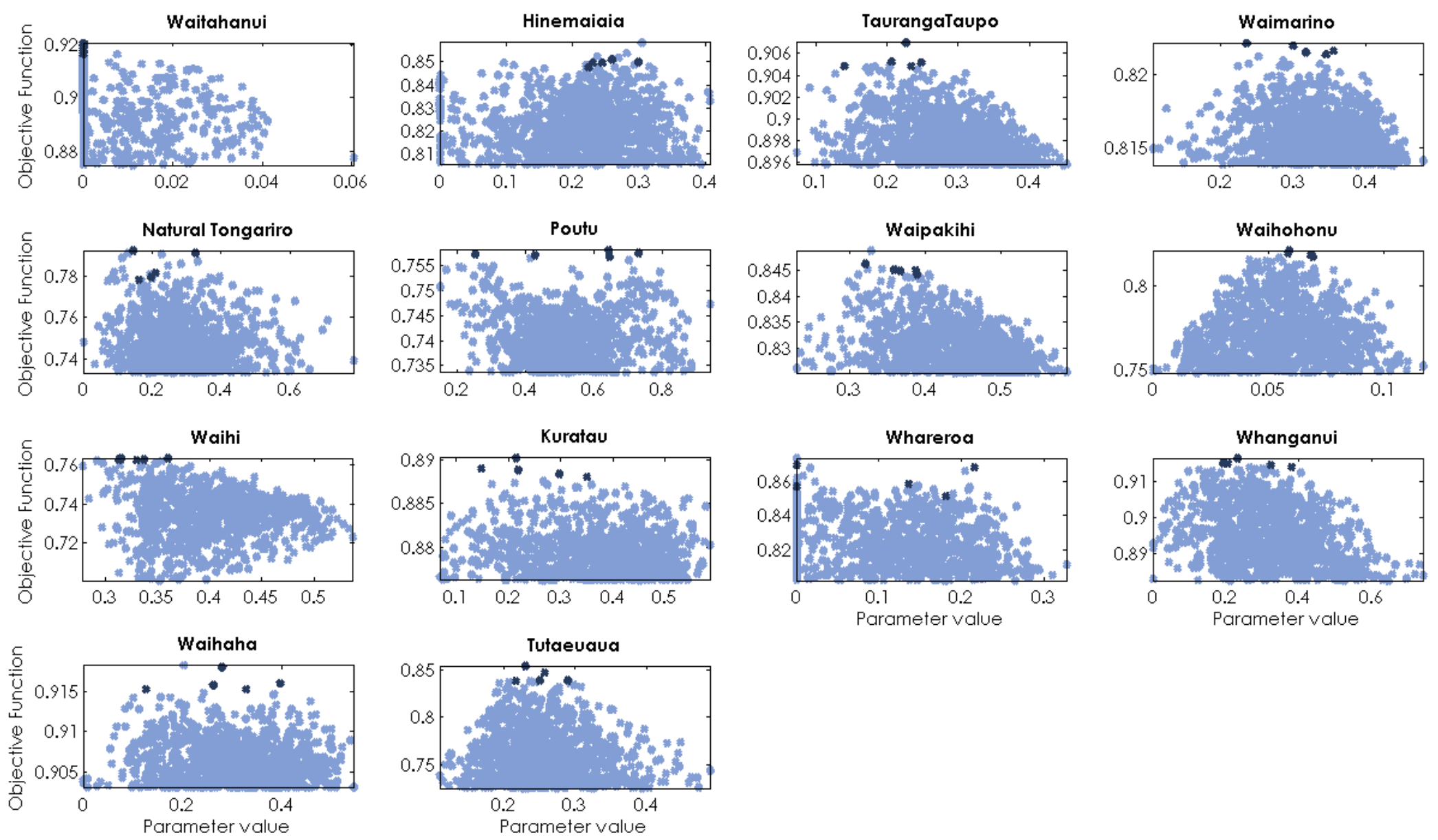

Figure 7.3 Scatterplot of fastflow parameter - most sensitive parameter over all 

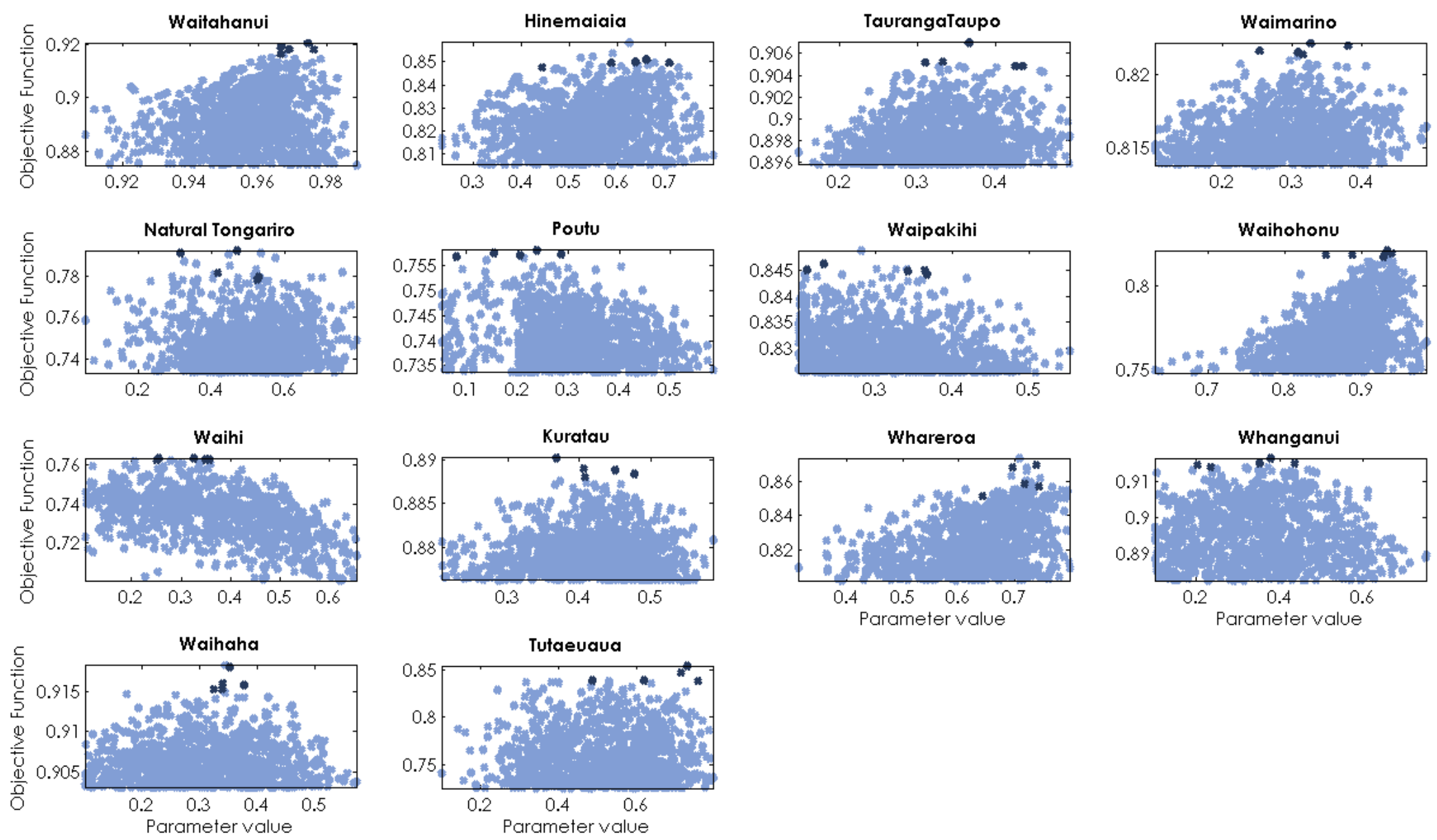

Figure 7.4 Scatterplot of baseflow parameter - most sensitive parameter over all 
In catchments which have a more defined flood peak, it may be easier for this parameter to be identified. In catchments with longer residence times and less direct runoff (such as the baseflow dominated Waitahanui), flood response may be dampened. Lag times in these catchments are less easily obtained because there is often no well-defined peak to fit to.

In terms of dominant flow pathways, the fastflow and baseflow proportions are the most sensitive. There is strong bivariate sensitivity between all three store proportions as they are directly constrained by the physical requirement that together they must not exceed one. The fastflow parameter is vital for simulating the flood (direct runoff) response of a catchment.

Baseflow is a considerable contributor to flow in all catchments, regardless of their physiographic attributes. This is consistent with the findings in Chapter 5 in which the range of baseflow index values is relatively small (0.69-0.76). Although the range of parameter values for baseflow proportion are wider, it is still very identifiable. Baseflow residence time is sensitive in only five catchments. This does not undermine the importance of this and other less sensitive parameters. Univariate sensitivity analyses are unable to identify parametric interaction, which can result in the non-identification of influential parameters (Wagener and Kollat, 2007). Bivariate sensitivity analysis directly compares the sensitivity of one parameter to another. In this study, baseflow residence times are sensitive to baseflow proportion in five catchments. It is least sensitive in catchments which are more variable and have lower baseflow volumes.

In the Waihi, Tutaeuaua and Tongariro catchments, the residence time for the fastflow store is one of the most sensitive and identifiable parameters found. This parameter influences flood peak attenuation. The shorter the residence time, the flashier the flood response. The Tutaeuaua and Waihi catchments are the smallest sub-catchments studied, allowing water to exit quickly. The steeper nature of the Waihi catchment reduces the amount of time water remains in the stores while the rounder shape and higher drainage density of the Tutaeuaua catchment has a similar effect.

Fastflow residence time is also important in the sub-catchments of the Tongariro as well, despite being much larger in size compared to the Waihi and Tutaeuaua catchments. Although the Waihohonu, Waipakihi, Poutu and lower Tongariro catchments are generally steep, draining the higher elevation areas of the Lake 
Taupo catchment, there are some clear differences. The Waihohonu catchment is largely covered in tussock grassland so there is less interception than would be expected in the Waipakihi catchment. Further, a large proportion of its soils consist of weakly developed raw soils with little water holding capacity. It also has one of the highest drainage densities. Despite a high baseflow contribution, these factors allow water to run through the fastflow reservoir more quickly. In contrast, the Waipakihi catchment is more elongated but also has a relatively high drainage density. Baseflow contribution is one of the lowest. The steepness of this catchment, in conjunction with the underlying geology and density of the drainage network, results in a flashy and responsive catchment.

It is not surprising that the fastflow residence time is also sensitive in the Poutu catchment, given that the Waipakihi and Waihohonu both drain into the Tongariro River upstream of the Poutu Intake. This time governing constant of fastflow recession is also important in the lower Tongariro catchment, albeit to a lesser extent. This sub-catchment is, in general, less steep which means that water travels through the catchment more slowly than steep catchments. It also has a large amount of permeable pumice soils and a range of vegetation types. This parameter is least sensitive in the spring fed Waitahanui catchment where baseflow is the highest of all sub-catchment of Lake Taupo.

Although not classified as sensitive in the Tauranga-Taupo and Waimarino catchments the fastflow residence time is significant in terms of the KolmogorovSmirnoff (KS) statistic. These two catchments (plus the Waipakihi catchment) have the highest streamflow variability index values and flood flow variability values of all catchments studied. Bivariate sensitivity analysis revealed that the catchment lag time is sensitive to this parameter. As the fastflow residence time increased the lag time also increased. Longer residence times tend to delay or subdue the peak response.

Finally, field capacity is sensitive in catchments that tend to have higher baseflow, such as the Waitahanui, Kuratau and Waihohonu catchments. Field capacity reflects the permeable and water holding capacity of the soil. However, field capacity parameter values are wide ranging and there is little interaction between this parameter and other parameters of the model, with the exception of the rainfall multiplier. The rainfall multiplier tended to increase as field capacity increased in eight sub-catchments, most of which tend to have a more variable and flashy response (Tauranga-Taupo, Waimarino, Waihi, Waipakihi and Tutaeuaua). 
It was hoped that correlation analysis of parameter values against the physiographic attributes used in Chapter 5 would be able to provide further insight into catchment hydrologic behaviour. While this analysis has been undertaken, many relationships could not be discerned with certainty because of a lack of identifiability (in a univariate sense) for some model parameters of some catchments. Multi-variate analyses, such as Sobol's global sensitivity analysis, would provide a more robust analysis of individual parameter influence and parameter interactions, but can be computationally expensive (Yang, 2011). Although the results of the correlation analysis are not included in this chapter, they are presented in Appendix E.

\subsection{Model calibration and parameter estimation results}

The conceptual rainfall-runoff model described in Chapter 6 is used to calibrate all historically gauged sub-catchments of Lake Taupo for the purpose of providing additional information on catchment hydrologic behaviour. The five best performing parameter sets in terms of both fit to the time series and the fit to the flow duration curve are presented. Calibrated parameter sets are evaluated over a non-overlapping period of data for all catchments (refer Section 6.2), where adequate data permits. Evaluation could not be reliably undertaken for Waihi, Whareroa, Waitahanui and Tutaeuaua catchments due to various issues relating to the short duration of some time series and problems with poor quality rainfall and/or streamflow data. Since these catchments are used for providing further information on catchment hydrologic behaviour, and not in the operational model, calibration (and evaluation) of these catchments is undertaken on as much of the streamflow record as the data permitted so as to include a wide range of possible hydrologic responses to identify suitable model parameters.

In this study, the aim is to achieve one million calibration runs per catchment. Although it is recognised that this is not sufficient to sample the entire parameter space given the number of model parameters, it does provide a balance between statistical accuracy and computational constraints.

Four catchments have less than one million. For the Waihohonu and Waipakihi catchments, 800,000 and 700,000 calibration runs are obtained, respectively, due to issues with some of the computing nodes in the Science Facilities High Performance Computing Facility. The Hinemaiaia catchment was first calibrated using a disaggregated rainfall record using the temporal (sub-hourly) distribution of 
rainfall from a nearby highly correlated station, with little success. As such, the catchment is calibrated using the Tauranga-Taupo rainfall record. A total of 500,000 calibrations have been obtained for this catchment (below the scheme). Initially, the Tutaeuaua catchment was calibrated using a rainfall gauge located to the south west of the catchment. Model calibrations (1 million) were not strong. A further 500,000 calibrations were undertaken for this catchment using an alternative rainfall record (located north of the catchment) which produced much higher KGE values. It is the results of this latter calibration that are included in this chapter. Despite the lower number of calibration runs, high performance index values for the majority of catchments are achieved.

\subsubsection{Unregulated catchments}

For the majority of unregulated catchments, the model is able to simulate the runoff response of the catchment reasonably well. Objective function values for respective calibration and evaluation periods are summarised in Table 7.2. KGE values are generally above 0.80 and as high as 0.92 for the fit to the time series, and greater than 0.95 for fit to the flow duration curve. These KGE values indicate that the model does a good job of simulating streamflow in the majority of catchments, indicating that the structure of the model is representative of most of the hydrologic responses in the Lake Taupo catchment. Visual inspection of modelled and observed streamflow shows that, in general, low flow and recession periods are modelled reasonably closely but peak events are often under- or over-estimated.

The Tauranga-Taupo catchment, for example, is a flashy catchment with considerable flow variability, a result of its steep topography, impermeable underlying geology and elongated shape. The proportion of streamflow routed to the fastflow store is as much as $25 \%$ and the associated residence times are less than half a day. Recession periods are simulated well, as are the timing and duration of events (Figure 7.5b). Peak events, however, are generally over-estimated, indicated by the negative residual flow in Figure 7.5c. Conversely, in the Waitahanui catchment (Figure 7.6), flow variability is low with the range of streamflow over the calibration period less than $3.5 \mathrm{~m}^{3} / \mathrm{s}$, despite some reasonable rainfall events. This is a highly baseflow dominated catchment; calibrated parameter sets ignore the fastflow store, apportioning subsurface flow between baseflow (0.97) and interflow (o.03) only. Direct runoff is not accounted for. In this catchment, peak flow events tend to be under-estimated (Figure 7.6b), although the error is small (Figure 7.6c). 
Table 7.2 Top five parameter sets and corresponding calibration and evaluation period KGE values for unregulated catchments

\begin{tabular}{|c|c|c|c|c|c|c|}
\hline \multirow[b]{2}{*}{ Catchment } & \multirow[b]{2}{*}{ KGE criterion } & \multicolumn{5}{|c|}{ Top 5 Parameter Sets } \\
\hline & & 1 & 2 & 3 & 4 & 5 \\
\hline \multirow[t]{2}{*}{ Waitahanui } & Calibration (Time) & 0.9166 & 0.9207 & 0.9184 & 0.9192 & 0.9180 \\
\hline & Calibration (FDC) & 0.9752 & 0.9828 & 0.9814 & 0.9841 & 0.9757 \\
\hline \multirow[t]{4}{*}{ Tauranga-Taupo } & Calibration (Time) & 0.9049 & 0.9070 & 0.9052 & 0.9052 & 0.9049 \\
\hline & Calibration (FDC) & 0.9879 & 0.9864 & 0.9799 & 0.9805 & 0.9882 \\
\hline & Evaluation (Time) & 0.8038 & 0.8042 & 0.8035 & 0.7988 & 0.8008 \\
\hline & Evaluation (FDC) & 0.8367 & 0.8397 & 0.8397 & 0.8330 & 0.8348 \\
\hline \multirow[t]{4}{*}{ Waimarino } & Calibration (Time) & 0.8222 & 0.8215 & 0.8214 & 0.8220 & 0.8216 \\
\hline & Calibration (FDC) & 0.9765 & 0.9809 & 0.9739 & 0.9735 & 0.9834 \\
\hline & Evaluation (Time) & 0.7994 & 0.7891 & 0.7994 & 0.7947 & 0.7938 \\
\hline & Evaluation (FDC) & 0.9205 & 0.9224 & 0.9029 & 0.9114 & 0.9123 \\
\hline \multirow[t]{4}{*}{ Waipakihi } & Calibration (Time) & 0.8450 & 0.8451 & 0.8442 & 0.8448 & 0.8462 \\
\hline & Calibration (FDC) & 0.9609 & 0.9604 & 0.9512 & 0.9610 & 0.9583 \\
\hline & Evaluation (Time) & 0.8655 & 0.8647 & 0.8796 & 0.8660 & 0.8674 \\
\hline & Evaluation (FDC) & 0.9375 & 0.9341 & 0.9765 & 0.9385 & 0.9358 \\
\hline \multirow[t]{4}{*}{ Waihohonu } & Calibration (Time) & 0.8178 & 0.8206 & 0.8180 & 0.8189 & 0.8168 \\
\hline & Calibration (FDC) & 0.9819 & 0.9676 & 0.9679 & 0.9694 & 0.9532 \\
\hline & Evaluation (Time) & 0.6856 & 0.6657 & 0.6880 & 0.6770 & 0.7085 \\
\hline & Evaluation (FDC) & 0.7942 & 0.7777 & 0.7847 & 0.7882 & 0.8259 \\
\hline \multirow[t]{2}{*}{ Waihi } & Calibration (Time) & 0.7466 & 0.7511 & 0.7596 & 0.7528 & 0.7538 \\
\hline & Calibration (FDC) & 0.8364 & 0.8411 & 0.8606 & 0.8546 & 0.8525 \\
\hline \multirow[t]{2}{*}{ Whareroa } & Calibration (Time) & 0.8679 & 0.8694 & 0.8583 & 0.8567 & 0.8512 \\
\hline & Calibration (FDC) & 0.9584 & 0.9535 & 0.9605 & 0.9617 & 0.9529 \\
\hline \multirow[t]{4}{*}{ Whanganui } & Calibration (Time) & 0.9138 & 0.9163 & 0.9148 & 0.9144 & 0.9149 \\
\hline & Calibration (FDC) & 0.9784 & 0.9796 & 0.9766 & 0.9746 & 0.9701 \\
\hline & Evaluation (Time) & 0.8238 & 0.8557 & 0.8366 & 0.8072 & 0.8035 \\
\hline & Evaluation (FDC) & 0.8679 & 0.8957 & 0.8644 & 0.8530 & 0.8347 \\
\hline \multirow[t]{4}{*}{ Waihaha } & Calibration (Time) & 0.9160 & 0.9153 & 0.9180 & 0.9158 & 0.9153 \\
\hline & Calibration (FDC) & 0.9713 & 0.9616 & 0.9714 & 0.9657 & 0.9679 \\
\hline & Evaluation (Time) & 0.8736 & 0.8654 & 0.8793 & 0.8431 & 0.8488 \\
\hline & Evaluation (FDC) & 0.9110 & 0.9005 & 0.9171 & 0.8715 & 0.8768 \\
\hline \multirow[t]{2}{*}{ Tutaeuaua } & Calibration (Time) & 0.8388 & 0.8472 & 0.8380 & 0.8543 & 0.8388 \\
\hline & Calibration (FDC) & 0.9043 & 0.9654 & 0.9363 & 0.9313 & 0.9327 \\
\hline
\end{tabular}




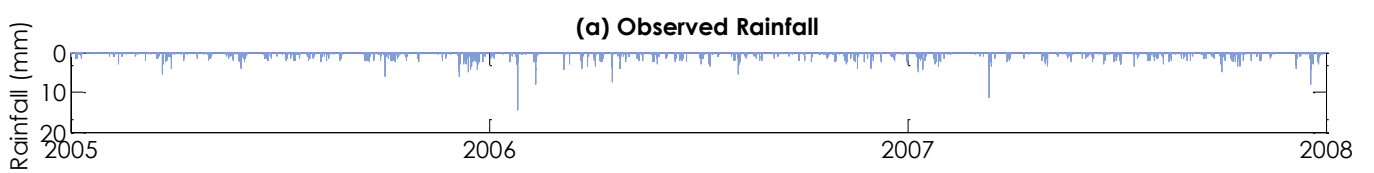

(b) Modelled vs Observed Streamflow

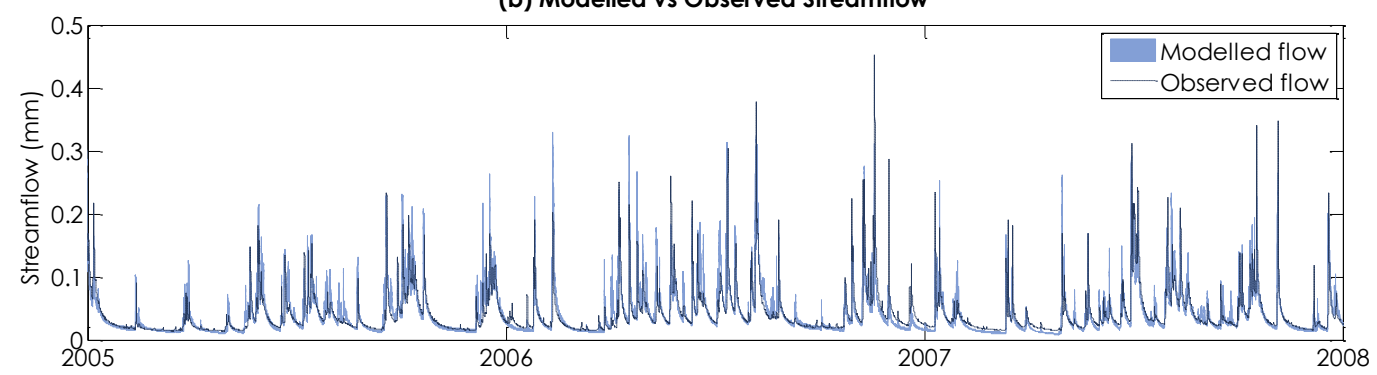

(c) Observed minus Modelled Streamflow

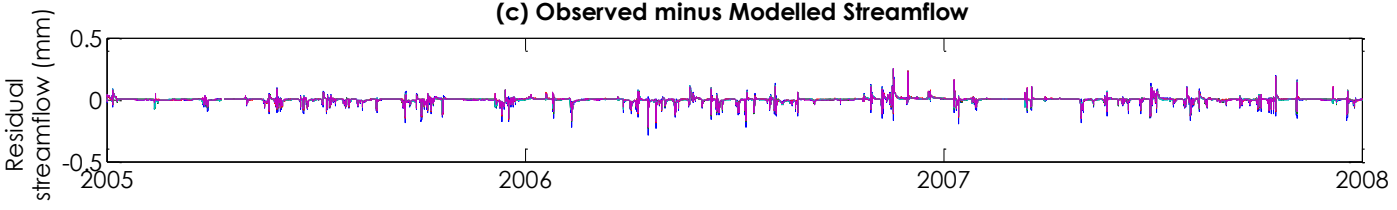

Figure 7.5 Modelled versus observed streamflow and corresponding rainfall for the Tauranga-Taupo catchment.

(a) Observed Rainfall

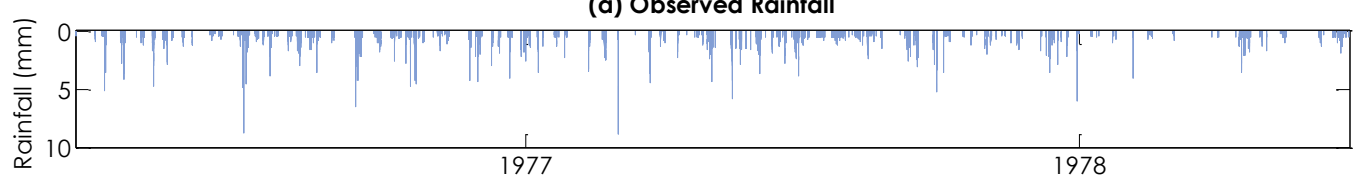

(b) Modelled vs Observed Streamflow
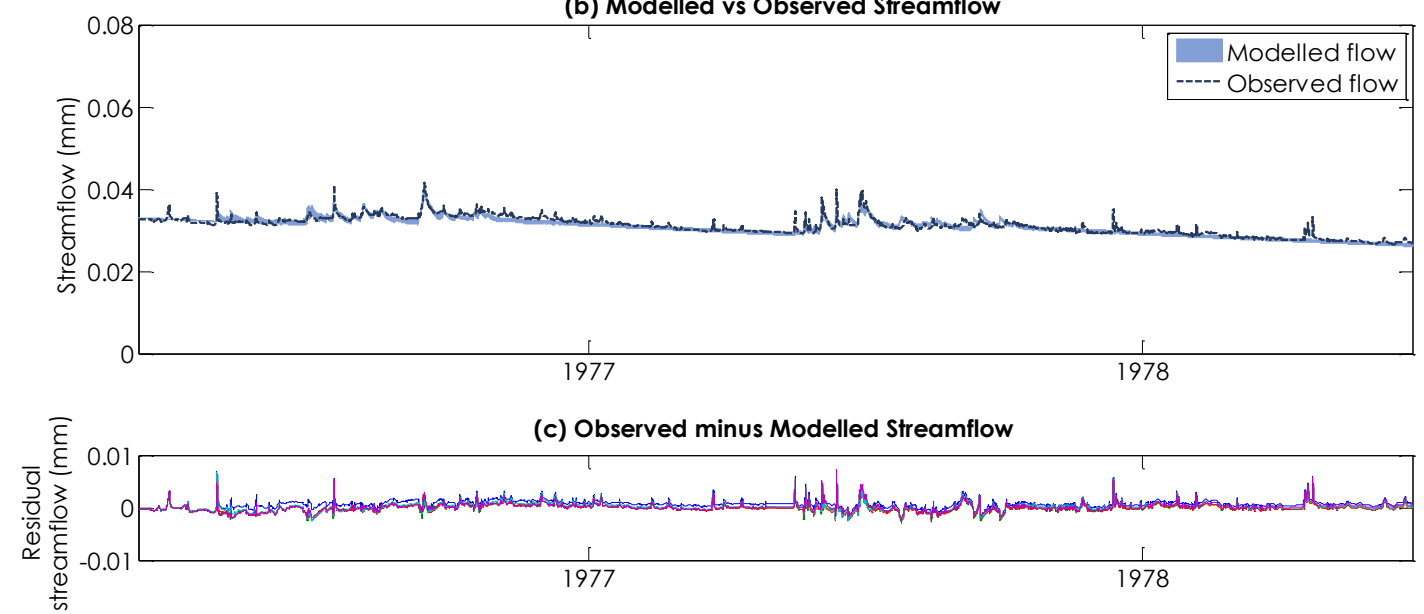

Figure 7.6 Modelled versus observed streamflow ( $\mathrm{mm} / 15$ minutes) and corresponding rainfall $(\mathrm{mm} / 15$ minutes) for the Waitahanui. 
In general, KGE values for evaluation periods are generally lower than the calibration periods but still above 0.78 for the time series and, in most cases, above o.8o for the flow duration curve. In the Waipakihi catchment, the parameter sets produced higher KGE values for the evaluation period in terms of fit to the time series with only a slight reduction in KGE values for the fit to the flow duration curve.

Parameter sets for two catchments did not perform as well as other sub-catchments. For the Waihi catchment $\left(9.8 \mathrm{~km}^{2}\right)$, the best performing parameter sets had KGE values for the fit to the time series from 0.7466 to 0.7596 . The corresponding fits to the flow duration curve are between 0.8364 and 0.8606 . The rainfall record used for this catchment is located several kilometres away in Turangi. Residual mass curves for the streamflow and rainfall records show relatively good correspondence although there are some months where the two records deviate (see Appendix C). Using this rainfall record, recession and baseflow response is captured reasonably well but the fastflow response is generally over-estimated except during very large events where it is under-estimated (Figure 7.7). The Waihi catchment is one of the smallest catchments studied. It is relatively steep and has a reasonably low drainage density, compared to other sub-catchments of Lake Taupo. A significant fastflow response could, therefore, be expected. However, observed responses appear to be dampened or even missed entirely given the corresponding rainfall input, indicating that a more suitable rainfall record may be required.

In the Waihohonu catchment (96 $\mathrm{km}^{2}$ ), despite relatively high KGE values for the calibration period ( $>0.81$ fit to time series and $>0.95$ fit to flow duration curve), the model does not seem to be able to adequately simulate the timing of either the baseflow or peak flood flow response (Figure 7.8). The Waipakihi rainfall gauge is used as input for model calibration. It is located outside of the catchment, although relatively close to the catchment outlet. The representativeness of this gauge may be an issue. The Tukino rainfall gauge, located on the flanks of Mt Ruapehu, was initially used for calibration but generated poor KGE values (KGE (time) <0.3, based on 500,000 calibration runs), so is not used for further calibration.

In addition, given its location on the slopes of Mt Ruapehu, for much of the year a considerable part of this catchment is covered in snow. In warmer spring and summer months, snow melt may raise water levels during periods when rainfall may be less, making it more difficult for the model to accurately simulate the baseflow response. This appears to be evident in Figure 7.8. During late 2002 (spring/ 
(a) Observed Rainfall

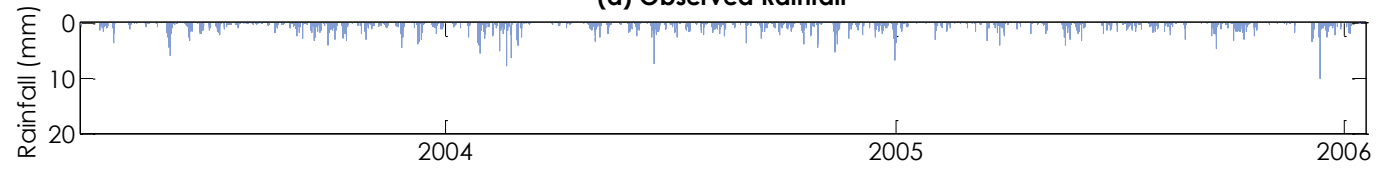

(b) Modelled vs Observed Streamflow
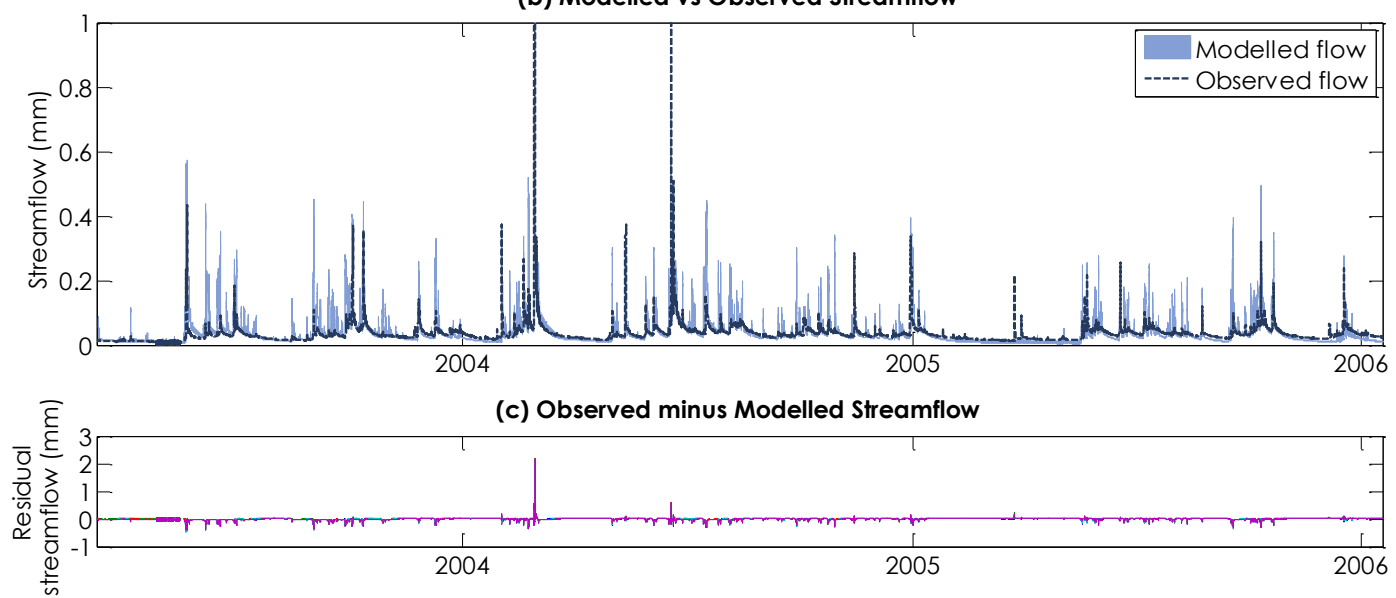

Figure 7.7 Modelled versus observed streamflow ( $\mathrm{mm} / 15$ minutes) and corresponding rainfall $(\mathrm{mm} / 15$ minutes) for the Waihi catchment. Note: maximum flow truncated for easier visual inspection.

(a) Observed Rainfall

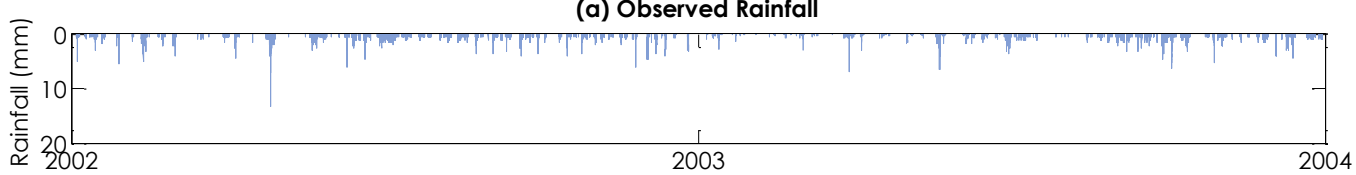

(b) Modelled vs Observed Streamflow

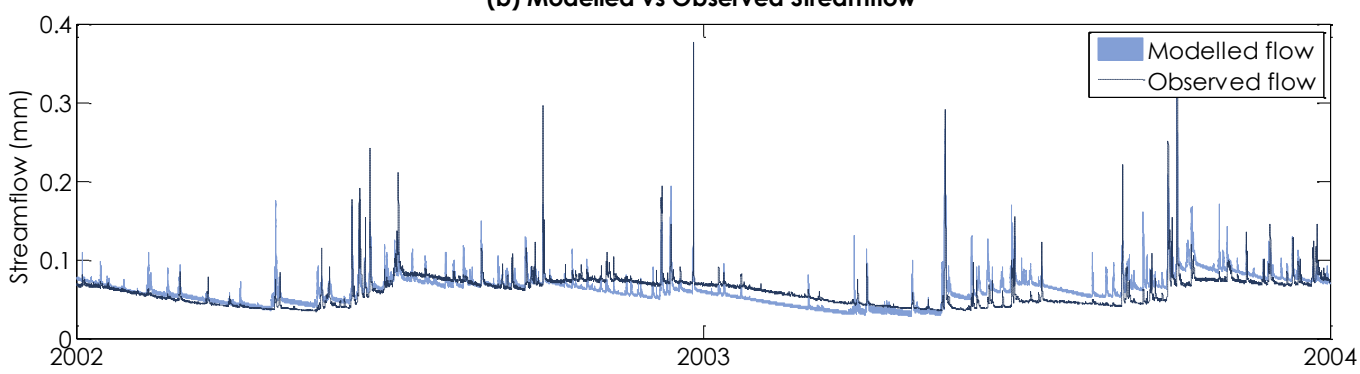

(c) Observed minus Modelled Streamflow

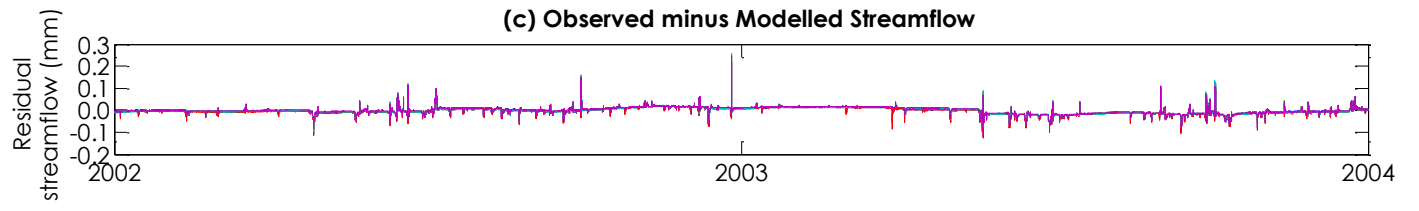

Figure 7.8 Modelled versus observed streamflow ( $\mathrm{mm} / 15$ minutes) and corresponding rainfall $(\mathrm{mm} / 15$ minutes) for the Waihohonu catchment. 
summer), modelled streamflow is lower than observed, when melt water may be contributing to streamflow. During winter 2003, a time when a large amount of precipitation would fall as snow, modelled streamflow is higher than observed. Model performance may be improved if a snowmelt routine is included. This routine may also be useful in other high elevation areas of the catchment (namely, Tauranga-Taupo, Waimarino and Waipakihi catchments) where snow may accumulate.

\subsubsection{Regulated catchments}

Simulating the response of regulated catchments is challenging and a number of approaches are used to model the inflow from these sub-catchments. Despite the limited availability of data and information specific to dam operation and scheduling, enough information on this regulation has been incorporated into the model structure to allow reasonable predictions to be made.

Objective function values for both calibration and evaluation periods for each subcatchment are summarised in Table 7.3. The unmodified Kuratau catchment (above the scheme) is included here because it is part of the larger regulated catchment (below the scheme) and its output is used to estimate the regulated discharge downstream. The Hinemaiaia catchment (below the scheme) is modelled because it is currently gauged and there is a high correlation between the two gauging stations above and below the scheme. The Tongariro catchment has been modelled in two parts - the regulated catchment above the Poutu Intake and the lower section between the Poutu Intake and Turangi. These two modelled outputs are combined to generate a streamflow prediction for the downstream Turangi location.

\section{Tongariro River}

The streamflow of the lower Tongariro catchment (between Poutu Intake and Turangi) is largely unmodified, although there have been some changes to the catchment as a result of the TPS. Prior to the TPS, Lake Rotoaira drained into the Tongariro River. As part of the scheme, most of its outflow has been redirected through the Tokaanu Power Station. A large part (over $140 \mathrm{~km}^{2}$ ) of the 'natural' Tongariro catchment no longer drains to the Tongariro River (see Section 2.3.1). A minimum compensation flow $\left(0.6 \mathrm{~m}^{3} / \mathrm{s}\right)$ is retained through the natural outlet (Poutu Stream) which has been used in the past to augment the Tongariro River flow to meet a previous minimum flow requirement at Turangi (Stephens, 1989). 
Table 7.3 Top five parameter sets and corresponding calibration and evaluation period KGE values for regulated catchments

\begin{tabular}{llccccc}
\hline \multirow{3}{*}{ Catchment } & & \multicolumn{5}{c}{ Top 5 Parameter Sets } \\
\hline Natural Tongariro & KGE criterion & $\mathbf{1}$ & $\mathbf{2}$ & $\mathbf{3}$ & $\mathbf{4}$ & $\mathbf{5}$ \\
& Calibration (Time) & 0.7925 & 0.7912 & 0.7817 & 0.7783 & 0.7796 \\
& Calibration (FDC) & 0.9554 & 0.9540 & 0.9502 & 0.9630 & 0.9536 \\
& Evaluation (Time) & 0.6445 & 0.6553 & 0.6661 & 0.6433 & 0.6406 \\
& Evaluation (FDC) & 0.6968 & 0.7021 & 0.7380 & 0.6952 & 0.6982 \\
\multirow{4}{*}{ Poutu } & Calibration (Time) & 0.7572 & 0.7570 & 0.7567 & 0.7574 & 0.7580 \\
& Calibration (FDC) & 0.9011 & 0.9002 & 0.9033 & 0.9008 & 0.9002 \\
& Evaluation (Time) & 0.6198 & 0.6020 & 0.5847 & 0.5684 & 0.6012 \\
& Evaluation (FDC) & 0.6819 & 0.6799 & 0.6820 & 0.6838 & 0.6980 \\
& Calibration (Time) & 0.8880 & 0.8888 & 0.8873 & 0.8890 & 0.8883 \\
& Calibration (FDC) & 0.9703 & 0.9693 & 0.9689 & 0.9614 & 0.9707 \\
& Evaluation (Time) & 0.3209 & 0.4029 & 0.3289 & 0.2382 & 0.3762 \\
& Evaluation (FDC) & 0.3295 & 0.4166 & 0.3377 & 0.2440 & 0.3879 \\
\hline \multirow{4}{*}{ Hinemaiaia (Below) } & Calibration (Time) & 0.8417 & 0.8381 & 0.8419 & 0.838 & 0.8479 \\
& Calibration (FDC) & 0.9506 & 0.9530 & 0.9642 & 0.9606 & 0.9538 \\
& Evaluation (Time) & 0.8310 & 0.8315 & 0.7962 & 0.8243 & 0.8426 \\
& Evaluation (FDC) & 0.9245 & 0.9097 & 0.8845 & 0.9265 & 0.9210 \\
\hline
\end{tabular}

Although this consent condition no longer exists, it is difficult to know without further information whether additional flow is released into this stream and at what time and in what quantities.

The rainfall multiplier implicitly accounts for these changes in catchment area, overcoming any bias resulting from the reduced streamflow. It cannot compensate for other effects such as changes in catchment dynamics (for example, additional streamflow through the Poutu Stream) without further system information which may not be easily obtained.

A number of issues also arise in the generation of a streamflow time series for this part of the catchment. Streamflow is estimated by removing the observed flow recorded downstream of the Poutu intake from that observed at Turangi, taking into account an estimated $\mathbf{1 . 5}$ hour lag time. There is often a mismatch between the timing of peak events which leads to sudden increases and decreases in inferred streamflow for the lower Tongariro sub-catchment which is inconsistent with typical hydrological behaviour. This is evident in Figure 7.9 where the inferred streamflow 


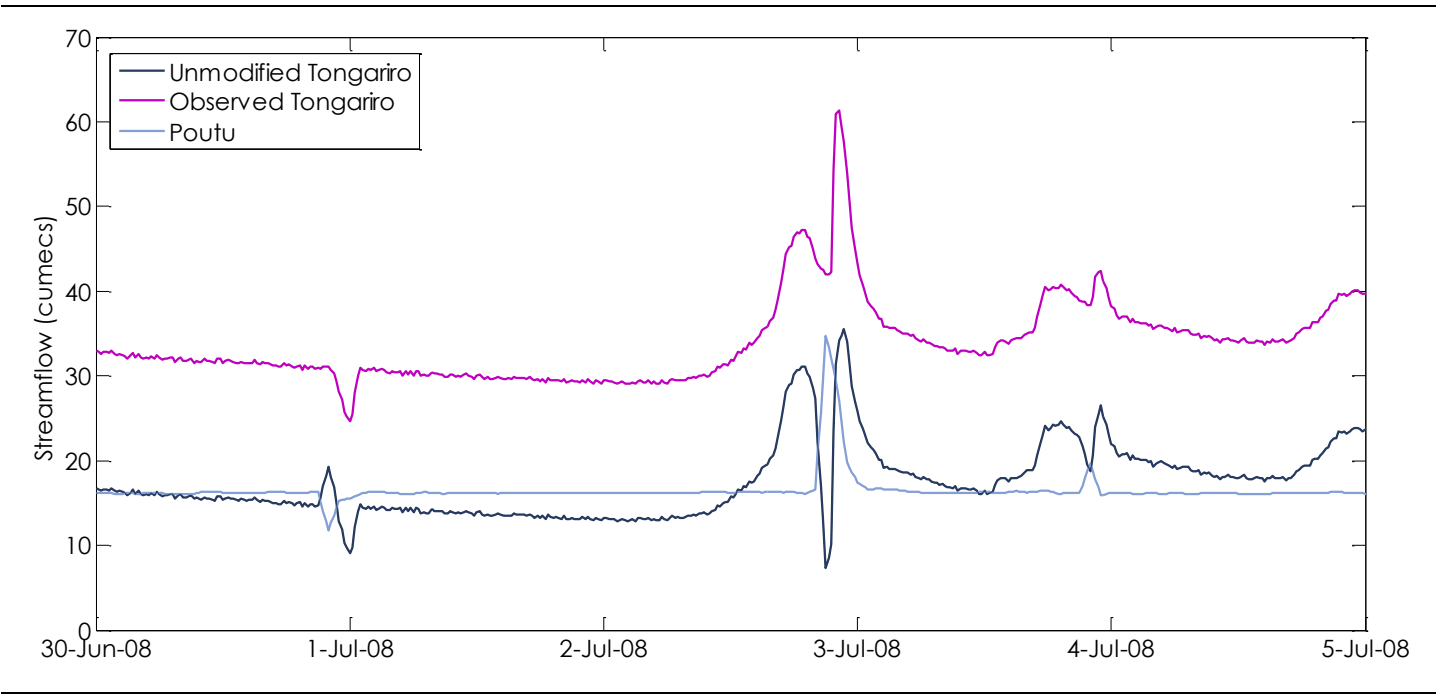

Figure 7.9 Issues with estimating the lag time between the observed Tongariro and Poutu catchments results in some physically inconsistent spikes in the inferred time series for the lower Tongariro catchment.

record oscillates briefly where the peak streamflow recorded at Poutu does not coincide with the peak observed at Turangi, even with the lag time applied. Further, because of this issue in some situations the streamflow at Poutu is higher than the corresponding flow at Turangi, resulting in a negative flow in the time series for the lower Tongariro catchment. During these times the negative flow values are replaced with mean flow values of the lower Tongariro section.

Despite these issues, the model does reasonably well in capturing the main hydrological response of the catchment. The top-performing KGE values are 0.7725 to 0.7848 for the time series and 0.9502 to 0.9630 for fit to the flow duration curve. KGE values for the evaluation period range between 0.6406 and 0.6661 for the time series and 0.6961 and 0.7369 for the flow duration curve. However, as shown in Figure 7.10, peak flows are generally over-estimated.

Model performance could be improved through better characterisation of the lag response between the Poutu Intake and Turangi. The lag time applied between the Poutu catchment and Turangi is set at 1.5 hours, calibrated to the overall best fit between the two observed time series. It does not take into account the fact that the speed at which water will reach the Turangi observation point will change depending on the volume of water in the river. It also assumes that the shape of the flood wave remains unchanged between the two observation points. Inclusion of a kinematic wave model would allow the flood wave to be propagated downstream 
(a) Observed Rainfall

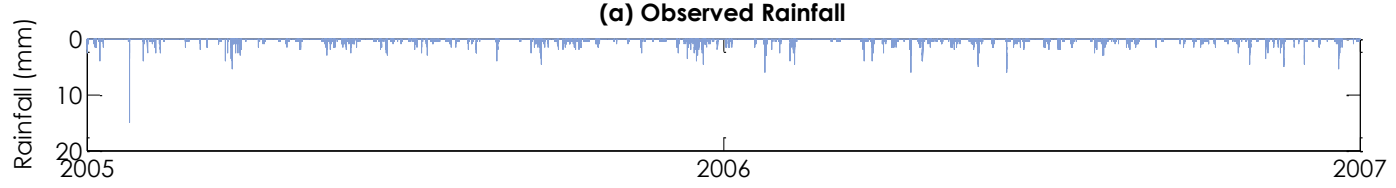

(b) Modelled vs Observed Streamflow
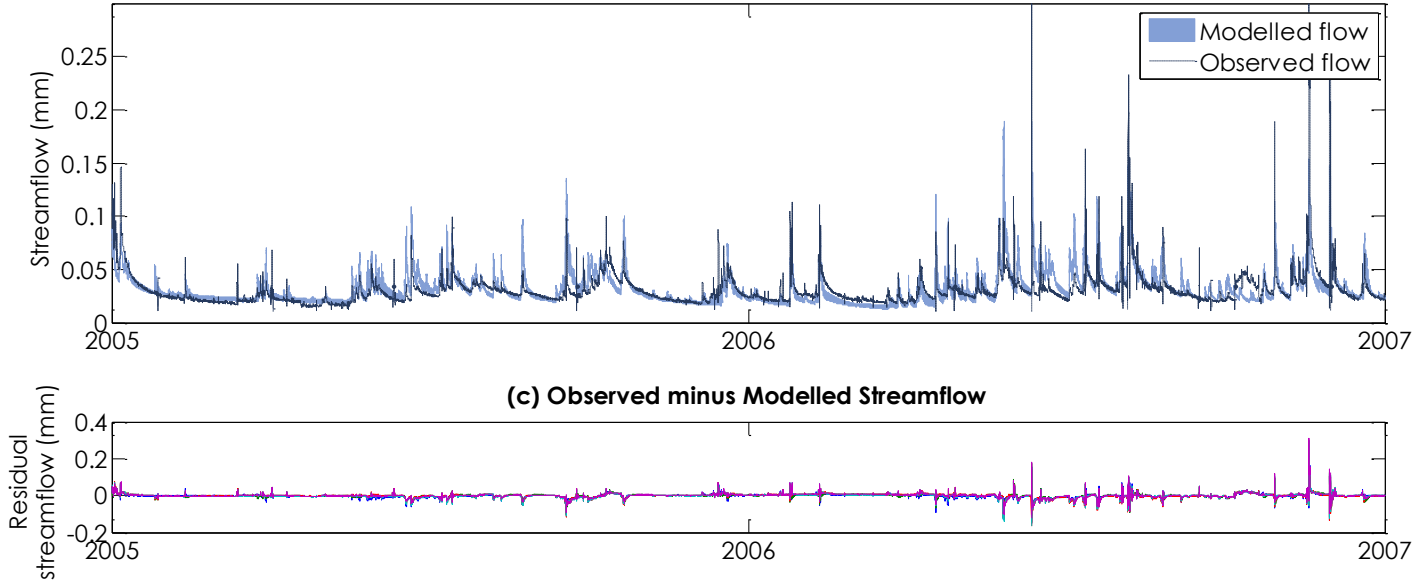

Figure 7.10 Modelled versus observed streamflow ( $\mathrm{mm} / 15$ minutes) and corresponding rainfall ( $\mathrm{mm} / 15$ minutes) for the lower Tongariro catchment.

taking into account the variation of discharge with time and distance (Singh, 2002). The timing and volume of water to arrive at Turangi from the upstream Poutu subcatchment would likely be more accurately predicted.

In terms of the Tongariro catchment above Poutu Intake, the model is unable to fully capture the complexity and regulation of this part of the Tongariro catchment (Figure 7.11). Constraints were applied to account for minimum flow, intake capacity and turbidity. These constraints make a number of assumptions that may not always hold. For example, the model assumes that at all times the Poutu Intake diverts the maximum amount of flow that can be taken given the constraints above. This may not always be the case. The TPS generally is a peak demand station and typically generates more power during peak demand times of the day. There is little storage in the scheme outside of Lake Moawhango (eastern diversion); Lake Rotoaira is operated within a $0.39 \mathrm{~m}$ operating range. The amount and timing of water diverted may correspond to peak demand times and may also be affected by how much storage there is in the various lakes of the scheme.

Model calibration is also complicated by the regulation upstream at the Rangipo Dam and the discharge from the Rangipo Power Station above Poutu Intake. Water 
(a) Observed Rainfall

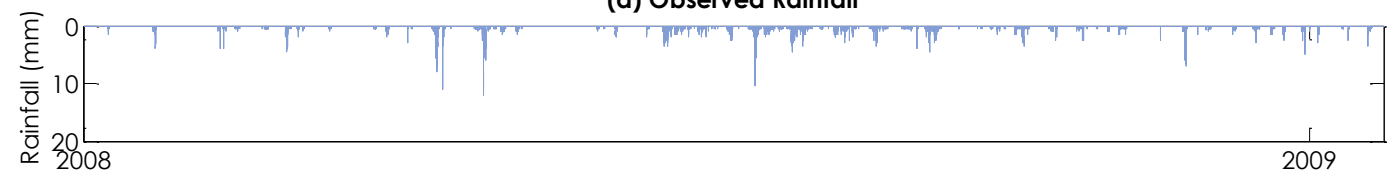

(b) Modelled vs Observed Streamflow
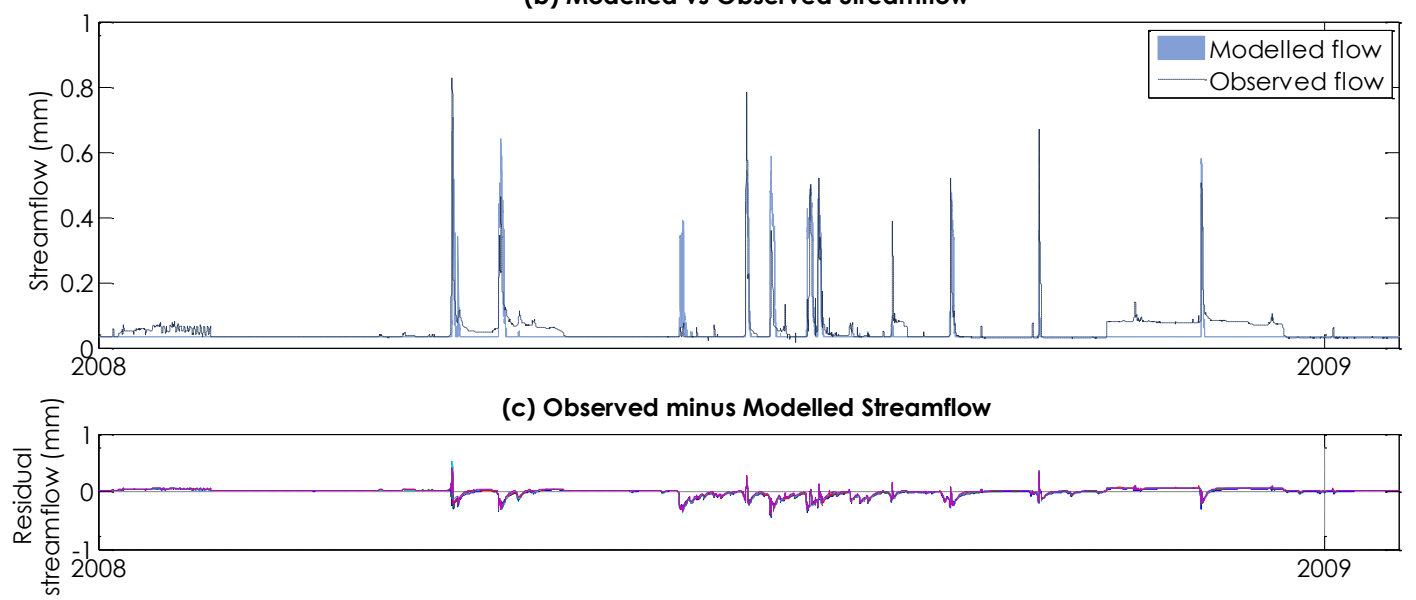

Figure 7.11 Modelled versus observed streamflow (mm/15 minutes) and corresponding rainfall (mm/15 minutes) for the Poutu Catchment.

from Rangipo Dam is diverted through the Rangipo Power Station before being discharged immediately above the Poutu Intake. Streamflow recessions are often interrupted as a result of the regulation so that they often do not follow natural recession patterns (Stephens, 1989). Nearly all water from Rangipo Dam is diverted through to Rangipo Power Station, but when this diversion/flow ceases unexpectedly water is spilled over the Rangipo Dam, resulting in an artificially induced surge in streamflow (Stephens, 1989). In addition, the recreational releases which occur at various times of the year present a hydrological response when there is no corresponding rainfall event. Unless the release schedules are known in advance, modelling these releases operationally would be difficult. With more information, the calibration and corresponding evaluation objective function values could be improved.

In terms of the LTIM (see Section 6.4.2), the modelled output from the two subcatchments of the Tongariro are combined to produce a single streamflow prediction at Turangi. This combined output is shown in Figure 7.12c. 
(a) 'Unmodified' Tongariro Catchment

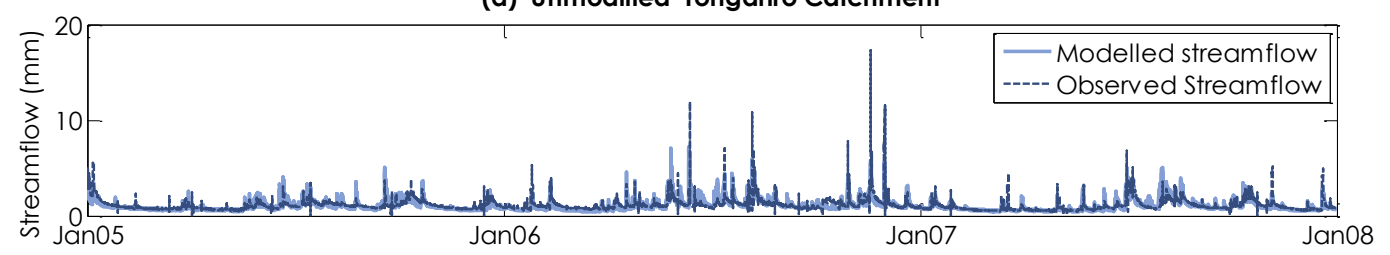

(b) Modified Tongariro (Poutu) Catchment

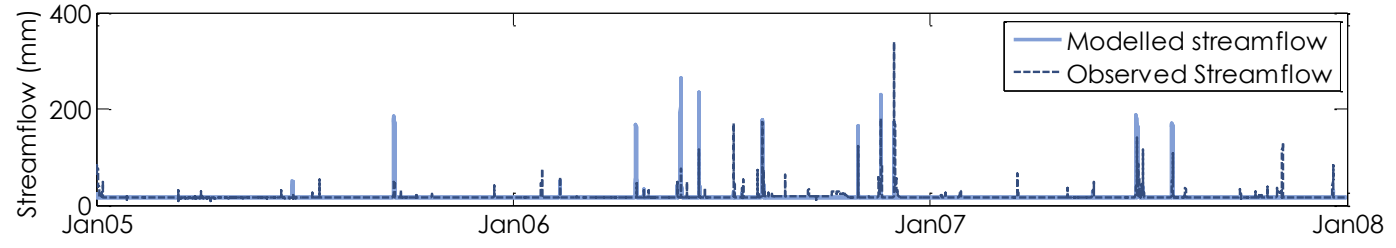

(c) Tongariro Catchment

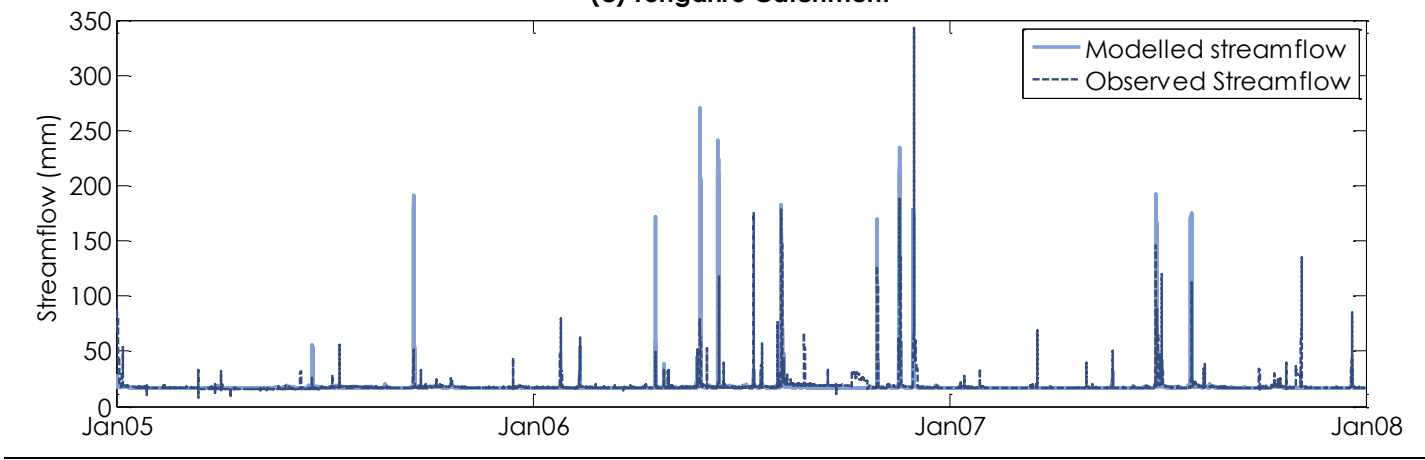

Figure 7.12 Modelled versus observed streamflow ( $\mathrm{mm} / 15$ minutes) for the (a) Lower Tongariro and (b) Poutu catchments. (c) The combined streamflow is compared against observed streamflow as recorded at Turangi.

\section{Kuratau River}

Despite relatively high calibration values for the Kuratau catchment (above the scheme), model performance over the evaluation period is significantly reduced to between 0.2382 and 0.4029 (fit to time series). Similar results were found for other periods in the record over which the parameter sets were evaluated. Figure 7.13 shows the modelled and observed streamflow for one of the evaluation periods. While the model seems to over-estimate peak flows, recessions and baseflow characteristics appear to be fairly consistent with the observations, suggesting that the KGE in this case is under-estimating the model's performance. The flow duration curve of the calibration period captured a wide range of hydrological responses at the higher and lower end of the curve, although mid-high range flows were less adequately characterised (Figure 7.14a). Residual mass curves of rainfall and streamflow for the calibration period were generally similar. However, during the middle part of the record, there are some inconsistencies between the two, indicating that rainfall is generally lower than the corresponding streamflow indicates (Figure 7.14b). This suggests that there is some seasonality in the rainfall 
(a) Observed Rainfall

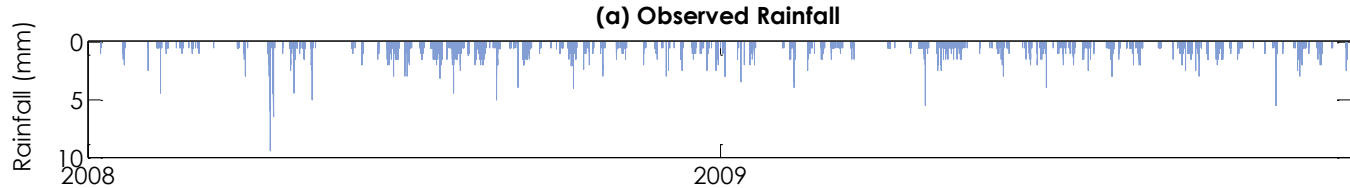

(b) Modelled vs Observed Streamflow

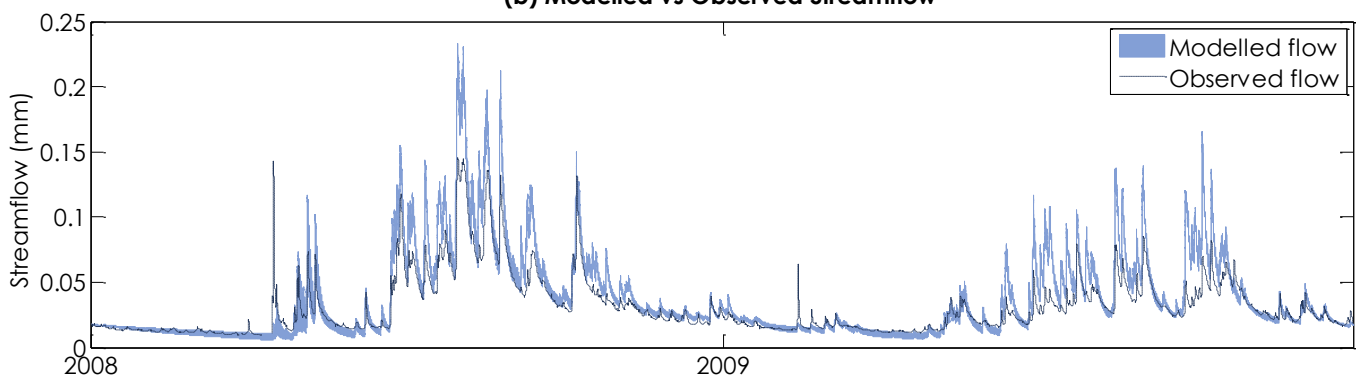

(c) Observed minus Modelled Streamflow

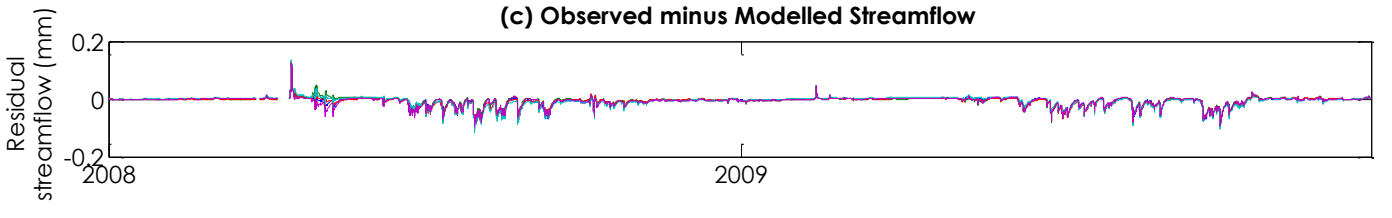

Figure 7.13 Modelled versus observed streamflow ( $\mathrm{mm} / 15$ minutes) for (a) the Kuratau catchment over the evaluation period and corresponding rainfall (b). While the modelled output overestimates peak flows it appears to capture the recession and baseflow characteristics relatively well despite low KGE values.
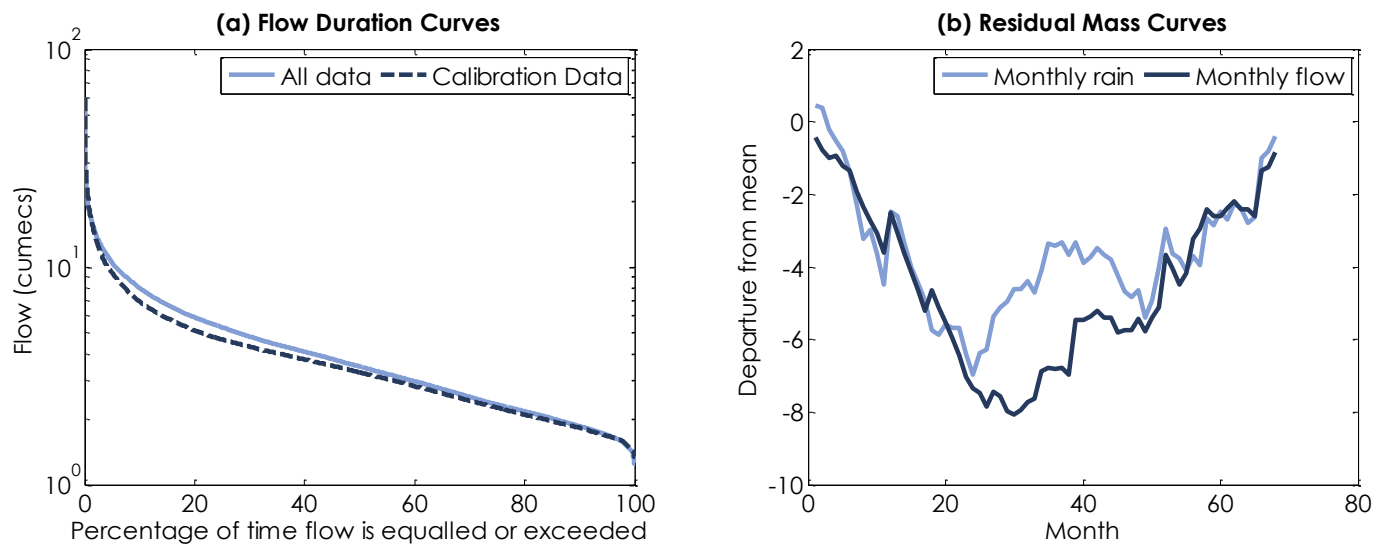

Figure 7.14 Flow duration curve and residual mass curve for calibration period for Kuratau Catchment (above the scheme)

180 | Model calibration and sensitivity analysis 
runoff relationship for which rainfall multiplier cannot account for. A rainfall multiplier based on the time of the year would improve model performance in many of the sub-catchments where a changing bias occurs (for example, the Waihohonu where some winter precipitation falls as snow and streamflow is augmented by melt water in warmer spring and summer months). Analysis of this bias by assessing seasonal or monthly mass balances would provide valuable information that could be included in the model structure.

To account for the downstream regulation of streamflow in the Kuratau catchment, a diurnal pattern consistent with the regulated discharge from the scheme is imposed on the modelled output for the unregulated section of the Kuratau River (above the scheme). The diurnal pattern is derived from the time series for the Kuratau River below the scheme between June 1976 and February 1979, and is described in Section 6.4.2.

It is difficult to evaluate the performance of the model in capturing the regulation in this catchment due to a lack of available data. The only comparative analysis can be undertaken over a three month period of overlapping observed data between November 1978 and February 1979. Over this period, the modelled output is able to predict the diurnal pattern well but under-estimated maximum river flow and overestimated minimum flows in the earlier part of the period (Figure 7.15). With a longer discharge time series (and, ideally, a more recent period of time to account for any shifts in climate) the diurnal pattern of discharge from the scheme could be

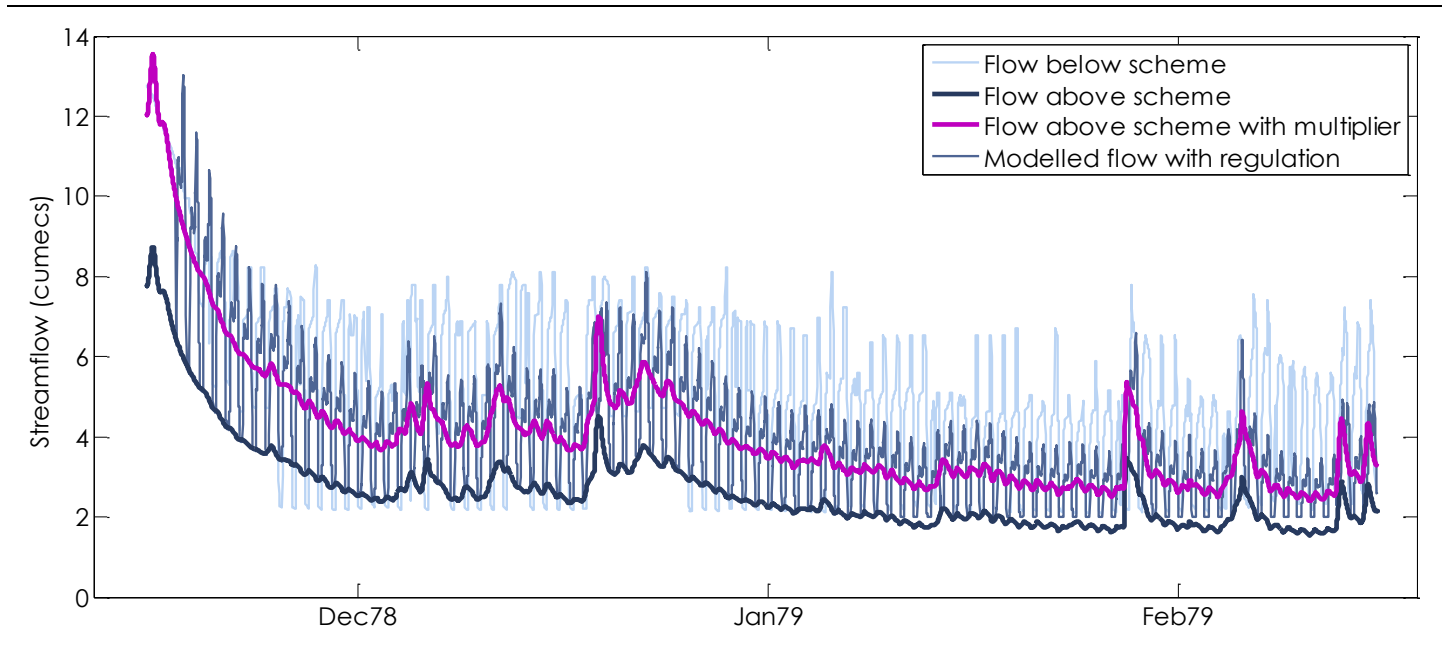

Figure 7.15 Modelled streamflow for Kuratau below the scheme compared to observed record. 
determined for each day and month of the year - similar to the statistical probability analysis for the TPS. Further, lag effects between the streamflow observed above the scheme and the discharge below the scheme could be included. Any specific data and information relating to the operation of the Kuratau Power Scheme would also be of benefit.

\section{Hinemaiaia River}

Of the three catchments, the Hinemaiaia is the least modified in terms of streamflow. The Hinemaiaia Power Scheme is a relatively small system with very little storage. There is little additional water contributing to the river between the two gauges above and below the scheme (mean flow for these two gauge locations is similar). There is, therefore, a high correlation between the streamflow recorded above and below scheme. The only known regulation is a minimum flow below Hinemaiaia $B$ of $3 \mathrm{~m}^{3} / \mathrm{s}$, where inflows into the Hinemaiaia A Lake permit (TrustPower Ltd, 2008). Since little is known of the storage and release of water from the scheme, and the fact that it is essentially run-of-river, streamflow is modelled without regulation. The minimum flow is not enforced since a low inflow above the scheme would correspond to a naturally low flow below the scheme as well. Using the Tauranga-Taupo rainfall record as input, the inflow from this catchment is modelled, with no regulation in place, except for the downstream minimum flow. KGE performance index values are relatively high, ranging between 0.838 and 0.848 for the fit to the time series and 0.950 to 0.965 for the fit to the flow duration curve. Model performance over the evaluation period is only slightly weaker with KGE performance index values for the fit to the time series ranging between 0.796 and 0.843 , and between 0.885 and 0.963 for the fit to the flow duration curve.

Close inspection of the modelled output and the observations shows that the model simulates the overall baseflow and recession characteristics of the catchment reasonably well (Figure 7.16). The more frequent smaller flood peaks are, however, often over-estimated. In larger events, peaks are generally under-estimated. It is thought that a large part of this error is largely due to the Tauranga-Taupo catchment rainfall being used as input to the model. Until 2005 a rain gauge collecting daily rainfall depths had been operational in the Hinemaiaia catchment for 40 years. Attempts to disaggregate this record into a higher resolution time series for calibration were not able to generate any satisfactory performance index values for the catchment. 


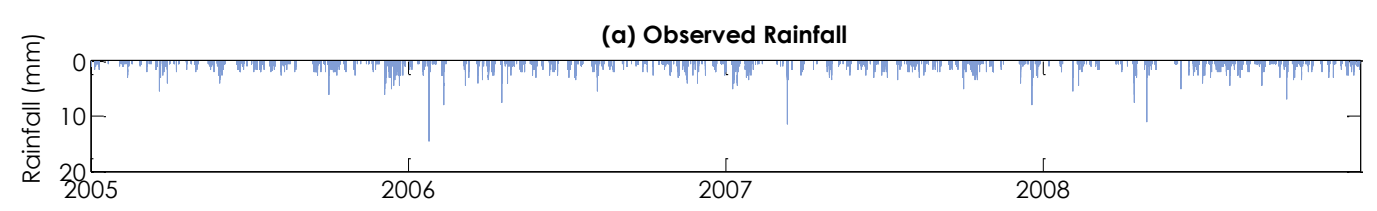

(b) Modelled vs Observed Streamflow
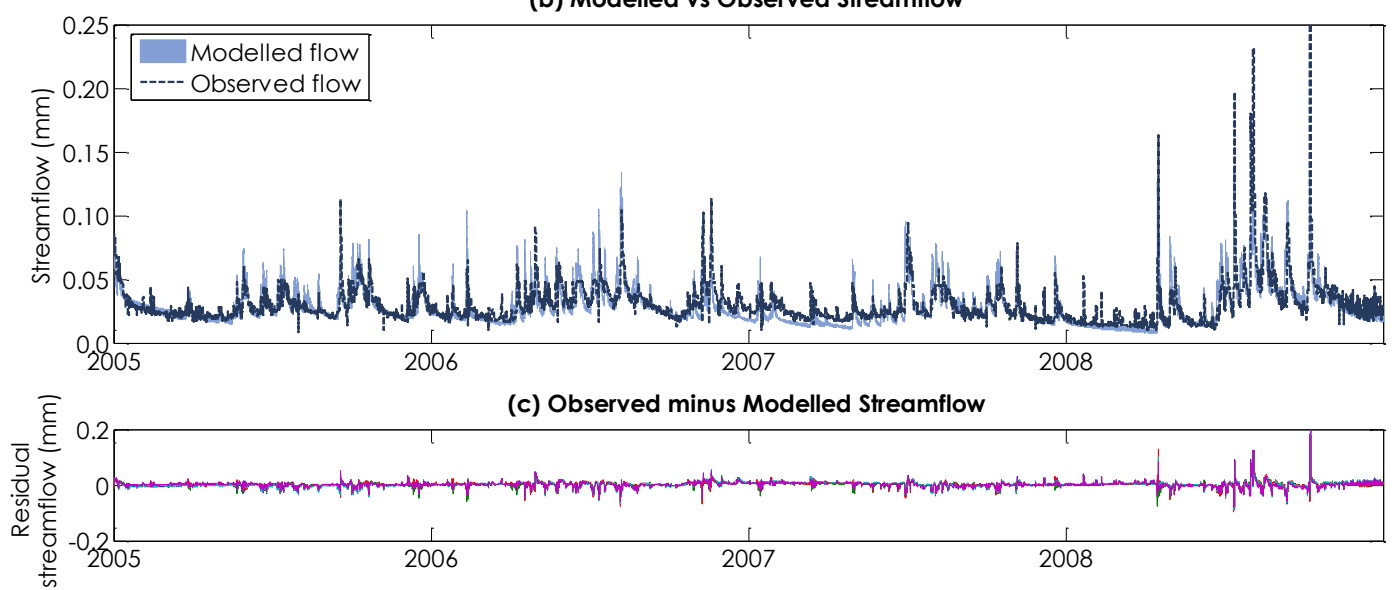

Figure 7.16 Modelled versus observed streamflow (mm/15 minutes) for (b) the Hinemaiaia catchment below the scheme and (a)corresponding rainfall ( $\mathrm{mm} / 15$ minutes) Residual streamflow ( $\mathrm{mm} / 15 \mathrm{minutes}$ ) is plotted in (c).

Toward the end of the time series shown (and beyond), more frequent oscillations appear in the record indicating greater regulation of discharge from the scheme. These oscillations begin in late 2008 and tend to follow daily energy demand profiles.

\subsection{Conclusions}

Calibration and sensitivity analysis results for thirteen historically gauged subcatchments are presented. Classic Monte Carlo sampling is used to randomly generate parameter sets from a feasible and pre-defined parameter space. Performance is determined using the Kling-Gupta Efficiency index.

One of the purposes of the model calibration process is to add to the existing knowledge of catchment hydrologic behaviour. Model identification and sensitivity analyses have confirmed that the amount of water distributed to the baseflow and fastflow stores is most important, hydrologically, in all catchments. This is not surprising since baseflow is a significant component of streamflow in all catchments despite considerable variability of catchment flood flow responses. 
Overall, the model simulates unregulated catchments reasonably well. In catchments where snow accumulates, incorporating a snowmelt module may improve model performance. A number of issues have been identified regarding the suitability and reliability of various rainfall records for model calibration. Obtaining long-term continuous rainfall records is often difficult. Records of short duration or with many (sometimes lengthy) gaps limit the amount of data available for model calibration. While performance may be good, it is difficult to know if the model parameters can simulate a wider range of hydrological conditions outside of this calibration period. Gaps could be infilled with observations from other gauging stations, but these are often several kilometres away. The temporal variability of rainfall at these locations may be quite different to the catchment they are being used to represent. Seasonality of some parameters has also been identified as an issue for which the current rainfall multiplier cannot account for. Allowing the rainfall multiplier to change with time (i.e. seasonally) could improve model performance, especially outside of the calibration period.

Despite a number of challenges, enough of the regulation associated with the three hydro power schemes in the Lake Taupo catchment is incorporated into the traditional conceptual model structure to produce reasonable simulations of streamflow. Model performance could be enhanced with additional information and data in relation to specific dam operation and scheduling in the Kuratau, Hinemaiaia and Tongariro catchments. 


\section{Lake Taupo Inflow Model}

The Lake Taupo Inflow Model (LTIM) is used to predict the overall inflow to Lake Taupo. It is designed so that, if needed, it can be used operationally (requiring coupling with meteorological forecasts and recalibration based on forecast inputs). Only those sub-catchments which are currently gauged are explicitly modelled, namely: Hinemaiaia, Tauranga-Taupo, Waimarino, Tongariro and Kuratau catchments. A statistical probability analysis estimates the inflow from the TPS. All other areas are considered ungauged and are estimated through regionalisation.

Since the previous chapter presents the model calibration results for the five subcatchments used in the LTIM, they are not presented here. This chapter presents the results of the regionalisation (Section 8.1) and the statistical probability analysis for the TPS (Section 8.2). The combined inflows from all sources are presented and evaluated over three events, representing a range of flow conditions (Section 8.3). To further improve the accuracy of model predictions, a constrained EnKF is the applied to gauged catchments (Section 8.4). Streamflow observations are used to correct for errors in state conditions for improved model performance. Mass and flux constraints are applied to each state to ensure perturbations are physically consistent. Without these constraints it is shown that the reliability of forward predictions is compromised; this has not been demonstrated in the literature before. 
Table 8.1 Lake Taupo Inflow Model catchments and data/parameters sets used

\begin{tabular}{|cc|}
\hline Catchments & Data/Parameters used \\
\hline Unregulated catchments & \\
Tauranga-Taupo & Own parameters and data \\
Waimarino & Own parameters and data \\
\hline Regulated Catchments & \\
Hinemaiaia & Own parameters, Tauranga Taupo rainfall \\
Kuratau & Own parameters and data \\
Tongariro & Own parameters and data \\
\hline Ungauged areas & \\
Waihaha & Kuratau parameters and rainfall \\
Whanganui & Kuratau parameters and rainfall \\
\hline Remaining ungauged areas: & Kuratau parameters \\
North/west & Tauranga-Taupo \\
South &
\end{tabular}

The performance of the filter is compared to the non-filtered model over the same three events used in Section 8.3 for each sub-catchment. A number of issues relating to the application of the filter are identified and possible solutions suggested. For clarity, Table 8.1 lists each of the sub-catchments of the LTIM and associated data and parameter sets used.

\subsection{Regionalisation}

For areas which are not currently gauged or have never been gauged, calibrated parameter sets from a gauged ('donor') catchment are applied through regionalisation. The donor catchment should show some hydrological similarity to the catchment being estimated.

In catchments with historical streamflow records, correlation analysis is used to determine hydrologic similarity. Based on these correlations, the parameters of the Kuratau catchment are used to predict streamflow from the Waihaha and Whanganui catchments. Streamflow from the remaining ungauged areas (1287 $\mathrm{km}^{2}$ ), where observations are not available, is estimated by identifying areas that have some degree of physical similarity available (using the information obtained in Chapter 5). In this study, the optimised parameters of the Kuratau catchment are used to estimate the flow from the remaining ungauged areas of the western and northern bays as well as the area around Taupo including the Waitahanui Catchment. This accounts for approximately $78 \%\left(1003 \mathrm{~km}^{2}\right)$ of the remaining 
ungauged areas. The remaining areas $\left(284 \mathrm{~km}^{2}\right)$ are estimated from the parameters of the Tauranga-Taupo catchment.

In all cases, the rainfall multiplier and catchment lag time are the only parameters that are calibrated. Calibration is undertaken against existing historic streamflow records in the case of the Whanganui and Waihaha catchments. An inferred streamflow record for the two remaining ungauged areas is estimated from known inputs, outputs and changes in lake level, as described in Section 6.4.4. Calibration of these time series is based on cumulative distributions due to the oscillatory effects in the lake level that persist in the inferred ungauged streamflow time series.

\subsubsection{Catchment specific regionalisation}

Although the Kuratau, Whanganui and Waihaha catchment are hydrologically similar, there are a number of differences in the physical characteristics of the subcatchments which may affect the performance of the Kuratau parameters in these areas. The Whanganui and Waihaha catchments drain areas of older Whakamaru ignimbrites which are less permeable than the andesitic and sedimentary lithologies prominent in the Kuratau catchment. Basement greywacke is also present in the headwaters of the Waihaha catchment. The Kuratau catchment is covered mainly by pumice soils, reflected in the model calibration by higher field capacity values than the Whanganui and Waihaha catchments.

Catchment size and shape also varies. The Whanganui is the most elongated (elongation ratio: 0.44$)$ and smallest of the three $\left(31.6 \mathrm{~km}^{2}\right)$ and has the highest drainage density. The Waihaha has an elongation ratio of 0.65 , while the Kuratau is 0.55. The Waihaha catchment is the steepest as it drains the higher elevated and steeper areas of the Hauhungaroa Ranges.

With these characteristics it is not unreasonable to expect the Whanganui and Waihaha catchments to respond more quickly than the Kuratau catchment. Residence times are similar between the Waihaha and Kuratau catchments, although considerably different to the Whanganui. Interestingly, there is little difference in proportion of flow routed through the fastflow store between these three catchments. Baseflow proportion is generally higher in the Kuratau but the Whanganui and Waihaha have higher interflow proportions.

Performance of the Kuratau parameters is compared against respective catchment calibrated parameter sets (Table 8.2). Despite the physiographic differences, the 
Table 8.2 Performance results for regionalisation of Whanganui and Waihaha catchments using Waihaha rainfall record and for the Waihaha using the Kuratau rainfall record.

\begin{tabular}{ccccccc}
\hline \multirow{2}{*}{ Catchment } & \multicolumn{7}{c}{ Top 5 Parameter Sets } \\
\hline \multirow{2}{*}{ Whanganui } & KGE criterion & $\mathbf{1}$ & $\mathbf{2}$ & $\mathbf{3}$ & $\mathbf{4}$ & $\mathbf{5}$ \\
& KGE (time) & 0.8345 & 0.8799 & 0.8918 & 0.7929 & 0.8563 \\
& KGE (fdc) & 0.8697 & 0.9211 & 0.9435 & 0.8182 & 0.8942 \\
\hline Waihaha & KGE (time) & 0.9003 & 0.8944 & 0.9025 & 0.9018 & 0.8950 \\
& KGE (fdc) & 0.9627 & 0.9426 & 0.9590 & 0.9627 & 0.9505 \\
\hline Waihaha & KGE (time) & 0.8435 & 0.7844 & 0.7018 & 0.9148 & 0.7841 \\
(using Kuratau rain) & KGE (fdc) & 0.8693 & 0.8048 & 0.7137 & 0.9652 & 0.8043 \\
\hline
\end{tabular}

Kuratau parameters are able to simulate streamflow reasonably well using Waihaha catchment rainfall ${ }^{10}$. It is concluded, therefore, that a combination of different factors are working together to give a similar hydrologic response.

Operationally, the rainfall recorded in Kuratau is used as model input for these two catchments. It is important, therefore, that the performance of the parameters are analysed with respect to the rainfall data that will be used to drive the operational model. Since there is no overlapping data between the Whanganui streamflow and Kuratau rainfall records, this analysis can only be undertaken on a short period of overlapping data for the Waihaha catchment. For the period July 1994 - April 1995, the Kuratau parameters and rainfall record produced KGE values between 0.702 to 0.915 for the fit to the time series and between 0.714 and 0.965 for the fit to the flow duration curve (Table 8.2). This suggests that the Kuratau parameters are suitable for estimating streamflow from these catchments.

Figure 8.1 compares the observed Waihaha streamflow with the modelled streamflow using the Kuratau parameters and rainfall, calibrated for the rainfall multiplier and lag time only. Over this relatively short period of evaluation, peak flood flows are under-estimated by the model and baseflow conditions are slightly higher. However, recession characteristics are consistent with the observations. Improvements could be made if a more suitable rainfall gauge could be found or the rainfall gauge was reinstalled. There is a rainfall gauge located closer to the Waihaha catchment than the Kuratau but this record only begin in 2004 and its suitability as

10 Waihaha rainfall is also used to calibrate the Whanganui River sub-catchment as it is the closest station to this catchment. 
(a) Observed Rainfall

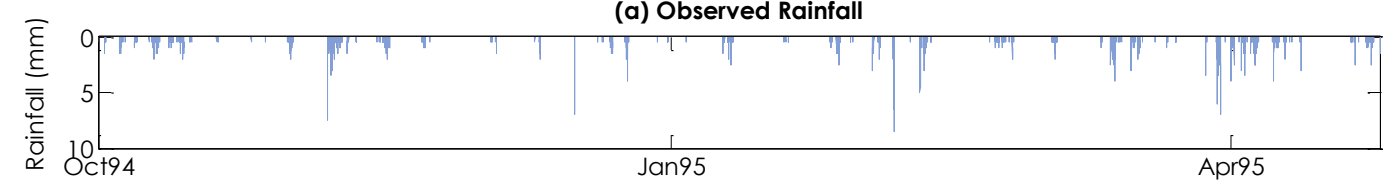

(b) Modelled vs Observed Streamflow
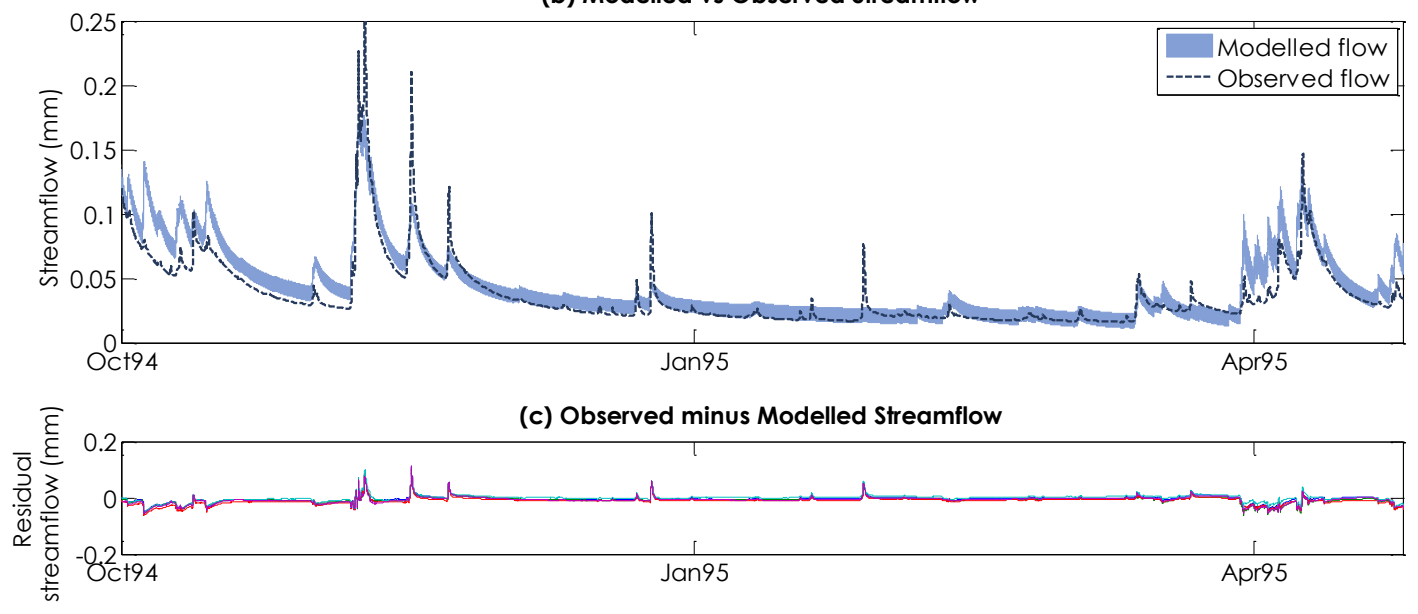

Figure 8.1 Calibration of Waihaha catchment using Kuratau rainfall record and Kuratau parameters. Units are $\mathrm{mm} / 15$ minutes.

input for the Waihaha catchment cannot be determined since there is no overlap between this rainfall record and the Waihaha streamflow record.

Given the relatively small contribution of these two catchments to Lake Taupo inflows, and the relatively good performance of the Kuratau parameters in estimating their respective inflows (notwithstanding their physical differences), these parameters and rainfall record are deemed suitable for estimating the inflow from the Waihaha and Whanganui catchments.

\subsubsection{Regionalisation of remaining ungauged areas and direct groundwater contribution}

The remaining ungauged areas of the Lake Taupo catchment are divided into two areas (refer Section 6.4.4). The Kuratau parameters are used for a large part of the ungauged areas north and west of the Lake Taupo catchment, from the Waihi catchment (in the south-west) around to the Hinemaiaia catchment in the east. The physical attributes of the Kuratau catchment are most representative of a large part of these ungauged areas in terms of land cover, geology and soils. From Hinemaiaia catchment south around to (and including) the Waihi catchment, parameters from the Tauranga-Taupo catchment are applied. Parts of this ungauged area drain the 
steeper areas of the Kaimanawa Ranges, from which the Tauranga-Taupo catchment also drains.

Initial calibration of these two parameter sets for the respective areas of the catchment provided substantially higher rainfall multipliers than expected. For the ungauged time series estimated from the Kuratau parameters the rainfall multiplier was 3.1 while for the area estimated from the Tauranga-Taupo parameters the rainfall multiplier was around 2. Given that these ungauged areas are generally in the lowland areas of the catchment coinciding with areas of lower rainfall, these rainfall multipliers would suggest that there is some water that has not been accounted for. The answer may be in the direct groundwater discharge to the lake.

Based on existing literature (Bou, 2007; Gibbs et al., 2005; Murphy, 2006; Piper, 2004), direct groundwater seepage to Lake Taupo could be as much as $20 \%$ of the inflow to Lake Taupo. This equates to approximately 30m $3 / \mathrm{s}$ (refer Section 2.3.2). Removing this amount from the ungauged time series reduces the rainfall multiplier to 2.05-2.32 for the area estimated by the Kuratau parameters and 0.77-0.85 for the area estimated by the Tauranga-Taupo parameters. KGE values of the cumulative distribution of these results are shown in Table 8.3 and the cumulative distributions for both areas are shown in Figure 8.2.

In both distributions modelled streamflow is higher than the observations around 1998 and 2000, shown by the change in slope for the modelled output relative to the observations. In the areas modelled by the Tauranga-Taupo parameters there is another deviation from the observations in 2000. Between 2004 and 2007 the reverse is seen. Toward the end of the calibration period, the areas modelled by the Tauranga-Taupo parameters show good correspondence with the observations. In the areas modelled by the Kuratau parameters, the period from 2003 to 2004 shows less modelled inflow than is observed, indicated by the steeper slope of the observed cumulative distribution than the modelled cumulative distribution. The slopes of the cumulative distributions are similar for the period 2005-2007 but then deviate in 2006. Modelled output again over-estimates the inflow from these areas at this time.

Table 8.3 Performance results for regionalisation of ungauged areas.

\begin{tabular}{ccccccc} 
Ungauged & Calibration Period & $\mathbf{1}$ & $\mathbf{2}$ & $\mathbf{3}$ & $\mathbf{4}$ & $\mathbf{5}$ \\
\hline Kuratau & Jan 1998-Dec 2010 & 0.9753 & 0.9887 & 0.9055 & 0.9883 & 0.9769 \\
Tauranga-Taupo & Jan 1998-Dec 2010 & 0.8775 & 0.8787 & 0.8727 & 0.8779 & 0.8754
\end{tabular}




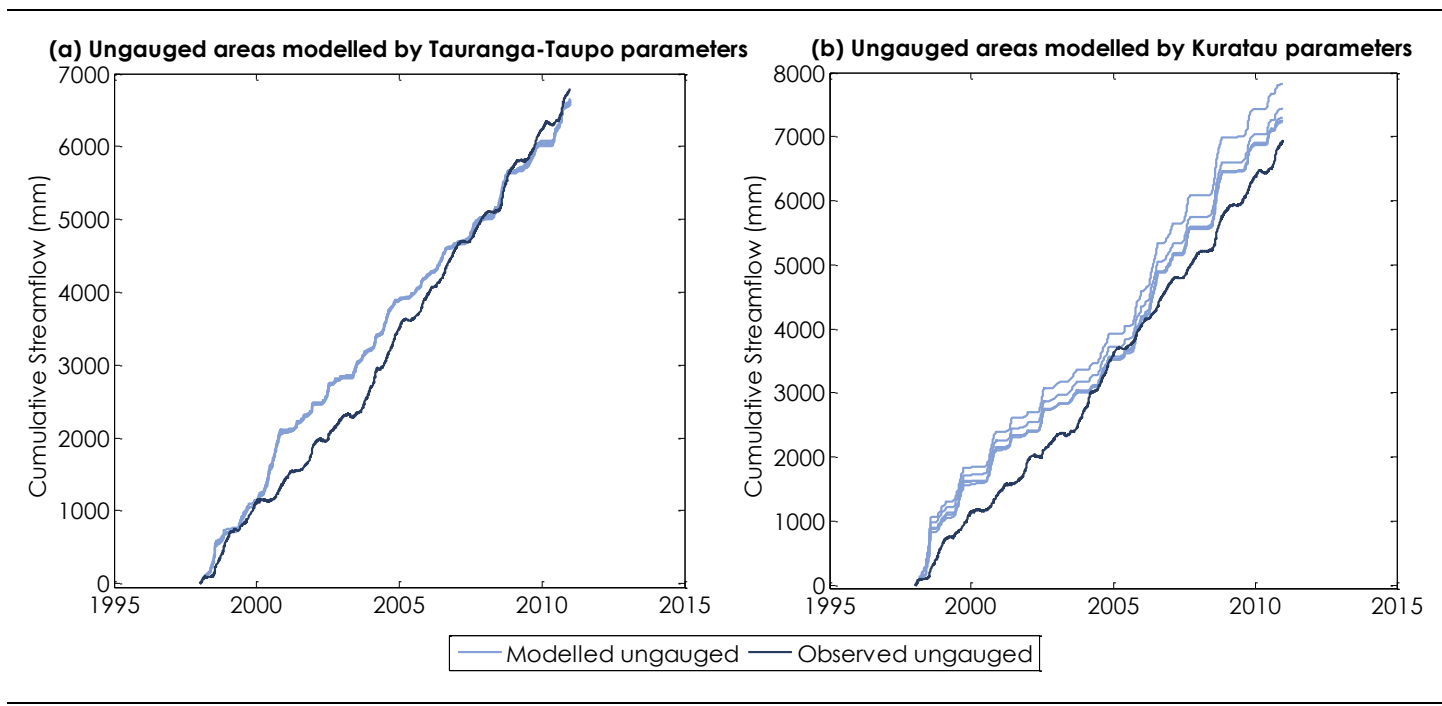

Figure 8.2 Cumulative distributions of modelled versus observed streamflow for ungauged areas. The areas estimated by the Tauranga-Taupo parameters (a) show relatively good correspondence but overestimate inflow between 2000 and 2005. The areas estimated by the Kuratau parameters (b) generally over-estimate inflow except for a period between 2005 and 2007. Units are mm/15 minutes.

It should be noted that the Kuratau parameters are used to estimate a much larger area of the catchment (than the Tauranga-Taupo parameters) and may be less representative of the hydrology of the northern bays and around Taupo. Dividing the large area of the north and west into smaller sub-areas and undertaking a more detailed investigation into utilising parameter sets from other historically gauged catchments would be of value.

There is also more spread in the cumulative distributions of the parameter sets indicating more uncertainty in this ungauged section of the Lake Taupo catchment. The rainfall multiplier for the northern/western areas is still higher than might be expected. Testing possible groundwater input values may reduce the multiplier further. In this study, the groundwater contribution is added to total lake inflow in the process of deriving the ungauged inflow time series. In doing so a number of assumptions are made. Firstly, direct groundwater input is assumed constant, irrespective of catchment conditions. Secondly, the rate of inflow from this source is based on reported estimated inputs from some sub-catchments of Lake Taupo. These estimated inputs are scaled to account for the total catchment area. Consequently, there is likely to be considerable error in this estimation. To reduce this uncertainty, the direct groundwater component could be added to the existing model structure as an additional linear store to be modelled. This is discussed further in Chapter 9. 
As a consequence of some of the issues identified above, the accuracy of lake level predictions is affected. These issues are, therefore, considered when evaluating model performance.

\subsection{Tongariro Power Scheme (TPS) Statistical Probability Analysis}

The inflow from the TPS is estimated using a statistical probability analysis based on the discharge time series from the Tokaanu Power Station. Analysis of the data indicates that the typical daily discharge profile follows the general pattern of energy demand (see Section 6.4.3). Figure 8.3 also illustrates how discharge from the scheme also changes with the time of year and day of the week. As this is a peak demand station, there is often zero discharge from the scheme, especially during lower demand periods overnight. The statistical probability analysis therefore predicts the likelihood of a discharge given the time, day and month. The calculated probability that water is discharged from the station given the hour, day and month is presented in Figure 8.4. As expected, the probability of zero discharge is highest at night when demand is lowest. During winter months, the probability of zero discharge is generally less.

During summer months water is not diverted via the western diversion in order to meet minimum flow requirements at Te Maire. During this time, there is a greater probability that there will be zero discharge from the Tokaanu Power Station, especially over weekends.

Figure 8.5 shows the likelihood of a discharge from the scheme for each hour, day and month. The light blue shaded region shows the range of flow between the $10^{\text {th }}$ and $90^{\text {th }}$ percentiles. The dark blue solid line shows the median flow $\left(\mathrm{Q}_{50}\right)$. The largest discharges occur on weekdays during winter months, when demand is generally highest. During drier summer months, discharge from the scheme is at its lowest. Lowest discharges are predicted for the months of March and April, which also coincides with the period of lowest rainfall and also the period in which the western diversion is shut off. During this period, water may be stored for generation at peak demand periods when the price of water and generation may be at their highest. 

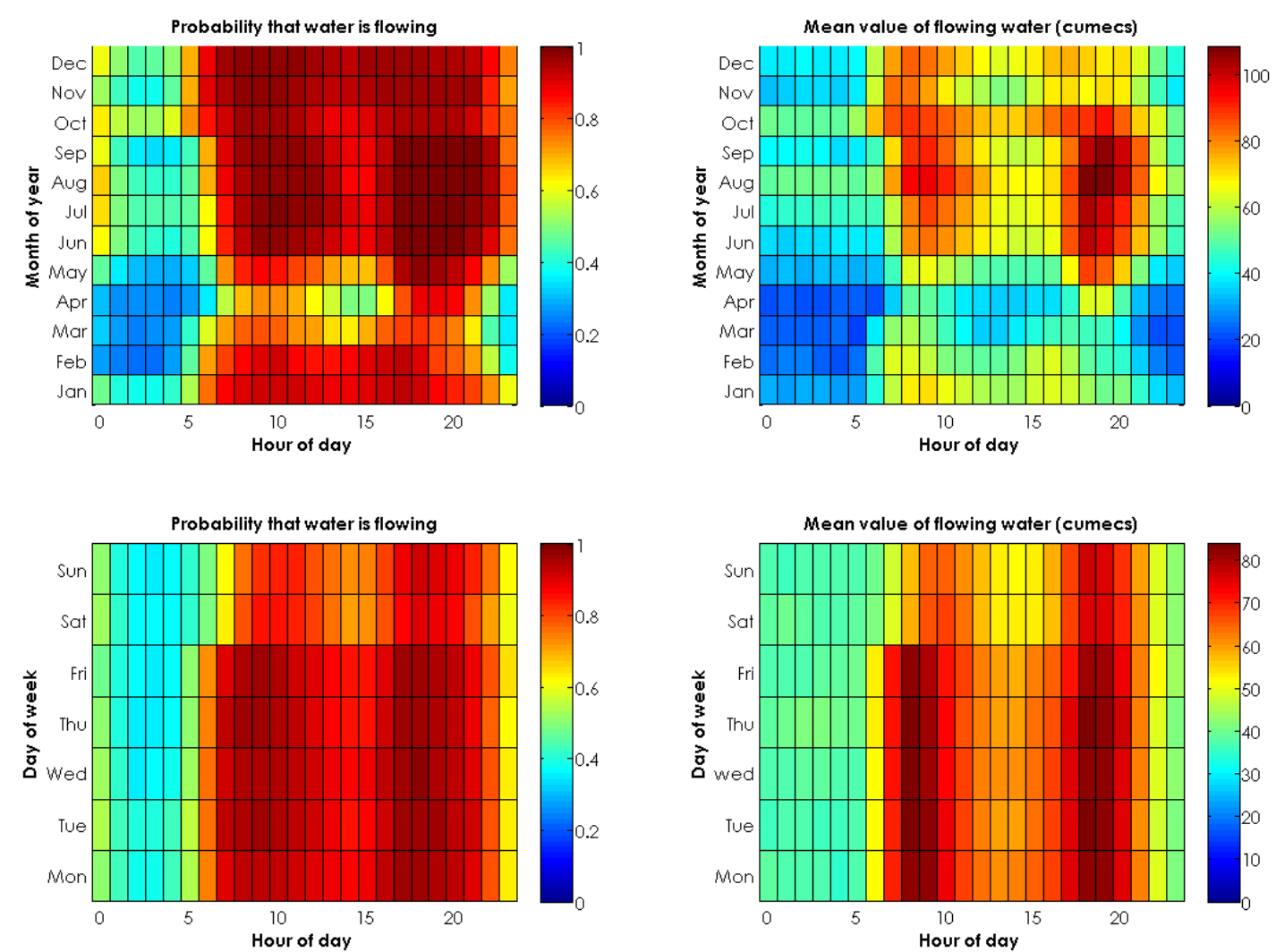

Figure 8.3 Probabilities associated with TPS in terms of whether water is flow and the mean flow of flowing water.

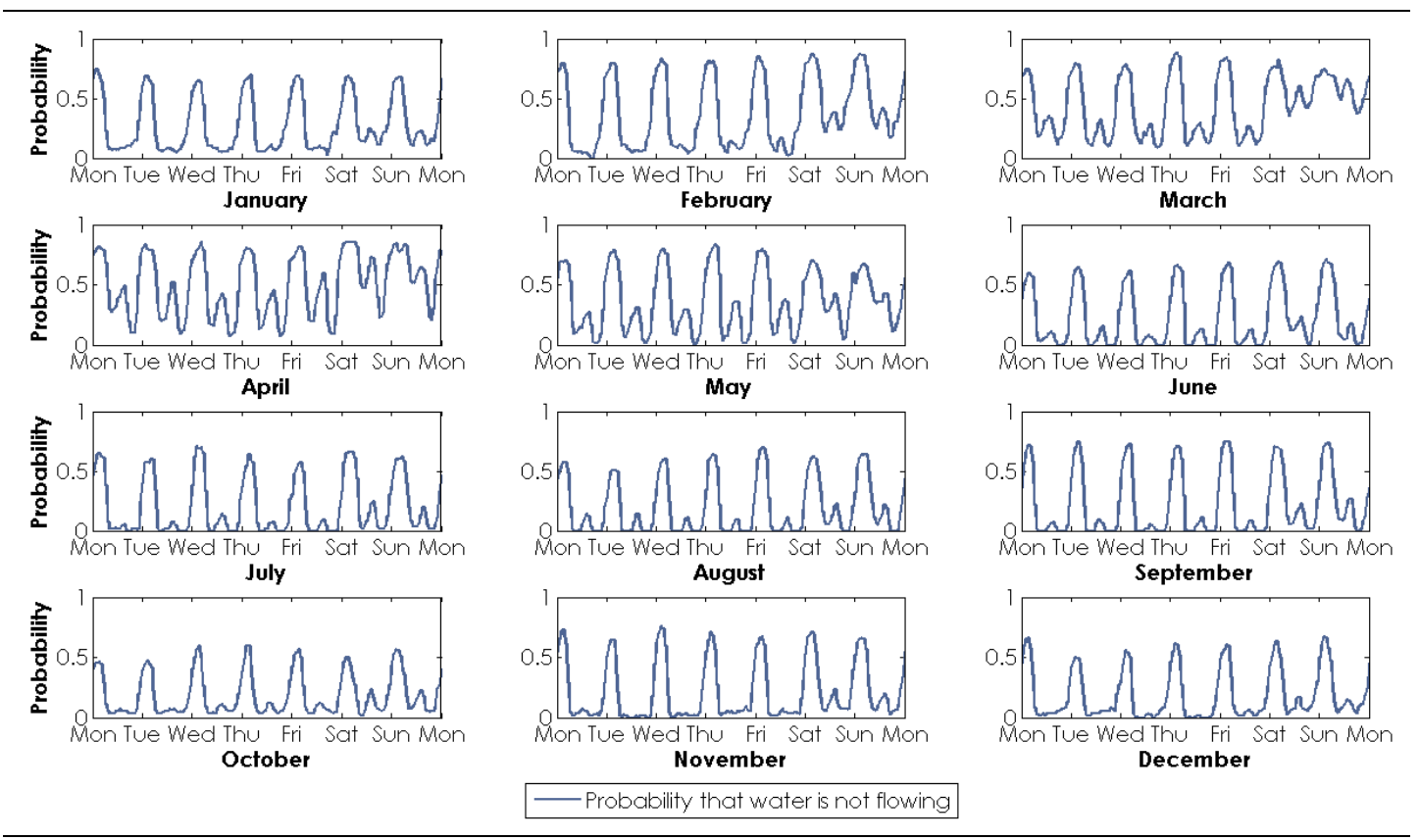

Figure 8.4 Probability that water is not discharged from the TPS given the time of day, day of the week and month of the year. 
In terms of prediction, the shaded region in Figure 8.5 demonstrates the range of flows possible for a given period, and hence the uncertainty associated with the probability. Given the significance of the TPS to the inflows to Lake Taupo, the accuracy of inflow predictions (and, therefore, lake level forecasts) could be significantly improved with more reliable predictions relating to the discharge from the TPS.

In the absence of information specific to dam operation and scheduling, storage and diversions, there are other external aspects of the system that may influence the amount and timing of discharge from the scheme that could be incorporated into the analysis to further reduce uncertainty. This may include information on the market price of hydro generation and weather.

In New Zealand electricity generators submit 'offers' to produce a certain amount of electricity for a specified payment for each future half hour generation period. These offers are ranked (by the System Operator), with the lowest cost offers selected first until demand is satisfied. The payment received by the generators selected is based on the highest priced offer required to meet demand (Electricity Commission, unknown). The payment associated with the offer will change with demand and supply. During dry periods, when storage lakes are low, generators may want to conserve their supply. To do this, they would place a higher value (price) on hydro generation making it less likely to be accepted for generation in the market. Conversely, the price of water may be reduced during winter periods when there is a lot of water in the system. This price of hydro-generation can, therefore, affect the amount and timing of discharge from the TPS.

The demand for electricity is also affected by weather, in particular temperature. There may be less demand for power during a mild winter than in a cold winter. Similarly, a cooler summer may increase demand.

As is common in time series data, the discharge from the TPS exhibits some temporal coherence (serial autocorrelation). That is, data points of the discharge time series located near each other are likely to be similar. For example, during a flood event consecutive data points may be high for a period of time. Similarly, the price of water is less likely to suddenly increase/decrease between consecutive observation points. Serial autocorrelation analysis can be included in statistical probability analysis to improve the predictions from this approach. 

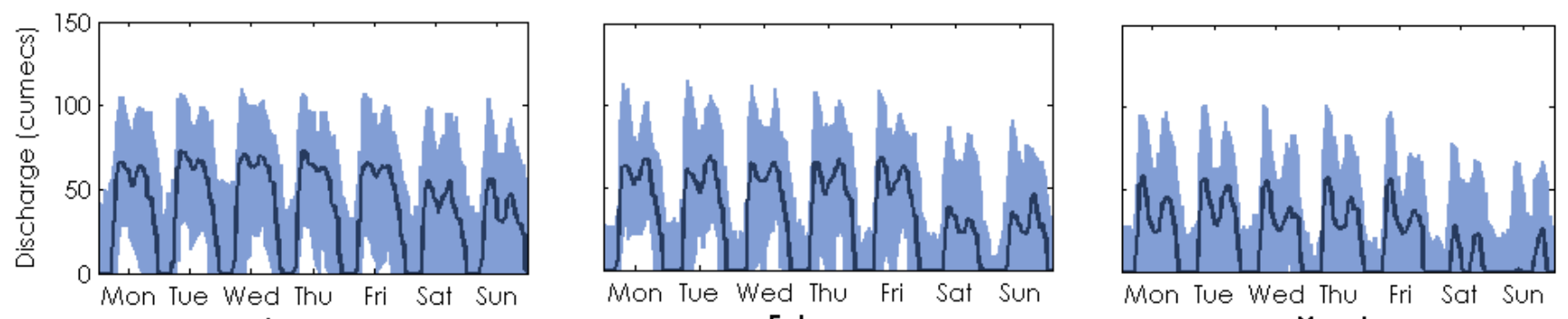

January

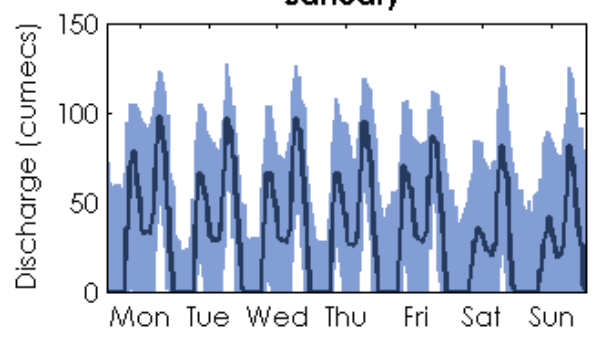

February

March

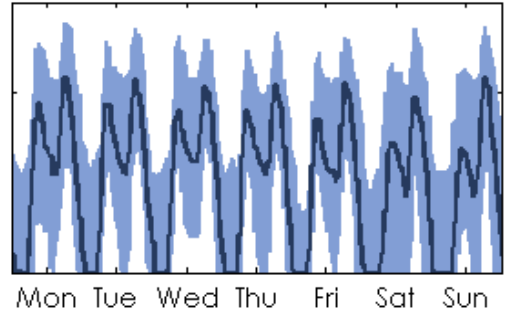

June

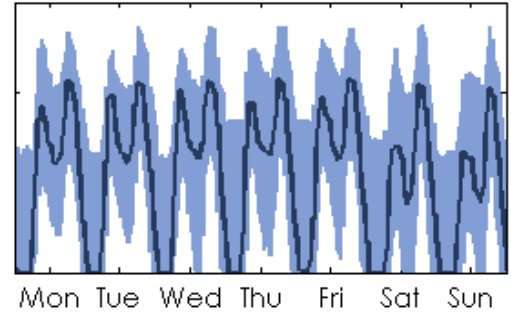

July

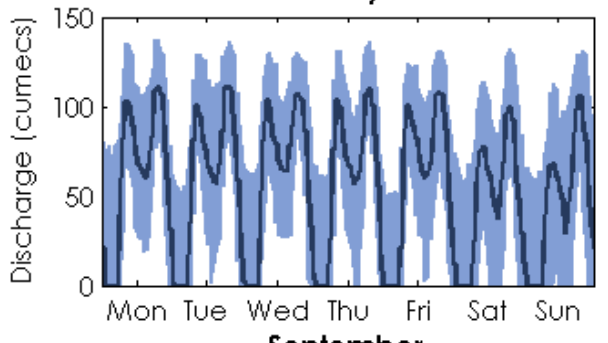

September
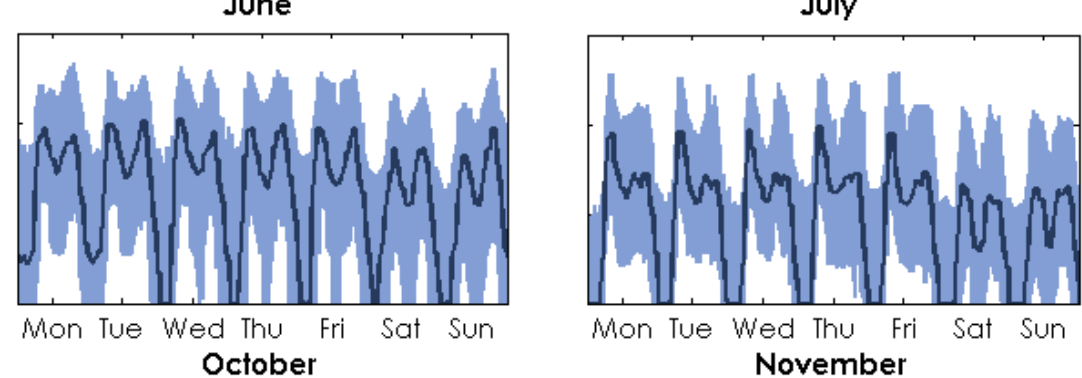

10/90th percentile - 50th percentile

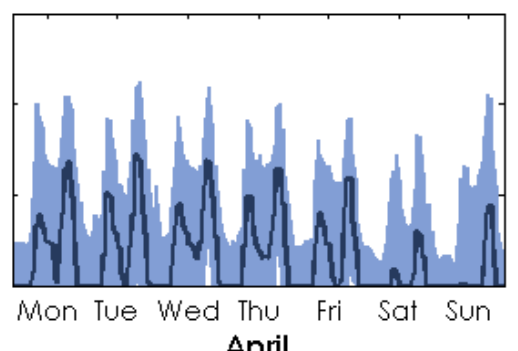

April

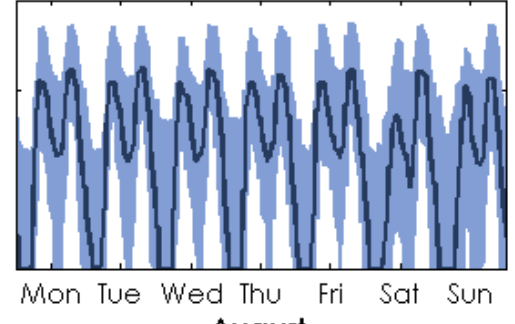

August

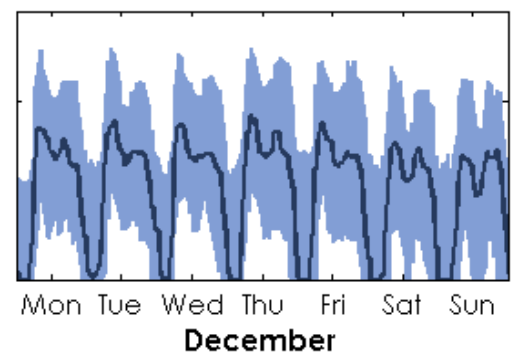

Figure 8.5 Results of the statistical probability analysis showing the possible range of discharges from the TPS given the time of day, day of the week and month of the year. The blue shaded region encompasses the range of possible discharges between the 10th and 90th percentiles. The dark blue line indicates the discharge at the 50th percentile. 


\subsection{Lake Taupo Inflow Model performance}

Model output is combined to generate an inflow volume to Lake Taupo. This combined inflow is compared against observations over three events between 1998 and 2010. These events represent a range of flow conditions including a flood event (July 1998), 'normal' operating conditions (November 2006) and period of drought (May 2010). These events were chosen because they show a range of inflow conditions to the lake, including two of the severest but opposing events of the 19982010 period. Figure 8.6 presents the total inflow from gauged and ungauged areas plus the predicted discharge from the TPS. Modelled output follows the general trend in the observations for all events, despite the erratic oscillations (a result of using residual inflows to derive streamflow from ungauged areas, refer Section 6.4.4). However, modelled inflows over the July 1998 event tend to be overestimated for the majority of the period. Since there are no direct observations from ungauged areas, improvements to the estimation of inflows from this source relate to refining regionalised parameter ranges and/or more direct observations to reduce the size of the ungauged area to be modelled. These issues are discussed further in Section 9.4.

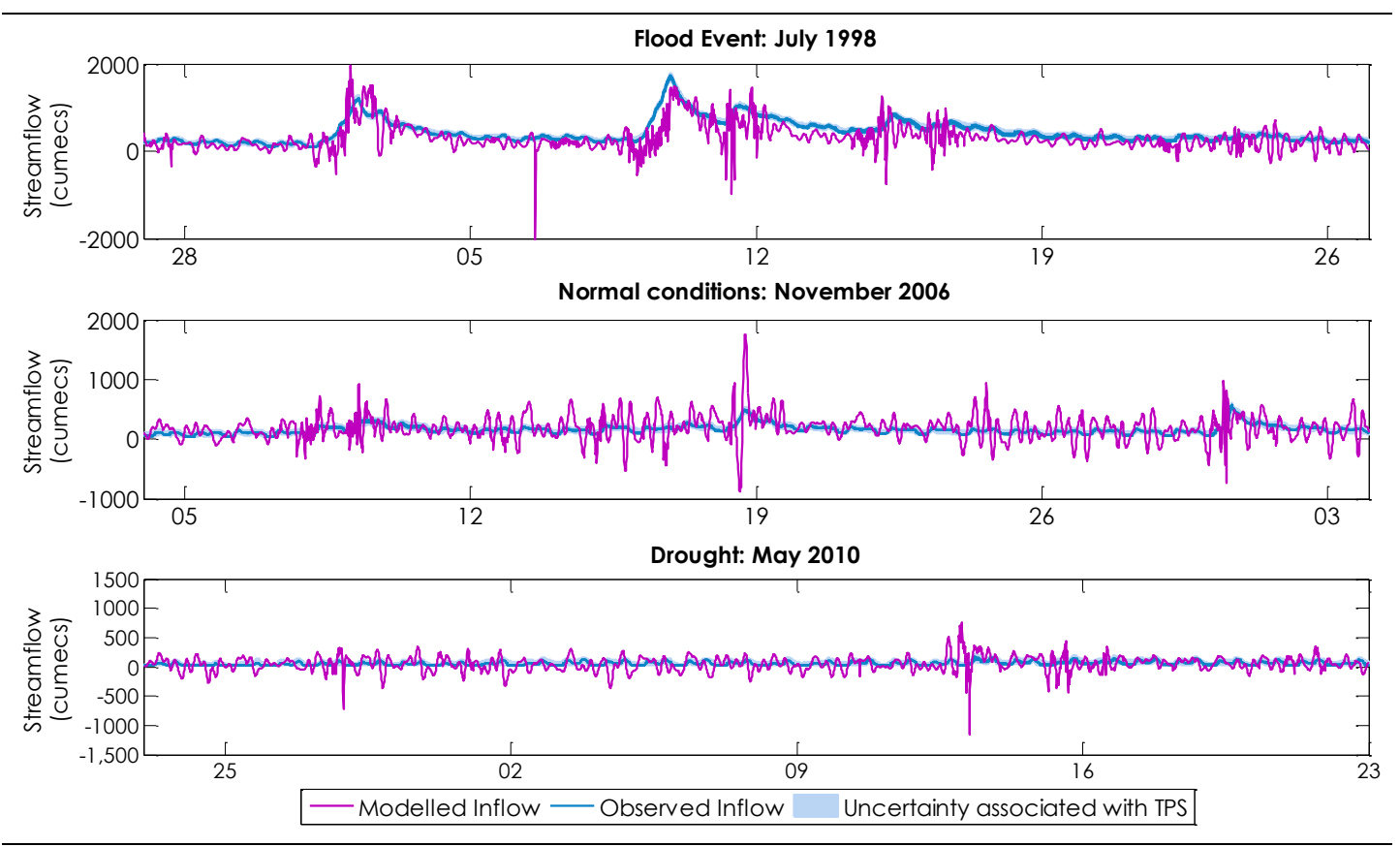

Figure 8.6 Lake Taupo Inflow Model performance: modelled versus observed inflows from gauged and ungauged areas plus predicted discharge from the TPS. 


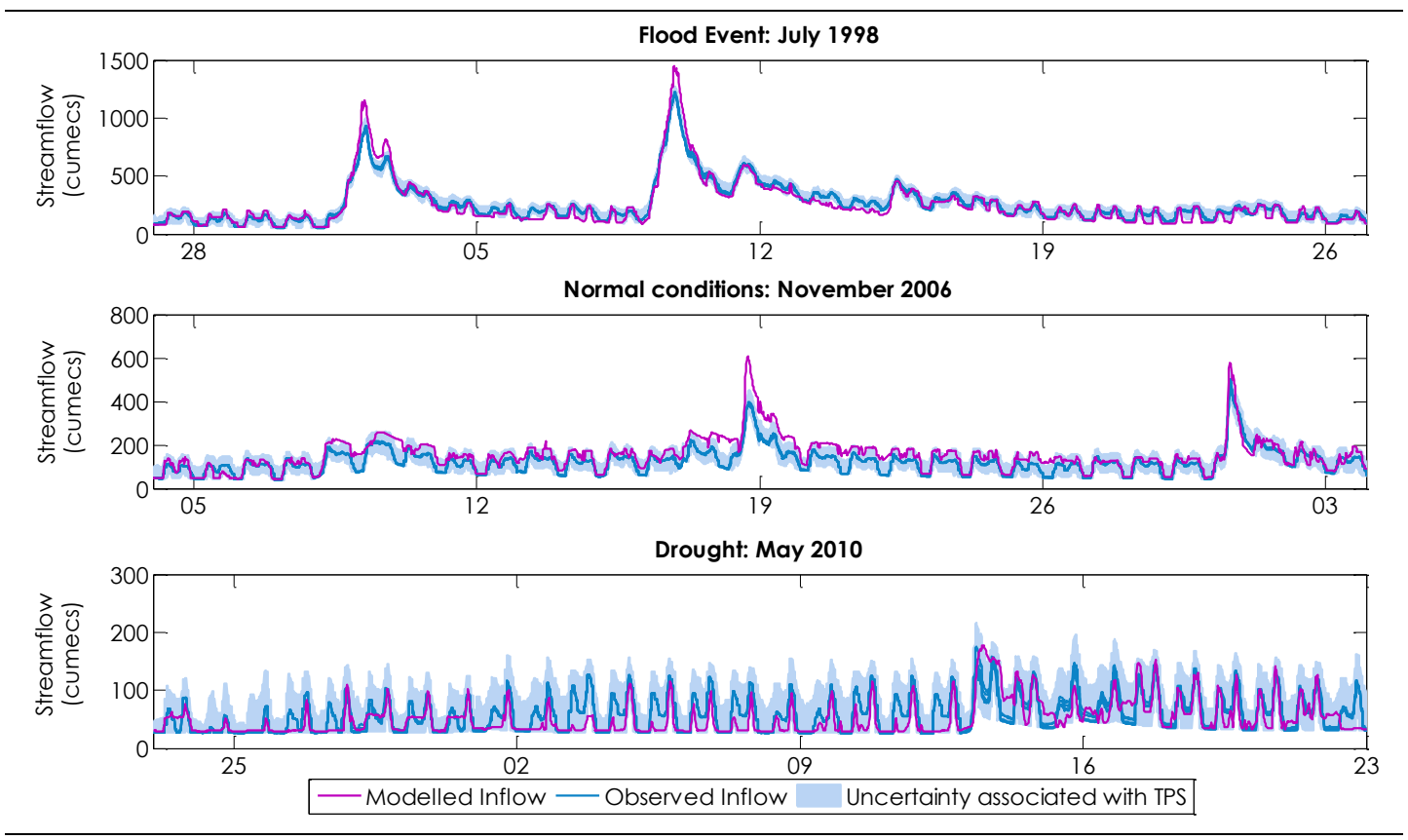

Figure 8.7 Lake Taupo Inflow Model performance: modelled versus observed inflows from gauged areas including the predicted discharge from the TPS.

Removing the inflows from ungauged areas gives a clearer picture of known inflows to Lake Taupo (Figure 8.7). Observed inflow generally falls within the range of inflows predicted for each event, given the uncertainty associated with the TPS. Peak flood events remain under-estimated. Strategies to reduce the uncertainty associated with the TPS can be found in Section 8.2.

Figure 8.8 shows the modelled inflows from gauged catchments (namely, Hinemaiaia, Tauranga-Taupo, Waimarino, Tongariro and Kuratau). Compared to the observed inflows, the model output simulates the flood event in July 1998 well, although peak flood events are under-estimated. This is also the case in the smaller events seen in November 2006. During drier conditions, recession and baseflow conditions are closely approximated but (smaller) flood responses tend to be overestimated. Parametric uncertainty is relatively low, indicated by the relatively small range of inflows predicted by the model output.

Differences between the observed and modelled streamflow stem from simplifications in the model structure, estimated parameters and imperfect data. The cumulative effects of data errors and/or incorrect model assumptions lead to internal discrepancies (e.g. in groundwater levels, soil moisture) that then cause large errors in predicted water fluxes and other essential model outputs. This has implications for the accuracy and reliability of model predictions. In the following 


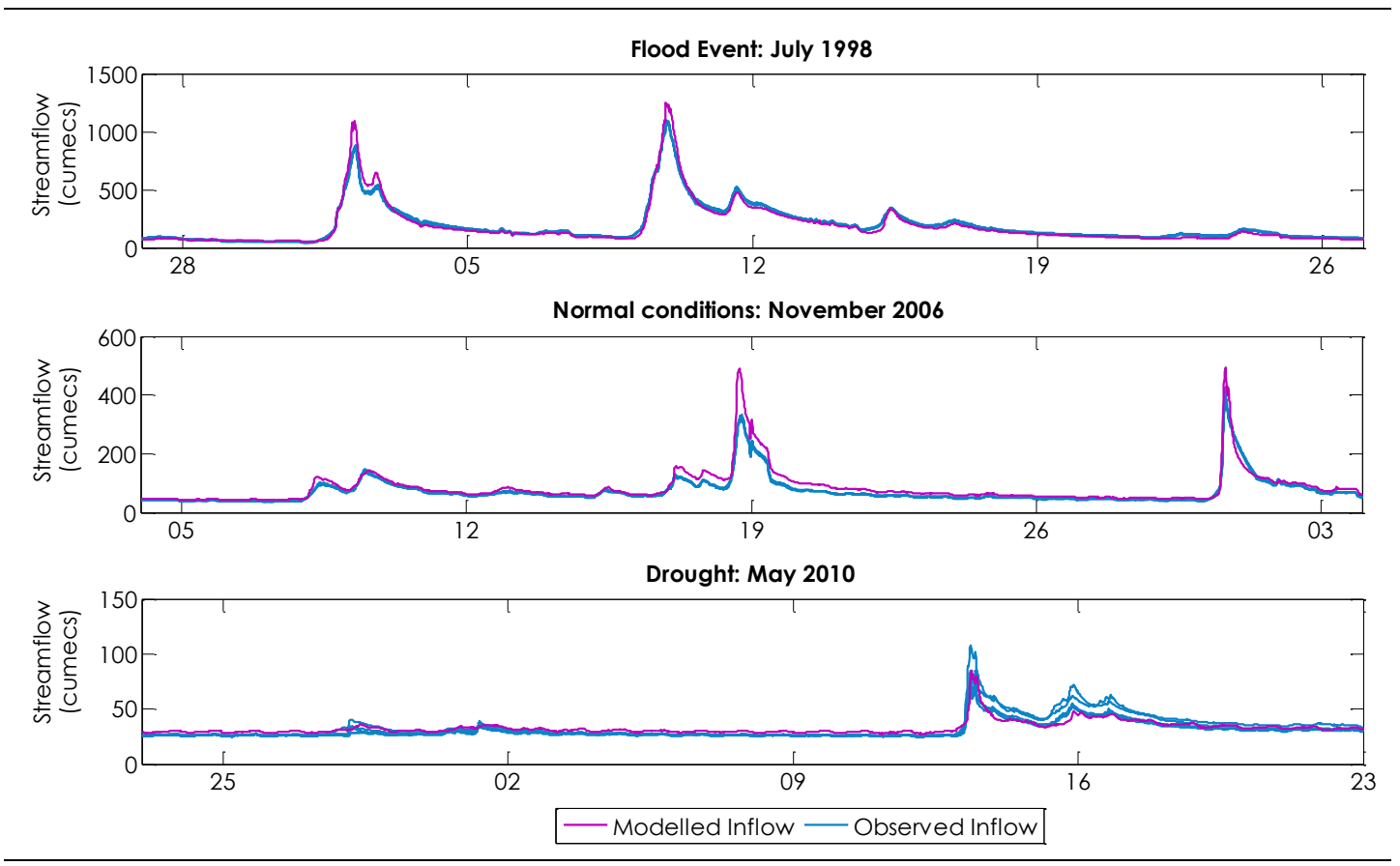

Figure 8.8 Lake Taupo Inflow Model performance: modelled versus observed inflows from gauged areas.

sections a constrained EnKF is applied to gauged catchments of the LTIM model to account for these areas and improve model performance.

\subsection{Constrained Ensemble Kalman Filter (EnKF)}

As shown in the previous section, the LTIM does a relatively good job of simulating inflow given considerable uncertainty associated with the inflow from the TPS and ungauged areas. However, it is apparent that even over the short term errors can accumulate due to imperfect data, simplified model structure and estimated parameters. To address this issue, a constrained EnKF is applied to the currently gauged catchments of the LTIM. The filter adjusts states using observations of streamflow (Section 8.4.1). Perturbations made to model states are constrained to ensure they are consistent with physical laws (Section 8.4.2). Without these constraints we show that the reliability and accuracy of model predictions can be compromised. Filter performance is evaluated over three events for each subcatchment it is applied to (Section8.4.3). A number of issues in the use of the filter have been identified and possible solutions are suggested (Section 8.4.4). 


\subsubsection{Filter performance}

A constrained EnKF is used to update model states for more accurate and reliable model output. Retrospectively, the constrained EnKF is able to improve model performance in all catchments with most catchments showing an improvement over the evaluation period by at least $10 \%$ in terms of the fit to the time series. KGE performance index values for all catchments for both filtered and non-filtered model output for the evaluation period (January 1998 - December 2010) are provided in Table 8.4.

To illustrate the improvement made by the filter, Figure 8.9 compares the nonfiltered (a) and filtered (c) time series for the Tauranga-Taupo catchment. Figure 8.9b and Figure 8.9d show the difference between the model output and the observations. While the non-filtered model is able to closely simulate the baseflow and recession characteristics reasonably well it is often over-estimating peak flood flows. There are also instances where a modelled response is seen but there is no

Table 8.4 KGE performance index values for filtered and non-filtered model output for 19982010 evaluation period.

\begin{tabular}{|c|c|c|c|c|c|c|c|}
\hline Catchment & & Parameter set & 1 & 2 & 3 & 4 & 5 \\
\hline \multirow[t]{4}{*}{ Hinemaiaia } & KGE (time) & Non-Filtered & 0.7916 & 0.7920 & 0.7920 & 0.7913 & 0.7913 \\
\hline & & Filtered & 0.9798 & 0.9768 & 0.9798 & 0.9794 & 0.9794 \\
\hline & KGE (fdc) & Non-Filtered & 0.9129 & 0.9129 & 0.9129 & 0.9129 & 0.9129 \\
\hline & & Filtered & 0.9817 & 0.9817 & 0.9817 & 0.9817 & 0.9817 \\
\hline \multirow[t]{4}{*}{ Tauranga-Taupo } & KGE (time) & Non-Filtered & 0.8208 & 0.8208 & 0.8208 & 0.8199 & 0.8199 \\
\hline & & Filtered & 0.9697 & 0.9703 & 0.9703 & 0.9700 & 0.9700 \\
\hline & KGE (fdc) & Non-Filtered & 0.9337 & 0.9337 & 0.9337 & 0.9340 & 0.9340 \\
\hline & & Filtered & 0.9698 & 0.9706 & 0.9706 & 0.9709 & 0.9709 \\
\hline \multirow[t]{4}{*}{ Waimarino } & KGE (time) & Non-Filtered & 0.7134 & 0.7134 & 0.7132 & 0.7132 & 0.7134 \\
\hline & & Filtered & 0.9832 & 0.9832 & 0.9834 & 0.9834 & 0.9832 \\
\hline & KGE (fdc) & Non-Filtered & 0.8539 & 0.8539 & 0.8539 & 0.8539 & 0.8539 \\
\hline & & Filtered & 0.9834 & 0.9834 & 0.9834 & 0.9834 & 0.9834 \\
\hline \multirow[t]{4}{*}{ Kuratau } & KGE (time) & Non-Filtered & 0.8054 & 0.8054 & 0.8054 & 0.8054 & 0.8053 \\
\hline & & Filtered & 0.9864 & 0.9864 & 0.9864 & 0.9864 & 0.9864 \\
\hline & KGE (fdc) & Non-Filtered & 0.8593 & 0.8592 & 0.8593 & 0.8592 & 0.8594 \\
\hline & & Filtered & 0.9872 & 0.9873 & 0.9872 & 0.9873 & 0.9872 \\
\hline \multirow[t]{4}{*}{ Natural Tongariro } & KGE (time) & Non-Filtered & 0.6242 & 0.6226 & 0.6240 & 0.6248 & 0.6229 \\
\hline & & Filtered & 0.9782 & 0.9616 & 0.9781 & 0.9792 & 0.9695 \\
\hline & KGE (fdc) & Non-Filtered & 0.7005 & 0.7011 & 0.7006 & 0.7011 & 0.7005 \\
\hline & & Filtered & 0.9791 & 0.9795 & 0.9791 & 0.9795 & 0.9791 \\
\hline \multirow[t]{4}{*}{ Poutu } & KGE (time) & Non-Filtered & 0.6879 & 0.6890 & 0.6907 & 0.6856 & 0.6902 \\
\hline & & Filtered & 0.9914 & 0.9914 & 0.9914 & 0.9914 & 0.9914 \\
\hline & KGE (fdc) & Non-Filtered & 0.8795 & 0.8773 & 0.8853 & 0.8800 & 0.8826 \\
\hline & & Filtered & 0.9921 & 0.9921 & 0.9921 & 0.9921 & 0.9921 \\
\hline
\end{tabular}


corresponding hydrograph in the observations. This is largely due to errors in the input rainfall used for this catchment which is not always representative of catchment-wide rainfall for all events.

The filtered model, on the other hand, can account for errors in input rainfall. Consequently, it does a better job at simulating streamflow because it is able to adjust model states given real time observations for more accurate model output. The EnKF assumes the observations are not perfect adding an error term to the observations resulting in the frequent oscillations about zero in the residual streamflow (Figure 8.9d).

Similarly, in the Kuratau catchment the non-filtered model output is also able to simulate baseflow and recession characteristics reasonably well (Figure 8.10a). Although some events are missed entirely, flood peaks are generally over-estimated (Figure 8.10b). It should be noted that the Kuratau parameters did not perform well outside of the calibration period (see Section 7.2.2), which may account for some of the error in the non-filtered model output. Despite this, the constrained filter is able to account for some of the data and model structure (and parameter estimation) error resulting in a much closer simulation to observed streamflow (Figure 8.10c).

The problem of inaccurate input data is highlighted in Figure 8.11 and Figure 8.12. In the first figure, the small amount of rainfall recorded is not enough to generate a hydrologic response due to modelled antecedent catchment conditions. There is, however, a hydrologic response in the observations indicating that in other areas of the catchment rainfall is likely to have been much greater and antecedent catchment conditions more saturated. Conversely, in Figure 8.12 a modelled response to input rainfall is shown. However, there is no significant corresponding event in the observed hydrograph. This event may have been localised around the gauge location leading to an over-estimation of catchment areal rainfall at this time. In both situations, the constrained EnKF is able to adjust the states to correct for errors in the driving data, allowing better characterisation of catchment water storage. These updated states are then used to forecast streamflow over the next prediction interval, reducing short-term biases.

Although the filter is able to deal with a large amount of the error in the input data, a smaller more attenuated flood peak is still evident in the filtered model output in Figure 8.12. Like the unfiltered model, the filter is responding to the input rainfall data which is, in this case, obviously over-estimated. This is an unavoidable trade- 
(a) Non-filtered streamflow versus Observations
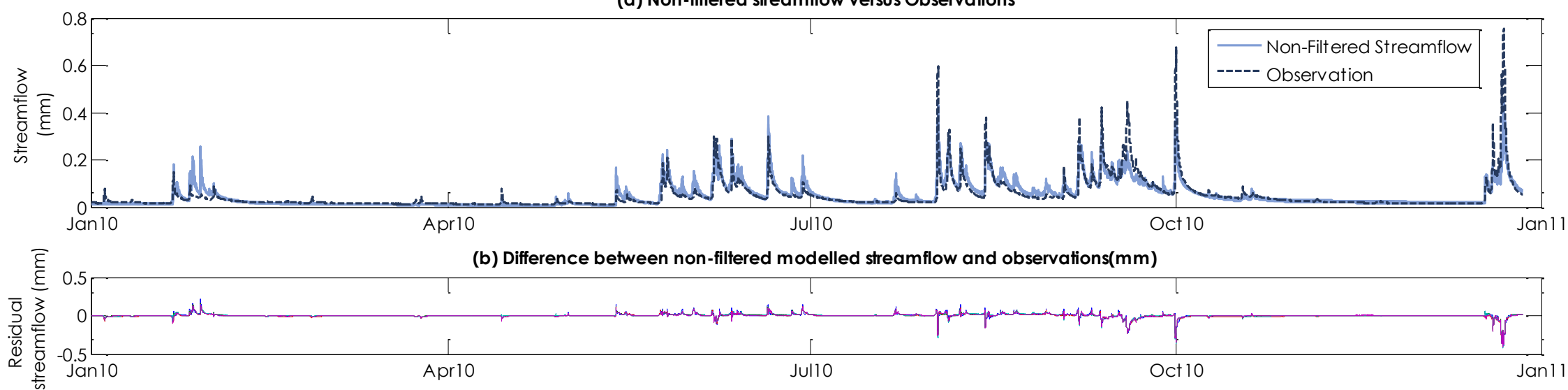

(c) Filtered streamflow versus Observations

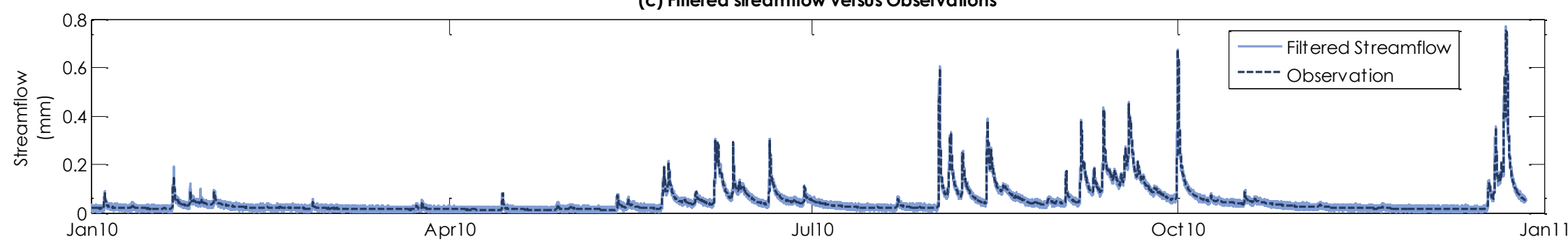

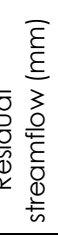

(d) Difference between filtered modelled streamflow and observations $(\mathrm{mm})$

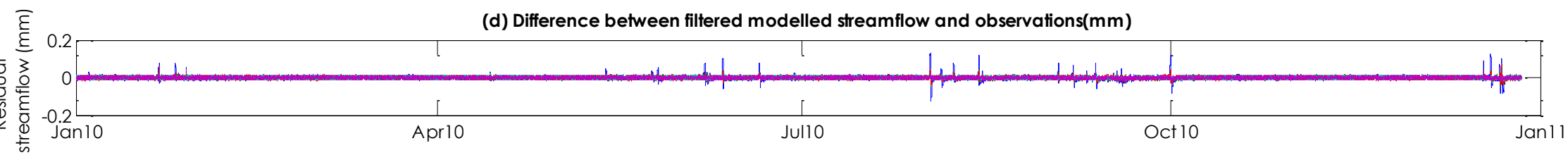

Figure 8.9 The constrained EnKF is able to improve the simulation of streamflow in the Tauranga+--Taupo catchment over 2010. (a) Non-filtered streamflow versus observations and (b) corresponding residual streamflow (observations minus modelled streamflow); (c) Filtered streamflow versus observations and (d) corresponding residual streamflow (observations minus modelled streamflow). Units are $\mathrm{mm} / 15$ minutes. 
(a) Non-filtered streamflow versus Observations

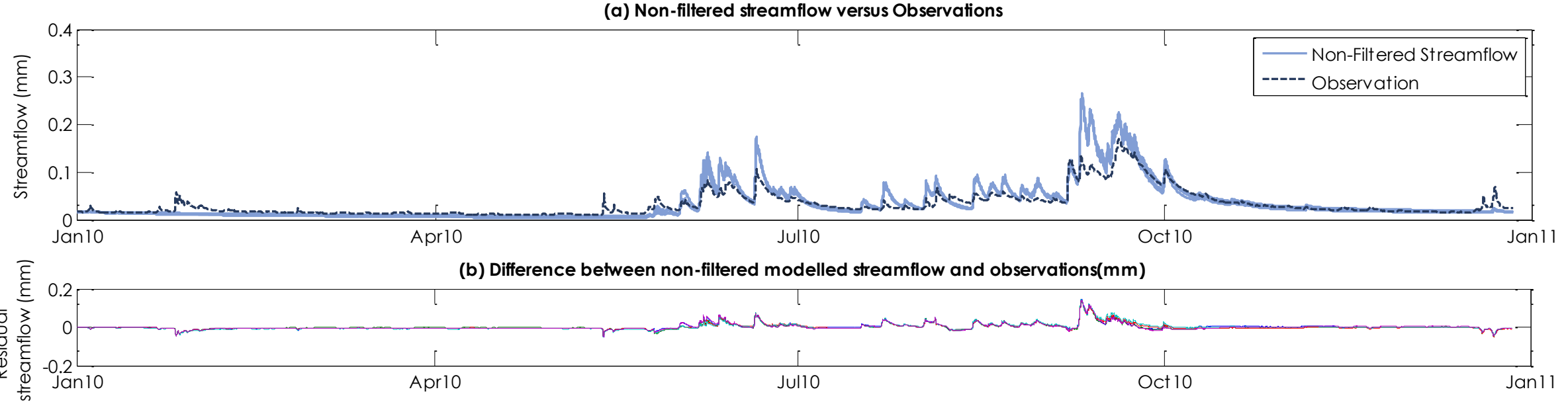

(c) Filtered streamflow versus Observations

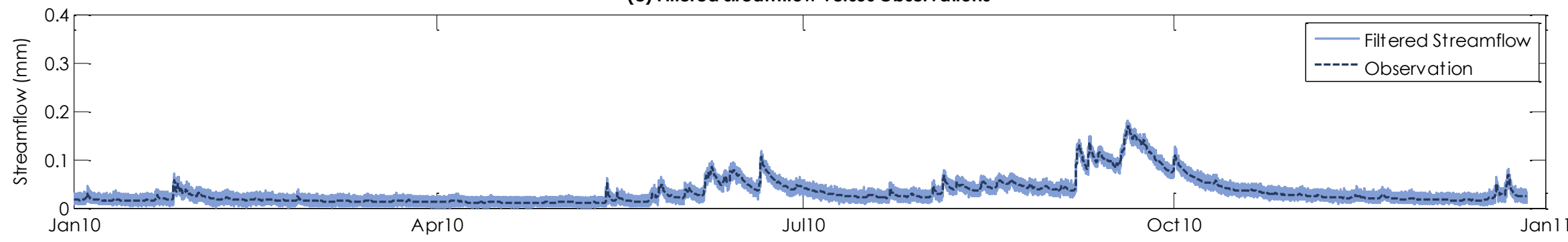

(d) Difference between filtered modelled streamflow and observations $(\mathrm{mm})$

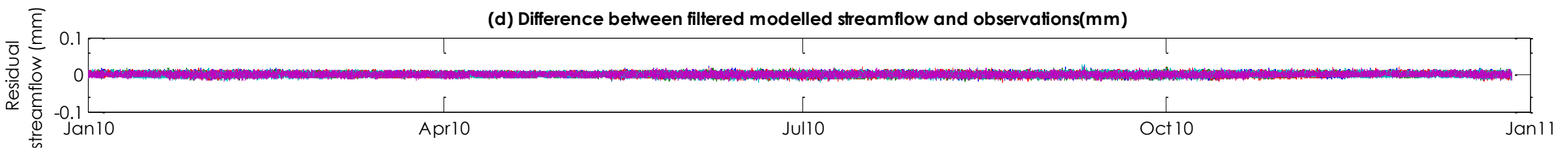

Figure 8.10 The constrained EnKF is able to improve the simulation of streamflow in the Kuratau catchment over 2010. (a) Non-filtered streamflow versus observations and (b) corresponding residual streamflow (observations minus modelled streamflow); (c) Filtered streamflow versus observations and (d) corresponding residual streamflow (observations minus modelled streamflow). Units are $\mathrm{mm} / 15$ minutes.

202 | Lake Taupo Inflow Model 

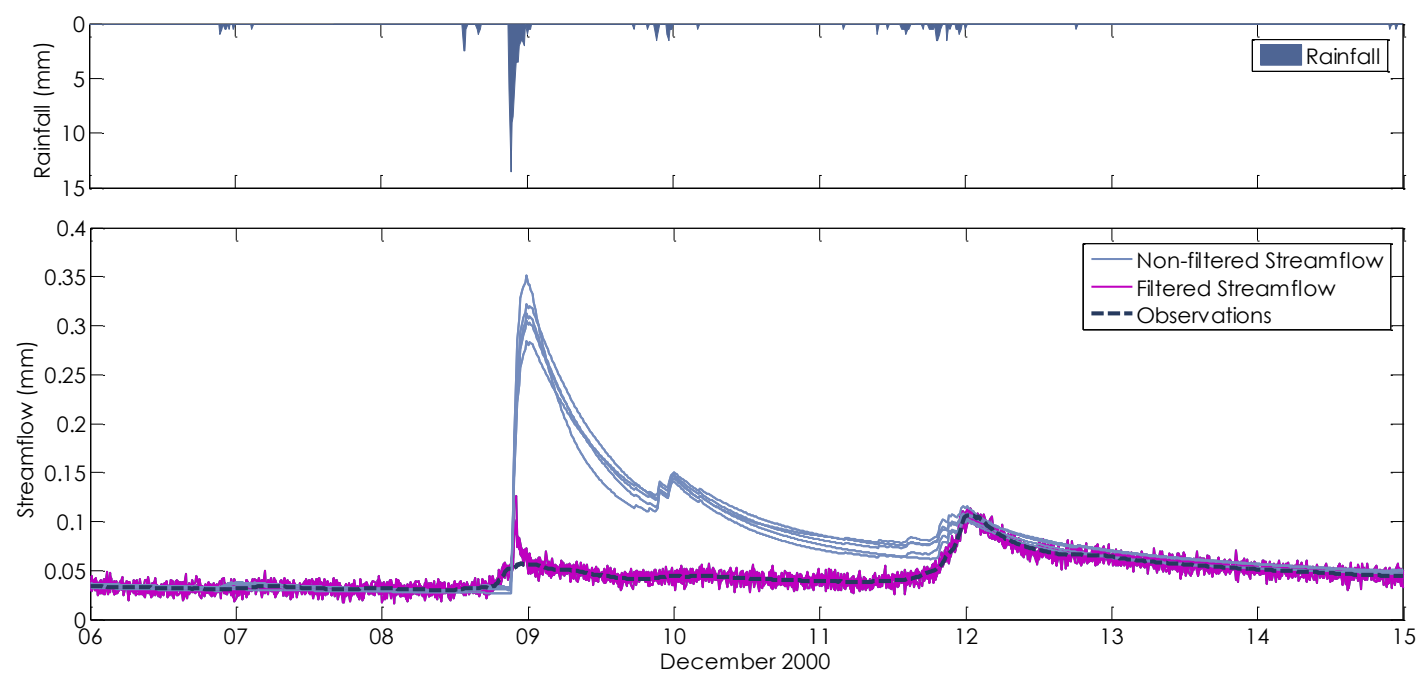

Figure 8.11 Filtered streamflow given errors in rainfall record. Estimated catchment rainfall (upper) and filtered, non-filtered model output compared to observed streamflow (lower). The filter is able to adjust for imperfect rainfall data. In this example, an observed hydrologic response is not seen in the modelled output due to inaccurate input rainfall. The filter can adjust modelled output to account for these data errors for a closer matched simulation with the real world. Units are $\mathrm{mm} / 15$ minutes.
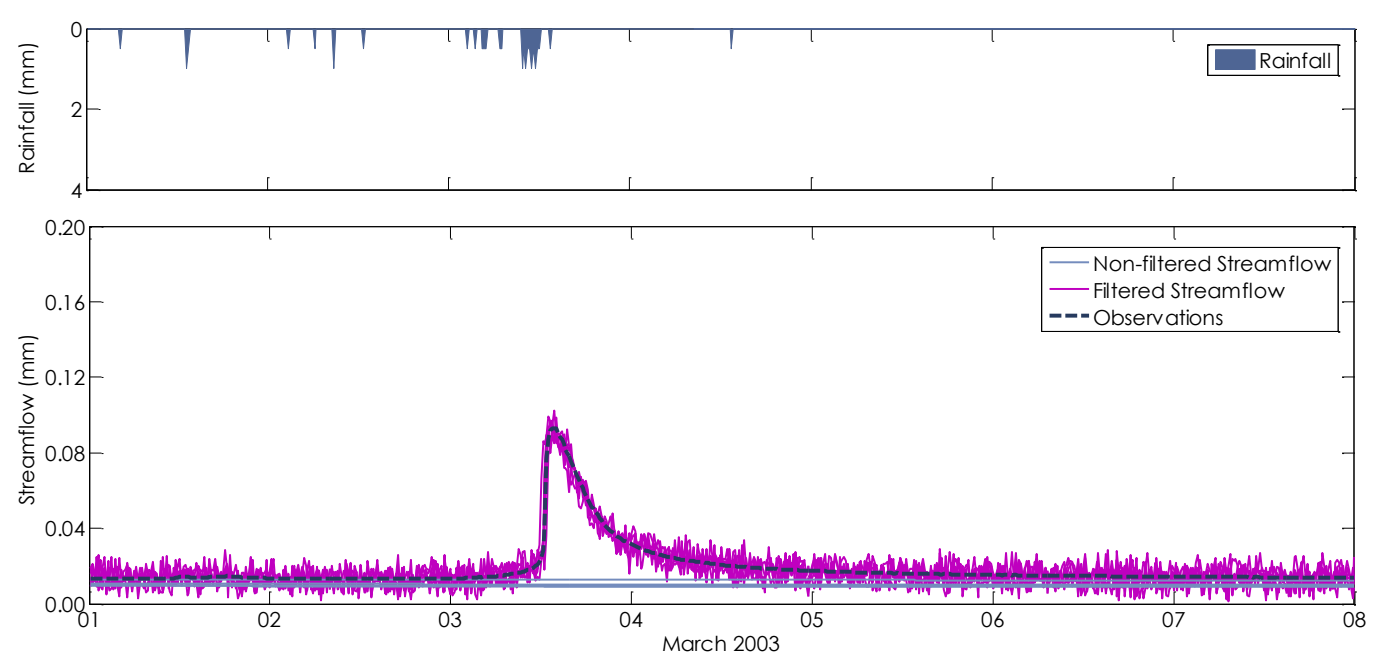

Figure 8.12 Filtered streamflow given errors in rainfall record. Estimated catchment rainfall (upper) and filtered, non-filtered model output compared to observed streamflow (lower). In this example, a modelled hydrologic response is not reflected in the observations indicating input rainfall is under-estimated. Again the filter is able to adjust for these errors in driving data for more accurate model output. Units are $\mathrm{mm} / 15$ minutes. 
off due to the need to constrain state updates. Better estimates of catchment rainfall would improve filter performance. Operationally, the model would be coupled with meteorological forecasts of catchment precipitation and evapotranspiration. As new forecasts arrive the LTIM would be updated with the new information for more reliable decision making over the coming few days.

\subsubsection{Physically consistent state updating}

While the filter performs well retrospectively, in an operational context its success should be measured in terms of the improvement to the accuracy and reliability of model predictions. Standard implementation of the EnKF allows model states to be updated with little regard for physical laws. Constraining the states simply by ensuring perturbations are within realistic ranges and that state volumes are physically consistent (non-negative), improves the accuracy and reliability of model predictions.

Without these constraints, the reliability of forward predictions can be compromised. This problem is demonstrated in Figure 8.13 and Figure 8.14. During this period, modelled soil storage drops below -20mm (for one parameter set) and there is also a significant increase in the volume of the baseflow state. At this point in time the filter reduced the volume of the soil state by $61 \mathrm{~mm}$. The baseflow state is increased by up to $4100 \mathrm{~mm}$, with the range of innovations (updates made to model states) between $2100 \mathrm{~mm}$ and $4100 \mathrm{~mm}$ for all parameter sets. Outside of this event and over the 6 month period shown, perturbations ranged between $\pm 10 \mathrm{~mm}$ for the soil state and $\pm 200 \mathrm{~mm}$ for the baseflow state. Figure 8.14 shows the corresponding hydrograph and prediction given the updated state volumes. Because the states have been adjusted to unrealistic ranges, the unconstrained filter also presents some unrealistic streamflow responses, indicated by the large streamflow response by one of the parameter sets. At the time of projection, due to the considerable volume of water in the baseflow state, the modelled flow remains high and flat over the projected period. The observed response shows streamflow is receding over the same period.

Once the filter is constrained, the states are updated to be consistent with physical laws (Figure 8.15). For the same period (and event) the states remain in positive territory. Perturbations to state volume are within realistic ranges as shown by the smaller range in the innovations over time $( \pm 4 \mathrm{~mm}$ for the soil state and $\pm 5 \mathrm{~mm}$ for 
(a) Soil Storage State

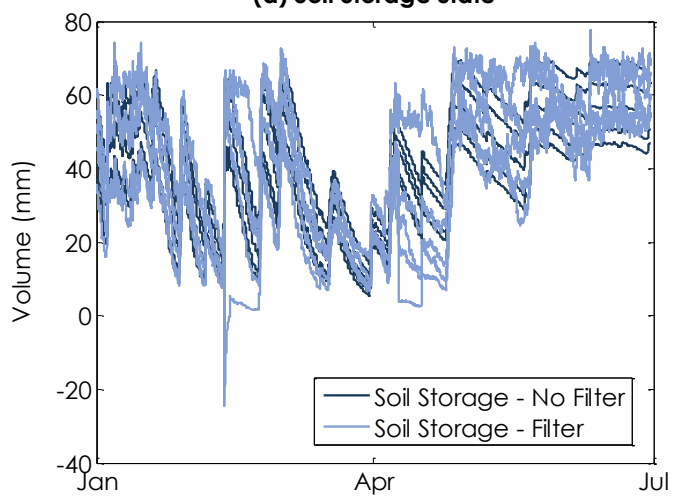

(c) Soil State: innovations over time

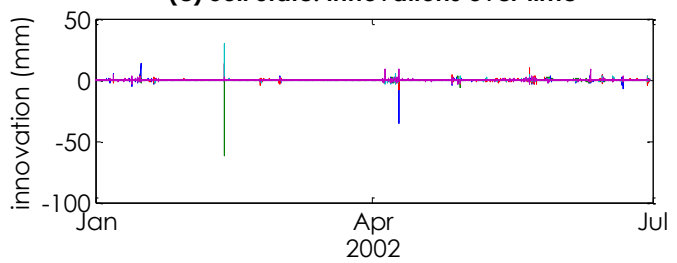

(b) Baseflow State

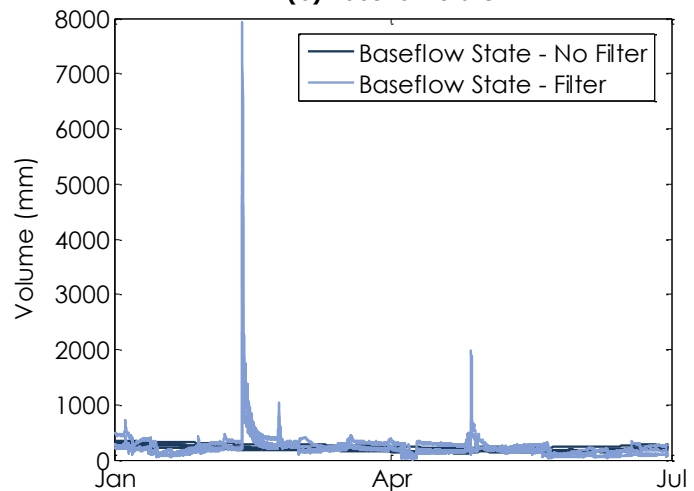

(d) Baseflow State: innovations over time

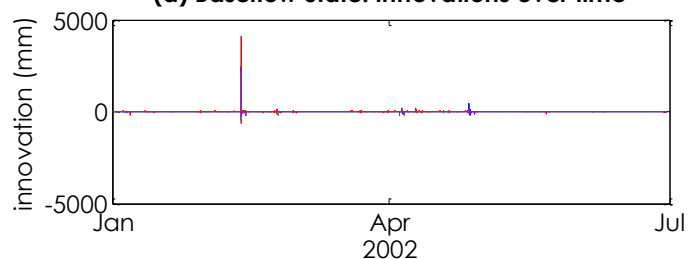

Figure 8.13 Model states when an unconstrained EnKF is applied. Model states can often be perturbed to physically inconsistent volumes. Units are $\mathrm{mm} / 15$ minutes.
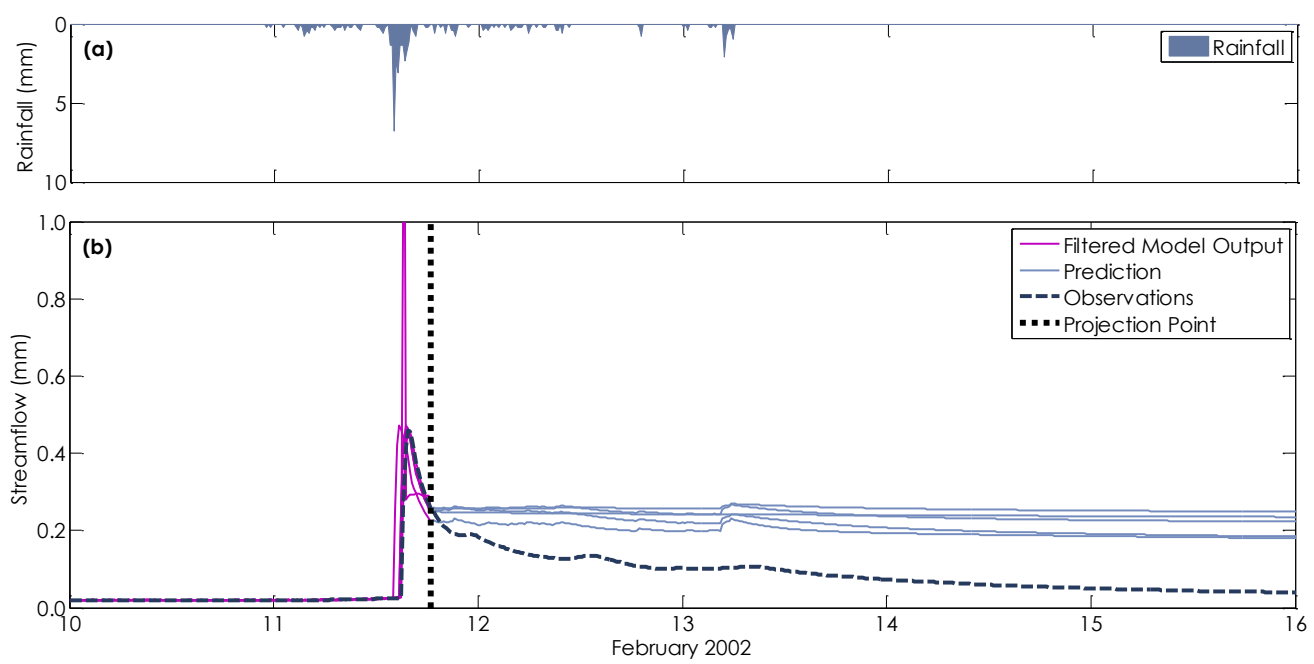

Figure 8.14 Estimated catchment rainfall (a) and modelled versus observed streamflow (b). Where model states are physically inconsistent can lead to unreliable forward prediction of streamflow. Units are $\mathrm{mm} / 15$ minutes. 


\section{(a) Soil Storage State}

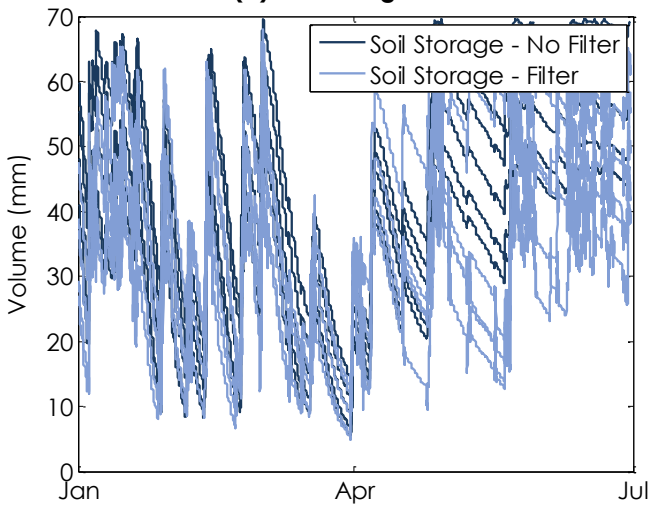

(c) Soil State: innovations over time

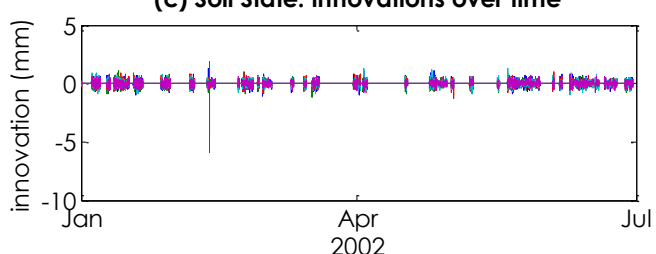

(b) Baseflow State

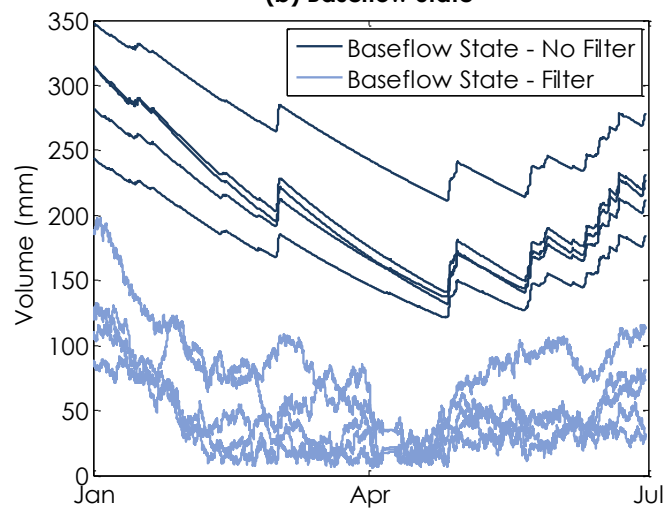

(d) Baseflow State: innovations over time

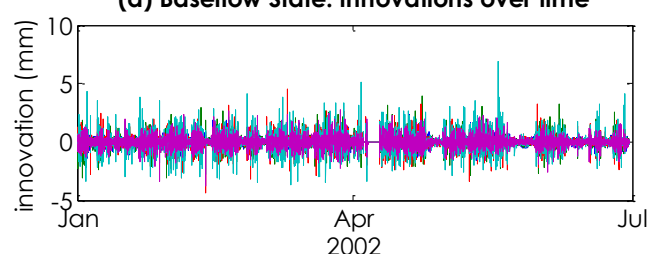

Figure 8.15 When the constrained EnKF is applied, state perturbations are kept within realistic ranges and state volumes remain within realistic ranges. Units are $\mathrm{mm} / 15$ minutes.
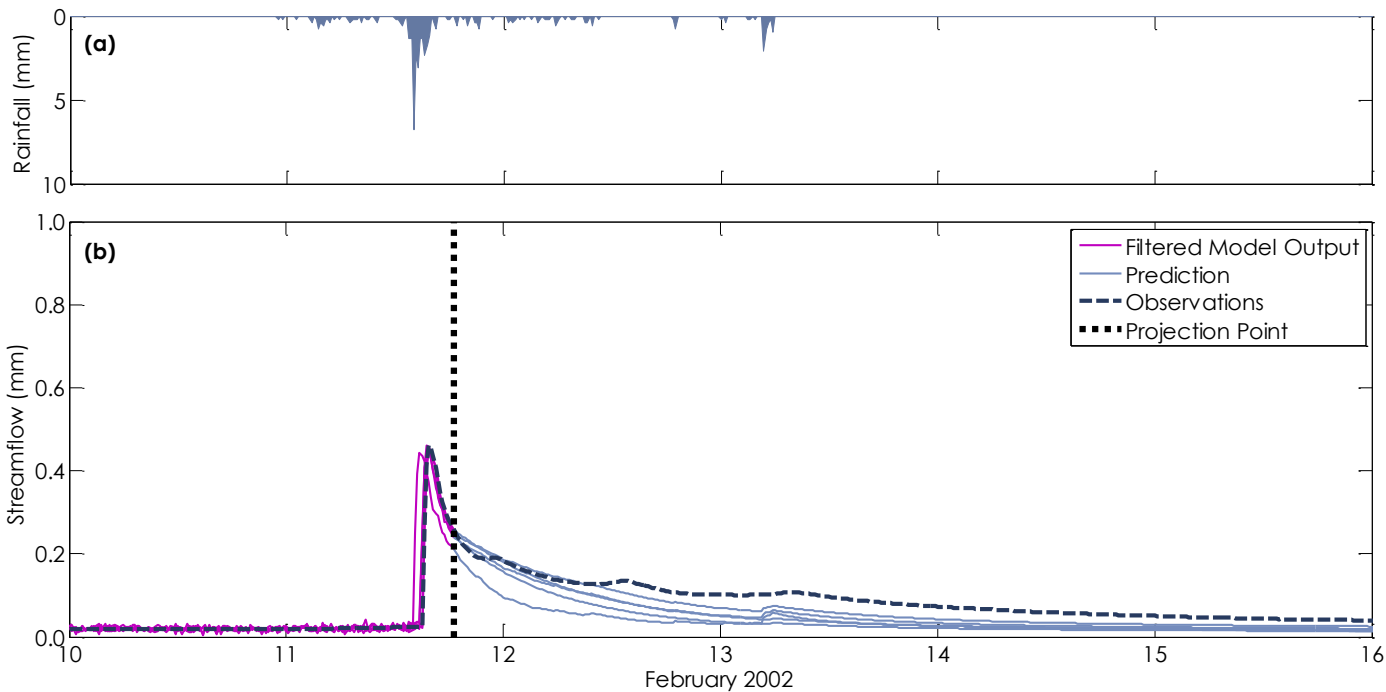

Figure 8.16 States which are constrained to be within physically consistent ranges result in more accurate and reliable forward predictions of streamflow. Units are $\mathrm{mm} / 15$ minutes. 
the baseflow state). In terms of forward prediction, model output is improved since the states are being updated to more realistic values. The model output now predicts streamflow will recede which is more consistent with the observations (Figure 8.16). Further out, streamflow is predicted to drop below the observed response. As more observations arrive, however, state values will continue to be adjusted so that the simulated response will more closely match actual streamflow.

\subsubsection{Improving the accuracy of model predictions}

Filtered and non-filtered model output is compared to streamflow observations for all four of the sub-catchments to which the filter is applied. Performance is assessed by visual inspection and the KGE performance index. The three events presented in Section 8.3 are also presented in this section; the first is the July 1998 flood event, the second represents 'normal' operating conditions (November 2006) and third, the drought event in May 2010. As noted earlier, these events are selected because they represent a range of inflow conditions to the lake including two of the severest but opposing events of the 1998-2010 period.

\section{July 1998: Flood Event}

In general, the filter is shown to be of particular benefit during the flood peak when either the inputs to the system are not perfect and/or the model structure and estimated parameters are under-estimating or, in the case of the Kuratau catchment, over-estimating the flood peak.

Prior to the peak of the event, both the filtered and non-filtered model output for the Tauranga-Taupo catchment (Figure 8.17) have KGE values of no better than o.62. As the peak arrives the filter is able to adjust the model states to reflect the actual conditions of the catchment and, consequently, generate more reliable forward predictions in the short-term. The non-filtered model output at this point is achieving KGE values of no more than 0.66 while the modelled output based on the updated states ranges from 0.74 to 0.98 . Closer inspection of the modelled output at various times during the recession period indicates that the filtered and non-filtered response is similar. However, it should be noted that as more observations become available, states will continue to be updated for more precise streamflow estimations. 
Similarly in the Waimarino catchment (Figure 8.18), filtered and non-filtered model output show similar KGE values leading up to the peak flow event. As the event arrives, errors in state conditions are corrected through the constrained EnKF and KGE values for the filtered model output are better than the non-filtered output.

Streamflow is generally over-estimated in the Kuratau catchment over the entire period (Figure 8.19). As observations are assimilated, errors are corrected and streamflow predictions simulate the observed response more closely. KGE (fit to time series) values from the various projection points are considerably higher for the filtered model output (maximum KGE of 0.9445) than for the non-filtered output (maximum KGE 0.6949) for the majority of the period. From 13 July, the nonfiltered model fit improves.

Of particular note is the offset between the filtered model output and the projected inflow at the time of projection for the Tongariro catchment. Projected streamflow combines the output from the lower Tongariro and Poutu catchments to provide a forecast of streamflow at Turangi. The EnKF is applied to the lower Tongariro catchment, but not to the Poutu catchment due to the imposed regulation, instead using the non-filtered model output for prediction. Because of the lag time between the Poutu and Turangi sites, the historical simulation combines the filtered model output for the lower Tongariro section and observed streamflow from the Poutu catchment (refer Section 6.4.2). At the point of prediction, however, the non-filtered model output from the Poutu catchment is used. If this is substantially different to the observations, a noticeable 'jump' in streamflow between the historical and projection periods is seen.

\section{November 2006: 'Normal' operating conditions}

In this study, 'normal' operating conditions relate to periods when lake level is well within lake level operating margins. Overall, there is relatively little difference between the filtered and non-filtered model output over the projection period, especially since most of the projection times have been during recession periods when there has been little difference in filtered and non-filtered output.

In both the Tauranga-Taupo (Figure 8.21) and Waimarino (Figure 8.22) catchments the response to rainfall events is largely under-estimated, although recession periods are simulated well. KGE values for the period were similar but generally low (<0.6 for Tauranga-Taupo and $<0.5$ for Waimarino). As observations arrive and are 


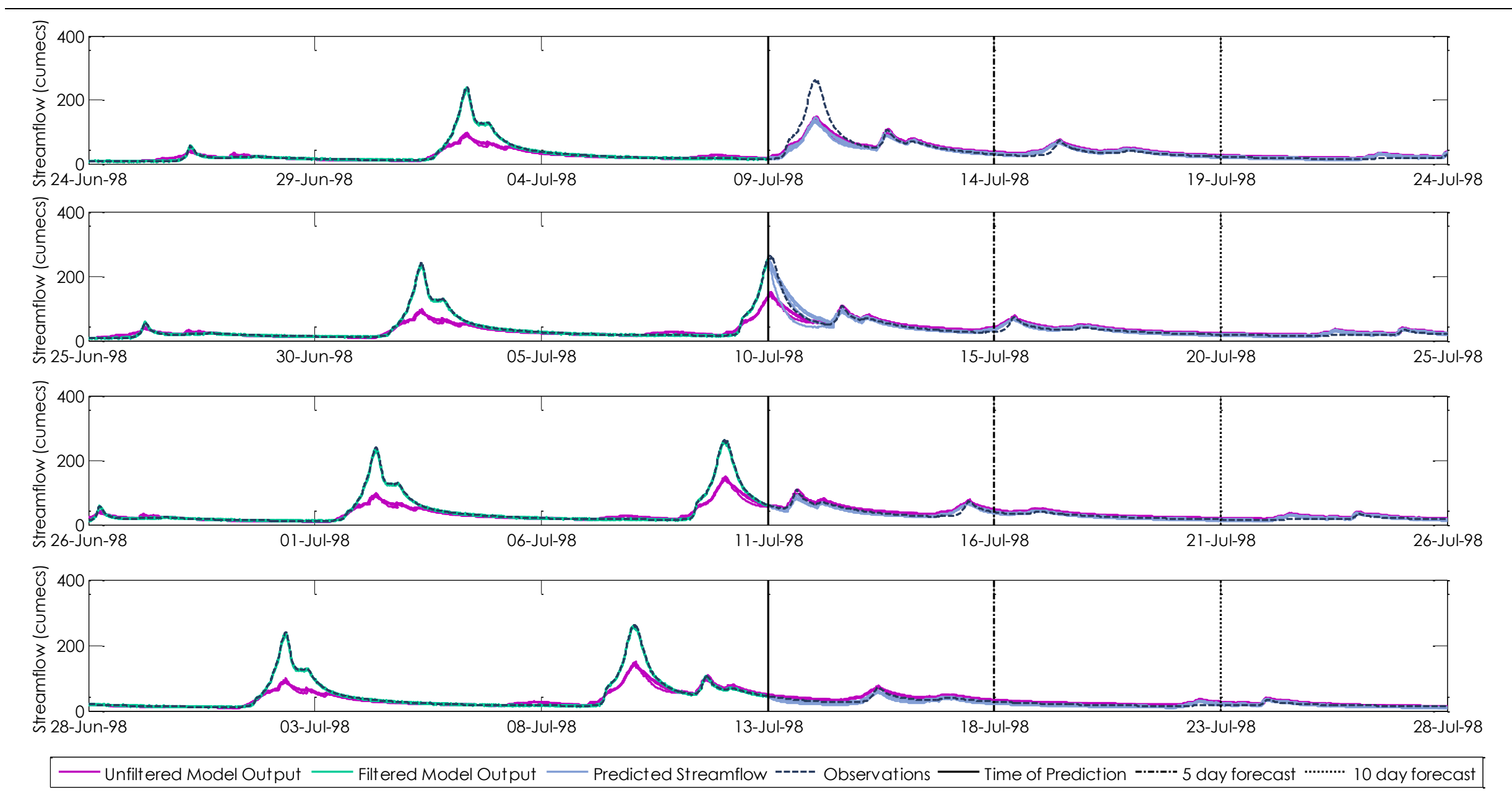

Figure 8.17 Filtered and non-filtered model output versus streamflow observations from various projection times for the July 1998 flood event: Tauranga-Taupo catchment. 

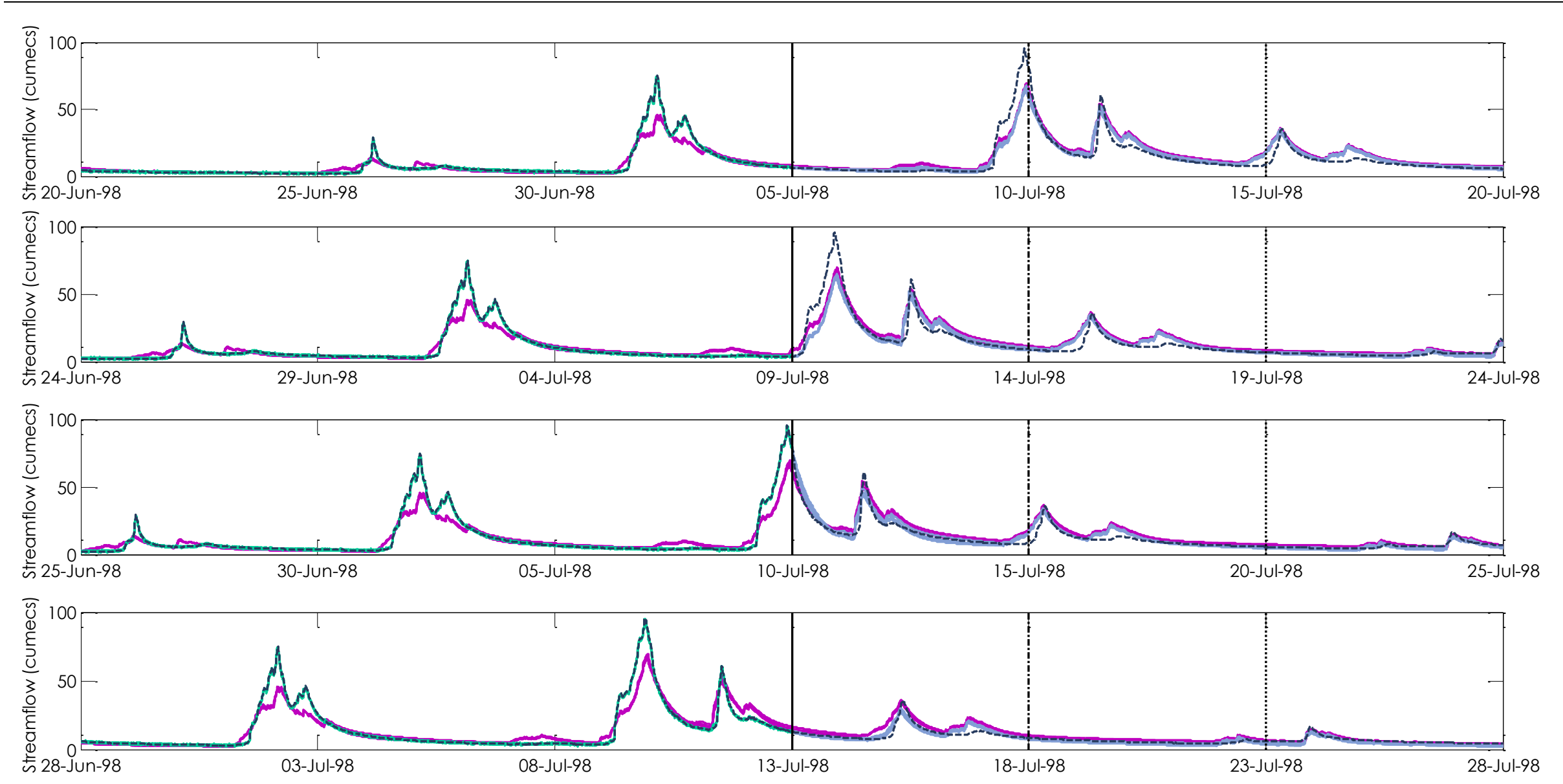

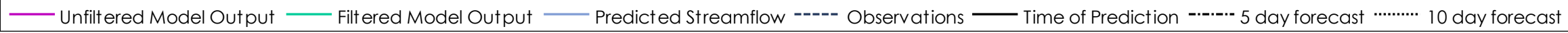

Figure 8.18 Filtered and non-filtered model output versus streamflow observations from various projection times for the July 1998 flood event: Waimarino catchment. 

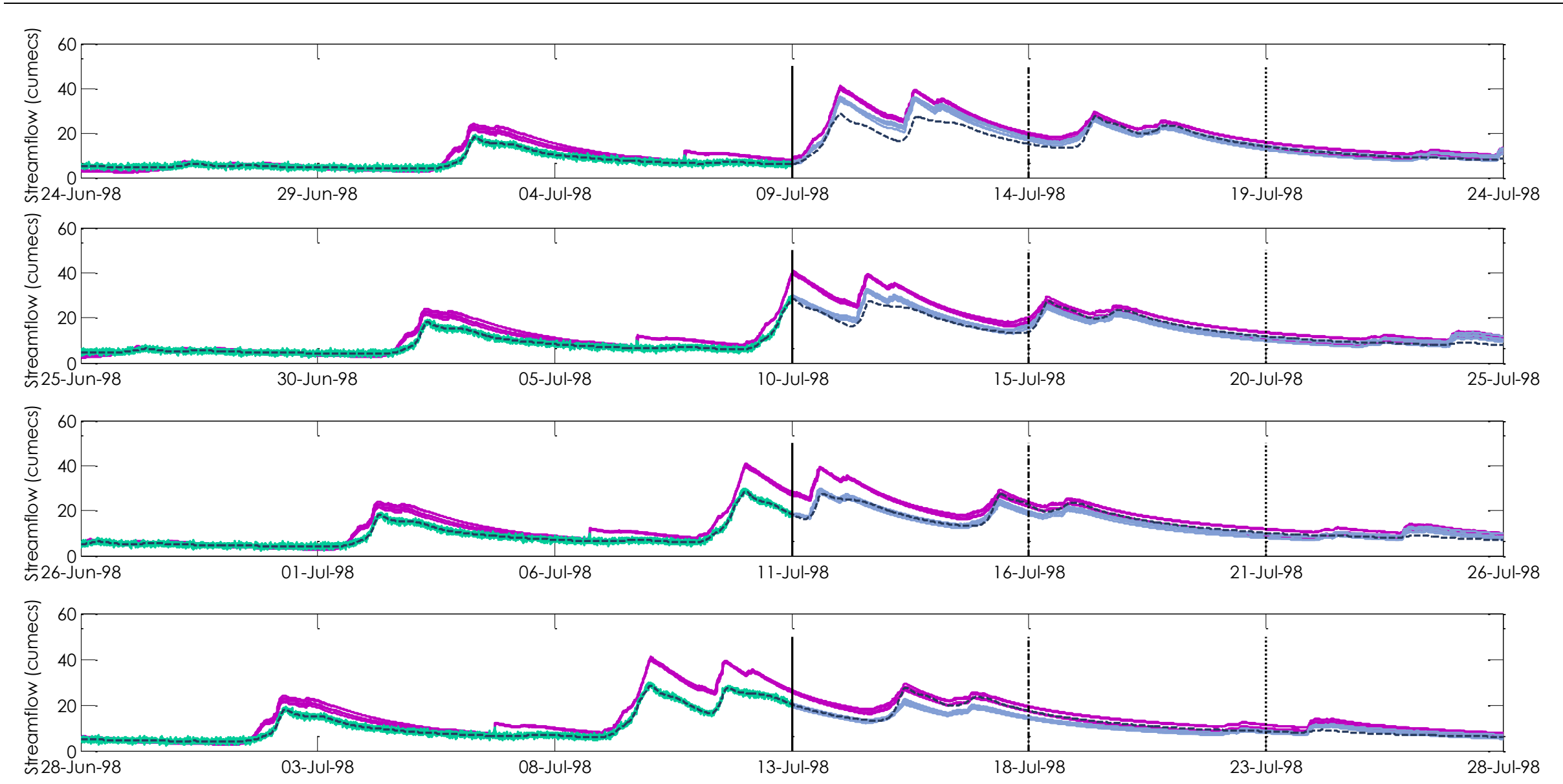

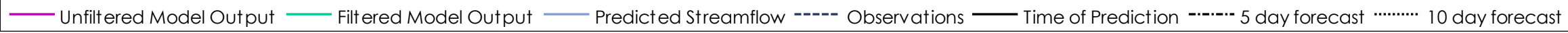

Figure 8.19 Filtered and non-filtered model output versus streamflow observations from various projection times for the July 1998 flood event: Kuratau catchment. 

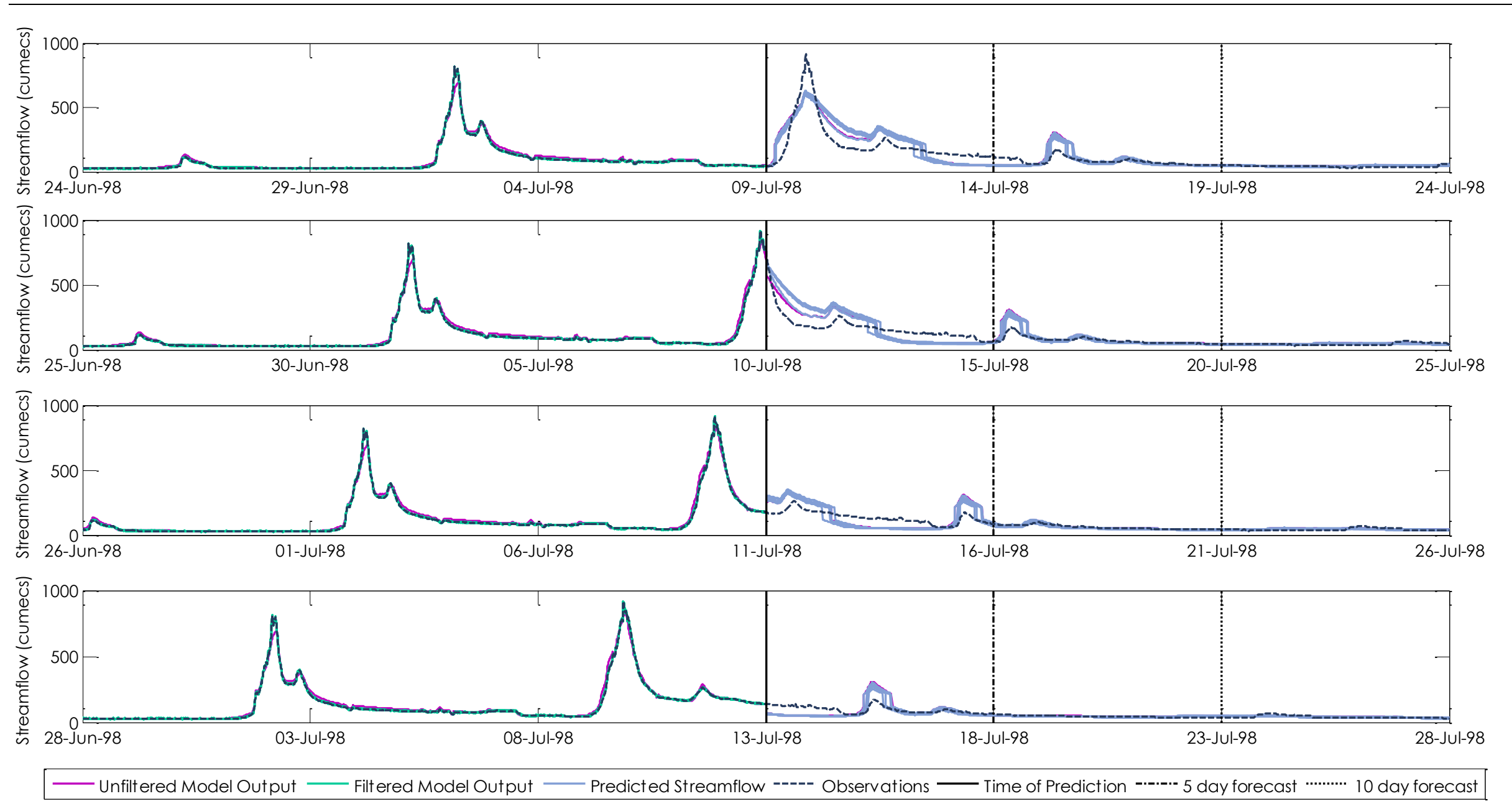

Figure 8.20 Filtered and non-filtered model output versus streamflow observations from various projection times for the July 1998 flood event: Tongariro catchment. 
assimilated the filtered response more closely fits to the observations, in the short term.

The events seen in the Tauranga-Taupo and Waimarino catchments are less significant in the Kuratau which shows very little response over the period (Figure 8.23). Although both the filtered and non-filtered model output is very similar, KGE values indicate that the non-filtered model output provides a better simulation than the filtered model output. This is probably due to the short period of data over which the KGE is applied and the smaller range in flows from which it is estimated. In this situation, a smaller difference in streamflow can impact on the performance rating of the KGE.

While the minimum flow conditions of the Tongariro catchment are simulated well, events are generally under-estimated (Figure 8.24). The effect of the regulation is generally well captured given the data and information available to model it. There is some improvement in predictive accuracy around 19 November, although the jump between the historical and the projected streamflow is again evident. KGE values over each of the four projection periods are similar, with slightly higher KGE values for the filtered output.

\section{May 2010: drought conditions}

Over the drought period observed in early 2010, the filter performance is more varied. In the Tauranga-Taupo catchment low flow conditions are well simulated by both filtered and non-filtered model output (Figure 8.25). Small rainfall events are simulated reasonably well, with only a small over-estimation of discharge. As state conditions are corrected, predicted model output improves. KGE values for the filtered model output are generally above 0.7 for the period. KGE values for the nonfiltered model output never rose above 0.7 in this event.

In the Waimarino catchment, projected streamflow is slightly less than observed streamflow for most of the low flow period. Rainfall events later in May are overestimated. KGE values are low over the four time periods (generally <0.6) for both filtered and non-filtered output, although the filtered model output is slightly better.

In the Kuratau catchment, low flow conditions are generally under-estimated and rainfall events are not predicted well, if at all (Figure 8.27). There is little difference between the non-filtered and filtered model output over this event and KGE values 

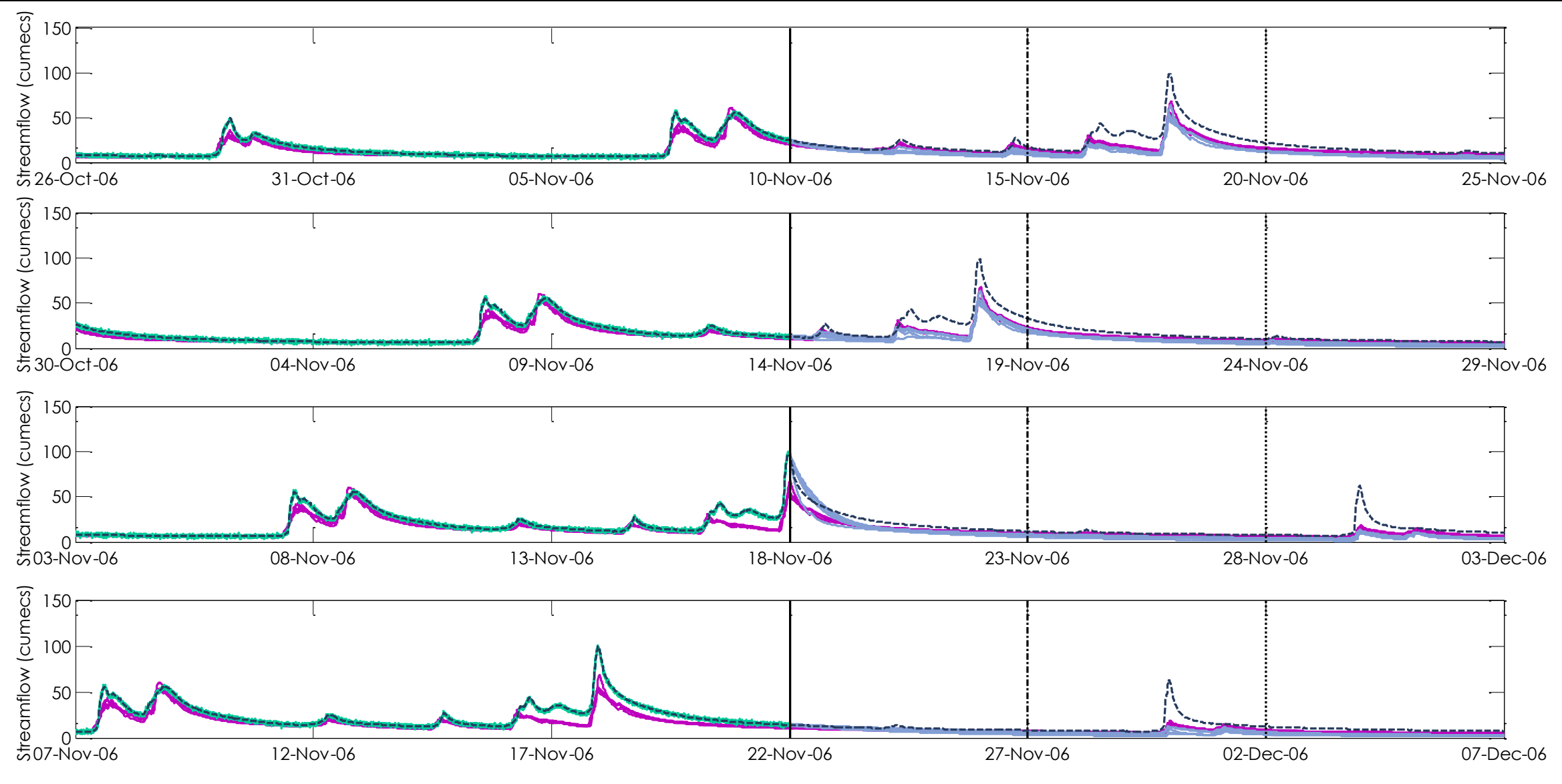

- Unfiltered Model Output —— Filtered Model Output —— Predicted Streamflow ------ Observations — Time of Prediction ------- 5 day forecast -........... 10 day forecast

Figure 8.21 Filtered and non-filtered model output versus streamflow observations from various projection times for the November 2006 'normal' operating conditions: TaurangaTaupo catchment.

$\mathbf{2 1 4}$ | Lake Taupo Inflow Model 

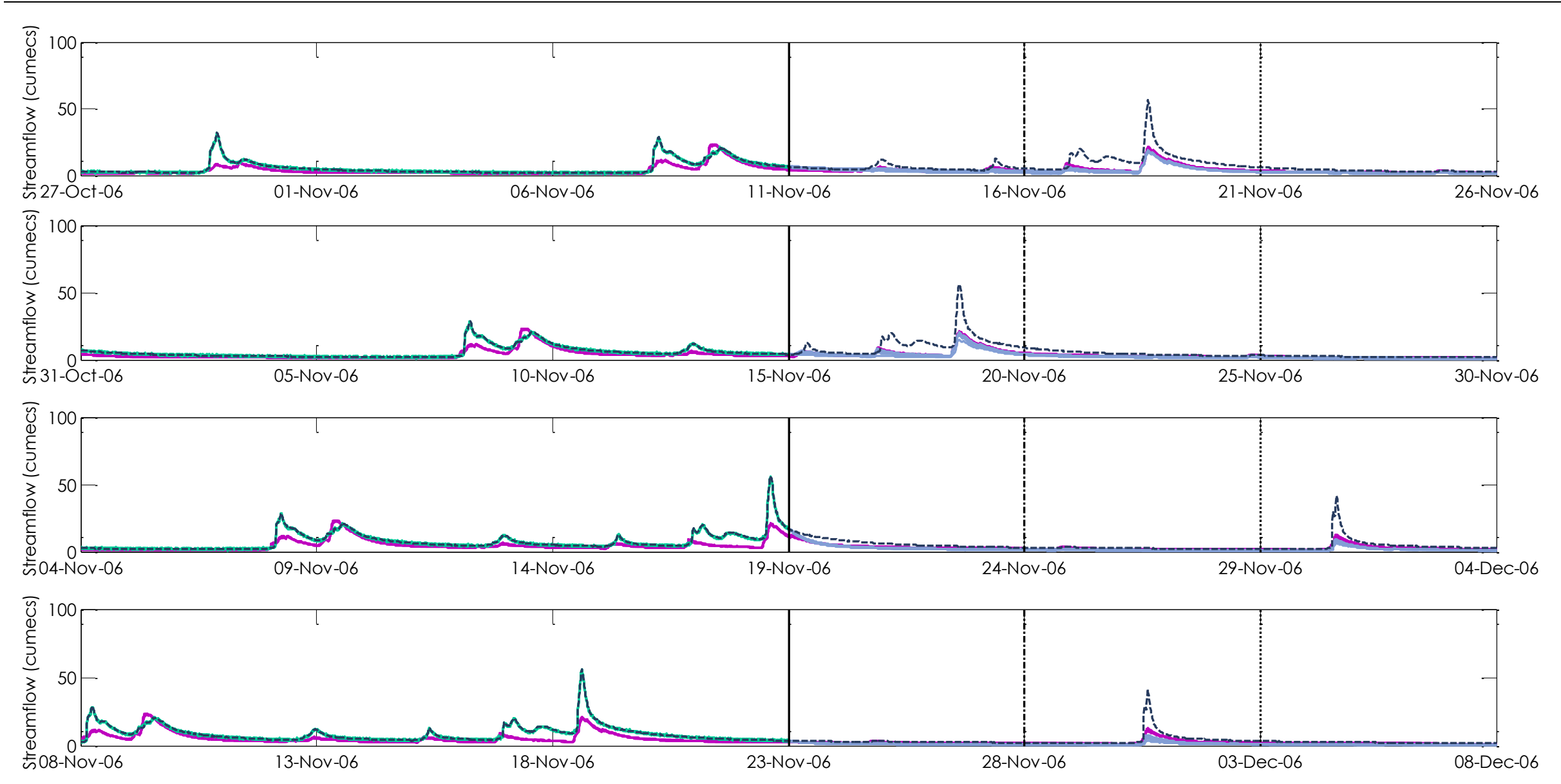

— Unfiltered Model Output —— Filtered Model Output —— Predicted Streamflow ------ Observations — Time of Prediction ---.-.- 5 day forecast -.......... 10 day forecast

Figure 8.22 Filtered and non-filtered model output versus streamflow observations from various projection times for the November 2006 'normal' operating conditions: Waimarino catchment. 

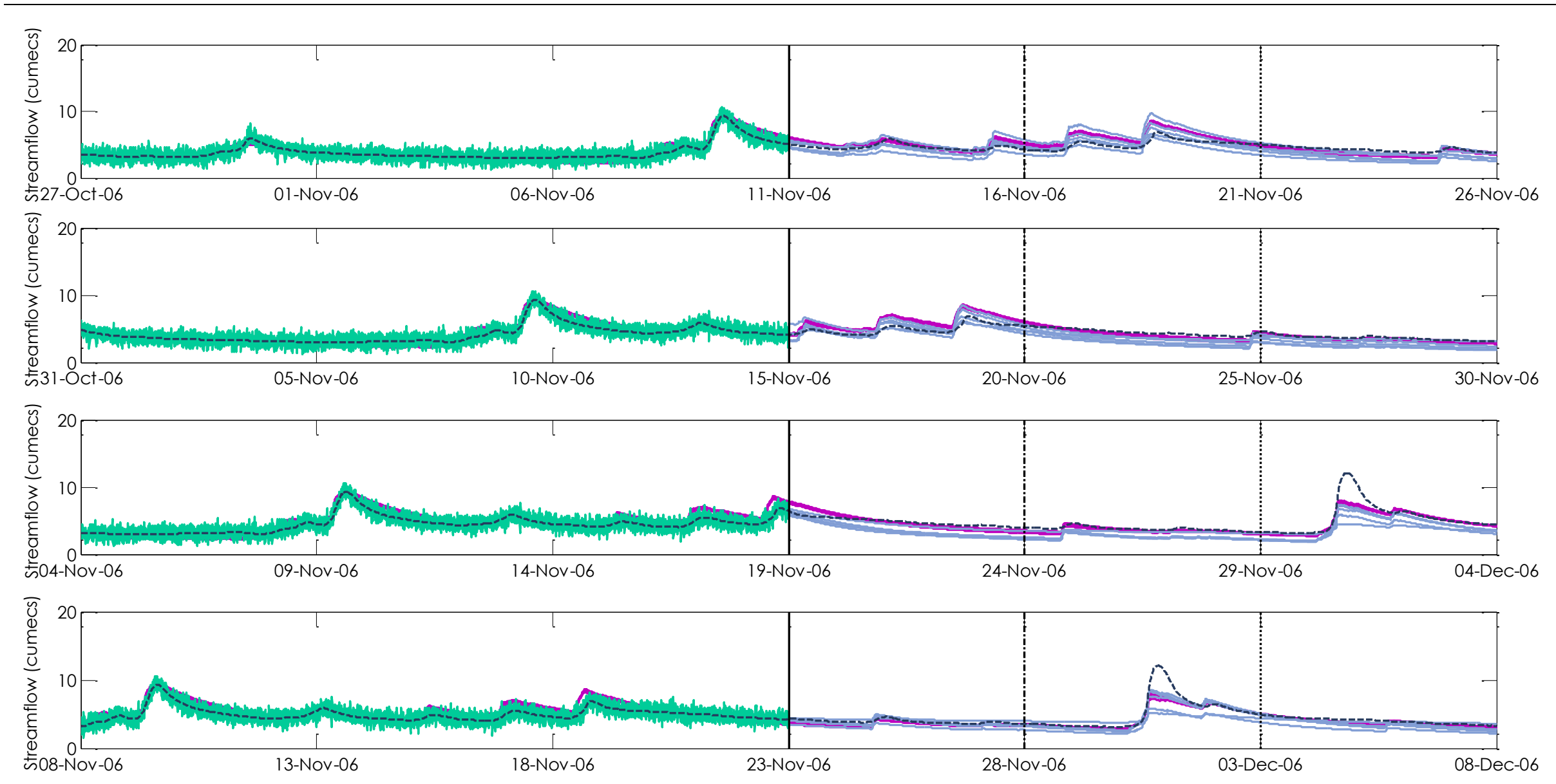

- Unfiltered Model Output —— Filtered Model Output —— Predicted Streamflow ------ Observations — Time of Prediction ---.-.. 5 day forecast -........... 10 day forecast

Figure 8.23 Filtered and non-filtered model output versus streamflow observations from various projection times for the November 2006 'normal' operating conditions: Kuratau catchment.

216 | Lake Taupo Inflow Model 


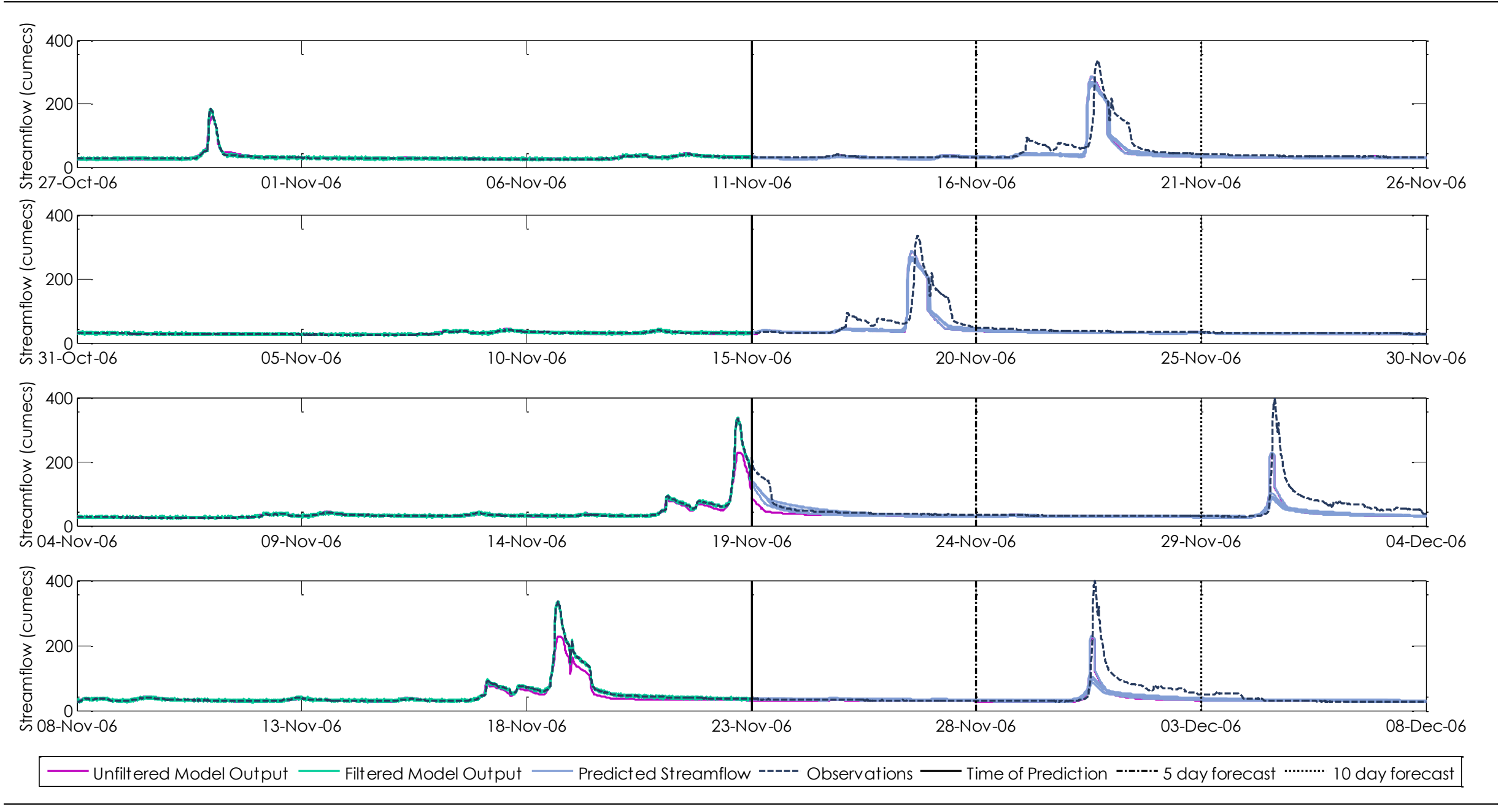

Figure 8.24 Filtered and non-filtered model output versus streamflow observations from various projection times for the November 2006 'normal' operating conditions: Tongariro catchment. 
are generally low. As discussed in Section 7.2.2, the Kuratau parameters did not perform well outside of the calibration period and therefore predictive accuracy is reduced. However, the filter is able to adjust state conditions to account for these errors resulting in slightly better short-term predictive accuracy. This is evidenced by the improvement in short-term prediction from 14 May 2010 when states are adjusted given an event which the model did not represent.

Although modelled streamflow is generally over-estimated in the Tongariro catchment, the filtered model output is able to simulate the low flow and recession characteristics reasonably well (Figure 8.28). Most of this error is associated with the lower Tongariro catchment since at the time of projection filtered streamflow is very close to the observed record. There is no offset from the Poutu input, indicating that modelled streamflow at this time is relatively good. During the small event on 13 May, one parameter set over-estimates the peak flow, but as observations arrive and are assimilated this error is dealt with and model predictions are improved. Without the assimilation, the model would continue to over-estimate streamflow in the Tongariro catchment for the entire period.

Overall, the constrained EnKF is able to improve the accuracy of model output by adjusting states to account for errors in the model structure, estimated parameters and data. Without state-updating, errors can accumulate, reducing the accuracy and reliability of model output. Although filtered and non-filtered model output was able to simulate low flow conditions reasonably well in most catchments, the filter is of real benefit during rainfall events when inaccurate data leads to errors in the estimation of catchment water content and, subsequently, streamflow.

\subsubsection{Issues and possible improvements to the constrained EnKF}

In the following sections, we discuss a number of issues identified in the application of the constrained EnKF and suggest possible improvements to its use.

\section{Further investigation of possible state constraints}

In the examples shown above, the constrained EnKF is shown to improve model forecast accuracy and reliability through more realistic state updating. In this study, the constraints imposed are fairly simple. State volumes are required to be nonnegative and the perturbations made to states need to be within sensible ranges. Perturbations could also be constrained based on the time of year, antecedent 


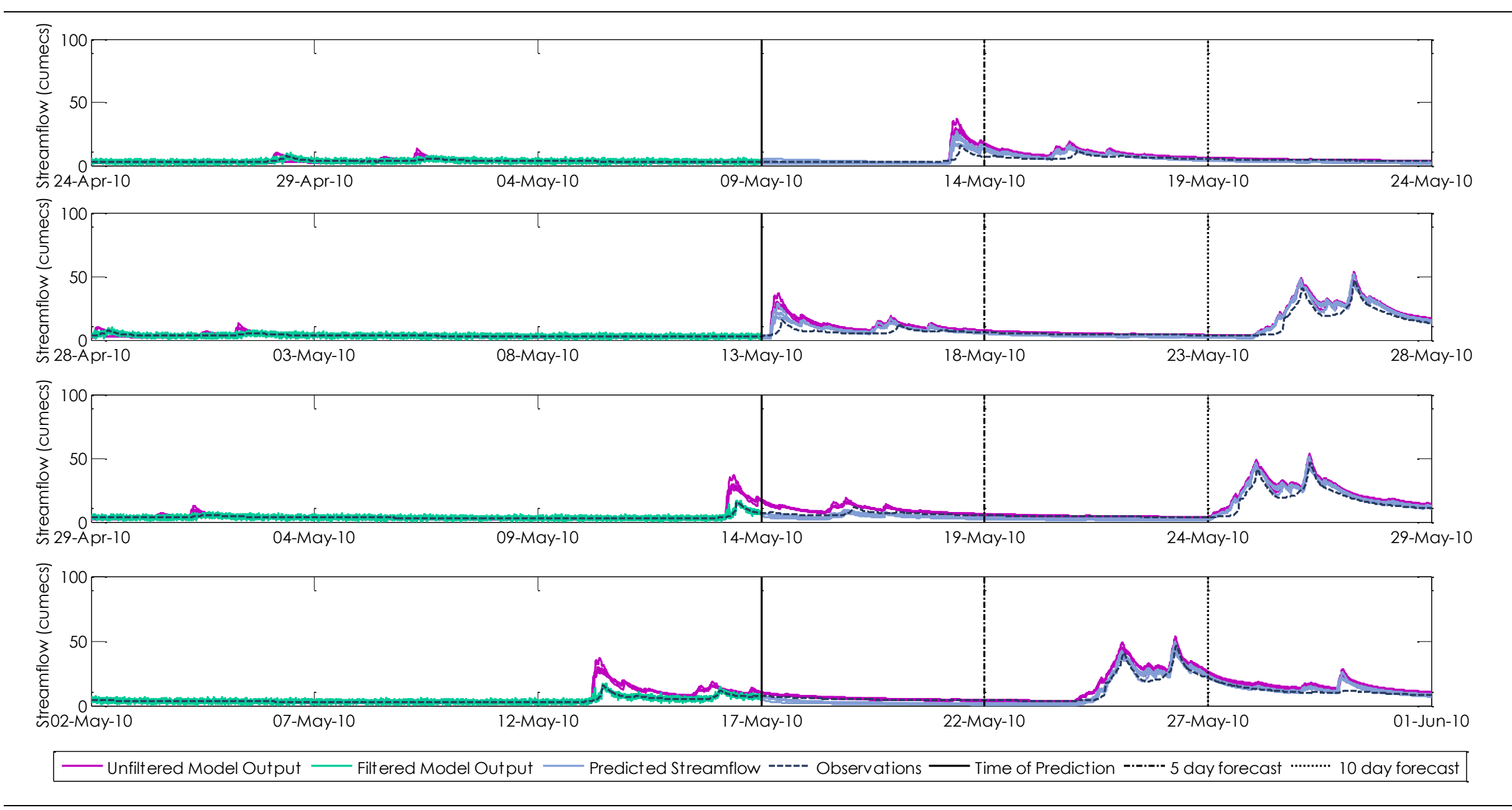

Figure 8.25 Filtered and non-filtered model output versus streamflow observations from various projection times for the May 2010 drought event: Tauranga-Taupo catchment. 


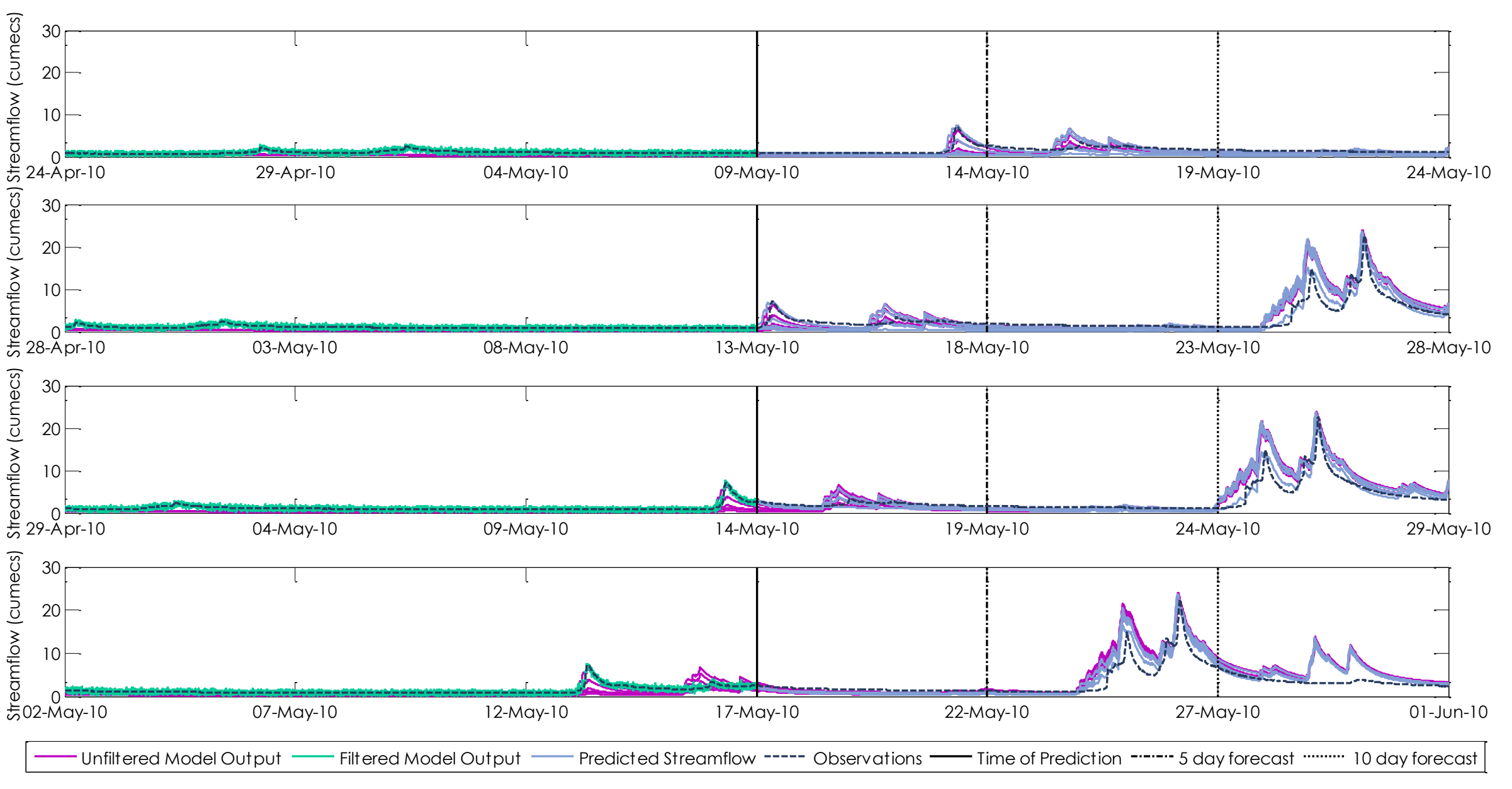

Figure 8.26 Filtered and non-filtered model output versus streamflow observations from various projection times for the May 2010 drought event: Waimarino catchment.

220 | Lake Taupo Inflow Model 

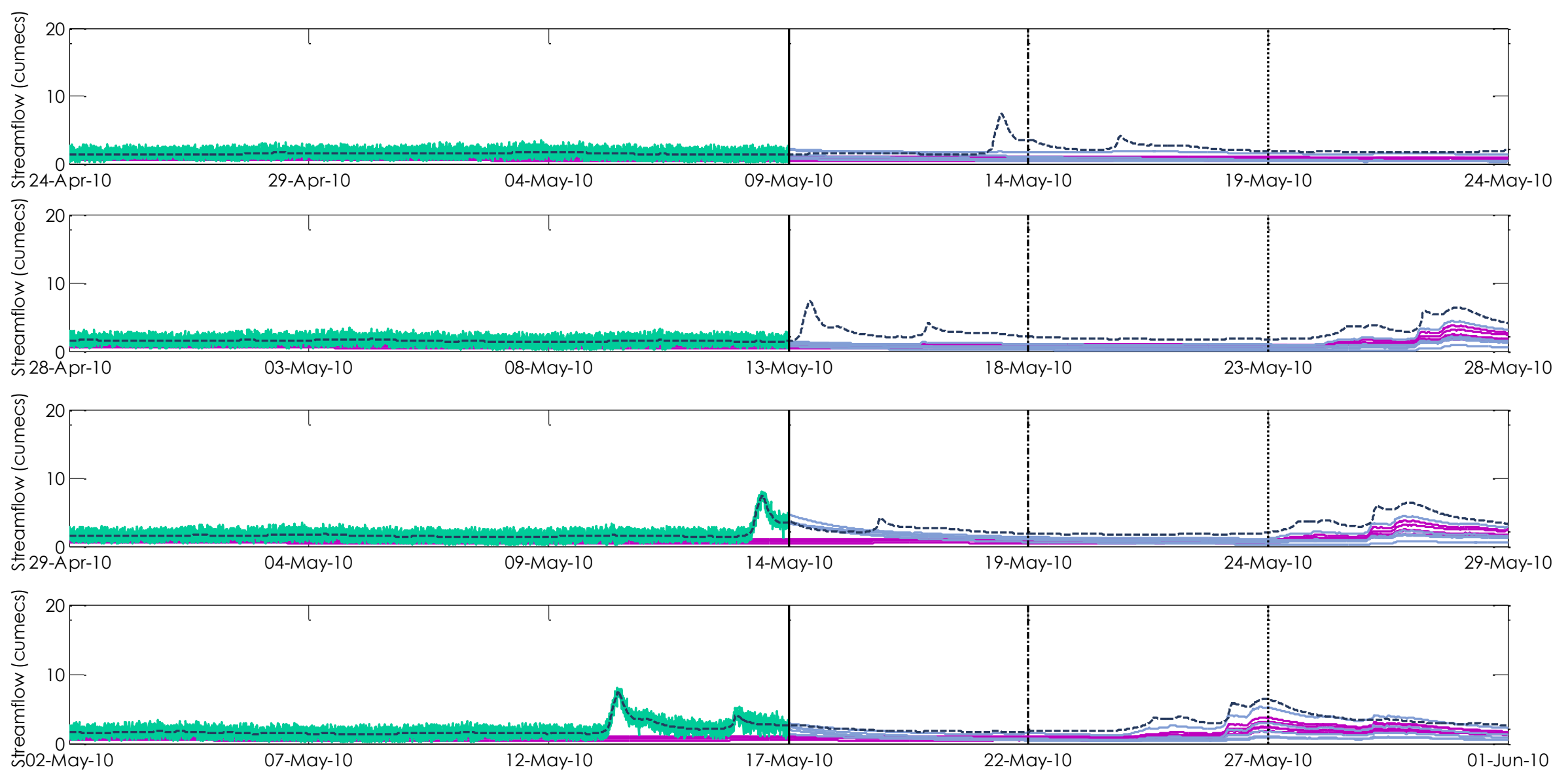
s02-May-10

07-May-10

12-May-10

17-May-10

22-May-10

27-May-10

10 day forecast

Figure 8.27 Filtered and non-filtered model output versus streamflow observations from various projection times for the May 2010 drought event: Kuratau catchment. 


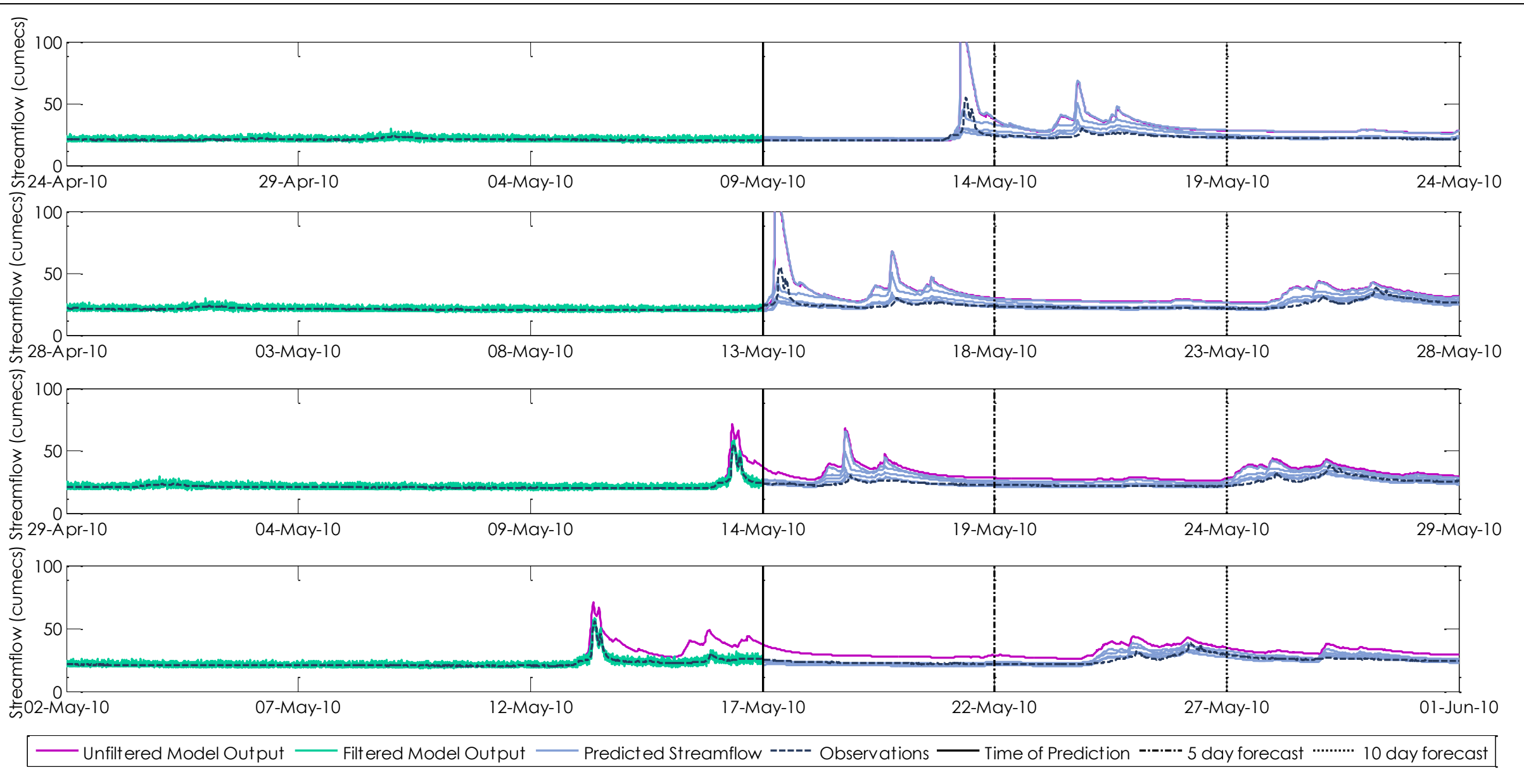

Figure 8.28 Filtered and non-filtered model output versus streamflow observations from various projection times for the May 2010 drought event: Tongariro catchment.

222 | Lake Taupo Inflow Model 
conditions, rainfall event intensity and state volumes. Optimisation of the filter algorithm could also improve filter performance. For example, in this study 100 ensembles are used. In some cases, where constraints are violated, some of these ensembles are excluded and can, in some instances, leave only a small number of ensemble members for state updating. Although this does not occur frequently (refer Section 6.5.3), it may affect the reliability of state estimation at these times.

The EnKF updates model states based on a minimisation of the mean square error. Essentially, the model is trying to find state conditions that will better represent the antecedent conditions to provide a closer simulation to the observations. There may, however, be many realistic approximations of state values within the constraints that could provide a physically consistent hydrologic response. The constrained filter would, therefore, be improved if updated states are required to produce good/realistic solutions to not only the current observation but also to subsequent observation(s) as well. In doing so, state updating could become even more consistent with physical laws. Model output accuracy could be increased with more observations used but such updating would also add to computational run times and would reduce the lead time for which the model predictions would be valid. The increase in computational burden needs to be weighed against the improvement in model output reliability and accuracy. Another issue is the temporal resolution of the available data. If only hourly (or longer) data is available, the predictions may become of less use, especially at times when high resolution forecasts are required (i.e. flood forecasting).

\section{Potential as a diagnostic tool for checking consistency of parameter sets}

The performance of the filter is also reliant on accurate estimates of parameters. In the example presented in Figure 8.29, one of the parameter sets for the Kuratau catchment far exceeds the observed response. This occurs in both the filtered and non-filtered model output. The likely cause is in the estimated parameter set itself. The performance of Kuratau parameters is much weaker in terms of the KGE objective function values outside of the calibration period (refer Section 7.2.2). This could impact on the reliability of future predictions. This highlights the importance of having a robust parameter estimation routine as part of the modelling process. 

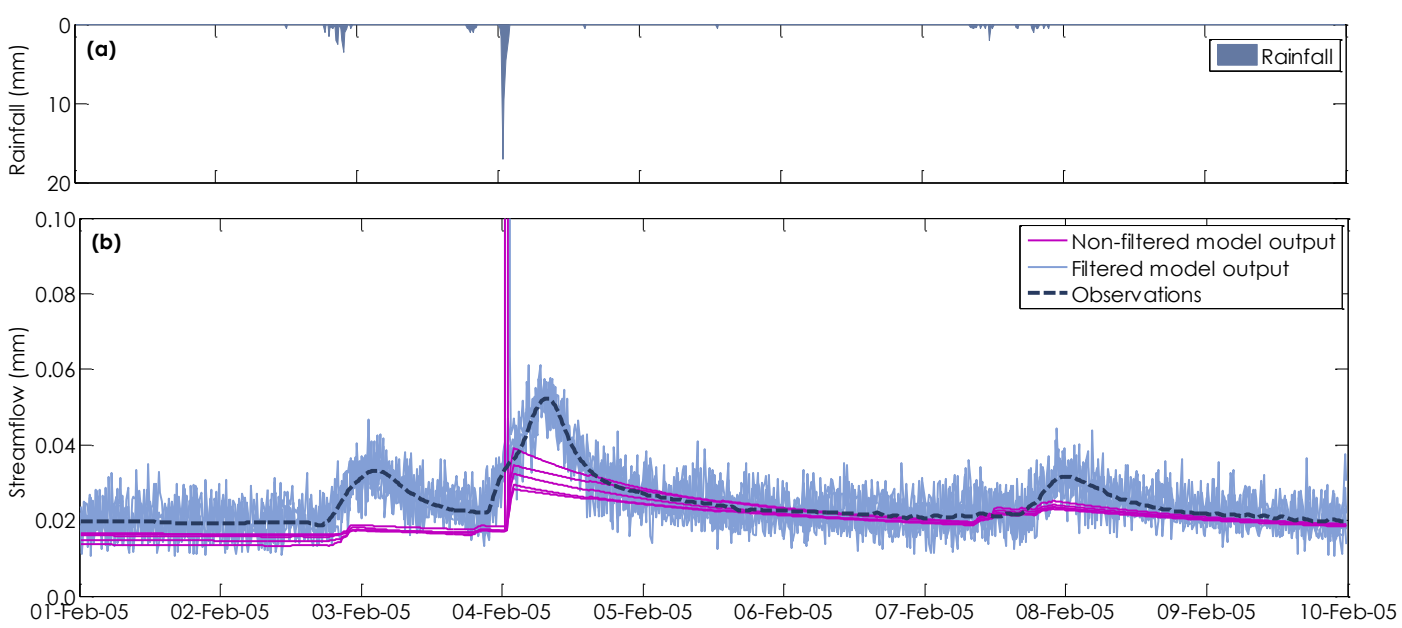

Figure 8.29 (a) Estimated catchment areal rainfall. (b) Filtered and non-filtered model output for the Kuratau catchment (above the scheme). Although not shown here, the unfiltered model output reaches $3.1 \mathrm{~mm}$ while the filtered output extends to a maximum flow of $135 \mathrm{~mm}$. Units are $\mathrm{mm} / 15$ minutes.

\section{Sensible observations for assimilation}

It is important that the observations being assimilated are sensible and consistent with the physical reality. In the lower Tongariro catchment, observed streamflow is determined by removing the flow as observed at Poutu (taking into account an estimated 1.5 hour lag time) from the streamflow time series observed at Turangi (refer Section 6.4.2). As discussed in the previous chapter, there are a number of issues with this approach and, as a result, the time series for the lower Tongariro catchment often displays erratic, hydrologically inconsistent, streamflow responses.

The filter is often forced to perturb states by large amounts given the observations despite the constraints. This is clearly evident during March 2004, when sudden increases and/or decreases in the observed hydrograph are seen (Figure 8.30a). The filter responds by adjusting the states to sometimes unrealistic values to account for the irregular behaviour (Figure 8.30b). In this example, although other states are also affected, the largest impact is in the interflow state. During this time, this state is perturbed by up to $305 \mathrm{~mm}$ (Figure 8.30c). Improvements could be achieved if a more accurate method for determining the streamflow time series for the lower Tongariro catchment is used. As suggested in Section 7.2.2, a kinematic wave model would reduce some of this error. Additional information relating to the regulation of the Tongariro River, in particular, the discharge from the Rangipo Station and any recreational releases may also be of value. 
(a) Filtered model output versus Observations

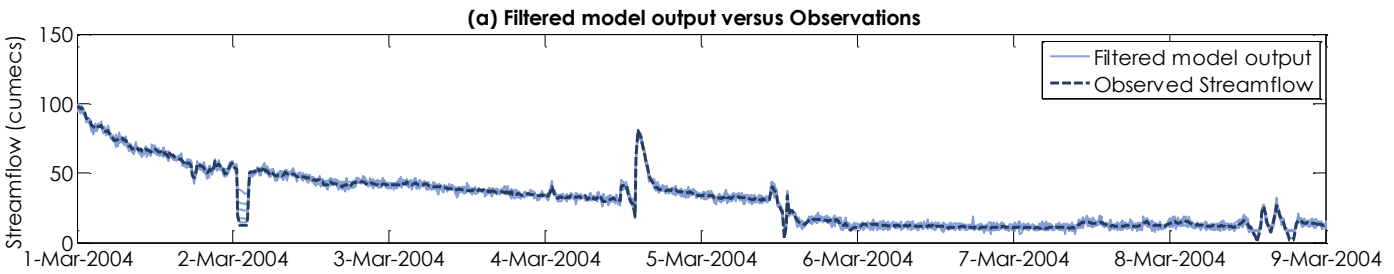

(b) Interflow State (Filtered and Non-filtered Response)
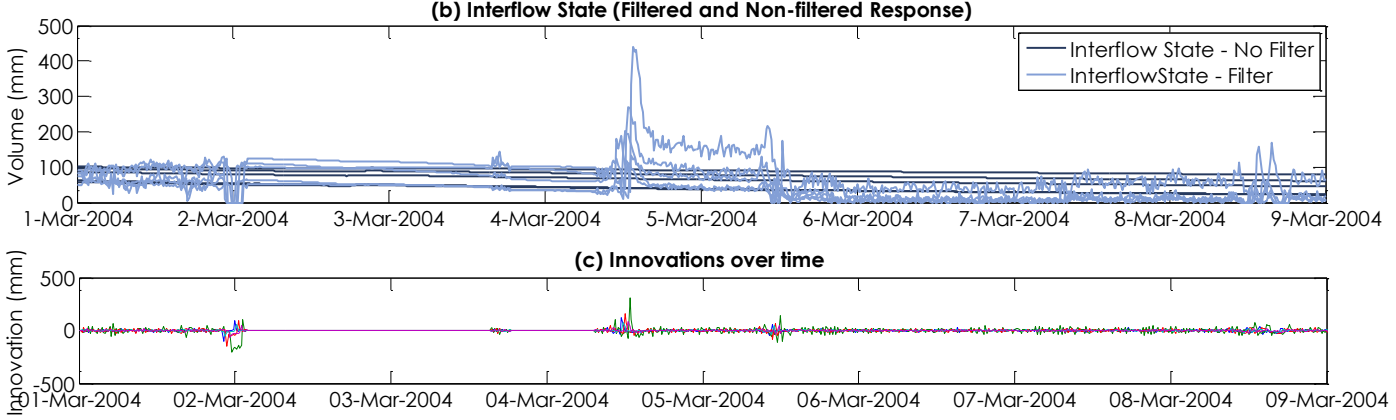

Figure 8.30 (a) Filtered model output versus observed streamflow for the lower Tongariro catchment. (b) Given the problems with deriving a sensible streamflow time series for this catchment the filter is often forced to violate constraints resulting in unreliable model output. (c) Updates made to states can be considerable to account for irregularities in streamflow time series. Units are $\mathrm{mm} / 15$ minutes.

The filter also relies on continuous/regular reliable observations to be available for assimilation. For various reasons, there may be times when these observations are unavailable. Infilling gaps in the streamflow time series with observations from other catchments can be problematic. In the example shown in Figure 8.31, the gap in the original time series has been infilled using the observations from a nearby catchment, scaled according to the mean flows of each catchment. Although the two catchments have a relatively high correlation in terms of streamflow, they are significantly different in many physical, climatic and hydrologic attributes. Ideally, catchments would be hydrologically similar. However, a lack of other gauged catchments for which corresponding observations are available limits the choice of data to use. It is clear that the 'donor' catchment is not suitable for infilling these gaps. There are significant and inconsistent jumps in the time series where the observed and infilled data meet. The filter tries to adjust to the large increases/ decreases in streamflow by adjusting model states to unrealistic volumes in order to provide a solution that fits the 'observed' response (Figure 8.32). Consequently, the filtered response of one of the parameter sets is an order of magnitude higher than the observed or other parameter sets (Figure 8.31) and the reliability of predictions from this parameter set at this time are compromised. 

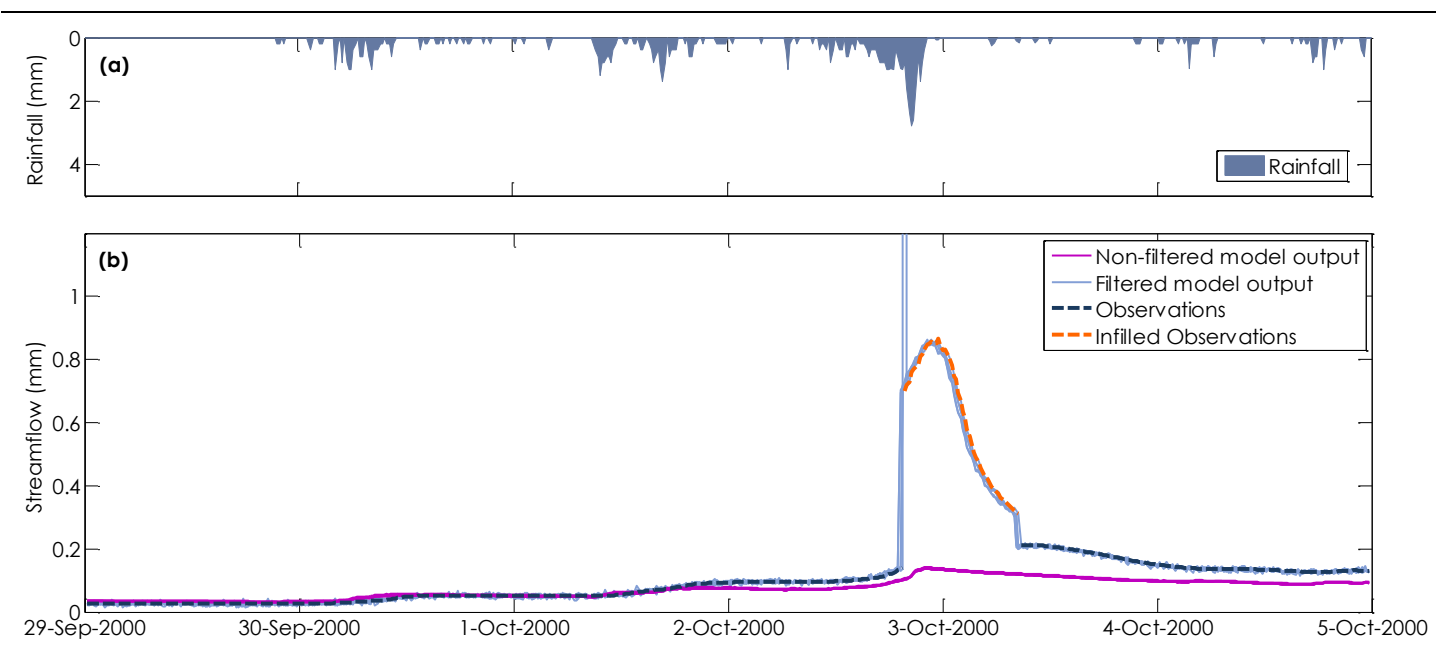

Figure 8.31 Filtered and non-filtered model output versus infilled observation time series for the Kuratau catchment. Missing observations are infilled with observations from another catchment. The suitability of these 'donor' observations is evident in the resulting hydrologically inconsistent streamflow response. Note that one of the parameter sets filtered response is as high as $26.5 \mathrm{~mm}$. This plot has been truncated for easier visual inspection. Units are $\mathrm{mm} / 15$ minutes.
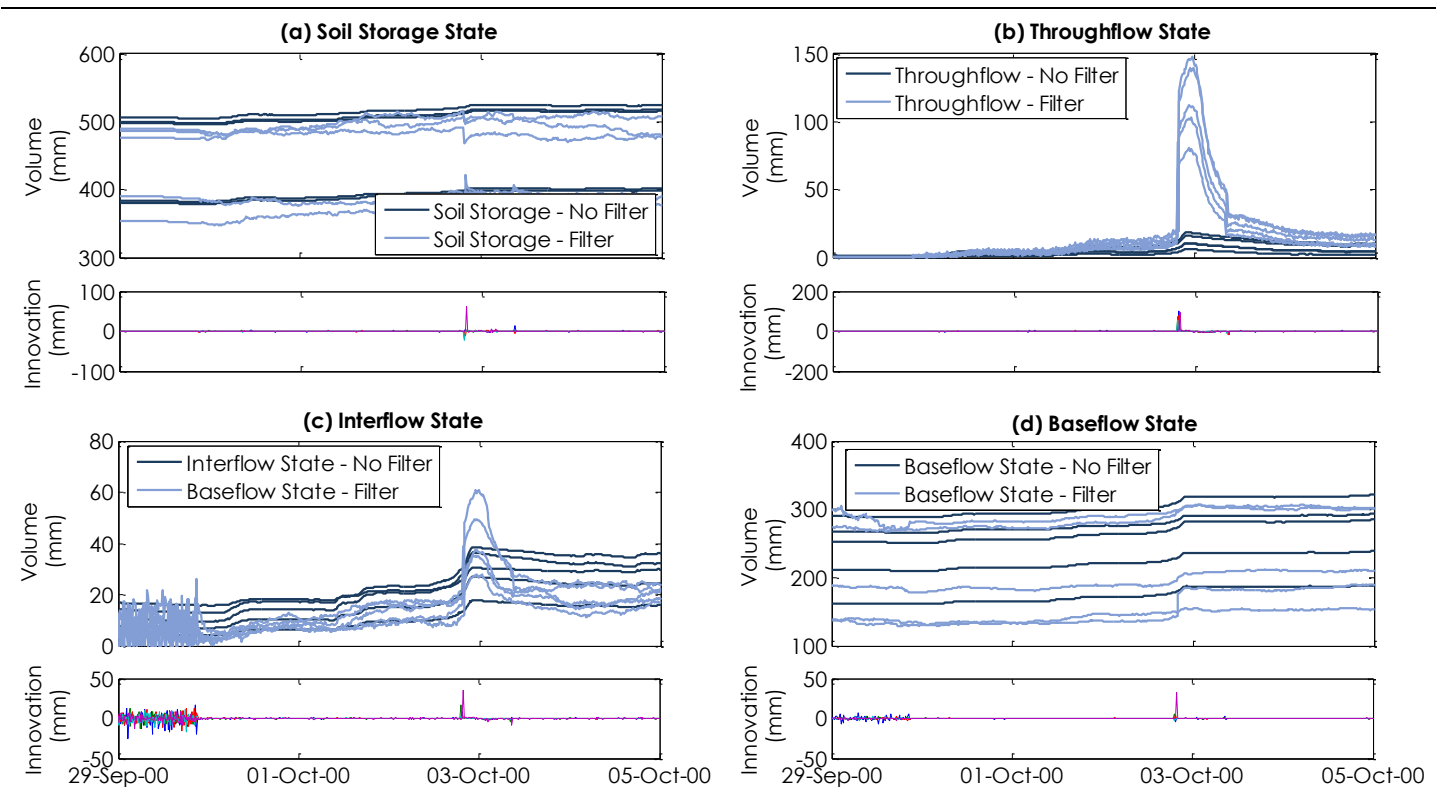

Figure 8.32 Corresponding state volumes over the same period show that at this time all states experienced a significant increase in volumes to account for the sudden increase in flow resulting from unsuitable data for infilling. Units are $\mathrm{mm} / 15$ minutes. 

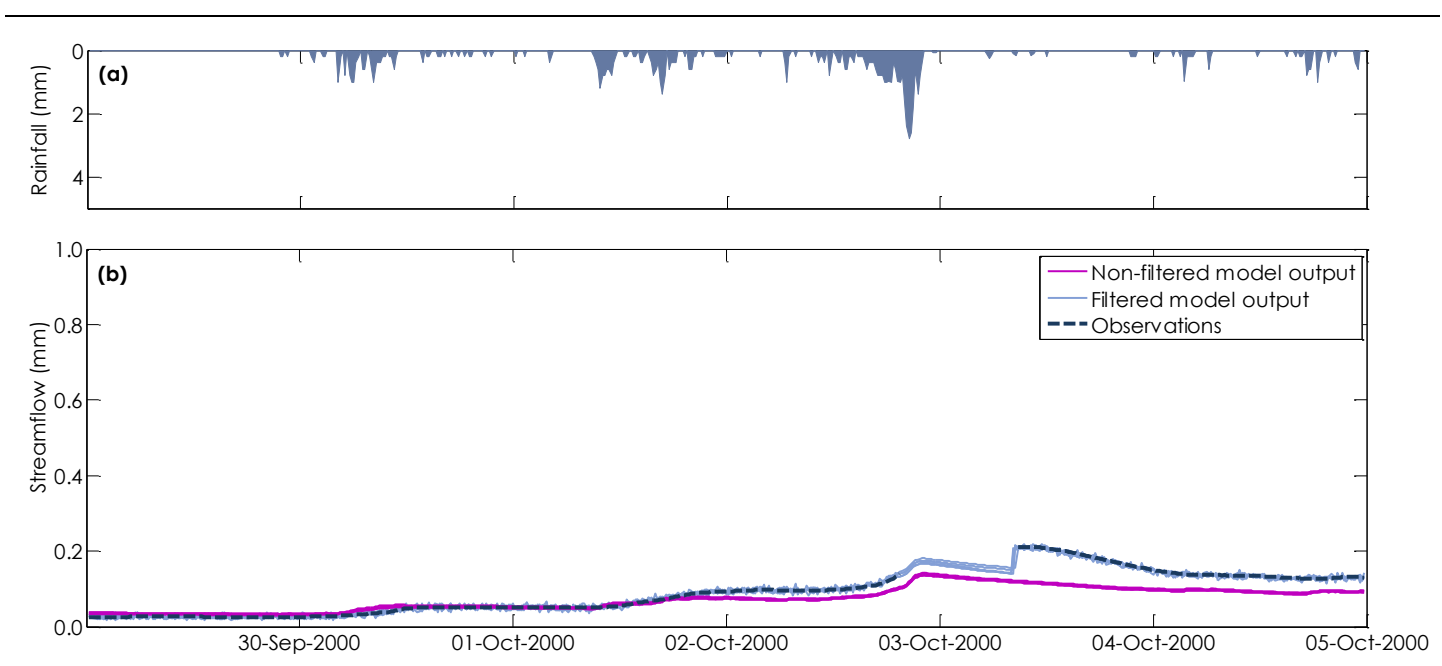

Figure 8.33 The unfiltered model is used to estimate streamflow from the last known updated state volumes during period of missing data. Assuming accurate input rainfall data, the model relies on accurate estimated parameters and representative model structure to ensure reliable model output. Units are $\mathrm{mm} / 15$ minutes.

(a) Soil Storage State
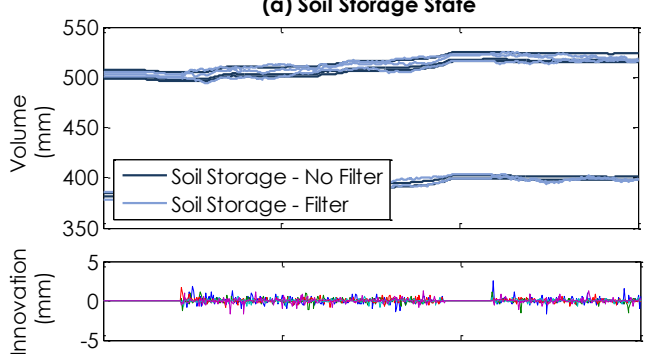

(c) Interflow State
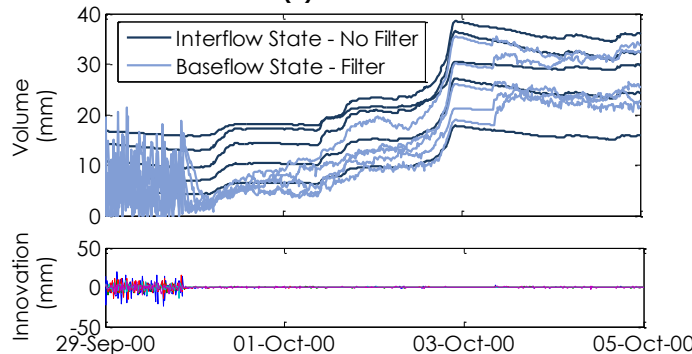

(b) Throughflow State

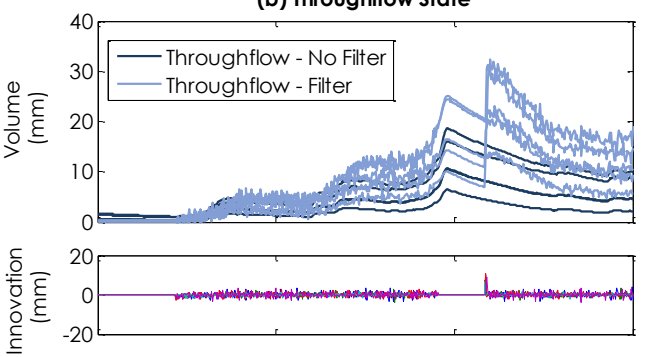

(d) Baseflow State

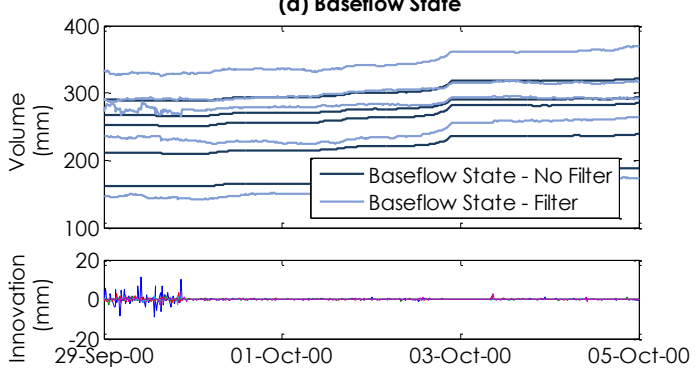

Figure 8.34 While an adjustment is required when observations resume, state updating is generally kept to within physically consistent ranges for more reliable model predictions. Units are $\mathrm{mm} / 15$ minutes. 
The filter performs better when the infilled data is not used. In Figure 8.33, streamflow predictions are determined from running the model without state updating for the period of missing data. Although an adjustment is still required when the observations resume, this is less significant, resulting in more consistent streamflow and state estimations (Figure 8.33 and Figure 8.34). Over large events or longer periods of missing records, the performance of the model is dependent on how well the model structure and estimated parameters can simulate a realistic response. It is also dependent on the representativeness of the rainfall data used to drive the model. Assimilating rainfall observations, in the absence of hydrological observations (or indeed at all times), could also improve the accuracy and reliability of the filtered model response.

In this dissertation, rather than using infilled data, updating only occurs when observations are available. During periods where there are no observations to assimilate, the unfiltered model is applied until observations resume. In doing so, it is assumed the model structure and estimated parameters are a close enough representation of the actual catchment response. Again, this highlights the importance of having accurate parameter estimates and a representative model structure.

\section{Assimilation of streamflow observations in regulated catchments}

In the regulated Hinemaiaia and Poutu catchments, the current constraints are not consistent with the regulation imposed. The filter is required to not only account for errors in the driving data but also any irregularities and regulation in the streamflow observations. As such the regulation imposed in the Hinemaiaia and Poutu catchments also affects the ability for the filter to keep within constraints.

In the Hinemaiaia catchment, streamflow is modelled without regulation. Despite reasonable KGE values ( 0.7913 - 0.7920), the modelled output in unable to capture the regulation in the observations. The filter is also adjusting for this regulation and not necessarily a change in state which the model is unable to represent. While it is able to do this successfully (Figure 8.35a), the filter is often required to adjust states beyond constraint limits. Of particular note are the considerable fluctuations evident in the interflow state (Figure 8.35b). Interflow state volume innovations are generally much higher than constraints would allow because the filter is trying to fit to the regulation imposed, resulting in erratic changes in state values. Constraints are guided by the maximum state volume changes identified in the unfiltered model 
output. For the interflow state of the Hinemaiaia catchment, this is in the order of $\pm 10 \mathrm{~mm}$. As can be seen in Figure 8.35c, this is often exceeded, although volumes stay within what would be considered physically realistic ranges. At these times, there is greater uncertainty associated with model predictions. Since these fluctuations are a direct result of the controlled storage and release of water from the scheme and do not reflect changes in state volumes, improvements could be made if the impact of this regulation on the natural streamflow was removed from the time series. Averaging the streamflow over the previous day would achieve this but would not be suitable operationally. With further investigation it may be possible to identify particular times when the streamflow change is likely to be due to the regulation rather than to a change in catchment conditions. Further information on the operation of the scheme could allow the associated regulation to be included in the assimilation framework. Alternatively, baseflow volumes could be assimilated directly if groundwater level data is available. A relationship between the groundwater level and baseflow fluctuations could be obtained and an algorithm to incorporate this relationship included in the data assimilation framework.

Despite the heavy regulation of the Poutu catchment, the filter does a good job of updating states to effect a good fit to the observations (Figure 8.36a). However, the filter is again required to adjust states to account for not only errors in driving data but also for the impact of the regulation which may not be adequately represented

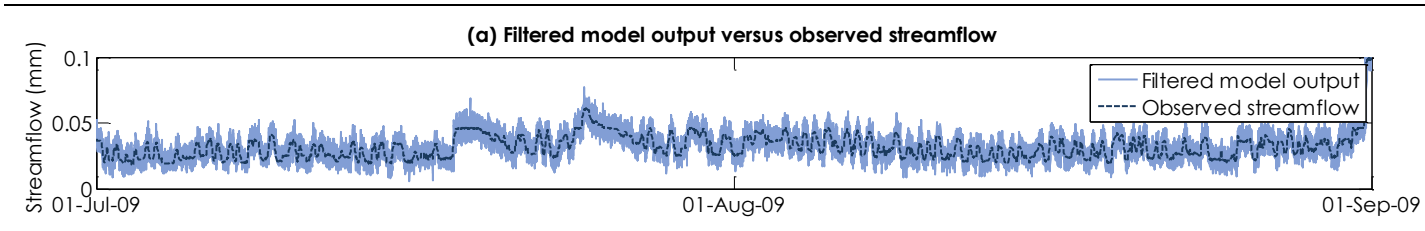

(b) Interflow State
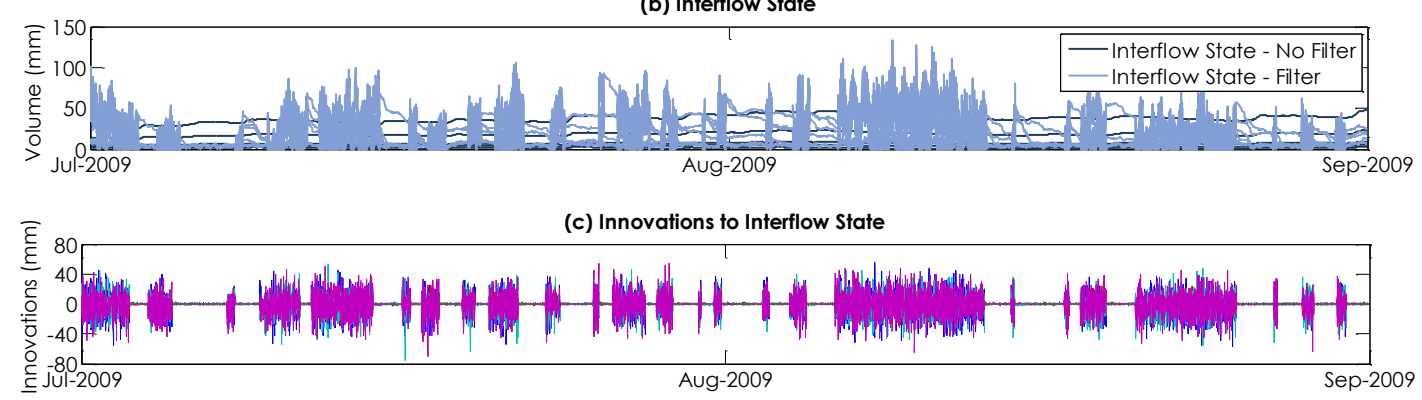

Figure 8.35 Filtered model output versus observed streamflow for the Hinemaiaia catchment. (a) The streamflow time series shows some diurnal fluctuations as a result of the regulation in the catchment. (b) Although interflow state volumes are generally within physically realistic ranges, (c) innovations indicate that constraints are often violated in order to account for the regulation which is not specifically modelled. Units are $\mathrm{mm} / 15$ minutes. 

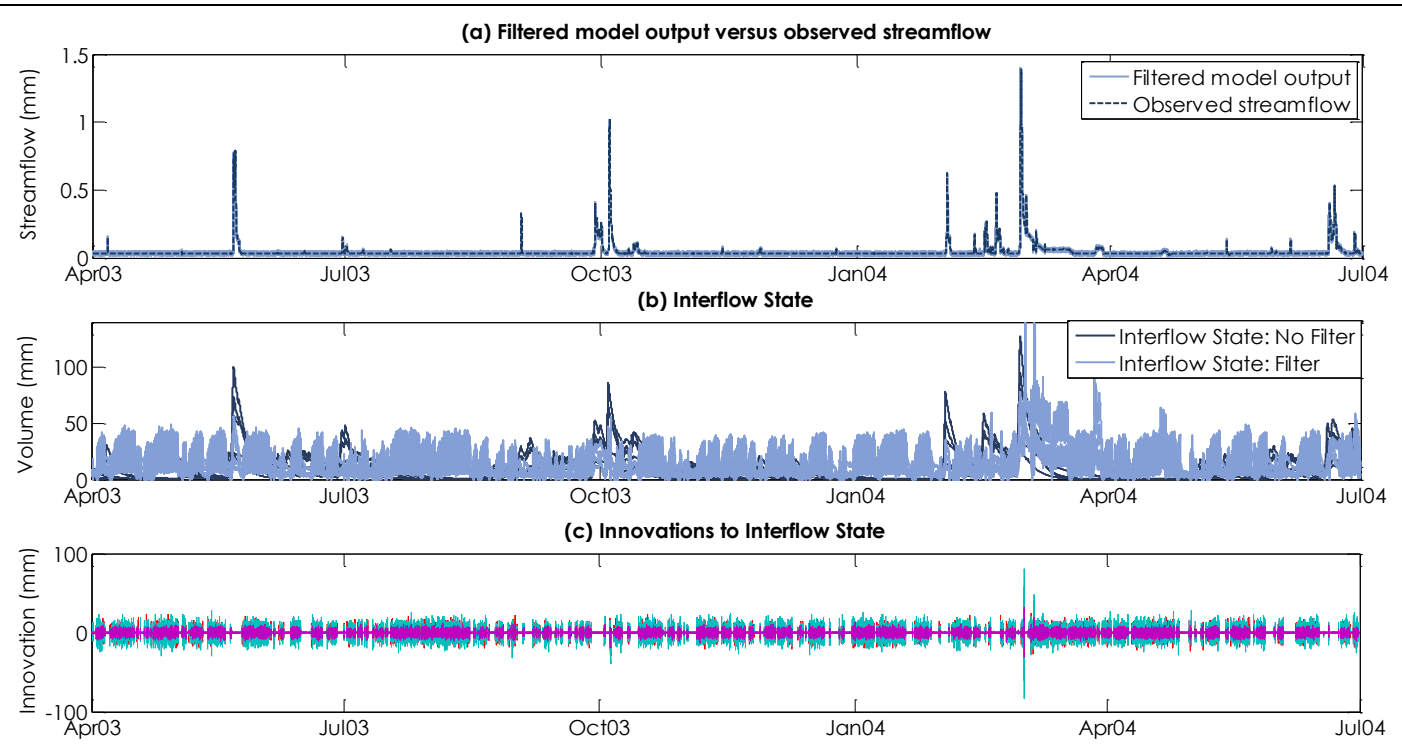

Figure 8.36 Filtered model output versus observed streamflow for the Poutu catchment. (a) the constrained EnKF is able to simulated observed streamflow well but (b) states are adjusted to account for errors in driving data and to account for regulation. (c) Innovations to state volume are generally within constraints, although two parameter sets tend to consistently violate these constraints in the interflow and baseflow states. Units are $\mathrm{mm} / 15$ minutes.

in the model output. Similar to the Hinemaiaia catchment, considerable fluctuations in some states are seen (Figure 8.36b and Figure 8.36c). Most commonly, state constraints are exceeded during significant flood events when diversions through the Poutu Intake are shut out. This can result in sudden increases in streamflow, leading to large updates to state volumes.

In both the Hinemaiaia and Poutu catchments the filter is able to effect a closer matched simulation to the observations historically. However, since the filter struggles to keep state perturbations within the constraints, the model predictions from these catchments are more uncertain. For this reason, the filter is not applied to these catchments in the operational model for the prediction of lake level.

\section{Innovation analysis}

Assimilation innovations provide additional information that could be used to further improve parameter estimation. The cumulative sum of innovations for each state shows where water is being added or removed. A representative parameter set would present little bias over the long term. Assuming state updates are sensible this information could be used to refine parameter estimation further. In the example shown (Figure 8.37), for the Tauranga-Taupo catchment the soil storage state shows 
little bias over the 1998-2010 evaluation period. In the baseflow state, three of the parameter sets seem to be doing reasonably well, with less than $1000 \mathrm{~mm}$ added or removed over the 13 year period. This equates to less than $0.009 \mathrm{~mm}$ per hour on average. Conversely, a large amount of water is taken out of the fastflow and interflow states indicating that the relative proportions for these states may be too high. Respective parameter values could be adjusted downwards as a result.

A preliminary analysis of cumulative innovations was undertaken in this dissertation for the Tauranga-Taupo sub-catchment using the standard implementation of the EnKF (no constraints), with the aim of using the information to refine parameter sets. Parameter sets were adjusted and re-calibrated on a test period of data. Of note, is that in order to use the information in the innovation analysis the relationship between the innovations and model state parameters needs to be identified. Time-constraints prevented any further progress with this aspect of the filter. More of a focus was the application of constraints for improving the reliability of model output. The potential for the filter to be used to improve model calibration and structural evaluation, therefore, remains an area of future work.
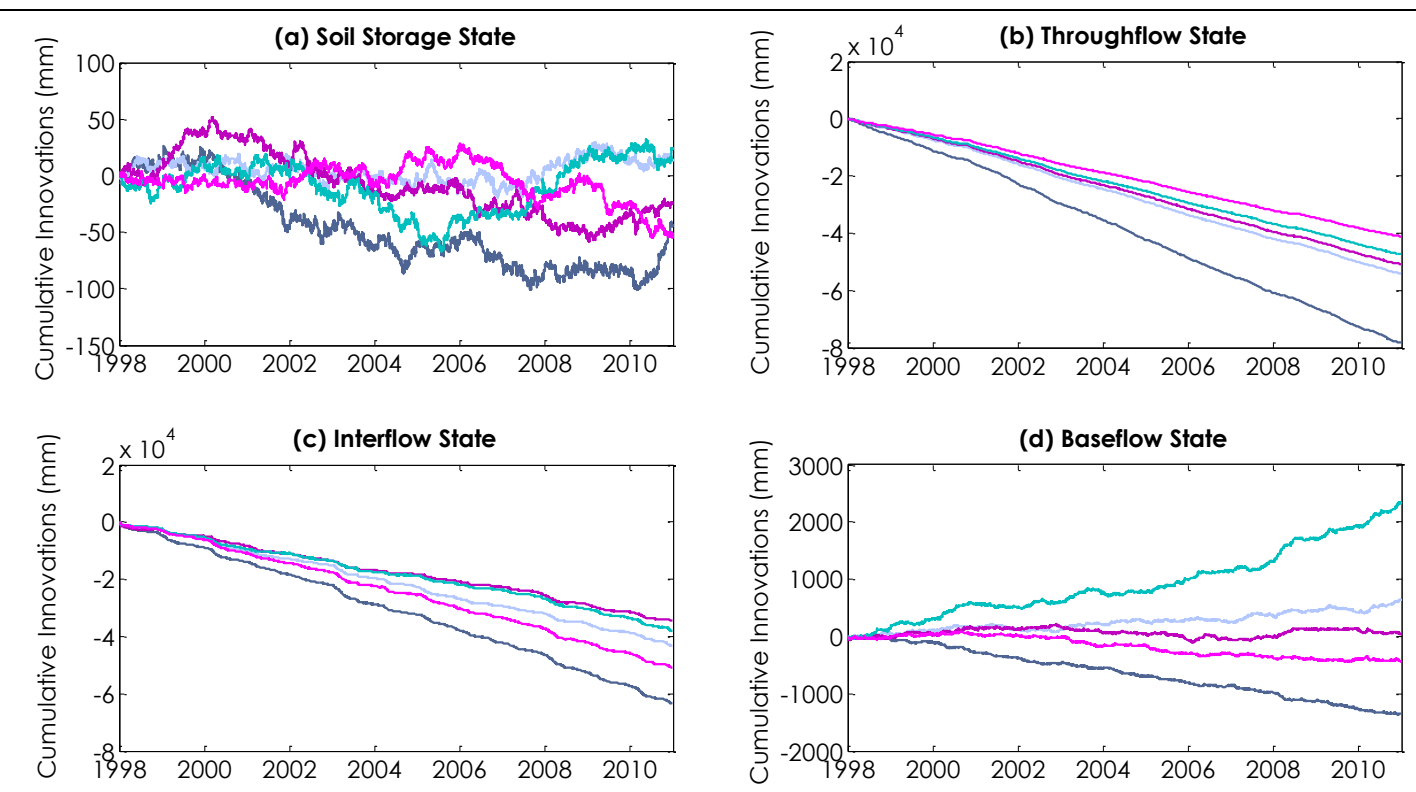

Figure 8.37 Cumulative sum of innovations for the (a) soil storage state; (b) fastflow state; (c) interflow state; and (d) baseflow state. Units are $\mathrm{mm} / 15$ minutes. 


\subsection{Conclusions}

The LTIM is made up of modelled inflows from five currently gauged catchments, discharge from the TPS and inflows from ungauged areas. The largest and most complex of the hydro power schemes is the Tongariro Power Scheme. A statistical probability analysis is used to estimate the discharge for the scheme providing a possible range of discharges based on the time, day and month. The discharge from this scheme accounts for approximately $20 \%$ of the outflow from Lake Taupo. It is therefore important that the uncertainty associated with this catchment is reduced further. Other than obtaining further information relating to the operation of the scheme (especially around the diversions and storages), this could be achieved by incorporating autocorrelation into the analysis and information pertaining to various price controls and climatic influences, such as air temperature.

Correlation analysis identified areas of hydrologic similarity between historically gauged catchments. The Kuratau parameters are used to estimate streamflow from nearby Whanganui and Waihaha catchments. All remaining areas of the catchment are considered ungauged. Because of the diverse characteristics of these areas, this catchment is divided into two regions (refer Section 6.4.4). Southern and eastern ungauged areas are modelled using the regionalised parameters of the TaurangaTaupo catchment. The remaining areas of the north and west are modelled by the regionalised parameters of the Kuratau catchment. Compared to the residual inflow time series (proportional to respective ungauged catchment areas), these parameter sets did reasonably well, although it is noted that there are periods where the modelled output over-estimates inflow from these areas. Further investigation into appropriate parameter sets or refinement of existing parameter ranges would be appropriate. The ungauged areas of the north and west may also benefit from being discretised into smaller sub-catchments.

Calibration of ungauged areas is improved when direct groundwater contribution is accounted for. Currently, a constant rate is assumed. Including this direct input as an additional linear store in the model structure would improve model performance and account for the temporal variability of this inflow. It would require some data collection or inference from existing studies to represent this inflow adequately and to define reasonable parameter ranges for calibration.

Although the model does a reasonable job of simulating inflows, there is still considerable uncertainty in the model output, especially during flood events. State- 
updating via a constrained EnKF is used to improve model output accuracy and reliability for catchments which are explicitly modelled in the LTIM. Streamflow observations are used to update soil storage, fastflow, interflow and baseflow states reducing errors in determining catchment water content. It is, therefore, not applied to the TPS or ungauged areas of the catchment. With storage biases corrected more accurate predictions of streamflow can be made.

The reliability of these predictions is improved when the filter is constrained so that states are updated to be consistent with physical laws. It is demonstrated that without these constraints the integrity of model predictions can be compromised. This has not been shown in the literature before.

Simple constraints have been applied in this study but there is scope for a wide range of possibilities to improve this aspect of the filter by allowing the constraints to vary depending on saturation levels, state volumes and/or rainfall intensities. The EnKF updates model states to better reflect catchment antecedent conditions and water content. Although in this study constraints are placed on the filter to ensure more realistic state updating occurs, these updates are based on fitting to a single observation. There may, however, be many realistic approximations of state values within the constraints that could provide a physically consistent hydrologic response. Investigation into ways in which multiple observations could be used to further improve state updating would be of benefit, although we note that the complex regulation in some catchments may still prevent this from improving predictive performance.

Overall, the filter performs well in the unregulated catchments of Lake Taupo. Over two significant events, the benefit of the filter is most evident at times when inaccurate driving data results in under-estimated peak flood flows. As streamflow observations are assimilated, and states adjusted accordingly, the prediction of streamflow is significantly improved, reducing short term biases.

In the regulated Poutu and Hinemaiaia catchments, the filter perturbs states not only to account for errors in driving data but also for any regulation that is not adequately modelled. However, constraints are often violated because the regulation imposed results in hydrologically inconsistent streamflow which can increase or decrease suddenly. States are adjusted accordingly but these updates are a response to the management of the streamflow rather than necessarily a change in states. Consequently, the reliability of predictions from these catchments is undermined. 
For these reasons, the filter is not applied in the operational model for predicting lake level of Lake Taupo. As an area of future work, investigation into the potential for using groundwater levels to relate changes in baseflow conditions could be useful, allowing the natural rise and fall of river levels to remain and ignoring short term fluctuations resulting from the regulation. This requires a groundwater level monitoring site(s) in or near the catchment being modelled. Streamflow observations could still be permitted when regulation does not occur.

The importance of obtaining robust and accurate parameters sets is highlighted in the Kuratau catchment, where one parameter set does not perform as well outside of the calibration period. In this case, the filter is unable to reduce the uncertainty associated with these estimated parameters, indicating that further work to improve parameter estimation for this catchment would be worthwhile. The value of assimilating realistic and sensible observations to improve the reliability of model predictions is highlighted. Unless a suitable, hydrologically similar catchment can be used to provide accurate estimations of streamflow at times when observations may not be available, state-updating should not occur. In the case of the lower Tongariro catchment, overcoming the problems with deriving a sensible streamflow record would improve filter performance.

An outcome from this analysis is the potential for the constrained EnKF to be used as part of the model calibration process. As noted above, the filter can be used to check for consistency of parameter sets. It can also be used to refine parameter ranges through analysis of state updates (innovations) time series. The value of this information is enhanced when state updates respect physical laws. 


\section{Predicting changes in lake level}

In the previous two chapters, the results of model calibration and constrained EnKF are presented. In this chapter, the performance of the LTIM is evaluated over a wide range of hydrological and meteorological conditions. In this chapter, an in-depth critical evaluation is undertaken on eight events chosen a priori as representation of both extreme and 'usual' conditions. For each event, the combined output for the Lake Taupo Inflow Model (LTIM) is converted into a corresponding lake level change and its performance evaluated over three dry/drought conditions (Section 9.1), two 'normal' operating conditions (Section 9.2) and three flood events (Section 9.2) between 1998 and 2010. These events are of particular interest because they represent a range of hydrological and meteorological conditions including some of the most extreme events/periods experienced in the catchment. By applying the LTIM to these events its performance can be evaluated over a wide range of hydrological conditions.

Model output from the five explicitly modelled catchments in the LTIM are combined with predictions of inflow from the TPS and regionalised ungauged areas. Sub-catchment inflows are assumed instantaneous; no lag is accounted for between the gauge and the river mouth. Although the model could not be developed in realtime (due to data issues), its capacity for forward prediction is evaluated using historical (gauge) rainfall and potential evapotranspiration data to drive the model. The total inflow from all sources is converted into a corresponding lake level change. 
Modelled lake level is compared against the (smoothed) observed lake level and performance evaluated. Lake level is projected 15 days ahead from various forecast times over the events/periods. The most critical time is in the first five days of the forecast, since many management decisions are likely to be based on reliable model output for these short-term periods. Between 5 and 15 days, the model output provides an indication of the persistence of a particular pattern and can indicate the arrival of any significant events that can be planned for in advance.

To understand the various sources of uncertainty in the modelled response, the individual components that make up this response are analysed. The uncertainty associated with the TPS is removed (by using observed discharge) to illustrate the potential improvement in model output if more information about this system is obtained. Modelled inflows from gauged and ungauged areas are compared against the observations, leaving direct lake rainfall, potential evapotranspiration and groundwater contribution as other sources of error.

In the final analysis, model output is presented for each event under different operational scenarios. These scenarios relate to various outflow rates from the lake. For the purpose of this study, the maximum outflow is set at $320 \mathrm{~m}^{3} / \mathrm{s}$ although it is recognised that this rate varies depending on height of the lake (pers comm. Mighty River Power 2011). The minimum outflow is set to $50 \mathrm{~m}^{3} / \mathrm{s}$. The average outflow is based on the mean outflow from the lake between 1969 and 2011. In an operational context, such output is useful for decision-making purposes. 


\subsection{Dry/Drought Conditions}

\subsubsection{August 2001}

During August 2001, Lake Taupo receded to its lowest level within the 1998-2010 period. On 17 August, a minimum lake level of 355.93 m a.s.l was observed (Figure 9.1). Lake level had steadily decreased from the beginning of the year. Turangi experienced its warmest May on record and August was also warm and dry (NIWA, 2002). Rainfall was particularly low for the first four months of the year (Figure 9.2).

Overall, the model does a good job of predicting lake level over this dry event. Observed lake level falls within the range predicted by the model (Figure 9.3) for all four forecast periods. Model predictions are reasonable out to five days with increasing uncertainty to 15 days. Replacing the statistical estimates of discharge from the TPS with actual observations allows inspection of model performance with this source of uncertainty removed. Model performance is greatly improved, with more closely simulated estimates of lake level for the majority of the period (Figure 9.4).

Lake level is over-estimated as it reaches its lowest level of the period. There could be three reasons for this: a) groundwater input b) groundwater seepage and/or c) estimation of direct evaporation and inflows from gauged and ungauged catchments. Given this is a lengthy period of low lake level reflecting an extended

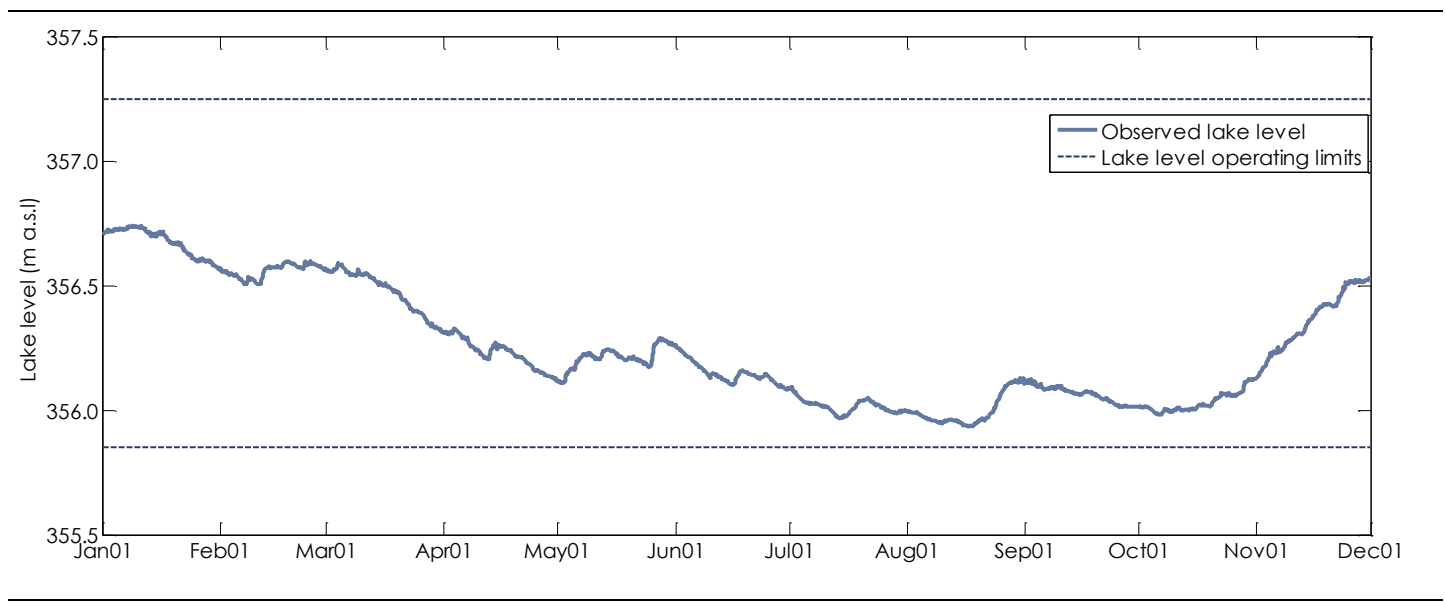

Figure 9.1 Observed (filtered) lake level: January - December 2001. 


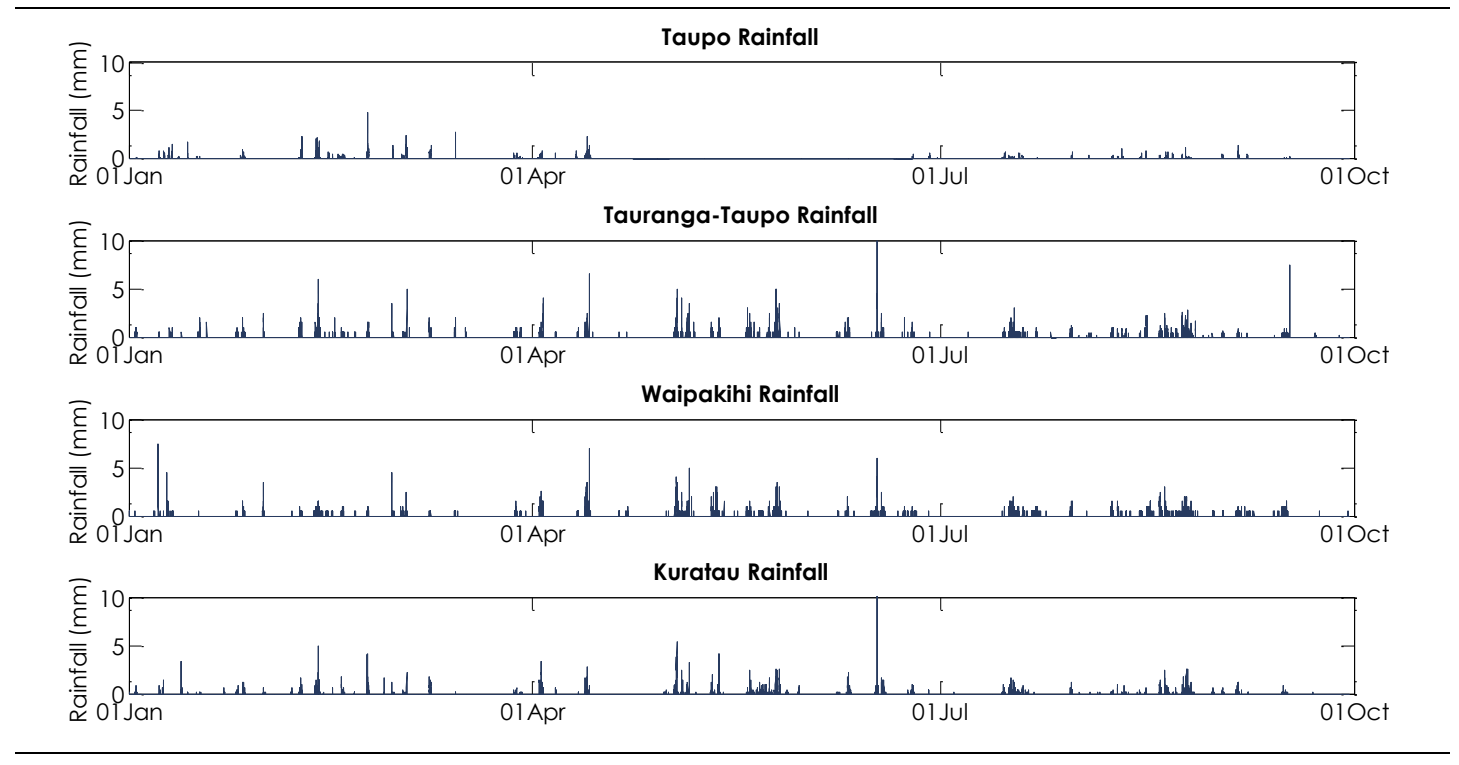

Figure 9.2 Observed rainfall for a selection of gauges in the Lake Taupo catchment: January - October 2001. Units are $\mathrm{mm} / 15$ minutes.

period of drier conditions, it would be reasonable to assume the direct groundwater input may be substantially less. In the absence of detailed information, Figure 9.5 demonstrates the effect of halving this input on the accuracy of lake level predictions. The model simulates lake level more closely over this minimum level but then tends to under-estimate lake level thereafter. In this model, groundwater seepage is not specifically simulated; a constant influx of $30 \mathrm{~m}^{3} / \mathrm{s}$ is assumed. This inflow source could be included in the model structure, possibly as an additional store to be calibrated separately or within the existing calibration framework. This is discussed further in Section 9.4.

Other sources of error include the estimation of direct evaporation and inflows from gauged and ungauged areas. NIWA calculates PE using the Penman Monteith method based on a wind function which tends to over-estimate open water evaporation by 10-15\% (Valiantzas, 2006). Further, while gauged inflows are fairly well simulated (Figure 9.6), ungauged areas of the north and west (estimated using the Kuratau parameters) are generally under-estimated for this period (Figure 9.7).

The scenarios presented in Figure 9.8 show that the minimum consented level would have been breached with maximum outflow within the first five days of each forecast. The model indicates that outflow from the lake should be less than the mean outflow to remain above the minimum consented level, with lower outflow resulting in an increase in lake level for the forecast period. 


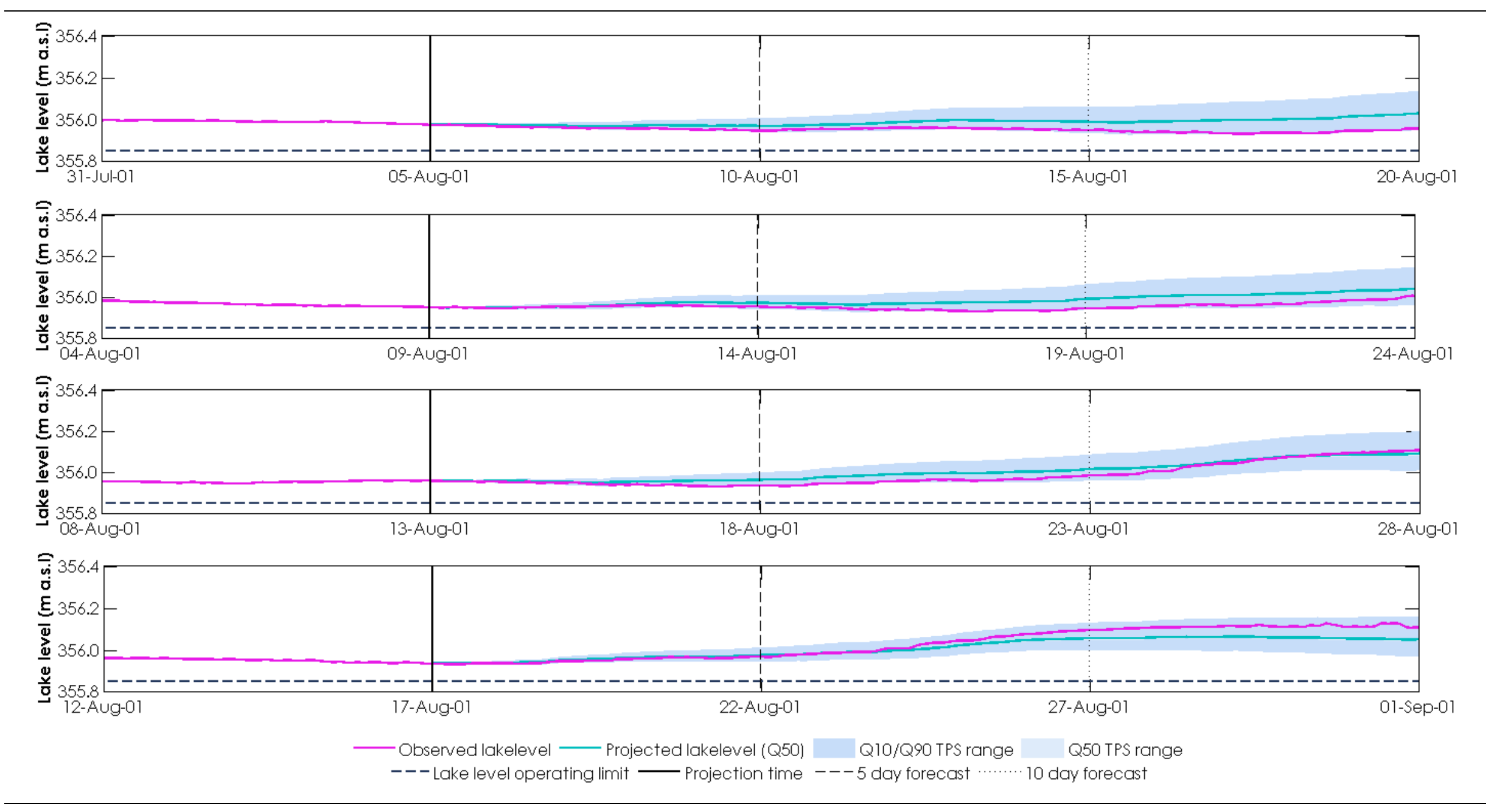

Figure 9.3 August 2001 dry conditions: modelled output from four forecast times leading up to the minimum lake level recorded on 17 August 2001.

239 | Predicting changes in lake level 


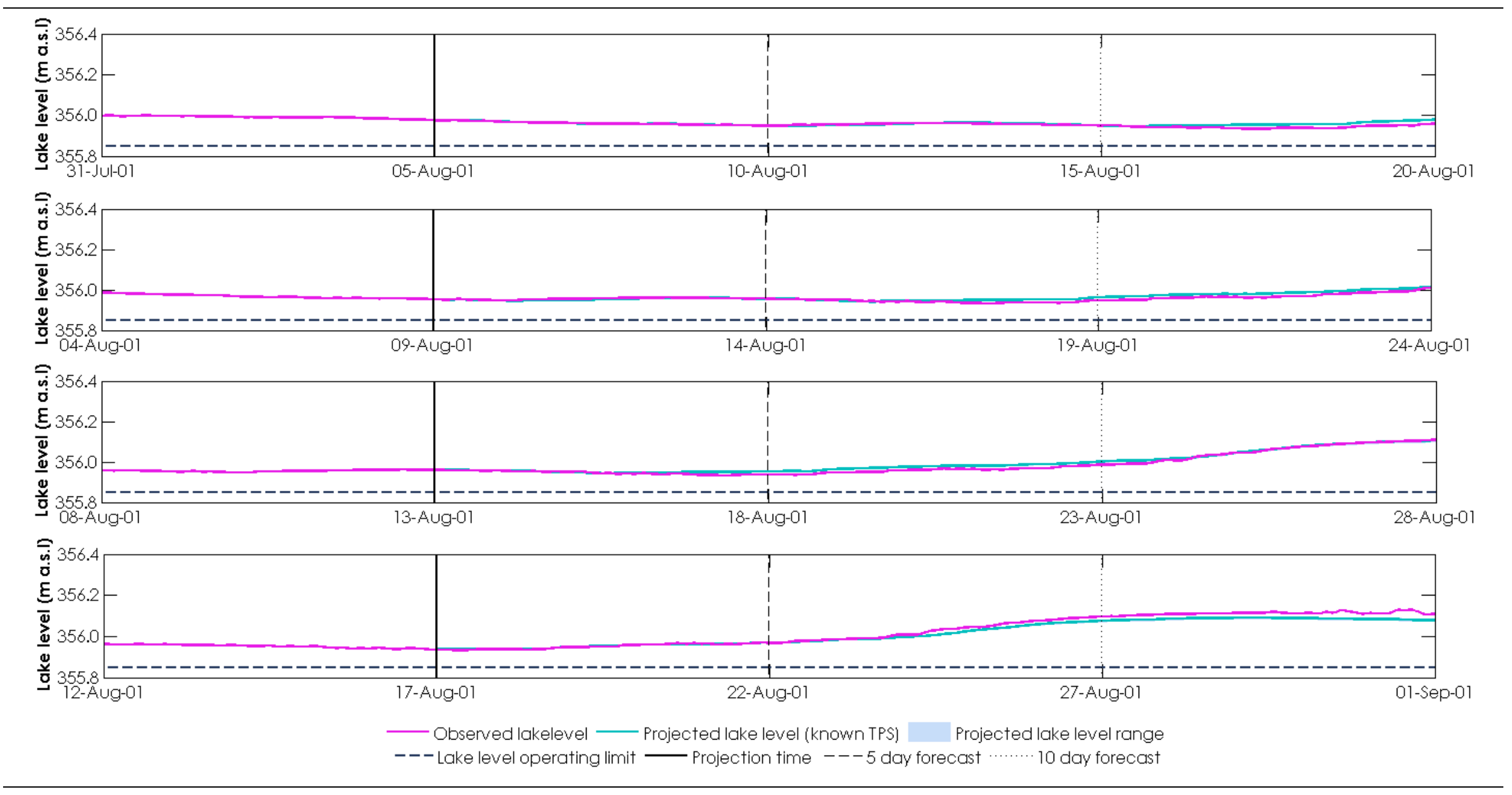

Figure 9.4 August 2001 dry conditions: modelled output when uncertainty associated with TPS is removed.

240 | Predicting changes in lake level 


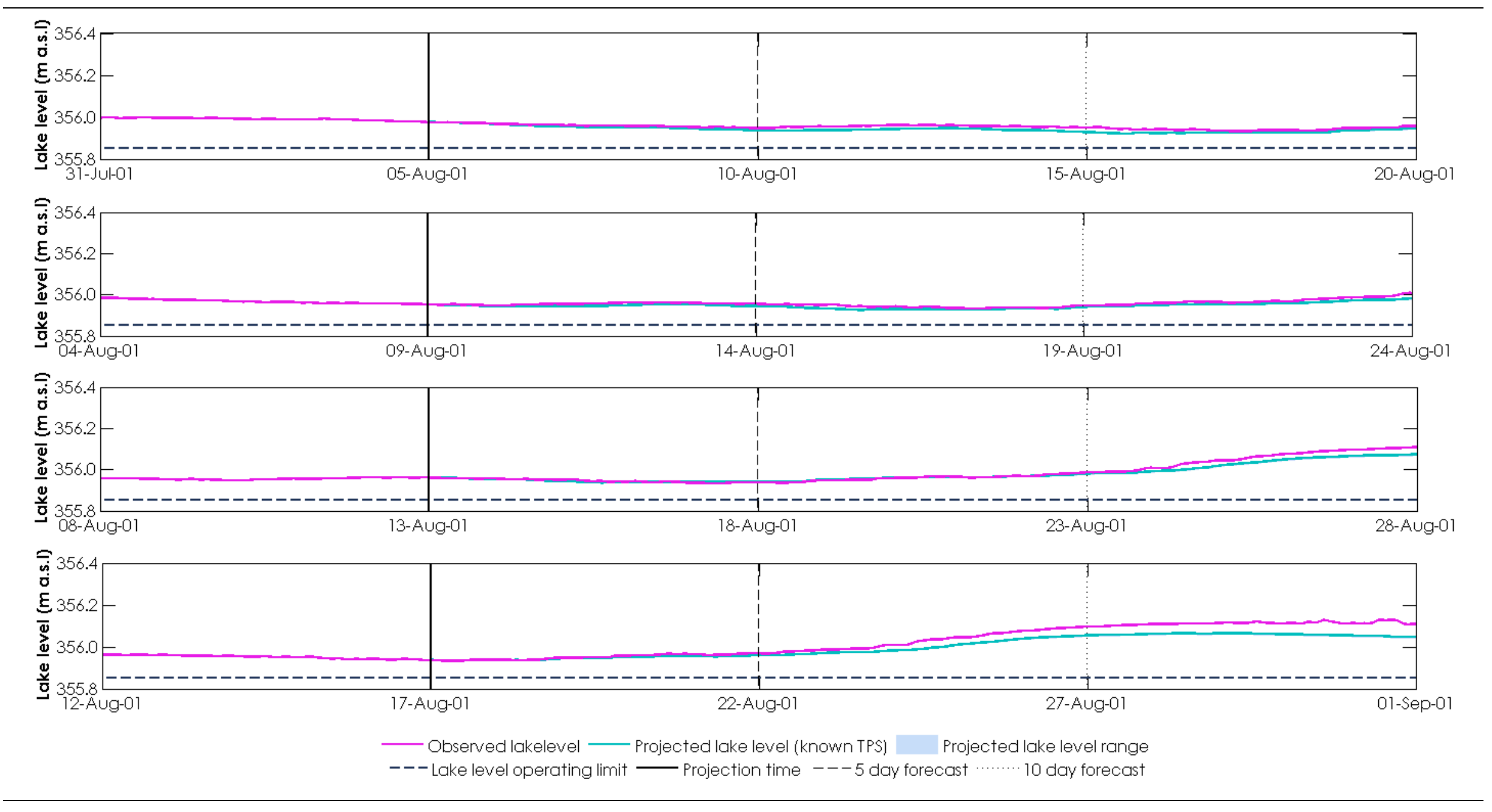

Figure 9.5 August 2001 dry conditions: modelled response when TPS uncertainty removed and groundwater contribution reduced by half.

241 | Predicting changes in lake level 

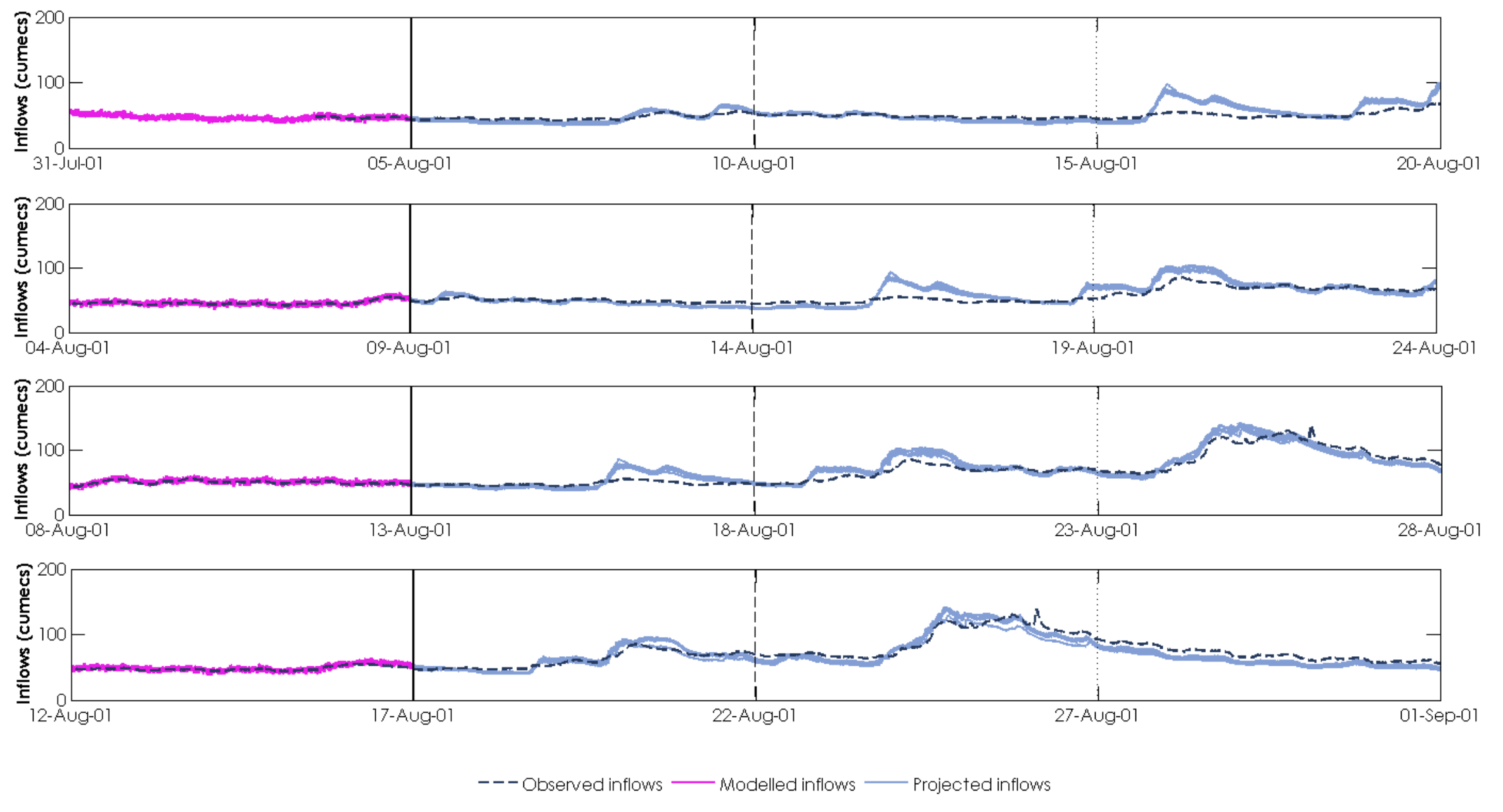

Figure 9.6 August 2001 dry conditions: Modelled versus observed streamflow for combined inflows from the five currently gauged catchments.

242 | Predicting changes in lake level 

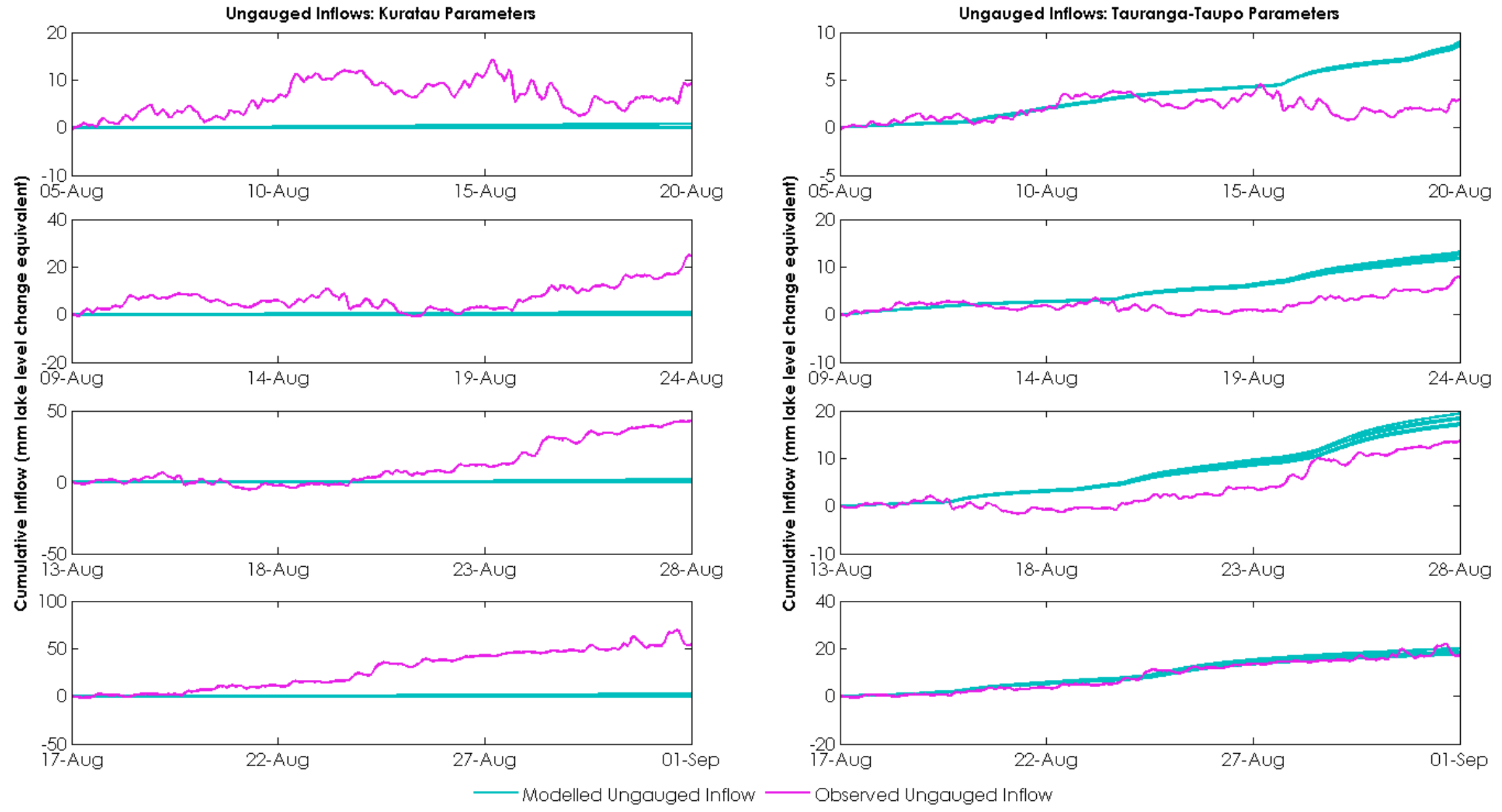

Figure 9.7 August 2001 dry conditions: Modelled versus observed cumulative inflows from ungauged areas. Units are mm/15 minutes.

243 | Predicting changes in lake level 

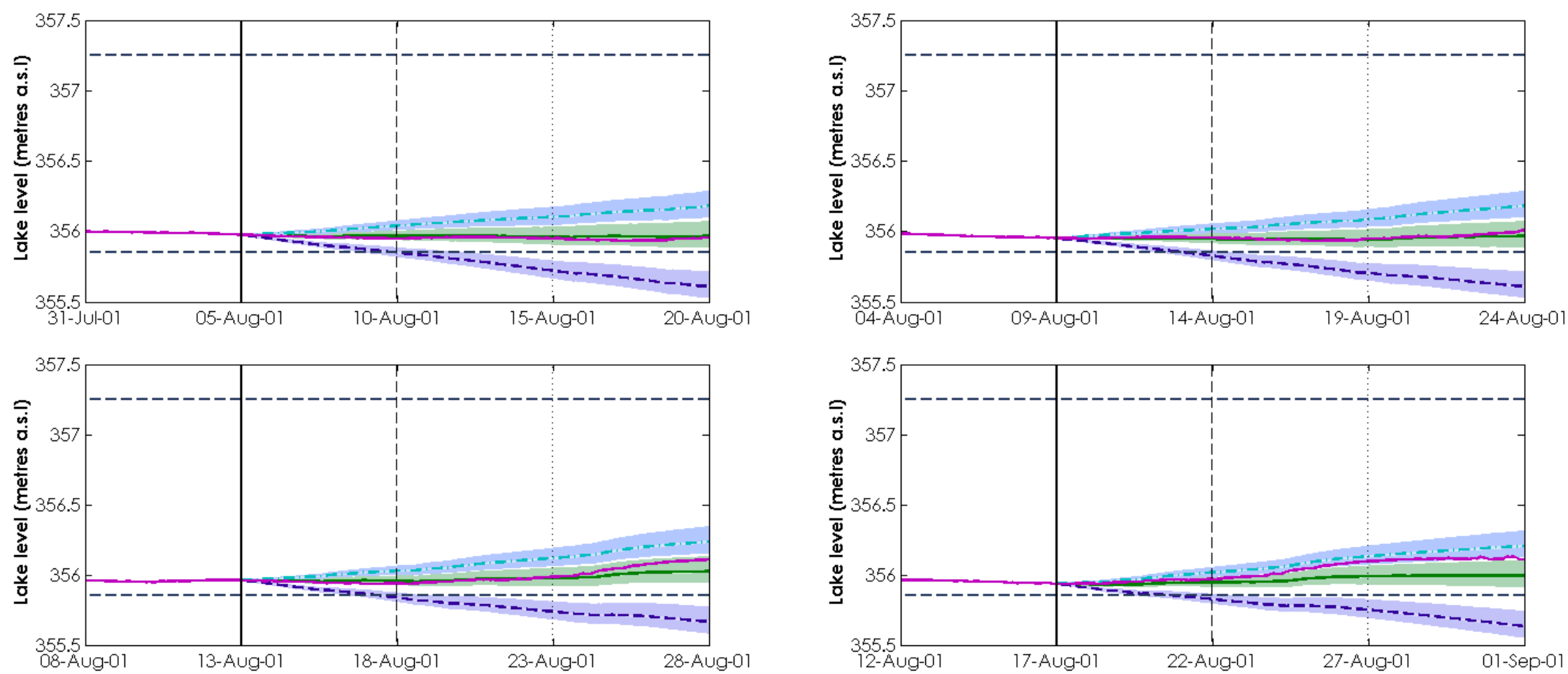

— Observed lakelevel - - - Lake level operating limit —- Projection time - - -5 day forecast $\cdots \cdots . . . . .10$ day forecast

--- Projected lakelevel-Maximum outflow (Q50)_Q10/Q90 TPS range-Maximum outflow Q Q50 TPS range - Maximum outflow

- Projected lakelevel - Mean outflow (Q50)_Q10/Q90 TPS range-Mean outflow Q50 TPS range-Mean outflow

-.-.-Projected lakelevel - Minimum outflow (Q50) Q Q10/Q90 TPS range-Minimum outflow Q50 TPS range-Minimum outflow

Figure 9.8 Predicted lake level based on three lake outflow scenarios for the August 2001 dry period.

244 | Predicting changes in lake level 


\subsubsection{August 2003}

The first five months of 2003 were characterised as a very dry period for southwestern areas of the North Island (NIWA, 2004a). Although May was particularly wet for the Tongariro and Taupo region, Taupo and Turangi both experienced their second warmest June on record (NIWA, 2003c). June was followed by below average rainfall during both July and August (NIWA, 2003a, b), reflected in Figure 9.9. Correspondingly, lake level is shown to be receding from January, increasing from May then lowering again over the drier July and August months to its low point at the end of August (Figure 9.10).

Lake level for the period is slightly over-estimated out to five days in the first three forecast periods, with improved performance from the end of August for the entire forecasted period (Figure 9.11). When the uncertainty associated with the TPS is removed, short-term model predictions (out to five days) follow the observed response closely through to 28 August (Figure 9.12). By the end of August, the overestimation is reduced through the constrained EnKF and correction of lake levels outside of the tolerance limit (refer Section 6.6). As a result, model performance is improved.
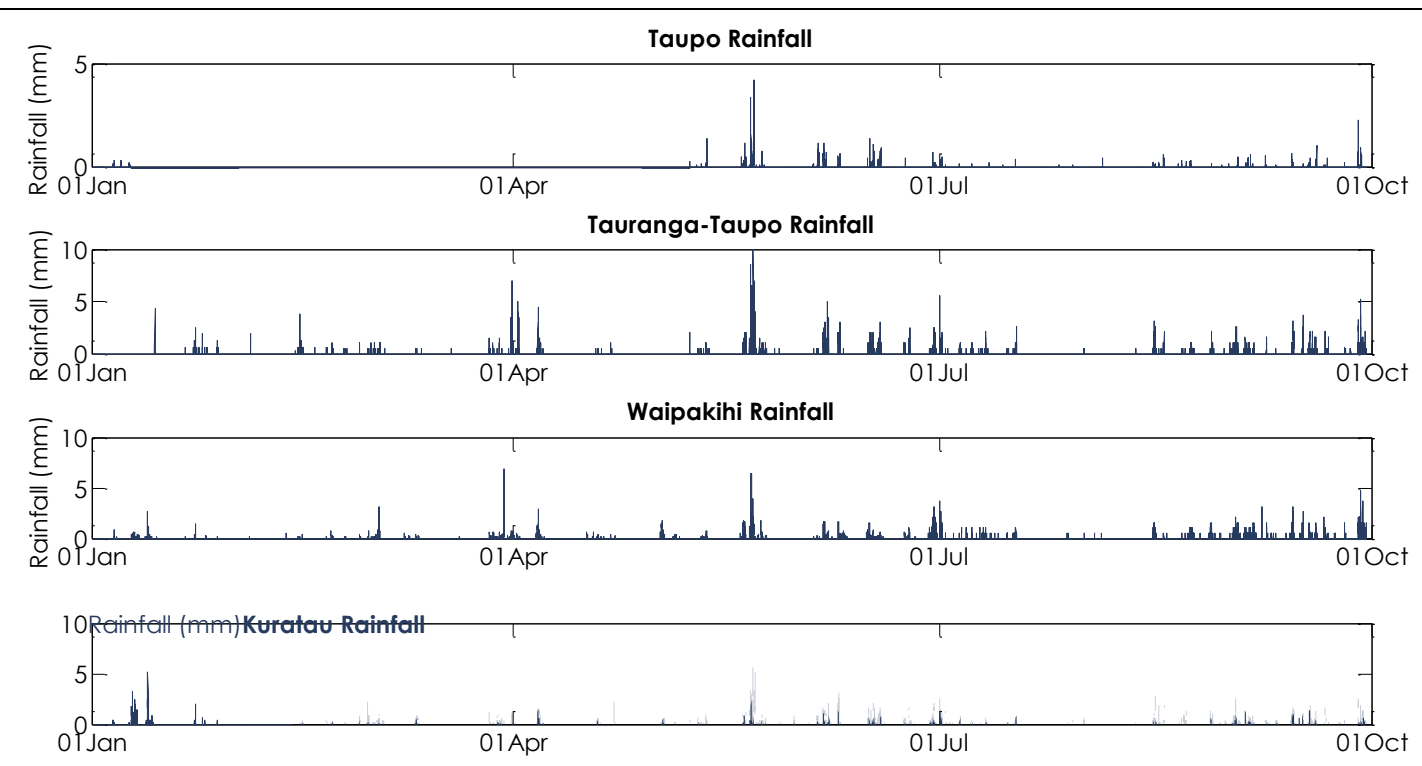

Figure 9.9 Observed rainfall for a selection of gauges in the Lake Taupo catchment: January - October 2003. Units are $\mathrm{mm} / 15$ minutes. 


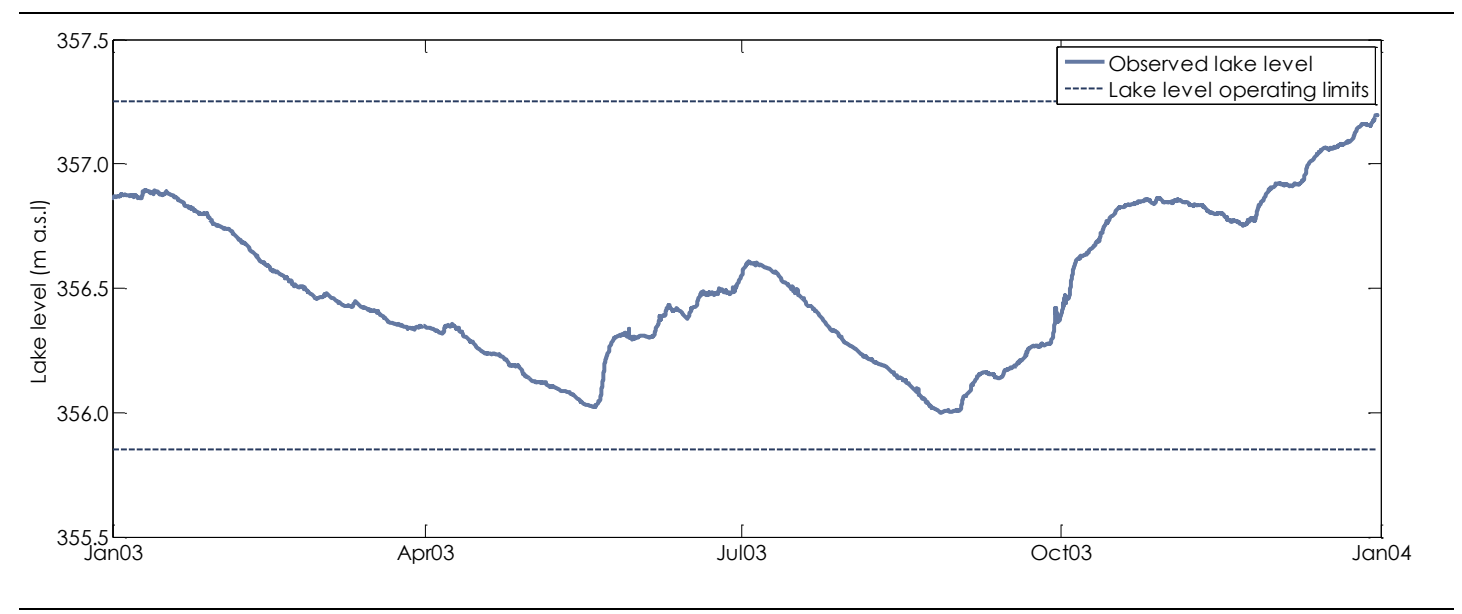

Figure 9.10 Observed (filtered) lake level: January - December 2003.

Once again, it is possible that the rate of inflow from direct groundwater seepage may be reduced during these drier periods. Halving the rate of input improves the simulation for the majority of the period, although lake level tends to be underestimated from early September (Figure 9.13). This coincides with an underestimated inflow around 2 September from gauged areas (Figure 9.14). It is also worth noting that ungauged areas regionalised using the Tauranga-Taupo parameters are producing good simulations over the period. However, inflows from the remaining ungauged areas tend to be under-estimated in late August (Figure 9.15).

The operational scenario plots shown in Figure 9.16 indicate that under a maximum outflow rate, lake level would drop below the minimum consented level 5-10 days from each of the forecast points. Outflow rates below this would keep lake level above the operating margin over the entire period.

Overall, the level of Lake Taupo is closely simulated over this event given the uncertainties associated with the TPS and errors in determining groundwater input. An under-estimation of catchment and direct lake rainfall resulted in lake level being slightly under-estimated from early September but, again, this could be resolved with more accurate estimations of these inputs over these periods. 


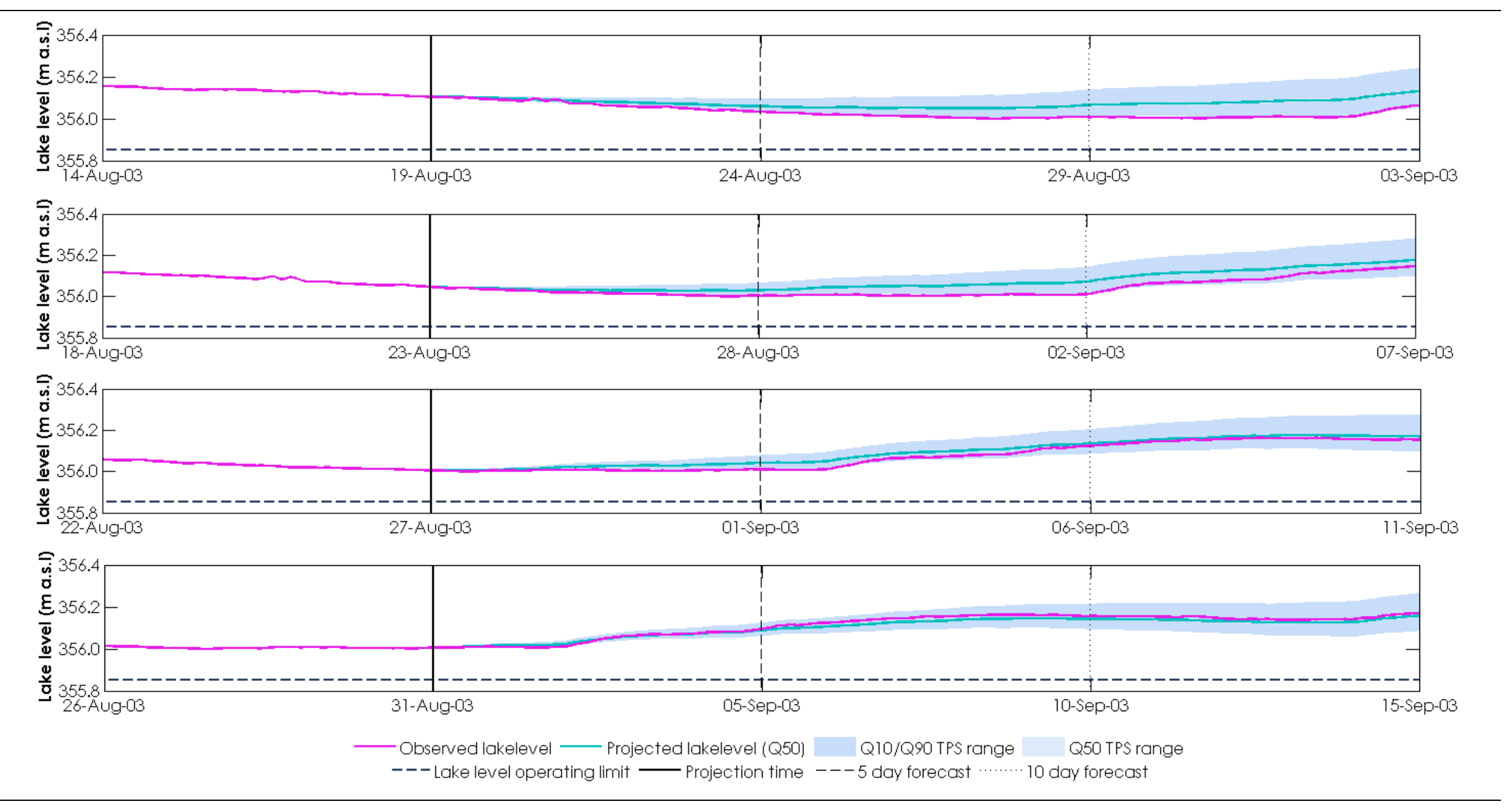

Figure 9.11 August 2003 dry conditions: modelled output from four forecast times leading up to the minimum lake level recorded toward the end of August 2001. 


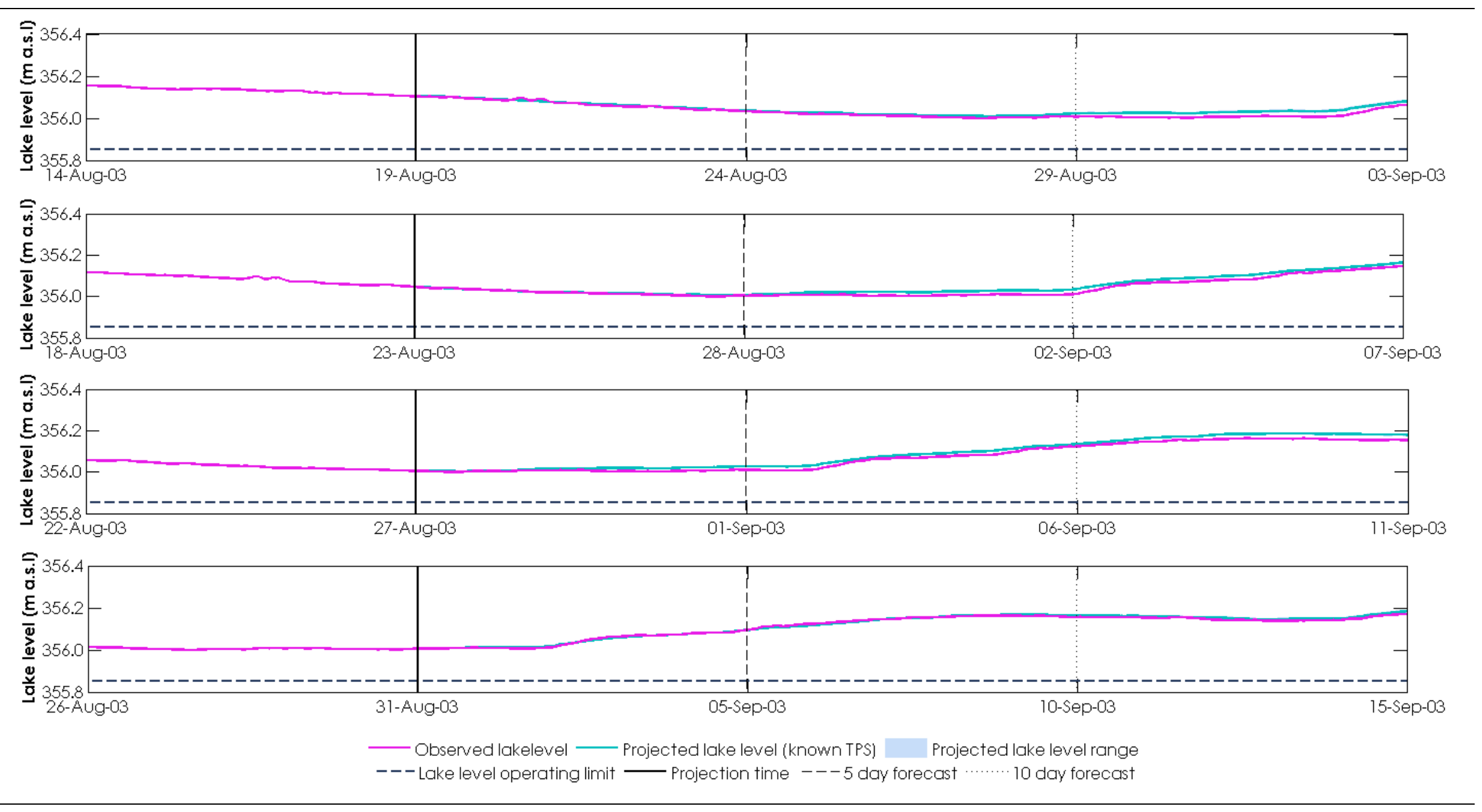

Figure 9.12 August 2003 dry conditions: modelled output when uncertainty associated with TPS is removed.

$\mathbf{2 4 8} \mid$ Predicting changes in lake level 


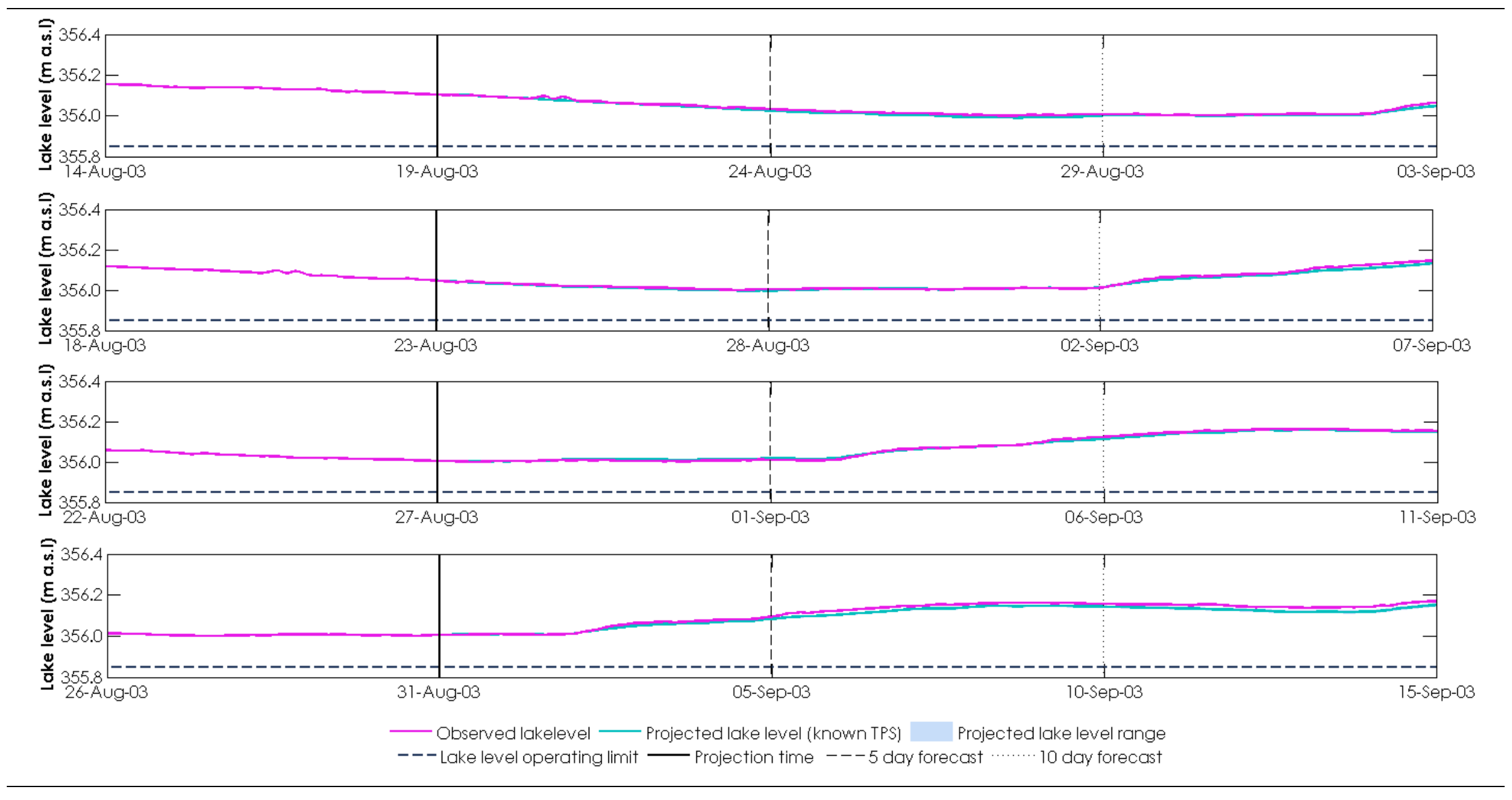

Figure 9.13 August 2003 dry conditions: modelled response when TPS uncertainty removed and groundwater contribution reduced by half. 

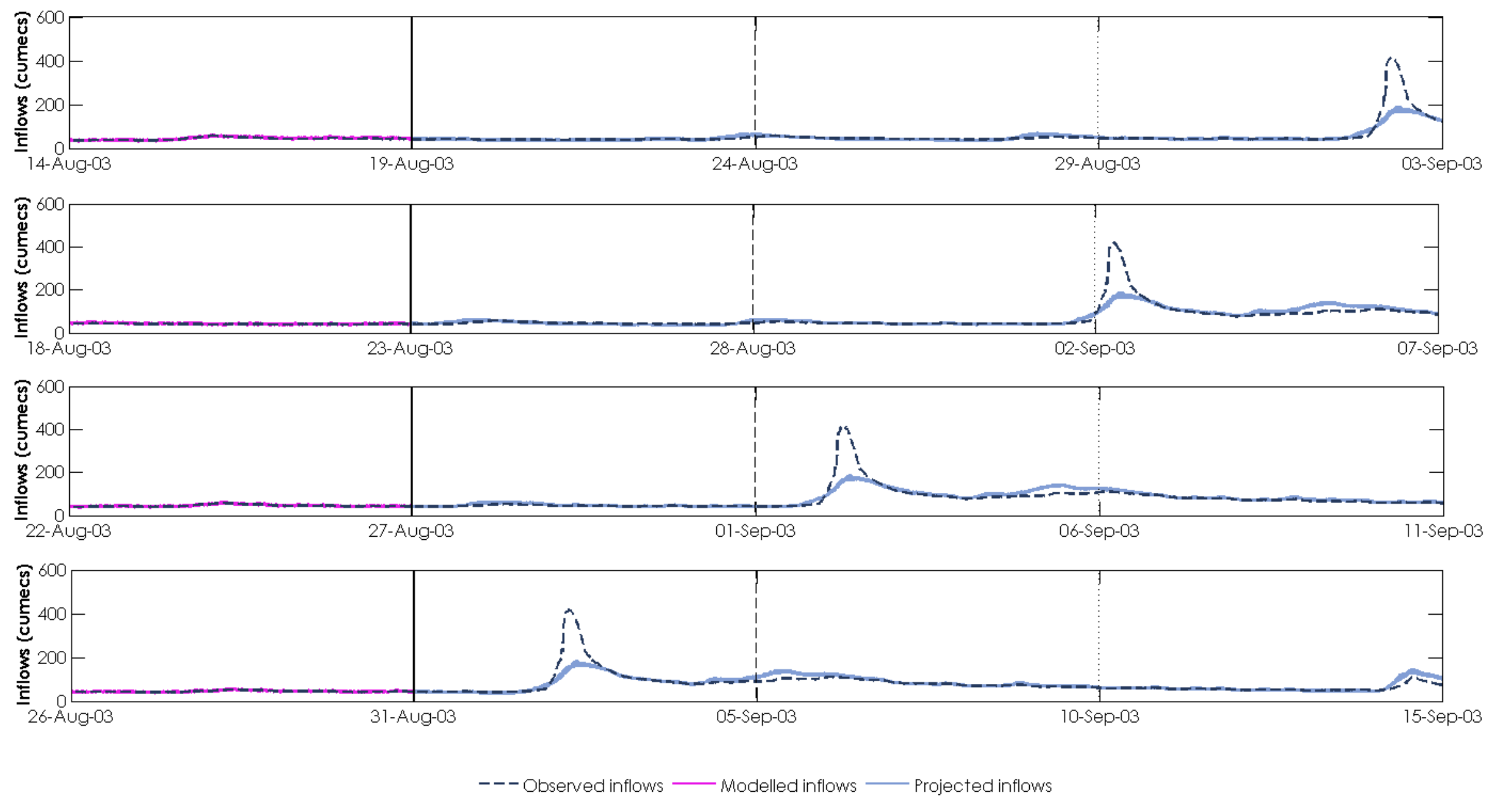

Figure 9.14 August 2003 dry conditions: Modelled versus observed streamflow for combined inflows from the five currently gauged catchments.

250 | Predicting changes in lake level 

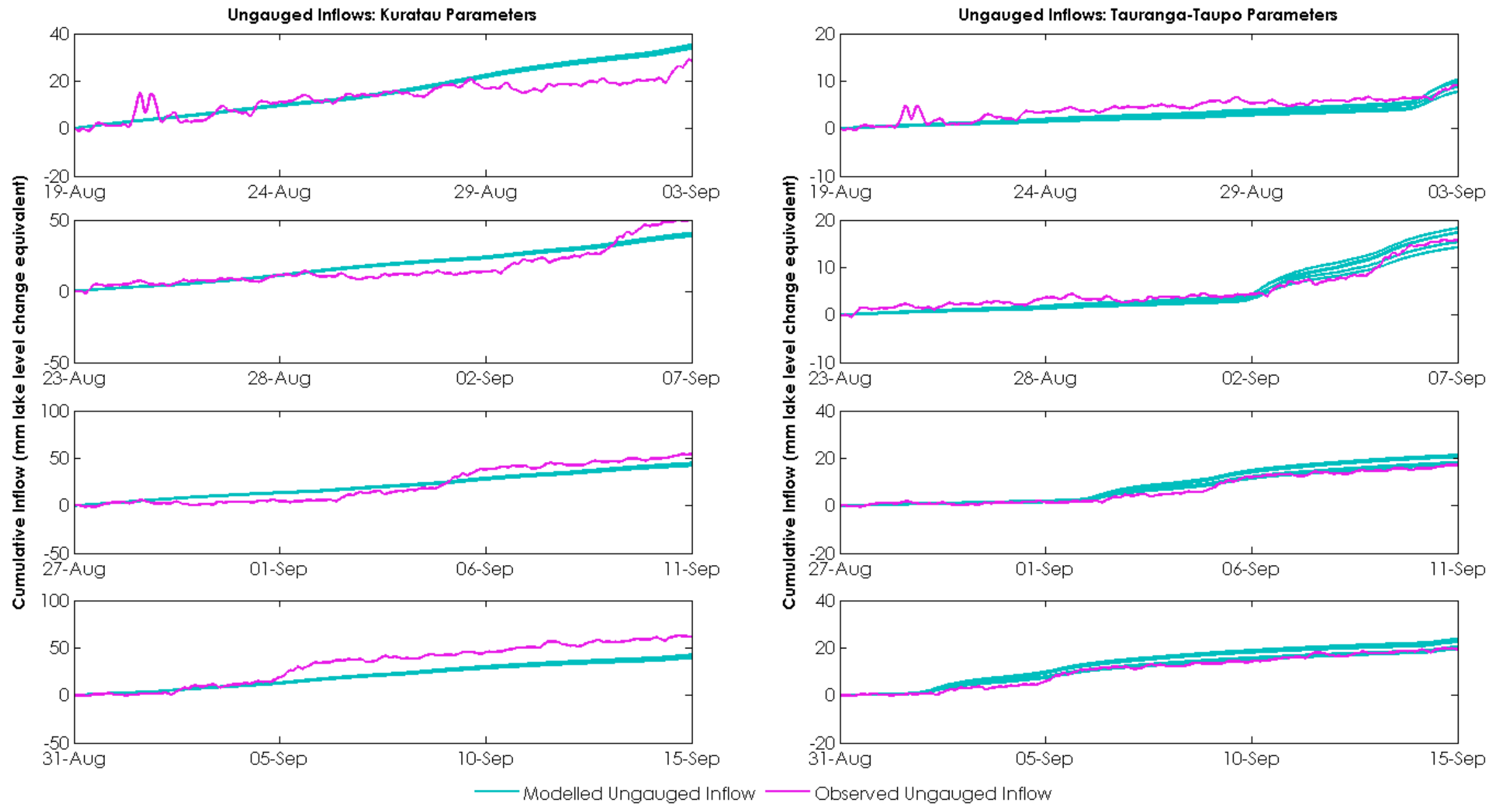

Figure 9.15 August 2003 dry conditions: Modelled versus observed cumulative inflows from ungauged areas. Units are mm/15 minutes. 

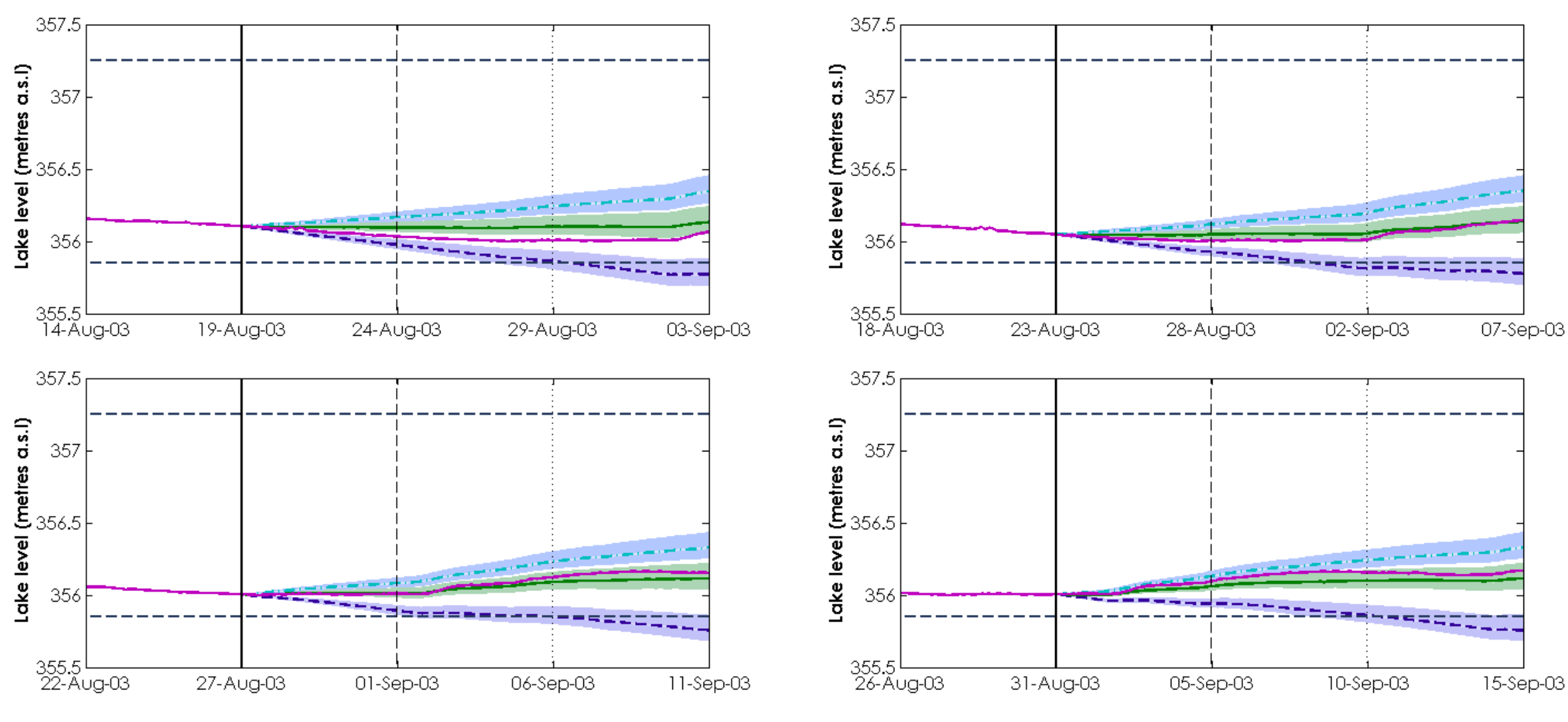

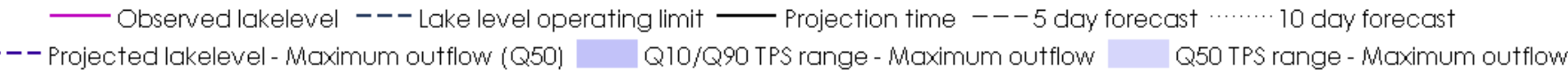

_- Projected lakelevel - Mean outflow (Q50) Q10/Q90 TPS range - Mean outflow Q50 TPS range - Mean outflow

-.-.-Projected lakelevel - Minimum outflow (Q50) Q Q10/Q90 TPS range - Minimum outflow Q Q50 TPS range - Minimum outflow

Figure 9.16 Predicted lake level based on three lake outflow scenarios for the August 2003 dry period.

252 | Predicting changes in lake level 


\subsubsection{May 2010}

NIWA's Annual Climate Summary for 2010 characterises this year by above average mean sea level pressures and an increased prevalence of anticyclones near New Zealand (NIWA, 2011). Drought was declared in January for the Waikato (and other areas of New Zealand) and was not broken until May (NIWA, 2011). Rainfall over the period was generally low (Figure 9.17), with Turangi recording only $12 \%$ of its normal monthly rainfall for March, its second lowest on record (NIWA, 2010a). Significant soil moisture deficits developed (NIWA, 2011). Lake level steadily decreased from February, dropping to $355.97 \mathrm{~m}$ a.s.l on 12 May 2010, its second lowest level of the evaluation period (Figure 9.18).

For the period of 2010 leading up to the observed minimum lake level (mid-May 2010), the model is applied and results analysed. The receding lake level is reliably predicted for the entire period; a rise in lake level around 13 May is also adequately reflected in the simulated results (Figure 9.19). Discharge from the TPS was again low over this time. Minimum flow requirements in various parts of the system and a requirement for natural river flows to be maintained in drought conditions results in some diversions being stopped. Using the observed inflow data from the scheme illustrates that with further information model output uncertainty is reduced (Figure 9.20). Lake level forecasts are improved, with good simulations out to 15 days for the entire period.

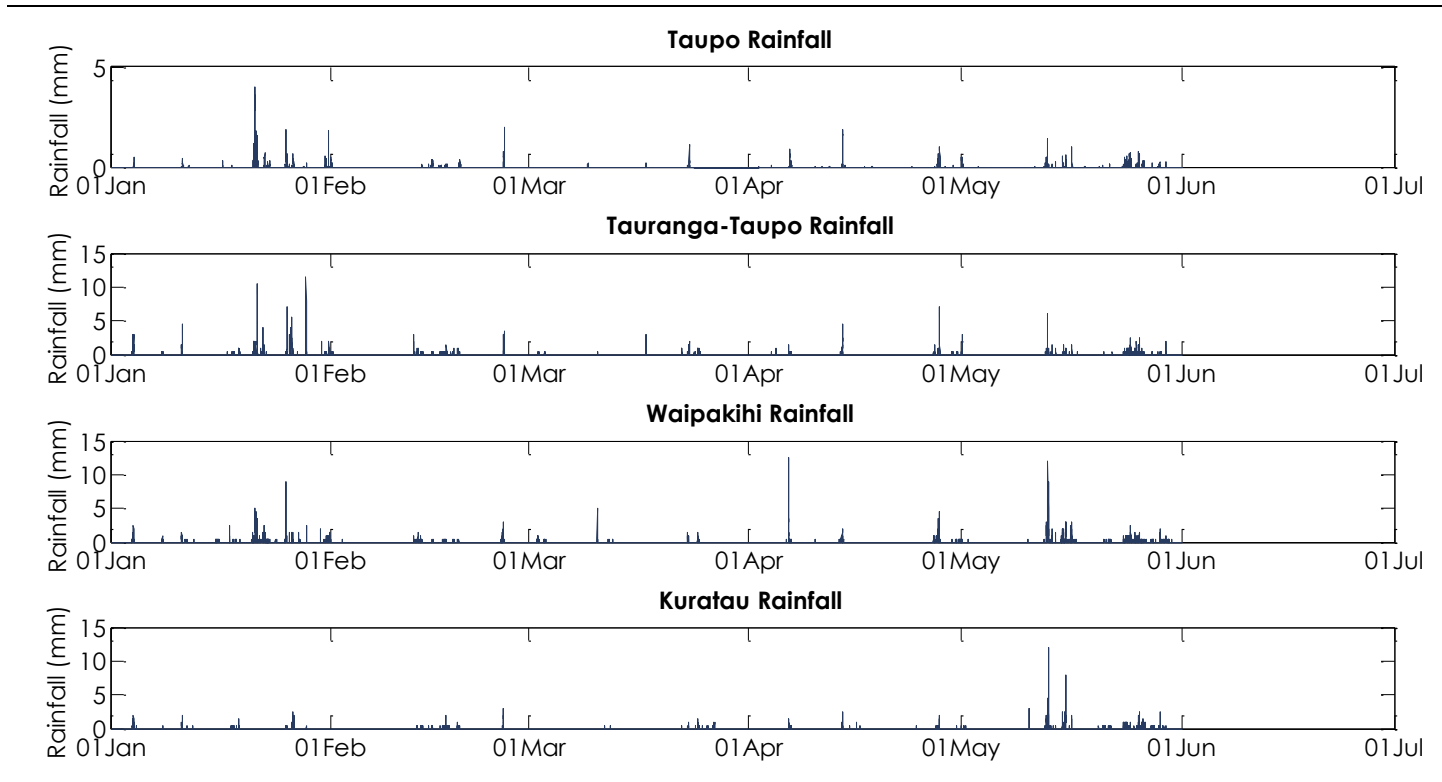

Figure 9.17 Observed rainfall for a selection of gauges in the Lake Taupo catchment: January - July 2010. Units are $\mathrm{mm} / 15$ minutes. 


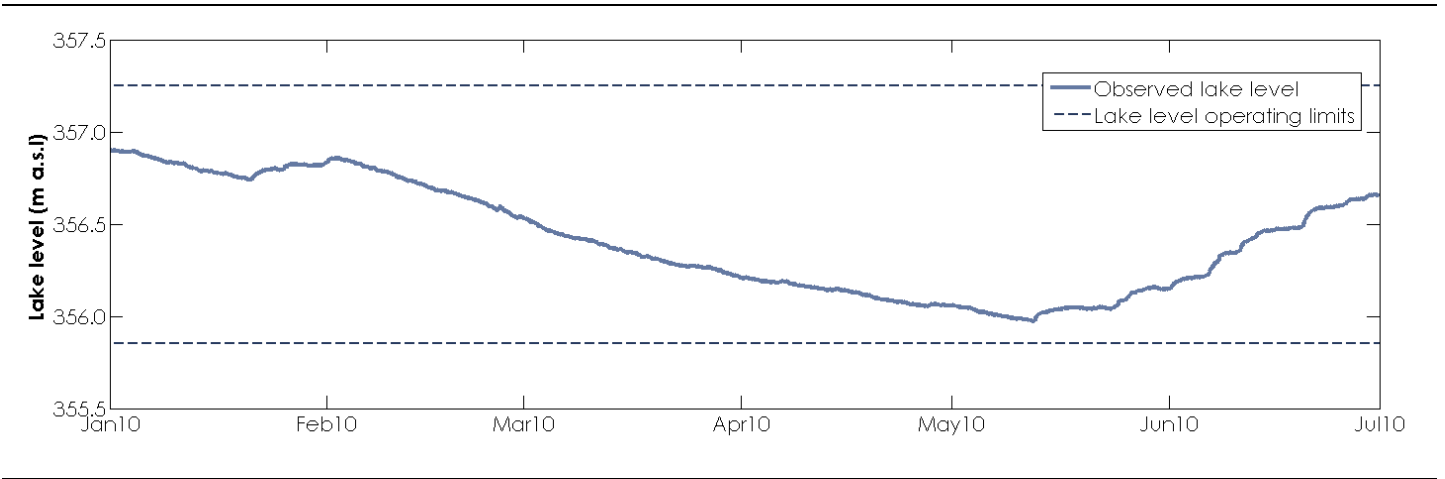

Figure 9.18 Observed (filtered) lake level: January - July 2010.

Reducing the direct groundwater input by half produces more precise lake level simulations up until mid-May (Figure 9.21). A small event is slightly underpredicted in the gauged inflows on 13 May (Figure 9.22), resulting in lake level being under-estimated thereafter. This is also the case in the ungauged areas predicted by the Kuratau parameters. Other sources of error include the possible underestimation of direct lake rainfall or over-estimation of lake evaporation over this period.

Maintaining average outflow would keep lake level above the minimum operating margin, although lake level continues to drop over the forecast period (Figure 9.24). A maximum outflow rate would result in lake level reaching the operating minimum within a week. Minimum outflow from Lake Taupo would maintain lake level initially, only slightly increasing it thereafter.

As with other dry events in this analysis, the model is doing a good job of closely simulating observed lake level for most of the period. Reducing the groundwater input slightly improves performance but more importantly reveals the effect of under-estimated inflows from ungauged areas. More accurate estimates of driving data as well as better representation of the ungauged areas around the west and north of the catchment would prove beneficial to the performance of the model overall. 


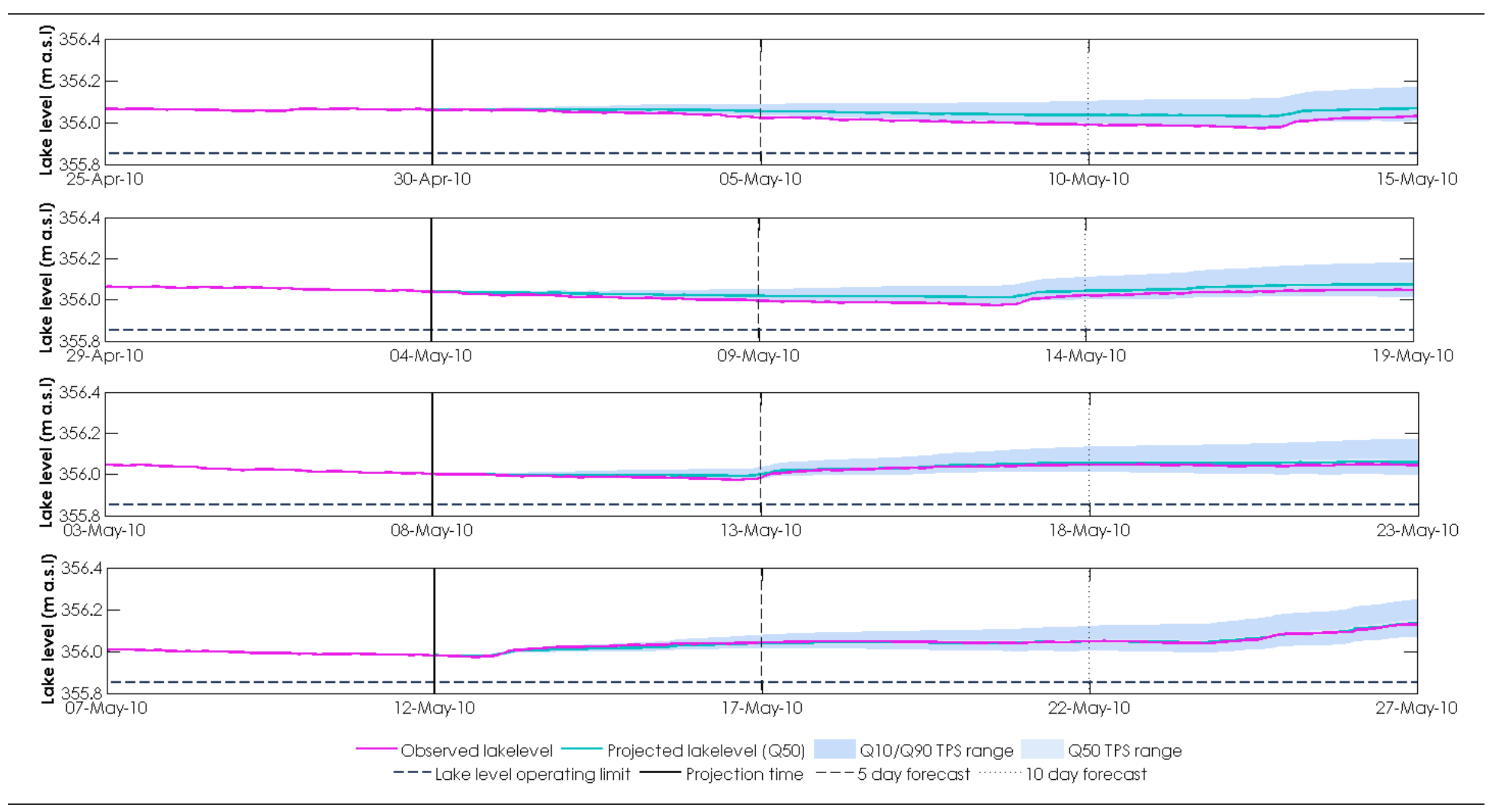

Figure 9.19 May 2010 drought conditions: modelled output from four forecast times leading up to the minimum lake level recorded in mid May 2010. 


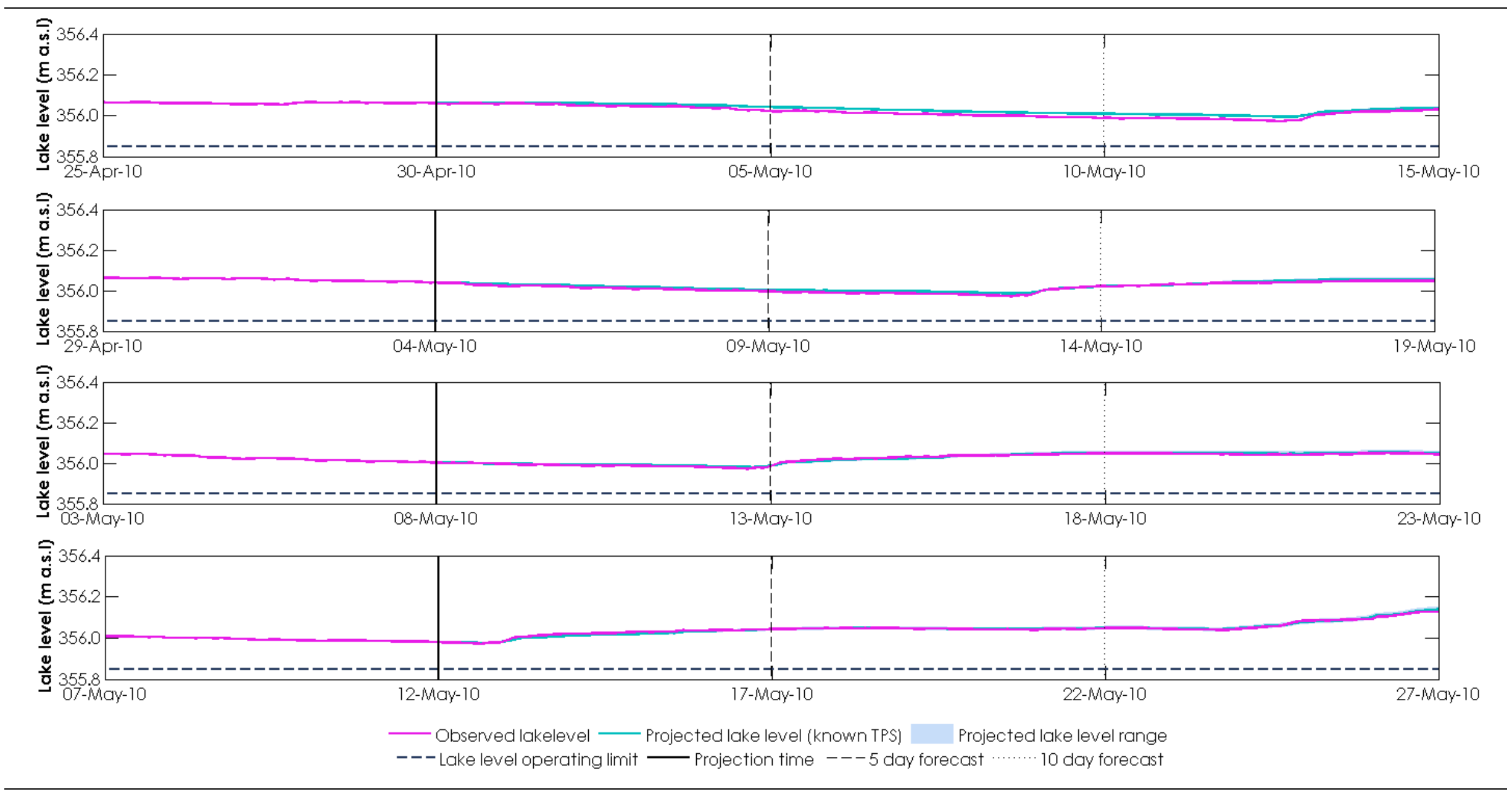

Figure 9.20 May 2010 drought conditions: modelled output when uncertainty associated with TPS is removed.

256 | Predicting changes in lake level 


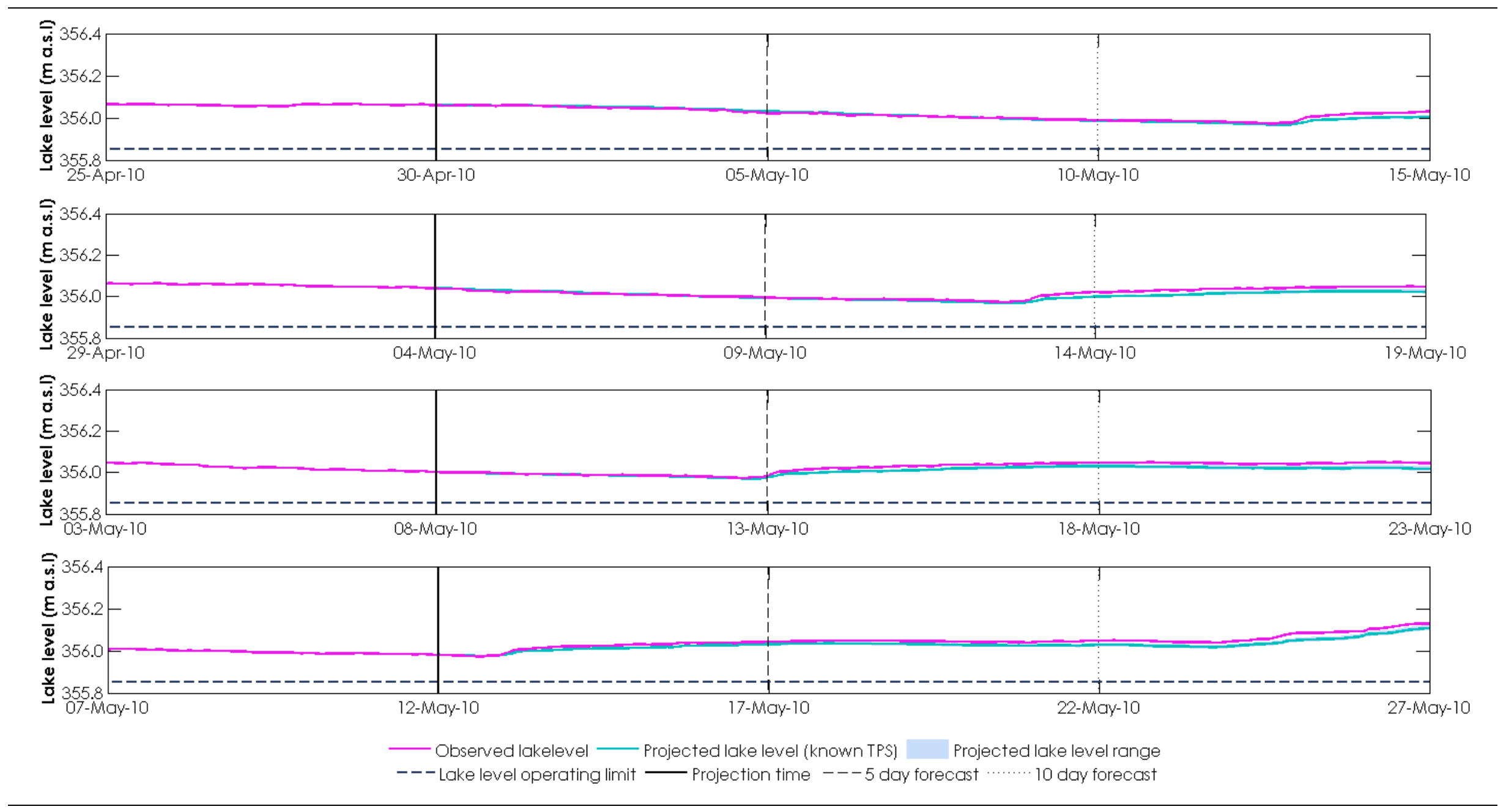

Figure 9.21 May 2010 drought conditions: modelled response when TPS uncertainty removed and groundwater contribution reduced by half. 

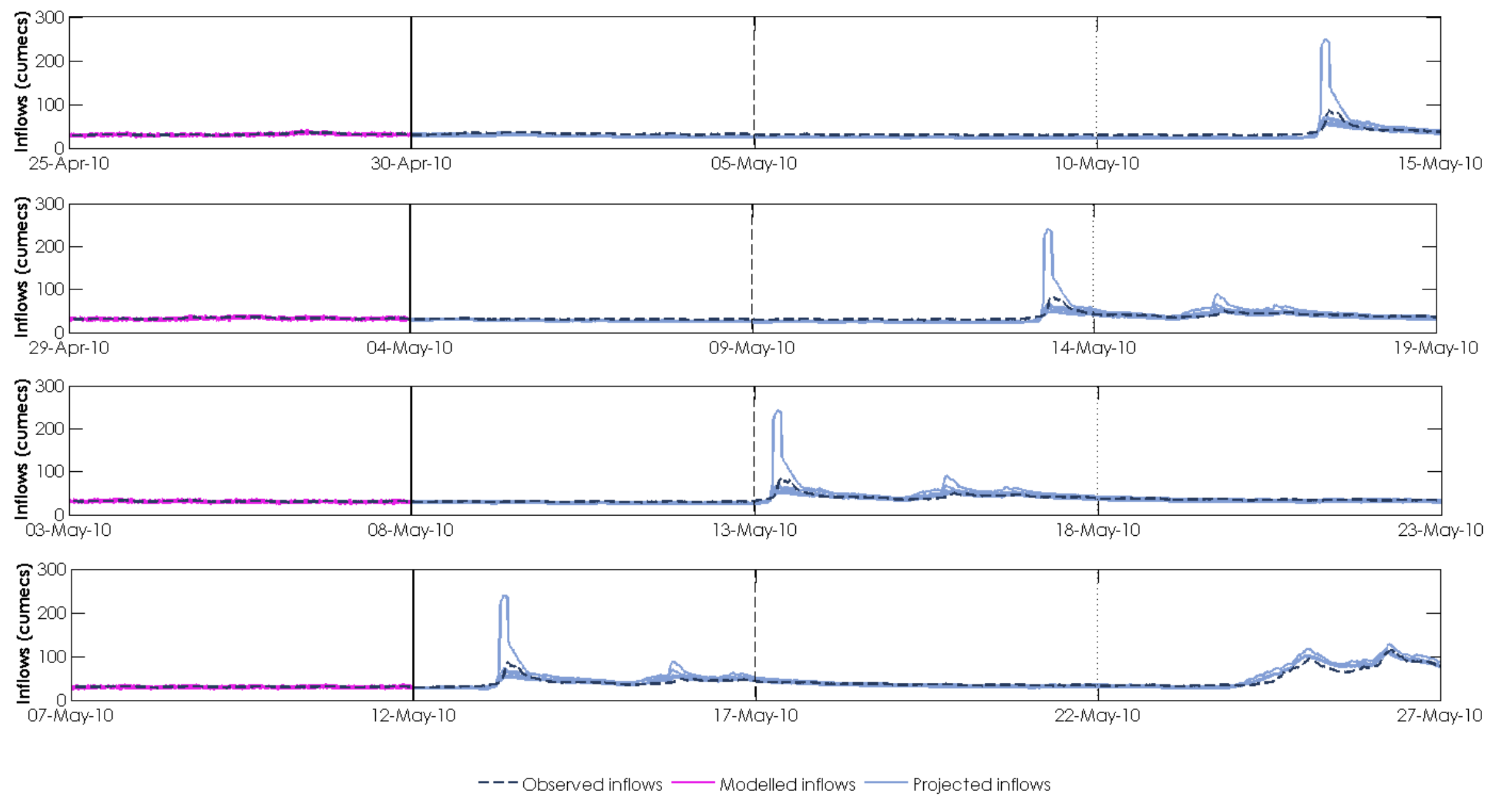

Figure 9.22 May 2010 drought conditions: Modelled versus observed streamflow for combined inflows from the five currently gauged catchmen ts.

$\mathbf{2 5 8} \mid$ Predicting changes in lake level 

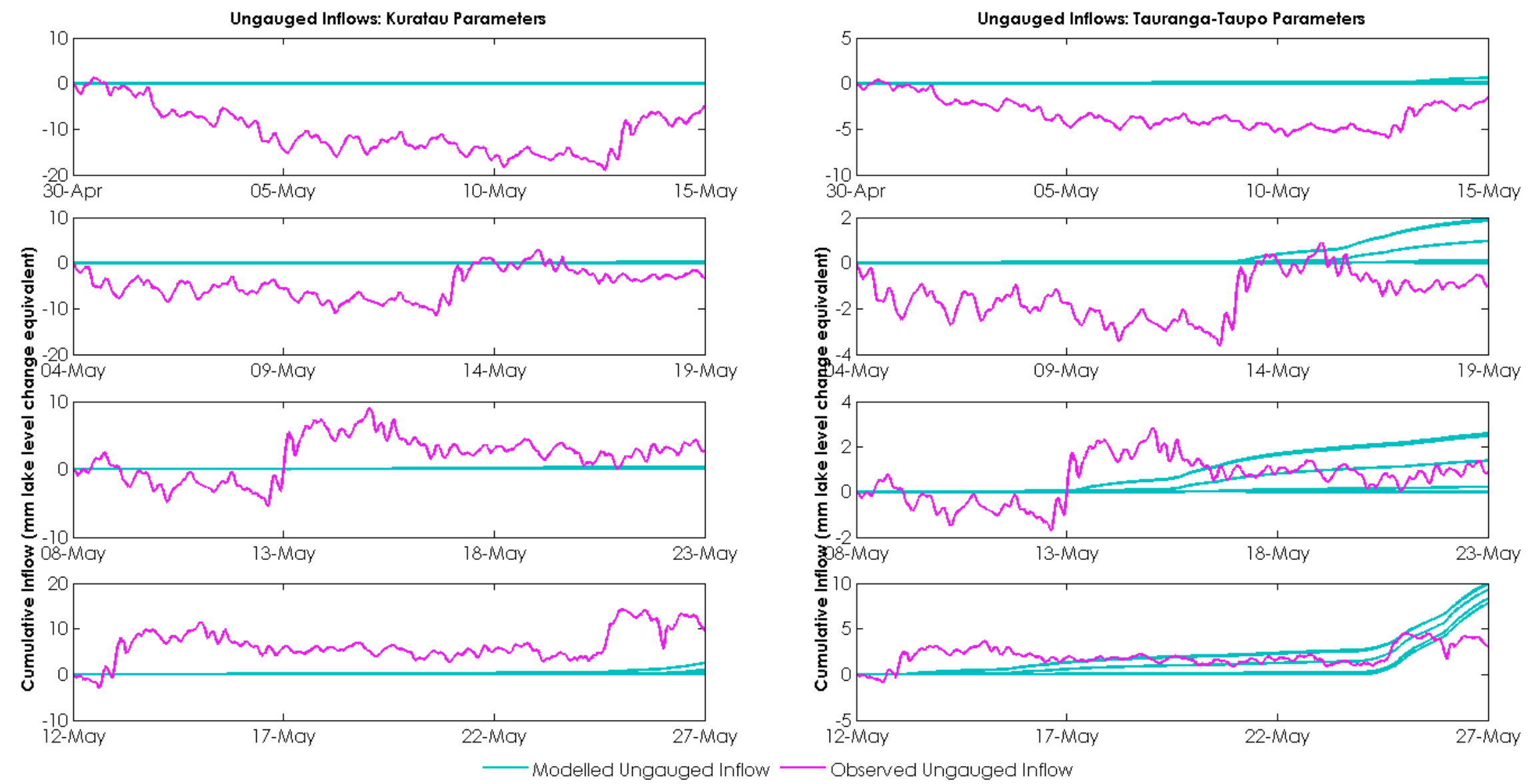

Figure 9.23 May 2010 drought conditions: Modelled versus observed cumulative inflows from ungauged areas. Units are mm/15 minutes. 

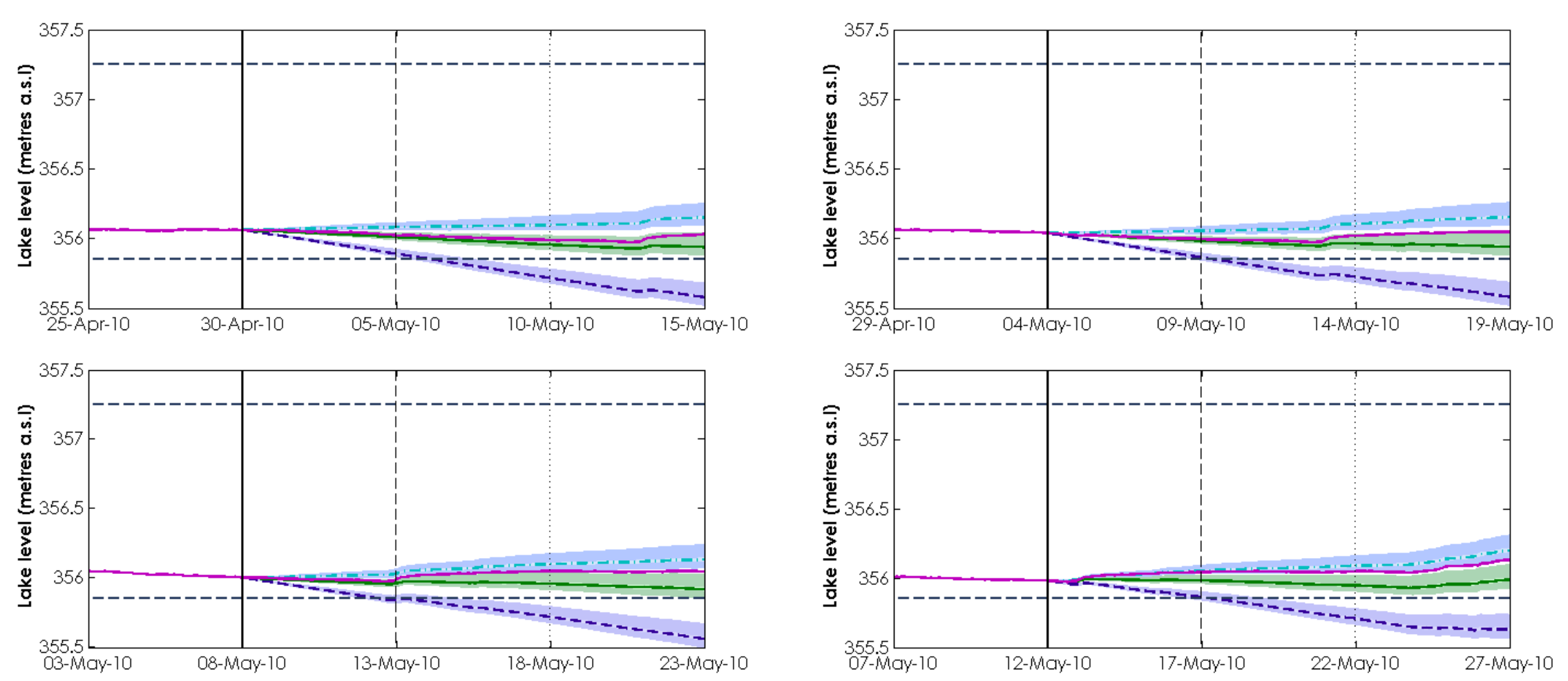

- Observed lakelevel - - - Lake level operating limit —- Projection time - - - 5 day forecas $\cdots \cdots \cdots \cdot 10$ day forecast

--- Projected lakelevel-Maximum outflow (Q50)_Q Q10/Q90 TPS range-Maximum outflow Q50 TPS range-Maximum outflow

_- Projected lakelevel - Mean outflow (Q50)__ Q10/Q90 TPS range - Mean outflow _ Q50 TPS range-Mean outflow

-.-. Projected lakelevel - Minimum outflow (Q50) Q10/Q90 TPS range - Minimum outflow Q50 TPS range - Minimum outflow

Figure 9.24 Predicted lake level based on three lake outflow scenarios for the May 2010 drought.

260 | Predicting changes in lake level 


\subsection{Normal operating conditions}

\subsubsection{November $\mathbf{2 0 0 6}$}

This period is characterised by 'normal' operating conditions in which lake level is well within lake level operating margins (refer Section 2.3.4). During November 2006, lake level did not exceed $357 \mathrm{~m}$ a.s.l (Figure 9.25). While there were frequent rainfall events, none were exceptional over the period (Figure 9.26). The synoptic weather maps show a low bringing rainfall to the area around 17-19 November (Figure 9.27).

Overall, the model does a good job of simulating lake level over this period. Modelled lake level corresponds well with the observations over the entire period, as shown in Figure 9.28. Lake level predictions are more precise given more information about the discharge from the TPS (Figure 9.29). The response to the rainfall event around 17-19 November is under-estimated in gauged catchments, but this error is accounted for as observations are assimilated (Figure 9.30). Modelled inflow from ungauged areas is good, especially for the first five days of each forecast period (Figure 9.31).

For decision-making purposes, the scenarios presented in Figure 9.32 show that a mean outflow is required to maintain lake level. The maximum consented level would be exceeded from early December if the minimum outflow is allowed.

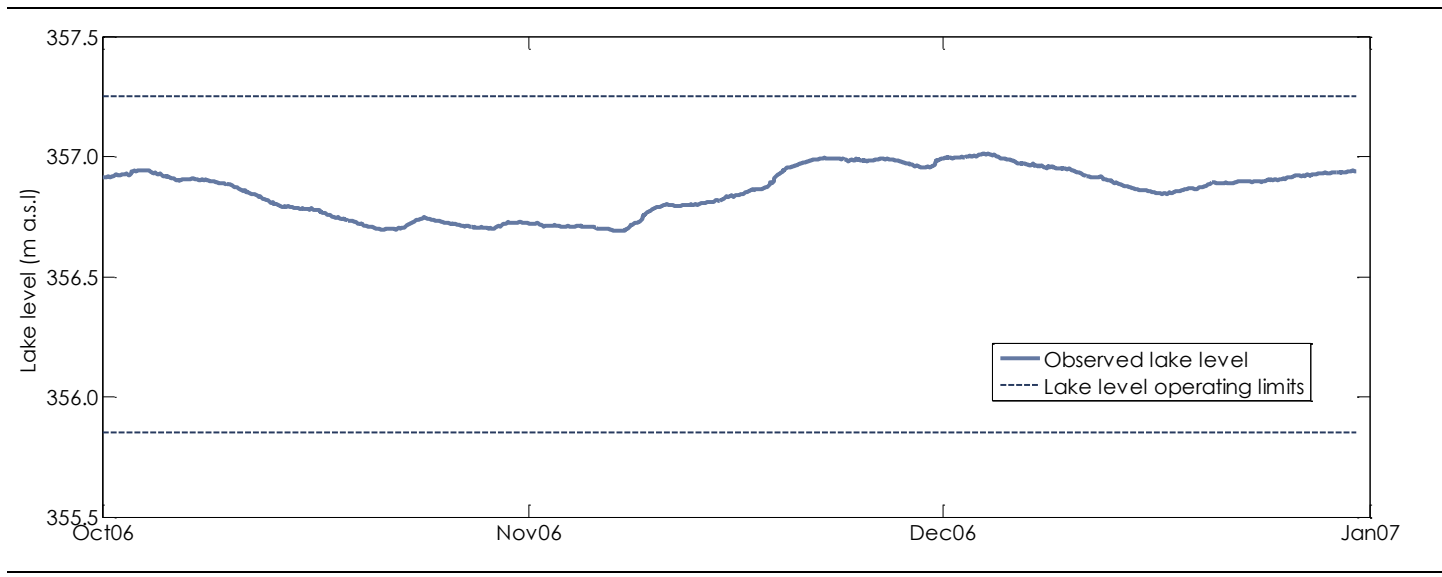

Figure 9.25 Observed (filtered) lake level: October - December 2006. 

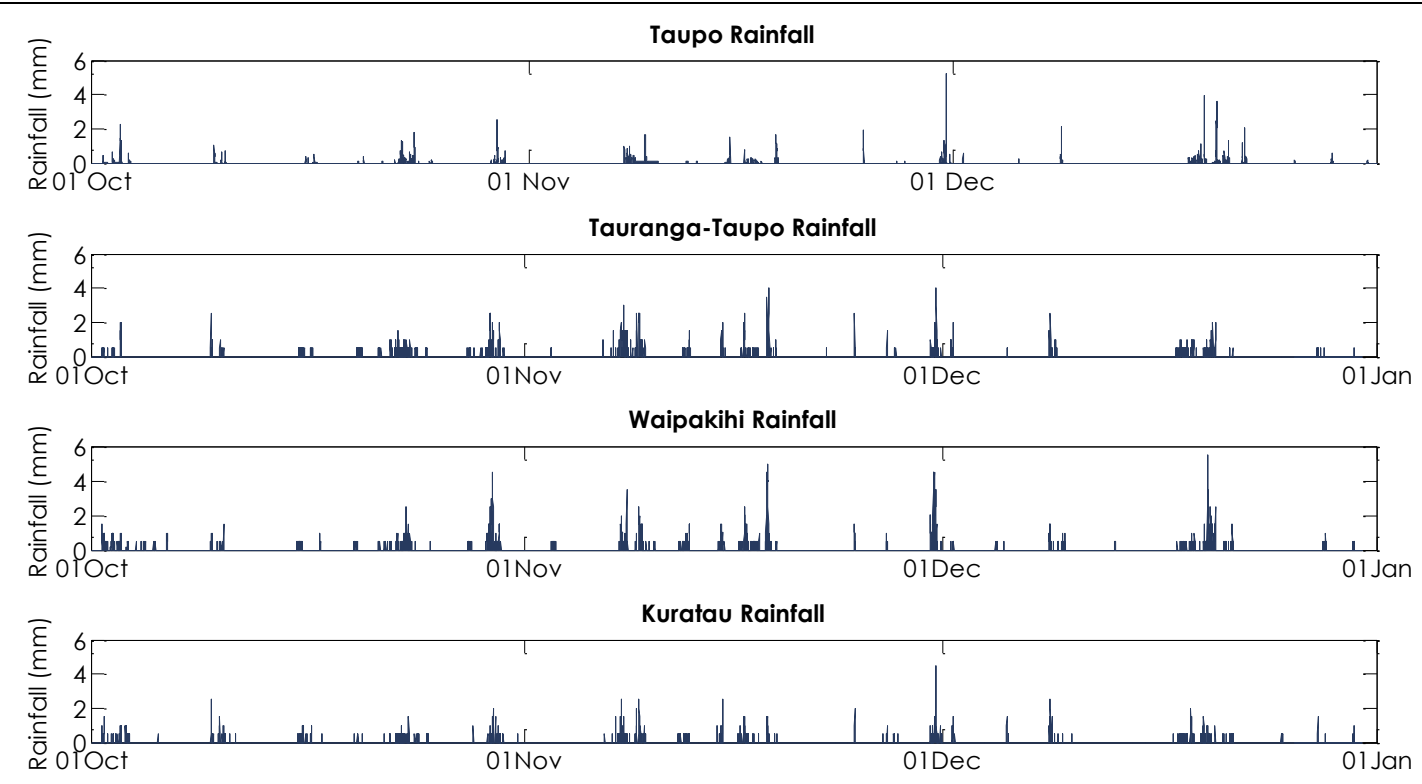

Figure 9.26 Observed rainfall for a selection of gauges in the Lake Taupo catchment: October December 2007. Units are $\mathrm{mm} / 15$ minutes.

(a) 12:00 am 18 November 2006 (UTC)

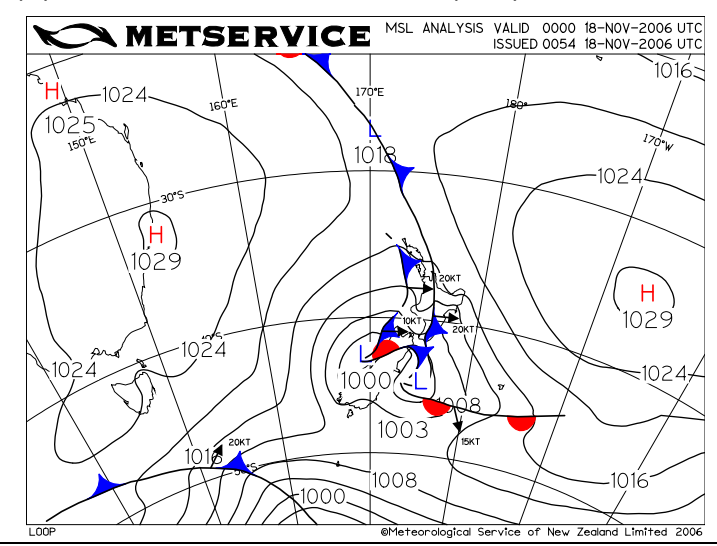

(b) 12:00 pm 18 November 2006 (UTC)

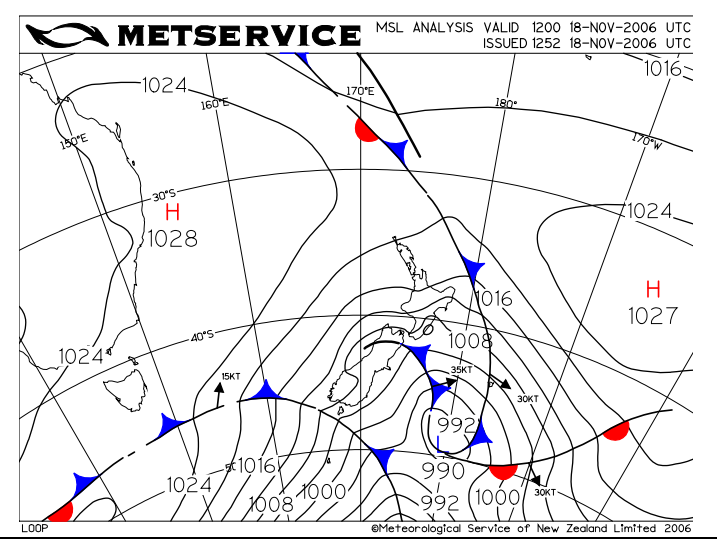

Figure 9.27 A selection of MetService synoptic weather maps for November 2006. 


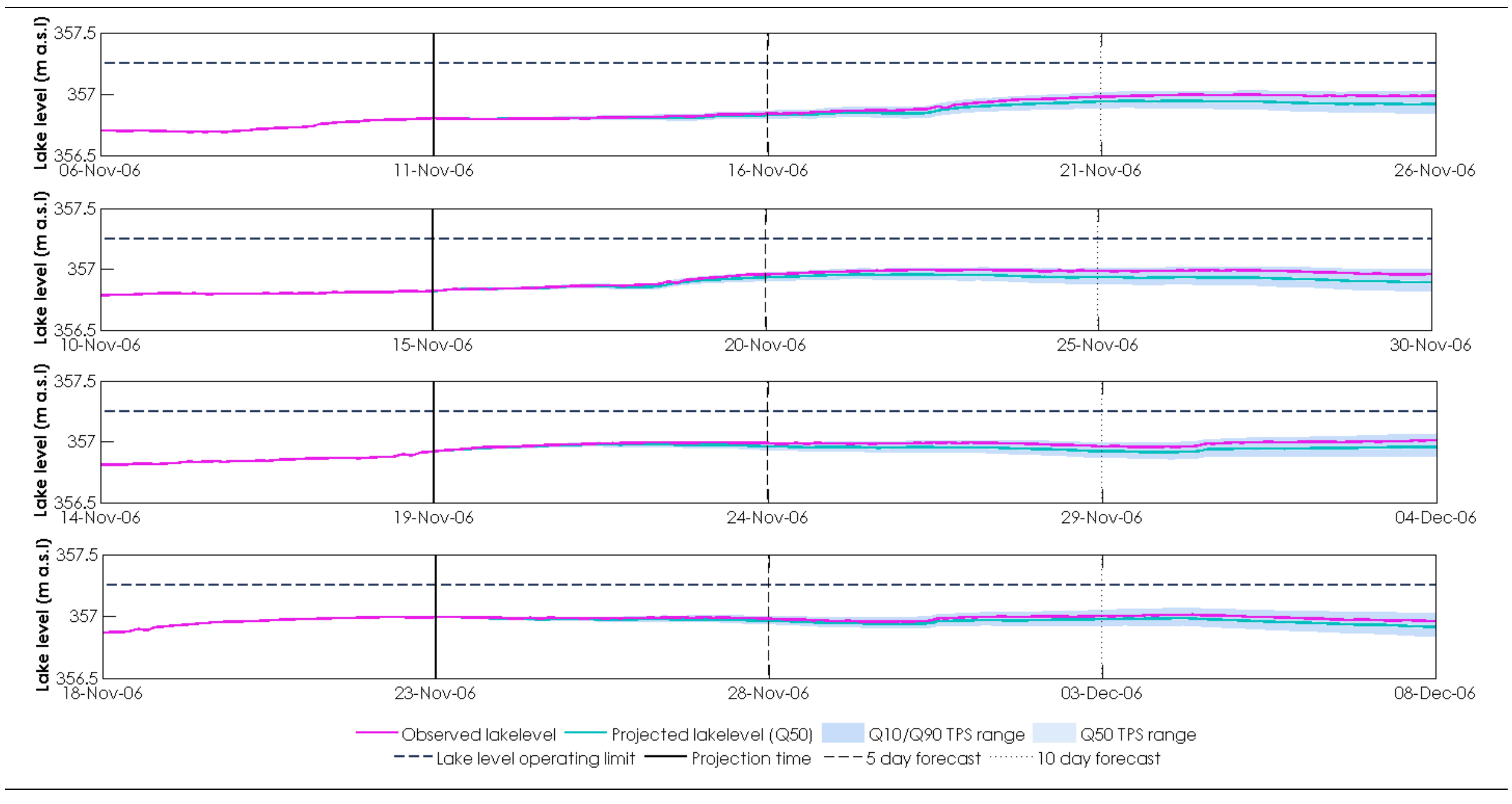

Figure 9.28 November 2006 'normal' operating conditions: modelled output from four forecast times over November 2006. 


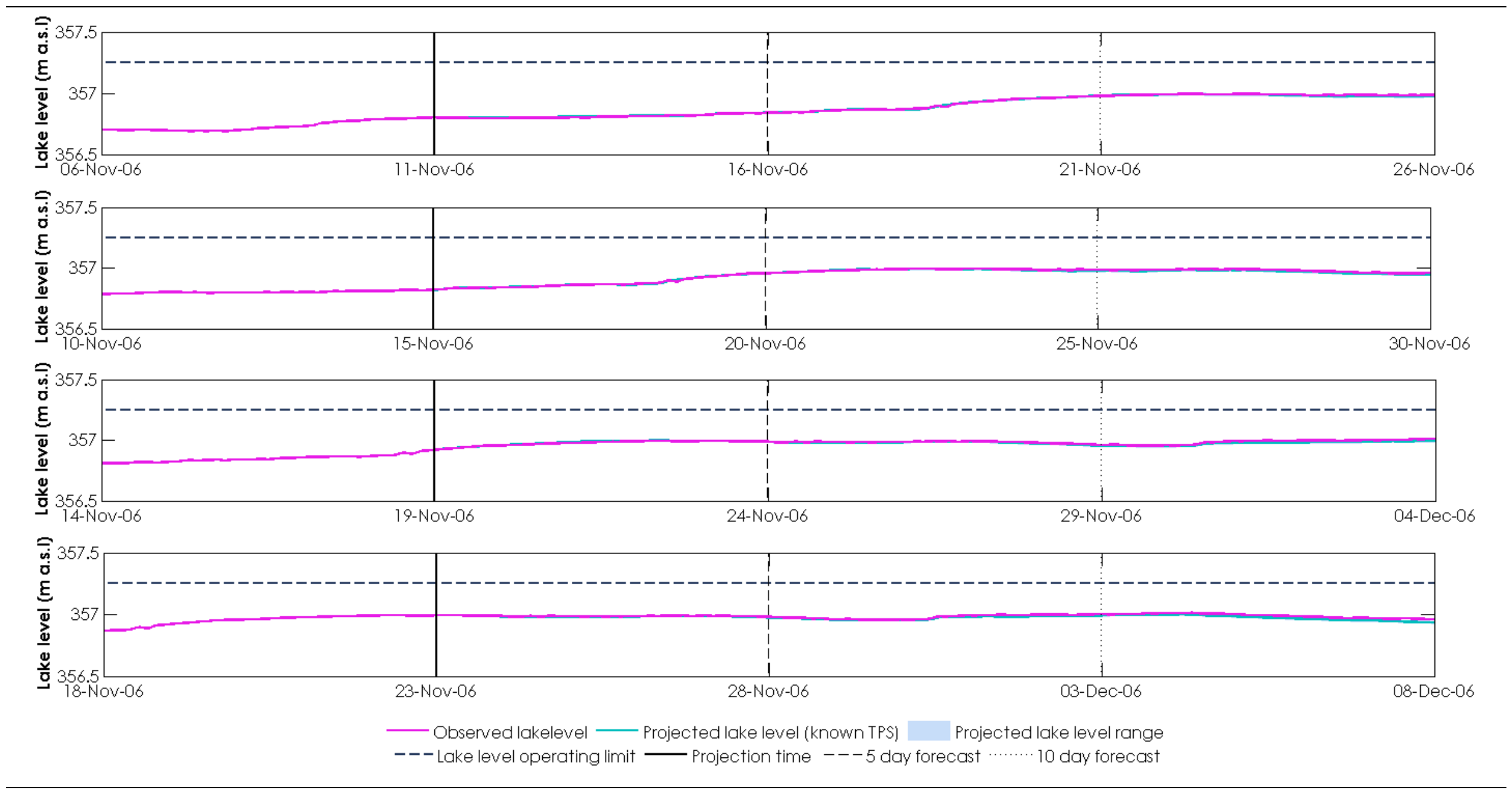

Figure 9.29 November 2006 'normal' operating conditions: modelled output when uncertainty associated with TPS is removed.

264 | Predicting changes in lake level 

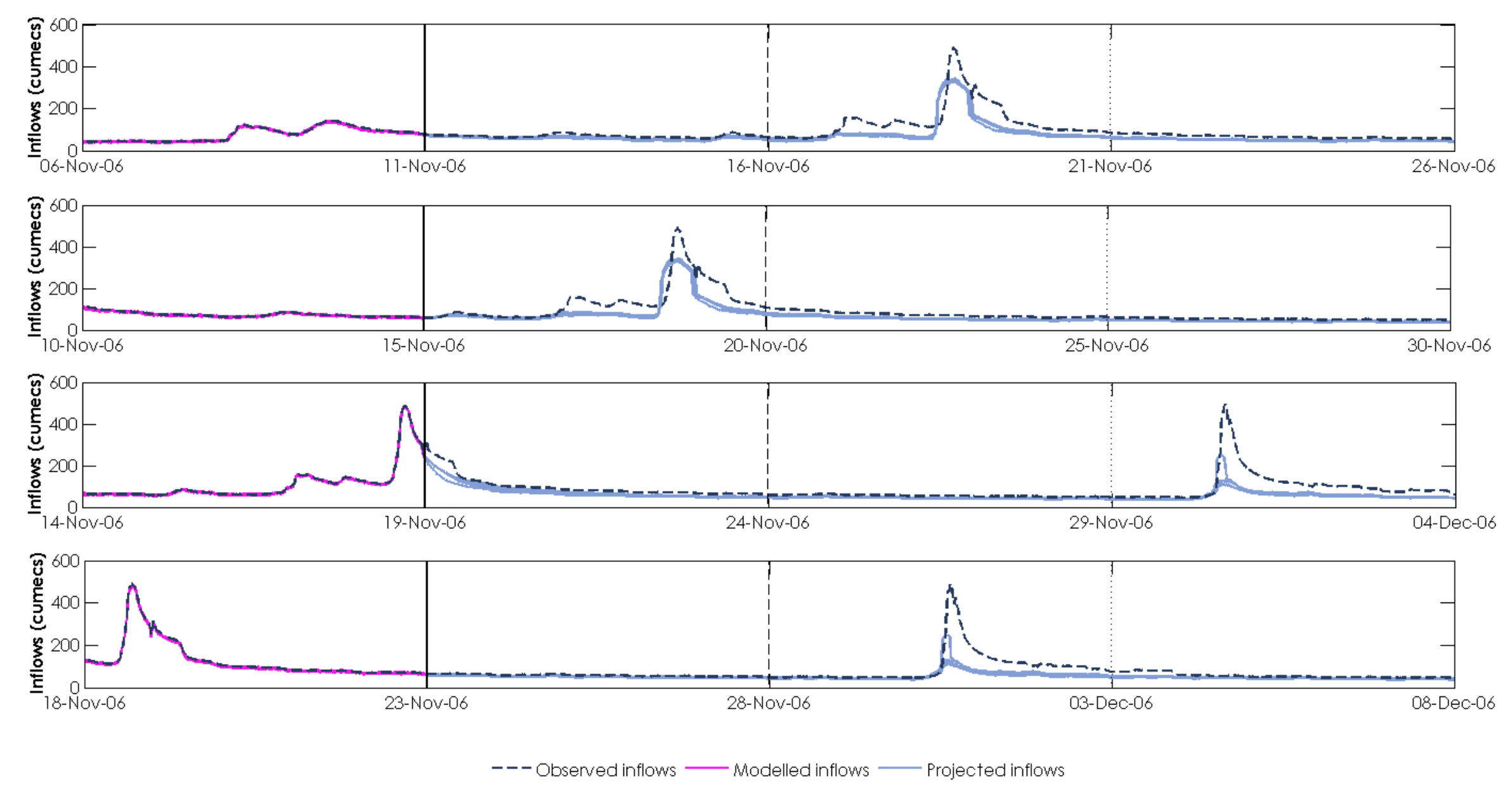

Figure 9.30 November 2006 'normal' operating conditions: Modelled versus observed streamflow for combined inflows from the five currently gauged catchments. 


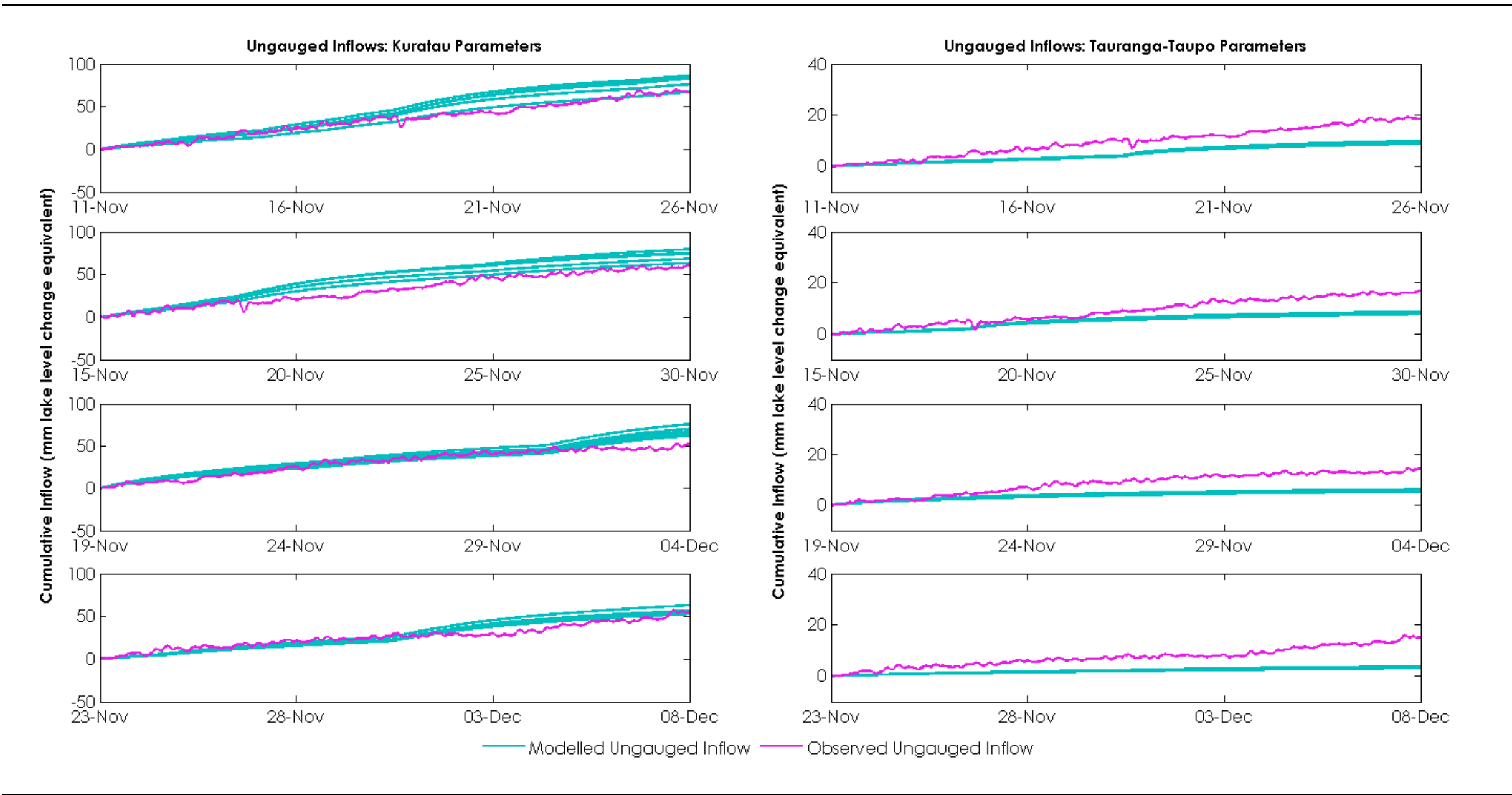

Figure 9.31 November 2006 'normal' operating conditions: Modelled versus observed cumulative inflows from ungauged areas. Units are mm/15 minutes.

266 | Predicting changes in lake level 

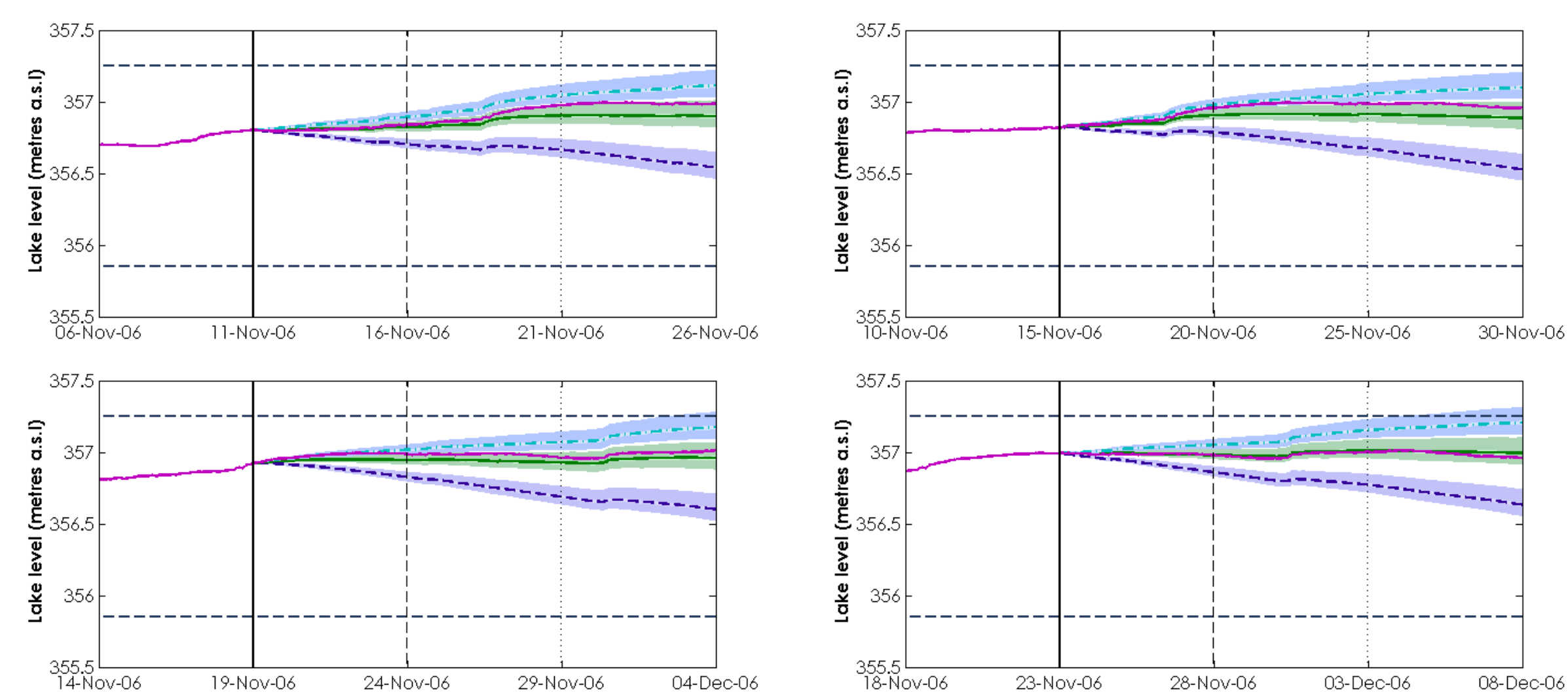

- Observed lakelevel - - - Lake level operating limit — Projection time - - - 5 day forecast $\cdots \cdots \cdots . . . .10$ day forecast

- - - Projected lakelevel - Maximum outflow (Q50)__Q10/Q90 TPS range-Maximum outflow Q Q50 TPS range - Maximum outflow

_- Projected lakelevel - Mean outflow (Q50)_Q Q10/Q90 TPS range-Mean outflow _Q50 TPS range-Mean outflow

-. - Projected lakelevel - Minimum outflow (Q50) Q10/Q90 TPS range - Minimum outflow Q50 TPS range - Minimum outflow

Figure 9.32 Predicted lake level based on three lake oufflow scenarios for November 2006. 


\subsubsection{March 2007}

Lake level in the early part of 2007 was generally declining so that by March it was below $356.8 \mathrm{~m}$ a.s.l (Figure 9.33). There had been very little rainfall over February 2007 (Figure 9.34) and most of March. As shown in the synoptic weather maps in Figure 9.35, a high pressure system sat over the area for the first part of March. This system begins to dissipate in mid-March. Around 18 March, a front moved up the country bringing rain to much of the catchment.

The model does an effective job of simulating lake level response, with observed lake level within the range of modelled lake level over the entire period (Figure 9.36). The slight over-estimation of lake level, evident when the uncertainty with the TPS is removed (Figure 9.37), may be a result of a lower groundwater input during this relatively dry period than the constant $30 \mathrm{~m}^{3} / \mathrm{s}$ input assumed in the model. Both gauged and ungauged inflows do not show a significant over-estimation at this time (Figure 9.38 and Figure 9.39, respectively). As mentioned previously, specifically modelling the groundwater input to the lake may add value. This is discussed further in Section 9.4. Inaccurate estimations of $\mathrm{PE}$ at this time may also be contributing to this small error.

To maintain lake level, outflow from the lake would need to be less than the average outflow. The scenario based on maximum outflow shows a relatively steep decline of lake level toward the minimum consented level over the period.

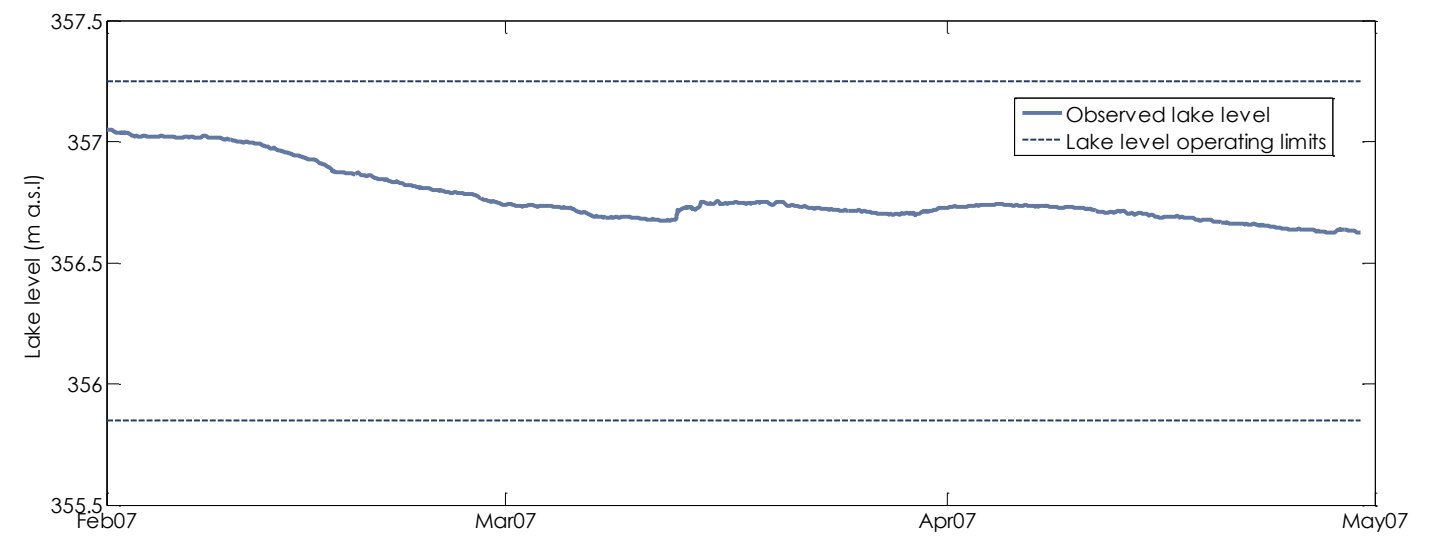

Figure 9.33 Observed (filtered) lake level: February - April 2007 


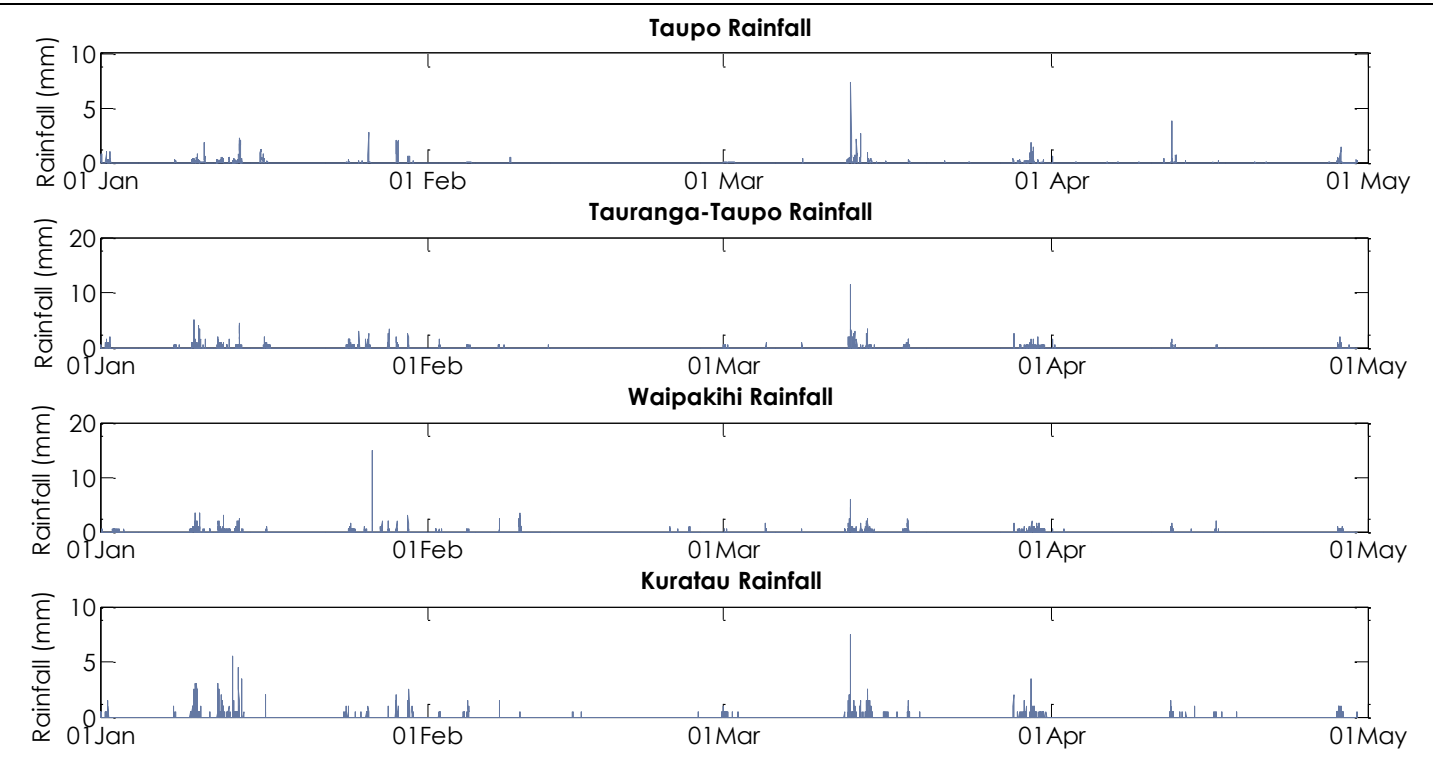

Figure 9.34 Observed rainfall for a selection of gauges in the Lake Taupo catchment: February - April 2006. Units are $\mathrm{mm} / 15$ minutes.

(a) 12:00 am 1 March 2007 (UTC)

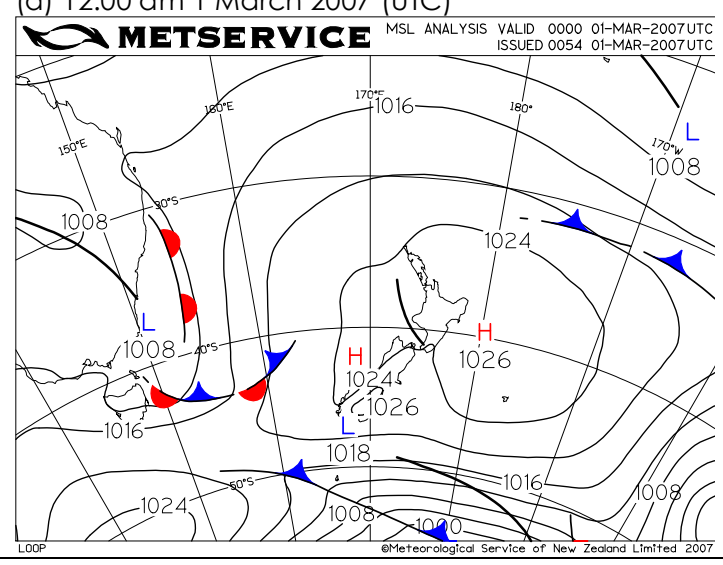

(a) 12:00 pm 17 March 2007 (UTC)

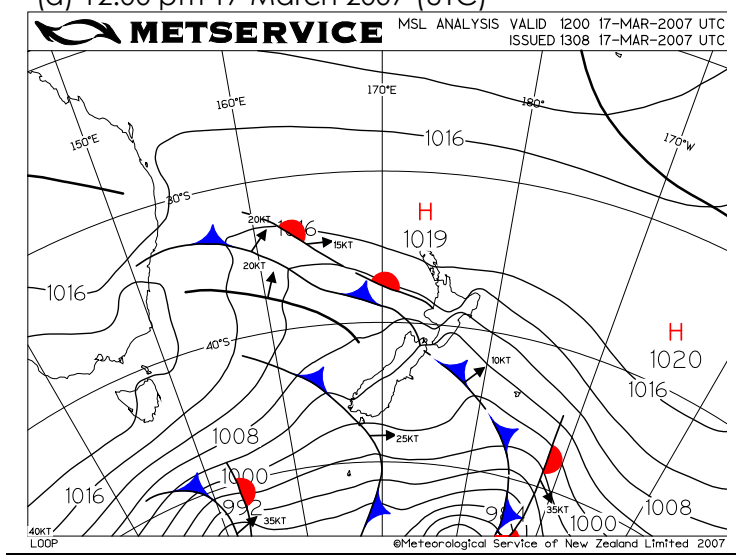

(b) 12:00 am 10 March 2007 (UTC)

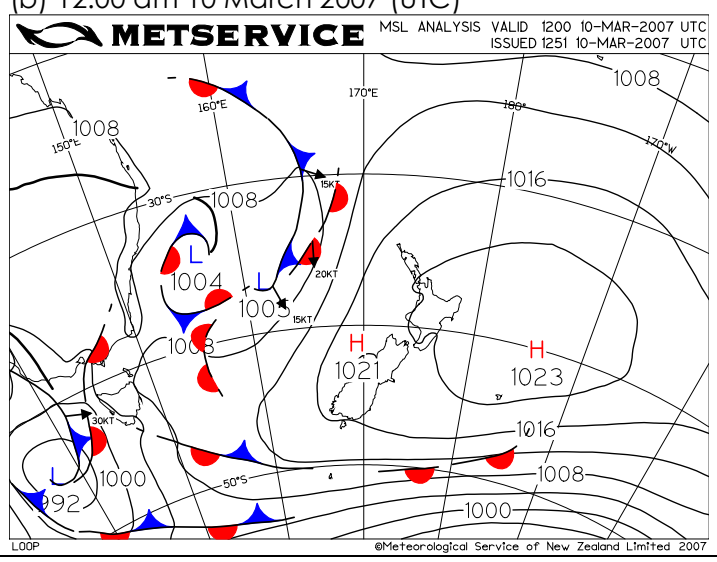

(b) 12:00 am 18 March 2007 (UTC)

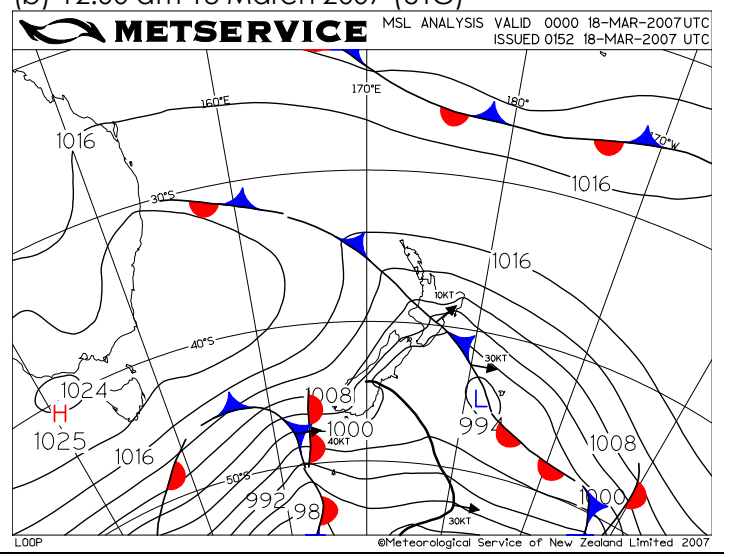

Figure 9.35 A selection of MetService synoptic weather maps for March 2007 


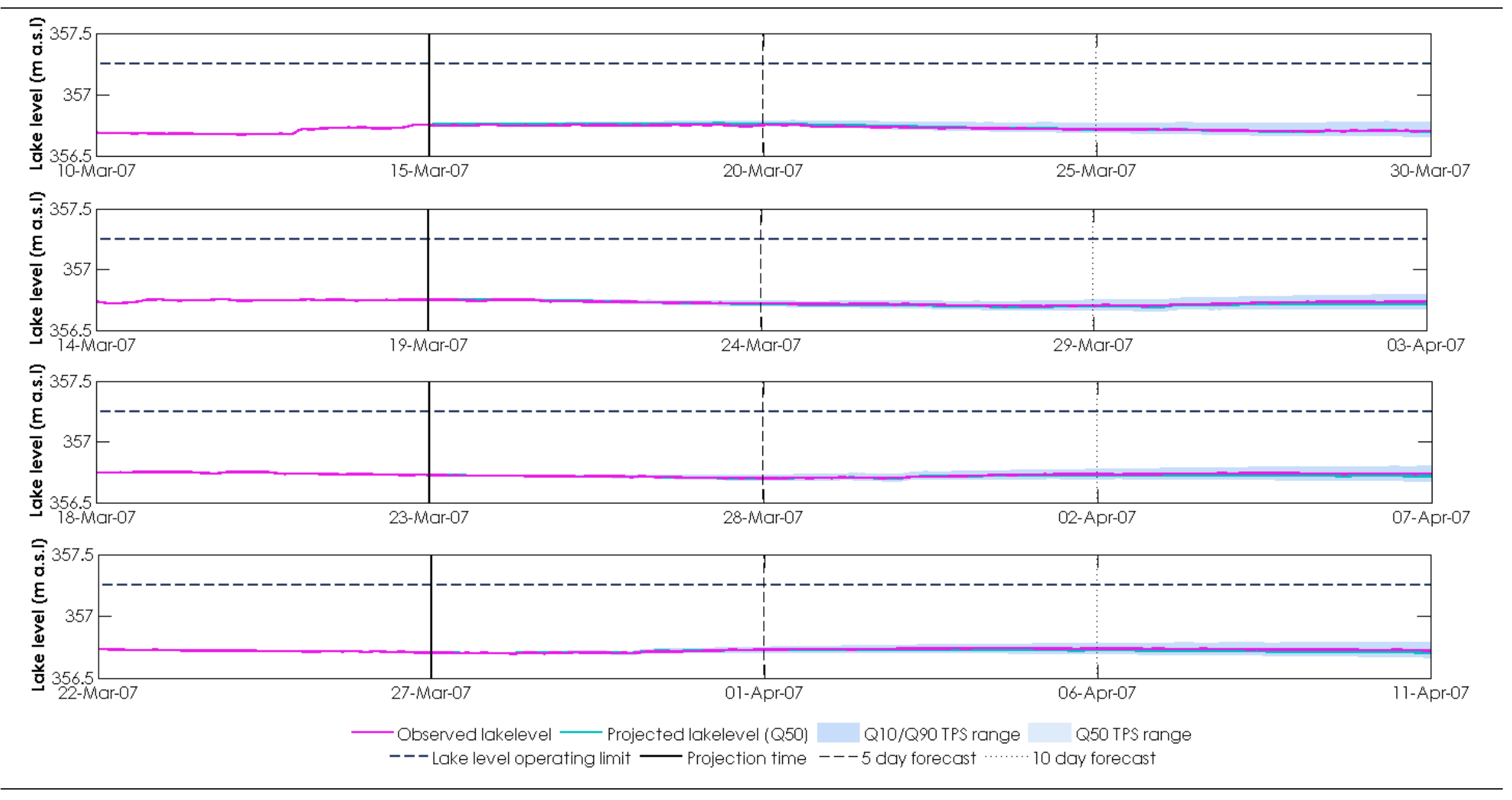

Figure 9.36 March 2007 'normal' operating conditions: modelled output from four forecast times over March 2007.

270 | Predicting changes in lake level 


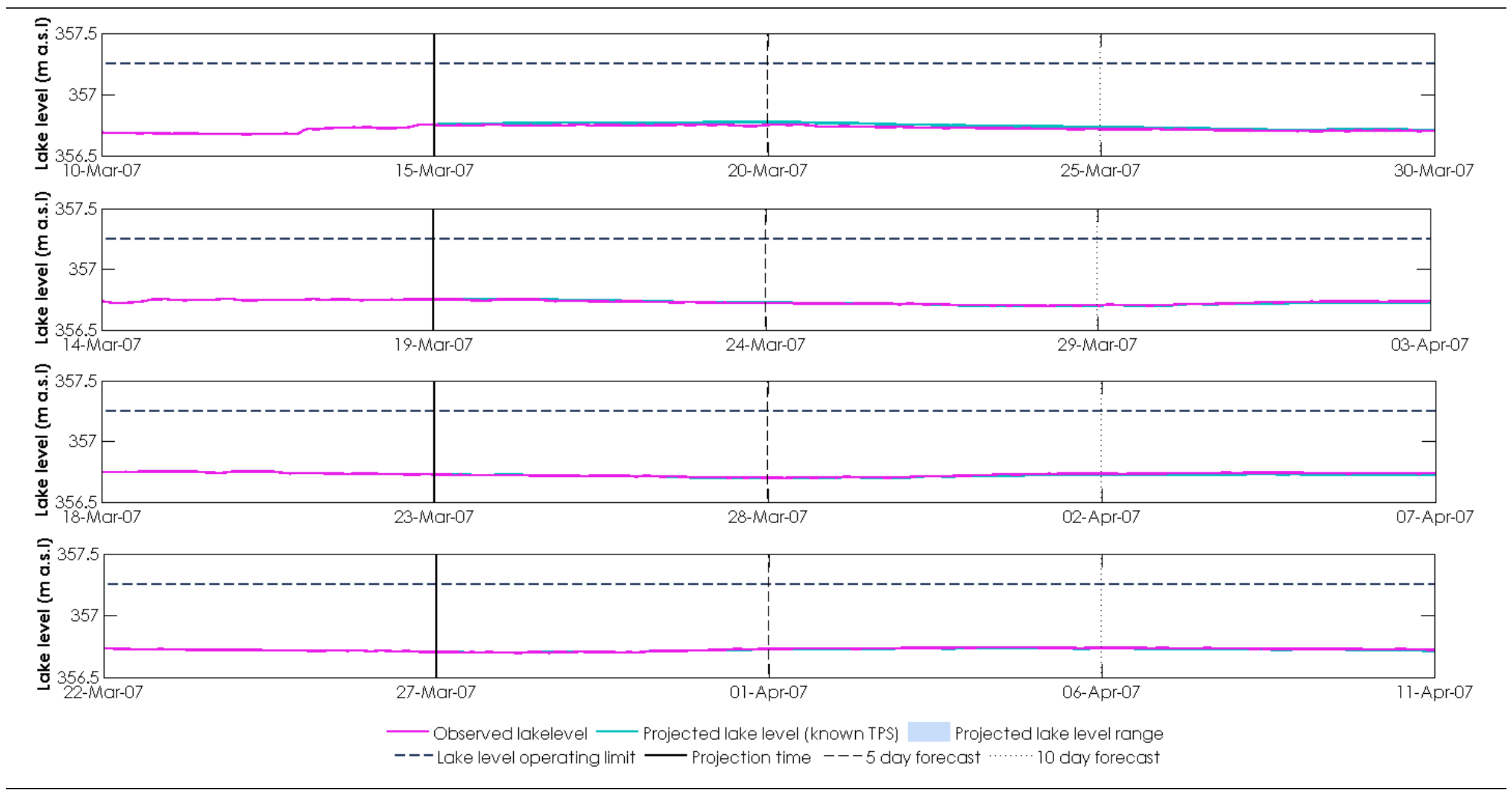

Figure 9.37 March 2007 'normal' operating conditions: : modelled output when uncertainty associated with TPS is removed. 

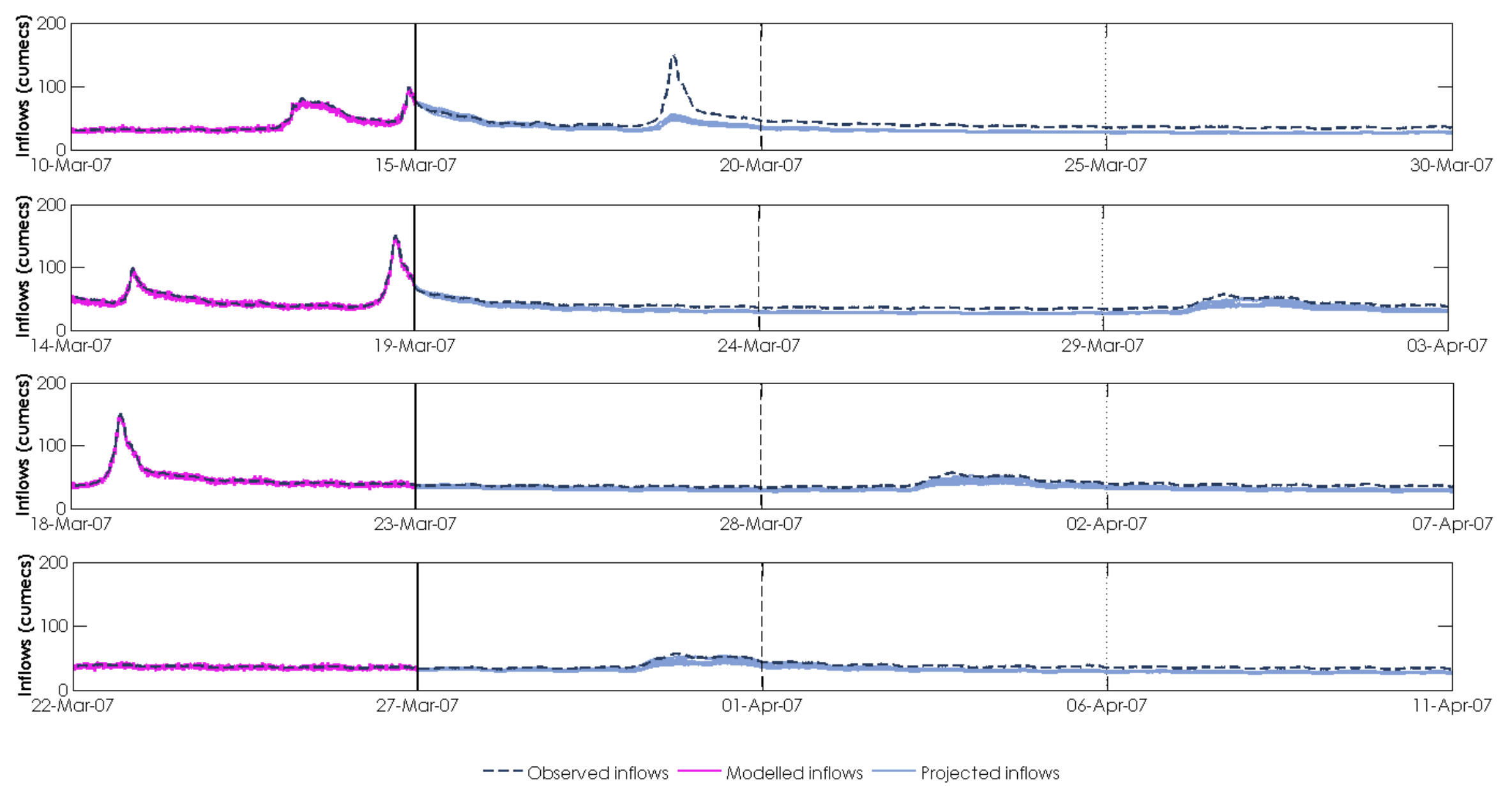

Figure 9.38 March 2007 'normal' operating conditions: Modelled versus observed streamflow for combined inflows from the five currently gauged catchments.

272 | Predicting changes in lake level 

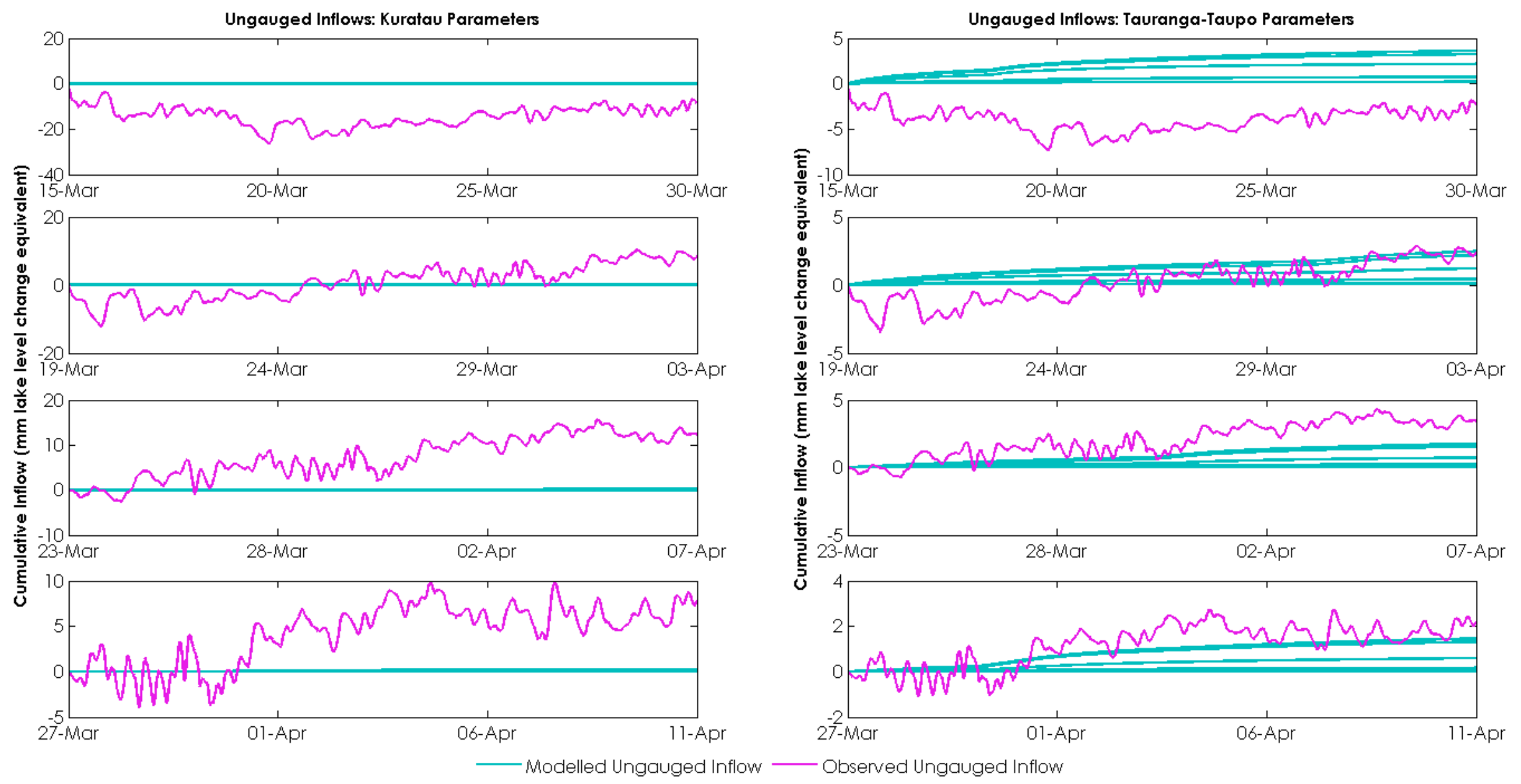

Figure 9.39 March 2007 'normal' operating conditions: Modelled versus observed cumulative inflows from ungauged areas. Units are mm/15 minutes. 

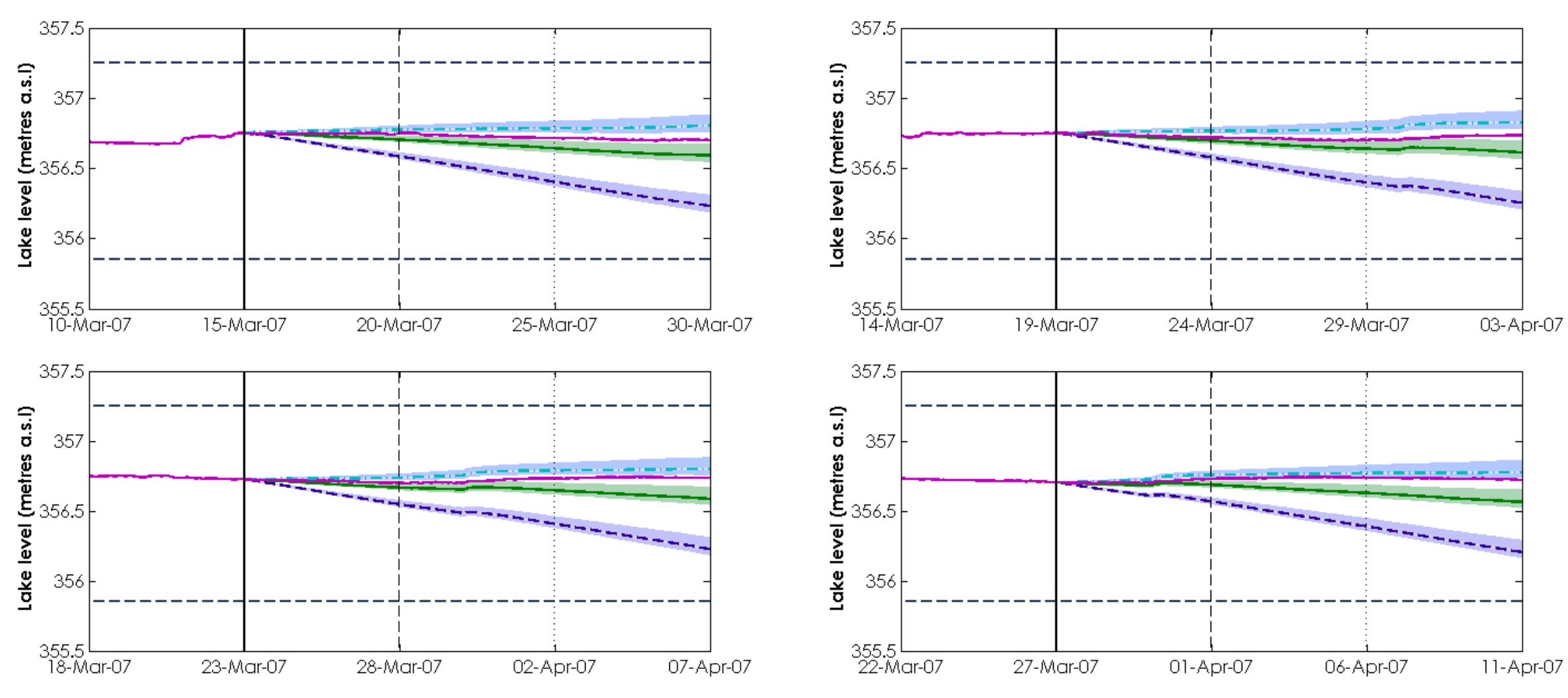

— Observed lakelevel - - - Lake level operating limit — Projection time - - - 5 day forecast $\cdots \cdots \cdots \cdot 10$ day forecast

-- - Projected lakelevel - Maximum outflow (Q50) Q Q10/Q90 TPS range - Maximum outflow Q50 TPS range - Maximum outflow

_- Projected lakelevel - Mean outflow (Q50) Q Q10/Q90 TPS range - Mean outflow Q Q50 TPS range - Mean outflow

-.-.-Projected lakelevel - Minimum outflow (Q50)_Q10/Q90 TPS range - Minimum outflow Q50 TPS range-Minimum outflow

Figure 9.40 Predicted lake level based on three lake outflow scenarios for March 2007.

274 | Predicting changes in lake level 


\subsection{Flood Events}

\subsubsection{July 1998}

The flood of July 1998 was one of the largest rainfall periods in the Waikato on record (as cited in Dravitzki, 2009). This was a long-duration multi-peaked event resulting from a series of cyclones which moved across the region in first 20 days of July. Rainfall for the period from three gauges in the catchment is shown in Figure 9.41. Prior to July, antecedent conditions and lake level had been relatively low for several months (Waugh et al., 1999). The first event was a mid-latitude cyclone which brought significant rain around 2 July (Figure $9.42 \mathrm{a}-\mathrm{b}$ ). This saturated the catchment so that when the main event arrived on the 9/10 July (Figure $9.42 \mathrm{c}-\mathrm{d}$ ) it caused widespread flooding (Waugh et al., 1999). The final event was a shallow cyclone with an associated warm front (Figure 9.42 e-f), bringing light but widespread rainfall as it passed over New Zealand (Dravitzki, 2009). During these events, lake level rose to $357.48 \mathrm{~m}$ a.s.l (Figure 9.43). The largest event was on 8-9 July with the maximum control level (MCL) exceeded on 12 July 1998.

For the most part, the model is substantially over estimating lake level with increasing divergence as each rainfall event arrives (Figure 9.44). From 12 July predictions are improved as observations are assimilated to reflect actual antecedent conditions. However, lake level is still over-estimated for the remainder of the

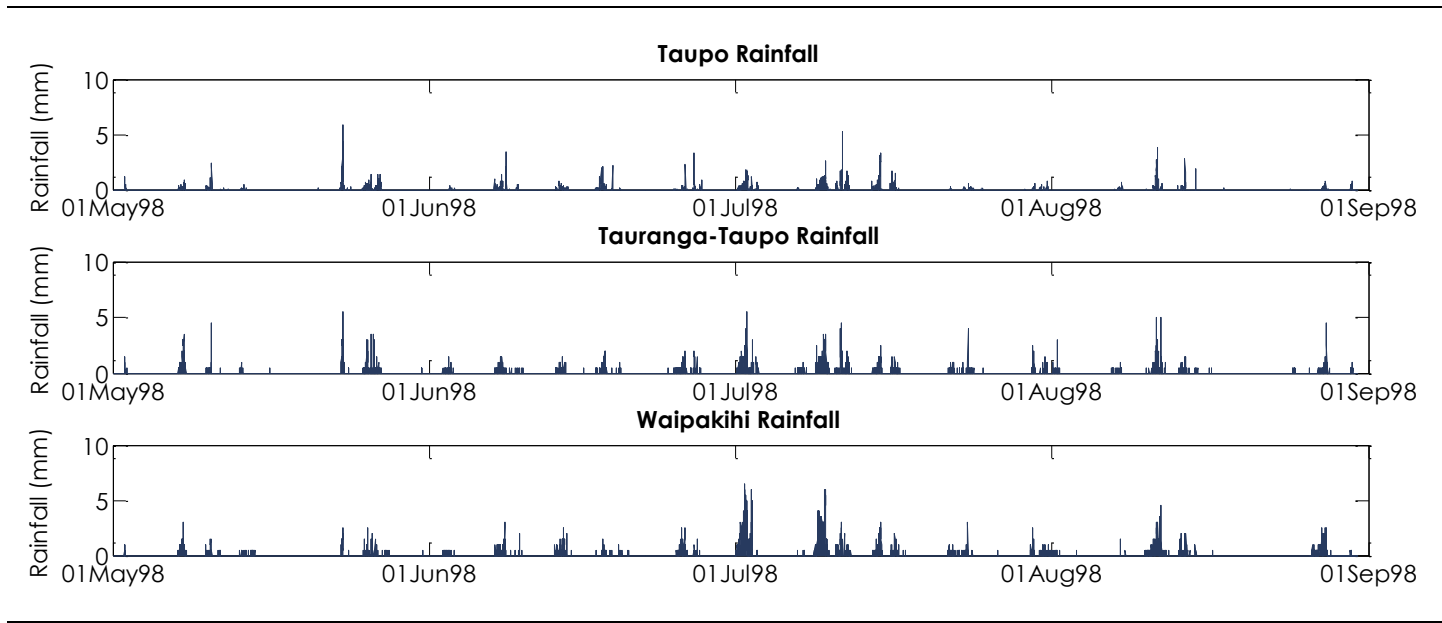

Figure 9.41 Observed rainfall for a selection of gauges in the Lake Taupo catchment: May- August 1998. Units are $\mathrm{mm} / 15$ minutes. 
(a) 12:00 am 1 July 1998 (UTC)

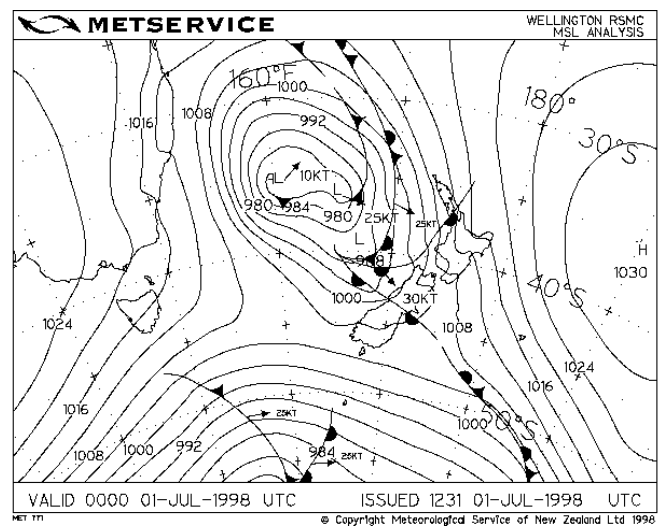

(c) 12:00 am 9 July 1998 (UTC)

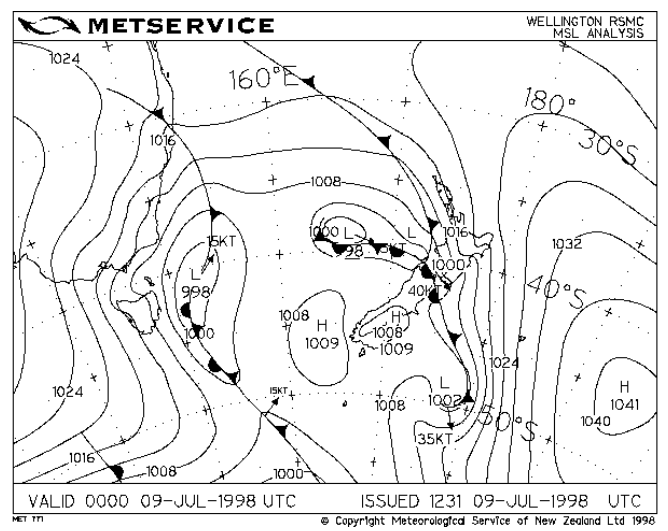

(e) 12:00 am 14 July 1998 (UTC)

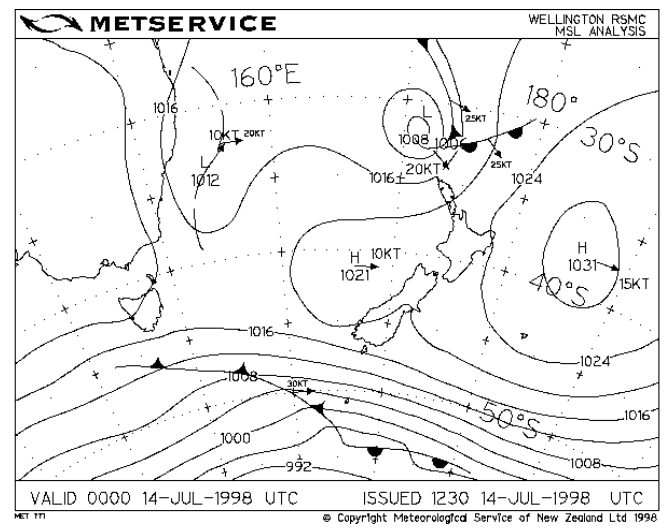

(b) 6:00 am 1 July 1998 (UTC)

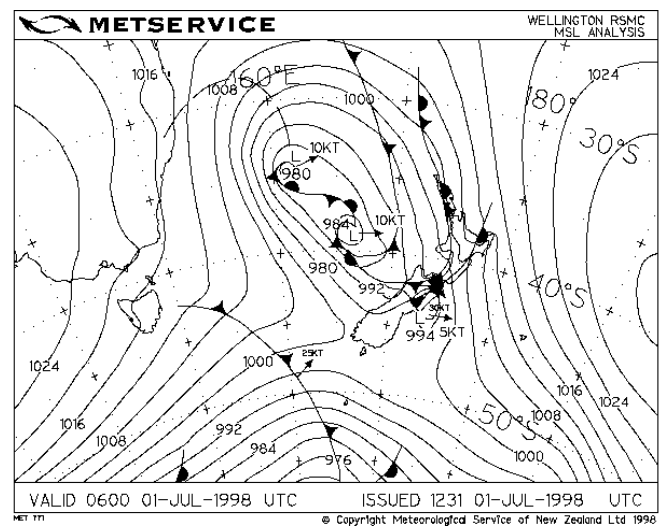

(d) 6:00 am 9 July 1998 (UTC)

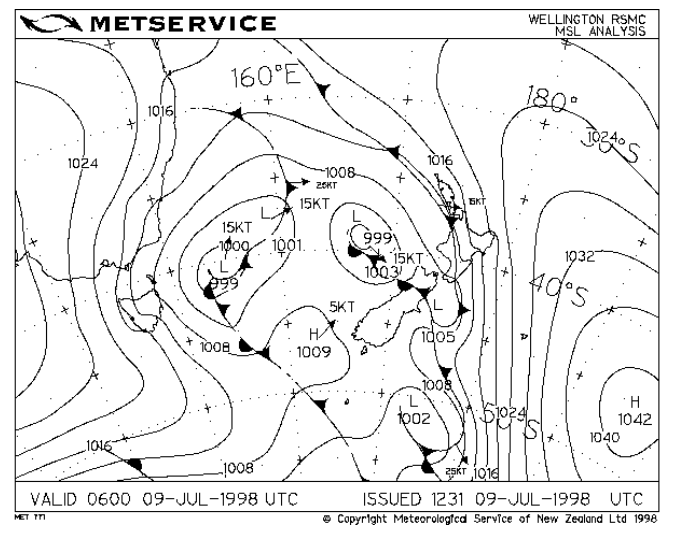

(f) 12:00 pm 14 July 1998(UTC)

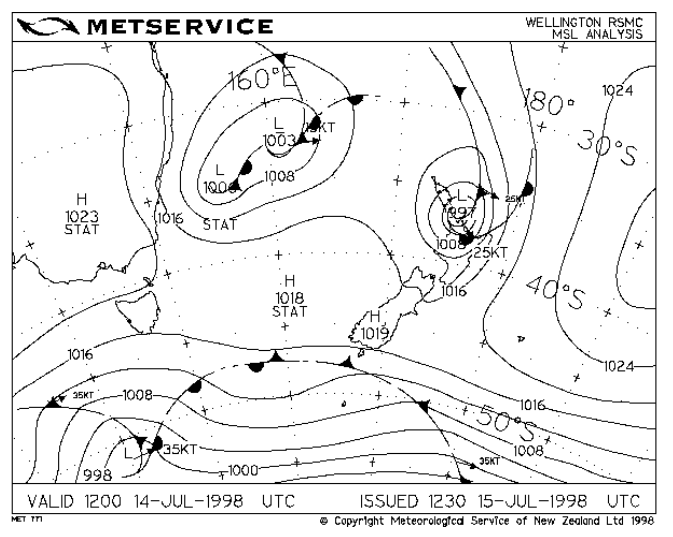

Figure 9.42 A selection of MetService synoptic weather maps for the July 1998 multi-peaked flood event. 


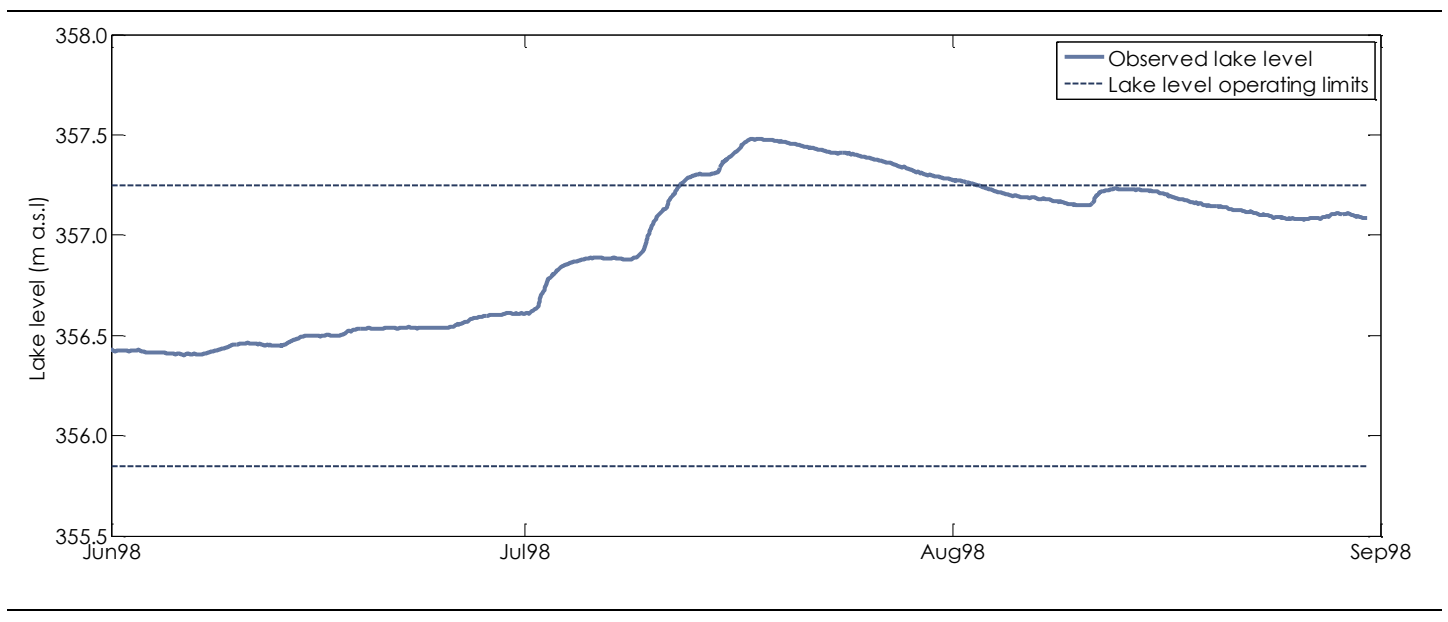

Figure 9.43 Observed (filtered) lake level: June - September 1998.

period. Discharge from the TPS during this period was low because diversions ceased over the event (Freestone et al., 1998). When this source of uncertainty is removed, the extent of error by other inputs to the lake is revealed (Figure 9.45).

The largest error in determining lake level over this event is from the estimation of inflows from ungauged areas (Figure 9.46). Although this event falls within what would be considered the warm-up period for the model, adjustment of initial conditions does little to reduce the over-estimation. The warm-up period minimises the effect of initial state variables. The length of this period is generally in the order of a year, although does vary between applications (Aubert et al., 2003; Madsen, 2003; Vrugt et al., 2003).

The model is predicting an inflow response from ungauged areas given the input rainfall used to drive the model. The ungauged time series is showing a general negative inflow during this time (Figure 9.47). This time series is derived from known inputs, outputs and changes in lake level. The negative inflow occurs because net inputs (excluding ungauged inflows) are larger than the corresponding change in observed lake level. There is a potential lag between the timing of net inputs and lake level change which has not been accounted for. Net inputs include inflows from gauged catchments, some of which are located several kilometres upstream from the lake. The extra travel time between the gauge and the lake would have an influence on the magnitude and timing of inflows to the lake and lake level response. This could be partially resolved by applying a kinematic wave model to propagate the flood wave downstream for a more accurate estimation of the shape and timing of the hydrograph as it enters the lake. 
Barometric forcing may also influence lake level. The Butterworth filter, used to smooth the lake level, removes the high frequency oscillations (refer Section 4.4) but does not remove the longer period oscillations, part of which may be due to barometric pressure perturbations. A reduction in atmospheric pressure can create a water level rise, in what is termed the 'inverted barometer effect' (Dingman and Bedford, 1984, an references therein). As a pressure gradient passes over a lake, the surface of the lake can tilt toward the area of higher pressure (Thompson and Ibbitt, 1978). While it has been noted that this effect may be measureable in Lake Taupo (James et al., 2002), it has not been quantified. Investigation into the effect of these pressure differences cannot be undertaken without further data and information. Currently, there is only one station within the Lake Taupo catchment which measures pressure.

Other sources of error include other modelled inflows and direct lake inputs. Errors in lake evaporation are unlikely to be significant, given the rainfall and time of year. Although recession characteristics are well represented, peak flood flow is underestimated (Figure 9.48). It is thought that this is due to errors in the model structure and/or imperfect driving data. An over-estimation of lake rainfall (and groundwater seepage) would contribute to an over-estimation of lake level. More accurate driving data would improve the overall performance of the model and the reliability of model predictions.

As a result of the issues identified in this event, the scenarios presented in Figure 9.49 are unreliable. Based on the model output, the scenarios suggest that even with a maximum outflow rate, lake level would continue to increase for the majority of the period shown. To reduce flooding downstream, however, outflow from the lake was minimal for much of this period. As such, the model suggest that with a lower outflow rate, lake level would be considerably higher than the observed.

The performance of the model in this event highlights the importance of obtaining more accurate input data and gaining a better understanding of the inflow-lake level response relationship of Lake Taupo. It also suggests that, given most of the overestimation in ungauged areas is in the areas of the north and west, substantial gains would be achieved if this area was discretised into small sub-areas, more suitable parameter sets identified and/or existing parameter values further refined (discussed further in Section 9.4). 

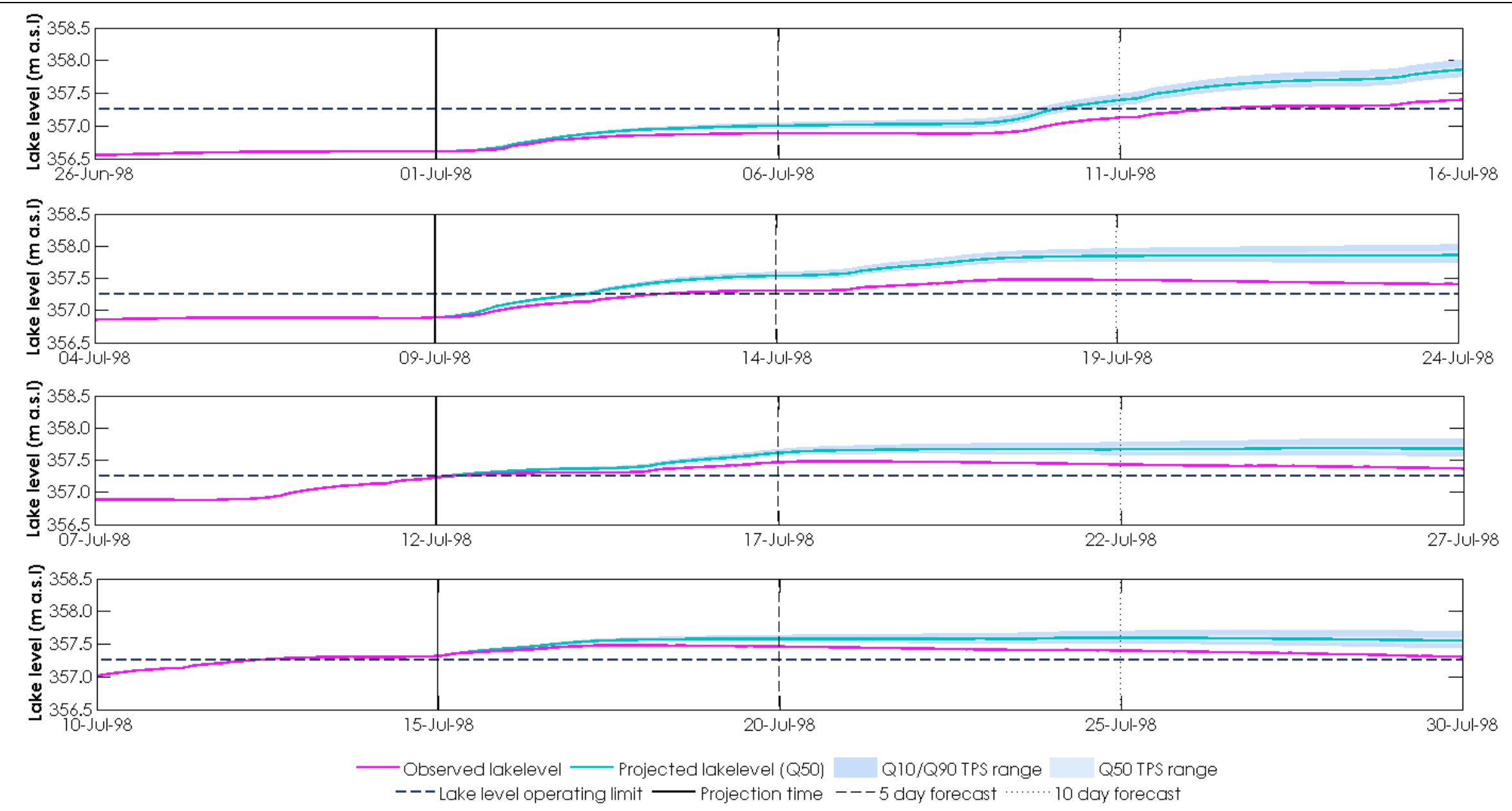

Figure 9.44 July 1998 flood event: modelled output from four forecast times before, during and after the event on 9/10 July 1998 . 


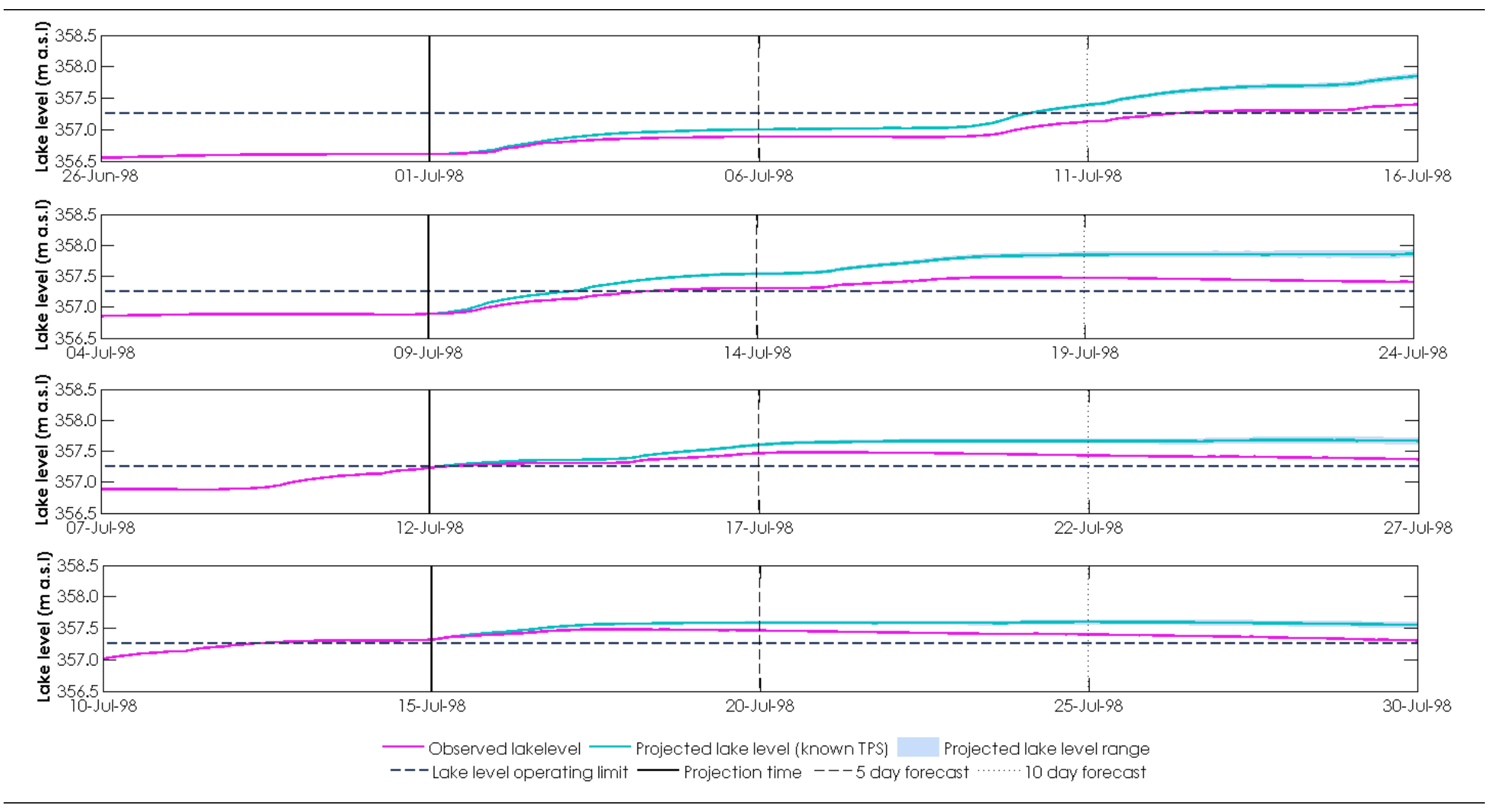

Figure 9.45 July 1998 flood event: modelled output when uncertainty associated with TPS is removed.

280 | Predicting changes in lake level 

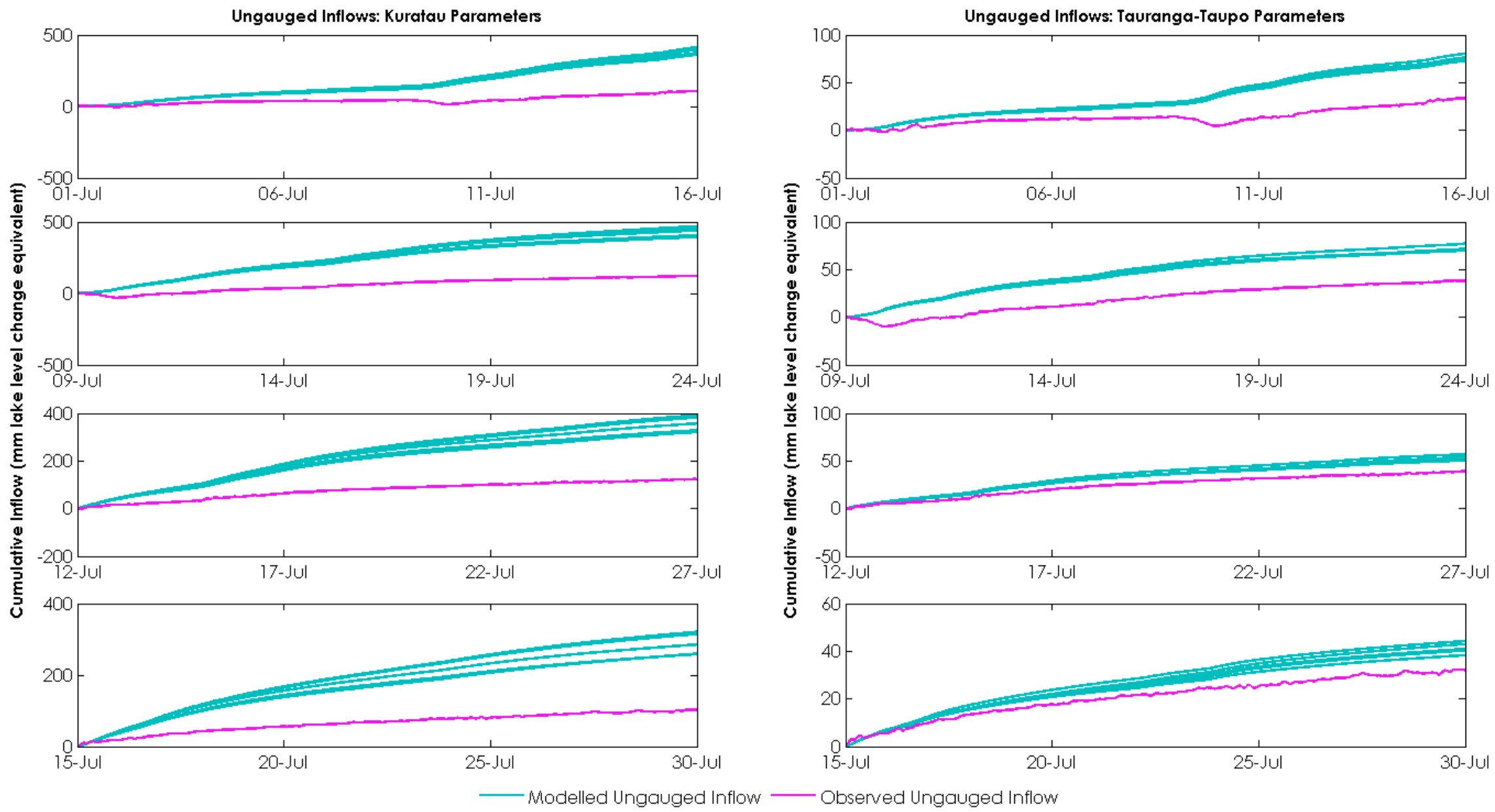

Figure 9.46 July 1998 flood event: Modelled versus observed cumulative inflows from ungauged areas. Units are mm/15 minutes. 
(a) Derived ungauged time series and lake level change

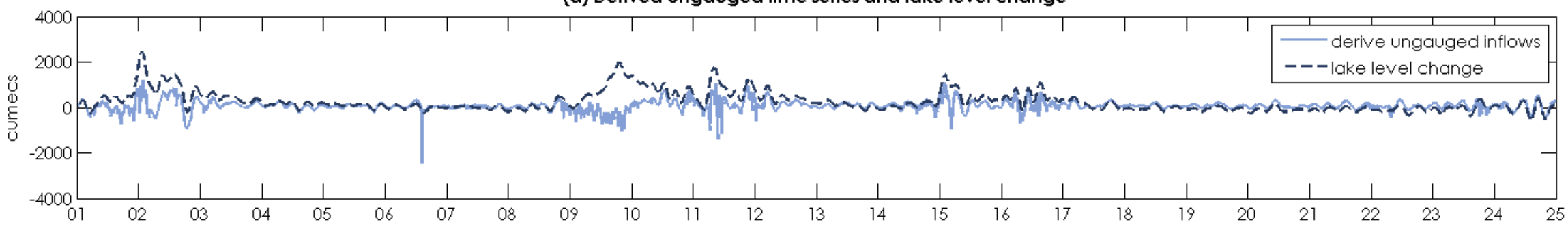

(b) Inflow and outflows

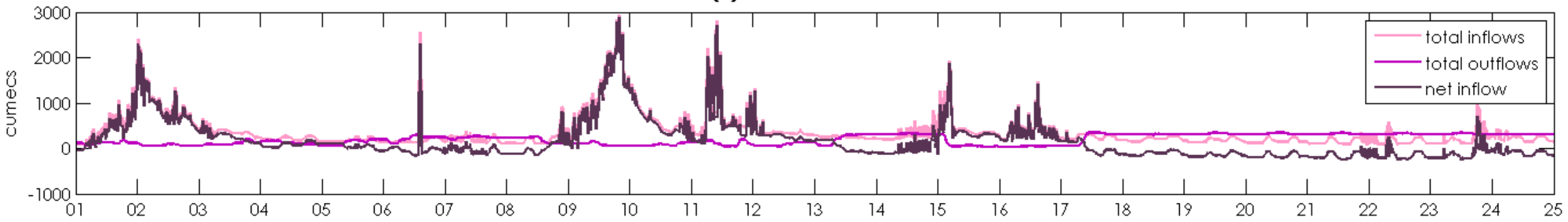

(c) Gauged inflows and rainfall

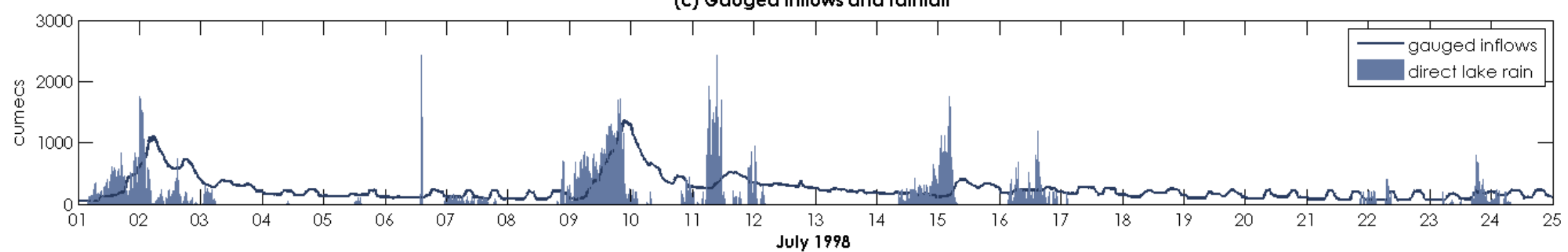

Figure 9.47 July 1998 flood event: Lake level change and derived inflow time series for the July 1998 flood event. (a) derived ungauged inflow time series compared to change in lake level for same period. (b) Total inflows, total outflows and corresponding net inflow for period. (c) Gauged inputs and direct lake rainfall. All values have been converted to cubic metres per second for comparison.

$\mathbf{2 8 2}$ | Predicting changes in lake level 

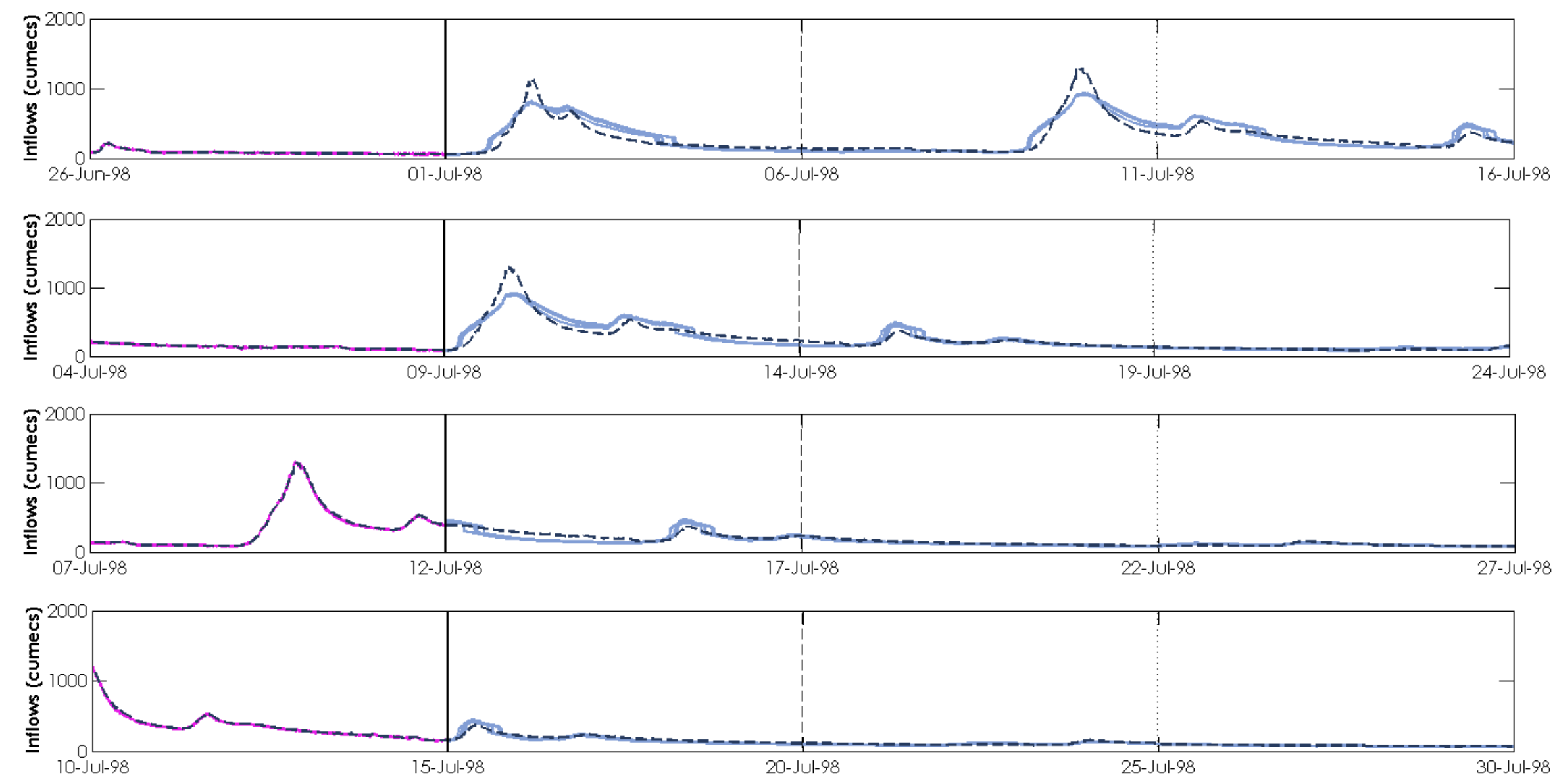

--- Observed inflows — Modelled inflows —- Projected inflows

Figure 9.48 July 1998 flood event: Modelled versus observed streamflow for combined inflows from the five currently gauged catchments. 

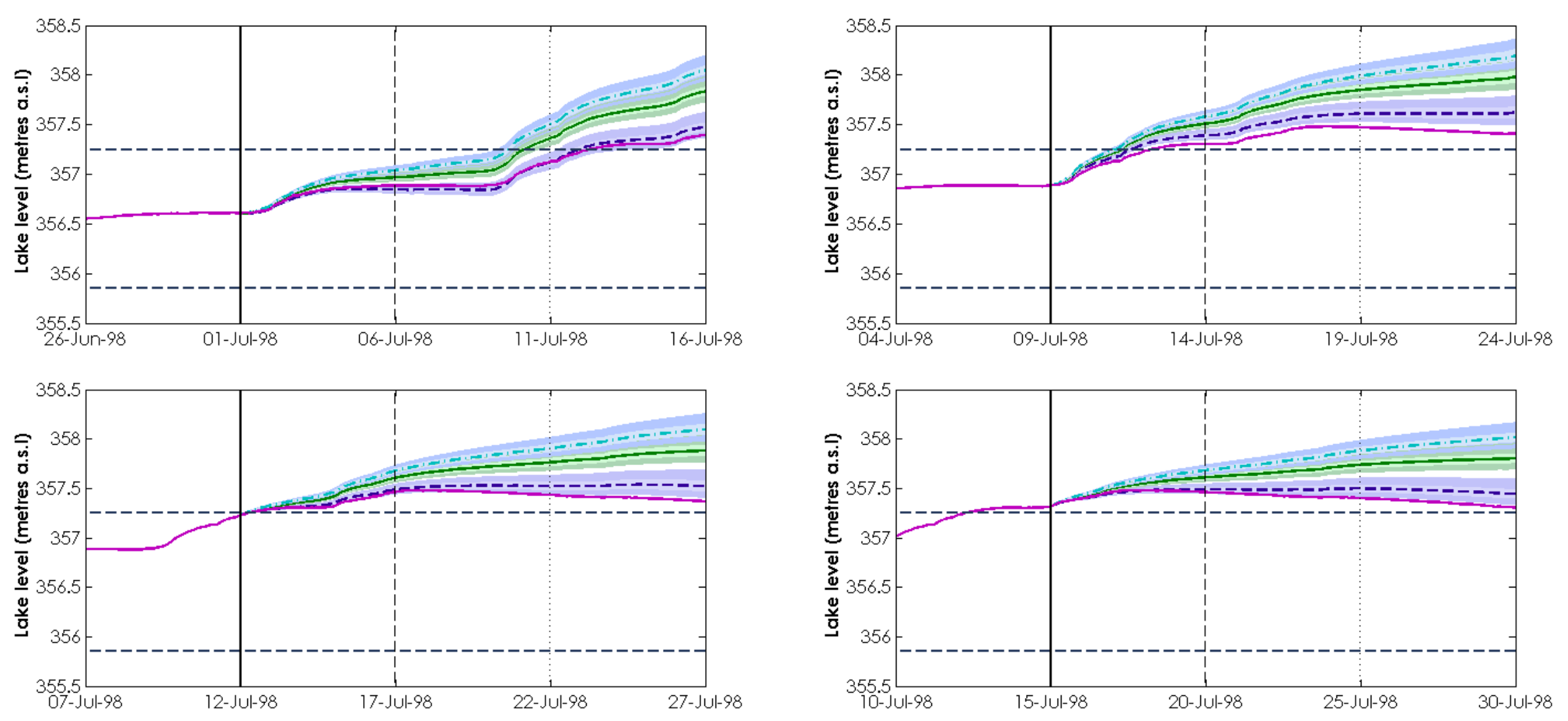

- Observed lakelevel - - - Lake level operating limit —— Projection time - - - 5 day forecast $\cdots \cdots \cdots \cdot . . .10$ day forecast

- - - Projected lakelevel - Maximum outflow (Q50) — Q10/Q90 TPS range - Maximum outflow — Q50 TPS range - Maximum outflow

_- Projected lakelevel - Mean outflow (Q50) _ Q10/Q90 TPS range - Mean outflow _ Q50 TPS range - Mean outflow

-.-.-Projected lakelevel - Minimum outflow (Q50) Q Q10/Q90 TPS range - Minimum outflow Q50 TPS range - Minimum outflow

Figure 9.49 Predicted lake level based on three lake outflow scenarios for the July 1998 flood event.

$\mathbf{2 8 4}$ | Predicting changes in lake level 


\subsubsection{February 2004}

The February 2004 event is another significant event which caused considerable flooding. Rainfall was heavy in the Lake Taupo catchment (Figure 9.50) with both Taupo and Turangi recoding their highest February rainfall on record (NIWA, 2004b). This was a high intensity event over a short duration on already saturated conditions. The event on 28 February 2004 was caused by the simultaneous arrival of frontal bands from a mid-latitude cyclone and ex-tropical cyclone (Dravitzki, 2009), as shown in Figure 9.51. Most rain fell on 28 February with associated flooding on 29 February. Antecedent conditions had been moderately wet leading up to February (Waugh and Freestone, 2004). Saturation levels increased as a number of events occurred through the month. Most of the rainfall fell in the western and southern parts of the catchment (Waugh and Freestone, 2004), as shown by the much greater rainfall for the Waipakihi catchment than the TaurangaTaupo and Kuratau catchments (Figure 9.50). Although mitigation measures were taken (Waugh and Freestone, 2004), lake level exceeded the MCL on 29 February, reaching a maximum level of $357.36 \mathrm{~m}$ a.s.l on 3 March 2004 (Figure 9.52).

The results show that the model is able to simulate the general characteristics of lake level change well, with errors reduced as observations are assimilated. Up until 29 February projected lake level is under-estimated (Figure 9.53). From 4am 29 February, diversions through the TPS ceased, in accordance with the 1977 Tongariro

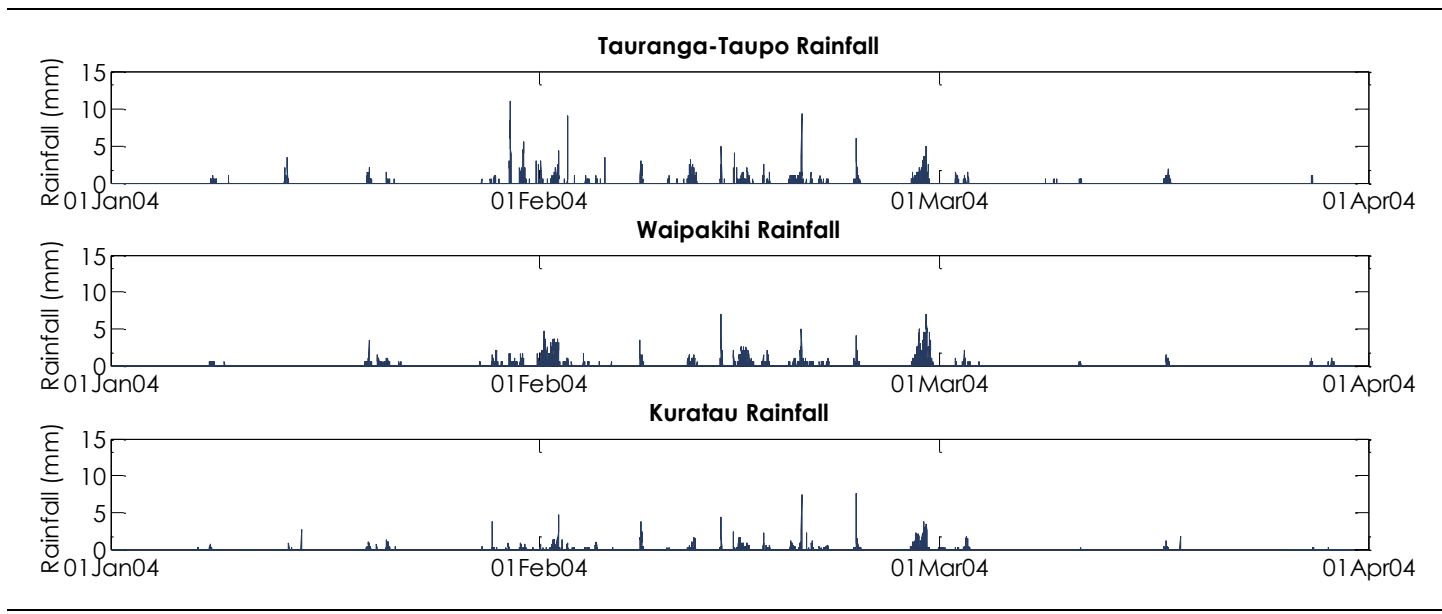

Figure 9.50 Observed rainfall for a selection of gauges in the Lake Taupo catchment: January - March 2004. Units are $\mathrm{mm} / 15$ minutes. 
(a) 12:00 am 28 February 2004 (UTC)

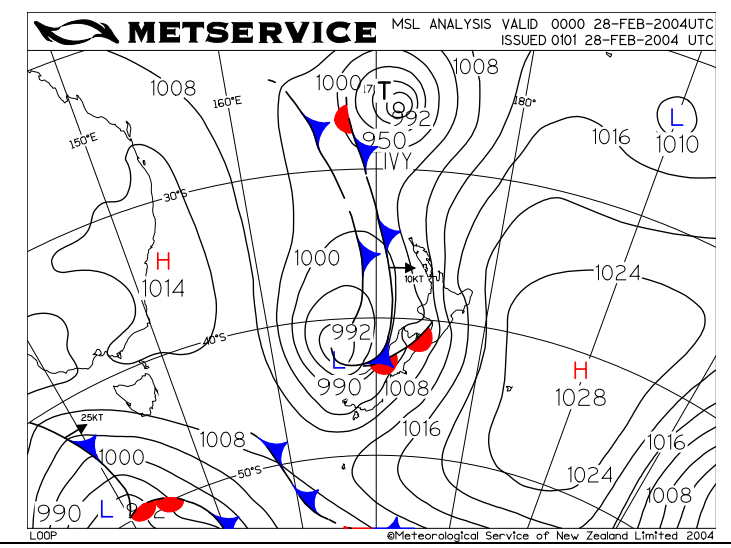

(b) 6:00 am 28 February 2004 (UTC)

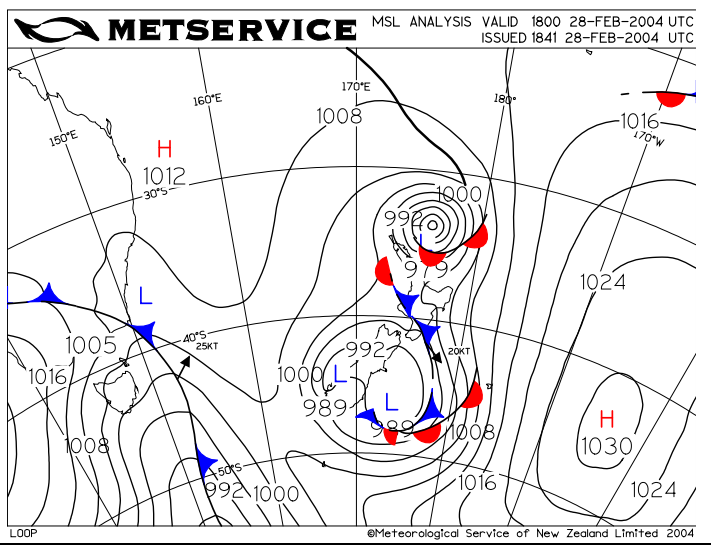

Figure 9.51 A selection of MetService synoptic weather maps for the February 2004 flood event.

Offset Works Agreement (Waugh and Freestone, 2004). A four month gap in the Tokaanu Station discharge time series between January and April 2004 does not allow comparison with observations. However, is it likely that discharge from the TPS would be at the lower end of the projected range shown in Figure 9.53.

In light of this information, the model is doing a good job of predicting lake level from 29 February. Prior to this, lake level is under-estimated. Gauged inflows over this period are closely simulated except during the peak flood event which appears under-predicted, despite a gap in the observations (Figure 9.54). This error could be a result of simplifications in the model structure and/or inadequate driving data. Inaccurate driving data has implications for other parts of the catchment as well.

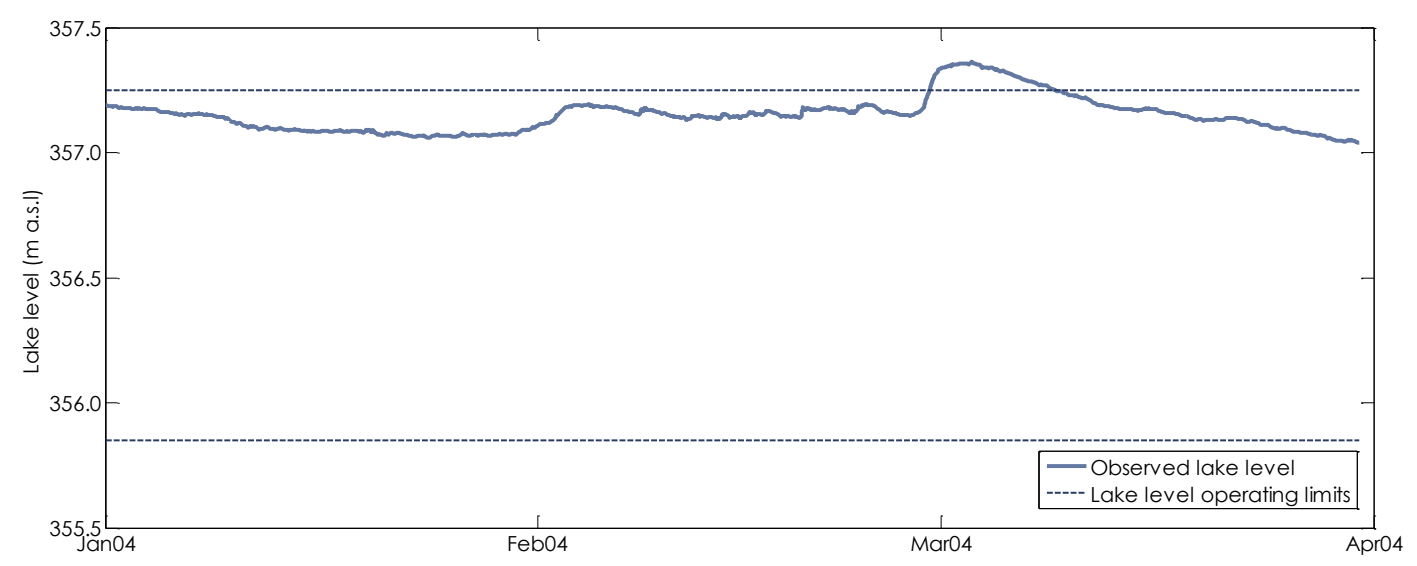

Figure 9.52 Observed (filtered) lake level: January - March 2004. 
Rainfall estimation for ungauged areas and direct rainfall to the lake is based on the observations at a number of the same stations used to predict rainfall in the gauged sub-catchments. In gauged areas, the constrained EnKF adjusts model states to account for these errors. However, in areas where data assimilation does not occur, this error can accumulate. This would partly explain the under-estimation of inflow from ungauged areas (particularly from the areas estimated by the Kuratau parameters) for the period (Figure 9.55).

Similar to the July 1998 event, the derived ungauged time series shows a general negative trend over the peak event on 29 February 2004 (Figure 9.56). The model is predicting inflow from these ungauged areas, which would account for the improvement in model performance around the time of this peak event.

The scenarios shown in Figure 9.57 show that outflow from the lake needed to be close to the maximum outflow rate for the entire period to reduce the amount of time lake level is above the maximum consented level. This is consistent with the observed outflow from the lake which, aside from a short period between 27-29 February, was at this higher rate until 12 March. Lower outflow rates would have resulted in lake level exceeding the maximum control level sooner and remain above this operating margin well into March.

Overall, the model gives reasonable predictions of lake level. Recession characteristics are well captured, and the assimilation of observations improves the accuracy and reliability of model output. 


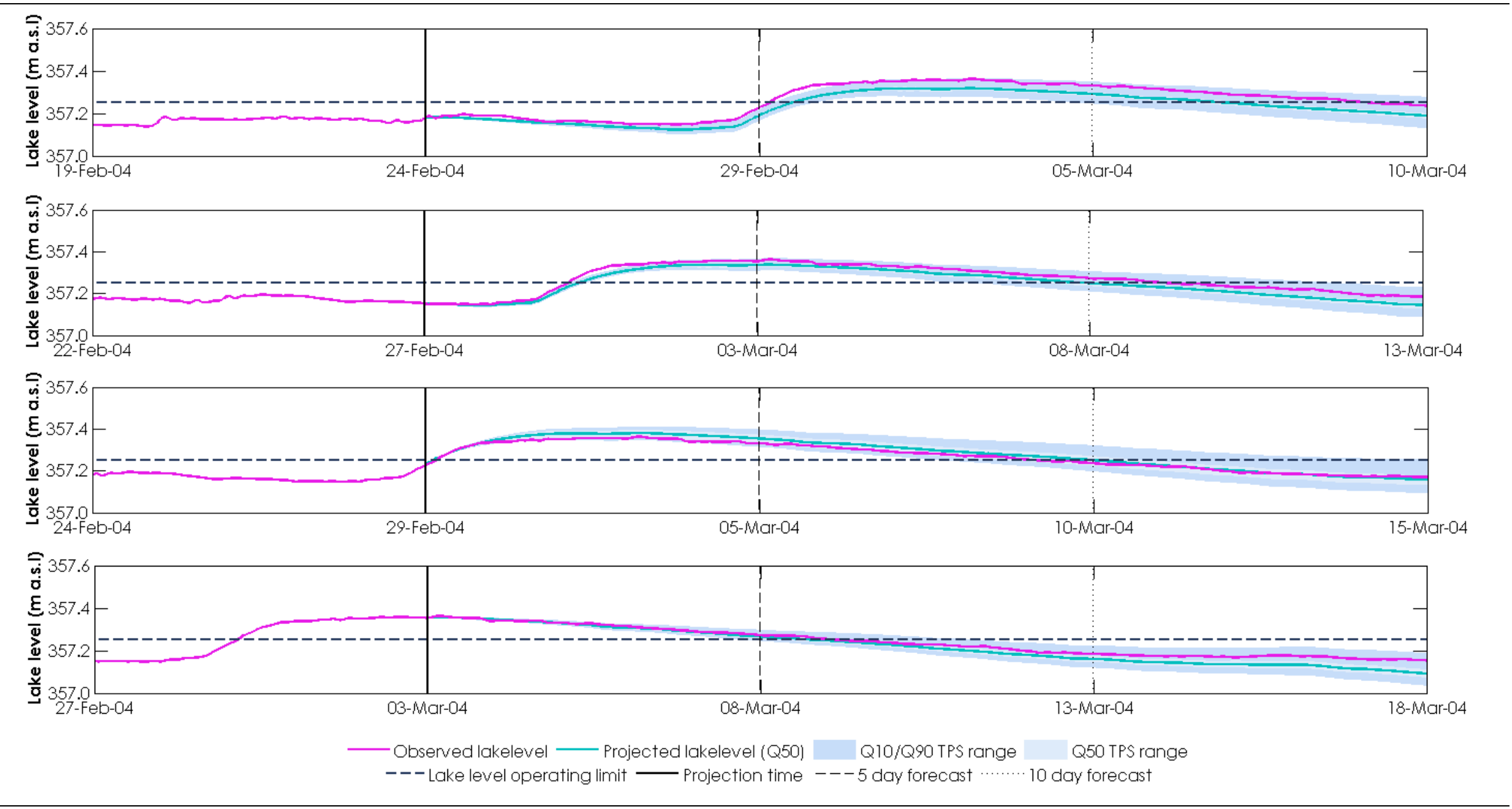

Figure 9.53 February 2004 flood event: This figure shows the modelled output from four forecast times before, during and after the event on 29 February 2004.

$\mathbf{2 8 8} \mid$ Predicting changes in lake level 

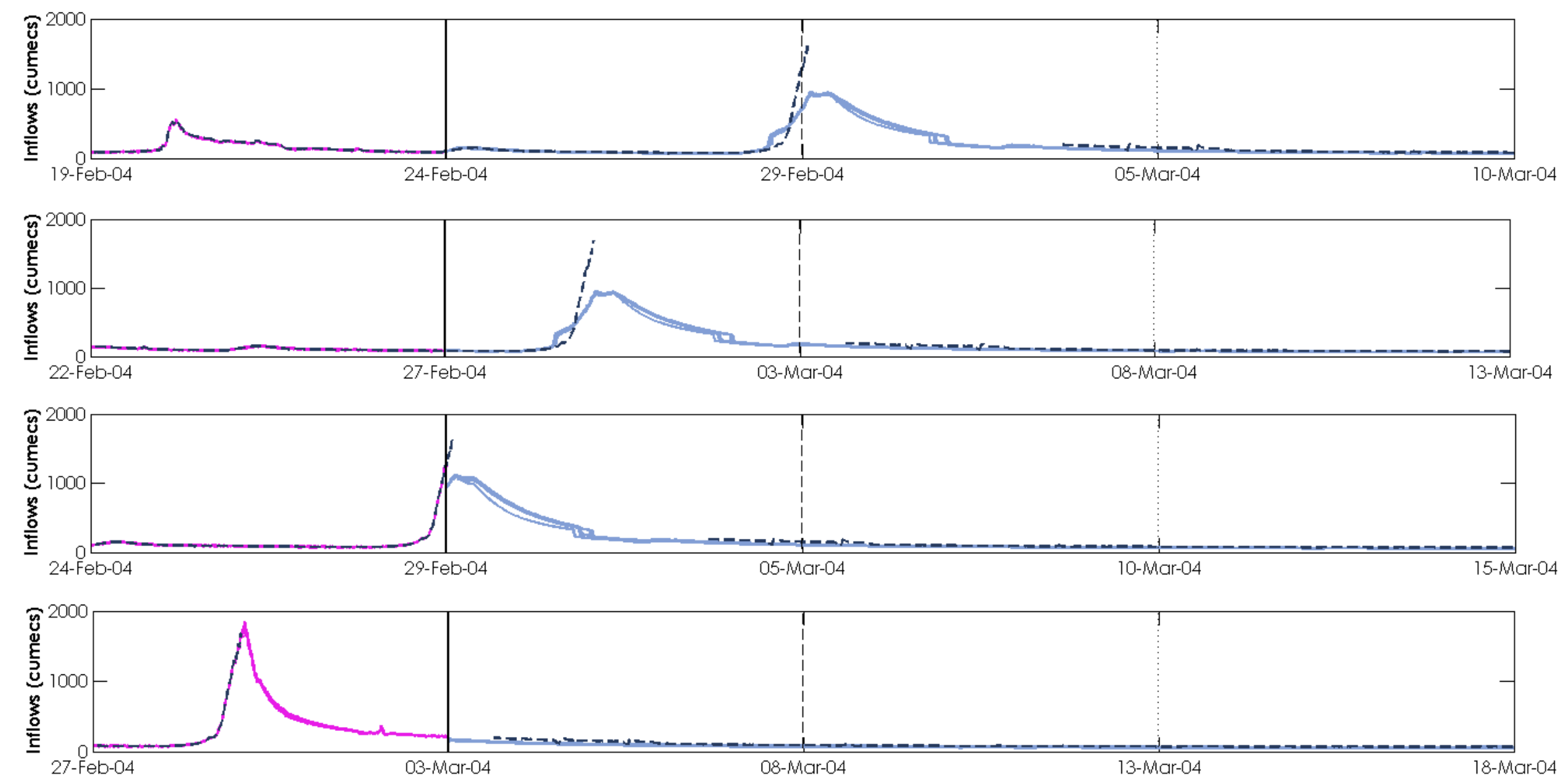

--- Observed inflows — Modelled inflows —- Projected inflows

Figure 9.54 February 2004 flood event: Modelled versus observed streamflow for combined inflows from the five currently gauged catchments. 

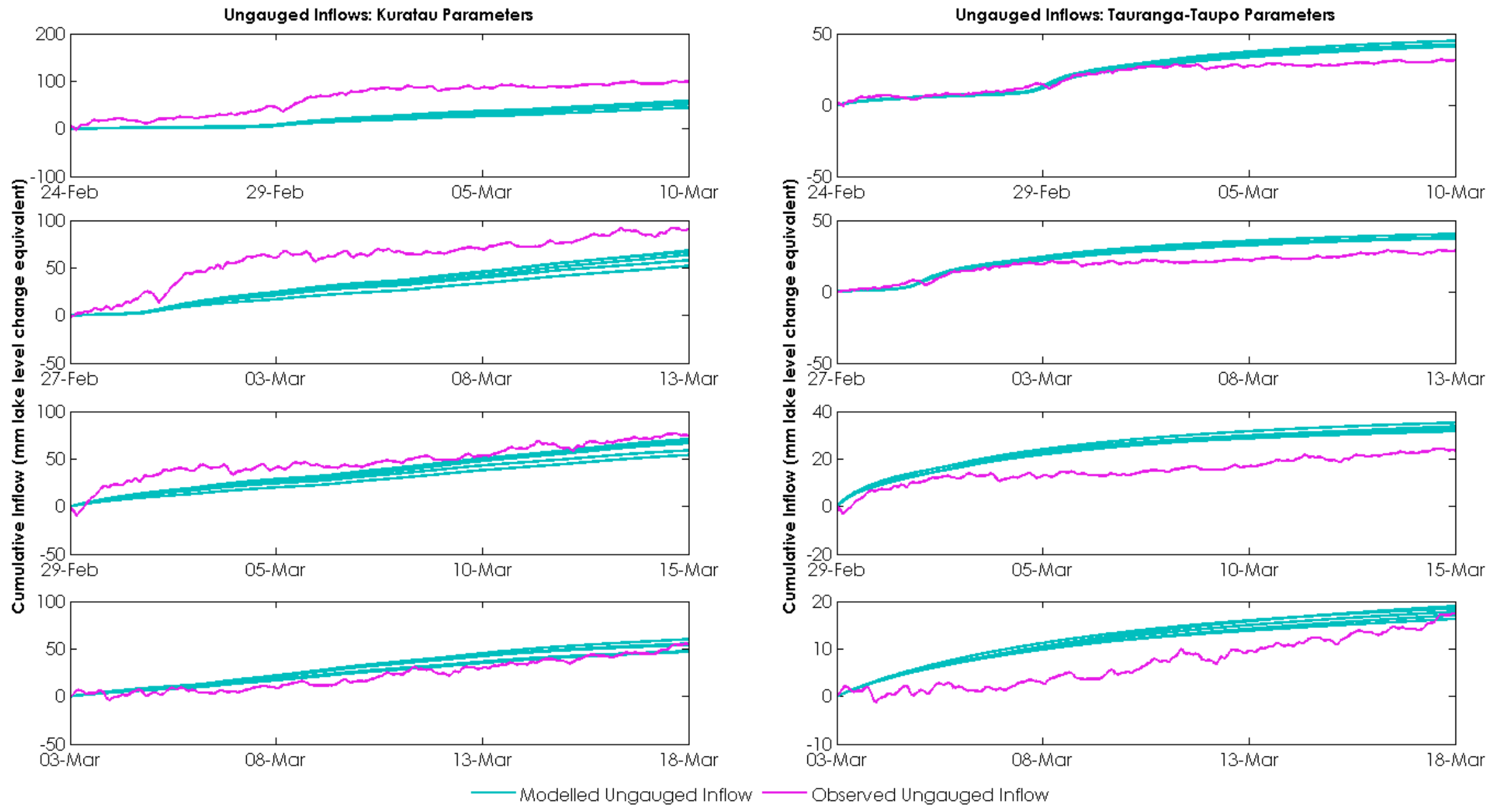

Figure 9.55 February 2004 flood event: Modelled versus observed cumulative inflows from ungauged areas. Units are mm/15 minutes.

290 | Predicting changes in lake level 
(a) Derived ungauged time series and lake level change

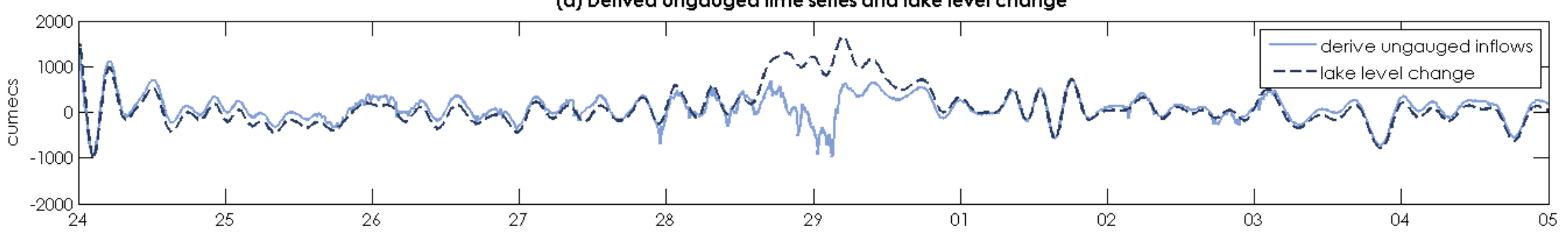

(b) Inflow and outflows

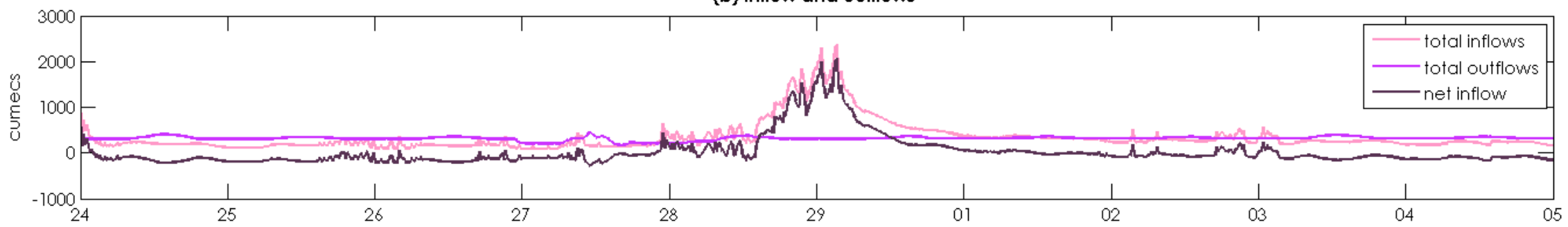

(c) Gauged inflows and rainfal

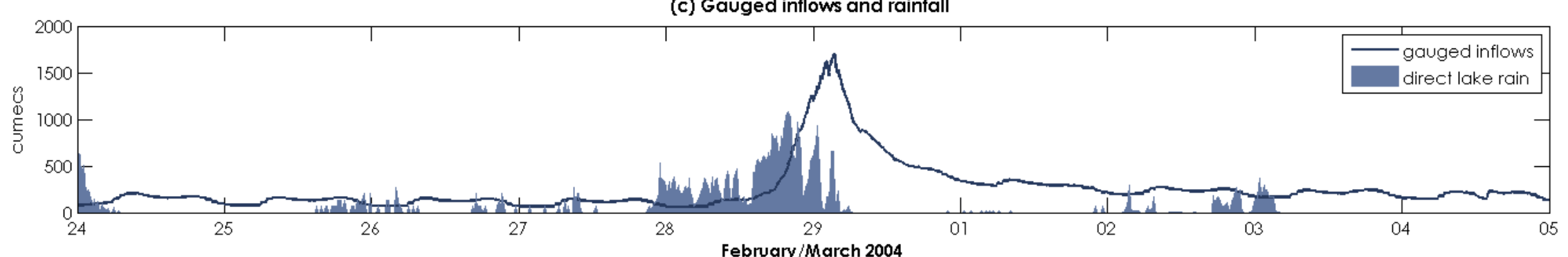

Figure 9.56 February 2004 flood event: Lake level change and derived inflow time series for the February 2004 flood event. (a) derived ungauged inflow time series compared to change in lake level for same period. (b) Total inflows, total outflows and corresponding net inflow for period. (c) Gauged inputs and direct lake rainfall. All values have been converted to cubic metres per second for comparison 

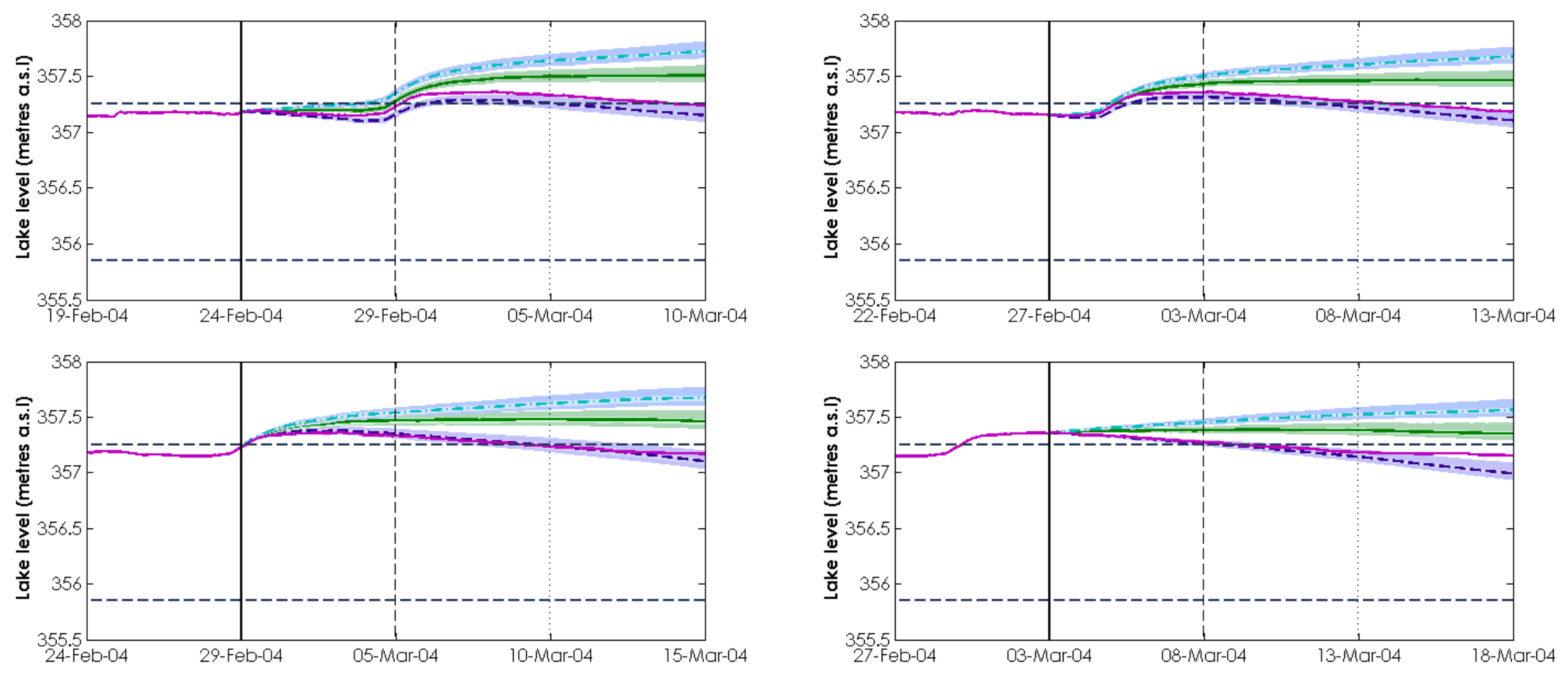

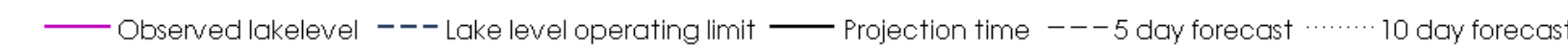

--- Projected lakelevel-Maximum outflow (Q50)_Q Q10/Q90 TPS range-Maximum outflow _ Q50 TPS range-Maximum outflow

- Projected lakelevel - Mean outflow (Q50) Q10/Q90 TPS range - Mean outflow Q Q50 TPS range - Mean outflow

-.-.-Projected lakelevel - Minimum outflow (Q50)_Q10/Q90 TPS range - Minimum outflow — Q50 TPS range - Minimum outflow

Figure 9.57 Predicted lake level based on three lake outflow scenarios for the February 2004 flood event.

292 | Predicting changes in lake level 


\subsubsection{September $\mathbf{2 0 1 0}$}

September 2010 was characterised by wet and windy conditions for the Waikato catchment and, more generally, extremely low pressure over New Zealand (NIWA, 2010b). This is a period of considerably unsettled weather following an extended period of drought in the first half of the same year. Lake levels had been considerably low for the first half of the year and steadily increased from August. Frequent low pressure systems tracked across the country early in September (Figure 9.59 a-d). A deep low which developed in the Southern Ocean pushed a succession of fronts up the country in mid-September (Figure 9.59 e-f). The result was frequent rainfall (Figure 9.58) which fell on an increasingly saturated catchment. During this period Turangi experienced its highest September rainfall on record (NIWA, 2010b). Lake level exceeded the MCL of $357.25 \mathrm{~m}$ a.s.l on 14 September (Figure 9.60). A maximum level of $357.37 \mathrm{~m}$ a.s.l was reached on 23 September 2010. Another significant event on 1 October kept lake levels high through to 8 October 2010. The analysis undertaken for this flood event covers the period over which the MCL was exceeded.

The model simulates the rise and fall of the lake well, with observed lake level at the higher end of the projected range (Figure 9.63). Up until 14 September, when the MCL was reached, the model is slightly under-estimating lake level. Discharge from

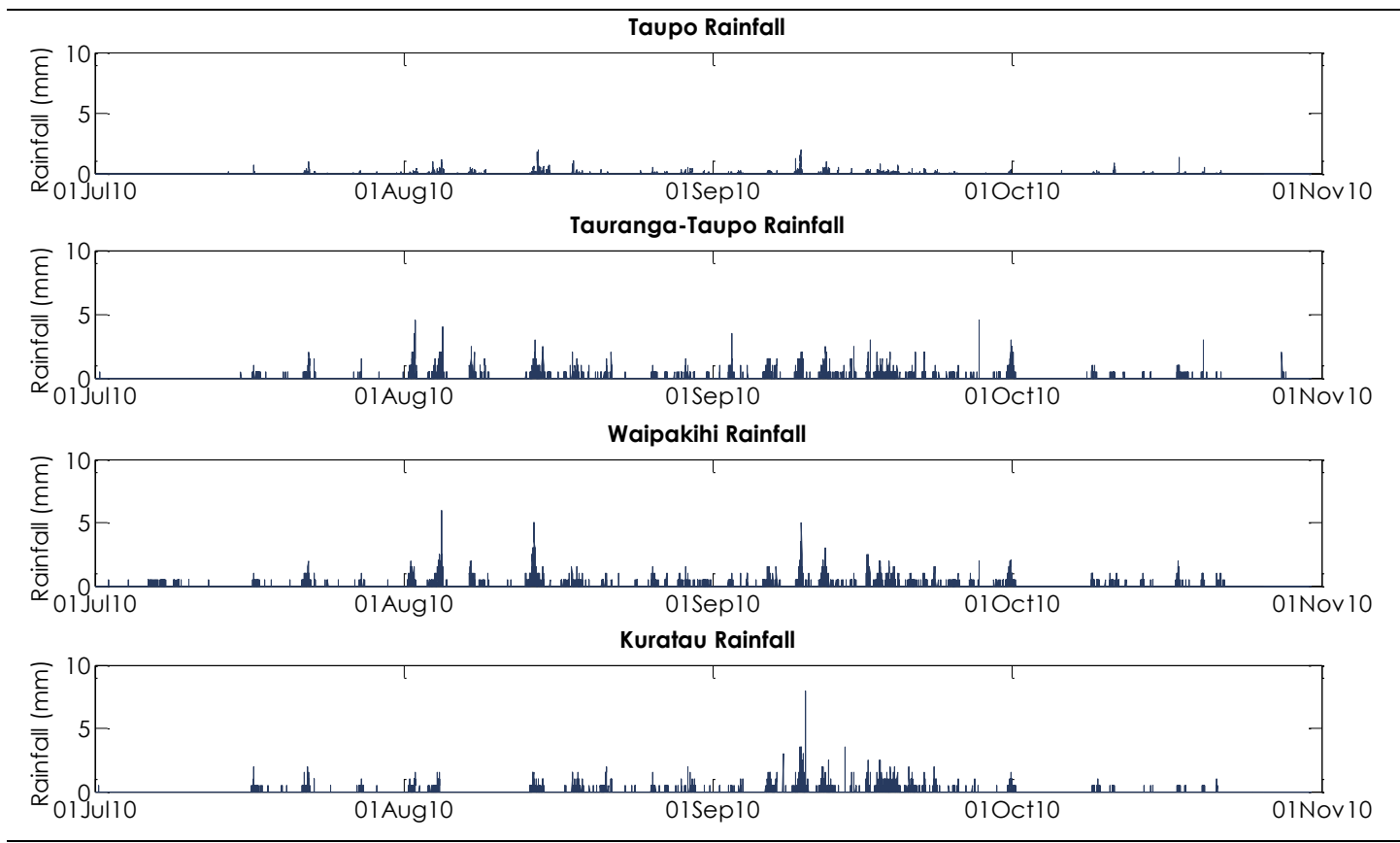

Figure 9.58 Observed rainfall for a selection of gauges in the Lake Taupo catchment: July- November 2010. Units are $\mathrm{mm} / 15$ minutes. 
(a) 12:00 am 2 Sep 2010 (UTC)

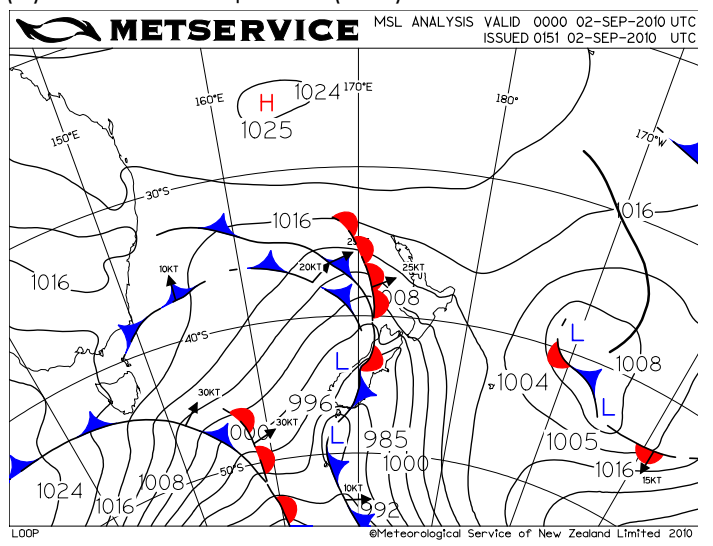

(c) 12:00 pm $11 \mathrm{Sep} 2010$ (UTC)

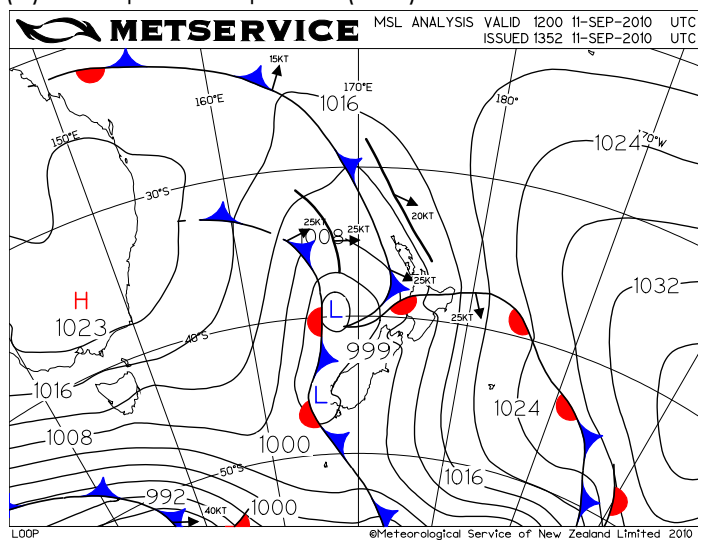

(e) 6:00 am 17 Sep 2010 (UTC)

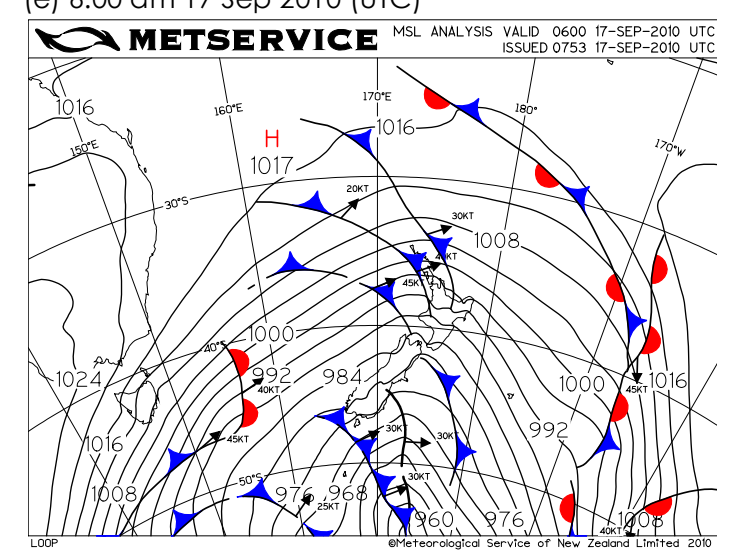

(b) 12:00 pm 6 Sep 2010 (UTC)

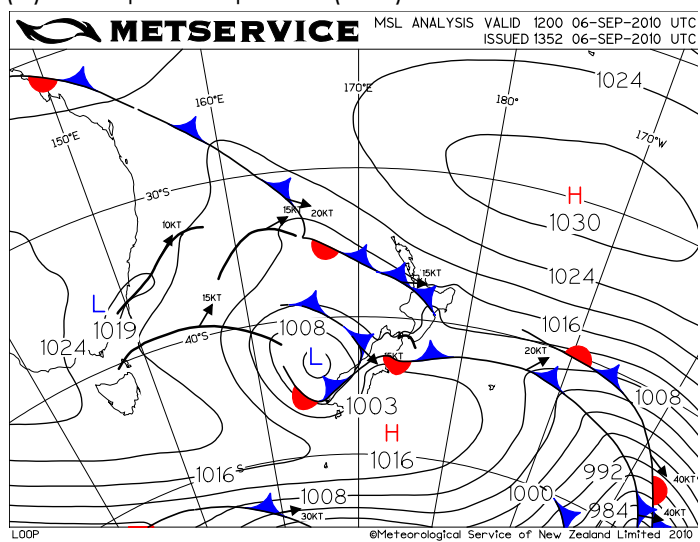

(d) 6:00 am 14 Sep 2010 (UTC)

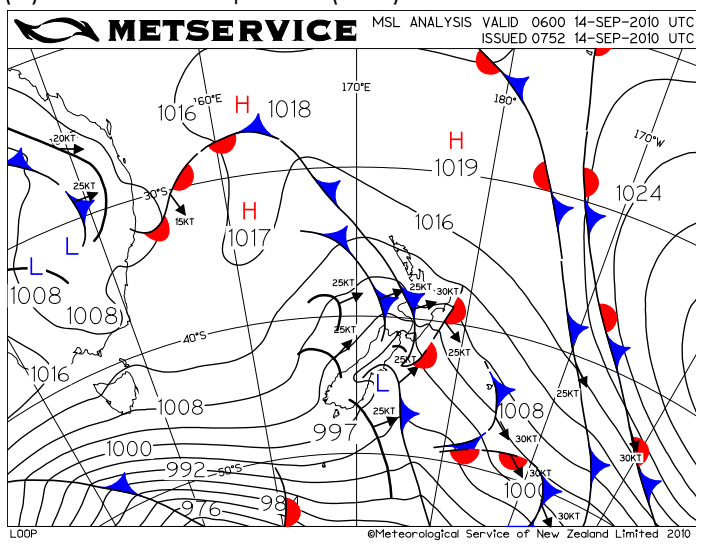

(f) 6:00 am 18 Sep 2010 (UTC)

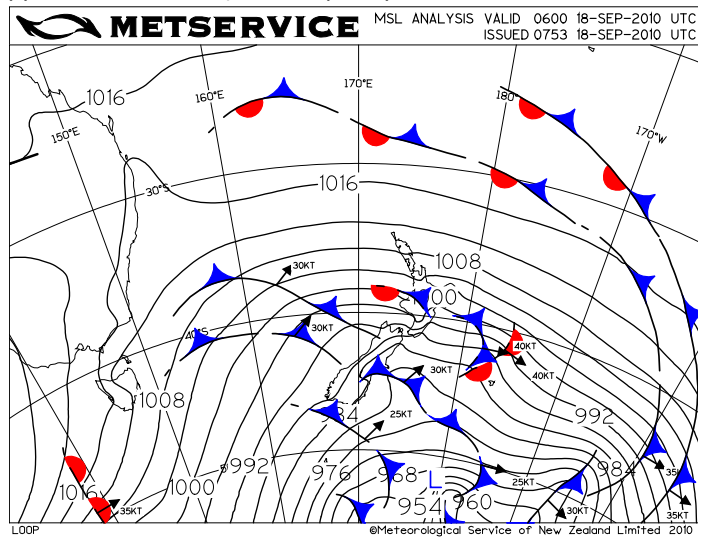

Figure 9.59 A selection of MetService synoptic weather maps for the September 2010 flood event. 


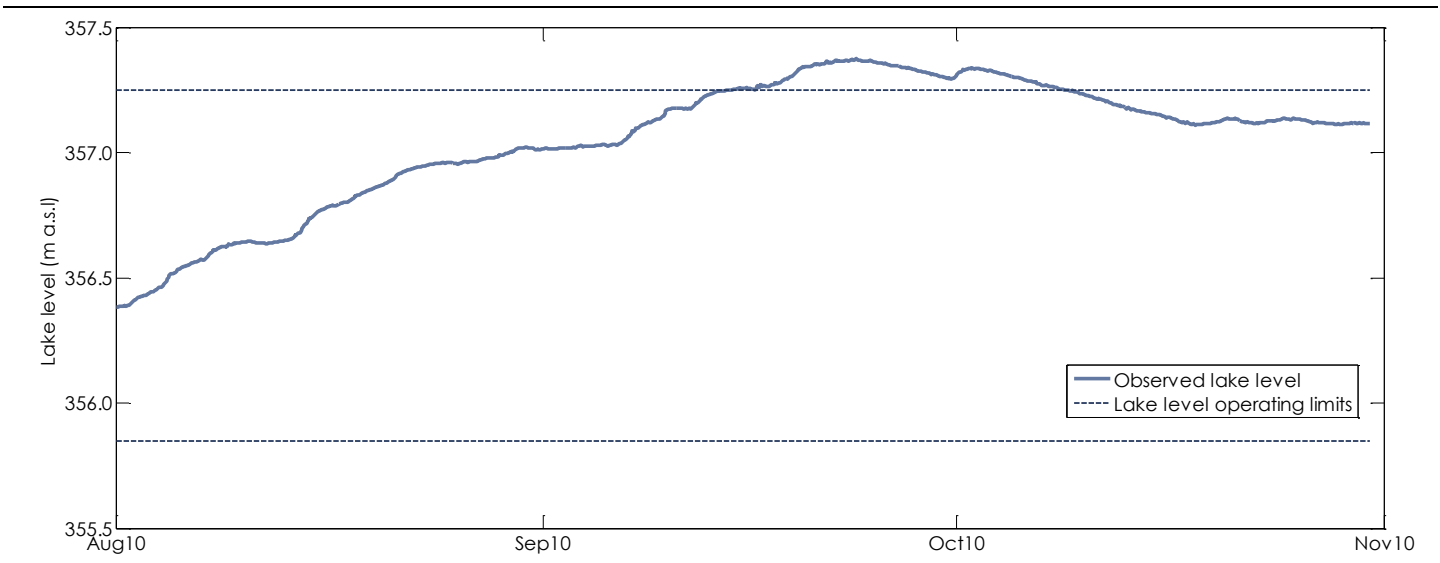

Figure 9.60 Observed (filtered) lake level: August - October 2010.

the TPS up to this time was high and often exceeded the projected range of inflow (Figure 9.62). Known in advance, this information can be incorporated into the model operationally for improved model performance. This is demonstrated in (Figure 9.64) when the observed TPS discharge is used, resulting in a close approximation to lake levels until 19 September.

The divergence between modelled and observed lake level on 19 September is a result of a significant under-prediction of a peak flood event in the gauged catchments (Figure 9.65). Most sub-catchments under-predict this event, but the under-estimation in the Tongariro catchment is significant - almost $200 \mathrm{~m}^{3} / \mathrm{s}$ (Figure 9.61). From the time series of TPS discharge it would appear that diversions at this time ceased, so it is unlikely that this error is from a substantial release of water from the Moawhango dam which the model could not simulate (Figure 9.62). This frontal event arrived from the south and observations across the region indicate that rainfall was heaviest and most persistent in the southern part of the catchment. It is probable that catchment rainfall for this event is not adequately represented.

In addition, while the ungauged area of the catchment estimated by the TaurangaTaupo parameters show no overall bias, the areas predicted by the Kuratau parameters tend to be under-estimated (Figure 9.66). These combined issues would affect the accuracy of lake level predictions around the time of this event and would keep lake level forecasts lower until observations are assimilated and/or when modelled lake level exceeds the tolerance limit and is adjusted accordingly (refer Section 6.6). 


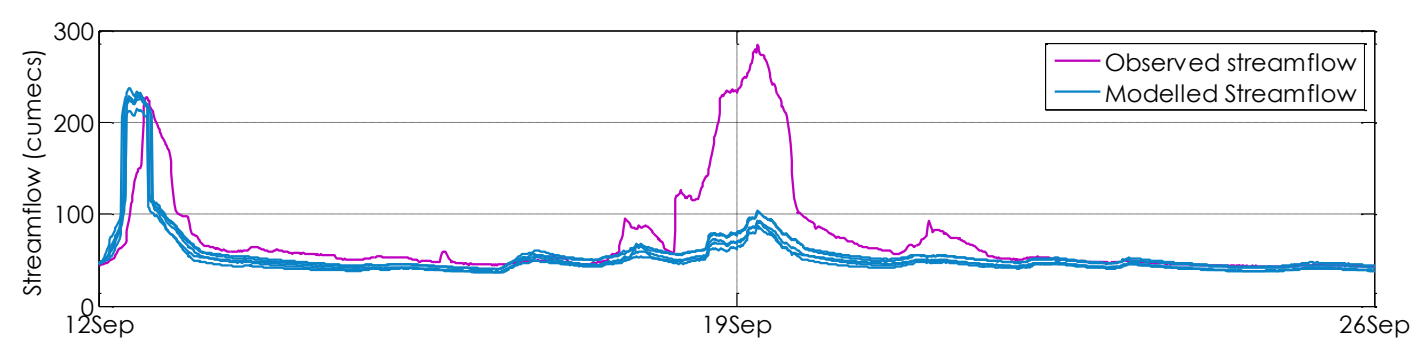

Figure 9.61 Observed versus model output for the Tongariro catchment September 2010.

Operationally, the model indicates that the maximum consented level would be exceeded during this event. Average outflow from the lake from 7 September keeps lake level below the operating margin until 12 September when the maximum rate of outflow is required to reduce lake level. Given that the outflow from the TPS is generally high during this event and that outflow from the lake was also at its maximum level, the model is providing reliable scenarios for robust decision making. This is particularly important for downstream flood mitigation.

For this considerably wet period, the model is doing a good job of producing reliable estimates of lake level for the majority of the period. The under-prediction of lake level around 19 September emphasises the need for better driving data but also further supports the use of data assimilation in predictive modelling to correct for these errors.

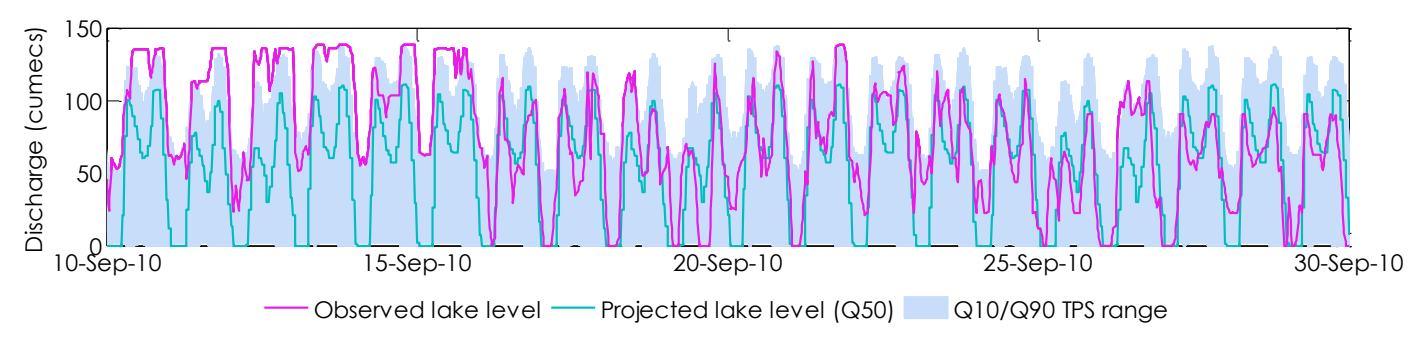

Figure 9.62 Comparison of observed discharge from the TPS against the results of statistical probability analysis for September 2010. 


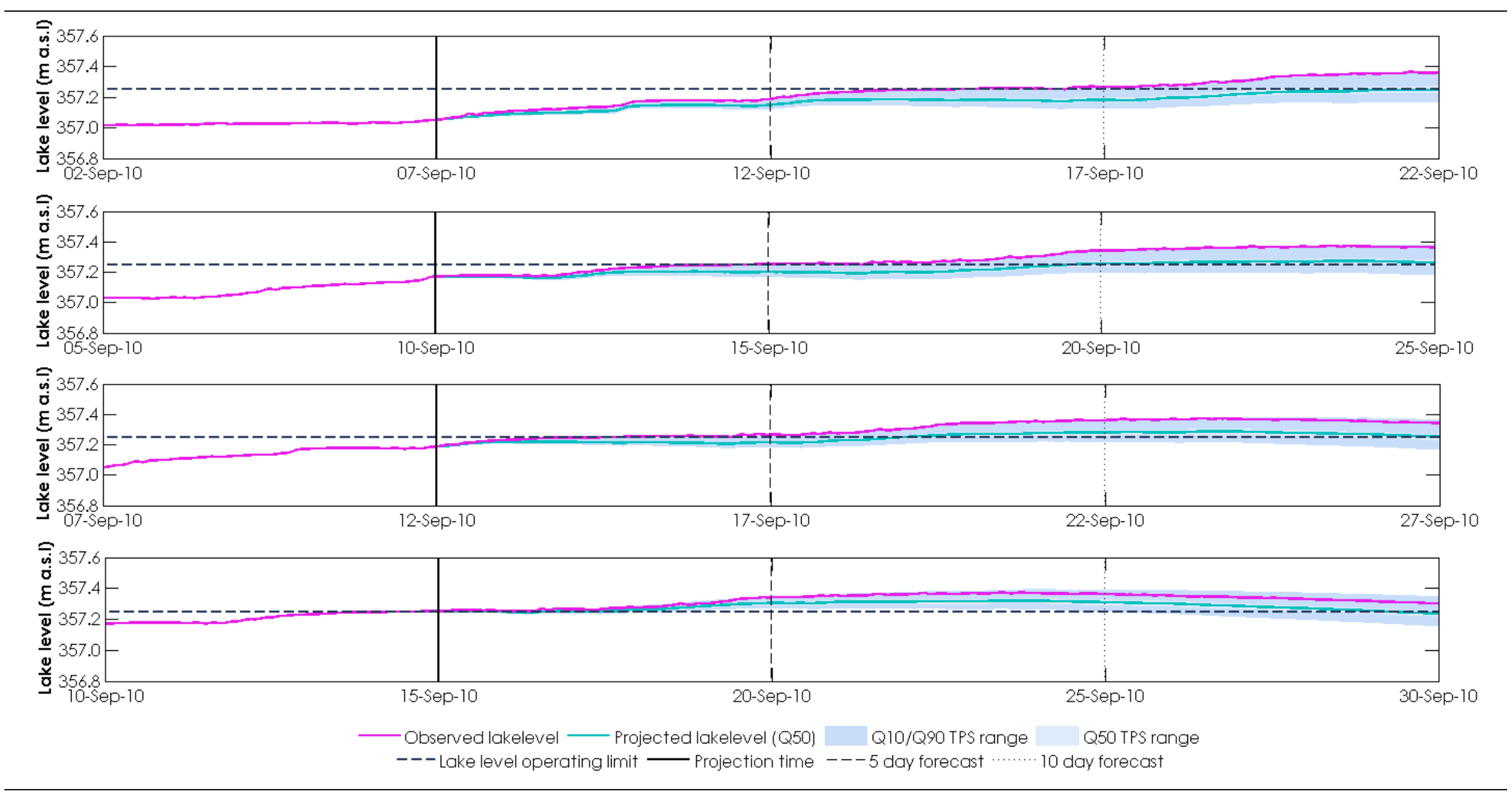

Figure 9.63 September 2010 flood event: modelled output from four forecast times over the period when lake level exceeded the MCL .

297 | Predicting changes in lake level 


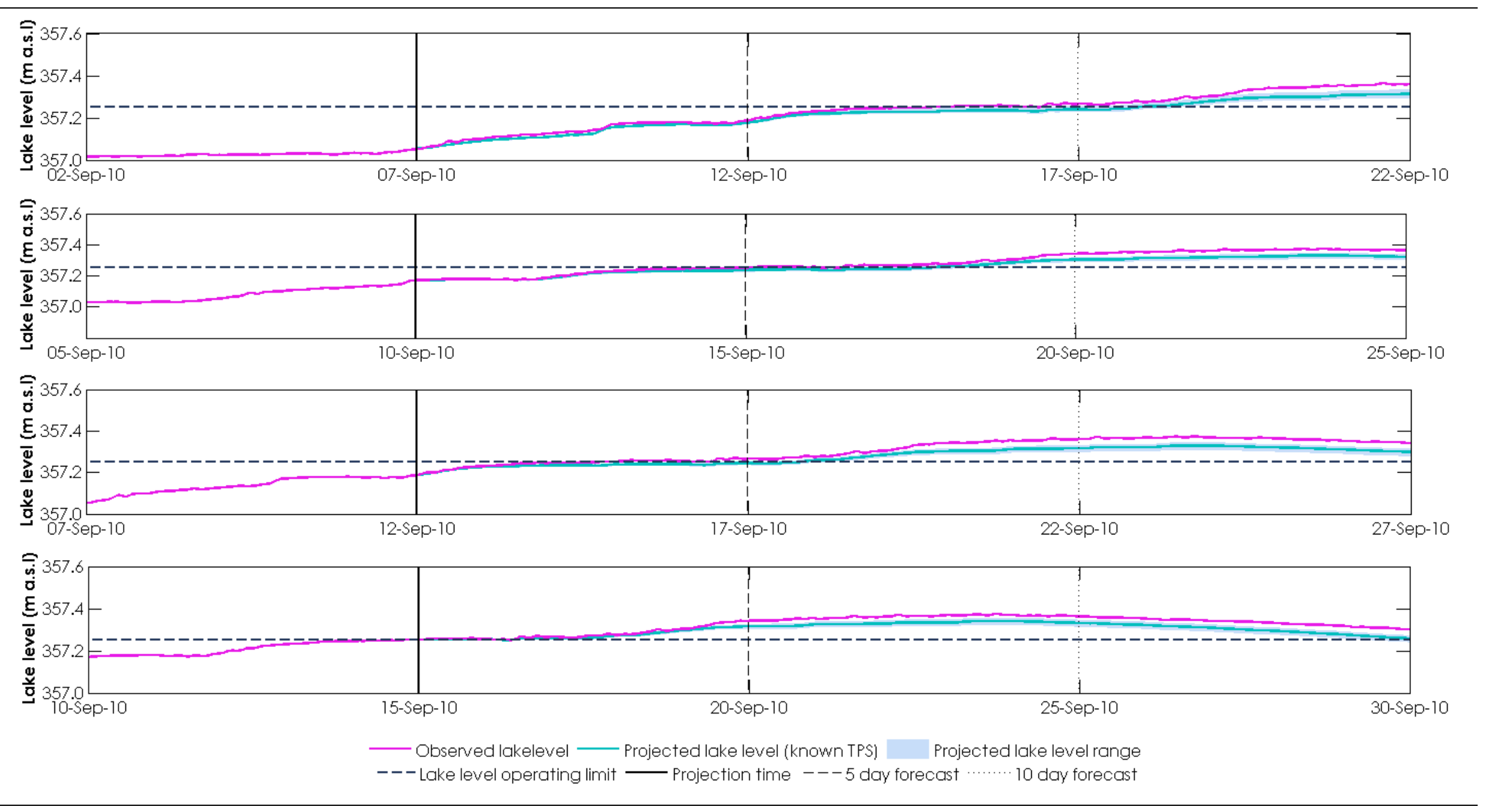

Figure 9.64 September 2010 flood event: modelled output when uncertainty associated with TPS is removed.

$\mathbf{2 9 8} \mid$ Predicting changes in lake level 

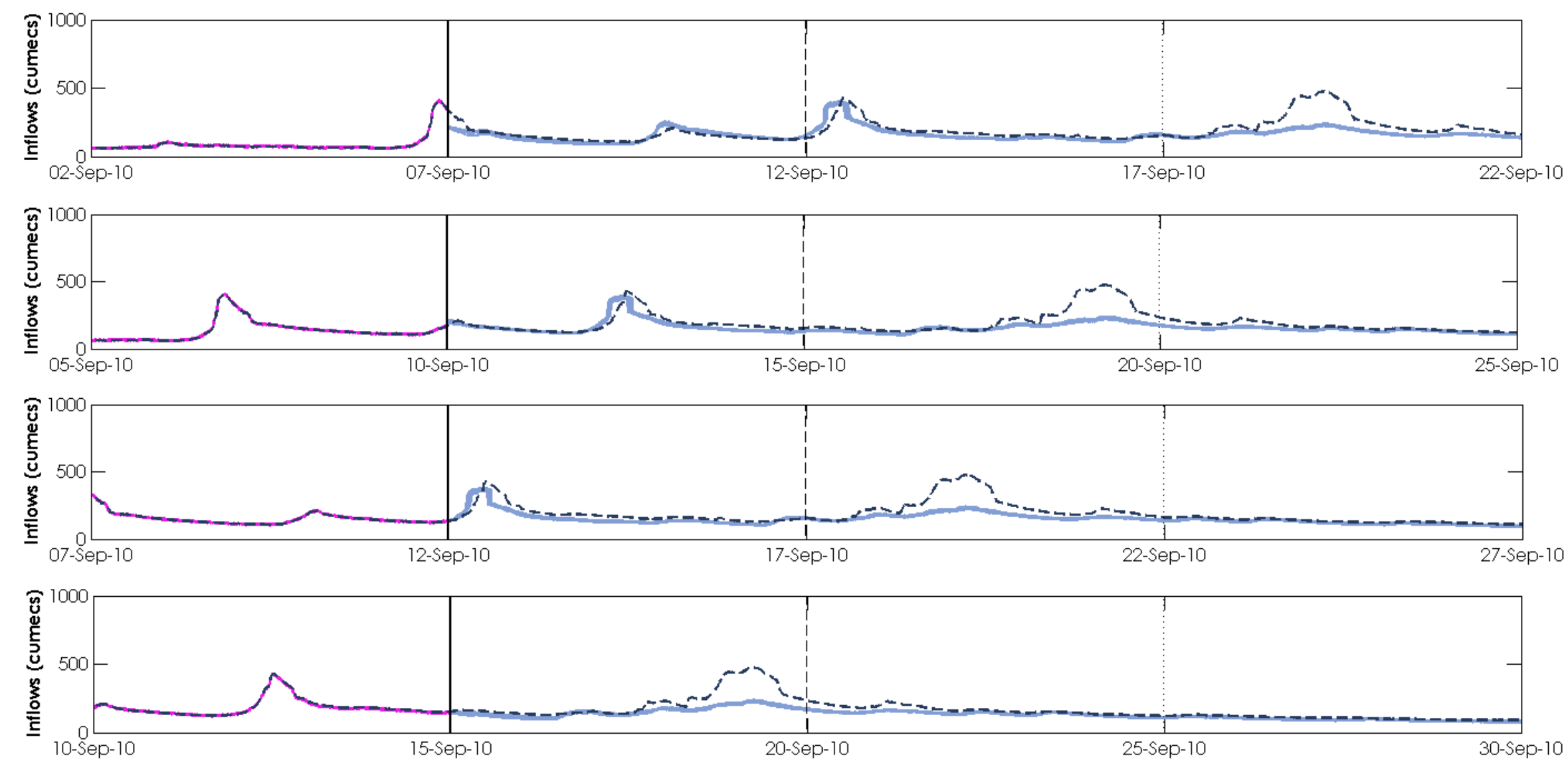

--- Observed inflows —— Modelled inflows _- Projected inflows

Figure 9.65 September 2010 flood event: Modelled versus observed streamflow for combined inflows from the five currently gauged catchments. Note; the jump in streamflow between the hindcast and forecast observed on 7 September is a result of streamflow prediction in the Tongariro catchment. This issue is discussed in Section 8.4.3.

299 | Predicting changes in lake level 

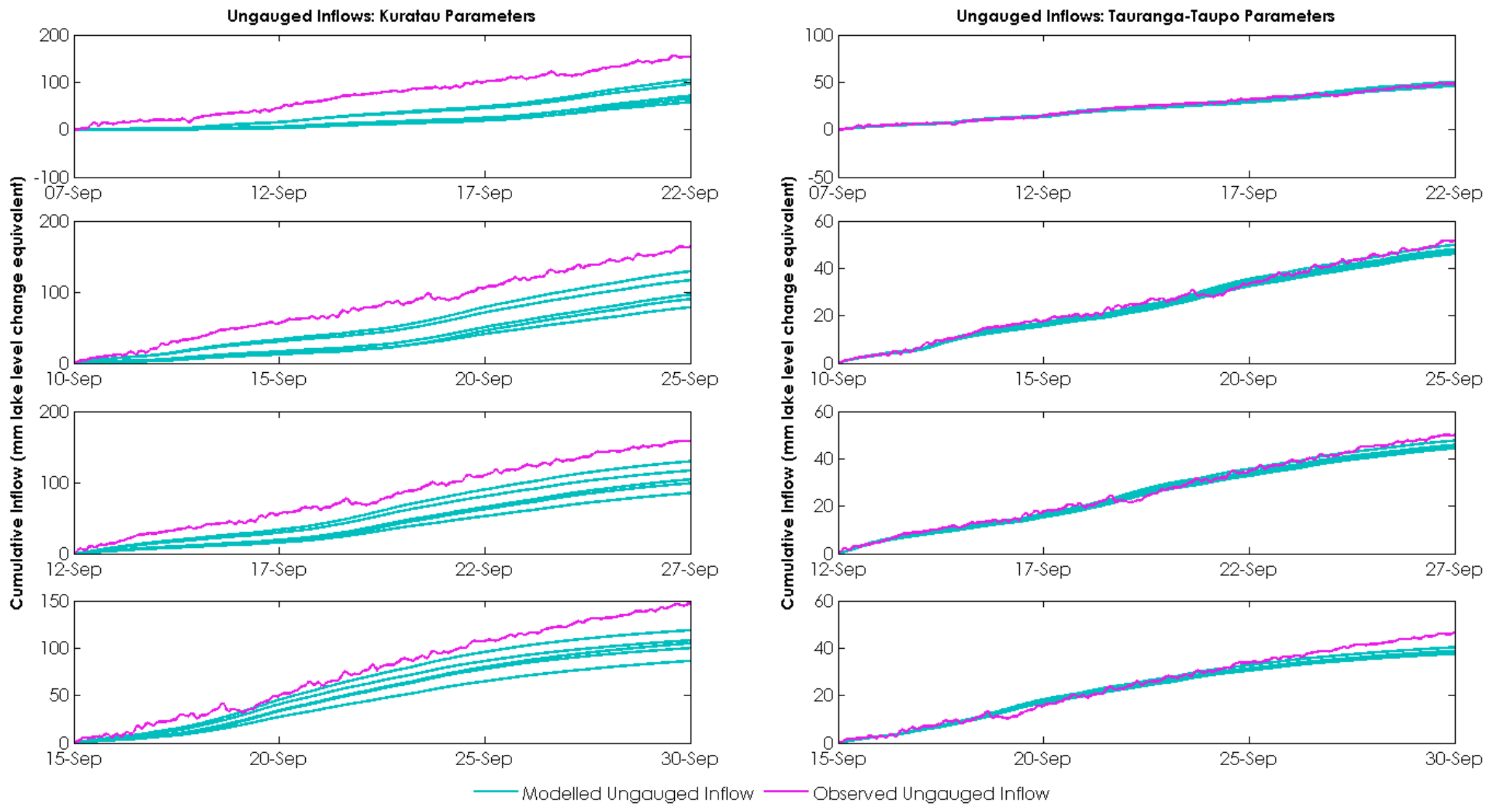

Figure 9.66 September 2010 flood event: Modelled versus observed cumulative inflows from ungauged areas. Units are mm/15 minutes.

30o $\mid$ Predicting changes in lake level 

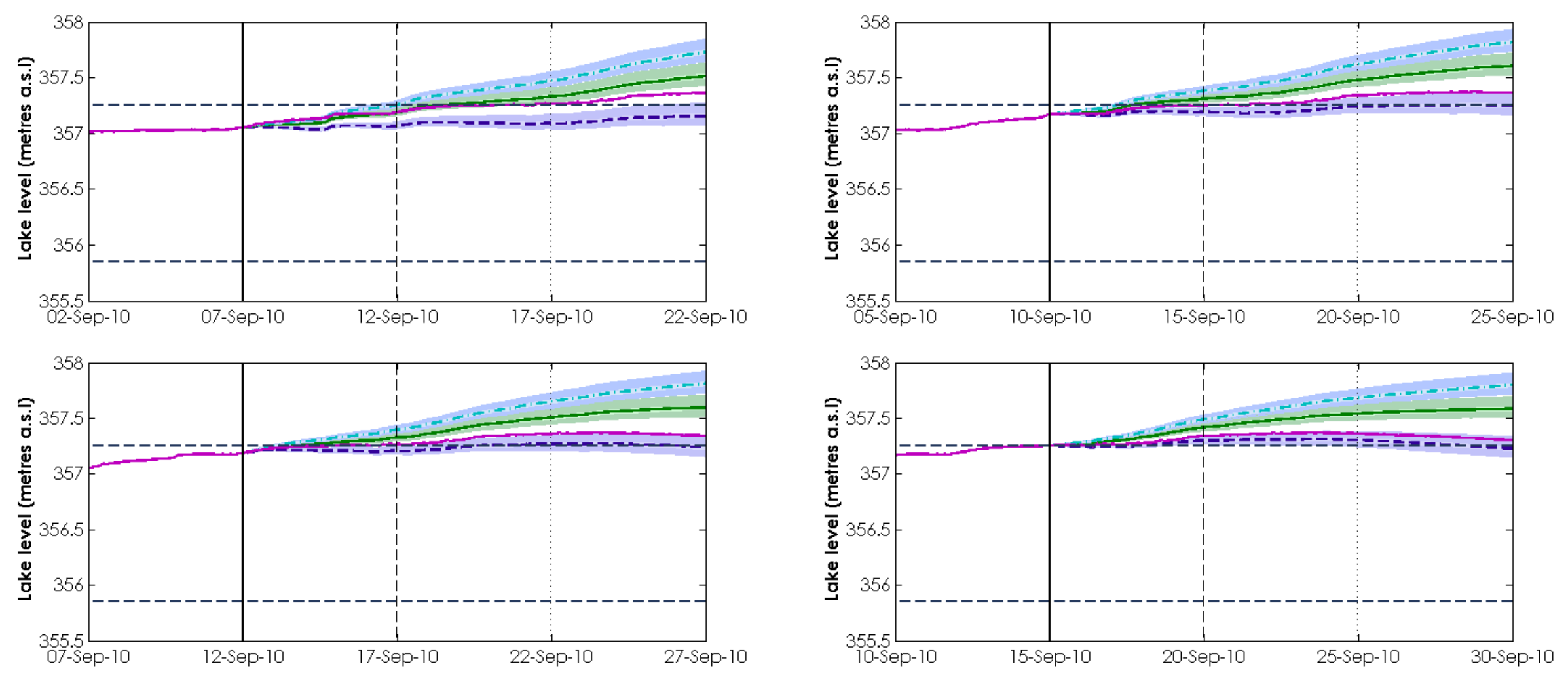

- Observed lakelevel --- Lake level operating limit —- Projection time - - 5 day forecast $+\cdots . . . . . .10$ day forecast

--- Projected lakelevel-Maximum outflow (Q50) Q10/Q90 TPS range-Maximum outflow Q50 TPS range-Maximum outflow

_- Projected lakelevel - Mean outflow (Q50)__Q10/Q90 TPS range - Mean outflow _ Q50 TPS range - Mean outflow

-.-. Projected lakelevel-Minimum outflow (Q50)_Q10/Q90 TPS range-Minimum outflow Q50 TPS range-Minimum outflow

Figure 9.67 Predicted lake level based on three lake outflow scenarios for the July 1998 flood event.

301 | Predicting changes in lake level 


\subsection{Discussion and Conclusions}

This chapter presents the results of the Lake Taupo Inflow Model, as applied to eight events between 1998 and 2010. While the performance of the LTIM is evaluated over a wide range of hydrological and meteorological conditions, these eight events have been selected $a$ priori for in-depth critical evaluation as representation of both extreme and 'usual' conditions. The events selected provide a range of hydrological and meteorological conditions experienced in the catchment.

In most cases, the model does a good job of simulating the rise and fall of lake level, given the data and information available. Observed lake level generally falls within the range projected by the model for the majority of the 15-day forecast periods, with most accurate and reliable estimates out to five days. Parametric uncertainty is relatively small across all events, compared to the uncertainty associated with the TPS. In all cases, with more information about the operation of the scheme, model performance would be substantially improved to give more precise lake level predictions. In the absence of such information, uncertainty would be reduced by incorporating auto-correlation into the analysis and by including some relationships to external factors such as price controls and air temperature (this is discussed in further in Chapter 7).

Model performance is most reliable during the three dry/drought periods and two 'normal' operating periods analysed. Event simulations of gauged catchments show that the model does a good job of simulating recessions and low flows in all events. During very dry conditions, minimum observed lake level is slightly over-estimated by the model. It is thought that errors in determining the direct groundwater input to the lake may be partially responsible for this. In this study, groundwater seepage is not explicitly modelled; it is assumed temporally constant at a rate of $30 \mathrm{~m}^{3} / \mathrm{s}$. Reducing this rate of inflow is shown to effect a closer approximation to lake level during dry events, indicating that the current assumption of a constant inflow is not representative. Explicitly including groundwater seepage as an additional store in the current model structure would allow this source of inflow to be better characterised. Although there have been a few attempts to estimate the groundwater seepage to the lake, these have been localised studies over small areas and over short time frames (Gibbs et al., 2005) or modelled at larger scales based on steadystate or annual water balance approaches (Bou, 2007; Murphy, 2006; Piper, 2004). More detailed information would need to be collected in order to ascertain suitable 
parameter ranges or identify characteristics of this inflow source for inclusion in the model.

In all three flood events, lake level recession is simulated well. Peak inflow events are under-estimated from gauged areas, probably from inaccurate estimates of catchment areal rainfall and possibly from errors in the model structure. Fortunately, the assimilation of observations reduces these short term biases. However, these errors can accumulate in the model predictions for ungauged areas and direct lake inputs.

During large rainfall events, the model is predicting inflow from ungauged areas, corresponding to the estimated rainfall depths. However, this does not correspond to the derived inflow time series which often shows a negative inflow trend. This time series is derived from known inputs and output from the lake and fluctuations in lake level. During these flood events, inputs sometimes exceed the corresponding volume change in the lake resulting in negative inflows from ungauged catchments to close the water balance.

A potential source of error is related to the timing of arrival of water from gauged catchments. Streamflow is often observed at locations several kilometres upstream from the lake. A lag effect between the streamflow observed at the gauging sites and its arrival at the lake may partially account for some of this error. A kinematic wave model, similar to that proposed for the Tongariro catchment (discussed in Section 7.2.2) would be appropriate. It would allow the flood wave to be propagated downstream given slope and channel characteristics and would be able to simulate any change in form/amplitude as it moves toward the lake. Other sources of error include the estimation of direct lake rainfall, the interpretation of river stage data and barometric effects on lake level, where the water surface responds to atmospheric pressure perturbations. As the pressure gradient passes over the area, lake level is often tilted so that under the area of higher pressure lake level is lower (Thompson and Ibbitt, 1978). In larger lakes like Lake Taupo, this could have a measureable effect (James et al., 2002). However, this effect may be difficult to discern given available data.

While this issue is evident in all three flood events simulated, it is most severe in the (9-10) July 1998 event. The reasons for this are unclear but may be due to a combination of effects described above (i.e., inflow timing, barometric data). Compared to the other flood events analysed, rainfall and streamflow during the 
July 1998 event is generally greater and persisted over a longer period of time. Streamflow observations may be over-estimating inflows at this time, an artefact of interpretation of stage height data during high flow conditions.

There is scope for improvement in the estimation of inflows from the ungauged areas of the north and west of the catchment. The Kuratau parameters are applied to this large area $\left(1003 \mathrm{~km}^{2}\right)$, which extends from south of the Kuratau catchment clockwise around to the Waitahanui catchment in the north-east. Although deemed the most appropriate parameter set to be applied to this vast area based on physically attributes, there are considerable differences between the modelled and derived time series, especially during flood events. There are several ways in which this uncertainty could be reduced. At present, the Kuratau parameters are applied with only the rainfall multiplier and catchment lag time calibrated. Dividing this large area into smaller sub-areas and adjusting these parameters based on the physical relationships found may reduce some of the error. Alternatively, there are a number of other historically gauged catchments which may be more representative of some of these smaller sub-areas, particularly in the north. Secondly, if more of the Lake Taupo catchment was gauged, more sub-catchments could be explicitly modelled and the constrained EnKF applied. This would reduce the area left ungauged and, hence, the uncertainty from this input.

In most events, the ungauged areas of the south appear to be well characterised by the Tauranga-Taupo parameters. This is a much smaller area $\left(284 \mathrm{~km}^{2}\right)$ covering a more localised portion of the catchment. There is often very little difference between the cumulative distributions of the 'observation' and modelled output for this area. In addition, the rainfall multiplier is more realistic, given that the gauges used to estimate rainfall in this area are generally located at higher elevations than most of the area it is being used to represent.

In summary, given the uncertainties associated with the TPS, the model does a good job of predicting lake level in most cases. Model output is most reliable during low flows and recessions as the model structure appears to represent these periods well. Flood flows tend to be under-estimated, reducing the reliability of forward predictions over these events. However, as observations arrive and are assimilated, states are adjusted to better reflect catchment antecedent conditions.

The predictive capability of the model is dependent on the accuracy and reliability of data used to drive the model and calculate respective inflows. Data assimilation can 
address some of the errors, reducing short-term bias for those catchments to which it is applied. Significant improvements would be achieved with more reliable driving data for the estimation of catchment areal volumes and better characterisation of inflows from ungauged areas. However, with knowledge of these shortcomings, and the strategies to account for them, the model significantly improves our ability to reliably assess lake level for decision-making purposes. 
306 | Predicting changes in lake level 


\section{Conclusions}

Lake Taupo is a highly regulated lake, located in the central North Island, New Zealand. It is managed between a $1.4 \mathrm{~m}$ operating range $\left(<1 \%, 0.855 \mathrm{~km}^{3}\right.$, of its volume) to reflect natural lake level fluctuations. The amount and timing of inflows to the lake effectively determine the amount of water available to generation. Three competing power companies control $60 \%$ of the inflows to the lake, while Mighty River Power Ltd manages lake level and outflow. Water is also received from areas outside of the natural Lake Taupo catchment, diverted as part of the Tongariro Power Scheme (TPS). A large portion of the catchment is also currently ungauged.

This dissertation sets out to develop a rainfall-runoff model to forecast inflows to, and lake level of, Lake Taupo. There are three principal aims:

- Investigate the physical processes controlling the movement of water through the Lake Taupo catchment by undertaking a hydrological assessment of catchment physiographic, climatic and hydrologic characteristics;

- Predict the inflows to Lake Taupo and consequently changes in lake level by developing a rainfall-runoff model that accounts for the data available and modifications to river flows given the extensive hydro power development in the catchment; and 
- Quantify the improvement in accuracy and reliability of model output through the use of data assimilation.

To achieve the first aim, a range of physiographic attributes are related to various hydrologic descriptors for each sub-catchment. Results from the model sensitivity analysis and calibration are also used to provide a general assessment of catchment hydrologic behaviour.

For the second aim, outcomes from the assessment above are used to build a perceptual model of the Lake Taupo catchment and to provide guidance on initial parameter ranges. The Lake Taupo Inflow Model (LTIM) developed is a semidistributed physically consistent conceptual model with soil moisture accounting and three linear stores. Drainage to these stores is related to the size of the saturation zone, reflecting the concept of a variable source area. The model incorporates some of the regulation of three catchments given the limited information and data available. Classic Monte Carlo sampling is used to identify optimal parameter sets from suitably chosen pre-defined parameter ranges. The Kling-Gupta Efficiency Index is used to measure performance. Regionalised parameters are used to model the inflow from ungauged areas. Inflow from the highly complex regulated Tongariro Power Scheme is estimated using a statistical probability analysis based on the time of day, day of the week and time of year.

While the model simulates the inflows from the various sub-catchments reasonably well, the simplified model structure, estimated parameters and imperfect driving data result in error accumulating, particularly when catchments are partially saturated, affecting predictive accuracy and reliability. To overcome this, the final aim of the thesis is to apply a constrained Ensemble Kalman Filter (EnKF) to explicitly account for model structure and data errors. Used in conjunction with the Monte Carlo simulations for parameter estimation, all three sources of uncertainty are addressed. The filter is constrained to ensure that updates to states are physically realistic. Although there is substantial scope for further development, particularly in relation to the constraints used and application to regulated inflows, the results show that the accuracy and reliability of model predictions are greatly improved when the constraints are applied.

This chapter presents the conclusions on the main findings of this work. Section 10.1 notes the specific contributions made to the stakeholders of the Lake Taupo catchment and more generally to the field of reservoir inflow modelling. Section 
10.2.1 comments on the quality of the data set used and notes implications for robust model calibration and predictive accuracy. Section 10.2.2 discusses the major controls on the movement of water through the Lake Taupo catchment obtained from correlation analysis and model calibration/sensitivity analysis steps. Section 10.2.3 considers the role of the constrained EnKF in improving predictive accuracy of the Lake Taupo Inflow Model, while Section 10.2.4 discusses the overall performance of the model in terms of predicting the lake level of Lake Taupo. Recommendations for future work are listed in Section 10.3. A final summary is given in Section 10.4.

\subsection{Main Contributions}

This dissertation has made a number of original contributions to the stakeholders and decision makers in the Taupo region, and more generally to the problem of reservoir inflow forecasting. These are:

- Robust analysis of the quality and reliability of data obtained for the Lake Taupo catchment: A model is only as good as the data used to drive it. In this study, the data is subject to rigorous analysis in order to identify inconsistencies and errors so that suitable data sets and data periods for model calibration and evaluation can be selected. This analysis provides valuable information for others intending to work and use similar data in the Lake Taupo catchment.

- Development of a predictive rainfall-runoff model for the highly regulated Lake Taupo catchment: Previously, inflows to Lake Taupo have not been modelled in any detail. The LTIM developed in this dissertation is the first to effectively and efficiently quantify sub-catchment contributions to total inflow and lake level change. This model has potential value for a variety of organisations in the Waikato region and, more generally, New Zealand.

- General guidance on how to incorporate regulation into traditional model structures: Sixty percent of the inflows to Lake Taupo are from regulated catchments. This research provides general guidance as to how some of this regulation can be incorporated into traditional model structures using available information and data relating to scheme operation, resource consent conditions and other physical and legislative constraints. These outcomes have potential value for other regulated catchments in New Zealand and overseas. 
- Demonstration of how physically-consistent state-updating via a constrained EnKF can improve model performance for robust decision making: Data assimilation via state-updating is increasingly recognised as an essential part of any hydrological forecasting application (Liu et al., 2012, in review). Data assimilation via state updating has received considerable attention in recent years, but there are few examples where it has been applied in a highly regulated catchment like Lake Taupo. Further, most studies ignore the challenge of physically consistent state-updating. Only one study in the hydrological literature provides any detail on constraint methods for state-updating. To the best of the author's knowledge, constraints have not been applied in an operational context. In this study, it is demonstrated that by constraining the filter to be consistent with physical laws, the reliability of forward predictions is improved allowing more robust decision making.

\subsection{Main Conclusions}

\subsubsection{Dataset implications}

Streamflow, rainfall and other data obtained for this study are assessed for quality, reliability and applicability for model calibration, data assimilation and use in the LTIM. While many records are of decent quality, well-commented and have gaps adequately noted, a number of inconsistencies in observations (for example, rapid rises in streamflow with no associated rainfall, hydrologically inconsistent patterns) were identified that prevented some periods of data or, in some cases, whole records from being used. In addition, many of the records obtained are of short duration (less than five years), and contain many gaps. In some catchments, these issues significantly limit the amount of data available for calibration/evaluation purposes and undermine the reliability of parameter sets obtained. In these instances, extrapolation beyond the calibration period may not be appropriate and may yield unsatisfactory performance results.

One of the major challenges in the Lake Taupo catchment, as in many others, is the estimation of catchment rainfall. The catchment is sparsely populated with rainfall gauges, and few are at elevation. In most cases there is only one rain gauge within or near the catchment being modelled. In other cases a rainfall gauge located several kilometres away is the nearest available gauge. Hence, in this study, observations 
from a single gauge located in or near the catchment are used to represent catchment volumes.

Observed rainfall is adjusted by a rainfall multiplier (parameterised during model calibration) so that mass balance is achieved. This accounts for the overall bias but not differences in catchment dynamics. Rainfall gauges are selected on their proximity to the area being modelled and representativeness from event based analysis. There are instances where localised rainfall events around the gauge result in over-estimated catchment areal rainfall, while rainfall in higher (ungauged) elevation areas may be missed entirely. Further, the multiplier is constant, which may not be a reasonable assumption. An investigation into the seasonality of this bias through monthly or seasonal mass balance analyses as well as better estimates of catchment areal rainfall and potential evapotranspiration to drive the model would be beneficial.

Lake level is affected by a number of seiches acting on the surface of the lake making it difficult to get an accurate lake level record. Previous studies have smoothed this record over coarse resolution and often required inflows and outflows to be adjusted in order to deliver a smooth lake level record. Because of the high resolution requirements of this study, a Butterworth filter is applied to raw lake level so that high resolution oscillations are removed but the genuine rise and fall of the lake is maintained. Although successful, some longer duration seiche effects are still evident. Removal of these low frequency oscillations is difficult because some of the genuine signal may also be removed. This has implications for the reliability of model calibration of ungauged areas, a time series for which is based on the residual inflow from known inputs, outputs and lake level changes.

\subsubsection{Catchment hydrologic function}

Correlation analysis is undertaken on six physiographic, two climatic and six hydrologic attributes obtained from observations for 14 sub-catchments of Lake Taupo (Chapter 5). The results, along with information obtained from data analysis, previous literature and an understanding of fundamental hydrologic principles, inform the development of the perceptual model of the Lake Taupo catchment, and provide guidance on initial parameter ranges. These results combined with the regional sensitivity analysis undertaken in Chapter 7 provide further information about the most important flow pathways in the Lake Taupo catchment. 
The main findings of the initial correlation analysis (Chapter 5) are consistent with Schouten et al. (1981). Baseflow is the dominant source of streamflow in most catchments influencing the shape of flow duration curves. Although the range of values for the baseflow index is relatively small (0.695 - 0.765), those with more baseflow are generally less variable and have flatter flow duration curves. Steeper catchments underlain with less permeable geology are variable, and generally have less baseflow contributing to streamflow.

Based on the sound understanding of catchment hydrologic function obtained, initial parameter ranges are guided by the information obtained from the correlation analysis, previous research and knowledge of catchment hydrologic processes. The proportion of streamflow draining to the sub-surface store reflects sub-catchment baseflow levels while store residence times varied depending on the underlying geology and overall steepness of the catchment.

The process of model identification (parameter estimation and sensitivity analysis) confirmed that the relative proportions of water entering different pathways (particularly baseflow and fastflow) and associated residence times are very influential in shaping catchment flow regimes. Identification of the most influential parameters for each sub-catchment allowed more attention to be given to these more important parameters in refinement of parameter ranges. It was hoped that modelled sub-catchment parameter values would provide further insight into catchment hydrologic behaviour. However, correlations between physiographic attributes and model parameters were generally weak. Some potentially strong relationships could not be discerned with certainty because of a lack of identifiability (in a univariate sense) for some model parameters of some catchments. Multivariate analysis may be worthwhile extension to this analysis. Although computationally expensive, analyses such as Sobol's global sensitivity method can reveal the individual parameter influence and parameter interactions from the model output (Yang, 2011), providing a more robust analysis of parameter sensitivities and influence on hydrologic response.

Three catchments have been modified for hydro generation. The impact of these schemes on river regimes varies. The Hinemaiaia scheme has limited storage and there is relatively little modification of natural streamflow behaviour with similar flow duration curves for gauging sites above and below the scheme. There is an obvious diurnal fluctuation in the discharge time series for the Kuratau scheme which coincides with the release of water which has been held back for generation at 
peak times. The TPS is the largest and most complex of the three hydro schemes in the Lake Taupo catchment. Its impact on the flow regime on the Tongariro River is significant. Streamflow between $16 \mathrm{~m}^{3} / \mathrm{s}$ and $160 \mathrm{~m}^{3} / \mathrm{s}$ is most affected as up to 80 $\mathrm{m}^{3} / \mathrm{s}$ can be diverted through the Poutu Intake. A comparison between hydrologic characteristics before and after the development of the TPS reveals that baseflow contribution remains largely unchanged, but flow variability is substantially reduced.

\subsubsection{Constrained Ensemble Kalman Filter}

A constrained EnKF is applied to the model output of the gauged catchments in the LTIM. Chapter 8 describes how observations of streamflow are used to update soil storage, fastflow, interflow and baseflow states to improve the accuracy and reliability of streamflow predictions.

States are updated to account for errors in driving data (as well as the model structure and estimated parameters). Simple mass and flux constraints are applied to encourage physically consistent state-updating. Without these constraints, it is demonstrated that states can be perturbed beyond what is physically possible, in turn, affecting the reliability of subsequent model predictions. To the author's knowledge, this has not been demonstrated in any previous literature.

The constrained filter performs well in the unregulated sub-catchments of Lake Taupo. States are kept within physically consistent levels, improving the reliability of model predictions. Streamflow assimilation in regulated catchments is less appropriate since streamflow response is due not only to changes in states but also to the regulation imposed on streamflow. With further investigation it may be possible to identify particular times when the streamflow change is likely to be due to the regulation rather than to a change in catchment conditions. Further information on the operation of the scheme could allow the associated regulation to be included in the assimilation framework. The assimilation of direct state observations (where available) would also allow the natural rise and fall of river levels to remain, ignoring the short term small scale diurnal effect of the regulation. Assimilation of streamflow could still be permitted during periods when regulation does not occur, for example during extreme low flow or flood flow events. These observations could also be useful in unregulated catchments to further constrain updates to model states. The most obvious way forward is to use groundwater level to infer changes in the baseflow state. This requires a groundwater level monitoring 
site(s) in or near the catchment being modelled. Groundwater level monitoring sites are extensive in the western and northern areas of the Lake Taupo catchment but none currently exist in eastern and southern areas where they may be most beneficial to this study.

The filter has the potential to be used, iteratively, as part of the model calibration process. In its application in this study, the filter highlighted inconsistent parameter sets that were subsequently removed and replaced by a more robust parameter set. The time series of state innovations also provided clues as to where parameter ranges could be further refined for improved predictive accuracy. Ensuring state updates are physically realistic is central to the practical application of the filter in this sense. This is an area worthy of further research as it extends the practical use of the filter as part of the calibration process.

\subsubsection{Lake Taupo Inflow Model}

This study has developed a semi-distributed conceptual rainfall-runoff model capable of incorporating some of the regulation associated with some of the inflows to the Lake Taupo catchment. The model is used to predict inflows to the lake and, subsequently, changes in lake level.

The model simulates changes in lake level well given the information and data available. It performs particularly well during low flow and recession periods during drought and 'normal' operating conditions, generally providing robust forward predictions at these times. It is thought that inclusion of an additional store in the model structure to model direct groundwater seepage would improve predictions, especially over very dry periods when inflow from this source is likely to be less than the temporally constant inflow of $30 \mathrm{~m}^{3} / \mathrm{s}$ currently used.

The model also does reasonably well during flood events, although peak flood flows tend to be under-estimated. Simplifications in the model structure and/or inaccurate estimation of catchment areal rainfall are likely causes. Despite best efforts to obtain a representative model structure and accurate parameter estimates, there is often a trade-off between some parts of the hydrograph. Data assimilation can deal with some of these issues for more reliable model output, especially in the near term (out to five days) when it matters most for decision making purposes.

In all large flood events, the model is predicting a substantial inflow from ungauged areas which is not consistent with the derived inflow time series determined from 
the residual of known inputs, outputs and lake level change. It is thought this is partially due to errors in the timing of arrival of inflows to the lake. Allowing for the lag between streamflow observed at the gauge and its subsequent arrival at the lake would allow greater consistency between inflows and lake level response and better representation of the inflows from ungauged areas for improved model calibration. Other sources of error include the estimation of direct lake rainfall, interpretation of river stage data for flood events and barometric effects on lake level, where the water surface responds to atmospheric pressure perturbations.

Using historical rainfall data as predictions, the model generates reasonable forecasts of lake level over most events. The majority of uncertainty is associated with the discharge from the TPS. Reducing this source of uncertainty would provide decision makers with greater confidence in model output. In the absence of direct operational information this uncertainty could be reduced by incorporating the temporal coherence and discharge relationships with external controls into the analysis. The recent extension of the radar network over the Taupo region ought to provide additional opportunities for nowcasting precipitation and assimilation purposes.

Operational use of the LTIM requires forecast rainfall and potential evapotranspiration for the whole Lake Taupo catchment. Global weather models are useful for predicting the overall behaviour of synoptic-scale weather, but do not account for the smaller scale processes which depend on local geography (Henry, 2003). Meso-scale models consider these local effects and can be run with grid resolution as small as $1 \mathrm{~km}$ for determination of local weather conditions (Henry, 2003). MetService runs such a model operationally every six hours over a forecasted period of 72 hours. Although model recalibration would be required, meso-scale model output for each grid point in the region of interest can be used to estimate catchment areal rainfall and potential evapotranspiration for input to the model for the forecast period over which it is valid. As new forecasts arrive the LTIM model would be updated with the new information for more reliable decision making over the coming few days.

\subsection{Recommendations for future research}

The following is a list of recommendations for future research in light of the outcomes from this dissertation. 


\section{Develop a sub-model for estimating direct groundwater seepage to Lake}

Taupo: At present, the direct groundwater contribution is kept at a constant 30 $\mathrm{m}^{3} / \mathrm{s}$ rate estimated from results in various literature. Including a sub-model to estimate the temporal and spatial variability would be of value. It could be incorporated into the conceptual model structure as an additional sub-surface store or directly linked in series to the baseflow store to mimic groundwater dynamics in the catchment.

Investigate the seasonality of model parameters: Of particular importance is the rainfall multiplier which scales observed rainfall for catchment wide estimates. In this study, this model parameter is assumed constant. However, in some catchments there is evidence that this multiplier may vary over the course of the year (refer Section 7.2.2). A comparison of monthly and seasonal mass balances may provide some insight into the temporal variability of this parameter, which could then be included in the model structure.

\section{Incorporate additional information in the statistical probability analysis}

for the TPS: The discharge from the TPS is a considerable input to Lake Taupo but there is little information available specific to its operation. Currently, inflow is estimated for the time of day, day of the week and time of the year but additional information could be included to reduce the uncertainty associated with these inflow predictions further. Aside from information specific to the various diversions, regulations and storage within the catchment, additional external factors may affect operational decisions of the scheme. For example, discharge from the scheme may, to some extent, be influenced by price controls and/or fluctuations in air temperature. An investigation into the relationships between these factors and discharge as well as temporal coherence of the time series and development of an algorithm that includes these in the prediction would be of value.

\section{Identify ways in which filter performance can be improved in regulated}

catchments: Streamflow response in regulated catchments is, in large part, due to the controlled storage and release of water from the scheme rather than necessarily a change in state. A relationship between upstream (unmodified) observations could be used to update modelled states below the scheme through a relationship between streamflow at both sites. This could be relatively easily undertaken in the Hinemaiaia catchment if upstream data was available or if the historic gauging site was reinstalled. In the Tongariro catchment, significant modification to the natural streamflow and diversion of foreign water into the river complicates this approach 
and would possibly require more information about the regulation of the Tongariro River to be included. Alternatively, assimilation of direct state observations through a relationship between groundwater level data and modelled baseflow would be advantageous. Although groundwater levels are extensively monitored in western areas of the catchment, it is not monitored in the east and south, where it would be most beneficial (for this study). To collect this information would require additional groundwater level monitoring sites to be established in the areas of interest.

\section{Optimise state-updating constraints by testing a range of flux and mass} constraints in the model: While the simple constraints applied in this dissertation go some way to ensure reliable state updating, further improvements could be made. Currently, flux constraints are temporally constant. These constraints could be altered to allow them to vary according to the time of the year, antecedent conditions or state volumes. In addition, if updated states were required to provide reasonable predictions of streamflow over multiple observations, states may be more representative of actual conditions and provide more reliable model output.

\section{Use the constrained Ensemble Kalman Filter as part of the model} calibration process: There is considerable scope for using the constrained EnKF as part of the model calibration process. As shown in this dissertation, the filter can be used to check for consistency of model parameter sets, identifying parameter sets which are unreliable, allowing for a more robust parameter set to be selected. Further, time series of state updates (innovations) can be used to identify potential model structure errors. These innovations represent the errors in unfiltered modelled states. Errors in estimated parameters and/or model structure are reflected in the cumulative distribution of these innovations; this information can then be used to refine parameter sets further for improved model performance. The reliability and practical application of the information obtained is dependent on states being updated in a physically consistent manner.

Investigate the use of radar information for input to the model: Radar has the potential to provide estimates of the spatial distribution and intensity of rainfall over the Lake Taupo catchment. The recent extension of the radar network over the region should provide an opportunity for nowcasting precipitation and assimilation purposes. The usefulness of this information is dependent on the accuracy of the conversion between reflectivity data and rainfall rate, as well as the timeliness in 
receiving the data for input to the model. Calibration to the ground network is required.

Finally, and most critically for operational purposes, obtain meteorological forecasts to drive the model, and recalibrate as appropriate: The model developed and applied in this study has shown its potential for application to real-time forecasting for Lake Taupo. The model would require meteorological forecasts out to, at least, a few days ahead to provide the necessary output required for decision making and planning. The model can be run as new updated forecasts arrive. Meso-scale meteorological models can provide small-scale estimates of rainfall and other climatological information at sub-catchment scale. Model recalibration would be required since the existing model is calibrated to historic gauge point rainfall data, which are scaled to catchment estimates.

\subsection{Final Summary}

The Lake Taupo Inflow Model provides reasonable predictions of lake level given uncertainties associated with the TPS, ungauged areas and driving data. The constrained EnKF lessens some of this error as observations are assimilated, reducing short-term bias so that states better reflect antecedent conditions.

In conclusion, this dissertation has successfully developed a predictive model for the highly regulated Lake Taupo catchment. General guidance with regard to the incorporation of regulation in the absence of direct operational information is provided. It is demonstrated that the application of a constrained EnKF improves the accuracy and reliability of model output. Although there is scope for further improvement, the model performs particularly well in dry conditions but also does a good job during rainfall events in light of errors associated with driving data. However, for real-time operational use the integration of the model with meteorological forecasts is required. Model recalibration would be required due to the issue of moving from point estimation to areal rainfall data. Once this is achieved, this operational model would allow robust decision-making and efficient management of the water resource for the Waikato Power Scheme. More generally, there is considerable potential for the constrained EnKF and methods for incorporating regulation to be applied in other catchments in New Zealand and internationally. 


\section{References}

Allen, R., Pereira, L.S., Raes, D., Smith, D., 1998. Crop evapotranspiration: guidelines for computing crop water requirements, in: FAO (Ed.), Irrigation and Drainage Paper 56, Rome, Italy.

Amenu, G.G., Killingtveit, Å., 2001. Real-time inflow forecasting for Gilgel-Gibe reservoir, Ethiopia, in: Honningsvåg, B., Midttømme, G.H. (Eds.), Hydropower in the New Millennium: Proceedings of the 4th International Conference on Hydropower Development. Swets \& Zeitliner B.V., Lisse, The Netherlands, Bergen, Norway.

Arnold, J.G., Allen, P.M., Muttiah, R., Bernhardt, G., 1995. Automated base flow separation and recession analysis techniques. Ground Water 33, 1010-1018.

Aubert, D., Loumagne, C., Oudin, L., 2003. Sequential assimilation of soil moisture and streamflow data in a conceptual rainfall-runoff model. Journal of Hydrology 280, 145-161.

Bandaragoda, C., Tarboton, D.G., Woods, R., 2004. Application of TOPNET in the distributed model intercomparison project. Journal of Hydrology 298, 178-201.

Becker, A., Serban, P., 1990. Hydrological models for water-resources system design and operation, World Meteorological Organization, Operational Hydrology Report No. 34, WMO No. 740.

Bednarek, A.T., 2001. Undamming rivers: A review of the ecological impacts of dam removal. Environmental Management 27, 803-814.

Berger, K.P., Entekhabi, D., 2001. Basin hydrologic response relations to distributed physiographic descriptors and climate. Journal of Hydrology 247, 169-182. 
Bergström, S., 1995. The HBV model, in: Singh, V.P. (Ed.), Computer Models of Watershed Hydrology. Water Resources Publications.

Beven, K., 1993. Prophecy, reality and uncertainty in distributed hydrological modelling. Advances in Water Resources 16, 41-51.

Beven, K.J., 2001. Rainfall-Runoff Modelling: The Primer. John Wiley \& Sons.

Beven, K.J., 2009. Environmental modelling: An uncertain future? Routledge.

Beven, K.J., Binley, A., 1992. The future of distributed models: Model calibration and uncertainty prediction. Hydrological Processes 6, 279-298.

Beven, K.J., Kirkby, M.J., 1979. A physically based, variable contributing area model of basin hydrology. Hydrological Sciences - Bulletin 24, 43-69.

Blöschl, G., Sivapalan, M., 1995. Scale issues in hydrological modelling: A review. Hydrological Processes 9, 251-290.

Bogner, K., Kalas, M., 2008. Error-correction methods and evaluation of an ensemble based hydrological forecasting system for the Upper Danube catchment. Atmospheric Science Letters 9, 95-102.

Bou, A., 2007. Groundwater model of the eastern Lake Taupo catchment. GNS Science Consultancy Report 2007/01.

Boughton, W., 2004. The Australian water balance model. Environmental Modelling \& Software 19, 943-956.

Boyle, D.P., Gupta, H.V., Sorooshian, S., 2000. Toward improved calibration of hydrologic models: Combining the strengths of manual and automatic methods. Water Resources Research 36, 3663-3674.

Bronstert, A., Plate, E.J., 1997. Modelling of runoff generation and soil moisture dynamics for hillslopes and micro-catchments. Journal of Hydrology 198, 177-195.

Bulygina, N., 2007. Model structure estimation and correction through data assimilation, Department of Hydrology and Water Resources. PhD Thesis, The University of Arizona.

Bulygina, N., Ballard, C., McIntyre, N., O'Donnell, G., Wheater, H., 2012. Integrating different types of information into hydrological model parameter estimation: Application to ungauged catchments and land use scenario analysis. Water Resources Research 48, Wo6519.

Burden, R.L., Faires, J.D., 1993. Numerical analysis, 5th ed. PWS Publishing Company, Boston, MA.

Burman, R., Pochop, L.O., 1994. Evaporation, evapotranspiration and climatic data. Developments in Atmospheric Science 22.

Burnash, R.J.C., 1995. The NWS river forecast system: Catchment modeling, in: Singh, V.P. (Ed.), Computer Models of Watershed Hydrology. Water Resources Publications. 
Calver, A., Wood, W.L., 1995. The Institute of Hydrology distributed model, in: Singh, V.P. (Ed.), Computer Models of Watershed Hydrology. Water Resource Publications, Highlands Ranch, CO, pp. 595-626.

Chan, K., Saltelli, A., Tarantola, S., 1997. Sensitivity analysis of model output: variance-based methods make the difference, in: Andradóttir, S., Healy, K.J., Withers, D.H., Nelson, B.L. (Eds.), Winter Simulation Conference.

Chapman, T.G., 1991. Comment on "Evaluation of automated techniques for baseflow and recession analyses" by R.J. Nathan and TA. McMahon. Water Resources Research 27, 1783-1784.

Chapman, T.G., Maxwell, A., 1996. Baseflow separation - comparison of numerical methods with tracer experiments, in: Engineers, I.o. (Ed.), Hydrology and Water Resources Symposium, Hobart, Australia.

Chow, V.T., 1964. Handbook of applied hydrology: A compendium of waterresources technology. McGraw-Hill, New York.

Clark, M.P., Rupp, D.E., Woods, R.A., Zheng, X., Ibbitt, R.P., Slater, A.G., Schmidt, J., Uddstrom, M., 2008a. Hydrological data assimilation with the Ensemble Kalman filter: use of streamflow observations to update states in a distributed hydrological model. Advances in Water Resources 31, 1309-1324.

Clark, M.P., Slater, A.G., Rupp, D.E., Woods, R.A., Vrugt, J.A., Gupta, H.V., Wagener, T., Hay, L.E., 2008b. Framework for Understanding Structural Errors (FUSE): A modular framework to diagnose differences between hydrological models. Water Resources Research 44.

Clayden, B., Webb, T.H., 1994. Criteria for defining the soilform - the fourth category of the New Zealand Soil Classification, in: Ltd, M.W.L.R. (Ed.), Landcare Research Science Series No.3.

Collischonn, W., Haas, R., Andreolli, I., Tucci, C.E.M., 2005. Forecasting River Uruguay flow using rainfall forecasts from a regional weather-prediction model. Journal of Hydrology 305, 87-98.

Collischonn, W., Tucci, C.E.M., Clarke, R.T., Chou, S.C., Guilhon, L.G., Cataldi, M., Allasia, D., 2007. Medium-range reservoir inflow predictions based on quantitative precipitation forecasts. Journal of Hydrology 344, 112-122.

Coulibaly, P., Anctil, F., Bobée, B., 2000. Daily reservoir inflow forecasting using artificial neural networks with stopped training approach. Journal of Hydrology 230, 244-257.

Croke, B.F.W., Norton, J.P., 2004. Regionalisation of rainfall-runoff models, in: Pahl-Wostl, C., Schmidt, S., Rizzoli, A.E., Jakeman, A.J. (Eds.), Complexity and Integrated Resources Management. Trans. Second Biennial Meeting of the Int. Environmental Modelling and Software Society, iEMSs. 2004, Manno, Switzerland, pp. 1201-1207.

Daniel, E.B., Camp, J.V., LeBoeuf, E.J., Penrod, J.R., Dobbins, J.P., Abkowitz, M.D., 2011. Watershed modeling and its applications: A state-of-the-art review. The Open Hydrology Journal 5, 26-50.

Davie, T., 2003. Fundamentals of Hydrology. Routledge. 
Davie, T., 2004. Soil water, runoff and streamflow generation, in: Harding, J., Mosley, P., Pearson, C., Sorrell, B. (Eds.), Freshwaters of New Zealand. New Zealand Hydrological Society \& New Zealand Limnological Societ, Christchurch.

Davy, B.W., Caldwell, T.G., 1998. Gravity, magnetic and seismic surveys of the caldera complex, Lake Taupo, North Island, New Zealand. Journal of Volcanology and Geothermal Research 81, 69-89.

Dawson, C.W., Wilby, R.L., 2001. Hydrological modelling with artificial neural networks. Progress in Physical Geography 25, 80-108.

de Goffau, J.E.J., 2006. The measurability of hydrological processes by means of gravimetric measurements, Faculty of Civil Engineering. Delft University of Technology, Netherlands.

DeChant, C.M., Moradkhani, H., 2012. Examining the effectiveness and robustness of sequential data assimilation methods for quantification of uncertainty in hydrologic forecasting. Water Resources Research 48, Wo4518.

Devore, J.L., 1982. Probability and statistics for enginnering and the sciences. Brooks/Cole, Monterey CA.

Dingman, C.L., Bedford, K.W., 1984. The Lake Erie response to the January 26, 1978, Cyclone. Journal of Geophysical Research 89, 6427-6445.

Dingman, L., 2008. Physical Hydrology, Second Edition ed. Long Grove, IL : Waveland Press Inc 2008, c2002 .

Dravitzki, S., 2009. Precipitation in the Waikato River catchment, School of Geography, Environment and Earth Sciences. PhD Thesis, Victoria Univeristy of Wellington, New Zealand.

Drogue, G., Leviandier, T., Pfister, L., Idrissi, A.E., Iffly, J.F., Hoffmann, L., Guex, F., Hingray, B., Humbert, J., 2002. The applicability of a parsimonious model for local and regional prediction of runoff, Hydrological Sciences Journal. Taylor \& Francis, pp. 905-920.

Druce, D.J., 2001. Insights from a history of seasonal inflow forecasting with a conceptual hydrologic model. Journal of Hydrology 249, 102-112.

Duan, Q., Ajami, N.K., Gao, X., Sorooshian, S., 2007. Multi-model ensemble hydrologic prediction using Bayesian model averaging. Advances in Water Resources 30, 1371-1386.

Duan, Q., Sorooshian, S., Gupta, V., 1992. Effective and efficient global optimization for conceptual rainfall-runoff models. Water Resources Research 28, 1015-1031.

Duncan, M.J., Woods, R., 2004. Flow Regimes, in: Harding, J., Mosley, P., Pearson, C., Sorrell, B. (Eds.), Freshwaters of New Zealand. New Zealand Hydrological Society \& New Zealand Limnological Society, Christchurch.

Dunne, S., Entekhabi, D., 2005. An ensemble-based reanalysis approach to land data assimilation. Water Resources Research 41, Wo2013.

Dunne, T., Black, R.D., 1970. Partial area contribution to storm runoff in a small New England watershed. Water Resources Research 6, 1296-1311. 
Eckhardt, K., 2005. How to construct recursive digital filters for baseflow separation. Hydrological Processes 19, 507-515.

Eckhardt, K., 2008. A comparison of baseflow indices, which were calculated with seven different baseflow separation methods. Journal of Hydrology 352, 168-173.

ECNZ, unknown. Lake Taupo: Lake Levels.

Electricity Commission, unknown. About the New Zealand Electricity Market.

EPA, 2010. Management Measure for Erosion and Sediment Control - III. Dams Management Measures, in: EPA Office of Water (Ed.). U.S. Environmental Protection Agency.

Evensen, G., 1994. Sequential data assimilation with a nonlinear quasi-geostrophic model using Monte Carlo methods to forecast error statistics. Journal of Geophysical Research 99, 10.

Fahey, B.D., Duncan, M., Quinn, J., 2004. Impacts of forestry, in: Harding, J., Mosley, P., Pearson, C., Sorrell, B. (Eds.), Freshwaters of New Zealand. New Zealand Hydrological Society and New Zealand Limnological Society.

Fenicia, F., McDonnell, J.J., Savenije, H.H.G., 2008. Learning from model improvement: On the contribution of complementary data to process understanding. Water Resources Research 44, Wo6419.

Field, A., 2005. Discovering Statistics using SPSS, Second ed. SAGE Publications.

Fitzharris, B., Lawson, W., Owens, I., 1999. Research on glaciers and snow in New Zealand. Progress in Physical Geography 23, 469-500.

Freestone, H.J., Ong, K.S.W., Waugh, J.R., Lynch, R., 1998. Waikato Power Scheme Operational Audit - Flood July 1998. Opus Consultants Ltd.

Froggatt, P.C., 1981. Stratigraphy and nature of Taupo Pumice Formation. New Zealand Journal of Geology \& Geophysics 24, 231-248.

Genesis Energy Ltd, 2008. Tongariro Power Scheme: Environmental Report 20072008. Genesis Energy Ltd.

Genesis Energy Ltd, 2010. Tongariro Power Scheme.

Genesis Energy Ltd, 2011. Tongariro Power Scheme: Environmental Report 20102011. Genesis Energy Ltd.

Gibbs, H.S., 1968. Volcanic-ash soils in New Zealand, Information Series No. 65, Soil Bureau Publication 386. New Zealand Department of Scientific and Industrial Research.

Gibbs, M., Clayton, J., Wells, N., 2005. Further investigation of direct groundwater seepage to Lake Taupo, Technical Report 2005/34. Environment Waikato.

Gilbert, D.J., 1978. Calculating lake inflow (Note). Journal of Hydrology (NZ) 17, 3943 . 
Gillijns, S., Mendoza, O.B., Chandrasekar, J., De Moor, B.L.R., Bernstein, D.S., Ridley, A., 2006. What is the ensemble Kalman filter and how well does it work?, American Control Conference, 2006, p. 6 pp.

Gilmour, A.E., 1991. Seiche characteristics in Lake Taupo, New Zealand (Note). New Zealand Journal of Marine and Freshwater Research 25, 163-166.

Gilmour, A.E., Butcher, C.N., 1987. Free oscillations in Lake Taupo - a triangular lake, DMFS Reports Division of Marine and Freshwater Science, Department of Scientific and Industrial Research, pp. 11-14.

Gilmour, A.E., Heath, R.A., 1989. Barotropic and baroclinic waves in Lake Taupo. New Zealand Journal of Marine and Freshwater Research 23, 189-194.

Gordon, N.D., McMahon, T.A., Finlayson, B.L., Grippel, C.J., Nathan, R.J., 2004. Stream hydrology: an introduction for ecologists, 2nd Edition ed. John Wiley \& Sons Ltd, Chichester, West Sussex, England.

Goudie, A., 1994. Geomorphological Techniques, 2nd Edition ed. Edited for the British Geomorphological Research Group, Routledge.

Graham, D.N., Butts, M.B., 2005. Flexible, integrated watershed modelling with MIKE SHE, in: Singh, V.P., Frevert, D.K. (Eds.), Watershed Models. CRC Press, pp. 245-272.

Grange, L.I., 1937. The geology of the Rotorua-Taupo Subdivision. Bulletin No. 37, Geological Survey Branch, Department of Scientific and Industrial Research.

Grindley, G.W., 1960. Sheet 8: Taupo, Geological Map of New Zealand, 1:250 000. Department of Scientific and Industrial Research.

Gupta, H., Sorooshian, S., 1985. The relationship between data and the precision of parameter estimates of hydrologic models. Journal of Hydrology 81, 57-77.

Gupta, H.V., Kling, H., Yilmaz, K.K., Martinez, G.F., 2009. Decomposition of the mean squared error and NSE performance criteria: Implications for improving hydrological modelling. Journal of Hydrology 377, 80-91.

Gupta, H.V., Sorooshian, S., Yapo, P.O., 1998. Toward improved calibration of hydrologic models: Multiple and noncommensurable measures of information. Water Resources Research 34, 751-763.

Gusyev, M.A., Toews, M., Morgenstern, U., Stewart, M., Daughney, C., Hadfield, J., 2012. Calibration of a transient transport model to tritium measurements in rivers and streams in the Western Lake Taupo catchment, New Zealand. Hydrol. Earth Syst. Sci. Discuss. 9, 9743-9765.

Hadfield, J., 2007. Groundwater flow and nitrogen transport modelling of the northern Lake Taupo catchment. Environment Waikato Technical Report 2007/39.

Hadfield, J., Nicole, J., Rosen, M.R., Wilson, C.J.N., Morgenstern, U., 2001. Hydrogeology of Lake Taupo Catchment -- Phase 1. Environment Waikato.

Han, X., Li, X., Hendricks Franssen, H.-J., Vereecken, H., Montzka, C., 2012. Spatial horizontal correlation characteristics in the land data assimilation of soil moisture. Hydrology and Earth System Sciences 16, 1349-1363. 
Harding, J., Mosley, P., Pearson, C., Sorrell, B., 2004. Freshwaters of New Zealand. New Zealand Hydrological Society and New Zealand Limnological Society, Christchurch.

Harlin, J., Kung, C.-S., 1992. Parameter uncertainty and simulation of design floods in Sweden. Journal of Hydrology 137, 209-230.

Harmel, R.D., Smith, P.K., 2007. Consideration of measurement uncertainty in the evaluation of goodness-of-fit in hydrologic and water quality modeling. Journal of Hydrology 337, 326-336.

Harte, D., Thomson, P., 2007. Hidden Markov models for New Zealand hydro catchment inflows: a preliminary analysis. New Zealand Electricity Commission.

He, M., Hogue, T.S., Margulis, S.A., Franz, K.J., 2012. An integrated uncertainty and ensemble-based data assimilation approach for improved operational streamflow predictions. Hydrology and Earth System Sciences 16, 815-831.

Henry, N., 2003. Numerical weather prediction, in: Management, M.o.C.D.a.E. (Ed.), Tephra.

Hewitt, A.E., 1993. Methods and rationale of the New Zealand soil classification, Landcare Research Science Series ; No. 2. Science Series No. 2, Manaaki WhenuaLandcare Research New Zealand Ltd.

Hewitt, A.E., 1998. New Zealand Soil Classification, in: Press, M.W. (Ed.), Landcare Research Science Series No.1, Second ed.

Hewlett, J.D., Hibbert, A.R., 1967. Factors affecting the response of small watersheds to precipitation in humid areas, in: Sopper, E.W., Lull, H.W. (Eds.), Forest Hydrology. Pergamon, Oxford, pp. 272-290.

Hicks, M., McKerchar, A., O'Brien, R., 2000. Lakeshore geomorphic processes, Lake Taupo, Client Report. National Institute of Water and Atmospheric Research, NZ.

Hillel, D., 2004. Introduction to environmental soil physics. Elsevier Academic Press.

Hopmans, J.W., Schoups, G.H., 2005. Soil water flow at different spatial scales, in: Anderson, M. (Ed.), Encyclopedia of Hydrological Sciences. John Wiley \& Sons Ltd.

Hornberger, G.M., Spear, R.C., 1981. Approach to the preliminary analysis of environmental systems. Journal of Environmental Management (United States) 12, 7-18.

Hotchkiss, R.H., Jorgensen, S.F., Stone, M.C., Fontaine, T.A., 200o. Regulated river modelling for climate change impact assessment: the Missouri River. Journal of the American Water Resources Association 36, 375-386.

Houghton, B.F., Wilson, C.J.N., McWilliams, M.O., Lanphere, M.A., Weaver, S.D., Briggs, R.M., Pringle, M.S., 1995. Chronology and dynamics of a large silcic magmatic system: Central Taupo Volcano Zone, New Zealand. Geology 23, 13-16.

Hughes, D.A., 1992. A monthly time step, multiple reservoir water balance simulation model. Water SA 18, 279-286. 
Ibbitt, R., Thompson, C., Turner, R., 2005. Skill assessment of a linked precipitation runoff flood forecasting system. Journal of Hydrology (NZ) 44, 91-104.

Ibbitt, R., Woods, R., 2004. Re-scaling the topographic index to improve the representation of physical processes in catchment models. Journal of Hydrology 293, 205-218.

Institute of Geological and Nuclear Sciences, 2008. Earth Beneath our Feet: 3D Geological Models for New Zealand.

Jain, S.K., Das, A., Srivastava, D.K., 1999. Application of ANN for reservoir inflow prediction and operation. Journal of Water Resources Planning and Management 125, 263-271.

Jain, S.K., Sudheer, K.P., 2008. Fitting of hydrologic models: A close look at the Nash-Sutcliffe Index. Journal of Hydrologic Engineering 13, 981-986.

Jakeman, A.J., Littlewood, I.G., Whitehead, P.G., 1990. Computation of the instantaneous unit hydrograph and identifiable component flows with application to two small upland catchments. Journal of Hydrology 117, 275-300.

James, M., Mark, A., Single, M., 2002. Lake Managers' Handbook: Lake Level Management, in: Ministry for the Environment (Ed.).

Julier, S.J., LaViola, J.J., 2007. On Kalman filtering with nonlinear equality constraints. Signal Processing, IEEE Transactions on 55, 2774-2784.

Kampf, S.K., Burges, S.J., 2007. A framework for classifying and comparing distributed hillslope and catchment hydrologic models. Water Resources Research 43 .

Kavetski, D., Clark, M.P., 2010. Ancient numerical daemons of conceptual hydrological modeling: 2. Impact of time stepping schemes on model analysis and prediction. Water Resources Research 46, W10511.

Kavetski, D., Clark, M.P., 2011. Numerical troubles in conceptual hydrology: Approximations, absurdities and impact on hypothesis testing. Hydrological Processes 25, 661-670.

Kavetski, D., Franks, S.W., Kuczera, G., 2002. Confronting input uncertainty in environmental modelling, in: Duan, Q., Gupta, H., Sorooshian, S., Rousseau, A.N., Turcotte, R. (Eds.), Calibration of Watershed Models. AGU Water Science and Applications, pp. 49-68.

Kelliher, F.M., Leuning, R., Schulze, E.D., 1993. Evaporation and canopy characteristics of coniferous forests and grasslands. Oecologia 95, 153-163.

Kelliher, F.M., Scotter, D.R., 1992. Evaporation, soil and water, in: Mosley, P. (Ed.), Waters of New Zealand. New Zealand Hydrological Society.

Kirchner, J.W., 2009. Catchments as simple dynamical systems: Catchment characterization, rainfall-runoff modeling, and doing hydrology backward. Water Resources Research 45.

Kitanidis, P.K., Bras, R.L., 1980. Real-time forecasting with a conceptual hydrologic model 1. Analysis of uncertainty. Water Resources Research 16, 1025-1033. 
Kokkonen, T.S., Jakeman, A.J., 2001. A comparison of metric and conceptual approaches in rainfall-runoff modeling and its implications. Water Resources Research 37, 2345-2352.

Komma, J., Blöschl, G., Reszler, C., 2008. Soil moisture updating by ensemble Kalman filtering in real-time flood forecasting. Journal of Hydrology 357, 228-242.

Landcare Research - Manaaki Whenua (NZ), 2008. New Zealand Land Resource Inventory.

Lane, E.W., Lei, A.K., 1950. Streamflow variability. American Society of Civil Engineers, Transactions 115, 1089.

Leathwick, J.R., Clarkson, B.D., Whaley, P.T., 1995. Vegetation of the Waikato Region: Current and historical perspectives. Manaaki Whenua - Landcare Research.

Lindström, G., Johansson, B.o., Persson, M., Gardelin, M., Bergström, S., 1997. Development and test of the distributed HBV-96 hydrological model. Journal of Hydrology 201, 272-288.

Liu, J., Han, D., 2010. Indices for calibration data selection of the rainfall-runoff model. Water Resources Research 46, Wo4512.

Liu, S., Graham, W.D., Jacobs, J.M., 2005. Daily potential evapotranspiration and diurnal climate forcings: Influence on the numerical modelling of soil water dynamics and evapotranspiration. Journal of Hydrology 309, 39-52.

Liu, T., Willems, P., Feng, X.W., Li, Q., Huang, Y., Bao, A.M., Chen, X., Veroustraete, F., Dong, Q.H., 2012. On the usefulness of remote sensing input data for spatially distributed hydrological modelling: case of the Tarim River basin in China. Hydrological Processes 26, 335-344.

Liu, Y., Gupta, H.V., 2007. Uncertainty in hydrologic modeling: Toward an integrated data assimilation framework. Water Resources Research 43, 18.

Liu, Y., Weerts, A.H., Clark, M.P., Hendricks Franssen, H.-J., Kumar, S., Moradkhani, H., Seo, D.-J., Schwanenberg, D., Smith, P., van Dijk, A.I.J.M., van Velzen, N., He, M., Lee, H., S.J., N., Rakovec, O., Restrepo, P., 2012, in review. Advancing data assimilation in operational hydrologic forecasting: progresses, challenges, and emerging opportunities. Hydrology and Earth System Sciences Discussion 9, 3415-3472.

Lohani, A.K., Kumar, R., Singh, R.D., 2012. Hydrological time series modeling: A comparison between adaptive neuro-fuzzy, neural network and autoregressive techniques. Journal of Hydrology 442-443, 23-35.

Lyons, R.G., 2001. Understanding digital signal processing. Prentice Hall, Upper Saddle River, NJ.

Madsen, H., 2003. Parameter estimation in distributed hydrological catchment modelling using automatic calibration with multiple objectives. Advances in Water Resources 26, 205-216.

Madsen, H., Skotner, C., 2005. Adaptive state updating in real-time river flow forecasting - a combined filtering and error forecasting procedure. Journal of Hydrology 308, 302-312. 
Maidment, D.R., 1993. Handbook of hydrology. McGraw-Hill, New York.

Manville, V., 2002. Sedimentary and geomorphic responses to ignimbrite emplacement: Readjustment of the Waikato River after the A.D. 181 Taupo eruption, New Zealand. The Journal of Geology 110, 519-541.

Manville, V., White, J.D., Houghton, B.F., Wilson, C.J.N., 1999. Paleohydrology and sedimentology of a post-1.8 ka breakout flood from intracaldera Lake Taupo, North Island, New Zealand. Geological Society of America Bulletin 111, 1435-1447.

Manville, V., Wilson, C.J.N., 2004. The 26.5 ka Oruanui eruption, New Zealand: a review of the roles of volcanism and climate in the post-eruptive sedimentary response. New Zealand Journal of Geology \& Geophysics 47, 525-547.

Massey, F.J., Jr., 1951. The Kolmogorov-Smirnov test for goodness of fit. Journal of the American Statistical Association 46, 68-78.

McCuen, R.H., 1973. The role of sensitivity analysis in hydrologic modeling. Journal of Hydrology 18, 37-53.

McCuen, R.H., 1998. Hydrologic Analysis and Design, 2nd Edition ed. Prentice Hall, Upper Saddle River, New Jersey 07458.

McGlone, M.S., 1983. Polynesian deforestation of New Zealand: a pre-liminary synthesis. Archaeology in Oceania 18., 11-25.

McKinnon, M., 2007. Volcanic Plateau, Encyclopedia of New Zealand.

McLaughlin, D., 2002. An integrated approach to hydrologic data assimilation: interpolation, smoothing, and filtering. Advances in Water Resources 25, 1275-1286.

McMillan, H., Clark, M.P., Woods, R., Duncan, M., Western, A., Goodrich, D., 2010. Improving perceptual and conceptual hydrological models using data from small basins, Status and Perspectives of Hydrology in Small Basins. IAH Publ., GoslarHahnenklee, Germany, pp. 336-308.

Melching, C.S., 1995. Reliability estimation, in: Singh, V.P. (Ed.), Computer Models of Watershed Hydrology. Water Resources Publications.

Mighty River Power Ltd, 2007. Lake Taupo: Lake Levels. Mighty River Power Ltd, Hamilton, NZ.

Mighty River Power Ltd, 2008. Lake level graphs - Overview, in: Mighty River Power Ltd (Ed.).

Ministry for the Environment, 2004. New Zealand Land Cover Database 2.

Minns, A.W., Hall, M.J., 2005. Artifical neural network concepts in hydrology in: Andersen, M.G. (Ed.), Encyclopedia of Hydrological Sciences. John Wiley \& Sons, Ltd.

Molloy, L., 1998. Soils in the New Zealand landscape: a living mantle, 2nd ed. New Zealand Society of Soil Science.

Moore, R.J., 2007. The PDM rainfall-runoff model. Hydrology and Earth System Sciences 11, 483-499. 
Moradkhani, H., Hsu, K., Gupta, H., Sorooshian, S., 2005a. Uncertainty assessment of hydrologic model states and parameters: Sequential data assimilation using the particle filter. Water Resources Research 41.

Moradkhani, H., Sorooshian, S., 2008. General review of rainfall-runoff modeling: Model calibration, data assimilation, and uncertainty analysis, in: Sorooshian, S., Hsu, K., Coppola, E., Tomassetti, B., Verdecchia, M., Visconti, G. (Eds.), Hydrological modelling and the water cycle. Coupling the atmospheric and hydrological models. Springer.

Moradkhani, H., Sorooshian, S., Gupta, H.V., Houser, P.R., 2005b. Dual stateparameter estimation of hydrological models using ensemble Kalman filter. Advances in Water Resources 28, 135-147.

Morgenstern, U., 2007. Lake Taupo streams - Water age distribution, fraction of landuse impacted water, and future nutrient load. GNS Science Consultancy Report 2007/150

Morgenstern, U., 2008. Lake Taupo catchment groundwater age distribution and implications for future land-use impacts. Environment Waikato Technical Report $2007 / 49$.

Mulligan, M., Wainwright, J., 2004. Modelling and model building, in: Wainwright, J., Mulligan, M. (Eds.), Environmental modelling: Finding simplicity in complexity. John Wiley \& Sons.

Murphy, A.H., 1988. Skill scores based on the mean square error and their relationships to the correlation coefficient. Monthly Weather Review 116, 24172424.

Murphy, B., 2006. Hydrogeology and groundwater quality of the Tauranga-Taupo settlement, Lake Taupo, School of Geography, Geology and Earth Sciences. Masters Dissertation (MSc), Victoria University of Wellington, New Zealand.

Narasimhan, S.V., Veena, S., 2005. Signal Processing. Alpha Science International Ltd., Harrow, U.K.

Nathan, R.J., McMahon, T.A., 1990. Evaluation of automated techniques for base flow and recession analysis. Water Resources Research 26, 1465-1473.

Neuman, S.P., 2003. Maximum likelihood Bayesian averaging of uncertain model predictions. Stochastic Environmental Research and Risk Assessment 17, 291-305.

NIWA, 2002. Annual Climate Summary - 2001.

NIWA, 2003a. National Climate Summary: August 2003.

NIWA, 2003b. National Climate Summary: July 2003.

NIWA, 2003c. National Climate Summary: June 2003.

NIWA, 2004a. Annual Climate Summary - 2003.

NIWA, 2004b. National Climate Summary: February 2004 
NIWA, 2010a. National Climate Summary - March 2010: Very dry in the northeast, Otago, Canterbury.

NIWA, 2010b. National Climate Summary: September 2010.

NIWA, 2011. New Zealand National Climate Summary 2010: Settled and warm.

Opus International Consultants Limited, 2009. Lake level history.

Opus International Consultants Limited, 2011. Taupo District Flood Hazard Study Kuratau River.

Opus International Consultants Limited, 2012. Taupo District Flood Hazard Study Tokaanu Stream.

Oreskes, N., Shrader-Frechette, K., Belitz, K., 1994. Verification, validation and confirmation of numerical models in earth sciences. Science 263, 641-646.

Otway, P.M., 1986. Vertical deformation associated with the Taupo earthquake swarm, June 1983. Royal Society of New Zealand Bulletin 24, 187-200.

Pan, M., Wood, E.F., 2006. Data assimilation for estimating the terrestrial water budget using a constrained ensemble Kalman Filter. Journal of Hydrometeorology 7, 534-547.

Partington, D., Brunner, P., Simmons, C.T., Werner, A.D., Therrien, R., Maier, H.R., Dandy, G.C., 2012. Evaluation of outputs from automated baseflow separation methods against simulated baseflow from a physically based, surface watergroundwater flow model. Journal of Hydrology 458-459, 28-39.

Pauwels, V.R.N., De Lannoy, G.J.M., 2006. Improvement of modeled soil wetness conditions and turbulent fluxes through the assimilation of observed discharge. Journal of Hydrometeorology 7, 458-477.

Pauwels, V.R.N., De Lannoy, G.J.M., 2009. Ensemble-based assimilation of discharge into rainfall-runoff models: A comparison of approaches to mapping observational information to state space. Water Resources Research 45 .

Pechlivanidis, I.G., Jackson, B., McMillan, H., 2010. The use of entropy as a model diagnostic in rainfall-runoff modelling, in: Swayne, D.A., Yang, W., Voinoy, A.A., Rizzoli, A., Filatova, T. (Eds.), 2010 International Congress of Environmental Modelling and Software. Modelling for Environment's Sake, Fifth Biennial Meeting. International Environmental Modelling and Software Society (iEMSs), Ottawa, Canada.

Pechlivanidis, I.G., Jackson, B.M., McIntyre, N.R., Wheater, H.S., 2011. Catchment scale hydrological modelling: a review of model types, calibration approaches and uncertainty analysis methods in the context of recent developments in technology and applications. Global NEST Journal 13, 193-214.

Peters, N.E., 1994. Hydrologic Processes, in: Molden, B., Černý, J. (Eds.), Biochemistry of Small Catchments: A Tool for Environmental Research. John Wiley \& Sons Ltd. 
Piper, J.J., 2004. Surface water/groundwater interaction and catchment influence on waters entering Lake Taupo, New Zealand, School of Geography, Geology and Earth Sciences. Masters Dissertation (MSc), Victoria University of Wellington.

Poff, N.L., Hart, D.D., 2002. How dams vary and why it matters for the emerging science of dam removal. BioScience 52, 659-668.

Post, D.A., Jakeman, A.J., 1996. Relationships between catchment attributes and hydrological response characteristics in small Australian mountain ash catchments. John Wiley \& Sons, Ltd, pp. 877-892.

Poyck, S., Hendrikx, J., McMillan, H., Hreinsson, E.O., Woods, R., 2011. Combined snow and streamflow modelling to estimate impacts of climate change on water resources in the Clutha river, New Zealand. Journal of Hydrology (NZ) 50, 293-311.

Pradhan, N.R., Ogden, F.L., 2010. Development of a one-parameter variable source area runoff model for ungauged basins. Advances in Water Resources 33, 572-584.

Refsgaard, J.C., Henriksen, H.J., 2004. Modelling guidelines - terminology and guiding principles. Advances in Water Resources 27, 71-82.

Reichle, R.H., 2008. Data assimilation methods in the Earth sciences. Advances in Water Resources 31, 1411-1418.

Reichle, R.H., McLaughlin, D.B., Entekhabi, D., 2002. Hydrologic data assimilation with the ensemble Kalman Filter. Monthly Weather Review 130, 103-114.

Riggs, H.C., 1985. Streamflow characteristics. Elsevier Science Publishers B.V.

Rijkse, W.C., 1987. Soils, agriculture and forestry of Taupo Region, North Island, New Zealand. Landcare Research.

Roper, D., 2001. Taupo Waikato resource consents assessment of environmental effects. Mighty River Power.

Rosen, M.R., Coshell, L., 1998. Influence of eruptive lithologies on surface and groundwwater chemical compositions, Lake Taupo, New Zealand, in: Arehart, G.B., R, H.J. (Eds.), Water-Rock Interaction. Balkema Rotterdam.

Rushton, K.R., Eilers, V.H.M., Carter, R.C., 2006. Improved soil moisture balance methodology for recharge estimation. Journal of Hydrology 318, 379-399.

Salamon, P., Feyen, L., 2009. Assessing parameter, precipitation, and predictive uncertainty in a distributed hydrological model using sequential data assimilation with the particle filter. Journal of Hydrology 376, 428-442.

Saltelli, A., Tarantola, S., Campolongo, F., Ratto, M., 2004. Sensitivity analysis in practice: A guide to assessing scientific models. John Wiley \& Sons Ltd, Chichester, West Sussex, England.

Sayama, A., Tachikawa, Y., Takara, K., Ichikawa, Y., 2006. Development of a realtime distributed flood prediction system in a flow regulated river basin, Proceedings of the 3rd APHW Conference on "Wise Water Resources Management toward Sustainable Growth and Poverty Reduction", Bangkok, Thailand. 
Schaefli, B., Gupta, H.V., 2007. Do Nash values have value? Hydrological Processes 21, 2075-2080.

Schouten, C.J., 1983. Budget of water and its constituents for Lake Taupo (New Zealand), Dissolve Loads of Rivers and Surface Water Quantity/Quality Relationships. IAHS Publ No. 141.

Schouten, C.J., Terzaghi, W., Gordon, Y., 1981. Summaries of water quality and mass transport data for Lake Taupo catchment, New Zealand. Ministry of Works and Development.

Schumm, S.A., 1956. Evolution of drainage systems and slopes in badlands at Perth Amboy, New Jersey. Bulletin of the Geological Society of America 67, 597-646.

Sefton, C.E.M., Howarth, S.M., 1998. Relationships between dynamic response characteristics and physical descriptors of catchments in England and Wales. Journal of Hydrology 211, 1-16.

Seibert, J., 1999. Regionalisation of parameters for a conceptual rainfall-runoff model. Agricultural and Forest Meteorology 98-99, 279-293.

Seibert, J., 2000. Multi-criteria calibration of a conceptual runoff model using a genetic algorithm. Hydrology \& Earth System Sciences 4, 215-224.

Selby, M.J., 1972. The relationships between land use and erosion in the central North Island, New Zealand. Journal of Hydrology 11, 73-87.

Seo, D.-J., Cajina, L., Corby, R., Howieson, T., 2009. Automatic state updating for operational streamflow forecasting via variational data assimilation. Journal of Hydrology 367, 255-275.

Seo, D.-J., Koren, V., Cajina, N., 2003. Real-time variational assimilation of hydrologic and hydrometeorological data into operational hydrologic forecasting. Journal of Hydrometeorology 4, 627-641.

Shuttleworth, W.J., 1993. Evaporation, in: Maidment, D.R. (Ed.), Handbook of Hydrology. McGraw Hill Inc.

Simon, D., Simon, D.L., 2006. Kalman filtering with inequality constraints for turbofan engine health estimation. Control Theory and Applications, IEE Proceedings - 153, 371-378.

Simon, D., Tien Li, C., 2002. Kalman filtering with state equality constraints. Aerospace and Electronic Systems, IEEE Transactions on 38, 128-136.

Singh, S.K., Bárdossy, A., 2012. Calibration of hydrological models on hydrologically unusual events. Advances in Water Resources 38, 81-91.

Singh, V.P., 2002. Is hydrology kinematic? Hydrological Processes 16, 667-716.

Sivapalan, M.S., 2005. Pattern, Process and Function: Elements of a Unified Theory of Hydrology at the Catchment Scale, Encyclopedia of Hydrological Sciences.

Smart, G., 2005. The higher lower Tongariro. Environment Waikato Technical Report 2005/49. 
Smith, R.C.M., 1991a. Landscape response to a major ignimbrite eruption, Taupo Volcanic Center, New Zealand, in: Fisher, R.V., Smith, G.A. (Eds.), Sedimentation in Volcanic Settings. SEPM (Society for Sedimentary Geology), pp. 123-137.

Smith, R.C.M., 1991b. Post-eruption sedimentation on the margin of a caldera lake, Taupo Volcanic Centre, New Zealand. Sedimentary Geology 74, 89-138.

Smith, R.C.M., Smith, I.E.M., Browne, P.R.L., Hochstein, M.P., 1993. Volcanotectonic controls on sedimentation in the Taupo Volcanic Zone, New Zealand, in: Balance, P.F. (Ed.), South Pacific Sedimentary Basins, Sedimentary Basins of the World 2. Elselvier Science Publishers B.V., Amsterdam, pp. 143-156.

Snelder, T.H., Biggs, B.J.F., 2002. Multi-scale river environment classification for water resources management. Journal of the American Water Resources Association $38,1225-1239$.

Spongberg, M.E., 2000. Spectral analysis of base flow separation with digital filters. Water Resources Research 36, 745-752.

Steenhuis, T.S., Winchell, M., Rossing, J., Zollweg, J.A., Walter, M.F., 1995. SCS runoff equation revisited for variable-source runoff areas, Journal of Irrigation \& Drainage Engineering. American Society of Civil Engineers, p. 234.

Stephens, R.T.T., 1989. Flow management in the Tongaririo River. Science and Research Series No. 16. Department of Conservation, Wellington, New Zealand.

Stewart, M.K., Morgenstern, U., 2001. Age and source of groundwater from isotope traces, in: Rosen, M.R., White, P.A. (Eds.), Groundwaters of New Zealand. New Zealand Hydrological Society Inc. , Wellington, pp. 161-183.

Szilagyi, J., 2004. Heuristic continuous base flow separation. ASCE Journal of Hydrologic Engineering 9, 311-318.

Taghi Sattari, M., Yurekli, K., Pal, M., 2012. Performance evaluation of artificial neural network approaches in forecasting reservoir inflow. Applied Mathematical Modelling 36, 2649-2657.

Tait, A., Henderson, R., Turner, R., Zheng, X., 2006. Thin plate smoothing spline interpolation of daily rainfall for New Zealand using a climatological rainfall surface. International Journal of Climatology 26, 2097-2115.

Taupo-nui-a-Tia, 2011. 2020 Taupo-nui-a-Tia Action Plan.

Thacker, W.C., 2007. Data assimilation with inequality constraints. Ocean Modelling 16, 264-276.

Thompson, C.S., 1984. The weather and climate of the Tongariro Region. New Zealand Meteorological Service.

Thompson, S.M., Ibbitt, R., 1978. Smoothing permanent records of lake level (Note). Journal of Hydrology (NZ) 17, 44-49.

Timperley, M.H., 1983. Climate and hydrology, in: Forsyth, D.J., Howard-Williams, C. (Eds.), Lake Taupo: ecology of a New Zealand lake. DSIR, pp. 45-54. 
Todini, E., 1988. Rainfall-runoff modeling - Past, present and future. Journal of Hydrology 100, 341-352.

Todini, E., 1996. The ARNO rainfall--runoff model. Journal of Hydrology 175, 339382.

Transpower New Zealand Ltd, 2010. Annual Planning Report.

TrustPower Ltd, 2008. Hinemaiaia Scheme, in: TrustPower Ltd (Ed.).

Valiantzas, J.D., 2006. Simplified versions for the Penman evaporation equation using routine weather data. Journal of Hydrology 331, 690-702.

Van Den Bos, R., Hoffmann, L., Juilleret, J., Matgen, P., Pfister, L., 2006. Regional runoff prediction through aggregation of first-order hydrological process knowledge: a case study, Hydrological Sciences Journal. Taylor \& Francis, pp. 10211038.

Vandergoes, M.J., Hogg, A.G., Lowe, D.J., Newnham, R.M., Dentone, G.H., Southon, J., Barrell, D.J.A., Blaauwh, M., Wilson, C.J.N., McGlone, M.S., Allan, A.S.R., Almond, P.C., Petchey, F., Dabell, K., Dieffenbacher-Krallk, A.C., 2012, in review. A revised age for the Kawakawa/Oruanui tephra, a key marker for the Last Glacial Maximum in New Zealand. Quaternary Science Reviews (Intimate Special Issue).

Vant, B., Smith, P., 2004. Inflows to Lake Taupo - nutrients and water ages. Environment Waikato.

Vertessy, R.A., Hatton, T.J., O'Shaughnessy, P.J., Jayasuriya, M.D.A., 1993. Predicting water yield from a mountain ash forest catchment using a terrain analysis based catchment model. Journal of Hydrology 150, 665-700.

Vrugt, J.A., Diks, C.G.H., Gupta, H.V., Bouten, W., Verstraten, J.M., 2005. Improved treatment of uncertainty in hydrologic modeling: Combining the strengths of global optimization and data assimilation. Water Resources Research 41.

Vrugt, J.A., Gupta, H.V., Bouten, W., Sorooshian, S., 2003. A shuffled complex evolution metropolis algorithm for optimization and uncertainty assessment of hydrologic model parameters. Water Resources Research 39.

Vrugt, J.A., Gupta, H.V., Nualláin, B.Ó., Bouten, W., 2006. Real-time data assimilation for operational ensemble streamflow forecasting. Journal of Hydrometeorology 7, 548-565.

Vrugt, J.A., Robinson, B.A., 2007. Treatment of uncertainty using ensemble methods: Comparison of sequential data assimilation and Bayesian model averaging. Water Resources Research 43.

Wagener, T., 2003. Evaluation of catchment models. Hydrological Processes 17, 3375-3378.

Wagener, T., Boyle, D.P., Lees, M.J., Wheater, H.S., Gupta, H., Sorooshian, S., 2001. A framework for development and application of hydrological models. Hydrology and Earth System Sciences 5, 13-26. 
Wagener, T., Gupta, H.V., 2005. Model identification for hydrological forecasting under uncertainty. Stochastic Environmental Resource Risk Assessment 19, 378387.

Wagener, T., Kollat, J., 2007. Numerical and visual evaluation of hydrological and environmental models using the Monte Carlo analysis toolbox. Environmental Modelling \& Software 22, 1021-1033.

Wagener, T., McIntyre, N., Lees, M.J., Wheater, H.S., Gupta, H.V., 2003. Towards reduced uncertainty in conceptual rainfall-runoff modelling: dynamic identifiability analysis. Hydrological Processes 17, 455-476.

Wagener, T., Sorooshian, S., Gupta, H., 2004a. Stochastic formulation of a conceptual hydrologic model. Hydrology: Science and Practice for the 21st Century $1,398-405$.

Wagener, T., Wheater, H.S., Gupta, H.V., 2004b. Rainfall-runoff modelling in gauged and ungauged catchments. Imperial College Press.

Wang, D., Chen, Y., Cai, X., 2009. State and parameter estimation of hydrologic models using the constrained Ensemble Kalman filter. Water Resources Research 45, W11416.

Waugh, J.R., Freestone, H.J., 2004. Flood Management Audit: 29 February 2004 Flood on the Waikato River. Opus Consultants Ltd.

Waugh, J.R., Lew, D.D., Frampton, M., 1999. Waikato catchment floods and flooding history. Opus International Consultants Limited,.

Weerts, A.H., El Serafy, G.Y.H., 2006. Particle filtering and ensemble Kalman filtering for state updating with hydrological conceptual rainfall-runoff models. Water Resources Research 42.

Weglarczyk, S., 1998. The interdependence and applicability of some statistical quality measures for hydrological models. Journal of Hydrology 206, 98-103.

Welsh, W.D., Vaze, J., Dutta, D., Rassam, D., Rahman, J.M., Jolly, I.D., Wallbrink, P., Podger, G.M., Bethune, M., Hardy, M.J., Teng, J., Lerat, J., 2012, in review. An integrated modelling framework for regulated river systems. Environmental Modelling \& Software.

White, E., Downes, M.T., 1977. Preliminary assessment of nutrient loads on Lake Taupo, New Zealand. New Zealand Journal of Marine and Freshwater Research 11, 341-356.

White, P.A., 2001. Groundwater resources in New Zealand, in: Rosen, M.R., White, P.A. (Eds.), Groundwaters of New Zealand. New Zealand Hydrological Society Inc., pp. 45-76.

Williams, A., Walton, T., 2003. Early landuse patterns in the Lake Taupo area. Department of Conservation.

Wilson, C.J.N., 1985. The Taupo Eruption, New Zealand II. The Taupo Ignimbrite. Philosophical Transactions of the Royal Society of London. Series A, Mathematical and Physical Sciences 314, 229-310. 
Wilson, C.J.N., 1993. Stratigraphy, chronology, styles and dynamics of late Quaternary eruptions from Taupo Volcano, New Zealand. Philosophical Transactions: Physical Sciences and Engineering 343, 205-306.

Wilson, C.J.N., 2001. The 26.5 ka Oruanui eruption, New Zealand: an introduction and overview. Journal of Volcanology and Geothermal Research 112, 133-174.

Wilson, C.J.N., Houghton, B.F., McWilliams, M.O., Lanphere, M.A., Weaver, S.D., Briggs, R.M., 1995. Volcanic and structural evolution of Taupo Volcanic Zone, New Zealand: a review. Journal of Volcanology and Geothermal Research 68, 1-28.

Wilson, C.J.N., Riggs, N.R., Ort, M.H., White, J.D.L., Houghton, B.F., 1997. An annotated atlas of post-1.8 ka shoreline features at Lake Taupo, New Zealand. Institute of Geological and Nuclear Sciences Limited.

Wilson, C.J.N., Rogan, A.M., Smith, I.E.M., Northey, D.J., Nairn, I.A., Houghton, B.F., 1984. Caldera volcanoes of the Taupo Volcanic Zone, New Zealand. Journal of Geophysical Research 89, 8463-8484.

Wilson, C.J.N., Walker, G.P.L., 1985. The Taupo Eruption, New Zealand I. General Aspects. Philosophical Transactions of the Royal Society of London. Series A, Mathematical and Physical Sciences 314, 199-228.

Woods, R., Hendrikx, J., Henderson, R., Tait, A., 2006. Estimating mean flow of New Zealand rivers. Journal of Hydrology (NZ) 45, 95-110.

Xie, X., Zhang, D., 2010. Data assimilation for distributed hydrological catchment modeling via ensemble Kalman filter. Advances in Water Resources 33, 678-690.

Xu, Z.X., Li, J.Y., 2002. Short-term inflow forecasting using an artifical neural network model. Hydrological Processes 16, 2423-2439.

Yang, J., 2011. Convergence and uncertainty analyses in Monte-Carlo based sensitivity analysis. Environmental Modelling \& Software 26, 444-457.

Yang, T., Yu, P., Chen, C., 2005. Long-term runoff forecasting by combining hydrological models and meteorological records. Hydrological Processes 19, 16971981.

Young, P.C., 2001. Data-based mechanistic modelling and validation of rainfall-flow processes, in: Anderson, M.G., Bates, P.D. (Eds.), Model Validation: Perspectives in Hydrological Science. J. Wiley \& Sons, Chichester, UK, pp. 117-161.

Young, R., Smart, G., Harding, J., 2004. Impacts of hydro-dams, irrigation schemes and river control works, in: Harding, J., Mosley, P., Pearson, C., Sorrell, B. (Eds.), Freshwaters of New Zealand. New Zealand Hydrological Society \& New Zealand Limnological Society, Christchurch.

Zecharias, Y.B., Brutsaert, W., 1988. The influence of basin morphology on groundwater outflow. Water Resources Research 24, 1645-1650.

Zhang, Y., Arthington, A.H., Bunn, S.E., Mackay, S., Xia, J., Kennard, M., 2011. Classification of flow regimes for environmental flow assessment in regulated rivers: The Huai River Basin, China. River Research and Applications. 


\section{Appendix A: Performance Measures}

\section{A.1 Background}

The work outlined in this Appendix compares the performance of the commonly used Nash-Sutcliffe Efficiency (NSE) index to the recently developed Kling Gupta Efficiency (KGE) index in two sub-catchments of Lake Taupo. The purpose is to determine which index is able to provide a better objective fit for model calibration and will be subsequently used in this study (see Section 6.3.2).

The Tauranga-Taupo and Waihaha River catchments are chosen because they represent some of the main physiographic and climatic differences in the Lake Taupo catchment. The Tauranga-Taupo catchment is a narrow basin draining a large area of impermeable basement geology in the south-eastern part of the catchment. It is moderately steep, has a relatively low baseflow component and high flow variability. Conversely, the Waihaha catchment (western bays) is rounder and is underlain by predominantly volcanic geology. It has higher baseflow and lower variability than the Tauranga-Taupo catchment.

Using the conceptual rainfall-runoff model developed in this study (refer Chapter 6), classic Monte Carlo sampling of pre-defined parameter ranges is undertaken for 100,000 model calibration runs. For the Tauranga-Taupo catchment the calibration period is from June 2003 to May 2008 (five years) and for a period of 3.5 years for the Waihaha catchment (May 1989 - October 1992). The model generates 15 minute time step output, but it is the hourly volumes that are used for calibration. 
A multi-criteria framework is applied where behavioural parameters sets are defined as those which fit well to the time series (objective function value $>0.7$ ) and the flow duration curve (objective function value $>0.95$ ). The multi-criteria application aims to find the top five parameter sets which are able to sufficiently simulate the hydrograph response in terms of timing of response and recession characteristics while also adequately capturing the variability and range of flow for the catchment. Performance is evaluated on how well these indices can simulate various observed catchment response characteristics.

\section{A.2 Results and discussion}

The top five parameter sets identified by the NSE and KGE are compared. The results are plotted and the respective performance assessed in terms of the multicriteria calibration approach and ability to simulate various observed catchment response characteristics outlined in Table A.2.1.

In the Tauranga-Taupo catchment, the KGE optimal parameter sets generated higher performance index values than those of the NSE (Table A.2.2). Visual inspection of the modelled streamflow against observed streamflow for both the KGE (Figure A.3.1) and NSE (Figure A.3.2) parameter sets show little difference, although the KGE tends to over-estimate peak flood responses more than the NSE. Statistics of the hydrological response characteristics generally show that the KGE is doing a better job of simulating different aspects of the hydrograph, although the NSE decreases errors in flow variability more efficiently (Table A.2.3). However, these estimates of variability may be underestimated (Gupta et al., 2009).

Table A.2.1 Time series characteristics for model evaluation

\begin{tabular}{|c|c|}
\hline Time series & \\
\hline Mean Flow & Mean of observations \\
\hline Standard deviation & Standard deviation of observations \\
\hline Coefficient of variation & Standard deviation/mean flow \\
\hline Mean of high flows & Mean of flows $Q_{30}$ and $Q_{95}$, as defined by the flow duration curve ${ }^{\dagger}$ \\
\hline Mean of medium flows & Mean of flows $Q_{5}$ and $Q_{30}$, as defined by the flow duration curve \\
\hline Mean of low flows & Mean of flows above $Q_{5}$, as defined by the flow duration curve \\
\hline
\end{tabular}


Table A.2.2 Comparison of KGE and NSE performance index values for the Tauranga-Taupo catchment.

\begin{tabular}{cccccc} 
Index & $\mathbf{1}$ & $\mathbf{2}$ & $\mathbf{3}$ & $\mathbf{4}$ & $\mathbf{5}$ \\
\hline KGE & 0.8596 & 0.8605 & 0.8602 & 0.8636 & 0.8599 \\
NSE & 0.7328 & 0.7319 & 0.7329 & 0.7317 & 0.7311
\end{tabular}

Table A.2.3 Comparison of results for the KGE and NSE performance indexes for the TaurangaTaupo catchment. Table shows the departure from the observed value.

\begin{tabular}{cccccccc} 
Index & $\begin{array}{c}\text { Par. } \\
\text { Set }\end{array}$ & Mean & Std. Dev. & COV & Low & Mid & High \\
\hline \multirow{2}{*}{ KGE } & 1 & $\mathbf{0 . 0 0 9 5}$ & $\mathbf{- 0 . 0 0 7 9}$ & -0.0176 & $\mathbf{- 0 . 0 0 7 6}$ & $\mathbf{0 . 0 8 3 7}$ & $\mathbf{- 0 . 0 0 5 4}$ \\
& 2 & $-\mathbf{0 . 0 0 0 8}$ & $\mathbf{- 0 . 0 2 6 1}$ & -0.0253 & $\mathbf{- 0 . 0 2 1 2}$ & $\mathbf{0 . 0 7 7 2}$ & $\mathbf{- 0 . 0 0 8 7}$ \\
& 3 & $\mathbf{0 . 0 2 6 8}$ & $\mathbf{- 0 . 0 1 7 9}$ & -0.0459 & $\mathbf{0 . 0 1 5 1}$ & $\mathbf{0 . 0 9 3 1}$ & $\mathbf{- 0 . 0 0 7 8}$ \\
& 4 & $\mathbf{0 . 0 2 6 3}$ & $\mathbf{0 . 0 0 8 1}$ & $-\mathbf{0 . 0 1 8 7}$ & $\mathbf{0 . 0 0 7 8}$ & $\mathbf{0 . 0 9 8 0}$ & 0.0299 \\
& 5 & $\mathbf{- 0 . 0 0 5 7}$ & $\mathbf{0 . 0 1 3 0}$ & 0.0186 & $-\mathbf{0 . 0 2 7 3}$ & $\mathbf{0 . 0 7 1 2}$ & $\mathbf{0 . 0 0 3 2}$ \\
& 1 & 0.0639 & 0.0741 & $\mathbf{0 . 0 1 0 9}$ & 0.0478 & 0.1313 & 0.0649 \\
& 2 & 0.0482 & 0.0378 & $-\mathbf{0 . 0 1 0 9}$ & 0.0299 & 0.1229 & 0.0252 \\
& 3 & 0.1010 & 0.0613 & $-\mathbf{0 . 0 4 4 1}$ & 0.0883 & 0.1675 & 0.0767 \\
& 4 & 0.0481 & 0.0217 & -0.0278 & 0.0353 & 0.1174 & $\mathbf{0 . 0 1 6 7}$ \\
& 5 & 0.0723 & 0.0815 & $\mathbf{0 . 0 1 0 0}$ & 0.0547 & 0.1448 & 0.0592
\end{tabular}

Table A.2.4 Comparison of KGE and NSE performance index values for the Waihaha catchment.

\begin{tabular}{cccccc}
\hline Index & $\mathbf{1}$ & $\mathbf{2}$ & $\mathbf{3}$ & $\mathbf{4}$ & $\mathbf{5}$ \\
\hline KGE & 0.8652 & 0.8681 & 0.8646 & 0.8637 & 0.8617 \\
NSE & 0.7439 & 0.7494 & 0.7418 & 0.7459 & 0.7446
\end{tabular}

Table A.2.5 Comparison of results for the KGE and NSE performance indexes for the Waihaha catchment. Table shows the departure from the observed value.

\begin{tabular}{|ccc|ccccc|}
\hline Index & Par. Set & Mean & Std. Dev. & COV & Low & Mid & High \\
\hline KGE & 1 & $\mathbf{0 . 0 0 9 8}$ & $\mathbf{0 . 0 1 4 2}$ & $\mathbf{0 . 0 0 4 4}$ & $\mathbf{0 . 0 3 9 5}$ & $\mathbf{0 . 0 1 9 9}$ & -0.3136 \\
& 2 & $\mathbf{0 . 0 4 7 0}$ & $\mathbf{0 . 0 1 5 1}$ & $\mathbf{- 0 . 0 3 3 4}$ & $\mathbf{0 . 0 7 1 9}$ & $\mathbf{0 . 0 5 3 2}$ & -0.2347 \\
& 3 & $-\mathbf{0 . 0 0 0 2}$ & $\mathbf{0 . 0 1 5 0}$ & $\mathbf{0 . 0 1 5 2}$ & $\mathbf{- 0 . 0 0 0 5}$ & $\mathbf{0 . 0 2 9 2}$ & -0.2392 \\
& 4 & $-\mathbf{0 . 0 1 6 7}$ & $\mathbf{- 0 . 0 0 2 7}$ & $\mathbf{0 . 0 1 3 8}$ & $\mathbf{0 . 0 0 8 2}$ & $\mathbf{- 0 . 0 0 9 9}$ & -0.2934 \\
& 5 & $-\mathbf{0 . 0 0 1 4}$ & -0.0416 & -0.0401 & $\mathbf{0 . 0 1 1 6}$ & 0.0348 & -0.3377 \\
NSE & 1 & 0.0470 & 0.0151 & -0.0334 & 0.0719 & 0.0532 & $-\mathbf{0 . 2 3 4 7}$ \\
& 2 & 0.0955 & 0.0515 & -0.0486 & 0.1039 & 0.1139 & $-\mathbf{0 . 1 4 5 0}$ \\
& 3 & 0.0555 & 0.0783 & 0.0242 & 0.0599 & 0.0791 & $-\mathbf{0 . 1 8 1 6}$ \\
& 3 & 0.0668 & 0.0997 & 0.0352 & 0.1006 & 0.0648 & $-\mathbf{0 . 2 3 6 5}$ \\
& 4 & 0.0098 & $\mathbf{0 . 0 1 4 2}$ & $\mathbf{0 . 0 0 4 4}$ & 0.0395 & $\mathbf{0 . 0 1 9 9}$ & $\mathbf{- 0 . 3 1 3 6}$
\end{tabular}


In the less variable Waihaha catchment, the KGE is also generating much higher performance index values than the NSE (Table A.2.4). The KGE captures the variability of flow more precisely than the NSE in four of the five parameter sets, although errors in high flow volumes were reduced further with the NSE (Table A.2.5). One of the parameter sets responded better under the NSE than the KGE. Figure A.3.3 shows that the parameters identified by the KGE do a better job of simulating the smaller floods ('freshes'), recession and low flow periods than the NSE parameter sets (Figure A.3.4). The statistics suggest that the NSE is able to better represent higher flows in this catchment.

\section{A.3 Conclusions}

Using the conceptual rainfall-runoff model developed in this study a comparative analysis of two objective functions is undertaken with the aim of determining which is more suitable for model calibration in the Lake Taupo catchment. Two catchments are selected. The Tauranga-Taupo catchment is relatively steep underlain by a large area of impermeable basement greywacke. It is characterised by lower baseflow volumes and higher variability. The Waihaha catchment is predominantly volcanic and rounder than the Tauranga-Taupo catchment. It drains some steeper areas of the Hauhungaroa ranges but is generally less steep the Tauranga-Taupo catchment.

While there is little difference visually between the KGE and NSE indexes for each catchment, based on the statistics the KGE is able to generate parameter sets which provide a better representation of the hydrological response characteristics of both catchments. Where the NSE did perform better the corresponding KGE value tends to be much closer the NSE value compared to areas where the KGE outperforms the NSE. It is therefore concluded that the KGE is a more suitable objective function to use in the Lake Taupo catchment. 
(a) Observed Rainfall

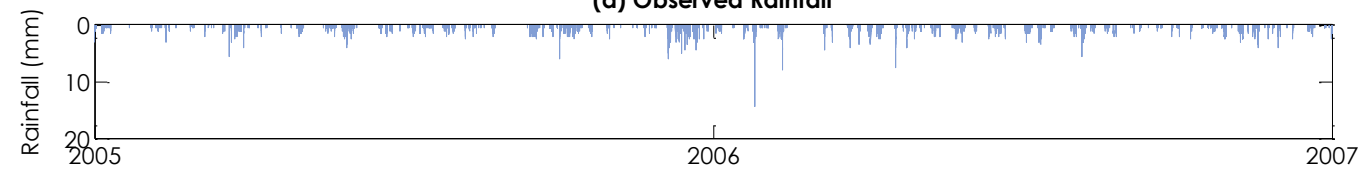

(b) Modelled vs Observed Streamflow

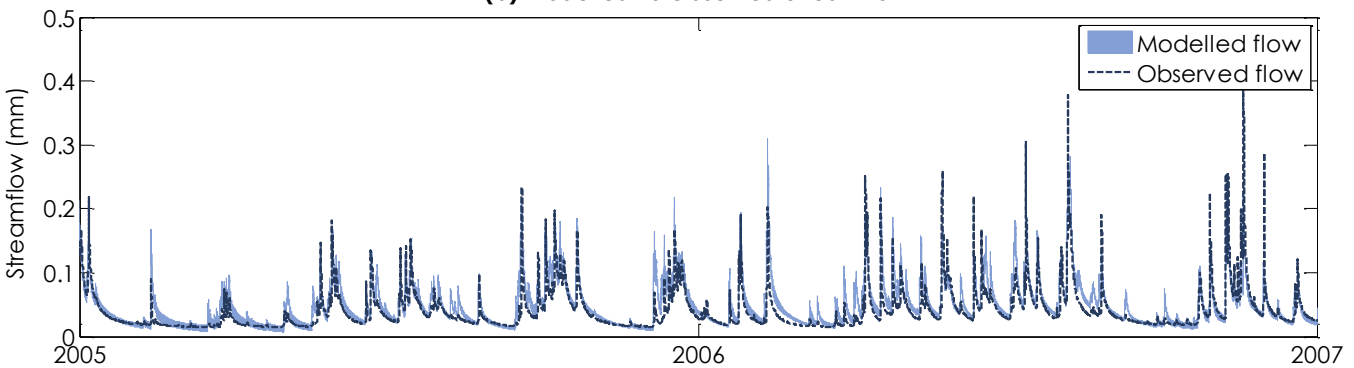

(c) Observed minus Modelled Streamflow

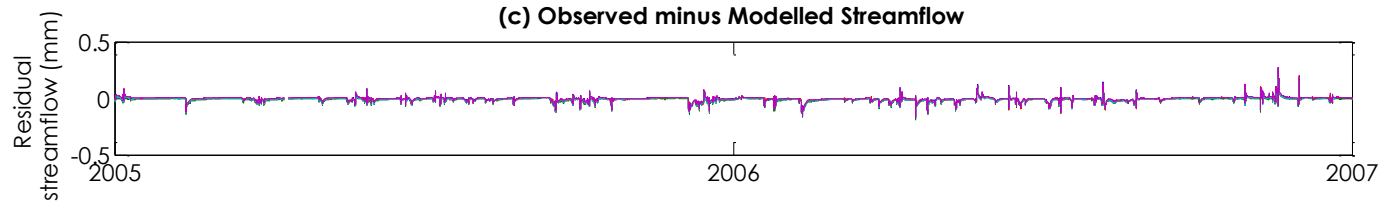

Figure A.3. I Calibration results of the top five parameter sets identified by the KGE performance index for the Tauranga-Taupo catchment.

(a) Observed Rainfall

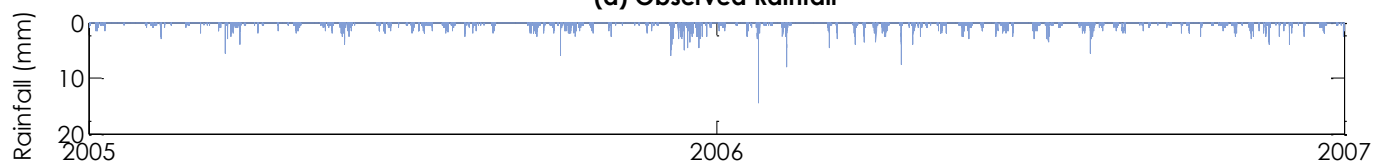

(b) Modelled vs Observed Streamflow

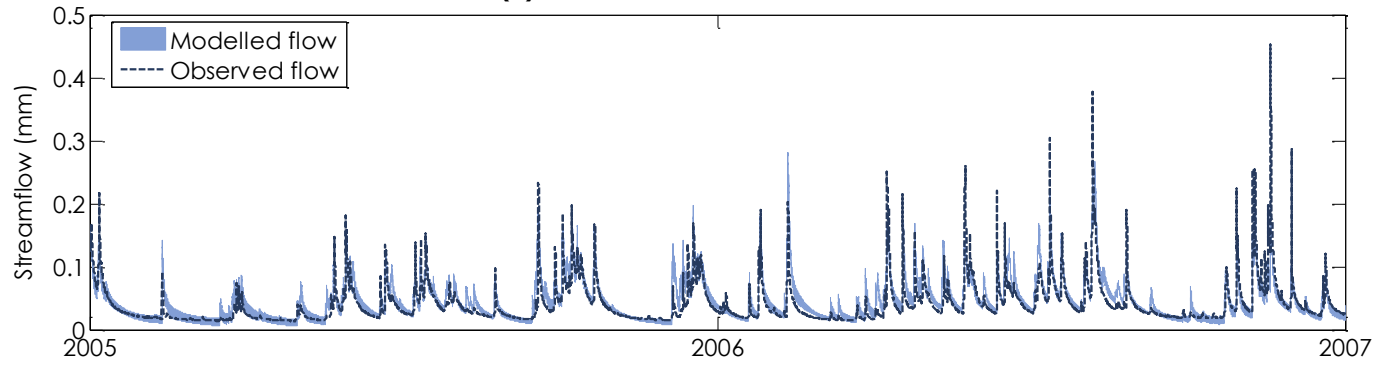

(c) Observed minus Modelled Streamflow

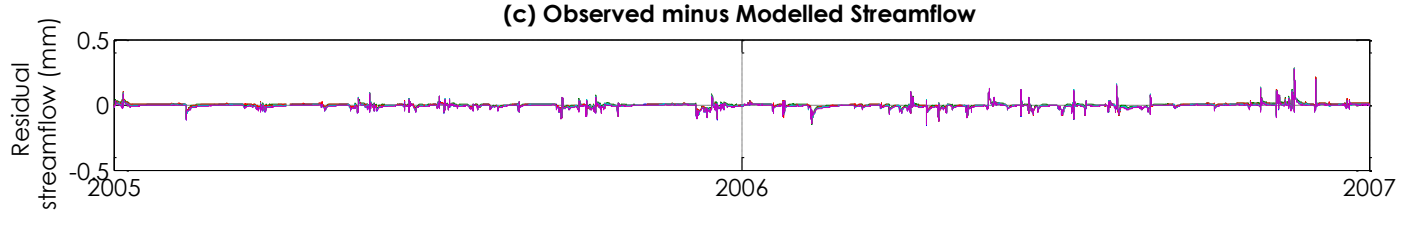

Figure A.3.2 Calibration results of the top five parameter sets identified by the NSE performance index for the Tauranga-Taupo catchment. 
(a) Observed Rainfall

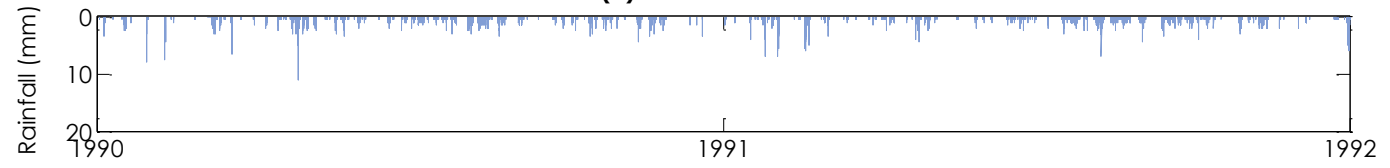

(b) Modelled vs Observed Streamflow

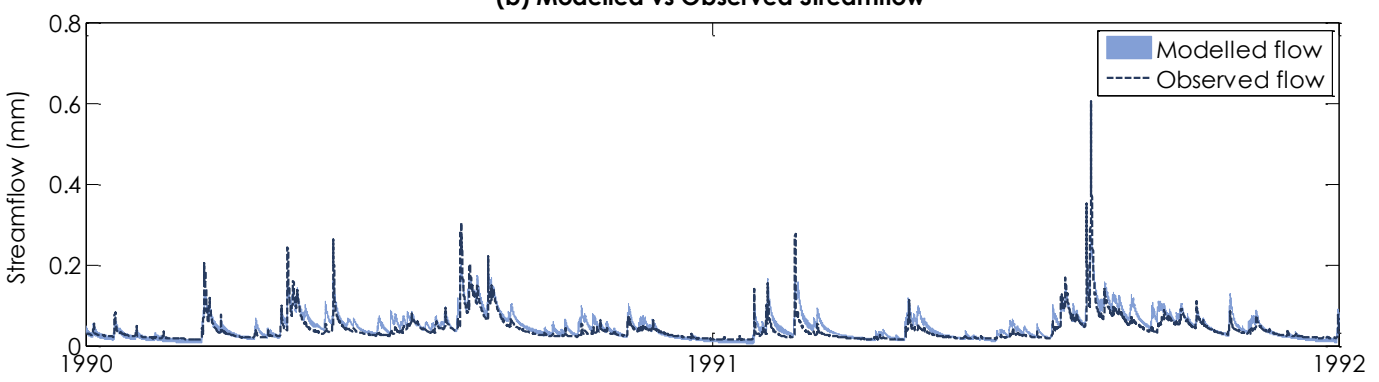

(c) Observed minus Modelled Streamflow

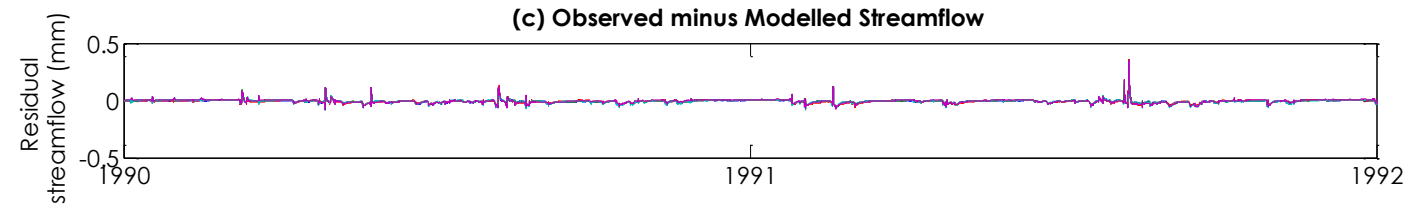

Figure A.3.3 Calibration results of the top five parameter sets identified by the KGE performance index for the Waihaha catchment.

(a) Observed Rainfall

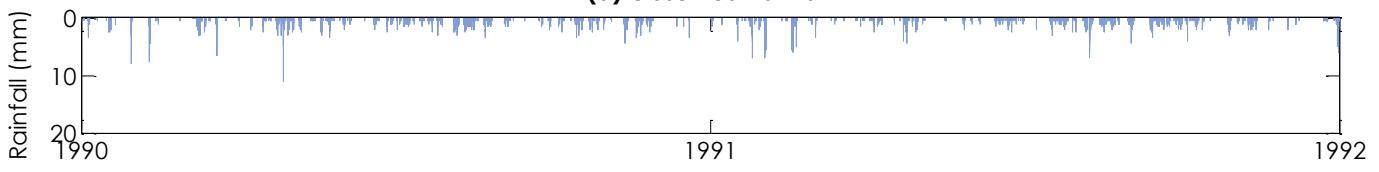

(b) Modelled vs Observed Streamflow

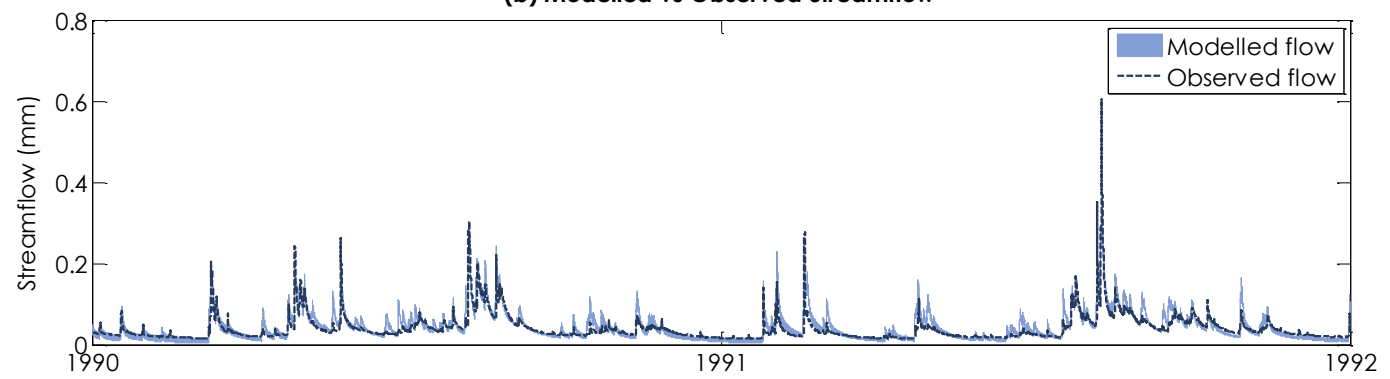

(c) Observed minus Modelled Streamflow

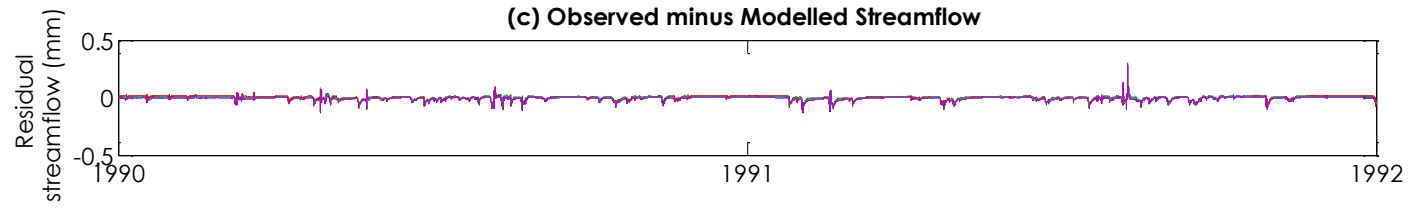

Figure A.3.4 Calibration results of the top five parameter sets identified by the NSE performance index for the Waihaha catchment. 


\section{Appendix B: Sub-catchment hydrological analyses}

In this Appendix, the physical and hydrological characteristics of each subcatchment are summarised. A brief description of catchment attributes is provided and draws on the data analysis undertaken in this study. The physical characteristics of each catchment (catchment area, altitude range, geology, soils, slopes and vegetative cover) are described. The description of land cover is based on the New Zealand Land Cover Database 2 (Ministry for the Environment, 2004). The delineation of soils and geology shown in the relevant figures are based on the New Zealand Land Resource Inventory (Landcare Research - Manaaki Whenua (NZ), 2008). More detailed information on the different lithologies is obtained from various literature including Bou (2007) and Morgenstern (2008) and the 1960 geological map by Grindley (1960).

The hydrological characteristics for the duration of the record are reported and also presented in the relevant charts for each sub-catchment. An analysis of time step lengths and distribution are included, with comments relating to the quality of the data obtained (where information is available). In this dissertation, a 'time step' is defined as the length of time between subsequent observations, whereas a ' $g a p$ ' is a break in the record due to instrument or other errors.

The results of this analysis can be found on the disc at the back of this thesis. 
344 | Appendix B 


\section{Appendix C: \\ Sub-catchment model calibration and sensitivity analyses}

The information provided in this Appendix can be found on the disc at the back of this dissertation and supports the results presented in Chapter 8 and Chapter 9. For each subcatchment analysis of the time series is used to identify periods of reliable rainfall and streamflow data for model calibration and evaluation (for more detailed information of what this analysis shows and how to interpret the respective charts, please refer to Section 6.2). The selection of suitable data periods is based on three separate analyses. The consistency between the rainfall and streamflow records is undertaken by identifying periods of no rainfall and or evapotranspiration and highlighting where streamflow is significantly rising during these recession periods. This assessment aims to show how representative the selected rainfall gauge is by illustrating how adequately it captures the events that are observed in the hydrograph.

Secondly, flow duration curves for the selected calibration period and the entire record are compared. Ideally, the calibration period would represent the range of hydrological phenomena experienced in the catchment including periods of floods, drought and normal flow conditions (Gupta and Sorooshian, 1985; Singh and Bárdossy, 2012). If the two curves are similar, then the calibration data is considered to be suitable for representing a wide 
range of hydrological responses experienced in the catchment. It is noted, however, that even with very long records not all possible hydrological responses may be represented.

Finally, residual mass curves are used to identify periods where there is inconsistency between the rainfall and streamflow records. This comparison is made using the cumulative departures from the respective means, using monthly data. The use of rainfall data which shows a significant difference to streamflow could result in poorer performance in terms of model calibration.

Once a suitable calibration period has been identified, the model is run and the five topperforming five parameter sets based on the results of the multi-criteria Kling-Gupta Efficiency index obtained (refer Section 6.3 and Appendix B). Modelled and observed streamflow are compared. The performance of each parameter set over calibration and evaluation periods is provided, as are corresponding parameter values. Parameters are then classified by degree of sensitivity and their corresponding $D$ statistic shown (refer Section 6.3.2). These results are also presented graphically in a series of scatterplots, sensitivity plots and calibration time series. 


\section{Appendix D: Bivariate Sensitivity Analysis}

This Appendix presents Scatterplots showing two-way parameter response surfaces with respect to the performance measure used. The values of two selected parameters are plotted against each other. Again, the top 1000 (unless fewer are obtained) behavioural parameter sets are plotted with the five highest highlighted. If these behavioural parameter sets are observed across the entire parameter space then there is little, if any, interaction between the two parameters. If the plots show some (positive or negative) relationship between the corresponding parameter sets, some form of parameter interaction can be assumed.

This bivariate sensitivity analysis is undertaken for each sub-catchment can be found on the disc at the back of this thesis. 
$\mathbf{3 4 8}$ | Appendix D 


\section{Appendix E: Correlation Analysis: physiographic attributes and parameter values}

\section{E.1 Correlation analysis}

Relationships between sub-catchment physical features and modelled parameter values provide additional information about the hydrological response and behaviour in the Lake Taupo catchment. Similar to the methodology outlined in Chapter 5, correlation coefficients are used to describe the strength of these relationships. Correlation coefficients provide an easy and convenient way to describe the strength of the relationship between two variables but do not imply a causal relationship (Gordon et al., 2004). The results of the analysis can found on the disc at the back of this dissertation. 